19.

$$
\text { (2) }
$$

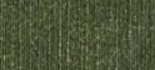

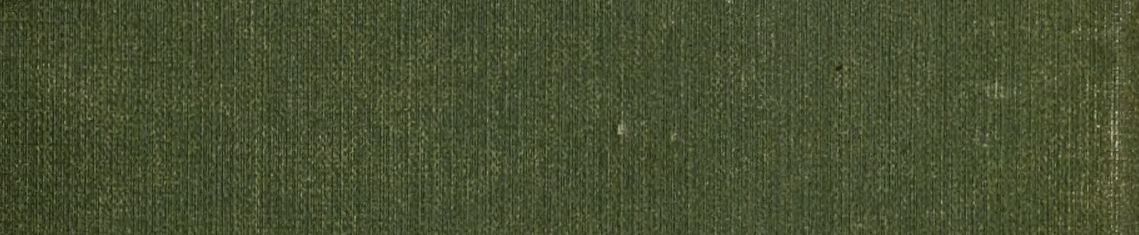

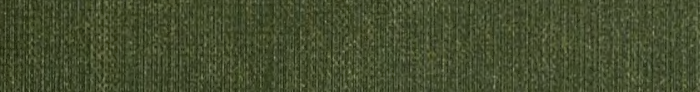





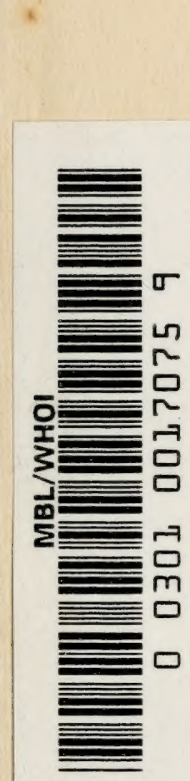





\title{
THE ANATOMY,
}

\section{PHYSIOLOGY, MORPHOLOGY,}

\author{
AND DEVELOPMENT \\ OF \\ THE BLOW-FLY. \\ (CALLIPHORA ERYTHROCEPHALA.)
}

A Stuon in the Comparative Anatomy and Aflorphologn of Fnsects.

WITH PLATES AND ILLUSTRATIONS EXECUTED DIRECTLY FROM THE DRAWINGS OF THE AUTHOR.

BY

B. THOMPSON LOWNE, F.R.C.S., F.L.S.,

HUNTERIAN PROFESSOR OF COMPARATIVE ANATOMY IN THE ROYAL COLLEGE OF SURGEONS ;

LECTURER ON PHYSIOLOGY IN THE MIDDLESEX HOSPITAL MEDICAL SCHOOL, ETC. ; AUTHOR OF 'THE ANATOMY AND PHYSIOLOGY OF THE BLOW-FLY' (I870); LATE PRESIDENT OF THE QUEKETT MICROSCOPICAL CI.UB.

VOL. II.

LONDON :

PURLISHED FOR THE AUTHOR BY

R. H. PORTER, i8 PRINCES STREET, CAVENDISH SQUARE, W.

I893-95. 



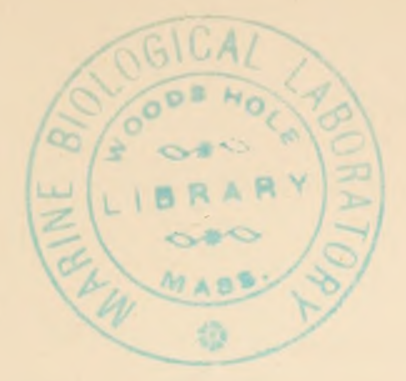

\section{O N T E N T.}

CHAPTER

X. The TRacheal System of the Imago -

SEC. I. General Morphology and Development of the Tracheal

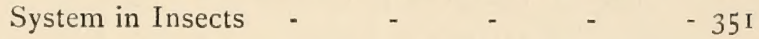

a. General Arrangement - $\quad-\quad-\quad-\quad-35 \mathrm{I}$

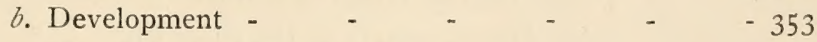

c. Morphological Significance - $\quad$ - $\quad$ - $\quad-355$

SEc. 2. The Tracheal System of the Blow-Fly - - $\quad-358$

a. The Spiracles and Spiracular Sacs - $\quad-\quad-358$

b. Structure of Tracheæ and Air Sacs - - - $\quad$ - 364

SEC. 3. The Development of the Tracheal System in the Blow-

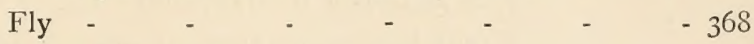

SEC. 4. The Physiology of Respiration in Insects - - 373

Appendix to Chapter X.-Calculation of Work done in Flight 387

Xi. The Alimentary Canal of the Imago $\quad-\quad c_{1} \quad-389$

SEc. I. The Mouth and Pharynx - $\quad$ - $\quad$ - $\quad$ - $\quad$ - 390

, 2. The Soft Parts and Mechanism of the Proboscis - 390 a. The Muscles of the Proboscis - $\quad$ - $\quad$ - 39I

b. The Oral Lobes and Structure of the Pseudo-tracheæ 393

c. The Mechanism by which the Proboscis is extended

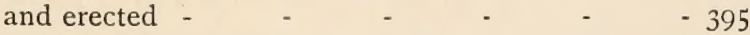

d. Function of Oral Lobes $\quad$ - $\quad$ - $\quad$ - $\quad$ - 397

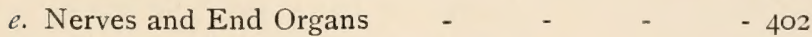

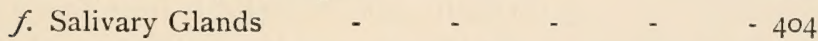

SEC. 3. The Esophagus, Stomachs and Intestines, and their

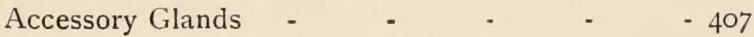

a. The Alimentary Tract - $\quad$ - $\quad$ - $\quad$ - $\quad-407$

b. The Malpighian Tubes - $\quad$ - $\quad$ - $\quad$ - $4 \mathrm{I} 2$

c. The Rectal Papillæ - $\quad$ - $\quad$ - $\quad$ - $\quad$ - 4I7 
SEC. 4. The Development of the Alimentary Canal - - 421

a. In the Embryo - - - - - - - $42 \mathrm{I}$

b. After Development - $\quad-\quad-\quad-\quad-426$

XII. THE Nervous SYSTEM - $\quad$ - $\quad$ - $\quad$ - $\quad$ - $\quad-433$

SEc. 1. Anatomy of the Nerve Centres - - - - 433

a. The Thoracic Nerve Centre of the Blow-Fly Imago - 435

b. General Structure of the Brain in the Arthropoda - 440

c. Details of the Structure of the Brain of the Blow-Fly

d. The Sensory Ganglia - $\quad$ - $\quad$ - $\quad$ - $\quad$ - 467

SEC. 2. The Physiology of the Nervous System in Arthropods 473

" 3. The Development of the Nervous System - $\quad 479$

XiII. The Senses and Sensory ORgans - $\quad$ - $\quad$ - 496

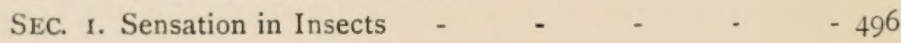

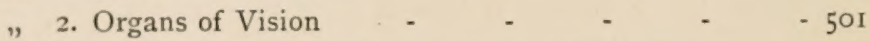

"3. The Median Ocelli, Stemmata, or Simple Eyes $\quad-510$ a. The Stemmata of the Blow-Fly - - $\quad-5$ IO

b. Morphology and Comparative Anatomy of Simple

Eyes in Arthropods - - - $\quad-512$

SEC. 4. General Remarks on the Compound Eye - $\quad$ - 515

" 5. The Compound Eye in the Blow-Fly - - $\quad-526$

a. Structure of the Dioptron - $\quad-\quad-526$

b. The Retina and Optic Nerve $\quad-\quad-\quad-533$

SEC. 6. The Development of the Compound Eye - $\quad-538$

a. In the Arthropoda generally - - $\quad-538$

b. The Development of the Compound Eye in the

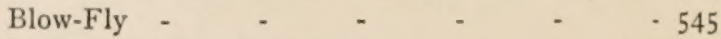

SEc. 7. The Theory of Arthropod Vision - - - 554

" 8. Further Remarks on the Optical Properties of the Compound Eye - $\quad$ - $\quad$ - $\quad$ - 572

a. On the Optical Properties of Refractive Cylinders, and the probable Relation of the several Types of Compound Eye in the Arthropoda - $\quad 572$

b. On the Illumination of the Retinal End Organs under the Dioptric and Mosaic Theories of Vision - 575

c. Accessory Optic Phenomena in the Compound Eye 577

d. Optical Constants of the Compound Eye of the Blow-Fly - $\quad$ - $\quad$ - $\quad$ - $\quad$ - 581 
SEc. 9. On the Structure and Functions of the Antennæ $\quad-582$

a. General Considerations $\quad$ - $\quad$ - $\quad$ - $\quad$ - $\quad$ - 582

b. In the Blow-Fly Imago - $\quad$ - $\quad-\quad-585$

c. On the Functions of the Antennæ in Insects generally 589

SEC. ro. Auditory and Sound-producing Mechanisms - $\quad 595$

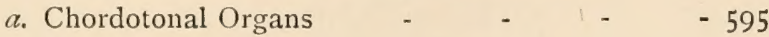

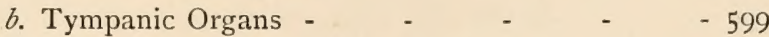

SEC. II. The Halteres of the Blow-Fly - - - - - 603

a. General Structure and Morphology - $\quad-603$

b. Special Sensory Structures - - - - $\quad$ - 609

c. On the Functions of the Halteres - _ - $\quad$ - 6I4

SEC. I2. The Wing Organs - - - $\quad$ - $\quad$ - $\quad-620$

" I3. The Tympanic Organs of the Blow-Fly - $\quad-623$

a. Structure of Tympanic Organs - - - - 623

$b$. On the Probable Function of the Tympanic Organs and their Relation to the Halteres - - - 626

SEC. I4. Concluding Remarks on the Phenomena of Hearing

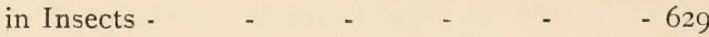

SEC. I 5. The Sense of Taste and the Gustatory Organs - 630

" I6. The Prosternal Organ - _ _ _ _ $\quad$ - $\quad$ - 633

XiV. The Circulation of the Blood and the Dorsal Vessel 635

SEC. I. The Circulation in Insects generally - - - $\quad 635$

"2. The Dorsal Vessel of the Imago of the Blow-Fly - 639

" 3. The Physiology of the Dorsal Vessel - _ - 650

"4. The Development of the Dorsal Vessel _ - - 656

XV. The Generative Organs $\quad$ - $\quad$ - $\quad$ - $\quad$ - $\quad-658$

SEc. I. Descriptive Anatomy of the Internal Generative Organs of the Male Blow-Fly - - - - - 660 2. Descriptive Anatomy of the Internal Generative Organs of the Female Blow-Fly - _ - - 666 , 3. The Structure of the Egg in the Blow-Fly - - $\quad-678$

"4. On the Development of the Internal Generative Organs 684 a. The Earliest Appearance of the Gonads in the Embryo and Larva $\quad$ - $\quad$ - $\quad$ - $\quad$ - 684

b. On the Supposed Origin of the Rudimentary Gonads in the Embryo from the Polar Cells of

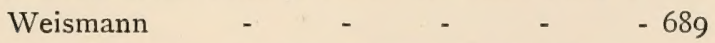

c. The Development of the Testes and their Ducts, and of the Paragonia in the Blow-Fly - - 69I

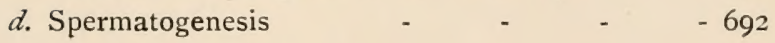


$c$. The Development of the Ovaries and Ova in the Pupa and Young Imago - - - - $\quad 698$

$f$. The Development of the Utero-Vaginal Tube and its Appendages, and of the Oviduct and Parovaria 703 $g$. On the Nature of Ova and the Relations of the Germ to the Vitellus

$h$. On the Changes which occur in the Germinal Vesicle and Free Nuclear Formation - - 711

i. On the Development of the Germ-Ova in the Epithelial Cells of the Parovarium - - $\quad-718$

$k$. Some General Remarks on the Similarity of the Generative Functions in Insects and Trematodes - $72 \mathrm{I}$ SEC. 5. The External Generative Organs -

a. General Considerations and Nomenclature of the Abdominal Segments

b. Development of the External Organs in Insects Generally - $\quad$ - $\quad$ - $\quad$ - $\quad$ - $\quad-730$

c. Comparative Morphology of the External Generative Organs

d. The External Generative Organs of the Male Blow-

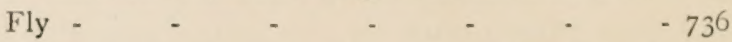

e. The External Generative Organs of the Female

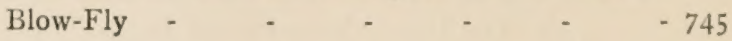

Bibliographies. -148 to 155 , p. $35 \mathrm{I} ; 156$ to 160 , p. $352 ; 161$ to 169 , p. $389 ; 170$ to 179 , p. $433 ; 180$ to 186 , p. $434 ; 187$ to 191 , p. 479 ; 192 to 195 , p. 496 ; 196 to 200 , p. 500 ; 201 to 217 , p. 501 ; 218 to 231 , p. $502 ; 232$ to 247 , p. 503 ; 248 to 252 , p. 504 ; 253 to 258 , p. 539 ; 259 to 263 , p. 582 ; 264 to 277 , p. $583 ; 278$ to 287 , p. 596 ; 288 to 300 , p. $603 ; 301$ to 305 , p. 631 ; 306 to 313 , p. $635 ; 314$ to 315 , p. $656 ; 316$ to 325 , p. 658 ; 326 to 334 , p. 659 ; 335 to 338 , p. 678 ; 339 to 348 , p. 684 ; 349 to 354 , p. 685 ; 355 to 358 , p. 693 ; 359 to 368 , p. 712 ; 369 , p. 723 ; 370 to 376, p. 725 . 


\section{LIST OF PLATES.}

PIATE

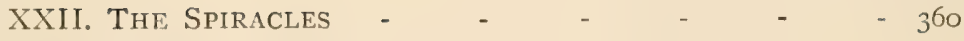

XXIII. Details of ORal Lobes - $\quad$ - $\quad$ - $\quad$ - $\quad 394$

XXiV. The Alimentary Canal of the Imago - - 408

XXV. The Development of the Alimentary Canal - 428

XXVI. The Nervous System of The Imago - $\quad$ - 436

XXVII. The Thoracic Ganglion of the Imago - - 438

XXVIII. The Brain of the IMAgo - - - - $\quad$ - 452

XXIX. " $\quad$ X

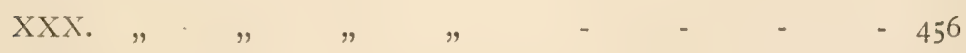

XXXI. " " $\quad$ XX

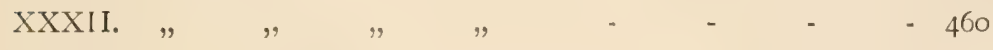

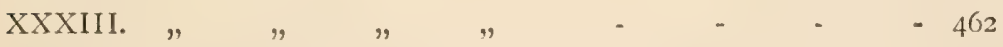

XXXiV. The Neuroblast of the Resting Larva - $\quad 484$

XXXV. The Compound Eye - $\quad$ - $\quad$ - $\quad$ - $\quad$ - 516

XXXVI. "

XXXVII. The Optic Ganglion of the Pupa - $\quad$ - $\quad 544$

XXXVIII. Detalls of the Compound Eye - - - - 548

XXXIX. DeVElopment of the Retina - - - - $\quad 552$

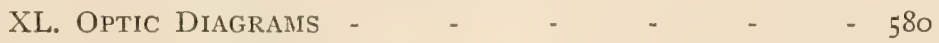

XLI. The Antenna And Palpus - $\quad-\quad-\quad 586$

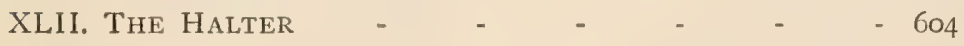


PLATE

XliII. The Halter and Tyapanic Organ - - - Gio XLIV. THE AUDitory Mechanism - - - - $\quad 624$ XLV. The DORSAL VESSEl - $\quad$ - $\quad$ - $\quad 640$ Xlvi. The Pericardial Septum - $\quad$ - $\quad 646$ Xlvil. The Female Generative Organs - - - 666 XLVIII. SPERMATOGENESIS - $\quad$ - $\quad$ - $\quad$ - $\quad$ - 694 Xlix. Developantent of the OVAry - - . . 698

L. The Invaginated Segments of the Male - 736 Li. The Male ORgaN- - - - - - $\quad 738$ LII. 


\section{CHAPTER X.}

THE TRACHEAL SYSTEM OF THE IMAGO.

\section{GENERAL MORPHOLOGY AND DEVELOPMENT OF THE TRACHEAL SYSTEM IN INSECTS.}

\section{a. General Arrangement of the Tracheal System.}

AlL perfect insects, if the doubtful case of some Collembola be excepted, breathe by means of a tracheal system, and respire air, which enters the tracheæ by external openings termed spiracles. In some aquatic larvæ, however, spiracles are absent, and the tracheal system is said to be closed; such larvæ usually possess tracheal gills.

The spiracles do not open immediately into the trachere

\section{Bibliography :}

148. Malpighius, Marcellus, 'Dissertatio Epistolica de Bombyce Societati regix.' Londini, I669. 4to.

149. Meyer, H., 'Ueber die Entwickelung des Fett-körpers, der Tracheen und der Keimbereitenden Geschlechtstheile bei den Lepidopteren.' Zeitsch. f. w. Znol., Bd. i., I 849 .

150. Landors, H., 'Der Tracheenverschluss bei den Insecten.' Zeitsch. f. w. Zool., Bd. xvii., I 867 .

151. Gegenbaur, C., 'Grundziige der Vergleichenden Anatomie,' ii. Auf. Svo. Leipzig, I87o.

152. Semper, C., 'Die Stammesverwandtschaft der Wirbelthiere und Wirbellosen.' Arb. aus d. Zool-zoot., Inst. zu Würzburg, Bd. ii., 1875.

153. Palaín, I. A., 'Zur Morphologie des Tracheensystems.' Helsingfors, I877, Svo.

154. Krancher, O. (aus Schneeberg), 'Der Bau der Stigmen bei den Insecten.' Zeitsch. f. w. Zool., Bd. xxxv., I881.

155. Hurst, C. H., 'The Pupa Stage of Culex: an inaugural dissertation for the Degree of Ph.D. in the University of Leipzig.' Svo., Leipzig, 1890. 
proper, but communicate with them through the medium of a pouch or sac, the spiracular sac or vestibule. The vestibule is separated from the trachea proper by a valve, the internal spiracular valve; and the spiracular opening is also closed by an external valve. Sometimes the external valve is situated at the inner extremity of a funnel-shaped or tubular depression of the integument, which forms the atrium of the vestibule.

The Atrium is frequently lined by numerous setit, and the ducts of wax slands (Pl. X.II., Fig. 8) open into it and on the surfaces of the external valves. Both sets of valves open inwards, and the vestibule is surrounded by loops of muscle fibre, the rhythmic contractions of which pump the air from the vestibule into the trachea proper; hence the vestibule performs the function of an air heart (see physiology of respiration).

The Tracheæ proper are the longitudinal trunks and the arborescent trachea. The longitudinal trunks are a pair of parallel vessels which extend from the anterior to the posterior extremity of the insect. They are connected with each other by transverse unbranched commissures, and with the spiracles by short lateral branches, which, in those larve with a closed tracheal system, are represersted by solid strings of cells attached to the integument at the spots where the spiracles are ultimately developed.

156. HURST, C. H., 'On the Life-history and Development of a Gnat (Culex).' Trans. of the Manchester Microscopical Society, ISgo.

The following papers deal with the function of respiration in insects:

157. REIAALIT ANI) REISET. 'Chemische Untersuchungen iber die Respiration der Thiere aus verchiedenen Klassen ( $p$ p. 129-179 and 257-321). 'Annalen der Chemie und Pharmacie,' Bd. Ixiii., 1850. lleidelberg (Wihler und Liebig): only a small section of this paper is devoted to the respiration of insects (pp. 298-300).

158. l'likon, 1., 'Sur l'Atmosphìre interne des Insectes comparíe it celle des Feuilles.' Comptes Rendus, Tom. cii., p. 1339. I 886.

159. 1) EWTT\%, H., 'Finige lieobachtungen, betreffend das geschlossene 'Tracheensystem bei Insecten larven.' \%ool. Anzeig., Bd. xiii., ISgo (pp. 525-531).

160. Cikmtins, A. B., The l'hysiolocy of the Inveriebrata.' Svo, London, 1892. 
The arborescent trachea are branching tubes which either arise directly from the spiracular sacs or from the longitudinal trunks or their commissures; their finest branches are the tracheal capillaries. In aërial insects both the arborescent branches and the great longitudinal trunks and their commissures are often replaced by chains of thin walled air vesicles or sacs.

\section{b. Development of the Tracheal System.}

Development of the Spiracular Sacs and Spiracles.-Observers are all agreed as to the manner in which the spiracular sacs are developed. They first appear as involutions or depressions of the epiblast. The neck of the sac forms the external spiracular opening, and the external valves are developed from its edges; a still further invagination of the epiblast, which occurs subsequently, forms the atrium, outside the external valve, when an atrium is present.

Development of the Tracheæ proper.-Great difference of opinion exists, however, as to the origin of the great longitudinal trunks and arborescent tracheæ. Some hold that these are, like the spiracular sacs, formed by invagination of the epiblast, a view which was originated by Bütschli [126] ; and others that they are developed from strings of mesoblast (parablastic) cells.

Kowalevski [97] says that in the embryo of Hydrophilus tracheal pouches are formed by invagination, and subsequently extend both forwards and backwards, and by their union form the longitudinal tracheal trunks. He further insists: 'The pouches not only form the stigmatic openings, but all the great tracheal stems' (p. 40); and of the embryo of the bee, Apis mellifica, he says: 'In the next stage (i.c., after the formation of the stomodæum and the rudimentary maxillæ and mandibles) invaginations of the epiblast take place on each side of the neural plate, which are the rudimentary stigmatic openings; these invaginations unite with each other and form the great longitudinal tracheæ.' 
A careful perusal of Kowalevski's work and a comparison of his figures with his text has convinced me that these statements are made on insufficient evidence. Kowalevski's sections do not apparently bear out his conclusions, and it is clear that, unless all the observations already cited, concerning the origin of the tracheal vessels from the parablast, are incorrect. Kowalevski must have been mistaken.

Weismann gives the most definite account of the manner in which the tracheal vessels are developed in the blow-fly embryo, and his observations agree with those of Leuckart [20] and with the more recent observations which derive the true tracheal system from the parablast (see p. 273).

According to Weismann, the longitudinal tracheal trunks of Musca appear in the embryo as solid cell-strings of mesoblastic origin, and Leuckart makes the same statement with regard to their origin in the Pupiparæ [20].

Weismann says [2, p. 76]: 'As Meyer has already remarked, the tracheal trunks and their finer end-branches have a different origin." First, as regards the trunks, there cannot be the slightest doubt they first appear in the embryo as thick solid strings of spheroidal embryonic cells.'

He continues: 'In the earliest observed condition, thick strings of loosely-compacted spheroidal embryonic cells extend forwards from the neighbourhood of the stigmatic furrow; these can be isolated, for a short distance only, from the gencral mass of mesoblastic cells with which they are united by numerous lateral branches, consisting of several cell layers, passing over into the general cellular mass. A little later it is possible to isolate the tracheal trunk with a number of its lateral branches, which can easily be recognised as the rudiments of the future tracheal network by their form and disposition, and the later the observation the further these branches extend towards the periphery.'

'The cells of which these strings are formed measure $20 \mu$ in diameter, contain one and often two nuclei, and have finely.

* For the development of the tiner branches of the trachear, see panges 4) and 273 . 
granular contents, occasionally intermixed with minute fat granules' [2, p. 77].

'As soon as these systems of cell-strings are capable of isolation, they are found to be no longer solid; but the larger, at least, exhibit a small lumen into which the convexities of the cells, forming the wall, project. The lumen is filled by a clear fluid and exhibits a special limitation due to a slight thickening of the cell-walls bounding the tube.'

'This thickening or rather delamination of the boundarywall forms a structureless intima, which at first follows the outline of the projecting spheroidal cells. As the intima thickens, the cells become fused by their adjacent walls, and the wave-like contour of the intima is straightened; the vessel then becomes a cylindrical tube and slight transverse striæ appear. These become more and more distinct, until at length they are seen as the spiral thread, which, as Leydig has already remarked, is not an independent structure, but a mere partial thickening of the intima [123, p. 387]. Meyer's [149] idea that the spiral thread is produced by a rupture of the intima, due to the entrance of air into the tracheæ, must be discarded, as the spiral thread is present long before any air enters the tracheæ' $[2$, p. 78$]$. This occurs, as Weismann observed, from two to six hours before the escape of the embryo from the egg, when the longitudinal trunks and their principal branches are filled with air, although the small twigs contain no air until after the escape from the egg [2, p. 8I].

\section{c. The Morphological Significance of the Tracheal System.}

Gegenbaur held [151] that the earliest animals possessing tracheæ were probably aquatic, and resembled the larvæ of our present Ephemeridæ; that the primitive form of the tracheal system was probably closed, without spiracles; he further supposed that the renewal of air was effected in primitive insects, as it is now in many aquatic larvæ, by tracheal gills, leaf-like or filamentous appendages projecting from the surface of the body, in which brushes of parallel tracheal 
capillaries, derived from the closed trunks, are exposed to the aërating influence of the surrounding water.

More recent researches render it probable that the earliest Tracheata were terrestrial and not aquatic as Gegenbaur supposed; but even if this is true, the tracheal gills of larval Termites, already mentioned (p. I6o), show that Gegenbaur's hypothesis does not necessarily break down, and his view is consonant with the origin of the tracher proper from the parablast.

A second view originated from Bütschli [128]; he regarded the trachere as homologous with the sericteria and Malpighian vessels, and with the segmental organs of Annelids. Semper also considered the tracheæ to be highly modified segmental tubes [152].

Moseley* regarded the tracher as highly modified cutaneous glands, and this view has of late been favourably received; it is, however, quite inconsistent with their developmental history, if, as can now scarcely be doubted, they arise from the parablast.

The most serious opponent of Gegenbaur's hypothesis is Palmén [153], whose work on the morphology of the tracheat is exceedingly valuable. Palmén believed Kowalevski's account of the development of the trachex to be correct, and held that the open, and not the closed, tracheal system is the primitive form. He discovered that the great longitudinal trunks of those larva, which have a closed tracheal system, are connected with the integument, at the points at which spiracles are subsequently developed, by delicate cellular strings; and that a solid rod of chitin is developed in the axis of each cell-string, which is continuous on the one hand with the integument, and on the other with the intima of the tracheal trunk; at each ecdysis the tracheal intima is drawn through the cell-string, which becomes for the time pervious, and is shed by the opening which afterwards becomes the spiracle. After the larval ecdysis the cell-cords close; but when the insect becomes terrestrial they remain permanently open.

* Phil. Trans., 1874, vol. clxiv., p. 777. 
These facts led Palmén to the conclusion that the spiracles are virtually, although not functionally, present in the larva, and that the closed system is a modification of the open system. This view does not necessarily follow, however, from the facts, for if the tracheæ are developed from parablast, the existence of cell-strings uniting the tracheal trunks and the skin might be expected; and the manner in which ecdysis takes place may be regarded as an adaptive modification.

The ecdysis of the intima of the tracheæ in the fly nymph occurs, nearly in the same way, as in larvæ with closed tracheæ; new spiracles are formed, which are quite independent of the larval spiracles, whilst the vestibule of the spiracle and the valves are developed from the integument, and not from the cell-string, through which the intima of the tracher of the pronymph is withdrawn (see Pl. XXII., Figs. 6 and 7).

Palmén further regarded the longitudinal trunks as originating by the anastomosis of tracheæ springing directly from the spiracular sacs. In the higher insects this does not appear to be their origin, and the existence of these vessels is so constant in all insects, whilst the position and number of the spiracles is so variable, that it can hardly be doubted, I think, that they originated in Tracheata in which the spiracular vessels did not exist.

The only instance in which the longitudinal trunks are absent in the less highly differentiated Tracheata are the highly abnormal Protracheate, Peripatus, and in some Thysanuridæ. In Peripatus the tracheal vessels are so irregular that they cannot be taken as the original form of the very constant tracheal system of the Myriapoda and Insecta, and it appears equally probable that the genus Peripatus is a highly degenerate form. With regard to the condition in some Thysanuridx, described by Palmen, it is quite as possible that the tracheal system has undergone retrograde metamorphosis. The Springtails cannot be regarded as generalised Orthoptera, and there is no evidence that retrograde follow the same lines as evolutionary modifications.

It appears to me most probable that the tracheal system is 
leveloped like the hemal system of vertebrates from the paral)last, and that the closed system is the primitive form; that the spiracular openings originated subsequently as pouch-like involutions of the epiblast.

Palmen entircly disposed of the old view, that the tracheal spiracles are modified gills, or originate by the shedding of the branchial appendages; they originate independently, and are sometimes segmental, sometimes inter-segmental, and vary greatly, both in position and number, in different insects.

If, as I have supposed, such is the origin of tracheal ressels, they probably at first contained a pseudo-hremal fluid, like the pseudo-hremal vessels of Annelids, as it is exceedingly difficult to understand how these vessels can have contained air in forms in which they are permanently closed. Dewitz has shown [159] that even in insects with tracheal gills there are temporary spiracles at some stage of development by which the trachee are first filled with air. In the young embryo the trachere are always filled with fluid, and it is only in the later stages of development, when the trachere are provided with one or more pairs of spiracles, that they contain air.

\section{THE TRACHEAL SYSTEM OF THE BLOW-FLY.}

\section{a. The Spiracles and Spiracular Sacs.}

In the adult Blow-fly there are three pairs of thoracic, and seven or eight pairs of abdominal spiracles.

These spiracles may be classed in three groups: The great inter-segmental thoracic spiracles, the tympanic spiracles, and the abdominal spiracles.

The Nomenclature and Position of the great thoracic spiracles has been already discussed (p. I8o). The tympanic spiracles are small and exclusively expiratory openings connected with the auditory and sound-producing mechanism. The abdominal spiracles are comparatively simple inspiratory orifices; there are five pairs opening externally on the ventral aspect of the lateral plates of the abdomen; and two 
or sometimes three pairs which open into the cloaca; they are situated in the corresponding region of the invaginated cloacal segments.

The abdominal spiracles are usually segmental, except the first pair, which are most frequently placed on the syndesmosis in front of the first abdominal segment. Dufour [19] considered the segmental or inter-segmental position of the spiracles of the abdomen in the Diptera as of great importance; but it appears that the position of these spiracles not only varies in different species of the same family, but also in different individuals of the same species. All the abdominal spiracles are probably inter-segmental at first, and they become enclosed in the chitinized plates of the dorsal arches, more or less completely, in relation to the size of these plates. In other words, the plates only enclose the spiracles when they are of large size, and the spiracles remain in the inter-segmental syndesmoses when the plates are little developed.

The second and fifth abdominal rings are always broader than the others, and they always enclose the spiracles, whilst the other plates either only just reach the spiracles, or the latter remain in front of them in the soft syndesmotic integument.

The Thoracic Spiracles.-The anterior and posterior thoracic spiracles differ in form, but exhibit the same valvular arrangement, and are identical in all essential particulars in structure. The posterior pair are larger, and are more easily examined, especially in the living insect. I shall therefore describe them and merely indicate the differences between them and the anterior pair.

The Posterior Thoracic spiracle is closed by an external valve, the epitreme, within which there is a shallow cavity, the vestibule; the internal wall of the vestibule forms an internal valve, beyond which the membranous tracheæ commence.

The external vaive is composed of two valve-plates (Pl. XXII., Fig. 2). Each consists of a thin membrane, strengthened by a number of dendriform tubes, and covered on either surface by numerous diverging hollow setæ, which communicate with 
the tubes. The tubes and seta are the terminations of the ducts of a series of wax glands, situated around the spiracle.

The glands are convoluted tubules, and contain cells similar to those of the sebaceous glands of vertebrates (PI. XXII., Fig. S). The wax is poured out on the surfaces of the valve-plates and over the adjacent integument; it serves to seal the valve, and prevents the adhesion of water to the spiracle and the surrounding integument. If a living fly is immersed in water a large bubble of air always adheres to each of the spiracles. After immersion in alcohol this no longer occurs.

I use the term wax rather than oil, but have no evidence of the real character of the secretion, except that it is fatty, is intensely blackened by osmic acid, and is soluble in alcohol and ether.

The internal valve consists of a calliper-like sclerite, enclosed

\section{DESCRIPTION OF P'LATF XXII.}

FIr. I. - The posterior thoracic spiracle of the Blow-fly seen from within the thorax: $m$, muscle which closes the internal valve; $m^{1}$ the elevator, and $m^{2}$ the depressor muscle of the halter; 0 , orifice between the open external valve plate: ; $s, s$, spiracular sac.

Fin, 2. - The external valve of the posterior spiracle seen from its outer surface.

F1: 3. - A portion of the external valve plate showing the hollow branching ribs ancl setre in which the wax ducts terminate, seen with a $\$$ objective.

Fur. 4. - The anterior thoracic spiracle seen from within the thorax. The spiracular sac has lieen removed from the right side to show the external valve plate and the calliper-like rod which supports the internal edge of the sac and acts as a valve. The small muscle which controls the internal valve is seen below.

Fil: 5. - The spiracular sac and internal valve of the anterior thoracic spiracle, with the origin of the tracheal trunks from the anterior spiracular sac: $s$, the sac; the muscles have been removed from its upper half to show the wax glands which lie at the outer margin of the spiracular sac; $t r$, tracheal trunks.

Fir:s. 6 and 7.--Sections through the anterior spiracles of the nymph : $i, c$, the pupa sheath ; $i, i$, intima of the trachea of the nymph; $p, p$, peritoneal coat which forms the tracheal intima of the imago; $s, s$, spiracular sac of the imago; s.c, stigmatic cornu of the pronymph; sp, spiracular cornu of the nymph; $t, t$, lumen of trachea of the nymph.

Fiti. 6.- A section through the anterior spiracle of the nymph on the twetfh day of the pupa.

Fu: $7 .-A$ similar section through the anterior spiracles of the nymph, alsout the seventh day of the pupa stage.

Fu. S. - A portion of one of the wax glands of the imago seen with a 1. inch oil immersion objective.

All the figures are drawn with an inch object glass except when otherwise stated. 
PLATE XYII.

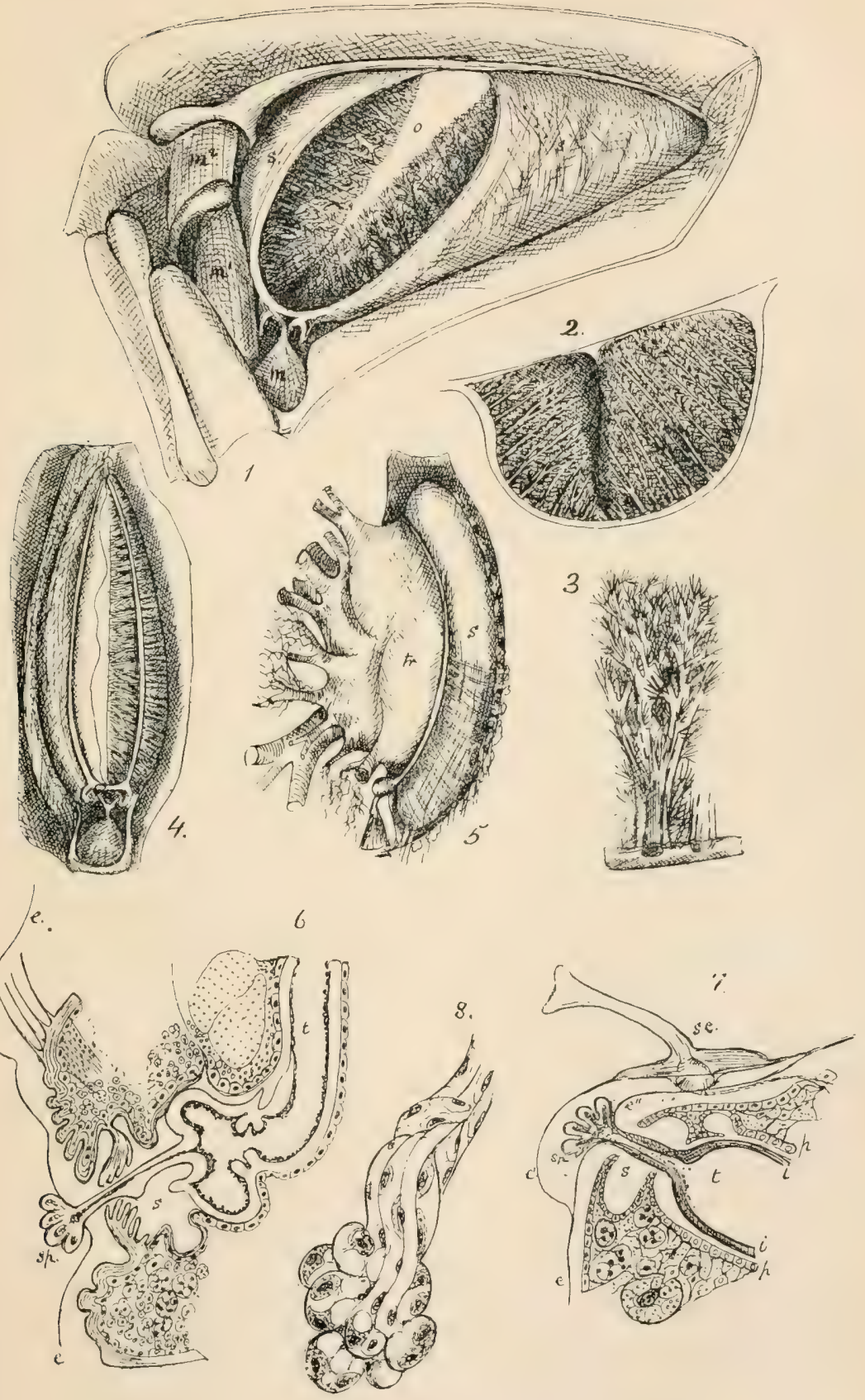



in a membranous fold of the air-vessel (Pl. XXII., Figs. I and 3). This valve is controlled by a small fan-shaped muscle. The internal valves were figured and described by Landois [150] and Krancher [154].

The Vestibule.-I have applied this term to the membranous sac between the external and internal valves. The vestibule is covered externally by a layer of muscles, which arise from the integument at the edges of the spiracle. The muscle may be termed the compressor vestibuli.

The Mechanism of the Spiracle and its Valves.--The external valve plates are of unequal size; the larger one is apparently fixed. The smaller valve is only attached by its base, and opens inwards. Landois describes it as opening outwards; but it is easily dislocated, so that it can then be turned outwards. Both valve-plates may be removed with a little care, even in the living insect, when the vestibule is exposed, and the movements of the internal valve can be watched.

The upper edge of the spiracular opening exhibits a kind of flange, against which the outer surface of the margin of the smaller valve-plate rests. The smaller valve-plate is opened by a few muscle fibres attached to its fixed border, and it is probably closed by the pressure of the air in the vestibule when the compressor vestibuli contracts.

The internal valve opens and closes rhythmically, like a pair of side curtains. Its movements were first seen by Landois. The removal of the external plates is not difficult, but it is most easily done from the anterior spiracle, as it is necessary to cut off the abdomen to see the valves of the posterior spiracle. Even after this operation the internal valves continue to open and close rhythmically for some time. The rate of movement after such an operation cannot, however, be regarded as normal; and is probably far less frequent than when the insect is uninjured.

It appears to me certain that the function of the vestibule is that of a pump, which drives air into the tracheal vessels.

The Anterior Spiracle only differs from the posterior in its form. It is possible to remove the whole spiracular apparatus, 
with a portion of the tracheal sacs and the surrounding integument, by an incision made about one millimetre from the edge of the spiracle, and surrounding it. If this is done, the tracheal sacs will be found full of air. If before removing the spiracle the insect is immersed for a few seconds in alcohol to remove the wax, the vestibule will be found full of fluid. The efficiency of the internal valve is then seen to be very great, as no air will escape from the tracheal sacs through the spiracle. Of course, the lissection must be made under water or dilute Müller's fluid. I use one part Müller to ten of water.

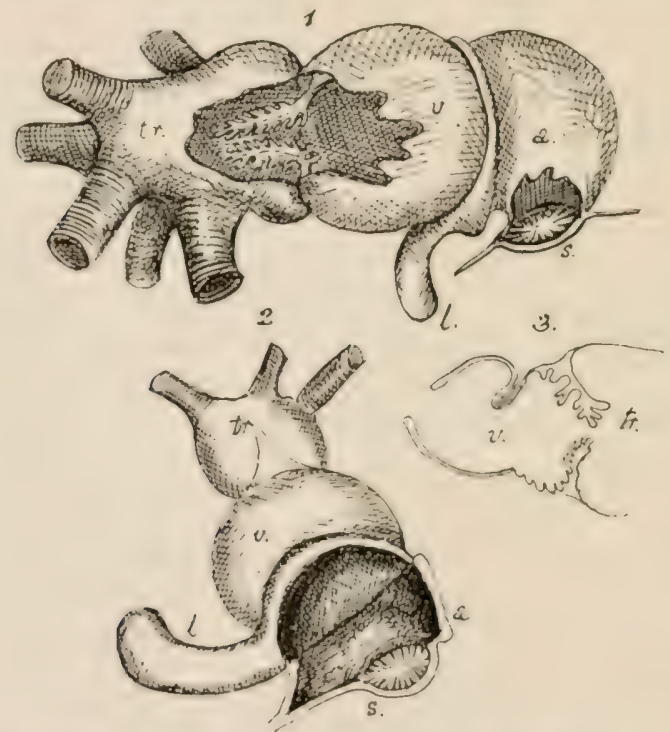

la: 4S. The Abluminal Spiracular Apparatus of the Imago: $r$, a semi-diagram. matic representation of the spiracular apparatus of the third alxlominal spiracle; $\therefore$ another view of the same, with a portion of the wall of the atrium removed to how the extermal valve; is a section of the vestilule and trachea, showing the llaps of the internal valve; $"$, atrium ; $l$, lever ; $s$, spiracle; $t r$, trachea; $v$, contractile vestibule.

I have frequently observed that the tracheal sacs expand when relieved from the pressure of surrounding parts, showing that they contain compressed air.

There are several valves opening inwards in the course of the 
spiracular trunks, but they are more easily demonstrated by the behaviour of the contained air than by any other method. Some sections show the valve flaps more or less perfectly.

The small Tympanic Spiracle is situated in the tympanic fissure (p. 187); it is connected with a complex auditory and sound-producing apparatus, to be described hereafter. It is controlled by a single valve, which resembles a clip, and closes the tracheal tube, with which it is connected. This spiracle is apparently exclusively expiratory, and I believe the issue of air from it is the cause of the humming sound made by the insect. it is the only spiracle from which air issues; all the others are exclusively inspiratory.

The Abdominal Spiracles are minute circular openings; each orifice is fringed by minute setæ springing from its edge. These undoubtedly serve to exclude dust. Immediately within the external orifice there is a short curved tube-the atrium-the inner surface of which is thickly set with fine double setæ, two setæ arising from a thickened base.

The inner extremity of the highly chitinized atrium is closed by the external valve; beyond this is the spiracular sac, which is separated from the true tracheal trunks by the inner valve (Fig. 48).

The External Valve consists of a half-ring of chitin, the bow (Verschlussbiggel) of Landois; from which a lever (Heber, Landois) projects. The extremities of the bow are united by a semilunar plate, the valve-plate (Vcrschlussband, Landois), by which the orifice can be hermetically closed.

The valve-plate opens inwards, and when closed its margin rests against the bow (Fig. 48, 2). One extremity of the bow is continuous with the lever, the other terminates in a slender spiral spring, which terminates in a ring surrounding the vestibule, and separates it from the trachea. This ring supports the inner valves, which resemble those of the veins of Vertebrates, and project into the tracheal trunk.

The lever is moved by a muscle, the contraction of which separates the inner and outer valves, and draws air into the vestibule or spiracular sac. The abdominal spiracular sacs 
open and close like bellows, on a hinge formed between the how and the spiral prolongation of the bow which supports the inner valve.

There is a layer of muscle fibres extending between the rings which support the inner and outer valves, and these, by their contraction, effectually empty the spiracular sac, forcing the air which it contains through the inner valve into the tracheae.

The outer valve is opened by the contraction of the muscle of the lever which depresses the bow; as soon as this muscle relaxes the outer valve closes. This is apparently effected by the clasticity of the curved atrial tube and of the bow; the muscle of the spiracular sac then contracts and draws the inner and outer rings together, at the same time opening the inner valve and driving the air into the trachere. The spiracular sac is opened again by the spring-like action of the spiral which supports the inner valves, and the depression of the lever which opens the outer valve. In short, the vestibule or spiracular sac is a small bellows which pumps air into the tracheal tubes.

The trachee, which arise from the first and second pairs of abdominal spiracular sacs, communicate directly with the aërostats (p. 2I 7 ) or abdominal pulmonary sacs; those of the remaining abdominal spiracles form arborescent trachee which are not directly connected with the thoracic trachea and with each other, except by small or capillary branches. These trachea do not dilate into air-sacs in the Blow-fly, although in many insects the abdominal trachere, like those of the head and thorax, dilate and form thin-walled air-sacs.

\section{b. Structure of the Tracheæ and Air-sacs.}

The Tracheæ and Air-sacs, in dissections made uncler water or glycurine, exhibit, as is well-known, a silvery' lustre, and appear with reflected light like tubes or vesicles filled with mercury. This appearance is due to reflection from the surface of the contained air. It is very beautiful, and may be preserved in dissections momnted in grlycerine; for if the cells are properly sealed, the air is not dissolved out of the larger or even moderate- 
sized trachex, although it soon disappears from the tracheal capillaries. I have specimens made thirty years ago, in which the silvery lustre, due to the contained air, still remains as a characteristic of the tracheal vessels.

Although the trachex consist in all insects primarily of an external cellular or peritoneal coat and of a cuticular intima, similar to those described in the larva (p. 48), the definitive condition in the imago varies considerably in different insects, and depends upon the relative development of these coats.

In some insects, especially in the Lepidoptera, the peritoneal coat persists as a continuous layer of thick cells, which become loaded with fat granules; whilst in others, as the Blow-fly, the external coat becomes exceedingly thin, and is seen to consist of stellate cells, which leave considerable lacunæ between their branches, where the wall of the vessel consists of cuticular intima only.

The intima of the larger cylindrical trachex always exhibits the well-known spiral fibre in the Blow-fly imago, but this is lost in the smaller branches and in the great dilated air-sacs. It only differs from the spiral fibre of the larval tracheæ in being finer and more closely coiled.

The Air Sacs have an exceedingly fine silvery-looking intima, thrown permanently into minute rugæ, which give it an iridescent appearance under certain conditions of illumination.

The rugæ are more marked and larger in the vicinity of the cylindrical tracheæ, which arise from the sacs; they are there seen to be due to a thickening of the membrane. This thickening is more marked in the vessels which are in contact with the brain, great eyes, and thoracic ganglion; and these exhibit a dark-brown tint. This thickening of the walls of the air-sacs apparently serves to protect the soft structures with which they are in relation from undue pressure.

In the nymph the air-sacs are deeply plicated and covered by a thick peritoneal coat, consisting of closely-united cells, which give off processes extending between the plicæ of the intima. In the imago, however, the great distension of the 
air-sacs, which occurs soon after the insect emerges from the pupa, separates the cells of the peritoneal coat, so that they ultimately form a mere stellate network on the outer surface of the intima. It may be best described as a delicate widemeshed reticulum of stellate cells.

The air-sacs give off numerous arborescent cylindrical ressels, which are distributed to the various internal parts, on the surface of which they form a delicate network, from which the tracheal capillaries arise. The distribution of their branches is precisely similar to that of the branches of the abdominal arborescent trachea, which arise directly from the spiracular sacs.

The intima of the smaller trachere exhibits no spiral marking, but, like that of the tracheal capillaries, is apparently structureless.

Intra-Tracheal Valves.-So far as I know, no writer has hitherto described valves within the air tubes except at their spiracular orifices, but such valves certainly exist, although they are not easily demonstrated by sections. They are apparently very numerous, and I believe they always exist in the narrow channels between the air-sacs.

These intra-tracheal valves are somewhat like the valves in the veins of Vertebrates, but they have corrugated surfaces and the ruga interlock when the valves are closed; these rugat give the valve-flaps a fimbriated appearance in sections (Fig. $\left.f^{8}\right)$.

I have on several occasions seen such valves between the great abdominal air-sacs and the paragastric trunks, which permit the air to pass forward, but not backwards; hence the contraction of the abdomen serves to raise the intra-thoracic air pressure by increasing the quantity of air in the thoracic cavity.

The movement of the air is alsu controlled, in some of the tracheat, by infoldings of the intima, which are opened and closed by muscles; such valves are found in the head, and serve to open and close the great tracheat of the proboscis (see Chapter XI.)

The valumar arrangements of the intima of the trachea 
become obvious, during the dissection of these vessels, as the air can be driven by pressure in one direction only, towards the smaller branches, but never backivards from the smaller to the larger trunks.

Relations of the Tracheæ to the Blood-Sinuses.-All the large tracheal sacs lie in blood-sinuses, which can be injected by inserting the needle of a hypodermic syringe into the dorsal thoracic sinus; the legs should be cut off to allow the blood to be replaced by the injection. The air-sacs may be described, therefore, as being surrounded by narrow blood-sinuses. In this sense there is a true peritracheal circulation, and the air is only separated from the blood by a thin cuticular plicated membrane. The larger cylindrical trunks also lie in the walls of blood-sinuses.

Peritracheal Circulation.-The manner in which the bloodcurrents follow the course of the tracheal vessels has been repeatedly observed, and Blanchard* described a blood-passage between the membranes of the tracher and the spiral thread, which he believed to be a separate structure. Blanchard's theory of an intra-tracheal circulation was the result of a misconception as to the structure of the tracheæ, and is, of course, not possible, but in the sense explained above the circulation is essentially peritracheal.

It is certain that all the tracher, even the finest capillaries, are bathed by the blood, and it is probably to the blood only that they give their oxygen, from which it is absorbed in turn by the tissue elements, and stored as intra-molecular oxygen.

The Arrangement of the Capillary Network indicates that there is no continuous air circulation. This is especially seen in the rectal papillæ, in which the capillaries form a tuft separated from those of other parts by a chitinous capsule. These organs have only a single tracheal trunk, and not an afferent and an efferent vessel.

The capillaries all ramify in the reticular connective tissue of the colom, and are therefore surrounded by the nutrient fluid; 
they do not enter the muscle-fibres and do not generally penetrate the epithelial walls of the body or viscera.

There are, however, some exceptions to this: trachere penetrate the nerve-centres, and dioptron; ramify between the large epithelial cells of the rectal papille, and also penetrate the thicker portions of the proventriculus.

I know no other parts in which the trachere enter the epithelial layer. IWhenever they do there are distinct prolongations of the reticular tissue of the colom between the epithelial elements.

\section{THE DEVELOPMENT OF THE TRACHEAL SYSTEM IN THE BLOW-FLY.}

The manner in which the first tracheal trunks are developed in the embryo has been already described, but, owing to the difficulties which beset the investigation, it is satisfactory to find that the subsequent changes, which occur in the larva and pupa, bear out the views of WTeismann on the development, and of Gegenbaur on the morphology of the tracheal system.

Development in the Larva.-As W Weismann oliserved [2, p. I I 5 ] the tracheal system is profoundly modified during the growth of the larva and the development of the nymph. In the larva the changes in the tracheal system are: (I) a continual increase in the number of arborescent traches, together with a corresponding increased complexity of the tracheal network, which invests all the internal organs and supplies the hypodermic layer of the integument; (2) The development of the anterior spiracles or stigmatic cornua; and (3) The re-derelopment of the posterior spiracles.

New Ramifications of the Tracheæ first appear as buds or solid outerrowths of the peritoneal coat of the old ones; these buds become hollow and are at first filled with fluid; a new intima is then developed, but no air finds its way into them until the next ecdysis, when the intima of the new branches is found to be continuous with the new intima of the older trunks. The capillaries are developed in the interior of the stellate cells of 
the reticular connective tissue, which are also formed from the proliferating cells of the peritoneal coat of the new tracheal vessels. The process is intrinsically identical with that by which the principal tracheal trunks are formed in the embryo; except that the germs of the new vessels are developed as buds, instead of being directly differentiated from the parablast.

The Posterior Spiracles of the newly-hatched larva are circular orifices in the transverse stigmatic furrow (Fig. 4I), but at the first moult these simple spiracles are replaced by the stigmatic plates. Each of these is at first perforated by two slit-like openings, but at the next ecdysis a third slit-like opening is developed between them, and the stigmatic plate assumes the characters of that of the adult larva already described (see p. 49).
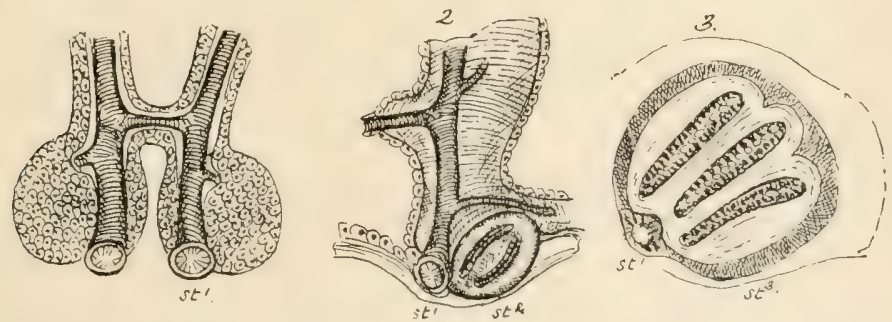

FIG. 49.--The Posterior Spiracles of the Embryo and Larva: 1 , the posterior spiracles of the fully-developed embryo, showing the bulbiform enlargements of the peritoneal coat of the main trachex from which the second set of trachex are developed; 2 , the posterior spiracles of the larva after the first ecdysis; 3 , the posterior spiracles of the larva after the second ecdysis; st, the first; st", the second, and $s t^{3}$, the third spiracles.

The Stigmatic Plate is developed from the hypodermis, and exhibits a scar on its inner edge produced by the closure of the circular spiracle of the mature embryo. The second spiracle is not formed by a modification of the first, but is a new formation. In the newly-hatched larva the great tracheal trunk exhibits a bulb-like projection of its peritoneal coat. This is at first solid, but ultimately becomes hollow; its cavity is continuous with a space formed by the separation of the peritoneal coat of the tracheæ from its intima. It is in direct relation with the nypodermis. 
The exart relative share taken by the hypodermis and the bullus enlargenent of the trachea in the formation of the second spiracle is not known, but analogy renders it probable that the vestibule origrinates from the hypodermis, as well as the stigmatic plate.

Anterior Spiracle.-The development of the anterior spiracle in the larra is not easily studied: but if it is developed in the same way as that of the nymph, which is most probable, the process must be very nearly as follows.

The spiracular tracheal trunk is probably developed in the usual way, by the proliferation of the peritoneal coat of a lateral cutaneous branch of the main trunk, which first appears as a solid bud; and the hypodermis on the outer surface of this loud is then invaginated. The finger-like processes are developed within the invagination. Subsequently the invagination is turned inside out and forms the larval stigmatic cornu. Hence there is no spiracular sac, and the outer surface of the cornu apparently represents it.

The question as to whether the stigmatic cornua of the dipternus larve and nymphs should be regarded as gills or as spiracles, has been the subject of some difference of opinion.

Veismann considered the anterior spiracular apparatus of Corethra to be intermediate between the digitate spiracular cornua of the larva in Musca and the tracheal gills of some Tipulidex, and Palmén groes even further [153] and says: 'The prothoracic horns of Corethra are identical with those of Culex; these are not stigmata but true tracheal gills, which are shed with the exuviax, and take no part in the formation of the prothoracic spiracles of the imagro:" Whether these respiratory appendages are closed as Weismann and Palmén believed, and as those of the Blow-fly apparently are in the adult larva, or whether they are open and functionally spiracles, as Hurst has recently shown them to be in Culex [155]; it is certain that they are shed and are not converted into the spiracles of the imago.

This fact is of interest in relation to Palmen's discovery that the spiracles of the imago in the Ephemeride are developed independently of the tracheal gills, and are not, as was 
formerly supposed, openings left by the shedding of the gills.

The researches of Dewitz [159], which show that the tracheal gills are developed from spiracles, render it probable that the stigmatic cornua of dipterous larvæ are homologous with tracheal gills, as Palmén supposed them to be. The question whether they are pervious or not is a secondary one, and it is possible that they may be pervious only for a short time. They are certainly closed when they are first formed, so that it is probable that Hurst and Palmén examined insects in different stages of development.

Development of the Stigmatic Cornua of the Pronymph. - The great cornu of the prothorax of the pronymph is undoubtedly. developed, as has been already stated, from the upper prothoracic disc. It first appears as an invaginated sac surrounding the tracheal trunk, which connects the anterior stigma of the larva with the great lateral trachea. This sac afterwards encloses the cuticular cornu, which comes to the surface as the prothoracic disc is everted; it is indubitably the homologue of the great stigmatic cornu of the nymph of Culex, which it also closely resembles. It is shed at a very early period in the development of the nymph, and no new spiracle is developed in relation with it.

The Development of the Stigmatic Intersegmental Cornua of the Nymph.-The manner in which the intersegmental cornu of the nymph is developed may be easily studied. A new tracheal trunk originates by the enlargement of the distal extremity of a cutaneous tracheal vessel, in the vicinity of the old spiracle. The wall of this vessel is separated from the old intima by fluid. The hypodermis is then invaginated in relation with the enlarged trachea, and the finger-like extremities of the cornu are developed within the invagination; this is afterwards everted, and forms a new digitate stigmatic cornu.

Development of the Anterior Spiracles of the Imago. - The anterior spiracles of the imago are developed in immediate relation with the stigmatic cornua of the nymph, by the further invagination of the integument and the ecdysis of the external 
portion of the intima and of the whole stigmatic cornu. The new tracheal trunk is at first constricted at its orifice, where the peritoneal coat remains in contact with the old intima, but internally to this point it becomes widely separated from the intima by fluid (see Pl. XXII.).

The stigmatic sac is developed from the invaginated hypoderm, and the outer valve-plates are also formed from the hypoderm. The internal valve is probably developed from the constricted orifice of the new trachea.

The Order of Succession of the Anterior Spiracles in the larva nymph and imago is as follows: The stigmatic cornu of the prothorax of the larva is shed with the larval integument which forms the pupa-case, but is replaced by the newly-formed stigmatic cornu of the pronymph. This resembles the respiratory siphon of Culex very closely; it is developed from the dorsal prothoracic inaginal disc, and is shed with the pupa-sheath.

Before the shedding of the pupa-sheath, however, a third spiracular apparatus appears behind and below the stigmatic cornu of the pronymph. This is the inter-segmental spiracle of the nymph. It is a digitate cornu similar to, but more simple than, the stigmatic cornu of the larva, inasmuch as it has fewer digitations. It is developed in relation with a new tracheal vessel given off behind the prothoracic spiracular trunk of the larva.

Lastly, a new spiracle replaces this, the anterior thoracic spiracle of the imago, formed by the invagination of the cellular integument of the nymph in immediate relation with it, and with the tracheal trunk which opens through it.

The existence of two sets of spiracles which are shed in the pupa stage, the stigmatic cornua of the pronymph, and the digitate inter-segmental spiracles of the nymph, indicate the existence of two virtual ecdyses, resulting in the pupa-sheath, and not one as has hitherto been supposed-the separation of the stigmatic cornu from the prothorax certainly occurs at an earlier period than that of the inter-segmental spiracle, and the latter appears to be covered by the pupa-sheath in some preparations (see Pl. XX., Fig. 3). 
In other preparations the pupa-sheath is seen to be connected with the base of the inter-segmental spiracular cornu. I am inclined to believe that the pupa-sheath of Weismann is the result of a second ecdysis; and, in parts, at least, the pupasheath is distinctly formed of several layers closely pressed together. It is probable, I think, that two or more ecdyses occur, which are either partial or complete; but owing to the extreme thinness of the shed layers it is extremely difficult to trace them. It appears to me probable that the first ecdysis is only partial, and is limited by the extent of the discs at the time of its occurrence, as there is no appearance of a continuous membrane enclosing the whole of the limbs in a single sheath, a condition which could hardly fail to exist if a complete ecdysis occurred before their evolution. The only indications of more than one ecdysis in the pupa are the early separation of the prothoracic stigmatic cornua, and the laminated structure of the pupa-sheath.

The Posterior Thoracic and Abdominal Spiracles of the imago are all new formations in the nymph, which had no predecessors in either the larva or pronymph; but they are developed in precisely the same manner as the larval spiracles and the anterior thoracic spiracles of the nymph; that is, by the invagination of the cellular integument, which forms the spiracle and vestibule, in relation with a newly-formed tracheal vessel, which is developed from one of the tracheal branches distributed to the integument.

\section{THE PHYSIOLOGY OF RESPIRATION IN INSECTS.}

It has been asserted that the respiration of insects, when in full activity, has the same energy as in the higher vertebrates; this statement is, however, misleading, and cannot be accepted without modification.

From the observations of Regnault and Reiset [157], it appears that insects absorb a weight of oxygen equal to $\frac{1}{1000}$ th of their body weight per hour. This estimate does not differ materially from that obtained amongst moderate sized 
mammals. In man the amount of oxygen absorbed is less than $\frac{1}{1000}$ th of the body weight per hour.

It must be observed, however, that in warm-blooded animals the proportionate amount of oxygen to the body weight increases very rapidly as the size of the animal experimented on diminishes; thus in the Dormouse it equals th of the body weight per hour, and in small birds it is even as much as -1 th, therefore it is clear that the comparison of the oxygen absorbed to the body weight of those warm-blooded vertebrates which approach most nearly to insects in size leads to a very different conclusion.

On the other hand, insects absorb about twenty times as much oxygen as cold-blonded vertebrates-Irogs and Lizards -weight for weight, from I,000 to 2,000 times more than the higher Mollusca, and 200 to 400 times as much as the higher Crustacea, if the observations recorded by various observers are correct.

The respiratory quotient, or the relation of the $\mathrm{CO}$ given off to the $\mathrm{O}$ absorbed $\left(\begin{array}{c}\mathrm{CO}_{2} \\ \mathrm{O}_{2}\end{array}=\cdot 79\right)$ is low; in man it is given as $0^{\circ} 9$. This, perhaps, indicates that the proteid metabolism is more rapid, but it is capable of other interpretations, as. for example, that more hydrogen is oxidized in proportion to carbon; but our knowledge is too limited to justify any conclusions on this point.

As a single Cockchafer (Mclolontha iulgaris) absorbs all the oxygen contained in seven cubic centimetres of air in an hour, the least quantity of air which must pass into the trachea in this time is $7 \mathrm{cc}=7,000$ culic millimetres, and that on the supposition that the whole of the oxygen contained in the inspired air is absorbed.

The spiracular sacs of the thorax are six in number, and I estimate their united cubic contents to be equal to about 6 cubic millimetres. The spiracular sacs of the abdomen are twelve in number, and I do not think their united capacity exceeds 2 cubic millimetres. The number of respiratory contractions of the spiracular sacs may be estimated at about reo per 
minute, and on these bases the eighteen spiracular sacs would drive 7,200 cubic millimetres of air into the tracheæ per hour. It may be assumed, I think, that during flight an even higher respiratory energy may exist; but even with 240 respiratory acts in a minute, a number which may probably be excessive, only 14,400 cubic millimetres of air could be taken into the tracheæ. On these grounds it may be safely concluded that the whole of the oxygen is taken from the inspired air.

Of course the above must be regarded only as an approximation to the truth, but it cannot be very far wrong.

Peyron [158] showed by actual analysis that the quantity of oxygen in the gases obtained from the interior of the bodies of insects does not exceed 8 or 9 per cent., whilst $7^{\circ}$ per cent. is nitrogen, and the rest carbon dioxide-the latter is probably in solution in the blood, and if this is so the tracheal air would consist of about Io per cent. oxygen, and 90 per cent. nitrogen.

In the Blow-fly similar conclusions may be arrived at on the same bases, but the numbers cannot be so accurately estimated. I think it is probable that the quantity of air capable of being inspired is proportionately greater than in the Cockchafer, perhaps even twice or three times as great, weight for weight; but a large quantity is expended in producing the buzzing sound in flight. This excess is probably supplied by the greater proportionate size of the thoracic spiracles and spiracular sacs. The small size of the abdominal spiracles and spiracular sacs must be remembered, and I do not think it possible that more than three or four cubic centimetres of air can enter the respiratory sacs and tubes per hour, and I suspect that considerably less is really inspired.

The inspired air gives up its oxygen entirely or partially to the blood, from which it is removed by the tissues, and stored by them as intra-molecular oxygen. That the tissues are richly supplied with oxygen in insects is evident from the length of time they survive when deprived of air.

Received View.-It is usually held that the spiracles act alternately as inspiratory and expiratory orifices, and that the influx 
of atmospheric air, and the efflux of air, vitiated by carbon dioxide, are produced by respiratory movements of the thoracic and abdominal walls.

This view originated with Treviranus; but both Reaumur [5] and Lyonet held that the air only passes into the trachea by the spiracles, and that expiration is effected by the transfusion of the carbon dioxide formed in the tissues, and of the inert nitrogen of the air through the whole surface of the integument and the walls of the alimentary canal.

Not only is the view of Treviranus negatived by my researches on the structure of the respiratory organs, but also by physical difficulties which are insuperable, and these, as will be seen, entirely disappear when we return to the theory of Reaumur aid Lyonet. This theory is supported not only by anatomical evidence, but by numerous physical facts, which I shall now proceed to investigate.

The Respiratory Movements of the Abdomen can only affect the compression of the air within the tracheal vessels, and could therefore only be expiratory. A very little consideration will show that the contraction of the muscles, which form a layer beneath the abdominal integument, must diminish the extent of its cavity. This is effected by the invarination of the segments, and the approximation of the lower edres of the dorsal arches and the sternal plates. The loose syndesmotic integument is infolded by muscular contraction, and although the elastic recoil of the dorsal arches may to some slight extent increase the vertical and transverse diameters of the abdome:n, its elasticity is powerless to protrude the invaginated segments.

The expansion of the abdomen is effected by the elasticity of the contained air, and the abdomen of a dead insect collapses. When the imago fly first emerges from the pupa, its abdominal integuments are soft and thick, and the whole carity is small; it is only when respiration has been fully established, and the tracheal ressels are distended, that the abdomen is enlarged to its full size; the expansion and thinning of the integument is produced by the pressure of the inspired air, and is not the cause of inspiration. 
The function of the abdominal muscles is to maintain the air-pressure, and to expel the generative products and fieces. The alternate contraction and expansion of the abdomen which occur during flight are not respiratory, but a means of regulating the intra-thoracic air-pressure. I have frequently convinced inyself that there are no rhythmic movements of the body wall in the blow-fly when at rest.

Thoracic Respiratory Movements. - At first sight it will appear, perhaps, as many have held, that inspiration is effected by the enlargement of the thorax, and I think it possible that when the intra-thoracic air-pressure is low, some air may be drawn into the thoracic tracheæ by the contraction of the longitudinal thoracic muscles (dorsales). There is, however, no doubt in my mind that the air-pressure in the tracheæ is normally higher than the atmospheric pressure; the air cannot in this case be renewed by expansion of the thorax.

The Intra-tracheal Pressure.-That the air contained in the tracheal tubes is compressed, is shown by the fact that the membranous tracheæ may frequently be seen to expand when relieved of the pressure of surrounding parts; and by the continuous nature of the humming sound produced by the escape of air from the tympanic spiracle. I have been unable to determine the internal pressure, but the following facts, I think, justify the assumption that it is not less than two or three inches of mercury, higher than that of the surrounding atmosphere, in a vigorous blow-fly.

If an opening is made into the great air vessels the insect becomes helpless. I believe the experiment, which has frequently been made to determine the function of the balancers by cutting them off, an operation which destroys the insect's power of flight, or even of supporting its own weight on its legs, really gives rise to these phenomena by reducing the internal air-pressure; as it is impossible to remove these organs without laying open the great tracheal trunks in the vicinity of the posterior spiracles.

The proboscis is exserted and erected (see Chap. XI., Sect. I) by the air-pressure in its great tracheal trunks, and, as 
Kraepelin pointed out, the flow of salivary secretion from the lingual glands is due to intra-thoracic pressure.

During flight the hypopterygia and sacculi are kept distended (erected) with air, notwithstanding its continuous escape, by which the humming sound emitted is produced.

Such an intra-tracheal pressure would be sufficient to account for the elasticity of the limbs and wings of the living insect, as the distended tracheal tubes would aid greatly in supporting its weight on its long slender legs, and would give the recluisite rigidity to its wings in flight. Such a pressure would be sufficient to enable the insect to support a weight equal to that of its own hody, with the extended proboscis; the strength of this organ when exserted indicates a positive air-pressure equal to about 50 to $75 \mathrm{~mm}$. (two or three inches) of mercury, a conclusion at which I arrive by an estimate of the tracheal surface of the expanded oral disc. Such a pressure would be maintained by a very moderate compression of the air in the main trachere, a diminution of its volume by one-tenth.

The entrance of the air into the finest tracheal capillaries, which do not exceed i $\mu$ to $2 \mu$ in diameter, whilst some are of immeasurable fineness, is a difficulty which can be more readily explained by a positive pressure in the larger air-trunks. Wistinghausen* has remarked that the finest capillaries are rapidly emptied after death, either by the elasticity of their walls, or by the absorption of lluid; so that it appears as if they are kept full during life by the intra-tracheal pressure.

Expiratory Pressure.-The received view of expiration in insects presupposes that the contraction of the body carity would drive air from the smaller to the larger air-tubes; as both would, however, be subjected to an equal increase of pressure, no such movement could occur. It is not clear, therefore, how an expiratory effort could effect a change of air in the tracheal vessels, even of the third or fourth magnitude. I have sought in vain for any cridence of an expiratory current from the spiracles. I formerly tried to extract the air from the trachea and replace it by immersine insects in fluid and * Zeitsch. f. w. Zoul., Bd. 49, p. 565. 
exhausting by means of an air pump, but never succeeded in doing so. It is true that bubbles of air do escape from the thoracic spiracles, when insects are put into hot water or even spirit; but in the former case the valves of the spiracles are dislocated or ruptured, and in the latter the air, which rises in bubbles to the surface, is that which adheres to the exterior of the spiracle and fills the vestibule. The tracheal vessels themselves remain full of air for a long time, a fact which is sufficiently manifest when the insect is dissected after immersion for an hour or more. When the waxy secretion is removed the efficacy of the external valves is destroyed, and the contracting muscles open the internal valves. Experiments which give rise to solution of the wax and to muscular rigidity, are therefore without value; such, for example, as immersing the insect in alcohol, or even in hot water.

The inadequacy of the supposed expiratory movement of the body wall to change all the gas in the tracheæ, or even a large proportion of it with each respiratory act, is so manifest, that it precludes the acceptance of the expiratory theory of Treviranus; if $\mathrm{I}$ am right in my conclusion that all or nearly all the inspired oxygen must be utilised to account for the metabolic activity of a lively insect.

Passage of Gases through the Integument--Herman Dewitz [159] made direct experiments on the passage of gases through the skin of the larva of Smerinthus ocellatus. He used the portion, which has no spiracles, to close the mouth of a test tube containing air, and immersed the tube in an atmosphere of carbon dioxide. He then found that the skin became very convex in an hour, showing that carbon dioxide passes in more rapidly than air passes out. He also reversed the experiment by filling the test tube with carbon dioxide, when the skin became deeply concave. In both experiments he observed on perforating the skin that equilibrium was restored by a rush of gas, which made a loud sound.

Dewitz does not mention the condition of the skin, whether moist or dry, but it was presumably moist.

There can be no doubt the passage of gas through the 
tracheal walls and the skin of insects is a complex phenomenon, and depends partly upon the solution of the gas, and partly upon transpiration. The external chitinous integument probably acts like a porous plate of gypsum, whilst its deeper layers, and the intima of the trachex, are moist films. The condition and tension of the carbon dioxide, of the oxygen and of the nitrogen of the absorbed air are different, and need separate consideration.

Absorption of 0xygen.-If, as I hold, the air is pumped into the tracheat by the contractile vestibules, the condensed yas is placed under circumstances which are especially favourable for its solution in the blood. The oxygen, once in solution, is probably immediately appropriated by the tissues, in which the oxygen tension, if we may judge by the phenomena observed in vertcbrates, is reduced to zero; the blood is therefore always ready to absorb more oxygen, and the percentage of oxygen in the trachere would therefore, probably, always be very low; as it is in the alveoli of the vertebrate lung. It is probable that all the oxygen is capable of beingr absorbed from the tracheajust as a mouse in a confined space absorls all the oxygen before it dies.

The Action of Tracheal Gills has always offered a difficulty, which, so far as I know, has as yet remained unexplained; but this difficulty ranishes as soon as the low percentage of oxygen in the trachea is admitted; as the oxygen, dissolved in the water, has the same tension as the oxygen in the air it would diffurse into the tracheal ressels, where they are exposed to the water in the gills.

Such diffusion would not occur into and distend empty tubes or tubes containing fluids, but I)ewit\% [159] has, I think, established the fact that the s()-called closed tracheal tubes of these insects are not closed: at least the anterior thoracic spiracles are open; and it appears probable that air is taken in from time to time, so that the tubes always contain a gas, into which oxygen diffusion from the water is possible. It is almost certain that the tracheal gills are only accessory respiratory organs, serving to renew the oxyeren in the air, contained in the 
tracher, as fast as it is removed from them by the blood. If, as appears probable, the oxygen tension in the fluids of the insect is reduced to zero, the tendency of the general integument will be to admit oxygen through its porous substance. With a pressure externally of $\mathrm{I} 53 \mathrm{~mm}$. of mercury, the normal oxygen pressure of the air, and a pressure of zero internally, unless the integument is impervious to air, oxygen must be absorbed through it. The transpiration of oxygen through the integument can hardly fail to occur, and is probably an important factor in the respiration of insects.

Excretion of Carbon Dioxide. - The received view, that expiration occurs through the spiracles, is rendered untenable by the physical difficulty involved in the entrance of the carbon dioxide, formed by tissue metabolism, into the tracheal tubes. There can be no doubt that the blood contains carbon dioxide in solution at a high tension, and that diffusion must occur into the adjacent air. That some may diffuse into the tracher is possible, but owing to the small quantity of air they contain, a very small quantity would raise the carbon dioxide tension in them to that of the blood, whilst the diffusion into the external air, through the body wall, is constant, the carbon dioxide tension of the surrounding air being practically zero. This difficulty is so great, that the idea that the tracher are concerned in the excretion of carbon dioxide must be entirely abandoned as soon as it is seriously considered.

That the carbon dioxide tension in the blood is considerable follows from the large percentage of carbon dioxide in the gases which can be extracted from the insect; and as its transpiration through the integument, from this high tension into the atmosphere in which the tension of carbon dioxide is practically zero, must take place as a physical necessity; there is no difficulty in the view that carbon dioxide is excreted from the general surface of the insect.

As I have already shown, the quantity of carbon dioxide which can pass into the tracheæ is limited, whilst its escape from the body surface is practically unlimited, and depends entirely on the rate of transfusion under a pressure from within outwards. 
Action of Films on Gases. - The escape of carbon dioxide from the surface is possibly complicated by another observed phenomenon. Graham showed that caoutchouc and other colloid sulstances have the property of condensing certain gases in their substance, and that these then escape from an exposed surface like a highly volatile liquid. Now, chitin is a colloid substance, and although it is permeable to all gases like a porous membrane, it is possible that it has a special power of absorbing carbon dioxide; which, from its weight, transfuses slowly when compared with oxygen and nitrogen. The rapid transfer of carbon dioxide observed by Dewitz [159 ] is suggestive of this explanation.

Transpiration of Nitrogen. - The greatest difficulty which occurs in the acceptance of the view here adrocated is the nitrogen of the air. It would appear at first sight that the nitrogen must accumulate in the tracheal tubes, owing to its slight solubility in the fluids of the body.

Graham showed that the transpiration of a gas is dependent on its pressure, and that equal weights of various gases underso transpiration in equal times. Now the tension of a gas in solution is dependent on the tension at which it is absorbed, and Peyron showed that the percentage of nitrogen is as large in the mixed gases abstracted from the insect as in the air ; as the solubility of nitrogen is small, and that of carbon dioxide is large, it follows that the greater part of the nitrogen is in the trachea in a gascous condition, whilst the greater part of the carbon dioxide is necessarily in solution in the fluids of the insect. It may therefore be concluded that the nitrogen pressure in the tracheal tubes is at least go per cent. of the total air-pressure in those tubes. If I am right in the view that the pressure of the air in the trachea is from $5^{\circ}$ to $75 \mathrm{~mm}$. above the atmospheric pressure, taking the lowest of these numbers and adding it to the atmospheric pressure, $-60+50=810 \mathrm{~mm}$., the intra-tracheal pressure, and if go per cent. is nitrogen pressure, this equals $729 \mathrm{~mm}$., whilst the partial pressure of the nitrogen in the atmosphere is approximately 600 mm., hence there is a difference of pressure 
equal to nearly $129 \mathrm{~mm}$. of mercury between the external and the internal nitrogen pressure, which would sufficiently account for the transmission of the nitrogen from the blood, in which the tension of nitrogen would equal the higher pressure, through the cuticular epidermis, to the atmosphere, by transfusion.

The objection that the passage of the dissolved nitrogen through the blood would be very slow is not a valid one, for although it would be undoubtedly very slow in a stationary fluid, there is no reason to believe that it would be slow in a circulating fluid, like the blood of an insect, which is alternately exposed to the tracheal tubes and the inner surface of the skin, and therefore to alternate differences of nitrogen pressure.

Moreover, a considerable quantity of the tracheal air escapes during flight, by the expiratory sound-producing spiracles, and this air must have the composition of the intra-tracheal air; so that the percentage of nitrogen in the tracheal tubes is always tending to that in the external air, as fresh air is being pumped into the tracher to maintain the total pressure. Hence the supposed difficulty due to the increase of the nitrogen, in the tracheæ, vanishes.

Movements of the Tracheal Vessels.-Rhythmic vibrations of the tracheal vessels have been observed, in the elytra of Coleoptera (Landois [150]) and in the legs of fleas (Furlonge).* These are readily accounted for by variations of pressure in the vessels. Landois considers them to be due to currents of blood, but this explanation is unsatisfactory, and could not possibly account for the rhythmic expansion and contraction of the vessels which I have myself seen in the leg of the Flea (Pulex). Such movements show rhythmic variations of the intra-tracheal pressure; and the wave-like movements of the finer tracheæ in the elytra of Coleoptera, if they result from changes of pressure, would greatly assist in the absorption of the included gases by the blood, by bringing a fresh layer of the circulating fluid into contact with the tracheal wall.

It is easily shown that the agitation of a fluid in contact

* Furlonge, on Pulex irritans. Journal of Quekett Mic. Club, Ist series, vol. iii., pp. $189-203$. 
with a gas greatly facilitates its absorption, and when the tension is reluced, efually facilitates the escape of dissolved gas from the lluid. This is seen when an effervescing liquid is arritated: so that the morements of the blood and of the trachea must assist in the transference of gases from higher to lower tensions.

I shall now endeavour to show that there is still further, and I think indisputable eridence, that all the oxyen inspired by an insect is actually used in the metabolic processes of the body.

Relation of the quantity of 0xygen consumed to the work done.If it is assumed that the same quantity of oxyren absorbed liberates the same amount of actual energy in the insect and in the vertebrate, the extermal work capable of being performed by the insect will be either equal to or greater than that capable of being performed by the vertebrate, weight for weight, as the heat produced remains the same or hecomes less.

It is usually held that about ! of the actual enerery of oxidization is capable of appearing as external work in mam.

On the assumption that the relation of heat to work remains about the same as in the mammalia: as 7 cc. of air contain $0^{\circ} 00225+$ srammes of $\mathrm{O}$, estimating the heat equivalent of one gramme of $O$ at $f, 000$ centisrade units, $0^{\circ} 002254$ erammes of $O$ give, in round numbers, g heat units per hour; which is

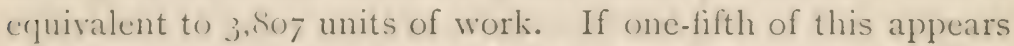
as cxternal work, is,ooo $\left(\because 3,3, S_{0}\right)$ units per day will represent the external work capable of being done, in round numbers.

I arrive at nearly the same result in another way, by estimating the work done in gramme-metres per day by man at 4,000 units per gramme of his body weight. This results from setting down ,j20,0)0,000 gramme-metres as a day's work for a man weighing so kilos. The absorption of Soo grammes of oxyen per day is perhays an under-estimate for this amount of work, but if it he taken and the weight of man estinated at so kilos, it grives, 1 , of a sramme of oxygen per day for each stamne of body weight. A Cockchafer weighing one cramme, taking in $7 \mathrm{cc}$. of air per hour, absorbs of a gramme of oxygen 
per day if all the oxygen is absorbed; this enables it to perform 20,000 metre-gramme units of work, or five times the work done by man, weight for weight.

The Work done in Flight. - It is well known that bodies falling through the air attain a constant velocity after a certain number of seconds, since the resistance of the air increases with the square of the velocity. Parachutes attain a constant velocity after a short time, which is determined by the resistance of the air; and it may be experimentally shown that a small parachute presenting a surface of I7 square centimetres and weighing one gramme, will attain a maximum velocity in falling of as nearly as possible one metre per second. As I find on measurement that a Cockchafer weighing one gramme has a surface of approximately I7 square centimetres when its wings and elytra are expanded, its maximum rate of falling may be taken as one metre per second. Hence one metre gramme of work per second will support it in the air.

The calculation given in the appendix to this chapter, page 387 , shows that this insect must expend at least $I^{\prime} 33$ metre grammes of energy per second to attain a velocity of 5 miles an hour. It may be objected that insects progress more rapidly than 5 miles an hour, but an insect weighing one gramme can only do so if it presents a less surface than 7 centimetres to the air. I have therefore calculated the maximum velocity an insect weighing one gramme could attain if it presented 3 centimetres of surface to the air. This I find to $b e=12.5$ metres per second, or 45 kilometres per hour, a trifle over 25 miles, with an expenditure of $2^{\circ} 2$ metre grammes of work per second to attain this velocity, which is, I think, the highest possible velocity, for an insect of similar weight presenting its wings almost edge-on to the air; no beetle with great elytra could, I think, attain it.

I believe 7 square contimetres of surface to be a fair estimate for the Cockchafer, but with a very small diminution of surface, say to 6 -and it is impossible to say it cannot expose 6 centimetres-its velocity would be 6.33 metres (nearly), or $22^{\circ} 788$ kilometres per hour (about $I_{3}$ miles), with an expenditure of 
- 63 metre-grammes of energy per second in its onward progression, and of $I^{\cdot} 63$ in total energy of flight. Such a rate of motion if possible is clearly exceptional.

In conclusion, I would observe that the rate of flight in the Cockchafer is undoubtedly between 5 and 13 miles an hour, with a total expenditure of energy of from $I^{\cdot} 33$ to $I^{\cdot} 6_{3}$ metre gramme units of energy per second. If we take the mean as $I^{\circ}+$, and multiply by 3,600 , we have 5,800 units per hour, so that in two hours the insect would expend considerably more than half its daily store of energy. As these insects are, however, very quiet during the greater part of the day, and only fly for about two hours in the evening, the remaining store of energy may suffice, but it is only on the supposition that all the oxygen inspired is absorbed that it is possible to account for the energy manifested.

The great strength of insects is well known. It is said that some insects can drag sixty-seven times their body weight, whilst a horse can scarcely drag three times its body weight; but such exertion is probably quite exceptional, and its duration short, so that such feats of strength only show that stored energy can be rapidly liberated.

The high velocities attained by many insects indicate more active respiration, and a proportionately small surface exposed in rapid progression with a large surface to counteract the effect of gravity, and a very light weight. Many insects can undoubtedly progress through the air with a velocity of considerably more than 30 miles an hour, and there are none which appear to have an organization better adapted for rapid flight than the Dragon-flies, Hymenoptera and Hawk-moths, which are well known to be extremely rapid fliers. Many of the Syrphide and Tabanide, amongst the Diptera, are equally rapid fliers, and their flight is usually sustained for comparatively long periods. As I have already stated, however, their respiration is exceedingly active, and they exhibit all the conditions necessary for the attainment of a high velocity with a small expenditure of energy. 


\section{APPENDIX TO CHAPTER X.}

CALCULATION OF THE WORK DONE IN FLIGHT.

ACCORDING to numerous experiments the pressure of the air is 0133 grammes per centimetre $\times v^{2}$, so that the pressure on I7 centimetres $=\cdot 233 \mathrm{I}$ grammes. Now, the pressure causing downward motion is I gramme, the weight of the insect, and the pressure resisting the motion is $a=\cdot 233$ I grammes per metre of velocity, therefore the maximum rate of falling $(x)$ is the velocity $(v)$ acquired under gravity $-a v^{2}$, when $v-a v^{2}=x$ is a maximum.

$$
\begin{aligned}
\text { Since if } x & =v-a v^{2}(\mathrm{i}) \\
\frac{d x}{d v} & =\mathrm{I}-2 a v \text { (ii) }
\end{aligned}
$$

And this is a maximum, when

$$
d x=0 \text {, and } \mathrm{I}-2 a v=0
$$

Then as $2 a=\frac{1}{2}$ nearly, $v=2$, nearly:

Putting this value of $v$ into $v-a v^{2}=x$, where $x$ is the maximum velocity of falling, we have, $2-4 \times \cdot 23=2-0^{\circ} 92$, or in round numbers, I metre per second, as the maximum rate of falling.

If one metre per second is the maximum rate of fall, the work done in sustaining its weight by a creature like the Cockchafer, having I7 centimetres of surface and I gramme weight, will be I metre-gramme per second, or more accurately I•08 metre-grammes per second.

As the surface presented to the air, in forward movement, is much less, and the only work to be done in progressing forward is that against the resistance of air, the work needed to 
attain a high velocity is small. I calculate that the surface resisting forward motion is about 7 square centimetres.

Using the same formulie (i and ii) and griving a the value of or $33 \times 7={ }^{\circ} 093 \mathrm{I}$, or say in round numbers $0^{\circ}$ is gramme:

We have $I-\frac{2 v}{I O}=0$ and $v=5$ : Hence $v-a v^{2}=5-2 \cdot 5=2 \cdot 5$ metres per second, and this is the maximum velocity which can be attained.

Now 2.5 metres per second $=3,600 \times 2.5$ metres per hour, or 9 kilometres (rather more than 5 miles per hour), is a rate of progression, against a resistance of $\mathrm{O}^{*} \mathrm{I}$ gramme, which needs - 25 gramme-metres of work per second.

Therefore, if the work needed to sustain the insect during flight is I'OS metre-gramme units, and that to urge it forwards is $0^{\circ} 25$ metre-gramme units (as $I^{\circ} 0 S+0^{\circ} 25=I^{\circ} 33$ ), the total encry of flight required to maintain this velocity is $\mathrm{r} \cdot 33$ metregramme units per second.

In all the above calculations, I have entircly neglected internal work; my aim has heen to show that the minimum work of flight is at least 133 metre-grammes per second. I have no doult it is greater in reality. The estimated rate of falling is certainly rather less than the real rate. That the work of flight is very large will be manifest to all who have tried to climb rapidly or even to run up a staircase. Fancy doing so at the rate of one metre per second for any length of time! The work done is not however independent of the wind and of currents of air, but on fine erenings I think the insects gain and lose about the same velocity from this cause as they appear to fly independently of the direction of the wind.

It can also be shown, that in order to perform $\mathrm{I}^{*} 3$ metregrammes of external work, the wings must vibrate at least 150 tines a second, assuming their surface to measure io square centimetres, and the ares of vibration of their apices to be f centimetres long, a result which agrees sufficiently well with observations already recorded (p. 207). 


\section{CHAPTER XI.}

THE ALIMENTARY CANAL OF THE IMAGO.

The Alimentary Canal of the imago in the Blow-fly extends from the cleft between the oral lobes of the proboscis to the posterior extremity of the abdomen, where it terminates in the anus beneath the epipygium and behind the genital armature, from which it is separated by the rudimentary ventral plate of the last abdominal somite (see generative organs).

The cephalic portion of the alimentary canal consists of the mouth, pharynx, and œsophagus.

\section{Bibliography:}

161. Treviranus, G. R., "Vermischte Schriften anatomischen und physiologischen Inhalts.' 3 Bde. 4to., Göttingen, I8I6-I820.

162. BASCH, SAMUEL, 'Untersuchungen über das chylopoetische und uropoetische Systems der Blatta Orientalis.' Sitzungb. der Akad. Wien. Math. Naturwissensch. Classe, Bd. xxxiii., I858 (5 plates).

163. Lowne, B. T., 'On the Rectal Papillæ of the Fly.' Month. Journ. Mic. Sc., vol. ii., 1869 .

164. Chun, C., 'Ueber den Bau, die Entwickelung und physiologische Bedeutung der Rectaldrüsen bei den Insecten.' Abh. d. Senkenbergischen Naturforsch. Gesellschaft, Bd. x., Frankfurt-a-M., I876.

165. Schindler, E., 'Beiträge zur Kenntniss der Malpighischen Gefisse der Insecten.' Zeitsch. f. w. Zool., Bḋ.xxx., I878.

166. Schiemenz, P., "Ueber das Herkommen des Futtersaftes und die Speicheldrüsen der Biene, Nebst. einem Anhange über das Riechorgan.' Zeitsch. f. w. Zool, Bd. xxxviii., I883.

167. Koestler, M., 'Ueber das Eingeweidenervensystem der Periplaneta Orientalis.' Zeitsch. f. w. Zool., Bd. xxxix., I883.

168. Hofer Bruno, "Untersuchungen uiber den Bau der Speicheldriisen und des dazu gehörenden Nervenapparats von Blatta.' Nova Acta, C. L. C. A., Bd li., 1887 .

169. EMery, C., 'Ueber den sogenannten Kaumagen einiger Ameisen.' Zeitsch. f. w. Zool., Bd. xlvi., I888. 


\section{THE MOUTH AND PHARYNX.}

The Mouth, like that of the Diptera generally, is very highly modified; it is a cylindrical tube extending from the discal sclerites (p. I 43 ) to the prepharyngeal tube, which may be regarded as its posterior limit or isthmus faucium. The comparative immobility of the prelabrum, owing to the overlapping of the edges of the haustellum and the fusion of the base of the ligula with it to form the prepharyngeal tube, prevent the insect from opening the mouth, like the bloodsucking Tabanidæ, so that food can only pass into it through the oral cleft and prestomum.

The Pharynx.-The term pharynx is applied to the space between the two plates of the fulcrum; it is dilated by the contraction of the dilator pharyngis muscle, and is entirely closed by the elasticity of the fulcrum, which brings its dorsal and ventral plates into apposition when the muscle is relaxed (p. 137).

The dilatation of the pharynx serves to draw food through the long tubular mouth, and its contraction forces it back into the osophagus. Although there are no valves, the fulcrum acts as an effective pump, probably by a rhythmic contraction of the muscles producing an undulating movement of the anterior (superior) plate. Food is frequently, probably normally, regurgitated and reswallowed, so that it is evident that the undulatory movement is capable of effecting a flow of fluid either from or towards the mouth. The mouth and pharynx have a chitinous cuticular lining, and with the exception of a double row of fine bristles, which project backwards in the pharynx, there is no evidence of the existence of any sensory structures in either.

\section{THE SOFT PARTS AND MECHANISM OF THE PROBOSCIS.}

The proboscis is a highly complex accessory to the digestive apparatus. The anatomy and morphology of its skeleton has already been discussed, the present section only deals therefore with a description of its soft parts and with those structures 
which are more especially concerned in the collection and ingestion of food, together with an analysis of what is known of its functions and mechanism.

The soft parts of the proboscis are the muscles, tracheæ, glands, nerve-end organs, and a complex quasi-tendinous system of cords contained in the oral portion of the organ. These parts may be studied either by dissection or in serial sections.

The greater part of the interior of the proboscis is occupied by numerous muscles and large tracheal sacs, which surround the fulcrum and tubular mouth. The organ is supplied by two pairs of nerves, the small pharyngeal and large maxillary nerves. The duct of the lingual salivary glands lies behind the fulcrum and terminates in a remarkable valve having somewhat the form of a larynx. This is connected by a rigid tube with the base of the hollow ligula, through which the salivary secretion is discharged into the mouth.

At the base of the oral sucker, a second accessory pair of salivary glands (Pl. VI., sg and Fig. 3I, 3) lie one on either side of the poculum (p. I44). These are the labial glands, the ducts of which discharge their secretion upon the oral surface of the terminal sucker. This surface, as has been already observed, is channelled by the pseudo-tracheæ.

\section{a. The Muscles of the Proboscis.}

The muscles of the proboscis have been very carefully and accurately described by Kraepelin [70]. Twelve pairs are readily distinguished with two sets of muscle fibres near the middle line, which may be regarded either as single muscles or as pairs. There are thus fourteen pairs or twelve pairs and two azygos muscles, which may be described as follows :

1. Retractors of the Fulcrum.-Each of these arises from the side of the epistome, runs backwards and upwards, and is inserted into the posterior cornu of the fulcrum. In the description of the direction of the muscles, I have supposed that the proboscis is hanging down below the head, so that the oral lobes are below, and the dorsal or anterior surface of the organ is in front. 
Kraepelin terms these muscles the retractors of the proboscis: their contraction causes the lower end of the fulcrum to describe a circular arc, and brings it into a horizontal position between the gena.

2. The Retractors of the Rostrum. - Each of these muscles arises from the inferior lateral margin of the occipital foramen. They are long and slender. They lie one on either side of the middle line, behind the lingual salivary duct; they are inserted into the sesamoid sclerites.

3. The Accessory Retractors of the Rostrum arise with the preceding, and lie behind them; they are inserted into the integument about midway between the sesamoid sclerites and the head capsule. These two pairs of muscles serve to invaginate the interument of the rostrum, when the proboscis is withdrawn into the head capsule.

4. The Flexors of the Haustellum arise from the inferior edge of the occipital foramen, between the retractors of the rostrum, and are inserted into the dorsal surface of the prepharyngeal tube. They serve to flex the haustellum upon the rostrum.

5. The Extensors of the Haustellum arise from the distal cornua of the fulcrum. and ascend and are inserted into the great apodéme of the labrum.

6. The Retractors of the Haustellum arise from the gena, and are inserted with the extensors of the haustellum. Kracpelin thinks that these and the last act together, and so, by pushing down the apodime of the labrum, straighten the proboscis by extending the haustellum on the rostrum. This appears to be probable.

7. The Flexors of the Labrum arise from the anterior surface of the fulcrum, and are inserted into the labrum. They undoubtedly $f(x)$ the haustellum on the rostrum. In those Diptera in which the labrum can be raised independently of the haustellum they serve to open the mouth.

8. The Retractors of the Fulcrum.-These are small bundles of muscle fibres which arise from the lower part of the frontal sac, and whirh are inserted into the muscular coat of the (esophagus between the fulcrum and the brain. They serve to draw the loop of the esophasus, which lies between the cephalic ganstia and the fulcrum. forward, when the proboscis is retracted. into the head capsulc. These fibres are not described by Kraepelin.

9. The Graciles. a pair of long and very slencler muscles, arise from the proximal extremity of the fulcrum, and descend behind it to the valve of the lingual duct. Their contraction evidently opens this valve. All the above muscles lie in the rostrum and head capsule.

A single muscle occupies the cavity of the fulcrum in front of the pharynx; it is the

10. Dilator Pharyngis. - This muscle arises from the lateral plates of the fulcrum, and its fibres converge and are inserted into a median raphe on the dorsal plate of the pharym; its action is to dilate the pharyngeal tube. It is undoubtedly the main agent in drawing fluid from the mouth into the pharynx.

The muscles of the haustellum are:

1. The Retractors of the Furca.-A pair of large muscles which arise, one on either side, from the upper half of the thyroid sclerite; the fibres of carch are inserted into a tendon, which is attached to the corresponding lateral 
process of the furca. The contraction of these muscles opens the oral disc, which is folded by the elasticity of the thyroid cornua acting on the - furca (see p. 143).

2. The Paraphysal Muscles arise from the paraphyses, and are inserted into the chordæe tendinex of the oral disc. Kraepelin described these muscles as having an insertion into the discal sclerite. I have been unable to discover any such insertion. I believe they render the disc concave by increasing the tension of the chorda tendinex; but I am by no means confident with regard to their function, nor is it easy to make out their exact insertion.

3. The Transverse Muscle of the Haustellum.-This consists of several muscular slips, which arise from the thyroid sclerite, near the median plane, and diverge and are inserted into the paraphyses. Kraepelin regarded it as an erector of the oral lobes, and supposed that its contraction drives the blood from the cavity of the haustellum into the lobes. I believe its real function is to approximate the paraphyses.

The last muscle I have to mention is the prelabral muscle.

The Prelabral Muscle consists of radiating fibres in the cavity of the prelabrum (Fig. 29, $\mathrm{Im}$.) It probably assists in dilating the tubular mouth.

\section{b. The Oral Lobes and the Structure of the Pseudo-Tracheæ.}

Much has been written on the structure of the oral surface of the suctorial disc, which has been for. years past a favourite study with microscopists, and mere surface views present appearances the interpretation of which is by no means easy.

The cuticle of the oral surface of the disc is perfectly transparent and colourless, but the chitinous rings of the pseudo-tracheæ are deeply coloured, frequently almost black in the mature insect. The edges of the pseudo-tracheal channels are also coloured and thickened, so that in surface views they have the appearance of small scales; these scales are more marked towards the margins of the disc.

Between each pair of pseudo-tracheæ two wavy lines are seen parallel with them; between these there are several nipplelike projections, which I regard as the orifices of the ducts of the labial glands; there are usually five or six in each interspace. Two, with the papillæe invaginated, are seen in the figure (Pl. XXIII., Fig. 2).

The pseudo-tracheal rings have the form represented in Fig. 3I, 5, and the forks are placed alternately right and left of the median channel by which the groove opens on the surface. 
The fork at the extremity of a ring bounds the edges of the scale (Fig. 50), and the single extremity of the ring runs through the middle of the opposite scale.

Anthony's Suckers.-(Pl. XXIII., Fig. 2) The figure is taken from a very beautiful photograph which Dr. H. M. Wright, of Sydney, N. S. Wales, has kindly sent me; it was taken by him with one of Powell and Lealand's latest apochromatic objectives.

The oval spaces between the teeth of the rings have the

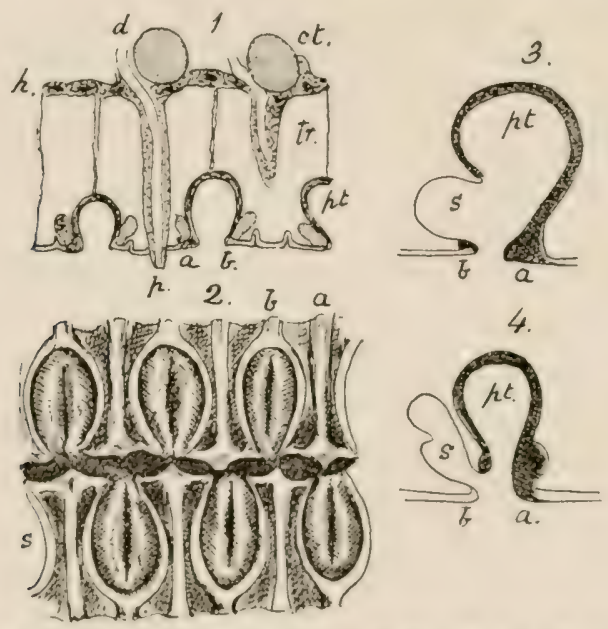

Fir: 50.-Details of the Pseudo-trachere. I, a section of the oral surface of the laluelix, transwerse to the pseudo-tracheal channels; 2 , a surface view showing Anthony's suckers; 3 and 4 , pseudo-tracheal rings showing the position of the sacculus forming Anthony's sucker. $a$, simple, and b, forked end of the rings; $c t$, tendinous cord; $d$, duct of labial gland; $h$, hypoderm ; $p$, papilla ; $p t$, pseudo-trachea; $s$, sacculus forming Anthony's sucker ; $t r$, tracheal vessels of disc.

\section{DESCRIPTION OF PlAte XXIII.}

Two surface views of a portion of the oral sucleer, showing the details of the l'seudotrachere and Anthony's suckers, from photographs taken by Dr. II. M. Wright, of Sydney, N.S.W., by whose kind permission they are published for the first time.

Fle. 1. $-A$ portion of the oral surface of the disc, showing the psendo-trachea and orifices of the duct of the labial gland.

Ftt: 2. - A more highly magnified view of a portion of the same, showing Anthony's suckers and the orifice of $t w o$ of the labial ducts. Taken with an apochromatic ${ }_{1}^{1}$. (l'owell and Lealand.) 


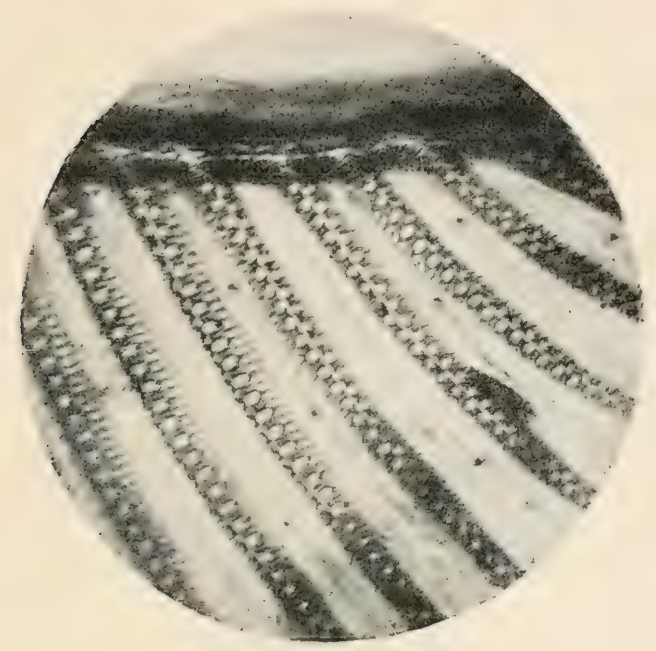

FIG, I.

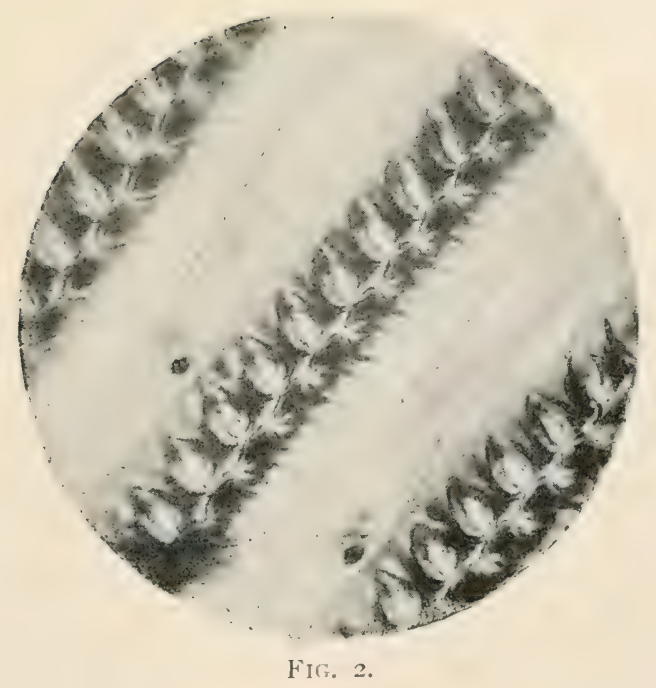



appearance first described by Anthony* and subsequently independently by Wright + as suckers; each appears as if closed by a thin membrane.

In Anthony's figure these membranes are represented protruding as sucker-like organs which he described as having the appearance of ' mouse ears,' or 'bat's ears.' I have observed a similar appearance in surface views of the oral disc of the proboscis, but more commonly these so-called suckers appear as they do in Wright's photograph (Pl. XXIII., Fig 2).

Sections of the oral lobes throw light on the true nature of these 'suckers.' Fig. 50 ( 3 and 7 ) shows the disposition of the thin cuticle between the fork of a ring; it forms a little sac $(s)$ by the side of the pseudo-tracheal channel. Now, it is manifest that such a sac would be easily everted, and it would then present the appearance described by Anthony; or, if partially everted, the appearance shown in Wright's photograph.

Between the pseudo-tracheæ, and covered by inflections of the hypodermis, a series of tendinous cords extend from the discal sclerite to the edge of the oral disc. These tendinous cords were first described by me [62, p. 49], but perhaps rather indefinitely. Kraepelin describes and figures them.

These cords are dissolved by boiling caustic potash, but do not seem to be affected by dilute acetic acid; they are developed from fusiform cells. The paraphysal muscles are inserted into them near their origin, so that they are probably inelastic and act as tendons.

\section{c. The Mechanism by which the Proboscis is Extended and Erected.}

It is quite certain that the retraction of the proboscis and the movements of the haustellum upon the rostrum are muscular acts, but it is also very evident that there are no muscles capable of exserting the proboscis. This fact has already been noticed by Gleichen [3], Macloskie [64], Dimmock [68], and

* Monthly Micros. Journ., vol. xi., p. 242, 1874 .

$\dagger$ Journ. Royal Micros. Soc., ser. ii., vol. iv., p. 1003, 1884 . 
Kraepelin [70], and these authors have all correctly ascribed the exsertion of the oran to the inflation of the tracheal airsacs, although the manner in which this is effected has hitherto remained unexplained.

The Air-Sacs of the Proboscis (Fig. 5I) are very capacious; they commence as a pair of nembranous ressels from the great cervical trachea (a) and descend in front of the jugum $(/)$, leneath the tentorium. Each trunk has a slender rod of chitin (h) in its anterior wall, which closes the tube by pressing agranst the jugum. This forms a valve capable of being opened by a small bundle of muscle-fibres (m), which arise from the front edge of the grena; their contraction opens the

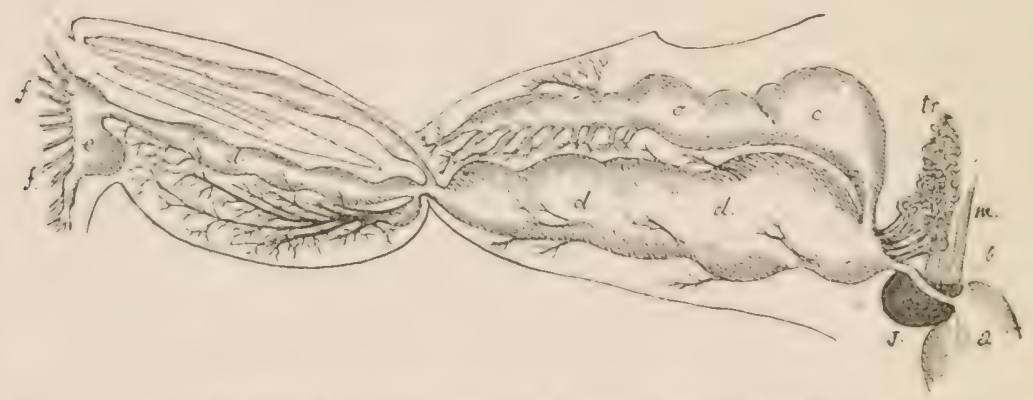

Fic. 51.- The Air-Sacs of the Proboscis. $a$, inferior cervical air-sac; $b$, valve in the anterior wall ; $c c$, anterior, and $d d$, posterior air-sac of the rostrum; $d$, air-sac of the haustellum ; $c$, azygos air-sac of the labellie; $f f$, tracheal vessels of the oral disc $; J$, the jugum; $m$, muscle controlling the valve $b ; t$, rete mirabile of the tentorium.

valve and pernits of the passage of air from the thoracic cavity into the tracheac of the proboscis. Immediately in front of this valve the tracheal trunk dilates and gives off numerous vessels (tr $t r)$ of small calibre, which are cylindrical and exceedingrly tortuous; they form a rete mirabile in the tentorium, and probalsly communicate with the large trachea above that membrane. The main trunk then divides into two branches: an anterior air-sac $(\tau)$ which lies on the outer side of the fulcrum, and a posterior sac (d d) which descends behind the fulcrum, conters and traverses the haustellum, and terminates ly uniting with its fellow in a trefoil-shaped aygros air- 
vesicle $(c)$ in the oral sucker. Both trunks give off numerous cylindrical and vesicular branches in their course.

As I have shown, there can be little doubt the air in the tracheal vessels of the thorax and abdomen is maintained at a higher pressure than that of the external air, and all the large membranous tracheal trunks of the anterior thoracic and cervical region are surrounded by loops of nuscle-fibres capable of compressing them and forcing air into the head capsule. The mere opening of the valve in front of the jugum probably suffices to fill the air-vessels of the proboscis; when the valve is closed, the air has still a passage from the air-sacs of the proboscis through the tentorial rete, by which they are probably emptied, as the organ is drawn into the head capsule, by the contraction of its retractor muscles.

Kraepelin at one time supposed that the frontal sac is concerned in adapting the size of the head capsule to its contents, and that its expansion accompanies the exsertion and its contraction, the withdrawal of the proboscis. In his finished memoir [70] he states that he no longer held this view. I am myself inclined to return to it, as a number of muscle-fibres cover the cephalic surface of the frontal sac; two bundles also arise from it and descend to be inserted into the pharyngeal extremity of the osophagus. The contraction of these muscles assists in the retraction of the proboscis, and can hardly fail to diminish the size of the frontal sac by pressing together its folds; if this is so, it would assist in drawing air through the tentorial rete mirabile into the upper part of the head capsule, thus emptying the tracheal sacs of the proboscis and assisting in its retraction.

\section{d. Function of Oral Lobes.}

The Inflation of the Oral Sucker.-The fact that the oral sucker is flaccid when folded and at rest, and turgid when in action, has long been well known, but authorities are divided as to the manner in which this change is effected. Kraepelin ascribes it to an injection of blood into the organ, but Gleichen, Macloskie, and Dimmock held that the distension of the lips is effected by the 
injection of air into its interior. Gleichen wrote: "The extension of the proboscis probably arises from the air which is driven by the fly into the base (rostrum), and from this into the middle tube (haustillum), and finally into the lips.' He further added: 'The fly can, indeed, drive air between the membranes of the proboscis into the lips, but he cannot take in air with them.' Dimmock [68, p. 46], says: 'That it is air, at least for the most part, and not fluid, which expands the inner surface of the labella, is easily proved by carefully pressing the head of a fly between the fingers until the proboscis is fully distended, and the labellie fully inflated; then, putting the fly under water, and pricking the inner surfaces of the labellix with a needle, they at once collapse, bubbles of air escaping at the same moment from the opening made in their surfaces by the needle.' Beside these notices, I have found nothing further on the subject; but in transverse sections of the oral sucker, made from a proboscis distended by dropping an insect into hot alcohol, the inflated air-channels are not equivocal.

I have represented a portion of a section in Fig. $50, I$, and it will be seen that each of the pseudo-tracheal channels forms the outer wall of two air-channels or modified trachex which separate the hypodermis from the cuticle of the disc. These channels all radiate from the azygos air-sac already mentioned (see Fig. 5I, c), and have the same distribution as the pseudo-tracheæ which they accompany.

Even when sections are made of a flaccid proboscis, it is not difficult to distinguish the air-channels, although their size is greatly diminished. In the pupa when the proboscis has arrived at the stage of development represented in Fig. 32, the separation of the hypoderm from the cuticle of the disc is very apparent; the intervening space, like the lumen of the trachere of the pro-imago generally, is filled with a watery fluid which is readily distinguished from the gramular blood in the bloodsinuses beneath the hypoderm.

The air in these channels, when the organ is erected, may be assumed to be compressed. My reasons for this assumption have been fully discussed in the section devoted to the tracheal 
system ; and the elasticity of the compressed air, acting against the tension of the tendinous cords on the one side, and the elastic recoil of the pseudo-tracheæ on the other, is, I have no doubt, the means by which the varied movements of the lips are mainly produced. Kraepelin admits that muscle-fibres are absent in the lips, except a few transverse bands near their anterior border, and these I have failed to recognise, although fibrous, probably elastic, bands of tissue are present.

It will be seen that the injection of air into the vessels between the tendinous cords and the pseudo-tracheæ would render the disc tumid and convex; the tension of the paraphysal muscles, on the other hand, acting on the tendinous cords, would draw the centre of the disc back and render it concave.

The Act of Suction.-The movements of the surface of the oral sucker during the act of suction were most graphically described by Reaumur. He says: "There is no one who has not seen flies apply the extremity of the proboscis or their lips to syrup or sugar thousands of times, but few have seen the act well, yet the method of doing so is very simple. I spread a little transparent syrup on the inner surface of the thin glass cover of a small box, and enclose flies of different kinds. These are so greedy for the syrup that they forget their captivity, and there are always some which at once alight upon their favourite food. If one observes these, he will see that they commence by extending the proboscis and applying the channelled surface of their lips to the syrup; the glass cover and the transparent syrup do not prevent a careful observation with a lens of what occurs at the extremity of the proboscis. I invite the curious to give themselves to this observation, with which they will assuredly be satisfied, as I have been many times.'

"Whilst the body of the proboscis is immobile its extremity is active, and one observes the most varied and rapid movements of the lips. The short transverse diameter of the disc is alternately increased and diminished. At one moment the two halves lie in the same plane, and at another they make an angle with each other which varies from moment to moment from an acute to an obtuse, and from an obtuse to an acute 
angle, or they form a deeper or shallower funnel, become flattened or tumid; sometimes the whole, sometimes a part only, of the disc is swollen. The most constunt phonomenon, hourci'r, is an undulatory moicment of all the channcls of the lips, accompanicd by rapid vibrations of their surface.'

'The end towards which these movements tend is not equivocal; they cause the syrup to enter the proboscis. Whilst on this subject, I would remark that the lips touch each other in the centre of the disc, but appear to leave two openings, one in front and one behind. The anterior of these may be called the mouth of the fly, and one may observe currents passing into it when the syrup is very fluid' $[1$, p. 206 (the italics are mine)].

Reaumur also observes [p. 205] that the channels of the lips (pseudo-tracheet) of certain flies are black when the lips are moderately distended, and that when fully distended they become white.

The vibratory movement of the discs and the altered appearance of the pseudo-trachea depend upon the air, which is alternately forced into and allowed to flow out of the trachere beneath the pseudo-tracheal channels. When these are distended, the pseudo-trachere open along their whole length, and as soon as the pressure of the air is diminished the recoil closes them. The extension of the air-channels enlarges and flattens the disc, or in an extreme case produces a convex surface, whilst the escape of air from them into the large trachere of the disc and haustellum diminishes the extent of the disc, which is rendered concave by the contraction of the paraphysal muscles and the tension of the tendinous cords.

There has been much difference of opinion as to the use of the pseudo-tracheal channels. Some observers have held that they are concerned in conducting the food into the mouth, and that they act as a strainer. Others regard them as conduits for the saliva secreted by the lingual glands. Kraepelin argues in iavour of the latter opinion, but I have repeatedly fed llies with hlood and with syrup decply stained with carmine, and afterwards found, by making sections of the proboscis, many of the pseudo-trachere filled with these substances. 
There are two distinct ways in which the sucker of the proboscis comes into operation, in drinking and in feeding on solid substances; in the former act the oral sucker is applied to the surface of the fluid, which necessarily passes by capillary attraction into the pseudo-tracher. The mouth-opening described by Reaumur is alternately opened and closed. When it is open, a current passes directly into the mouth; but when it is closed, fluids may flow into the prestomum from the pseudo-tracheal channels, driven into it by their elastic walls, which exhibit quasi-peristaltic movements as the air passes into and out of the air-channels. When, however, the insect feeds on solids, the oral sucker is applied by its edges to the food, and the pseudo-tracheæ distribute the salivary secretion of the lingual glands over the anterior surface of the sucker; this dissolves the food, assisted, perhaps, by the disintegrating action of the stomal teeth, which, as Suffolk [58, p. 339] remarked, leave lines upon the food material; and the fluid, with small particles in suspension, is drawn into the oral cavity. Under these circumstances, as I formerly suggested [62], the pseudo-tracheæ probably conduct it into the prestomum and mouth and act as strainers.

That the little pouches of thin integument in the forks of the rings, which Anthony regarded as suckers, are the main agents of suction, as he appears to suggest, is an untenable hypothesis ; but that they may assist in the passage of fluid into the pseudotracheæ is, I think, exceedingly probable. Flies undoubtedly collect moisture from damp foliage and smooth surfaces which have only a film of moisture on them, and it appears to me probable that these pouches may be alternately emptied and filled by the alterations in the tension of the oral lobes which occur during the ingestion of food. The disposition of the sacs is such that it is easy to see that they may alternately open on the surface, and into the pseudo-tracheal channels. Moreover, capillary attraction may assist in filling the pseudo-tracher through the minute orifices of these pouches.

The mouth frequently contains air, whether drawn into its cavity by suction or expelled from the alimentary canal, and 
occasionally the food is rendered frothy by the expulsion of this air, which frequently passes through the pseudo-tracheæ. This was also observed by Reaumur [1, p. 209].

It does not appear to me probable that the tubular mouth exerts any very considerable power of suction, as the size of its cavity is not apparently capable of any great variation. No doubt it is slightly increased by the contraction of the labral muscles and of the transverse muscles of the haustellum. I believe the food material is forced into it by the oral sucker rather than drawn into it by the expansion of its cavity. The main suction is due to the contraction of the dilator pharyngis, whilst the recoil of the elastic wall of the pharynx certainly drives the food back into the abdominal crop. It is afterwards regurgitated into the mouth and prestomum, or even forms a drop between the partially-closed lobes of the oral sucker before it is finally swallowed and transmitted by the proventriculus to the chyle stomach, a fact known to and recorded by Reaumur.

It is possible that all the food is not first transmitted to the crop, and that some may pass at once into the proventriculus. The crop may only serve to store food when the chyle stomach is already actively digesting, but flies usually regurgitate their food before it passes into the chyle stomach.

\section{e. Nerves and Nerve-end Organs.}

The Nerves and Nerve-end Organs of the Proboscis.-The pharyngeal nerves are a pair of slender nerves which lie one on either side of the cesophagus ; they are chiefly distributed to the muscles of the pharynx and labrum. The labial nerves are much larger, and descend behind the fulcrum; each gives a larere branch to the palpus. They also supply the retractor muscles of the proboscis and traverse the haustellum, to the muscles of which they give branches; they terminate in numerous twigs, which end in special sensory terminals at the bases of the setae which fringe the oral sucker.

These setie are grooved, and the nerve-end organs at their bases so closely resemble grlands that Kraepelin describes them 
as such, although Leydig, and more recently Otto Rath [133], recognised their nervous character.

Each end-organ consists of a very thin capsule of flat cells, loaded with dark-orange pigment granules. These cells are a part of the hypoderm, which is also similarly pigmented in the neighbourhood of the setæ. Within the pigmented cells is a layer of eight or ten fusiform nerve-cells, in which the nervefibres terminate; these enclose a single large cell, the trichogenic cell, which extends into the seta. The trichogenic cell is clear and transparent, or possibly filled with fluid; the nucleus is pressed to one side of the cell by what appears to be a large vacuole. The sheath of the nerve is continued as a thin membrane between the pigmented sheath and the nervous elements, and is apparently attached to the base of the seta.

I am inclined to regard these organs as touch corpuscles. It is possible, however, they may be special organs of taste. I have sought in vain for organs of taste on the lips and ligula. Künckel d'Herculais describes and figures such organs on the ligula of Volucella, but I find no trace of any in the Blow-fly. The only organs which appear to me to have the character of organs of taste are on the maxillary palpi. The palpus receives a very large branch from the labial nerve, and numerous ganglion cells exist in the interior of the organ, connected on the one hand with the nerve-fibres, and on the other, by numerous branches, with several layers of small cells which lie immediately under the skin, and are most numerous towards the extremity of the palpus.

The setæ on the palpus are of two kinds: large tactile setæ, few in number; and small transparent setæ, which are very numerous. The large setæ have similar organs to those connected with the setæ of the labial lobes. The small cells which underlie the cuticle give off processes which enter the fine setæ; and these are either grooved or hollow, and contain a substance which stains deeply with carmine and logwood. In this character they differ from all the other setæ I have examined. They appear to act as capillary tubes, which become filled with the staining agent. It is well known that 
insects examine their food with the maxillary palpi, and I have frequently seen the palps immersed in a drop of regurgitated fluid, when the proboscis is withdrawn into the head capsule. Near the extremity of the palpus there are always a number of transparent spots, which appear as perforations. I have been unable to obtain a section showing these as openings in the cuticle; beneath each there is what appears to be a trichogenic cell surrounded by nerve-cells. These perforations have been described as pores, and it has been supposed that they permit sapid fluids to come into contact with the nerve-end organs.

The pharynx contains two rows of fine sete, which are undoubtedly connected with nerve-terminals. These are situated on the epipharyngeal plate, one row on either side of the median raphé. The extremities of these setæe are directed backwards towards the œsophagus.

\section{f. The Salivary Glands.}

In the imago of many insects two very distinct forms of salivary glands are frequently present in the same individual, besides one or more pairs of small accessory glands - the tubular sericterial glands, lingual glands, which either form, as in Blatta and the larva of Musca, large thin-walled sacs, or, as in the imago of Musca, long convoluted tubes; and a pair of racemose glands, the ducts of which join the ducts of the lingual glands. In Volucella and the Syrphida, and probably in all pollen-feeding Diptera, as well as in the Hymenoptera, the racemose glands are largely developed; whilst in the Muscidae they are absent, and only the tubular sericterial glands are present. The latter are just as well developed in the Syrphida which possess racemose grlands, as in the Muscidae; hence we cannot regard them as modifications of one and the same organ. Neither can I hold that the large sac-like glands in Blatta are mere salivary reservoirs, as is usually held. I must regard them as sericterial and homologous with the tubular form of gland which co-exists with the racemose glands in so many of the Insecta. 
The so-called salivary reservoir in Blatta is identical with the larval sericterial gland of Musca in form and structure, and this is replaced in the imago of Musca by the tubular lingual gland; whilst the lobulated glands of Blatta do not differ from the racemose glands of Volucella and Syrphus, which coexist with a tubular lingual gland in the imago of these insects.

In the imago of the Blow-fly two pairs of glands exist, which, as they discharge their secretion either on the lips of the proboscis, labial glands, or into the mouth, lingual glands, may fairly be classed as salivary.

Kraepelin describes a third pair which discharge their secretion into the pharynx, but I have been unable to satisfy myself that any such glands exist in Calliphora Erythrocephala; they may be present, however, in some allied insects, such as Lucilia and Sarcophaga.

The Labial Glands (Pl. VI, and Fig. $3 \mathrm{I}, s \mathrm{~g}$ ) are situated at the distal extremity of the haustellum, one on either side of the poculum. The ducts of these glands run parallel with the pseudo-tracheæ, and terminate in nipple-like orifices between them; four or five of these are seen between each pair of pseudo-tracheæ (Pl. XXIII.).

Each gland consists of a sac lined by large columnar cells with a distinctly rodded structure; these cells are similar to those of the sericterial (lingual) glands of the imago. I have been unable to detect any cellular lining to their branching ducts, which are usually distended with a coagulable fluid.

Kraepelin believed that these glands open by short wide ducts into the poculum, an opinion which I formerly held; but I have so frequently traced the ducts to the nipples between the pseudo-tracheæ that I can no longer agree with Kraepelin. Further, Kraepelin regards these nipples as sensory organs, a view which is not supported by any of my sections. I have been quite unable to trace nerves to these papillæ.

The purpose of the labial glands is clearly to keep the surface of the sucker moist with a tenacious viscid fluid which differs entirely from the clear watery secretion of the lingual glands.

The Lingual Glands or Sericteria.-These glands replace the 
sericteria of the larva. Each consists of a single long convoluted tube, which commences in a blind extremity near the posterior end of the abdomen. The gland tube is wavy rather than convoluted in the abdomen, but forms a long coil in the thorax, which lies externally to and in relation with the chyle stomach. If uncoiled, the gland tube would probably exceed $6 \mathrm{~cm}$. ( 2 inches) in length; it consists of a basement membrane, lined by a single layer of beautiful rodded cubical epithelial cells, 20 to $25 \mu$ in diameter. The gland tube measures from 0.2 to $0.3 \mathrm{~mm}$. in diameter.

In Lucilia it terminates in a cylindrical reservoir, from which the duct arises, but in Calliphora the gland tube opens directly into the salivary duct; this converges towards its fellow, with which it unites before passing through the cervical region to form the common lingual duct.

The ducts of the lingual glands and the common lingual duct are exceedingly elastic, and consist of a peritoneal membrane, lined by a cuticular intima, which exhibits a spiral fibre similar to that of a cylindrical tracheal vessel. The external coat of the lingual duct is very thick, yellow in colour, and thrown into ruge when the proboscis is retracted. The duct is very extensile.

Near the distal extremity of the rostrum (Pl. VI., $s i$ ) the common duct changes its character. It loses its spiral fibre and its extensibility. It becomes transparent, and dilates into a cavity shaped somewhat like a larynx. This cavity is closed by a very perfect valve, formed by its anterior wall, which is elastic and pressed in towards the posterior wall of the cavity.

The indented portion receives the insertion of two long slender muscles, which arise from the proximal extremity of the fulcrum; their action is to render the tube patent and thus permit the escape of the saliva, which Iraepelin says is jetted out by the intra-thoracic pressure. Beyond the valve the lingual duct is a chitinous tube, which enters the base of the hollow ligula through which the salivary fluid flows; the orifice of the duct is at the apex of the ligula. 


\section{THE CEOPHAGUS, STOMACHS AND INTESTINES, AND THEIR ACCESSORY GLANDS.}

\section{a. The Alimentary Tract (Plate XXIV.).}

The œsophagus, crop, proventriculus, chyle stomach, proximal intestine, distal intestine, and rectum constitute the alimentary tract.

The esophagus commences at the posterior extremity of the fulcrum, and, curving sharply backwards, passes between the supra- and infra-osophageal nerve-centres and through the cephalo-thoracic opening; above the great nerve-trunk and beneath the dorsal vessel and median splanchnic nerve, which are in relation with it.

In the thorax it lies upon the thoracic nerve-centre and the metasternal entothorax, immediately beneath the chyle stomach, with the coiled salivary glands on either side of it. It passes back into the abdomen and enters the great pyriform bi-lobed crop.

Immediately below the proventriculus, it gives off a short vertical tube, the proventricular œsophagus, which enters that organ and transmits the food to the chyle stomach.

The Crop (Pl. XI., s s) occupies a considerable portion of the base of the abdomen, and lies behind, below, and between the great abdominal pulmonary sacs (Pl. XI., $p s$ ).

Structure.-The muscular coat of the œsophagus is thicker than that of the rest of the alimentary canal, and both the longitudinal and circular fibres are well striated, and resemble those of the ordinary skeletal muscles; the muscle fibres of the crop are indistinctly striated, and are flattened bands which anastomose with each other, and present large meshes when the organ is distended.

The epithelium of both consists of thin pavement cells; the cuticular intima is very thick in the œsophagus, and is thrown into permanent longitudinal folds, into which the epithelial cells penetrate as they do in the crop of the larva. The cuticle of the crop is thin, and does not exhibit any distinct infoldings. 
The Proventriculus (PI. XXIV., Fiers. 2 and 3 ) is ovoid, flattened above and below. It may be described as an intussusception of the stomodieum into the mesenteron, and, except in form, it differs but little from the same orran in the larva. It consists of a thick cellular plug, perforated by the proventricular branch of the cesophagus in its centre and grooved around its edge, surrounded by the wall of the proventriculus, which presents a thick ridge fitting into the groove in the plug.

The outer wall of the proventriculus is continuous with the anterior edge of the groove in the plug, on the one hand, and with the wall of the chyle stomach, from which it is separated by a sphincter, on the other; it is covered by a continuous layer of radiating muscles, which arise from the junction of the œsophagus with the plug.

Both the central plug and the thickened ring of the outer wall consist of a tissue which is almost cartilaginous, formed by the fibrillation of the epithelial cells (see p. 2So).

The distribution of the tracheal vessels to the proventriculus is very remarkable. A tracheal ring surrounds the proventricular cesophagus, and is decply imbedded in the plug: and from a dozen to eighteen radial vessels arise from this ring and arch over the outer surface of the proventriculus. These vessels are continued as parallel vessels over the outer surface of the chyle stomach. The ring receives air from longitudinal trachese which lie close to the nesophagus, and it gives off

\section{DESCRIPTION OF PLATE XXIV.}

The alimentary canal of the Imago:

Fil: 1. - The alimentary canal from the prosentriculus to the rectum, removel from the botly. The chyle stomach is seen from its side, lout the rest of the alimentary canal is represented from its dorsal aspect : $\mathrm{Ch}$, chyle stomach; $\mathrm{Cr}$, crop; $d i$, distal intestine; $m m$, Malpighian vessels ; $n$, oesophagus ; $p i$, proximal in. testine ; $\rho s$, prosentricular ganglion ; $r$, rectum ; $r \hat{\imath}$, rectal papille ; $t r$, trachex: Ir s, tracheal sacs.

Fl:, 2,- I vertical submedian sec:ion through the proventriculus and part of the chyle stomach ; pv, proventriculus.

Fic. 3.-A median vertical section of the proventriculus.

Fig. 4. - A section through the rectal valve.

FIt: 5. - I transwerse section of the intestine about wo millimetren above the rectal salve. 

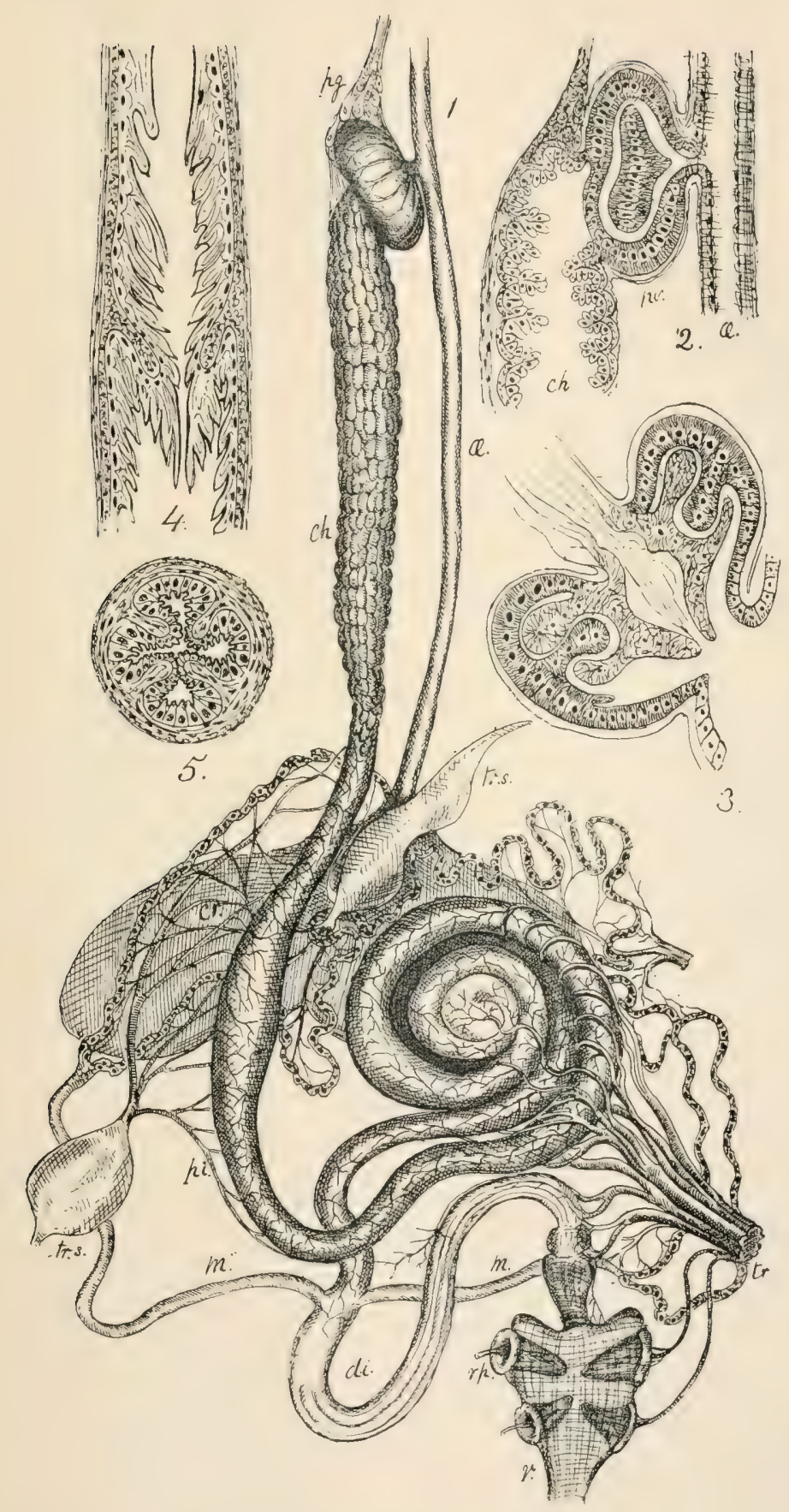

numerous small vessels, which apparently perforate the quasicartilaginous tissue of the plug, which thus affords a rare exception to the rule that the trachex do not penetrate into the substance of the organs which they supply.

Functions of the Proventriculus.-Many opinions have been held with regard to the functions of the proventriculus. It is undoubtedly homologous with the gizzard of manducatory insects, and it may serve for crushing soft, semi-fluid food. Weismann asks if it may not be regarded as glandular, but such a view is in no way suggested by its structure. More recently Emery has ascribed a suctorial function to the proventriculus in Ants (Formicidæ) [169], which closely resembles that of the Diptera. The arrangement of the plug, which resembles the plunger of a pump, lends some support to this view; but, on the whole, I am inclined to think it is a gizzard and nothing more.

The Proventricular Ganglion differs but little from the same structure in the larva. It consists of large ganglion cells, and lies in front of the proventricular œsophagus. It gives off numerous nerves to the chyle stomach, proventriculus, and œsophagus.

The Chyle Stomach commences in front above the proventriculus, traverses the thorax, enters the abdomen beneath the mesophragma, and curves upwards and backwards in the middle line; at the posterior margin of the second abdominal segment it deviates to the right, and after a short course terminates in a narrow pylorus, which enters the proximal intestine.

The thoracic portion is covered by small hemispherical projections, except at its anterior extremity, which is smooth like the abdominal portion. Hence the chyle stomach may be said to consist of three parts or segments: the caput, the thoracic or intermediate part, and the pyloric extremity or abdominal part. The muscular coat of the caput and the pyloric parts of the organ is continuous ; but in the intermediate portion its external longitudinal coat is arranged in six longitudinal bands, whilst the circular fibres are arranged in 
rings, so that the basement membrane and epithelial coats project between the muscle-fibres, and give it its characteristic sacculated appearance.

The sacculi or crypts formed in this way probably represent the four blind glands of the larva. In many insects the whole exterior of this part of the chyle stomach is covered by long crypt-like glands, and the crypts are lined by true glandular cells. I have sought in vain for gland cells in the rudimentary crypts of the chyle stomach of Calliphora, such as Frenzel figures from the chyle stomach of Blatta, Bombus and Hydrophilus [130].

The epithelial coat of the caput and of the pyloric portion of the chyle stomach consists of cubical rodded cells (see p. 279) exactly like those of the lingual salivary glands. These I regard as secreting cells, whilst the epithelium of the sacculated intermediate region consists of large conical cells, which may be compared to unicellular villi. These cells are united with each other at their base only, which stains deeply; the projecting conical portion of the cells stains less readily and exhibits a transparent mucoid border, this is apparently shed from time to time as a series of thin layers, which appear as a spongy reticulum, in sections, separating the more solid particles of food from the epithelium. I have never observed vacuoles or granules of secretion in these cells, and I conclude that they are concerned in the absorption of dissolved material, peptones and carbo-hydrates.

In the young imago and the nymph the cells of the intermediate portion of the chyle stomach are not conical, but columnar, and are covered by a thin layer of mucus. These cells in imperfectly prepared sections often exhibit the goblet condition, or the mucigenous portion of the cell may split into rods, which sometimes give it the appearance of being ciliated. I believe these appearances are the result of post-mortem changes, due to imperfect fixation of the cells.

The Proximal Intestine.-In the Cockroach (Blatta) and in many other insects the proximal intestine is not developed, or is merely a part of the chyle stomach, so that it is usually 
omitted in text-books or treated of as part of the chyle stomach. In the Diptera it is frequently represented by a mere dilatation of its posterior extremity.

The proximal intestine in Calliphora, and the Muscidx generally, is exceptionally long and forms a flattened helix, which lies on the right side of the middle line; it is more capacious than the abdominal part of the chyle stomach, makes two turns and a half, then returns on itself and deviates to the left side, where it makes a loop, returns to the middle line, and receives the Malpighian ducts at its posterior extremity.

Its external surface is smooth, and, except at its upper and its dilated lower extremity, it is lined with conical epithelial cells similar to, but longer than, those of the chyle stomach. Its upper and lower portions, as well as the ducts of the Malpighian tubules, are lined with rodded cells like those of the pyloric extremity of the stomach and of the salivary glands.

The Netenteron (distal intestine or hind gut). - I include under this term that part of the intestine which intervenes between the ducts of the Malpighian tubes and the rectal valve. In the Blow-fly the metenteron is very short, its muscular coat is thicker than that of the proximal intestine, and when the intestine is empty it is thrown into longitudinal parallel folds. The epithelium of its upper three fourths is cubical, with a distinct basilar border. The cells are vacuolated and contain numerous granules (Pl. XXIV., Fig. 5).

In the feeding larva, in which the metenteron is very long, its epithelium is loaded with fatty granules, whilst that of the chyle stomach and proximal intestine is clear and transparent. These facts are of interest in relation to the probable function of the Malpighian secretion, and indicate that it is concerned in the digestion and absorption of fat. It will be observed that in the imago, in which fat does not enter into the food, the distal intestine is very short, whilst in the larva it is very long and is always loaded with emulsified fat.

In the imago the lower part of the distal intestine and the valve which separates it from the rectum are lined by chitinized cells which have spines projecting into the lumen of the gut. 
In transverse sections the cavity of this part of the intestine is diminished by the projection of four thick lonsitudinal folds of the intestinal wall into its irterior (Pl. X.MIV., Figs. $f$ and 5).

The Proctodeum or rectum, as has been already stated, consists of three parts. The first part is dilated into a small sac lined with cubical cells, covered by a thin cuticular layer near the valve, but usually naked below. It is possible that the remains of the food are subjected to trituration as they pass through the distal portion of the distal intestine and the rectal valve, and that the residuum of nutritive matter is absorbed in this part of the rectum.

The first part of the rectum is separated from the second part by a well-marked sphincter muscle.

The second part of the rectum is a large pouch-the rectal pouch. It is lined by a single layer of flattened epithelium, and has a distinct cuticular intima. The rectal papillit project into its cavity, which is usually occupied by the thick semifluid excrement which is not unlike the urine of birds and reptiles.

The third portion of the rectum, the anal rectum, is tubular, narrowing towards the anus. It is lined by a thick cuticular intima continuous with the cuticular integument supported by pavement epithelium. The muscular coat is very thick. The lumen of this part of the intestine is reduced to a mere fissure except during the passage of excrement.

\section{b. The Malpighian Tubes.}

The Malpighian Tubes are four in number, two on each sicle: they exhibit a moniliform appearance, and are usually of a bricht yellowish-brown colour. The two tubes on either side unite at an acute angle and form a wide duct about $2 \mathrm{~mm}$. in length, which opens into the lower extremity of the proximal intestine.

The length of each of the Malpighian tubes is probably an inch or more, but they form such complex coils that I have found it impossible to unravel them. They lie on either side of and around the coils of the proximal intestine. 
Each tube consists of a basement membrane enclosing a number of cells; these cells measure about $50 \mu$ in diameter and give the tubes, which are only about $75 \mu$ in diameier, a somewhat moniliform character.

Transverse sections show only one or two cells in each, with a narrow channel, which is usually crescentic, between them. The cells are vacuolated with irregular cavities, and contain oil and pigment granules and minute colourless particles. The portion of the cell nearest to the wall of the tube consists of reticular protoplasm, and contains the nucleus; that portion of the cell next the lumen is frequently seen to be partially dissolved, and often exhibits the appearance of being bounded by ragged fringes.

The distal or blind ends of the tubules contain smaller cells, and have a narrower lumen than the end nearer the intestine. The ducts of the glands are lined with rodded cubical epithelium similar to that of the salivary (lingual) glands.

The tubes and their contents are rendered intensely black by osmic acid, and the secretion contains minute fatty granules as well as pigment granules.

The Malpighian tubules have been described as urinary organs by all modern authors; formerly they were regarded as hepatic or liver tubules. It appears to me that their relation with the intestine is entirely adverse to the modern view, and that they ought rather to be regarded as a hepatopancreas.

Schindler [165], in an elaborate paper, maintained the thcory that they are analogous to the kidney tubules, and gives the following arguments in favour of this view:

(I) They are developed from the proctodeum, and open into the rectum. (2) They appear at a very early period of development, when a liver would be useless, but when a renal organ would be of functional import. (3) They agree with kidney tubules in anatomical and histological characters. (4) Their secretion contains urates; and (5) Their secretion agrees in no way with the bile of other animals.

I shall examine each of these statements in detail, and shall 
then endeavour to state as briefly as possible the other view of their nature.

(I) 'They are developed from the proctodeum.' This statement is usually regarded as correct. I will only observe here that in both the embryo and the nymph the Malpighian tubules communicate with the mesenteron and not with the proctodeum.

Graber, although he holds the view that they are developed from the proctodeum, figures them in an early embryo opening into the mesenteron [114, Taf. III., Fig. 27], and according to my observations his figure is correct.

The statement that 'they open into the rectum' is incorrect. In nearly every insect they open into the pyloric or distal extremity of the chyle stomach or into the commencement of the proximal intestine. In the Blow-fly larva there are $35 \mathrm{~mm}$. of intestine between the anus and the Malpighian ducts, and in the imago $6 \mathrm{~mm}$. When the statement has been made, the authors who have made and accepted it had probably only those insects in mind like the Cockroach in which the distal intestine is very short.

(2) 'They appear at a very early period of development.' So do the liver tubules of the vertebrate. Remak says 'They appear in the embryo chick later than the rudiment of the Wolffian duct, but before the first Wolffian tubules.'

(3) 'They agree anatomically and histologically with urinary tubules.'

As diverticula of the intestine high up in its course, they certainly resemble a tubular hepato-pancreas rather than a kidney. The cells are large, contain fat and pigment, and undergo partial disintegration at least during secretion. All these characters point to a hepato-pancreas rather than a kidney.

(4) 'They contain crystals of uric acid.'

I have examined many hundreds of sections of Malpighian tubules, and I never yet saw any crystals in them except of artificial origin. In imperfect preparations numerous crystals are liable to form in the fat bodies, alimentary canal and blood. 
But even if uric acid has been found in the Malpighian tubes of some insects, this does not prove their renal function, since the liver contains a large quantity of urea in mammals and of uric acid in birds.

(5) 'The secretion of the Malpighian tubes agrees in no way' with the hepatic secretion.'

Authors have repeatedly stated that the so-called bile tubes of invertebrates never contain the bile acids, and Griffiths [160] criticising my statements already published, says: 'It may be stated in passing that according to B. T. Lowne the Malpighian tubules of Calliphora Erythrocephala are "hepatic" in function. If by hepatic he means that these tubules have the function of a vertebrate liver, his conclusions are erroneous, for neither biliary acids nor glycogen are present in these tubules. Again, if he means by "hepatic," they have a pancreatic function; this is also erroneous, because these tubules do not yield any digestive ferment or ferments' (p. 96).

These statements are sweeping, and would be serious if they were accurate. I cannot positively state that the Malpighian tubules of the Blow-fly or of its larva contain cholalic acid, but I can positively affirm that those of the larva give Pettenkofer's reaction with great brilliancy, which is, to say the least, an indication, and a strong one, that they do contain cholalic acid or some closely-allied substance. On moistening a portion of the tubules with a weak solution of cane sugar, draining off the excess and treating with dilute sulphuric acid, draining off the excess again and heating carefully to dryness, they become an intense cherry red, and the above is the most delicate test I know for the presence of cholalic acid.

I am quite aware that Pettenkofer's reaction is unfortunately not distinctive of cholalic acid, and that it occurs in the presence of proteids and other organic substances, thus the fat bodies and even the blood of the larva give a brick-red reaction with this test; but, as Halliburton states,* no organic

* 'Text-book of Chemical Physiology,' London and New York, s89r, p. 682 . 
substance (other than cholalic acid) gives the test so readily except $a$ naphthol.

Nothing can exceed the beauty of this reaction on the Malpighian tubes of the feeding larva; but the result is less definite in starved resting larva, such as are sometimes obtained in the winter months from shops where fishing-tackle, etc., are sold.

With regard to the statement that glycogen is absent, it should rather be, the presence of glycogen has not been proved; but how anyone could expect to prove its presence is more than I can understand. The cells of the Malpighian tubules contain so much granular pigment that the iodine test is inapplicable. Lastly, the statement that the tubules yield no ferment can only be regarded as an assertion. The absence of a ferment is not casily proved. I find that the Malpighian tubes of the larva are powerful agents in the emulsification of oil. By rubbing up a minute drop of oil in water on a glass slip, it is quite possible to form an imperfect emulsion; but the granules are not long in reuniting; if, however, a fragment of a Malpighian tubule of the Blow-fly larva is added a very perfect milk-white permanent emulsion may be easily produced. This evidence of the existence of an emulsive ferment is at least as good as that on which the existence of a ferment has been denied.

Lastly, the remarkable rodded epithelium at the lower extremity of the tubules indicates a secreting function, and its similarity to that of the sericteria and of parts of the intestines is in favour of the view that these tubules secrete a zymotic fluid.

When I stated that the Malpighian tubes are probably: hepatic in function, I only intended to indicate that they are digestive glands, and not lidney tubules. I have no objection to regarding them and the 'so-called' livers of Crustacea, Arachnids and Molluscs as pancreas-like glands. I do not know what constitutes a liver; if it is the presence of cholalic acid and glycogen, then as I am inclined to think cholalic acid, or some ncarly allied body, and glycogren are both present in 
these Malpighian tubules, and I see no objection to ascribing an hepatic function to them.

That the Malpighian tubes are the morphological representatives of the vertebrate liver is no contention of mine. If the 'so-called' livers of crabs, molluscs and other invertebrates are in future to be spoken of as pancreates, I suppose the Malpighian tubes should be so named. Fashions change, but it is difficult for one who has spoken of a gland for forty years as a liver, to see the impropriety of the term because some recent writers have suddenly discovered that it should be called a pancreas.

That something may be said in favour of the term liver or hepato-pancreas does not seem doubtful to me; I know no vertebrate in which the cells of the pancreas are loaded with pigment and oil-drops, like those of the so-called livers of many invertebrates.

I do not wish to discuss this matter further, as it is only a question of convenience. One term is as good as the other if the meaning is obvious, and I cannot conceive how, with this explanation, any difficulty can occur in understanding anything I have written on the subject.

\section{c. The Rectal Papillæ.}

The Rectal Papillæ are four hollow, conical bodies, two on each side, which project into the rectum. They are about $75 \mathrm{~mm}$. in length, and from $25 \mathrm{~mm}$. to $3 \mathrm{~mm}$. in diameter at their base.

The wall of the papilla is composed of a single layer of large pyramidal cells, which are from $40 \mu$ to $80 \mu$, or even ' I mm. in length: their rectal surface is covered by a cuticular sheath, the outer sheath, continuous with the lining cuticle of the rectal pouch; the inner extremities of the cells rest on a reticular connective pouch, the immer sheath, which bounds the cavity of the papilla (Fig. 52).

The base of the papilla is covered by a layer of radiating muscle-fibres, which connect the inner and outer sheath.

The cavity of the papilla is continuous with the body cavity; 
a large tracheal vessel, after dividing into several branches, enters the papilla and forms a tuft of anastomosing vessels in its interior, from which numerous capillaries pass outwards through the inner sheath, and ramify and form a network between the epithelial cells.

Historical.-Although the rectal papilla of several insects were known to and figured by Swammerdam [4], and attracted the attention of Lyonet* and Treviranus [161], the first description of their structure in the Blow-fly appeared in Leydig's text-book on histology in I857. I described them in

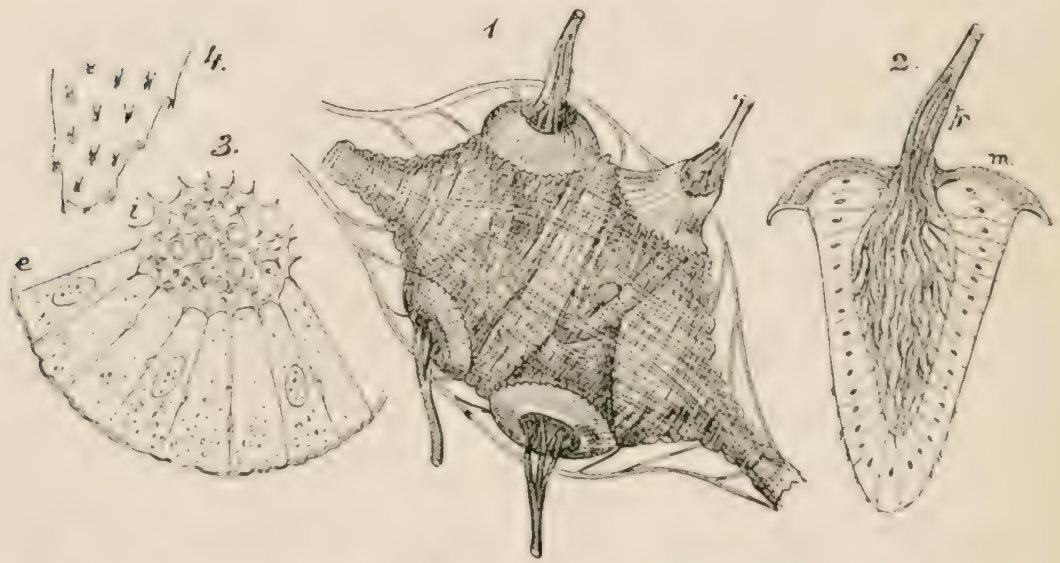

Fic. 52.-The rectal papillx. I. The rectal pouch, showing the four rectal papilla: 2. A radial section through the axis of one of the papilla. 3. A transverse section through the same, more highly magnifieci. \%. The apex of the outer sheath, showing the cuticular setx.

$e$, External, and $i$, internal sheath ; $m$, Muscle ; and $t r$, Trachex.

I869, and Chun published a valuable monograph upon the rectal papillæ of insects in 1876 [164].

The External Sheath is plicated longitudinally, and is covered by a number of chitinous sete, which are exceedingly numerous towards the apex of the papilla. These were described by Leydig, and also by Chun, who failed to observe the grouping of these seta and their relation to the openings or pores in the * 'Mem. du Muséum,' tom. xx. 
sheath, which he entirely overlooked, although I drew attention to them seven years before his monograph appeared [163]. Indeed, he does not seem to have read my paper on the subject, at least he makes no reference to it.

There are a number of minute hollow projections on the external sheath, the extremities of which are only closed by the large secreting cells. Each of these projections is overhung and protected by a small group of setæ, usually five or six in number; they are evidently the excretory orifices of the papilla.

The margin of the external sheath is strengthened by a crenated edge, into which the muscular coat of the rectum is inserted on one side, and the radiating muscles of the base of the papilla on the other.

The Internal Sheath consists of adenoid tissue formed by branching cells; it is continuous with the peritoneal coat of the rectum; and is connected by fibres which penetrate the muscular tissue with the basement membrane beneath the muscles. It is also apparently inserted into the chitinous margin of the external sheath, thus separating the epithelium of the rectal pouch from the columnar cells of the papilla.

Chun describes the cuticle of the rectum as splitting into two layers, one forming the external and the other the internal sheath of the papilla, but he believed the rectum to be devoid of epithelium. In the young imago and in the nymph it is easy to see the transition of the flat pavement cells into the great cylindrical cells of the papilla, which are clearly a modification of the rectal epithelium. I cannot, therefore, regard the internal sheath as a portion of the cuticular lining of the rectum. In the young state it is indubitably continuous with its peritoneal coat; neither is the internal sheath a cuticular membrane.

The Tracheal Vessels.-Chun says that each papilla receives two tracheal trunks. There is no constancy in the number of cylindrical tracheæ which enter each papilla, but they invariably arise from a single large tracheal trunk. There is not, therefore, an efferent and an afferent trachea, a point of great 
importance in relation to the physiology of the tracheal system.

The Secreting Cells.-These are the largest cells in the imago. Each cell contains a giant nucleus. The protoplasm is very reticular towards the external part of the papilla, and stains feebly ; towards the central cavity and the adjacent edges of the cells it stains more deeply, and the reticulations are much less distinct. The part of the cell towards the external sheath appears to be vacuolated by drops of secretion.

The Cavity of the papilla has a feeble reticular connective tissue uniting the trachere with the internal sheath. It contains leucocytes (blood corpuscles) and blood:

Nerves.-Chun and Leydig both describe a large nerve which enters the papilla. I can, however, trace no nerve into the papilla, but the thoracic ganglion gives off a median nerve from its posterior extremity, which extends to the posterior part of the abdomen and divides into two branches. These run one on either side of the rectum, and give branches to its muscular coat; they also supply the generative organs. Each gives several branches to the radiating muscles of the rectal papillæe. The branches of these nerves have no sheath, and resemble the visceral nerves of the insect in other parts (Fig. 52, I).

Morphology.-There cannot be the slightest doubt that the rectal papillae are developed from the epithelium of the proctodaum. In the young stage of the pupa they first appear as a thickening of this epithelium. In many insects they retain this character, and have neither an internal cavity nor a muscular base. Moreover, they are identical in structure with the so-called rectal gills of the Dragon-flies (see Chun's description [164]).

Function.-Authorities are divided with regard to the function of the rectal papillae. They are universally regarded as respiratory in the Dragon-flies (Libellula), and I think it indubitable that they have a secondary respiratory function in these insects, as the tracheal tuft is prolonged beyond the secreting epithelium into a whip-like process, which is con- 
stantly bathed by water renewed by the pulsatile action of the rectal pouch ; but, as Chun [164] observes, they cannot have a respiratory function in the fly, in which they are usually closely surrounded by a mass of excrement. Treviranus [161] and Newport regarded them as glands, an opinion which I held in I879 [163], and which I still maintain as correct.

This view has not been accepted by the majority of authors. Neither Leydig nor Chun so regard them, yet, if the folding of the wall of the rectum were reversed, no one would for a moment have doubted their glandular character.

In my former paper on these glands I suggested that they are renal organs. In the pupa stage they secrete insoluble urates, which give the murexide test with great ease, but in the adult fly their secretion is fluid. The excrement gives off ammoniacal fumes when heated, and fails to give the murexide test.

Rhythmic Pulsations.-During life the rectal papillæ pulsate rhythmically. These pulsations can be observed in the female through the transparent skin of the ovipositor when the latter is exserted, as these organs then lie within it. The pulsations are due to the contraction of the radiating muscles and the elasticity of the outer capsule; they evidently serve to insure the influx and efflux of blood to and from the central cavity.

\section{DEVELOPMENT OF THE ALIMENTARY CANAL.}

\section{a. In the Embryo.}

The origin of the stomodæum, mesenteron, and proctodæum of the embryo has already been discussed, in relation with that of the hypoblast. There is a perfect concord amongst observers as to the origin of the alimentary canal from three distinct sources. The stomodæum and proctodæum are derived from the epiblast, and the mesenteron from the hypoblast; and numerous observations, my own included, indicate the correctness of this view.

It is not difficult to demonstrate the limits of the stomo- 
deum, since it remains a comparatively simple tube, and exhibits at all times in the life of the insect the characters of an epiblastic structure; a flat pavement epithelium and a distinct chitinous intima. It is true that it is somewhat difficult to define the precise limit of the stomodaum in the proventriculus, and to determine how far the development of this organ is from epiblastic and how far from hypoblastic cells; but if we adopt the evidence afforded by the character of the epithelium, it is clearly chiefly developed from the hypoblast of the mesenteron-a view which is rendered probable by the manner in which the development of the proventriculus takes place.

It is quite another matter, however, to determine the fate of the proctodæal involution. Many observers, including myself, have seen a distinct proctodxal involution in the early stages of embryonic life. In the Blow-fly embryo, however, Graber has evidently regarded my blastopore as an anus and my metenteron as a proctodieum. If the section from which my figure (Fig. 2) is taken is to be interpreted as I have interpreted it, there is clearly a proctodaum, which is quite distinct from the dorsal invagination; but I have been quite unable to determine its fate.

I have carefully searched for evidence that the hind-gut is formed from the proctodieal involution; and I am not aware that anyone has been more successful than myself in actually tracing the development of the hind-gut (metenteron) to the proctodxum. Bütschli's figures [126, Taf. XXVII.] are far from convincing as to the real origin of the Malpighian tubes, especially Fig. $3 \mathrm{r}, \mathrm{b}$, in which these tubes appear to arise from the mid-gut; and his figures of a still earlier stage are capable of another interpretation (see p. 426).

The frequently repeated text-book statements that the Malpighian vessels originate from the anterior extremity of the proctodeum rest upon indirect, rather than direct, evidence.

Although Swammerdam figured the alimentary canal of the lice larva [4, Pl. XXIV., lig. 6], and represented it as a continuous alimentary tract, it has been more recently described as consisting of a proctodeum which is blind at its 
anterior extremity, and a mesenteron which is a wide sac opening only by the œsophagus, and entirely disconnected with the proctodæum, which terminates in front in the four large Malpighian tubes. This condition was described by Dohrn, $R$. Leuckart and others, who regarded it as an anterior stage of development to that described by Swammerdam.

I have no doubt that the condition so described is a subsequent stage characteristic of the resting larva. Dohrn says, 'In many Hymenoptera the union of the hind-gut and mesenteron only occurs at the end of the larval period. It may be observed that if a fairly full-grown Ant larva is hardened and cut through vertically, the mid-gut forms a sac, which is bounded by a layer of large cells, and contains within it about twenty cuticular layers enclosing a brown mass of fæcal material; whilst the hind-gut forms many coils, and is often found to terminate in front in a blind end.' I think it is clear that Dohrn was dealing with a resting larva or young nymph, as the conditions described are similar to those seen in the fly nymph (pronymph stage). The supposition that, in the feeding larvæ of the Hymenoptera, a blind mid-gut unites with the hind-gut after the functional activity of the organ has ceased, and just before the whole alimentary canal undergoes histolysis, is scarcely probable; on the other hand, it is extremely probable that, as in the fly nymph, the union between the parts of the alimentary canal becomes very narrow (see Pl. XXV., Fig. I), or may even become a mere fibrous cord. It is possible that the whole of the Malpighian tubes and the metenteron are expelled through the short, wide intestine in the Bee nymph, and that the new metenteron and new Malpighian tubes are developed, as in the fly nymph, from the saccular mid-gut.

Leuckart, in his great paper [20] on the development of the Pupiparæ, does not represent the alimentary canal as discontinuous; but in a previous note* he announced that he had discovered a similar want of continuity in the nymphs of these insects; again, I think he had to do with a subsequent and * 'Bull. Acad. Sci. Bruxelles,' xxi., 1854, pp. 851, 852. 
not a prior stage, and that if such a discontinuity is established, which I think possible, so far as the lumen of the alimentary canal is concerned in the Hymenoptera and some Diptera, it only occurs after the larva ceases to feed; and it is probable, I think, that the peculiar modification in the histolytic process which I have described in the Blow-fly nymph depends on the great length of the narrow hind-gut of the larva. It is easy to understand that the expulsion of the remains of the metenteron may be effected where it is a short wide tube, as it is in the Hymenoptera, by the anus.

There appears to be little doubt that the anal extremity of the intestine is closed in the Bee larva, during all the earlier stages of its development; and this is inconsistent with the view that it is developed from a proctodaal involution. At. least, it is quite as likely that a secondary closure of the communication between the chyle stomach occurs as that the intestine becomes blind-as it almost always is at its anal extremity in the embryo insect-if it is really developed from a capacious proctodæum.

I suspect the received view originated from the following statement of Weismann [2, p. 74]. He says: " $\Lambda$ s the blind catc are developed from the anterior end of the mid-gut, so the Malpighian vessels arise from the anterior end of the hindgut. But,' he adds, 'I have seen no earlier stages which support this view, yet I think it must be accepted, as it is supported by histological structure.'

Weismann gives a figure in which he represents the midgut, with the Malpighian tubes growing from a mass of cells which are continuous with its wall. He also represents both the intestine and the tubes as solid, and in another figure he shows the posterior end of the stomodaum as a solid mass of cells.

I have made numerous sections of embryos in this and in earlier stages of development, and have invariably found both the Malpighian tubes and the intestine hollow. I can quite understand the difficulty which Weismann laboured under, as he had to rely entirely on dissections, and it is impossible in 
surface views to distinguish the lumen in the embryonic stages of development.

Although there are no figures representing actual sections or dissections in which the Malpighian tubes are seen opening into the proctodæum, Graber has, as has been already stated, figured them opening into the mesenteron [114, Taf. III., Fig. 27], as my own observations have led me to conclude they do.

The difficulties which are met with in the investigation of the development of the alimentary canal in the embryo are very great, and it is rarely a single section gives any complete demonstration as to the manner in which the several parts of the alimentary canal are related to each other.

The following account of the development of the alimentary canal in the embryo agrees in many important particulars with that given by Weismann.

The fore-gut is primarily an invagination of the epiblast; it remains from the first without convolutions, and is a hollow epithelial tube; the crop is formed as a sac which grows from its ventral wall. All the parts developed from the stomodæum have in their definitive stage a pavement epithelium, and a well-marked chitinized intima.

The mid-gut orginates as an ovoid sac enclosing yelk cells; it is so large that in the nymphoid embryo it occupies the greater part of the interior of the body. The proventriculus is formed from a ring of cells attached to the epithelial wall, by which the posterior blind end of the stomodæum is enclosed. The Malpighian vessels are developed in relation with the posterior extremity of the mesenteron.

The metenteron (mihi) arises from the hypoblast, and, like the mesenteron, has a columnar epithelium in its definitive stage of development.

The rectum of the larva is very short; it has a structure precisely similar to that of the parts formed from the stomodæum. I have been unable to determine that it is developed from the original proctodæum, but I think that it most probably is, and that only a part, probably a diverticulum, 
of the original proctodrum becomes the rectum, which, according to Schindler, always makes its appearance at a late period, and which is entirely wanting in many larvæ.

Further, it is possible, and I think probable, that the original proctodxum is largely concerned in the formation of the discs from which the generative ducts and cloaca of the imago are subsequently developed. In the early stage on which Bütschli [126, Taf. XXVI., Fig. 22, $a, b, c]$ chiefly relies for his evidence as to the origin of the Malpighian vessels, it is more probable, I think, that he saw the rudiments of the sexual organs than those of the Malpighian vessels, as the union of the two sacs into a common tube, described by him on page $5+2$, is not consonant with what is known of the development of the Malpighian vessels, nor with the fact that they open by a pair of ducts into the alimentary canal.

In all insects the anus is apparently developed late, and the blind posterior extremity of the alimentary canal is certainly not suggestive of the idea that the hind-gut originates from the large primitive proctodæal involution.

The narrowing and lengthening of the chyle stomach, which gives it its cylindrical form, occurs during the last five or six hours of the embryo state, and the posterior part of the intestinal tube grows rapidly in length during the same period. The first flexure, which takes place as the result of the increase in the length of the alimentary canal, is apparently the permanent hermal flexure between the Malpighian tubes and the chyle stomach; subsequently the intestinal coil is developed, but this is proportionately very large in the embryo and newlyhatched larva, so that it occupies nearly the whole body cavity. These stages are figured by Weismann [2, Taf. VI., Figs. 79 and 80$]$.

\section{b. After-development of the Alimentary Canal.}

As has been already mentioned, the whole of the alimentary canal of the larva, with the exception of the asophagus and the posterior extremity of the metenteron, becomes enclosed within a fusiform sac, developed from parablastic elements 
(pp. 33I-2). This is subsequently converted into an epithelial sac, the epithelial elements of which are apparently derived from three groups of embryonic cells, which can be made out in the alimentary canal of the larva; the histoblasts of the proventriculus, of the chyle stomach, and the ring at the orifices of the Malpighian vessels.

It is by no means easy to understand how these groups of cells become a portion of the mesenteric sac, but it appears to me probable that the proventricular ring originates the anterior extremity of the epithelial sac; the manner in which the cells of the chyle stomach form a continuous layer on the inner surface of the sac has been already described (p.332), but the greatest difficulty is to understand how the ring at the orifices of the Malpighian vessels is related to the mesenteric sac. The sac certainly contains both the distal and proximal intestine, as well as the remains of the Malpighian tubes of the larva. It appears to me probable that the distribution of the tracheal vessels is concerned in the process, and that the new parablastic tissue is brought into relation with the ring through the medium of the tracheal trunks which supply it.

It is certain that those branches of the tracheæ which are connected with the imaginal rudiments preserve an embryonic structure, and have an external coat, consisting of very small cells, totally unlike the peritoneal coat of the vessels which undergo rapid degeneration during the development of the pronymph. Hitherto, however, I have entirely failed to substantiate by observations the manner in which the Malpighian vessels of the larva are related to their successors, the Malpighian vessels of the imago.

It may be admitted that the ring of small cells discovered by Ganin, and described by Kowalevski, which I will term Ganin's ring, are the rudiments of the Malpighian vessels and metenteron of the imago, as this appears most probable, but I have entirely failed to trace the changes which this ring undergoes.

When the mesenteric sac is fully developed, no traces of intestine or Malpighian vessels are seen in sections outside the sac, and the whole of the structures concerned are so friable 
that it is impossible to make out their relations by dissection, although it is possible to unravel the greater part of the larval metenteron from the interior of the mesenteric sac, soon after it is first enclosed in it. At a later period sections show that the sac is lined with epithelium, which is developed most strongly at its two ends, the cells corresponding to the proventriculus and what I take to be the cells derived from Ganin's ring.

It is possible that Ganin's ring becomes split on its dorsal aspect, as the histoblastic tissue of the chyle stomach does, and so grows over the posterior surface of the sac from its ventral towards its dorsal aspect.

A pouch-like prolongation of the posterior end of the mesenteric sac is next formed, from which the Malpighian vessels and new metenteron are developed. The blind cxtremity of the latter soon comes into relation with the new proctodieal pouch which contains the rudiments of the rectal papillae. It is by the invagination of this pouch over the blind extremity of the metenteron that the rectal valve is probably formed.

\section{Description of Plate XXV.}

Details of the alimentary canal of the nymph and pro-imago:

Firi, 1. - The alimentary canal of the pro-imago about the tenth day of the pupa state.

Fuc, 2. - l'osterior end of the mesenteron of the nymph, about the seventh day of the pupa state.

Fur. 3.--The proximal intestine and Malpighian vessels, about the tenth day of the jupa.

Fil: 4.-The Malpighian ducts and junction of the distal and proximal intestine on the twelfth day of the pupa state.

FiG. 5. - The same at the end of the pupa stage.

Fic: 6. - The rectal pouch and valve on the tenth day of the pupa state. There is apparently a complete septum between the rectum and distal intestine.

Fis. 7.- The rectum, distal intestine, Malpighian ducts, and sphincter between the distal and proximal intestine at the end of the pupa sleep. From a winter fly. The distal intestine and rectum are distended with urates, and the secretion of the Malpighian tubes is seen in the proximal intestine.

Fir, \&. - A portion of a Malpighian tube from the same insect, blackened with osmium peroxide.

$C h$, chyle stomach or mesenteron; $d$, distal intestine; $m, m$, Malpighian ducts; $m t$, Malpighian tubes; $p$, proximal intestine; $r$, rectum; $r p$, rectal papillie; spe shincter muscle at the junction of the proximal and distal intestines; $s$, septum between the distal intestine and rectum. 


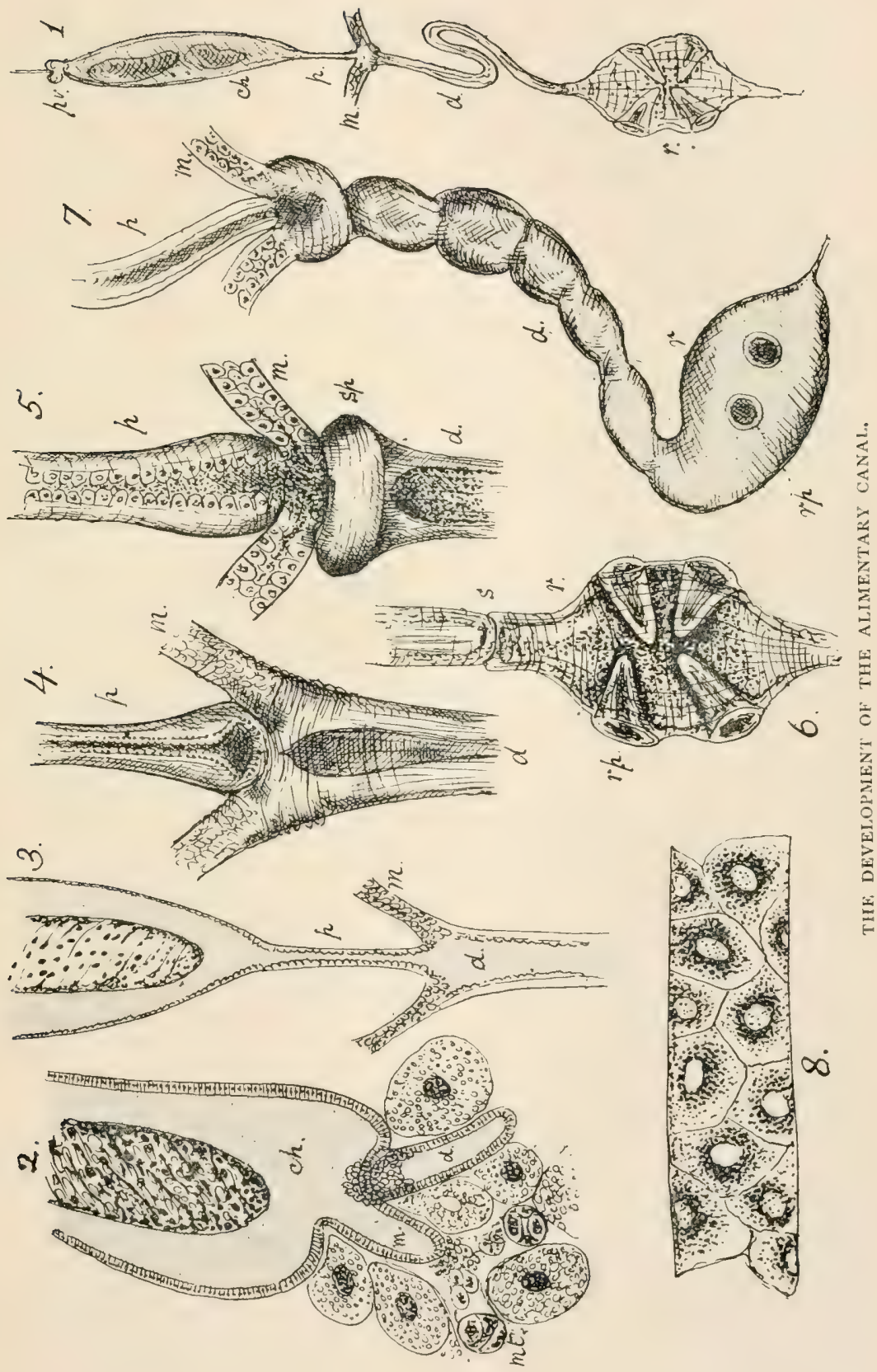



In arriving at this conclusion, I have been guided by the fact that the rectal valve is similar to the proventriculus in the reduplication of the intestinal wall. It is well known that the latter is formed as an invagination, and I have frequently observed the distinct septum which separates the metenteron from the proctodeum (Pl. XXV., Fig. 6, s) both in dissections and in sections.

The Malpighian vessels and ducts are at first outgrowths from the cells derived from Ganin's ring (Pl. XXV., Fig. 2, $m, m t$ ), and the proximal intestine only appears at a later date as a thin straight transparent tube lined with columnar epithelium. The muscular coat of the intestine is first seen as a sphincter muscle close to the orifices of the Malpighian tubules, and then the canal connecting the proximal and distal intestines appears to be closed (Pl. XXV., Figs. 4 and 5). I have not been successful in obtaining a section in the proper plane to show the relation which subsists at this period between the lumen of the distal and proximal intestines; but if the intestine of a pupa is dissected out and examined, a slight pressure on the cover glass shows that the closure of the canal is due to the above-mentioned sphincter, and that there is no organic septum between the orifices of the Malpighian tubes and the proximal intestine.

At a later period, or from about the seventh to the eighth day of the pupa, the distal intestine is filled and distended with a clear coagulable fluid precisely similar to that contained in the mesenteron; and judging from the appearance of the Malpighian tubes, they have not as yet commenced to pour any fluid into the intestine. They are quite twice the diameter they have subsequently, are perfectly cylindrical, and of a paleyellow colour; their cells contain both pigment granules and minute spherules of oil in great abundance. The latter are rendered intensely black by the action of osmium peroxide (PI. XXV., Fig. 8).

The rectal papillæ have by this time attained very nearly their final stage of development, and the rectal pouch is filled with a milky fluid. This fluid is an emulsion of fine granules of 
urates, which are perfectly opaque by transmitted light, but guite white when illuminated by direct light. Osmic acid does not blacken these particles or the contents of the distal intestine, as it does the contents of the Malpighian tubes.

On the last day of the pupa state, the rectal pouch is greatly distended with urates, and its contents have passed back into the distal intestine, and extend upwards in a gradually decreasing quantity to the sphincter which separates the distal and proximal intestine (Pl. XXY., Fig. 7). The Malpighian vessels are now seen to communicate with that part of the intestine which is above the sphincter, the contents of which have assumed a yellowish tint.

The white opaque semi-solid matter which fills the rectum and distal intestine consists almost entirely of urates, and gives the murexide test readily, but there are no traces of urates in the Malpighian vessels, which are loaded with granules of oil. These granules are intensely blackened by osmic acid, so that the tubules become striking objects from their inky blackness (Pl. XXV., Fig. 8).

The accumulation of urates in the rectal pouch, its very great distension, and the moderate subsequent distension of the distal intestine, undoubtedly point to the secretion of this substance by the rectal papillex, and not by the Malpighian tubes, whilst the fluid from the latter is undoubtedly bile-like.

As soon as the secretion of the Malpighian tubes begins to be excreted into the proximal intestine, the latter grows rapidly. in length and thickness, and the helicine coil first becomes apparent between the orifices of the Malpighian tubes and the chyle stomach. This coil is completed during the last day of the pupa and the first few hours of the imaginal condition.

For some days, two or more, before the insect emerges the contents of the chyle stomach have assumed an amber-yellow colour, and the corpora lutea undergo rapid solution; this is apparently the result of the passage of the secretion of the Malpighian tubes into the mesenteric section of the alimentary canal.

I have not been able to determine the exact period at which 
the stomodxal portion of the alimentary canal opens into the mesenteron, but the insects drink greedily an hour after they emerge from the pupa. The crop is first distended with fluid, but if the insect is fed on coloured syrup this passes into the chyle stomach as soon, or almost as soon, as the insect is able to fly.

I believe the lumen of the osophagus communicates with the chyle stomach as early as the middle of the pupa state, and there is apparently a continuous lumen at least two days before the insect emerges from the pupa, although no fluid ever passes back from the chyle stomach into the osophagus during the latter days of the pupa stage.

Development of the Salivary (Sericterial) Glands.-So far as I know, no direct observations are extant as to the manner in which these glands are developed in the egg, but they are usually regarded as invaginations of the epiblast of the labium or of that at the root of the maxillæ or mandibles, and they are seen as open epithelial tubes at an early stage of development.

In the pupa, the tubular salivary glands of the imago of the Blow-fly are developed according to Kowalevski [145] from imaginal cells, which, he says, are found at the junction of the duct and gland sac of the larva. Van Rees [147, p. 76] differs widely from Kowalevski in his account of the manner in which the sericteria of the larva disappear, for whilst the latter states that they remain attached to their duct until after the development of the head, Van Rees figures and describes a new duct at this period which terminates in a blind end in the basal part of the proboscis, and says the degenerated gland masses are already separated from their ducts.

I have carefully examined the new duct, and in young nymphs it is certainly not seen in transverse sections, except near the distal part of the rostrum. It appears to me to be an entirely new formation, having no connection with the larval sericteria.

At a later stage, such as is represented in Pl. XXI., the blind end of this duct is connected by solid cell strings, which surround the cephalo-thoracic nerve cord with two masses of cells, one on either side of the œsophagus. It is from these 
that the convoluted gland tubes are developed, and they remain connected with the exophasus, as Weismann represented them $[2$, Pl. IX., Fig. I5], for a long time.

Hence, I think it is probable that the new gland tubes are developed from cells formed by proliferation from the blind end of the duct, just as the gland tubules originate in the mammary, salivary and lachrymal glands of Vertebrates, as solid cell growths from the Malpighian layer of the epidermis. The invaginations which form the distal extremities of the ducts either appear at a subsequent stage or are comparatively short when the gland is first formed; the latter condition has apparently led to the received view with regard to the manner in which the tubular glands of insects are developed from the epiblast.

Addendum. - When the above was already in type, my attention was drawn to a very important paper by Paul Mayer* on the development of some decapod Crustacea. Mayer describes the development of the hind-gut, as Graber did from the blastoporal invagination. In this he completely agrees with my views, except that he describes no proctodieum in the sense in which I have used the term. Great confusion has arisen by the use of the words hypoblast and mid-gut with meanings which are special to works on insect embryology. If the mid-gut is ever developed from free yolk cells in Arthropods, hypoblast is not an appropriate designation for the layer of cells which forms its wall; nor can the term proctodieum be properly applied to a blastoporal involution. The application of the latter sometimes to one and sometimes to another involution has led to erroneous generalisations.

* Mayer, I’aul, '/ur Entwickelungsegeschichte der Dekapoden.' Jenaische Zeitsch. f. Naturwissenschaft, Bd. xi., 1877. 


\section{CHAPTER XII.}

THE NERVOUS SYSTEM.

\section{ANATOMY OF THE NERVE CENTRES.}

THE somatic nerve centres of the Blow-fly (Pl. XXVI.) are two in number, the cephalic and thoracic. The former consists of the supra-œsophageal ganglia, united with the infra-œso-

\section{Bibliography :-}

170. Dujardin, F., 'Mémoire sur le Système nerveux des Insectes.' Ann. Sc. Nat. Zool., 3me ser., tom. xiv., I 850.

171. Faivre, E., 'Du Cerveau des Dytisques considéré dans ses rapports avec la Locomotion.' Ann. Sc. Nat. Zool., 4 me ser., tom. viii., I857.

172. Owsjannikow, 'Recherches sur la Structure intime du Système nerveux des Crustacés et principalement du Homard.' Ann. Sc. Nat., 4me ser., tom. xv., I86I.

173. FAIVRE, E., 'Recherches expérimentales sur la distinction de la Sensibilité et de l'Excitabilité dans les diverses parties du Système nerveux d'un Insect, le Dytiscus marginalis.' Ann. Sc. Nat. Zool., 5 me ser., tom. i., I 864 .

174. Lemoine, V., 'Recherches pour servir à l'histoire des Systèmes nerveux, musculaire et glandulaire de l'Écrevisse.' Ann. Sc. Nat. Zool., 5 me ser., tom. ix., I868.

175. DietL, MI. J., 'Die Organisation des Arthropodengehirns.' Zeitsch. f. w. Zool., Bd. xxvii., I876.

176. Dogiel, I., 'De la Structure et des Fonctions du Cœur des Crustacés.' Archiv. de Physiologie, ser. ii., tom. iv., I 877.

177. FLÖGEL, I, H. L., 'Ueber den einheitlichen Bau des Gehirns in den verschiedenen Insecten Ordnungen。' Zeitsch. f. w. Zool., Bd. xxx., Suppl., I877.

178. BeRGER, E., 'Untersuchung über den Bau des Gehirns und der Retina der Arthropoden.' Arb. Zool. Inst. Univ. Wien, 1878, und Zool. Stat. Triest, tom. i., I878.

179. YUnG, E., 'Recherches sur la Structure intime et les Fonctions du Système nerveux central chez les Crustacés Décapodes.' Archiv. de Zool. Exp., tom. xvii., I 878 . 
phageal metameral gangria of the head, and is conveniently termed the brain isee p. 63): the latter represents the remaining gangria of the ventral chain. The cephalic and thoracic centres are united by the cephalo-thoracic nerve cord. The abdominal nerve cord from the posterior extremity of the thoracic ganglia gives off nerves on either side to the abdominal organs; but exhibits no ganglionic enlargements. All the abdominal ganglia are apparently united with those of the thorax to form the thoracic nerve centre.

180. Newtox, E. T., 'On the Brain of the Cockroach, Blatta Orientalis.' Quart. Journ. Microsc. Sc., vol. xix, iS79.

181. Micheis, H., 'Beschreibun des Nervensystems ron Oryctes nasicornis im Larven, Puppen, und Käferzustände.' Zeitsch. f. w. Zool., Bd. xxxiv., 1880 .

182. P'ICKARD, A. S.. "Monograph on the Brain of the Rocky Mountain Locust.' United States Entom. Commission, 1880.

183. BELlonci, "Intorno alla Struttura e alla Connessioni du lobi olfattori negli Artropodi superiori e nei Vertebrati.' Reale Acad. dei Lincei, 1881-82.

184. BELLoNCI, 'Intorno al Ganglio Ottico degli Artropodi superiori.' Monthly Internat. Journ. Anat. and Physiol., vol. iii., 1886.

185. Vhathases, H., 'Etudes histologiques et organologiques sur les Centres nerveux et les Organes des Sens des Animaux articulés.'

Mem. I. 'Le Ganglion optique de la Langouiste.' Ann. Sc. Nat., Gme ser., tom. xrii. : et Bib. de l'École des hautes Fitudes, tom. xxiv., 18 .

Miem. 2. 'Le Ganglion optique de la Libellule.' Ann. Sc. Nat., ome ser., tom. xviii.; et Bib. de l'École des hautes Etudes, tom. xxxi.

Mem. 3. 'Le Ganglion optique de quelques Larves Diptères.' Ann. Sc. Nat., Gme ser., tom. xix., 1885 ; et Bib. de l'École des hautes Études, tom. xxxi.

Mem. 4. 'Le' Cerveau de la Guêpe.' Ann. Sc. Nat. Zool., 7 me ser., tom. ii., 1887.

Mem. 5. 'Le Cerveau du Criquet, CEdipoda cœrulescens et Calaptenus italicus. Comparaison du Cerveau des Crustacés et des Insectes; et le Cerveau et la .Iorphologie du Squelette céphaliçue.' Ann. Sc. Nat. Zool., 7 me ser., tom. iv., 1887.

186. Crecatl, I, "Uber die Organisation des (ichirns der Somomya (Calliphora) Erythrocephala.' Zeitsch. f. w. Zool., Bd. xlvi., 1888. 


\section{a. The Thoracic Nerve Centre of the Blow-fly Imago.}

The thoracic nerve centre (Pl. XXVII.) is far more simple in structure than the cephalic. It is fusiform, and exhibits three pairs of hemispherical enlargements on its ventral surface (PI. XXVII., $a, b, c)$, corresponding with the three pairs of thoracic segmental ganglia (Pl. II., Fig. I, I, 2, 3) of the generalised nervous system. Its dorsal surface exhibits a central band of longitudinal fibres, a continuation of the cephalo-thoracic nerve cord. On either side of this band there are three dorsal enlargements (Pl. XXVII. $c, f, h$ ) of the central stroma (p. 66). These I term the dorsal mesoand meta-thoracic and the abdominal ganglia. There are also tivo pairs of deeply seated masses of stroma (seen in the section Pl. XXVII., Fig. 4, $d$ and $f$ ). The anterior pair I shall term the dorsal pro-thoracic lobes and the posterior pair which give origin to the great nerves of the halteres may be distinguished as the great or central ganglia of the halteres.

Nerves.-Nine pairs of nerves arise from the thoracic ganglion. Three ventral pairs (Pl. XXVI., $\left.v^{\prime}, v^{\prime \prime}, v^{\prime \prime \prime}\right)$ from the ventral enlargements which supply the three pairs of legs, and six pairs of dorsal nerves. Three of the latter are very large, they are the dorsal pro-, meso- and meta-thoracic nerves ( $d^{\prime}$, $\left.d^{\prime \prime}, d^{\prime \prime \prime}\right)$.

The pro-thoracic dorsal nerves supply the muscles of the neck and the anterior lateral wing-muscles. The second pair, the meso-thoracic dorsal nerves, supply the remainder of the thoracic muscles, the dorsales, sterno dorsales, and the posterior muscles of the wing root. The third pair of dorsal nerves are entirely sensory and terminate in the small ganglia at the bases of the halteres (the peripheral ganglia of the halteres).

The pro- and meso-thoracic dorsal nerves each arise by two roots, a dorsal bundle of fibres which may be traced into the median dorsal band, and a second, or ventral, bundle about 
equal to the former in size, which divides into a number of fasciculi, some of which are lost in the cellular cortex, whilst others enter the corresponding reticular enlargement of the stroma.

The nerve to the halter has only one root, which is similar to the ventral root of the pro- and meso-thoracic dorsal nerves; it arises from the great ganglion of the halter, partly from the central stroma and partly from the cortex (see 'Physiology' of Nervous System ').

The remaining nerves may be termed the anterior $\left(a d^{\prime}\right)$ and posterior $\left(a d d^{\prime \prime}\right)$ accessory dorsal, and the first pair of abdominal nerves $\left(a b^{\prime}\right)$.

The accessory dorsal nerves arise from the lateral region of the thoracic sanglion, between the dorsal and ventral nerve roots. As only two pairs are developed, which terminate near the spiracles, it is highly probable that they supply the spiracular muscles, but owing to their extreme fineness I have been unable to trace them into these muscles.

The abdominal nerves of the thoracic ganglion are two in number, one on each side (ab'), they pass beneath the mesophragma, and are distributed to the muscles and skin of the basal part of the abdomen.

The dorsal band, much reduced in size, is continued as a single nervous trunk, the abdominal cord, which gives off four pairs of nerves in the abdomen, and terminates in several branches.

According to Meigen, guoted by Iiurmeister [8], the Blowfly hat two small ganglia on the abdominal nerve-cord, one in the second abdominal segment, and one between the ovaries

\section{DESCR HPION OF P'IATE XIVI.}

The central nervous system of the imago seen from its dorsal aspect.

$a$, antennal nerves; $a b^{\prime}$, abdominal nerves arising from the thoracic nerve centre; al" (1) ali"', alulominal nerves ariving from the ventral ablominal nerve cord ; $a d^{\prime \prime}, a d^{\prime \prime}$, anterior and posterior accessory dorsal nerves ; $d^{\prime \prime}, d^{\prime \prime}, d^{\prime \prime \prime}$, pro-, meso- and meta-thoracic dorsal nerves; $m x$, maxillary nerves; 0 , ocelli; $x$, esophageal opening between the crura : $s$, optic ganglia : $0 n$, optic nerve: ph, pharyngeal nerves; $z^{\prime}, v^{\prime \prime} v^{\prime \prime \prime}$, ventral thoracic nerves. 'The hemispherical caps on the optic nerves represent the retina. 
PLATE XXVI.

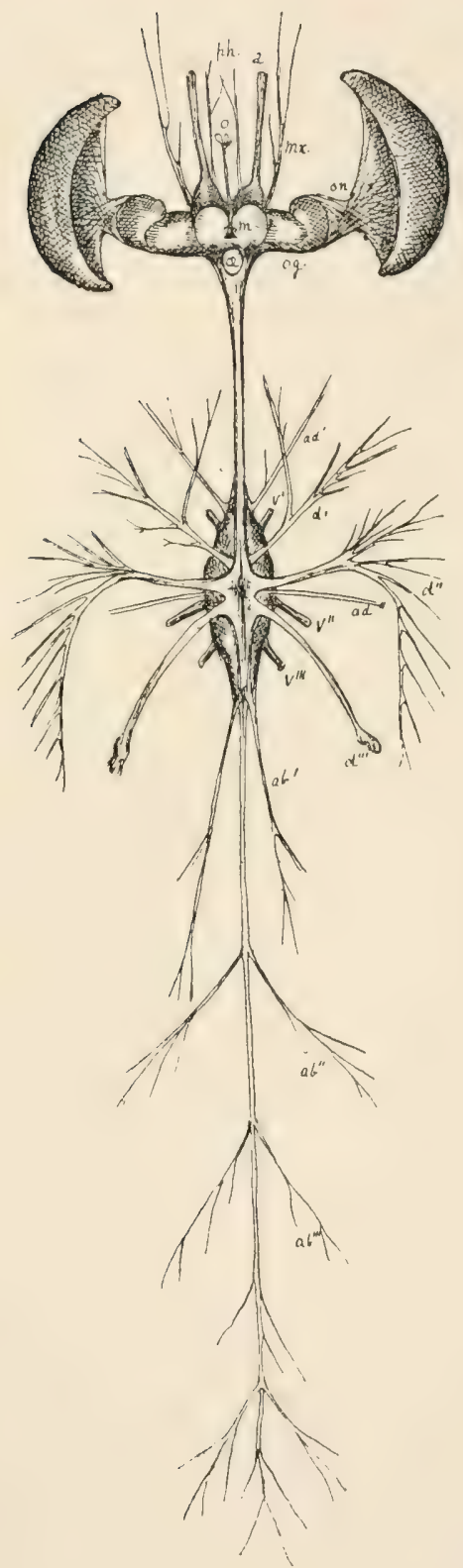



in the female and the vesicula seminales in the male. After a most careful search I have been unable to find any traces of these ganglia.

Longitudinal Sections of the Thoracic Ganglion (Pl. XXVII.) show that the various ganglionic enlargements of the core are united by numerous distinct bundles of fibres, some of these pass into the dorsal band and unite the thoracic and cephalic centres, others are merely commissural between the component ganglia of the thoracic nerve centre.

The great cephalo-thoracic nerve cord divides into three sets of fibres-a dorsal median set (Fig. 3, c) which form the dorsal band; a second set which lie in a lower plane, and are connected with the dorsal ganglia (Figs. I and $f_{f}$ ); and a third set which enter the ventral ganglia (Fig. 2).

The commissural fibres between the component ganglia are vertical, transverse, or longitudinal ; so that all the ganglia are connected in the most complex manner. These connections have not, however, been worked out in detail ; some are represented in the figures.

Owsjannikow [172] describes the longitudinal nerve fibres of the segmental ganglia in the Crustacea as of two kinds : a dorsal set of large fibres which are superficial-these, he says, are united with the large nerve cells of the cortex and are motor in function-and a deeply-seated set of small fibres, which are connected with the small cells; these he regarded as sensory.

In the Blow-fly the dorsal band of fibres clearly correspond with the superficial dorsal fibres of Owsjannikow, and they are probably directly connected with the large nerve cells, with the dorsal nerve roots, or with both; but they also have deep connections with the central stroma.

The deeper longitudinal fibres scarcely differ in size, however, from the dorsal set; they are most probably sensory. As the fibres which constitute the dorsal band are far more numerous than those of the cephalo-thoracic nerve cord, it is certain that they do not all come from the cephalic centres, and possibly none of the cephalo-thoracic fibres are connected 
with the nerve roots or ventral abdominal cord without communicating with ganglion cells in the thoracic ganglion.

Many of the fibres of the thoracic nerve centre are simply commissural, uniting its several constituent ganglia. Such fibres are probably concerned in the co-ordination of the movements of the thoracic appendages.

The Vesicular or Gray Cortex covers the surface of the nerve centre. Its thickness is subject to considerable variation, it is thickest between the ganglionic enlargements and around the nerve roots; it is very thin on the dorsal aspect of the centre. and is entirely wanting above the central dorsal band.

The nerve cells of which it is composed are of two kindsvery large stellate cells and smaller fusiform cells. The former are found in groups close to the nerve roots, and the latter cover the intervening portion of the centre, and are the more numerous. Between the large and smaller cells are others which are intermediate in dimensions.

The gray cortex also passes into the interior of the ganglion between the component lobes of the central stroma; this is well seen in the figures.

All the cells of the cortex are connected by fine processes with the central stroma, and other processes from many of them can be traced into the nerve roots. But the fibres of the nerve roots are not all of them connected with the cells of the cortex directly. Many of them can be traced into the medullary stroma, and others, as has been already stated, come from the

\section{DESCRIPTON OF P'LATE XXVII.}

Details of the thoracic nerve centre.

Fic. 1. - A lateral section through the ventral ganglia, showing the origin of the ventral nerve roots.

Fis: 2. $\rightarrow$ A similar section nearer to the ventral surface.

I.16. 3.--A vertical longitudinal (sagittal) section, showing the origin of the clorsal and ventral nerve roots.

Fir: 4.-A similar section nearer the medium plane and somewhat oblique.

tr, b, c, pro-, meso-, and meta-thoracic ventral ganglia; $d$, dorsal prothoracic fanglion; $e$, dorsal meso-thoracic ganglion; $f$, root of the nerve to the halter and great ganglion of the same; $s$, in Fig. 3 , meta-thoracic ventral ganglion, in Fier of dorsal ganolionic enlarement corresponding to the abotominal ganglia; h, ganglion at the root of the first aldominal nerve. 


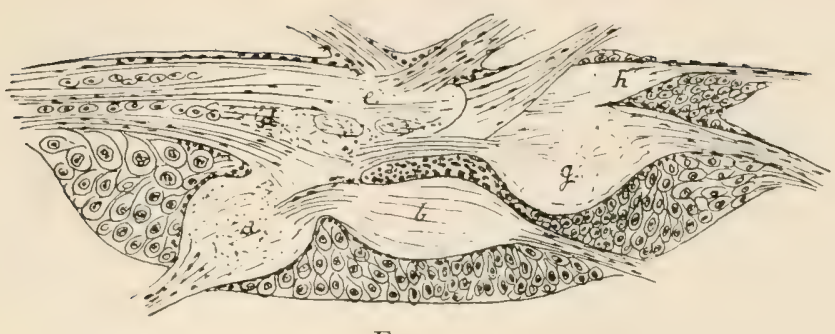

FIG. 3 .

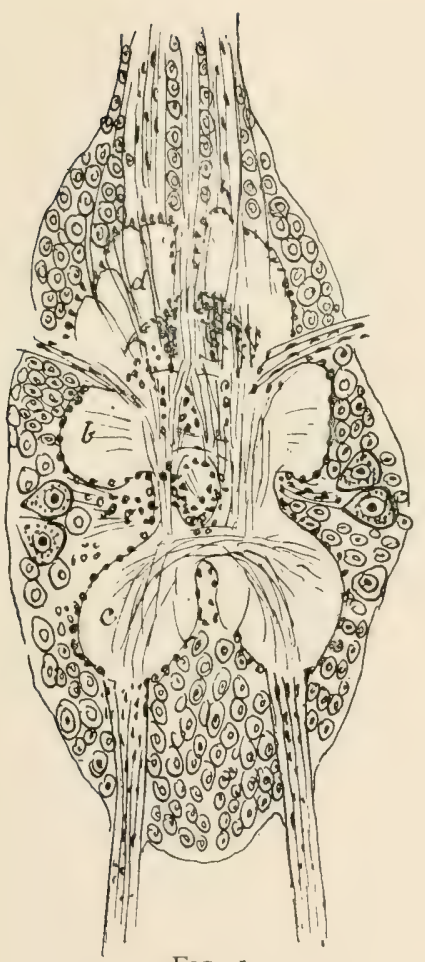

FIG. I.

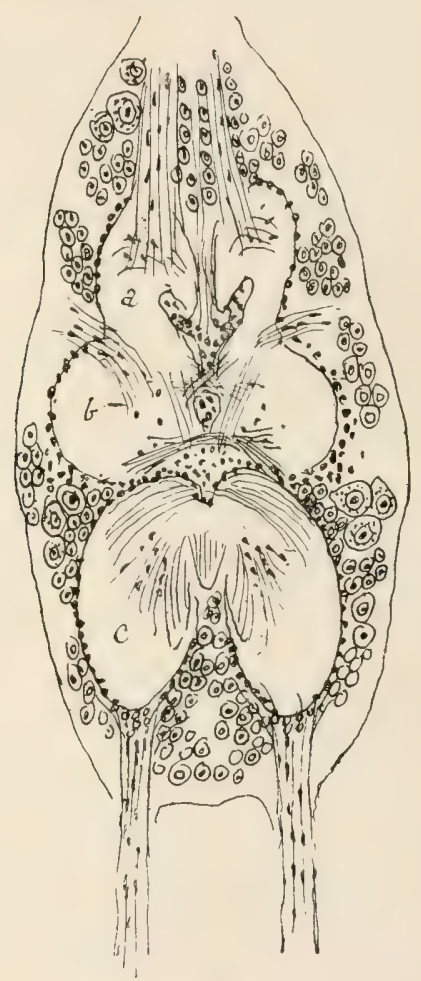

FIG. 2.

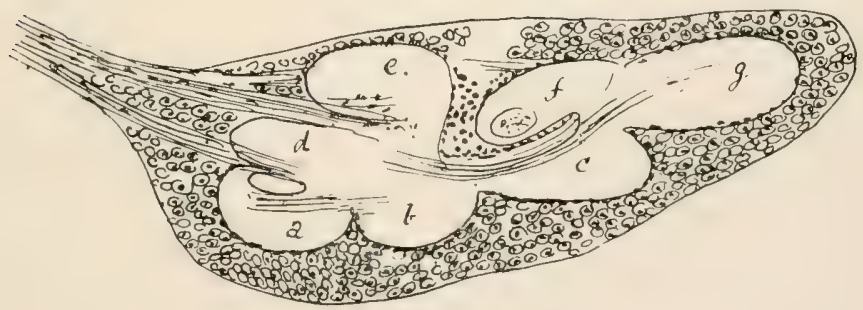

FIG. 4. 

dorsal band. Such fibres, however, may be, and probably are, connected with the cortex in other parts of the thoracic ganglion.

The arrangement of the cells and fibres and their relations to the nerve roots in the thoracic ganglion are in consonance with the view that the ventral chain, which it represents, has functions similar to those of the medulla spinalis and medulla oblongata in the Vertebrata. I shall hereafter show that the evidence we possess indicates that the ventral chain in the Arthropoda consists of a series of reflex centres and conducting cords. The reflex character of the thoracic ganglia becomes very apparent after the cephalo-thoracic cord has been divided in the Diptera; an indication that the cephalic centres exhibit an inhibitory influence on their reflex functions.

Morphology of the Thoracic Nerve Centre.-Although sections through the thoracic nerve centre exhibit considerable deviations from the typical form of the ventral ganglionated cord of the more generalised Arthropoda, there can be no doubt that it is composed of the three pairs of ventral ganglia corresponding to the three thoracic segments, and of two or more pairs of abdominal ganglia. The segmentation of the neuroblast only occurs in the early stages of the formation of the nymph; there is no such segmentation in the larva. The four anterior segments, like those of the Pupiparæ, become far larger than any of the others, which apparently undergo absorption or, after having become greatly reduced in size, are fused with the fourth segment (compare Figs. 8 and 9, Pl. II.). The subsequent development of the dorsal ganglia takes place by the enlargement and sub-division into two parts of each of the primitive thoracic ganglia (see 'Development of the Nervous System ').

The union of the abdominal ganglia with the thoracic is by no means confined to the Diptera and Hymenoptera, but is apparently characteristic of all the higher groups of insects. Thus Herold [140] has shown that the first pair of abdominal ganglia are fused with the thoracic in the butterfly, Pontia Brassicæ; whilst the figure given by Straus Durckheim [40] 
of the nerrous system of the Cockchafer shows that all the ablominal ganglia are united with the thoracic to form the thoracic centre in that insect. For some further remarks on the comparative morpholory of the nerrous system in insects see p. 62.

\section{b. General Structure of the Brain in the Arthropoda.}

Flizgel, as early as I877 [177], pointed out, in no equivocal terms, the great similarity of structure in the brains of the must diverse insect-types. With the single exception of the Wasp (I espal), he showed that the differences which exist are not such as to justify the opinion that the cephalic centres are differently constituted in different insects. He speaks with astonishment of the erreat deviation of the wasp's brain from the common type. That Fliggel was mistaken in attributiner marked exceptional characters to it is now, I think, indubitable. As yet, however, a uniform morphological nomenclature is wantines, so that the general impression is that the brains of insects differ so miuch from each other, and from those of other Arthropods, that no such nomenclature is possible.

Viallanes, in Isis $[183$, Mem. 4], said: 'In different orders of insects, and often in genera of the same orler, the brain exhibits unexpected peculiarities. Thus, without exaggeration, it may le said that the brain of a Coleopterous differs from that of a Hynenopterous insect as much as the brain of a Fish does from that of one of the higher Mammalia.' And he adds: ' $A$ t the present time every hypothesis concerning the interrelations of insects' brains must be regarded as rash, as it is without a basis of support.' And Viallanes confesses that he adopts a 'monographic style, so that the interest of special facts may not be masked ly hazardous generalisations.' Such a style is very characteristic of the majority of memoirs on the insect brain.

So far as mere difference in the proportionate size of the lrain and the body weight is concerned, there is, I think, less variation in Arthropods than in Vertebrates: and, so far as structure is concerned, it appears to me that only 
a very limited modification occurs even in widely distinct types. I should judge that the brains of Arthropods scarcely differ more than those of Fishes and Amphibians, if the lower forms of Crustacea are excepted, and these, perhaps, do not differ more from the common Arthropod type than that of Amphioxus does from those of other fishes.

The connective cords between the supra-and infra-œesophageal ganglia differ greatly in length; and the proportionate development of the several parts is very dissimilar in widely different groups of Arthropods. The transverse commissures of insects exhibit a complexity unknown in the Crustacea ; but otherwise there is so close a conformity of structure that, until a definite nomenclature is adopted, nothing but confusion can exist. No real advance of knowledge can be expected until someone is bold enough to pass from a special to a general description which may serve to connect facts otherwise so special and technical that few can feel any interest in them.

If the brains of the Blow-fly and the Wasp were totally unlike those of Arthropods generally, and if the brain of each insect group must be studied 'monographically,' then I for one do not think the study worth entering upon. My object is not to give my readers a description of the brain of the Blow-fly and nothing more, but to show that its study throws light on the whole Arthropod sub-kingdom, and is important because it enables the student of Nature to see further into the arcana of organic life, and adds to our knowledge of the relations of Arthropods and other groups of animals.

Whatever the ultimate fate of Gaskell's bold hypothesis [45] as to the relation of the alimentary canal in Arthropods and the axial canal of the nervous system in Vertebrates, it is indubitable Gaskell and Patten [48] have done a service in reopening a question which has long lain dormant, as to the relation of the supra-œsophageal ganglia and the ventral cord of Arthropods to the central nervous system of Vertebrates.

As I have already remarked, there are grave difficulties which must be cleared away before Gaskell's hypothesis can be accepted, and not the least of these is the vesicular character of the 
supra-cesophageal centres in the embryo 13low-1ly, as according to Gaskell's view no such vesicles should exist. Nevertheless the existence of these vesicles and the general arrangement and characters of the nerve centres of Arthropods indicate analogies and, perhaps, homologies with the central nervous system of a Vertebrate, which cannot be lightly disregarded. It has long been known that three pairs of great ganglia exist in the supra-cesophageal centres of insects; the antennal ganglia; the central ganglia, of which the optic ganglia have been regarded as mere lateral off-shoots; and the ganglia of the crura, developed in relation with the osophageal connectives, between the supra-xsophageal and the metameral infrawesophageal ganglia. Viallanes [185] includes the central and optic ganglia under the term protocerebron, whilst he terms the antennal ganglia the deutero- and the crural ganglia the tritocerebron.

There are good reasons, I think, for discarding this nomenclature. The antennal ganglia and the ganglia of the crura are merely special structures connected with the roots of the antennal and pharyngeal nerves, whilst Viallanes' protocerebron includes not only the optic ganglia, which are, perhaps, comparable with the antennal ganglia, in the same sense that the olfactory bulb and the ganglionic retina of Vertebrates may be compared; but also all the complex structures of the brain proper, which I shall show exhibits three distinct paired groups of nerve centres.

In orler to understand the insect's brain it is necessary to compare it with the brain of the more reneralised crustacean type. This has been attempted by Viallanes, but, although in many points his work is accurate, his knowledge of the Crustacean brain is so imperfect that he has entirely overlooked many important facts, and has used his knowledge rather for the purpose of establishing his theory that the insect's brain is composed of a proto-, deutero- and tritocerebron, than for the purpose of attempting a real elucidation of the structure of the Arthropod brain.

E. Yung, [179], whilst he recognised a general similarity 
between the brain in the Orthoptera and in the Decapoda, contents himself with generalisations, and does not descend to particulars; he says: "The cerebroid ganglion, or brain, is constituted on the same plan in the Macroura and the Brachyura, and this is analogous to that described by various authors in the Insecta.'

It has long been known that the ganglia, from which the nerves of the antennules spring in the Crustacea, correspond with those of the antennæ in insects, and there is not the slightest difficulty in recognising the identity of the optic ganglia in the two classes; but, beyond these points, our
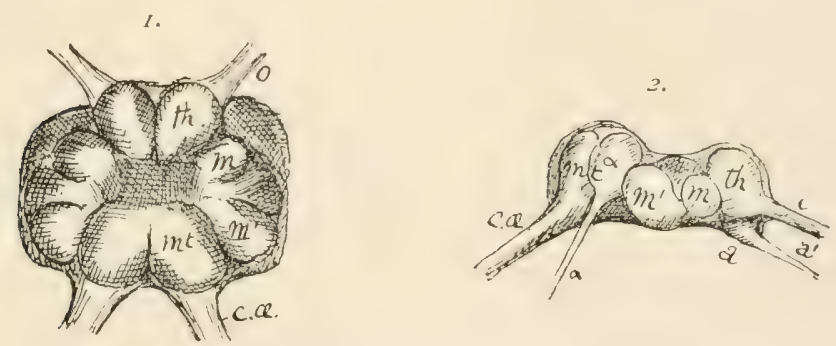

Fig. 53. - The brain of the Crayfish : $I$. Seen from above; 2 . Seen from the side. $a$, olfactory ganglion ; $\alpha^{\prime}$, nerve to antennule ; $\alpha$, ganglion of the crus ; $\alpha^{\prime}$, nerve to great antenna; c. $a^{\prime}, c . a$, œesophageal connectives; $m, m^{\prime}$, mesocerebron; th, thalamon; $m t$, mt, metacerebron; o, optic peduncle.

knowledge of the actual structure of the brain in insects has been too incomplete to permit any accurate comparison.

I have taken the supra-œsophageal ganglia of the Crayfish (Astacus) as a fair type of the preoral centres of the generalised Arthropod. In the dorsal view (Fig. 53, I) three pairs of ganglia are recognisable in the central brain mass; three pairs of sensory ganglia also exist, connected with the eyes, antennules and antennæ. So that there are six pairs of ganglia. Three pairs which belong to the brain proper, the central ganglia, and three to the sensory organs, sensory ganglia.

The anterior and posterior pairs of central ganglia each consist of a single reticular nucleus, but the lateral pair are more complex; each contains two reticular nuclei, separated by a 
lare fasciculus of fibrils, corresponding with the peduncle and trabecula of the insect brain. This terminates in the cortex and penetrates a very remarkable group of small round cells, which I shall term the corpus fungiforme, as I regard it as the homologue of the corpora fungiformia of insects.

Lateral sections ( 1 ig. $54, I$ and 2 ) show that the three pairs of central ganglia are united by three transverse commissures, which are separated from each other by small groups of nerve cells.

These three primary divisions of the Arthropod supra-esosphageal centres have not hitherto received distinctive names;
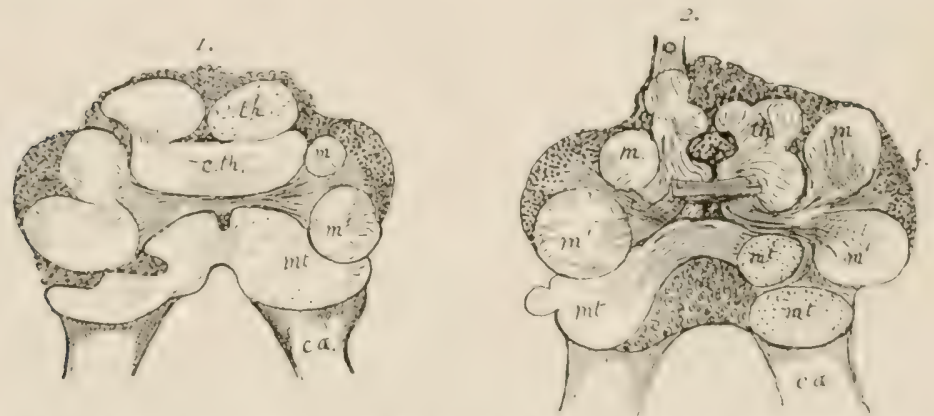

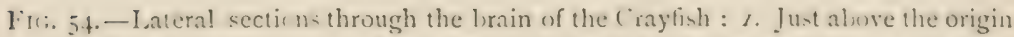
of the optic peduncle; 2. Near the upper limit of the mesocerebron. cth, commissure of the thalamon; $c n$, osophageal connectives; $m$, anterior, and $m^{\prime}$, posterior reticular nucleus of the meso:erebron; $m t$, metacerebron; 0 , optic peduncle ; th, thalamic lobes.

as they exist in all Insects, and probably in all Crustaceans, some distinctive names should be applied to them. As these three sroups of sanglia are apparently dereloped from three vesicles (in the Diptera), and are in many respects analogous to the thalamencephalon, the mesencephalon and metencephalon of Vertebrates, I propose to designate them as the thalamon (Figs 5t, $t h$ ), the mesocerebron ( $m$ ), and the metacerebron (ml) respectively. These terms have the arlvantage of being easily remembered, and can, I think, grive rise to no confusion; even if future researches should not confirm the view I hold, that they are really the representatives of the 
thalamencephalon, mesencephalon, and part of the metencephalon of Vertebrates.

The Thalamon consists of a pair of thalamic lobes. These give origin in the Crayfish to the greater part of the optic peduncle (o), and are intimately connected below with the ganglia of the antennules, which, like the antennal ganglia of insects, have a special and peculiar structure, identical with that of the cortical layers of the olfactory lobes of Vertebrates; a fact placed beyond dispute by the researches of Dietl, Bellonci, and Viallanes. This structure is so peculiar that I regard it as indubitable that they are olfactory in function; a view which I shall hereafter show is confirmed by the structure of the antennæ in many insects, and by their comparative development in various families.

In front of and between the olfactory and below the thalamic lobes, in the Crayfish, there is a minute tongue-like unpaired process of reticular substance covered thickly by ganglion cells (Fig. 55, cl). This process is hollow and communicates with a ventricle. I regard it as the representative of a pair of convoluted lobes in the Blow-fly (PI. XXIX., Fig. I, $c l$ ), and propose to term it the procerebron. This structure has not, so far as I know, been previously seen in the Crayfish. Thus the thalamon may be said to consist of (I) a pair of thalamic lobes $(t h),(2)$ of the olfactory ganglia $(a)$, and (3) of the procerebral lobe $(c l)$.

The Mesocerebron $\left(m, m^{\prime}\right)$ consists of a pair of spherical ganglia united by a thick transverse commissure (Fig. 5t, I). The medulla of the mesocerebron is divided into two masses in each lateral ganglion by a lamina of radiating fibres, which terminate in a thick layer of the cellular cortex, the cells of which are small and like those of the corpus fungiforme of an insect's brain.

It appears to me that the lamina of radiating fibres, which is gathered up within the brain into a well-marked bundle (Fig. 54, 2), represents the peduncle and trabecula of the corpus fungiforme. Like the trabecula, this bundle gives off definite fasciculi of fibres to all the other parts of the brain. 
This riew agrees with that of lung [179], who compares these structures with the trabecula and corpus fungiforme ("corps en gobelet '), whilst he recognises the complexity of their connections with the rest of the brain.

The optic peduncle $(o)$ in the Craytish arises partly from the mesocerebron, although its principal origin appears to be from the thalamic lobe $(t h)$. Berger [178] indeed regards the corpus funcriforme as the optic lobe; and Yung [179] says, "We regard the lateral ganglia $\left(m, m^{\prime}\right)$ as the optic lobes par excellence.' From the context it is evident, I think, that he includes the corpus fungiforme as part of the lateral sanglia. Berger held the same opinion.

Bellonci [183], however, considered the corpus fungiforme as representing the cerebral lobes of the vertebrate-an opinion which corresponds with the views of Dujardin [170] and Faivre [171].

Rabl-Rückhard* observed that the corpora fungiformia are perfectly normal in the blind ants of the genus Typhlopone, and argues from this that they cannot be optic lobes, as Berger supposes.

My own riew is that the corpus fungiforme, or corpora fungiformia-for these organs are usually two in number on each side-are not to be regarded as part of the basal ganglia from which the optic nerves are derived, but should rather be considered as similar to the cerebellum of vertebrates, or, to use the nomenclature of Meynert, $\uparrow$ as part of the cerebro-cerebellar projection system.

I shall endeavour to show hereafter that their connections with the rest of the cephalic contres resembles in many points those of cerebellum in vertebrates.

It is interesting to observe that the optic tract in the Crustacea appears to arise mainly from the thalamic lobe; whilst in Insects its connection with the thalamic lobe is less easily seen, and it arises mainly from the mesocerebron. Thus there

* Rabl-Ruckhard, 'Studien uber Insectengehirne, . Irchiv f. Anat. Physiologie u. w. Medicin, 1875. p. 488.

† Sitzungsberichte d. k. Acad., Wien, 1869. 
is a precisely similar shifting of the origin of the optic tract in Arthropods and in Vertebrates from the thalamus to the mesencephalon as development advances, or when the less differentiated are compared with the more highly differentiated forms.

The Metacerebron consists of two pairs of reticular nodules; an internal pair, which are connected with the great œesophageal connectives (crura of the cerebron), and which are united with each other by a transverse commissure; and an external pair, from which the nerves of the great antennx arise.

Thus each of the great divisions of the brain in the Crayfish consists of a pair of central ganglia and a pair of sensory ganglia. The ganglia of the antennules belong to the thalamon, those of the great compound eyes should be regarded as the sensory ganglia of the mesocerebron, and those of the antennæ are undoubtedly the sensory ganglia of the metacerebron.

In Insects the metacerebron is but feebly developed; it consists of a commissure and of the ganglia of the crura, which, like the metacerebron of the Crustacea, give off the pharyngeal and stomo-gastric nerves.

The Crura of the Cerebron, as in Insects, are connected not only with the metacerebron, but with the mesocerebron, thalamon and optic peduncles, and probably with every part of the supra-œsophageal nerve mass. In the Crayfish these form a thick layer on the ventral surface of the whole supra-œsophageal nerve centre, and many of the fibres decussate across the median plane (Fig. 55).

Ventricles. - In the Craytish there are three distinct groups of nerve cells, which penetrate into the interior of the brain from its dorsal surface; one in the thalamon, a second between the thalamon and the mesencephalon, which lies above the commissure of the mesencephalon, and a third behind and between the lobes of the metencephalon. These cavities in the reticular substance are filled with nerve cells; but in Insects they are frequently developed into distinct ventricular cavities. 
Even in the Craydish the anterior or thalamic central gray matter exhilits a cavity which extends into the procerebron, giving it a vesicular character (Fig. 55, 2, x). Moreover, it is connected with a small and very remarkible cavity $\left(\mathrm{I}^{\mathrm{i}} \mathrm{ig} \cdot 55,2, q\right)$ which one is almost tempted to compare with the hypophysis of the vertebrate brain. I have at present been unable to investigate this curious organ more fully, and I have seen nothing like it in any insect.

The Supra-œsophageal Nerve Centres of the Cockroach (Blatta

$\int$.

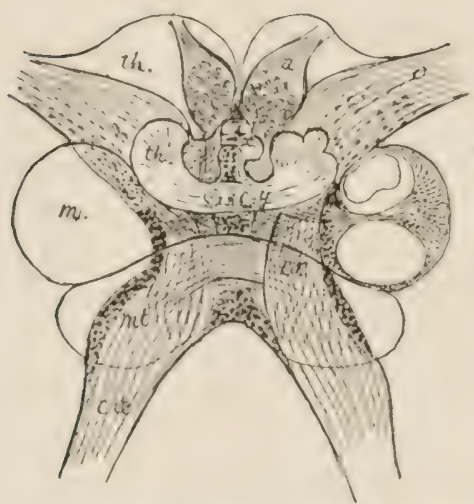

2.

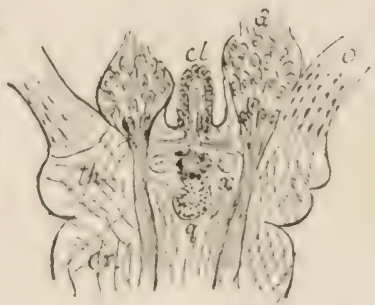

IIG. 55.- - . A lateral section through the base of the brain of a Crayfish (Astacus fuviatilis): $a$, olfactory ganglion; $c a$, osophageal connective ; $c r$, crus; $m$, mesocerebron; 0 , optic peduncle; th, thalamon; $y$, ascending fibres.

2. A more highly magnified section nearer the ventral surface of the ganglia: $c l$, procerebral vesicle; $x$, ascending fibres; $q$, ventricular cavity. The anterior part of the ventricular cavity, containing a fan-shaped group of cells is seen between the two bundles of ascending fibres. The other references as in $\pi$.

()ricntalis) closely resemble those of the Crustacea. The principal points of distinction are the smaller size of the thalamic lobes, the far erreater derelopment of the mesocerchron and corpora funciformia, and the transference of the origin of the optic peduncle to the mesocerebron. Only a small portion of it arises in Insects from the thalamic lobes: but a lumble of fibres can, so far as I linow, always be traced on the anterior surface of the optic peduncle into the thalamon. The procerebron, althourh still very obscure, is lobulated, and the 
anterior ventricle is far larger than in the Crayfish; lastly, a great commissure--the commissure of the mesocerebron, or corpus centrale--occupies the central cavity, and separates the anterior and middle ventricles.

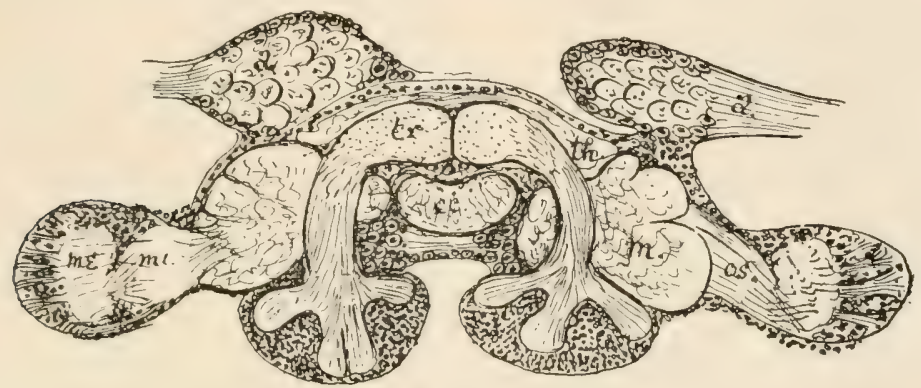

FIG. 56.-Frontal section of the supra-œsophageal nerve centre of the cockroach (Blatta orientalis) : $a, a$, antennal (olfactory) ganglia; $c c$, corpus centrale; $m$, mesocerebron; $m e$, external, and $m i$, internal medullary nucleus of the optic ganglion; $0 s$, optic peduncle ; $t r$, trabeculæ.

In the Crickets (Gryllidre), as in the Crustacea and the Cockroach, the infra-œsophageal are separated from the supraœsophageal ganglia by long nerve-like crura, the œsophageal

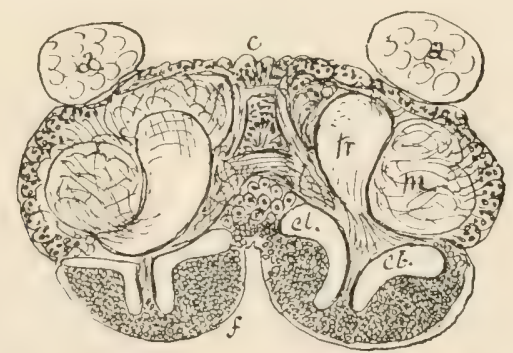

FIG. 57.-An oblique section from above and behind, downwards and forwards, through the supra-œsophageal centres of the same insect: $c l, c l$, the calices; $c$, procerebral lobes ; $f$, corpus fungiforme. The ventricular cavity is seen in front, between the bundles of fibres which support the rudimentary procerebral lobes. The great cells behind the ventricle and between the inner calices are the cells of the pyramidal ganglion.

connectives, but there is a distinct advance towards the type exhibited by the more specialised Insecta. This is especially seen in the reduction of the proportionate size of the corpora 
funcriformia and their trabeculie, and the increase of the procerebral lobes, which I take to be the lateral lobes of the midile protocerebron of Viallanes. This structure in the higher Insecta, as in the Blow-1ly, assumes a new import from its remarkable connections and its cerebroid character.

\section{c. Details of the Structure of the Brain of the Blow-fly Imago.}

The brain of the imago of the Blow-1ly, and under this term I include all the cephalic nerve centres, agrees in structure very closely with that of all the higher Insecta. It is formed upon the same ground plan as that of the Arthropoda in general.

Size of the Brain as compared to the Body-weight.-The proportionate bulk of the brain in insects to that of the body has been frequently estimated, and the following table, taken from Graber $[10]$, represents the results arrived at. The bulk of the brain is:

In Dytiscus $\frac{1}{400}$ of that of the body.

In Melolontha vulgaris $\frac{1}{3000}$.

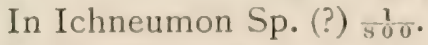

In the Honey-bee $\frac{1}{200}$.

In the Ant $\frac{1}{2} \times$.

In the Blow-fly I find it to be $\frac{1}{400}$.

These numbers do not, however, fairly represent the proportion owing to the large air-spaces of the body. I have endeavoured to determine the relation of the weight of the brain as compared to that of the body in the Blow-fly, and it may be set down approximately at between body-weight. Taking the Bee and Thasp as standards of comparison, its proportionate weight is less than in these Hymenoptera, in which I should estimate it as between, 160 and 200 of the body-weight. Cuvier gave an estimate of the proportion of the weight of the brain to that of the body in several groups of Mammals, and he found the weight of the brain in the larger carnivora varied between $2 \frac{1}{6}$ and 360 of the bodyweight. In small birds it is about ten times greater, or from 
1) to $\frac{1}{30}$. These numbers show that the proportionate weight of the brain is greater in small than in large animals. Thus, in the goose the brain is $3 \frac{1}{00}$, and in small finches $\frac{1}{; 0}$ or more of the body-weight. In the same class and amongst animals of nearly the same bulk the proportionate size of the brain varies perhaps with their intelligence and skill; but even this cannot be certainly affirmed, except approximately. The statements are, however, worthy of being remembered, as great misconception exists as to the proportionate development of the nervous system in Insects as compared with that of Vertebrates. In Insects the weight of the brain as compared with that of the body varies from $\frac{1}{2} 5_{00}$ to $\frac{1}{50}$, and in Vertebrates, according to Cuvier, from $T_{15}^{1}$ in some small birds to $\frac{x}{37000}$ in some of the larger fishes, as in the Tunny (Thynnus). Of course, all such estimates are approximate, as the nervous system is always proportionately larger in young animals; and it is not possible to make due allowance for bone, fat, chitin, and other tissues which are either feebly supplied by nerves, or are extra nervous.

The External Form of the brain of the Blow-fly imago is exceedingly simple, as all the principal fissures and divisions between the lobes and lobules of the central medullary mass are filled with cortical substance. The cephalic nerve centres are somewhat flattened from before backwards, and consist of a central portion, formed of two lateral halves, which is subspheroidal, with the two mammiform antennal lobes in front, and the great wing-like optic ganglia on either side, extending to the inner surface of the dioptra of the great eyes.

The form of the central medulla is, however, sufficiently complex, as will be seen by a reference to the plates which represent the parts in section, and to the stereographic figures in Plate XXVIII., which have been constructed from a careful study of numerous sections.

The brain is perforated by the oesophagus, and it will be convenient to describe the several parts in reference to this opening. Below the œsophageal canal the infra-œsophageal centre is readily distinguished, giving origin to the maxillary nerves 
(PI. XXYIII., $i, m x$ ). On either side of the opening are the crura, and above it the great mass of the supra-œsophageal centres, which form by far the largest part of the brain. The

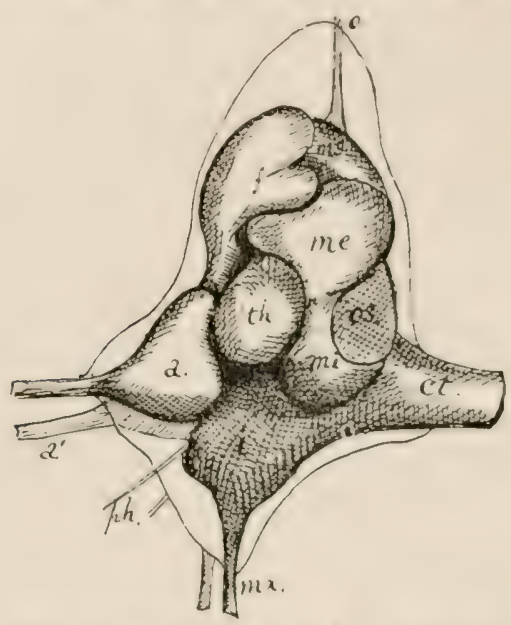

FIG. 58. - A stereograplic representation of a side view of the brain of the Blow-fly imago. (See description of Plate XXVIII.) The optic peduncle has been cut through close to the mesocerebron: mi', external lobe of the mesocerebron: ms, superior lobe of the mesocerebron. The other references as in Plate XXVIII.

parts of the supra-œesophageal centres are the antennal ganglia, $a a$; the central nerve-masses or cerebron; the optic peduncles, $o s$; and the optic cap, or the external medullary mass of the optic ganglion, $o c$.

\section{DESCRIPTION OF PLATE XXVIII.}

Stereographic figures of the brain of the Blow-lly imago. (These figures were constructed in the following manner: a numler of drawings were made from several series of serial sections ly means of a camera lucicla ; every section was drawn to the same scale; from these a clay murlel was constructerl, and the figures were taken from this model by means of a camera.) The external outline represents the surface of the gray matter, the shaded drawing represents the medullary reticular substance. Fig. 58 is a side view of the same model.

Fir. 1.- The brain seen from in front.

Fig. 2.-The ventral aspect of the same.

$a$, antennal ganglion ; $a^{\prime}$, antennal nerve ; $c l$, cephalo-thoracic cord; $f$, frontal lobe of the meso-cerebron: $f c$, external, and $f i$, internal corpus fungiforme: $i$, infra-nesophageal centre; $m i$, inferior lobe of the mesocerebron ; $m x$, maxillary nerve; $o$, nerve to the ocelli ; os, optic peduncle ; $0 i$, optic cap; ph, pharyngeal nerve ; $t h$, thalamon. 


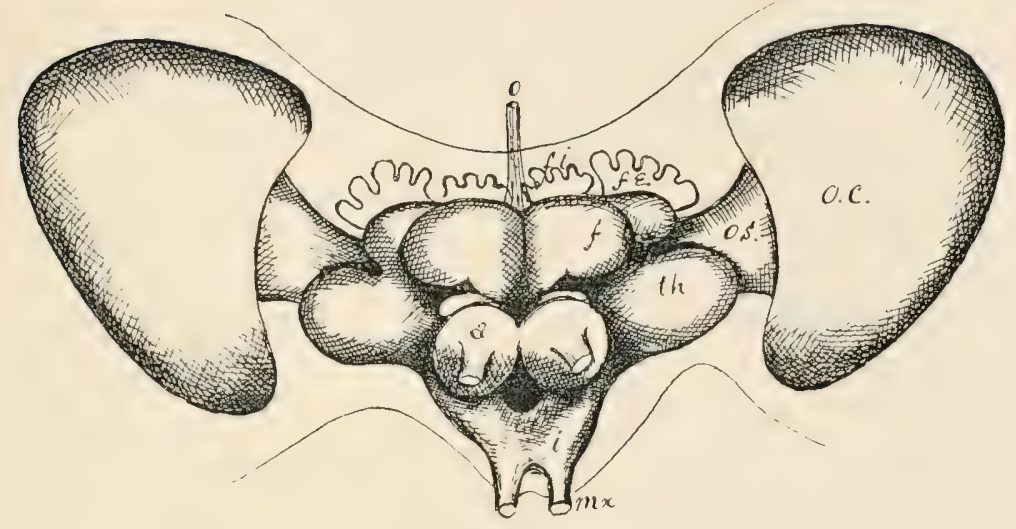

FII. I.

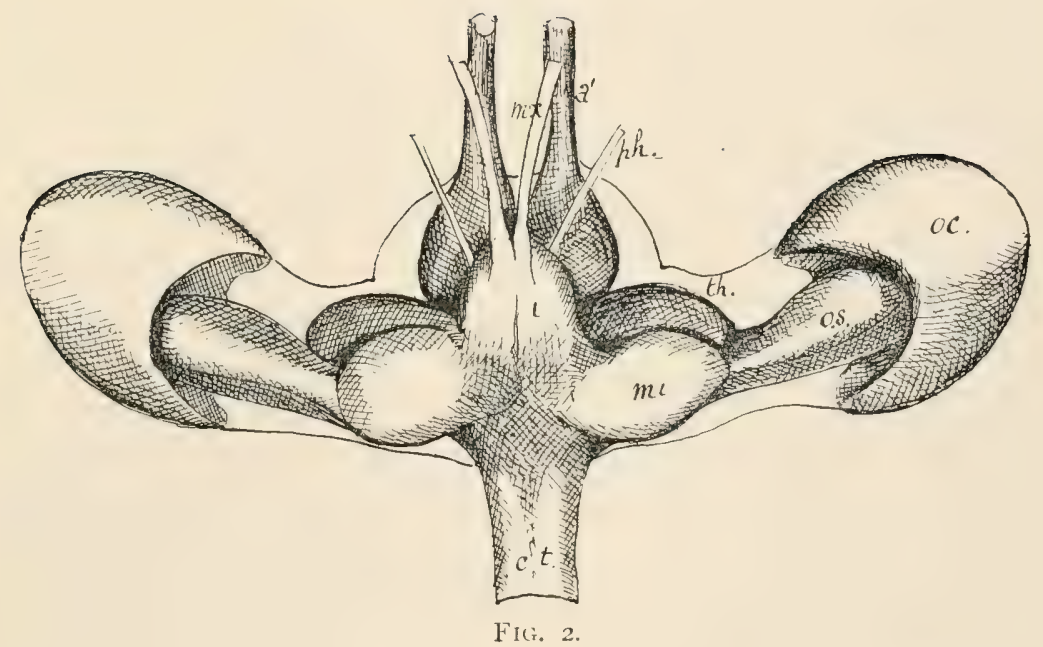



Nerves.-The following nerves arise from the brain: the antennal nerves from the olfactory lobes, the pharyngeal nerves $(p h)$ from the crura, and the maxillary nerves $(m x)$ from the infra-œsophageal ganglia. A single median nerve makes its exit between the hemispheres of the cerebron from the upper part of the organ; it supplies the ocelli, or simple eyes.

The term optic-nerve has been applied to the peduncles of the great pyriform optic ganglia, and also to the crossed fibres which arise from their external convex surface. I term the former the optic peduncles, and the latter the optic nerves.

The Cerebron.--Under this term the whole central mass of the brain above the oesophagus is included. It consists of a pair of sub-hemispherical, lobulated, concavo-convex discs of reticular substance, known as the hemispheres, which enclose a central cavity, containing the trabeculæ, the corpus centrale, the nodulus, and the procerebral lobes, as well as the pyramidal ganglion. The hemispheres consist in great part of the mesocerebron, which is far more largely developed than the thalamic lobes and the metacerebron in the Diptera. The thalamic lobes $(t h)$ are so intimately united with the mesocerebron that they merely form lobes of the hemispheres, and the metacerebron is entirely concealed in the posterior part of the mesocerebron. It is represented by little more than a commissure (Pl. XXXII., Fig. 3).

The Median Fissure.-The two hemispheres are separated from each other above by a median fissure, which extends from the posterior part of the cerebron, commencing above the transverse commissure of the metacerebron, to the antennal ganglia in front. It is wide behind and narrow in front, and its anterior part is closed by the commissures of the frontal lobes of the mesocerebron and of the procerebral lobes. It is filled by the cortex which passes from the surface into the central cavity. The nerve to the ocelli traverses it above the pyramidal ganglion.

Lobes of the Mesocerebron. - Externally the mesocerebron is connected with the optic peduncles (Fig. 58,o s.) Above and 
in front of these peduncles the following lobes may be distinguished: the superior middle and frontal lobes of the mesocerebron. Below the optic peduncle there is a considerable swelling, which may be termed the inferior lobe. In front of the middle and inferior lobes there is a hemispherical enlargement, which I regard as the thalamic lobe. The relations of these lobes will be seen in Plate X.TiIII. and Fig. 56 .

The Lateral Fissure.-This is a very remarkable fissure which has somewhat the form of an inverted $y$; its upper limb is curved, and separates the frontal and midule lobes of the mesocerebron; its two descending limbs embrace the thalamic lobe. The upper portion of the sulcus is merely a superficial furrow; but the anterior and posterior limbs, and the lower part of the upper limb, are very decp, and extend into the central cavity. The lateral fissure separates the thalamic lobe from the surrounding lobes of the mesocerebron, just as the Silvian fissure separates the Island of Reil from the surrounding parts of the cerebrum of a vertebrate. Like the longitudinal fissure, it is filled by a process from the cellular cortex. It is well seen in section in PI. XXX., Fig. I, on the left side, and also in Pl. XXXII., Fig. 2, and in Pl. XXXIII., Fig. 3, surrounding the thalamic lobe $(t h)$.

Comparison of the Lobes of the Cerebron of the Blow-fiy and of the Cricket.- Viallanes terms the hemispheres protocerebral lobes, and gives the following description of these structures in the Cricket $[185, . \mathrm{Mem} .5]$ : "The protocerebral lobe is the most voluminous part of the brain : externally it is mited with

\section{DESCRIPTION OF P'ATE XXIX.}

FIG. 1.-A lateral olslique section of the cerebron, cut from abnve downwards and liehind forwards, represented diagrammatically. Seen from above and in front. $a$, right antennal ganglion; $a^{\prime}$, left antennal nerve ; $(1)$, left brachium ; $c c$, corpus

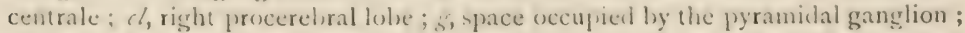
$m$, left hemisphere, in section; $n$, nodulus; $0 \mathrm{~s}$, left optic peduncle; $t ;$, left trabecula. The shacled portions of the central cavity represent its floor and the upper surfaces of the trabecula.

Fig. 2.-A semi-diagrammatic representation of the cerebron of the ny, scen from himse and in front, showing the princigal huntles of parallel fibes: ant, antennal nerve; $c$, crus; $m$, inferior commissure of the mesocerebron; $m x$, maxillary nerves ; $o$, nerve to ocelli; $\alpha$, ocsophageal canal ; os, optic peduncle; $t r$, trabecula. 


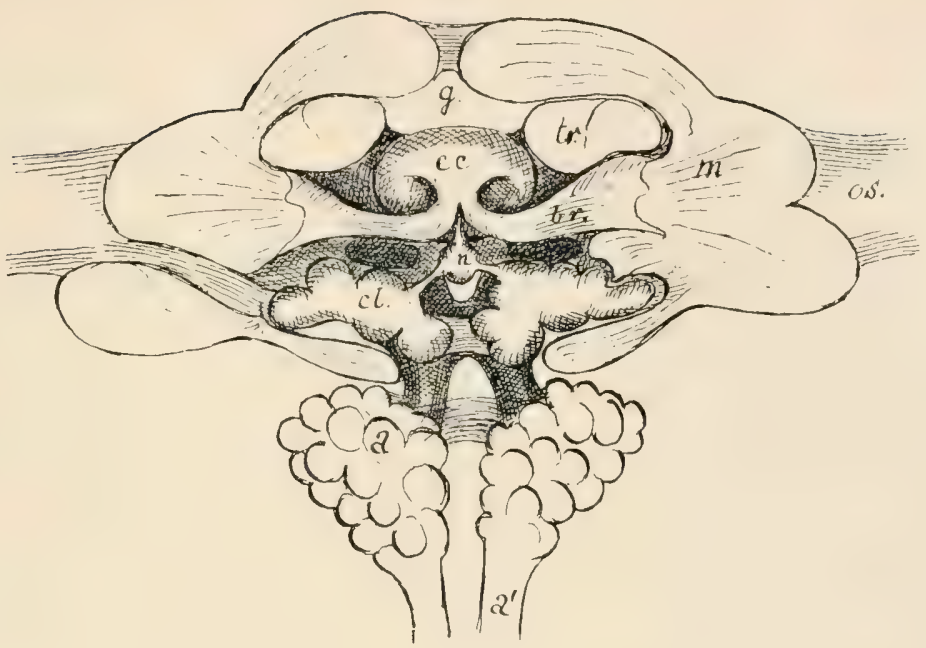

Fic. I.

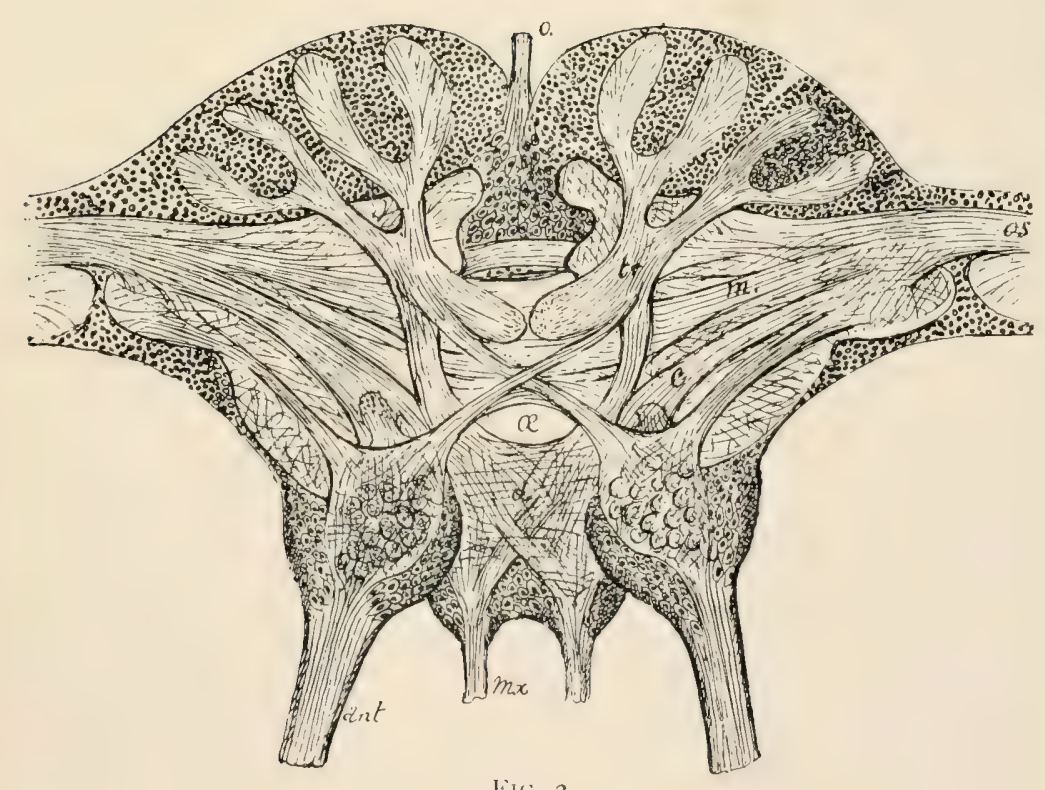

Fisi, 2. 

the internal medullary mass (optic peduncle), and internally with its fellow, in front and behind. The cavity enclosed by these lobes contains the median protocerebron' (my procerebron and corpus centrale). 'It presents in its antero-lateral region a deep fissure (the lateral fissure), which extends from' (the cavity containing) 'the corpus centrale to the)' (front of the) 'inferior lobe.' Thus, the lobes of the cerebron consist of two parts, separated by the lateral fissure (sillon lateral), an anterior and a posterior, of which the latter is far the larger. Viallanes' external lobe of the middle protocerebron in the Cricket appears to me to correspond with my thalamic lobe, and both lie within the lateral fissure. Thus, in the main points there is apparently but little difference between the hemispheres of the Cricket and the Blow-fly; and a comparison of the manner in which the trabeculæ are related to the lateral fissure, at their anterior extremities, confirms the closeness with which these parts agree in the two insects.

Morphology of the Lobes of the Cerebron. - Although in the above description of the hemispheres I have regarded all the lobes except the thalamic lobes as belonging to the mesocerebron, I am by no means convinced that the frontal lobes are part of it. In separating the thalamic lobes, and regarding them as part of the thalamon, I have been chiefly guided by the manner in which they are related with the optic peduncles, and with the procerebral lobes. The union of these masses with the basal part of the mesocerebron is so intimate that, until more definite information can be attained as to their manner of development, this must be regarded as a provisional view; it is one, however, which commends itself very strongly to my mind.

The Procerebral Lobes (Pls. XXIX., XXX., and XXXII., c l). -These are very largely developed in the Blow-fly, and consist of two lobulated masses of medullary substance. They are situated in the anterior part of the cavity of the cerebron, and are concealed by the frontal lobes and antennal ganglia, so that they cannot be seen externally. These lobes are united with each other by a transverse commissure (Pl. XXXII., 
Fig. 3), and are only connected with the rest of the brain by two pairs of bundles of fibres, the peduncles and the pedicles.

The Peduncle is a short, thick, round cord, which enters the under side of the procerebral lobe (Pl. XXX., Fig. I) near its inner ancle, and connects it with the thalamic lobe. It receives a considerable bundle of fibres from the trabecula, and another from the antennal (olfactory) ganglion.

The Pedicle is a slender bundle of fibres, which passes from the nodulus to the procerebral lobe (PI. XXIX., Fig. I).

The Commissure of the procerebral lobes is a thick median band of transverse fibres, which connects the two procerebral lobes with each other; it lies immediately behind the commissure of the antennal ganglia.

The Nodulus (Pl. XYIX., $n$ ) is a very remarkable spheroidal body, which is connected with the hilus of the corpus centrale? by a single slender, round, median cord. This cord, which may be termed the fillet of the nodulus, consists of fibres which radiate from each other in the substance of the corpus centrale. They apparently pass through the nodulus into the pedicles of the procerebral lobes.

\section{DFSCRIPTION OF PLATE XXX.}

Details of the anatomy of the brain of the Blow-fly imago. All the figures in this and the three succeeding plates were drawn from sections to the same scale with a camera lucida and a half-inch objective.

Fic. 1. - A frontal section of the brain of an adult I3low-fly, between the antennal ganglia and the corpus centrale, drawn from the tenth section of a series numbered from hefore lackwards. The plane of the section is slightly oblique from before backwards and above downwards: $c$, procerebral lobe; $\mathrm{cr}$, outer fibres of the crus; $f$, frontal lobe of mesocerebron $; i$, infra-resphareal ganglia; $m$, lateral lobe of mesocerebron; $n$, nodulus; $t h$, thalamon; $t r$, trabecula ; $t i$, internal tubercle; $\ell a$, anterior tubercle.

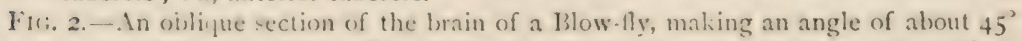
with the frontal plane. The plane of the section is from above and behind, downwards and forwards. It passes through the posterior part of the corpus centrale behind and below the brachia : $c c$, corpus centrale; $i$, infra-resophageal sanglion; $m$, superior lobe of the mesocerebren; mi, internal mechullary mass of the optic ganglion; $h$, peduncle of the corpus centrale; $t h$, thalamon; $t r$, trabecula.

Fic: 3.--A lateral section of the same, immerlintely above the cesophagus: $a$, antennal lobe; $\mathrm{cr}$, ascending fibres of the crus ; $\mathrm{s} \mathrm{cr}$, ganglion of the crus, with two bundles of ascending fibres on its inner surface; th, lower lobe of the thalamon. 
PLATE XXX.
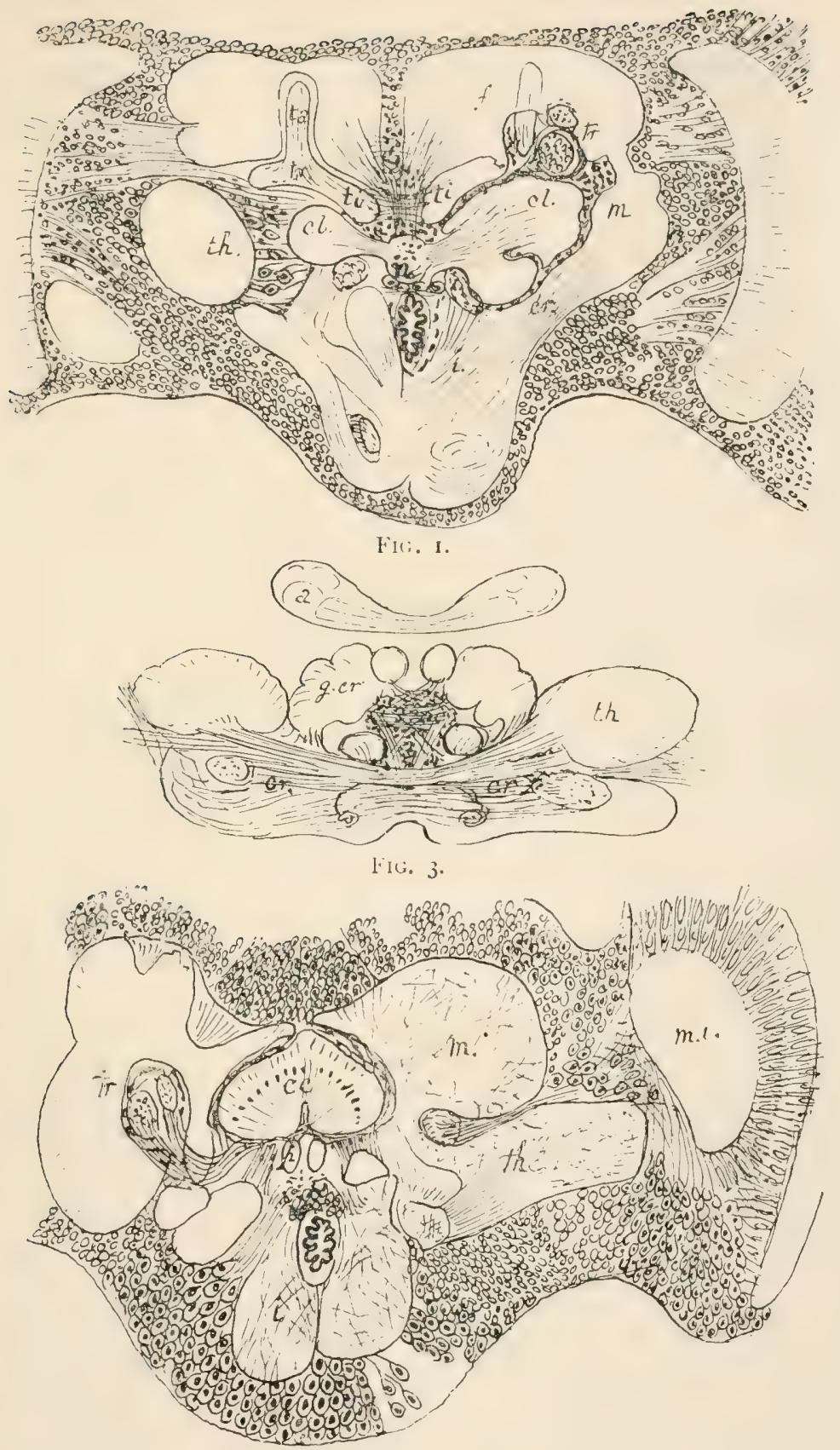

FIri, 2 . 

Dietl, although he does not mention the procerebral lobes, has figured them in the Bee (Apis mellifica) [175, Pl. XXXVI., Fig. I], in which they are apparently far larger than in the Fly. The nodulus is also larger, and is shown in Dietl's figure to be connected with the radiating fibres of the corpus centrale.

There is also a distinct indication of the procerebron in one of Cuccati's figures [186, Pl. XX., Fig. 6]. It is to be regretted that all Cuccati's figures are too small, and are insufficiently described in the text.

In 1870 I first discovered the procerebron in the Blow-fly by removing the surrounding parts. I gave a figure of the appearance they presented in a preparation made by dissection, displayed by the pressure of the cover-glass [62, Pl. VII., Fig. 4], and I was able to state, as the result of the rude methods employed in those days, that they are pedunculated lobulated organs united by a well-marked median commissure. At the same time I suggested that they are possibly analogous to the cerebral lobes of vertebrates, an opinion which has been rendered more probable by my more recent researches.

I suspect that the parts described by Viallanes in the Cricket as the lateral lobes of the median protocerebron consist in part of the representatives of my procerebron, and in part of my thalamic lobes.

The Corpus Centrale (Fig. 59) is a complex commissure, situated in the cavity of the cerebron, behind the nodulus, and in front of the pyramidal ganglion. It is largely developed in all the Insecta, but is apparently entirely wanting in the Crustacea. Perhaps this remarkable body may be best described by comparing it to a broad band folded S-wise. The upper limb of the $\mathrm{S}$ forms the capsule (Fig. 59, c); it overlaps the rest laterally, in front, and behind. The remainder of the $\mathrm{S}$ forms what has been termed the ellipsoid body $(c)$. Between the capsule and the ellipsoid body is the hilus, into which fibres from the nodulus pass; these form the fillet of the nodulus. 
The capsule is comnected with the mesocerebron by the brachia, and by a number of radiating fibres, which ascend from the crura and leave its convex surface: these fibres cross each other in various directions, after their exit from the capsule, and form what Viallanes terms the atmosplive fibruse in the layer of gray substance around it. The lower part of the ellipsoid body is connected with the crura of the cerebron by a pair of peduncles $(p)$.

The Peduncles of the Corpus Centrale descend one on either
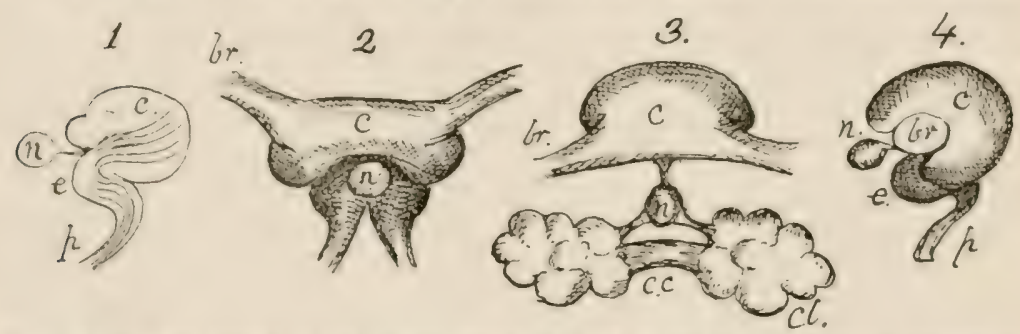

Fu: 59.-Four figures of the corpus centrale of the Illow.fly: 1. A sagittal section of the corpus centrale. 2. A semi-diagrammatic stereographic representation of the corpus centrale seen from in front. 3. A similar figure seen from above, showing the procerebral lobes. 4. A similar lateral view of the corpus centrale. The lettering is the same as in the plates and other figures.

side, and enter the crura. The fibres of which they are formed, after traversing the ellipsoid body, decussate with each other, and spread out like an open fan in the capsule. Many of them pass out by the posterior surface of the capsule, and after traversing the gray layer which surrounds the corpus centrale, enter the inner surface of the hemispheres or terminate in the pyramidal granglion. The fibres of the fillet of the nodulus are so intermixed with those of the peduncles of the corpus centrale that they cannot be traced separately.

\section{DESCRIPTION OF PLATE XXXI.}

Fir. 1. A frontal section of the brain of the Blow-1ly, through the anterior part of the corpus centrale: os, the optic peduncle. The other references as in l'late $\mathrm{XXX}$.

Fu: 2. - A similar section through the midhle of the rorpus centrale, showing its inner and outer capsules. References as in Fig. 1.

Fir. 3.-A lateral section through the brachia and corpus centrale: $b r$, $b r$, the brachia : $f, f$ corpora fungiformia ; $s$, pyramidal ganglion. 
PLATE IXXI.
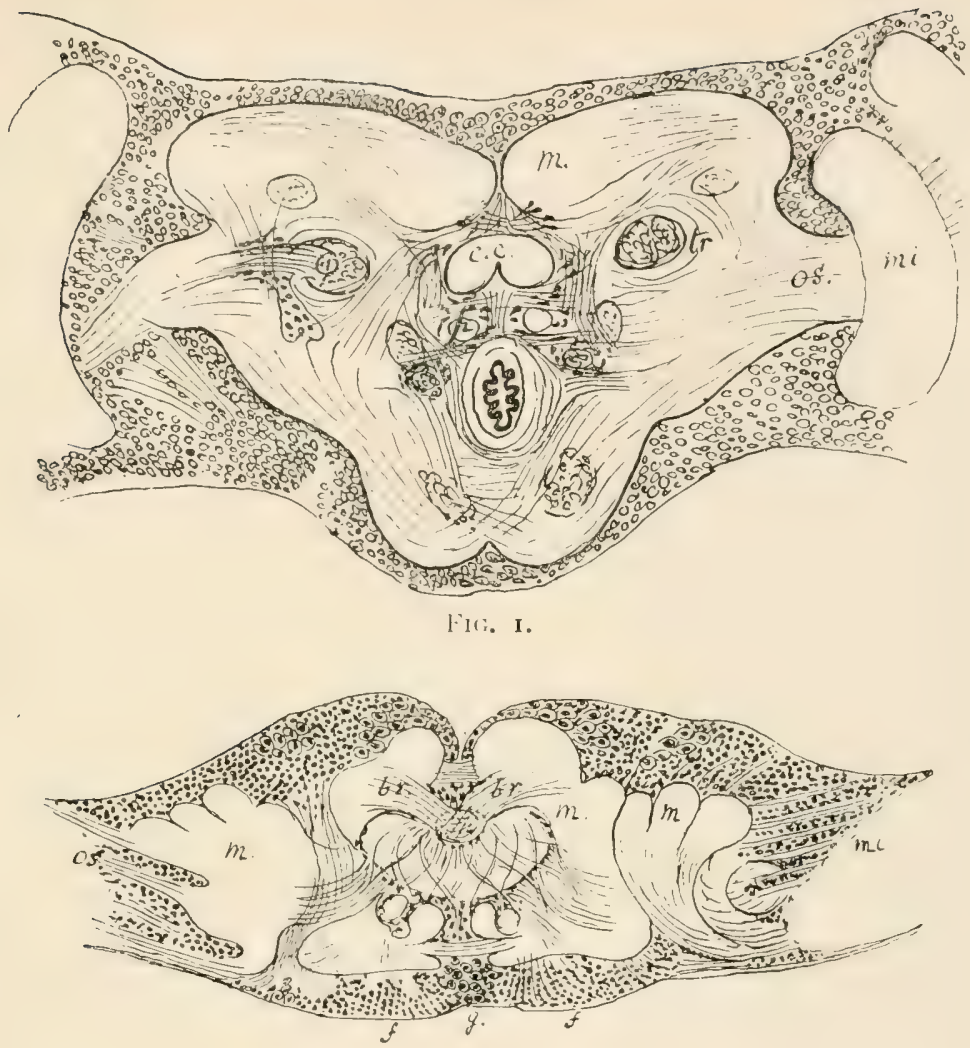

Fili, 3 .

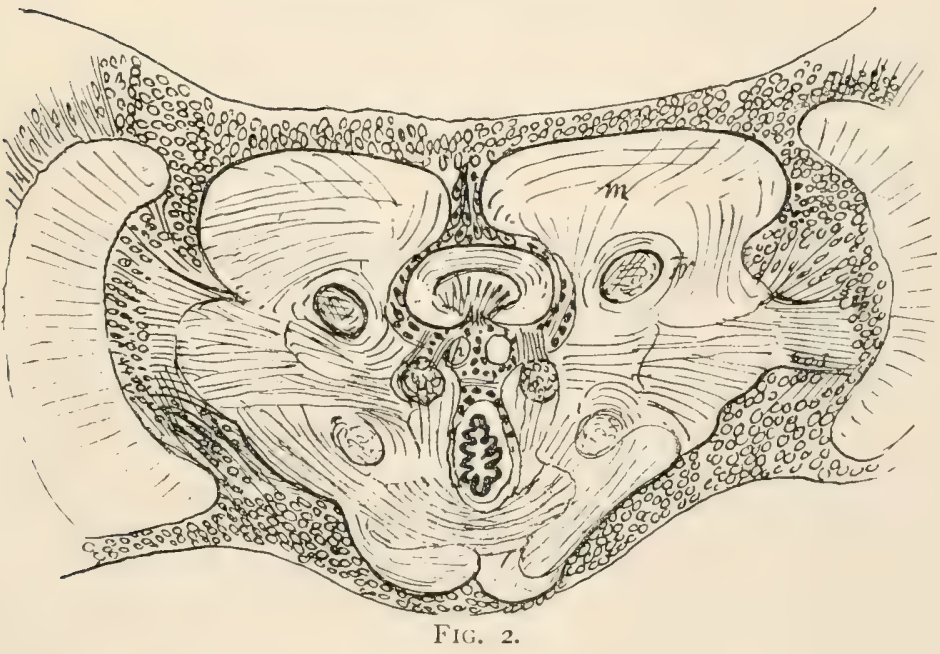



The Brachia enter the sides of the capsule of the corpus centrale. The fibres of which they are composed form the greater part of the substance of the capsule, decussate in the median line, and enter the opposite brachium. Some of these fibres also probably descend to the crus through the peduncle.

Cuccati [186] terms the corpus centrale the fan-shaped body, and gives the following description of it in the Blow-fly: 'It occupies the centre of the brain, its principal axis is directed from above and in front, downwards and backwards; it is distinctly divided into two parts, one of which is behind, and the other in front. The posterior part appears like an open fan, in sections perpendicular to its principal axis; the antcrior part I term the body of elliptical section, owing to its form; it hangs by a fine net-like substance below the superior part.' It is evident that Cuccati has described a section through the posterior part of the capsule and the middle of the ellipsoid body, and his fine net-like substance consists of the fibres of the fillet, which spread out between the capsule and the ellipsoid body. The above is all thet has been hitherto published, so far as I know, on the corpus centrale of the Blow-fly.

Viallanes has described the corpus centrale of the Cricket [185, Mem. 5] as consisting of 'two zones or capsules, separated by a curved plane parallel with its upper and lower surfaces.' He adds: "The superior is much thicker than the inferior capsule, and its lateral edges overhang the edges of the inferior capsule. The whole organ is somewhat compressed from before backwards, and suspended in a loose fibrous reticulum (atmosphère fibreusc). It divides below into two crura, which curve from before backwards and are lost.'

In the Wasp Viallanes [184, Mem. 4] says: 'The corpus centrale may be compared to a hemisphere strongly compressed from before backwards with a slightly concave base. It receives fibres from all the important parts constituting the protocerebron; and these, before they are lost in the substance of the corpus centrale, form a fibrous atmosphere around it.' 
'The superior capsule descends, behind, to the same level as the inferior, except in the middle line, where it is deeply. notched; on either side of this notch a short peduncle arises, which immediately expands into a spherical tubercle, the tubercle of the corpus centrale. The opposite tubercles are united with each other by a short fibrous fasciculus.' In the Blow-fly the peduncles of the corpus centrale are apparently longer. I have not been able to recognise any tubercles upon them, but they evidently have connections with the thalamic lobes as well as with the crura (see PI. XXXI., Fig. 2).

The Cortex of the Brain.-The cellular cortex of the brain not only covers the whole surface with a layer of variable thickness, but it penetrates the interior and becomes continuous with the great pyramidal ganglion, with the lamina of sray matter surromding the corpus centrale, and with that surrounding the thalamic and procerebral lobes.

The cortex consists of cells similar to those of the thoracic ganglia, but the optic ganglia and the posterior part of the cortex are formed almost entirely of small round cells similar to the cortical cells of the cerebellum, and to those of the nuclear layers of the retina in the Vertebrata.

The whole superior and posterior region, in which these small cells are larsely developed, is divided into four very remarkable areas, two on each side, known as the corpora fungiformia.

The rest of the cortex is not divided into distinct areas, but groups of large stellate cells occur around the roots of the

\section{Description OF Plate XXXill.}

Lis; 1. - I frontal section of the brain of the Blow-fly, with a slight olliquity from above downwards and behind forwards, behind the nodulus. The upper half of this section is behind, and the lower half in front of the plane of the section seen in I'late XXX., Fig. I. a, antennal ganglion; $c l, c l, c l$, lobes of the procerebron; $t h$, thalamic lobe; $m, m$, $m$, superior lobe of the mesocerebron.

Fig. 2.-A similar section through the corpus centrale from the same brain: $c c$, corpus centrale; $C r, c$, brachium of the corpus centrale; $i$, infra-asophageal (crural) ganglia ; $t r$, trabecula. The other references as in Fig. 1.

Fic: 3.-A lateral section of a Blow-fly's lorain through the lower part of the corpus centrale : $m$, mesocerebron; $m$, metacerebron; 0 , optic peduncle. The other letters as in Figs. $\mathbf{I}$ and 2. 


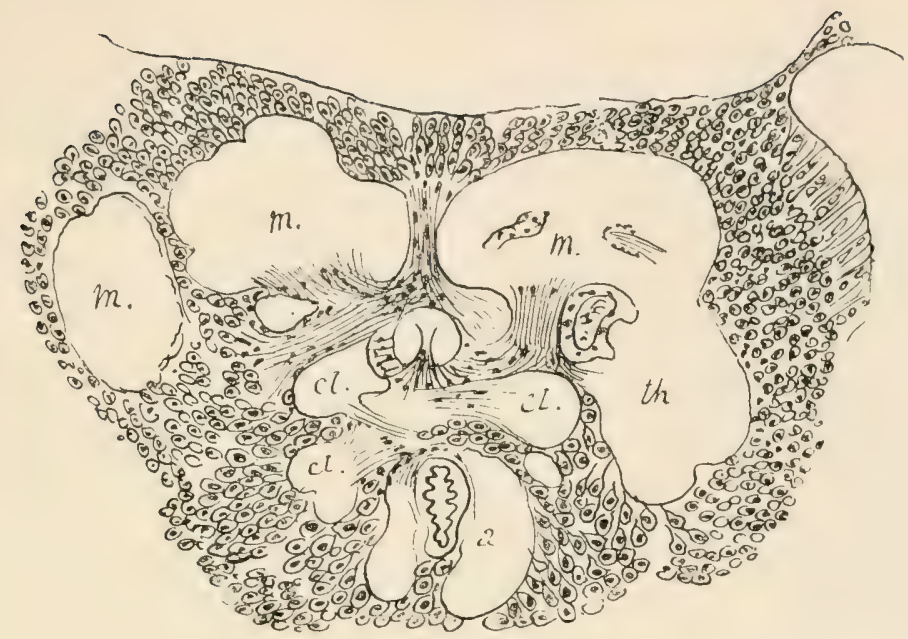

Fis. I.

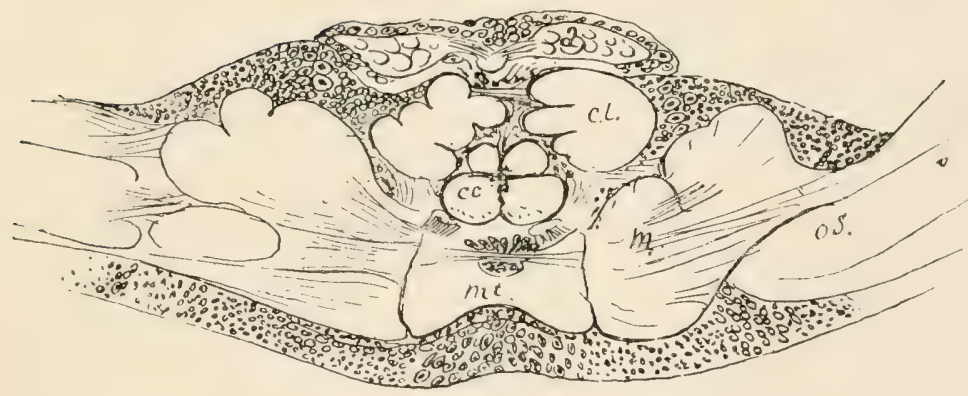

FIC. 3 .

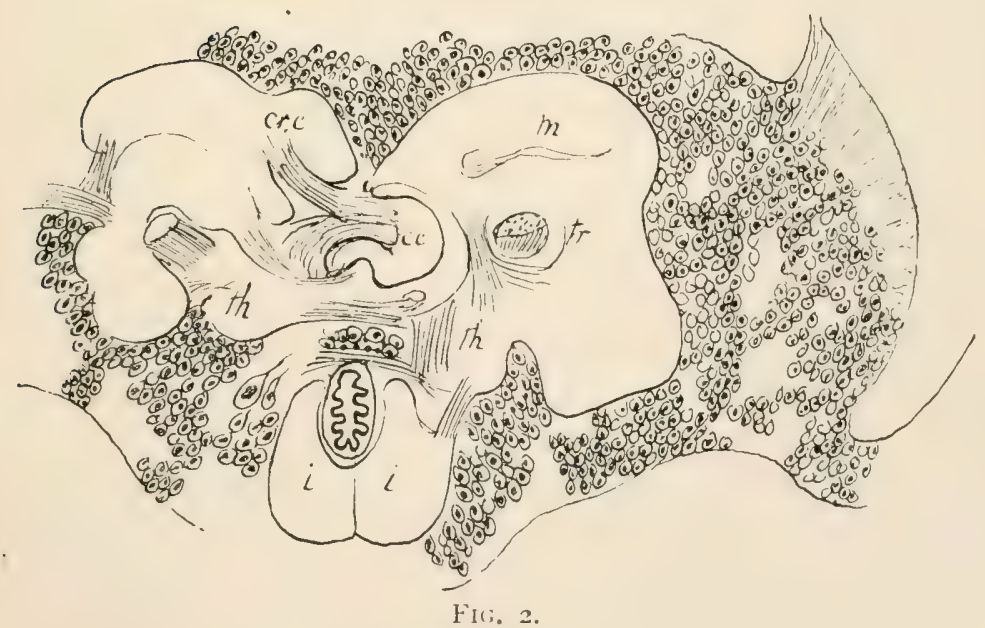



pharyngeal, maxillary and antennal nerves. The pyramidal ganglion consists of large cells closely packed together, and there are several gigantic nerve cells in the gray matter surrounding the æesophagus, resembling the largest stellate cells of the anterior cornua of the spinal cord of Vertebrates.

The Corpora Fungiformia are two in number, on each side of the brain, an external and an internal corpus fungiforme. These bodies may be described as cup-shaped prolongations of the medulla, filled by and imbedded in the cellular cortex on the posterior surface of the brain.

Each corpus fungiforme is said to consist of a calix, filled by and covered with small nerve cells.

Each calix is funnel-shaped, supported by a stalk or peduncle at its narrow extremity. The peduncles of the internal and external calix perforate the medullary core, or hemisphere of the mesocerebron, and unite with each other, forming a thick bundle of parallel fibres; this bundle is termed the trabecula. The trabecula crosses the internal cavity to the anterior surface of the brain, and terminates in a rounded caput in the lower part of the frontal lobe. From the caput two short thick processes are given off at right angles to each other, one ascends through the frontal lobe, the anterior tubercle; the other takes a nearly horizontal course to the medium line, the internal tubercle. In the Orthoptera the trabeculie are far more massive than in the Diptera or Hymenoptera (compare Fig. 54).

The Calices.-Each calix is a hollow cone of very fine fibres, which radiate from the apex of the cone, where they form the peduncle of the corpus fungiforme (Hinterast, Flögel; Pilzstiel, Dietl); these fibres extend from the calix into the gray substance; and the small round cells of the cortex are frequently seen in sections, arranged in radial lines corresponding to the course of these fine fibres (Pl. XXXIII., Fig. 2). The calix itself is formed by the union of these fibres in their course to the trabecula. It is not circular in transverse sections, but is seen to be corrugated irregularly in a longitudinal direction.

Historical and Comparative Anatomy of the Corpora fungiformia. Dujardin first discovered the Calices in Bees (Apis and 
bombus) [170], and also in Sphex and the Formicidar he termed them 'Disques radies:' Leydig described them in Vespa [42], I)ietl in Acheta domestica and Gryllotalpa [175]; and Flïgel discovered them in 13latta [177]. Filiggel demonstrated the presence of these organs in a more rudimentary form in the Coleoptera. Whilst Bellonci [183] and Cuccati [186] first described them in the Diptera.

The calices, in those groups in which they remained longest unknown, are distinguished by the remarkable fineness of their constituent fibres. Hitherto the only insects in which they have escaped detection are the Hemiptera, and it appears probable that they really exist in these, which in many other points resemble the Diptera. It is usually stated that they are absent in the Crustacea, but similar structures are certainly present in the Crayfish (Astacus), on the sides of the mesocerebron, as has been already stated (p. 445).

The corpora fungiformia are relatively largest in the Orthoptera, when compared with the rest of the brain. In the Crickets there is only one calix in each hemisphere (Tiallanes $[185, M(\mathrm{~cm} .5])$. In the Bee, Masp, and Ant, these organs are very large and readily separate from the surrounding gray matter, so that they are seen as distinct bell-shaped projections, which were figured by Dujardin.

\section{DESCRIPTION OF P'LATE XXXIII.}

Fic. 1.- A frontal section of the brain of a lilow-fly through the posterior part of the corpus centrale. This section is somewhat oblique, the right sile slightly behind the left side. The external corpus fungiforme is seen on the left side: $i$, infraosophageal ganglia; $m$, mesocerebron; $m i$, internal medulla of the optic ganglion : $t r$, trabecula.

lifi. 2.- I section of the internal corpus fungiforme and pyramilal ganglion behind the section seen in Fig. $\mathbf{I}$, from the same brain: $c l x$, calix of the internal corpus fungiforme; s, great ganglion cells of the pyamiclal ganglion, leneath which the roots of the nerve to the ocelli are seen. The other letters as in Fig. I.

Fu: 3. - A lateral section through the lorain between the resuphagus and the corpus centrale: $a$, antennal ganglia; $c r$, crural ganglia; fm, middle capsule; $m c$, external, and $m i$, internal medulla of the optic ganglion; $m t$, metacerebron; os, optic peduncle ; $f$, posterior capule of the optic ganglion ; fol, pectuncles of the corpus centrale; th, thalamic lobe.

The two bundles lying in the crural ganglia are the ascending fibres of the crus ; the oval commisture behind the perluncles of the corpus centrale is part of the inferior commissure of the mesocerebron. The ascending fibres of the crus are also seen in Fig. 1 , and the commissure of the mesocerebron in Fig. 2. 
PLATE XXXIII.
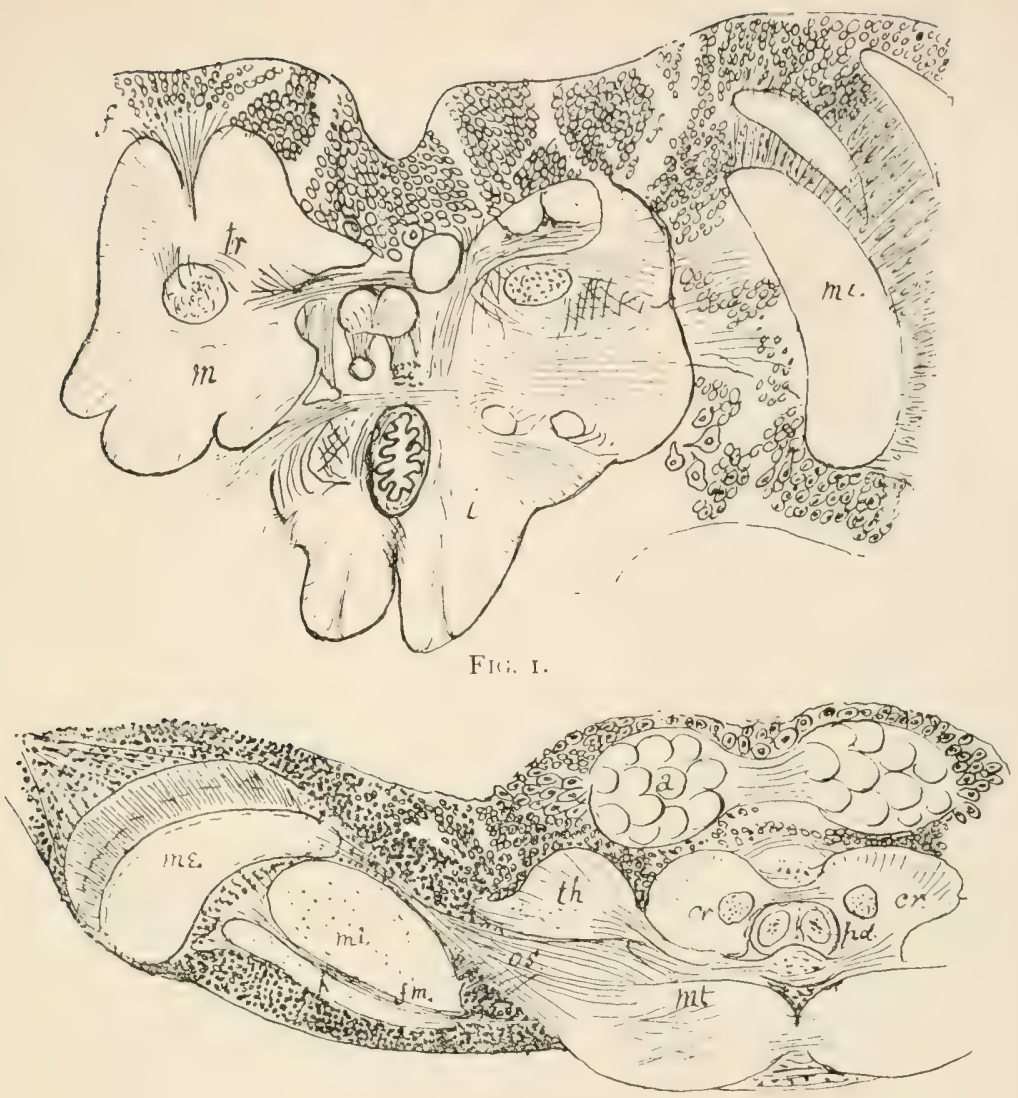

Fin. 3 .

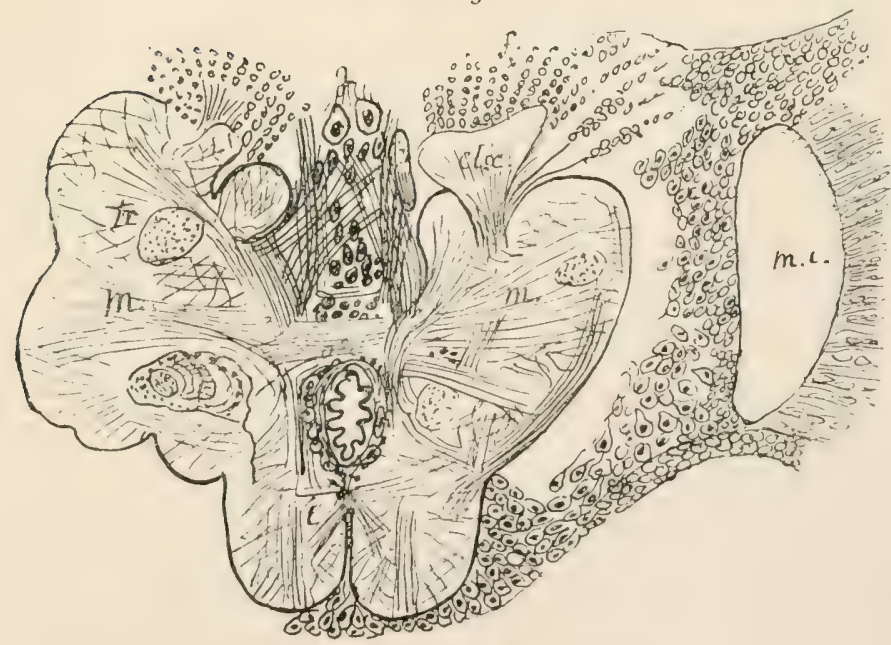

FIs: 2. 

The Fibrous tracts of the Brain.-The reticular medulla of the brain is traversed by a great number of well-defined tracts or bundles of parallel fibres. In the crura, infra-œsophageal region and more central parts of the cerebron, these bundles entirely, or almost entirely, replace the reticular substance. Indeed the latter is formed by the decussation of radiating fibres, connecting such definite tracts with various parts of the cortex.

The fibrous tracts may be divided into four groups, (I) ascending and descending bundles, which belong to the crura and cephalo-thoracic nerve-cord; these unite the metameral and supra-œsophageal centres; (2) commissural bundles which unite the opposite halves of the brain; (3) the trabecular system, or the tracts which terminate in the calices of the corpora fungiformia; and (4) inter-ganglionic tracts, which join the antennal, optic and infra-œsophageal (crural) centres with each other.

The Crura consist mainly of fibres, which connect the cephalothoracic nerve-cord, the maxillary nerves and the gray matter of the infra-œsophageal centres, with the various parts of the cerebron, and with the optic and antennal lobes.

All these fibres apparently decussate in the infra-œsophageal centre. This is very apparent in the case of those which come from the maxillary nerves and from the ganglion cells of the infra-œsophageal ganglia, and I shall subsequently show that there is good physiological evidence that the right half of the cerebron corresponds with the left half of the body, and vice versa.

The crura ascend on either side of the œsophagus, above which they are separated into numerous distinct fasciculi by the three great commissures which form the floor of the central cavity of the cerebron. The most important of the fasciculi into which the crura divide are (I) a large bundle of fibres which enters the optic peduncle (Pl. XXIX., Fig. 2); (2) a bundle which joins the trabecula; (3) a fasciculus which enters the antennal ganglion; (4) a great bundle of ascending fibres which is lost in the mesocerebron (Pl. XXXIII., Figs. I and 2); 
and (5) the peduncle of the corpus centrale. Other sets of fibres can be traced to the thalamic lobe (Pl. XXXII., Fig. $2, t / 2)$ and the metacerebron (PI. XXXIII., Fig. 2).

The Commissures of the Lateral Halves of the Cerebron.-Irrespectively of the complex corpus centrale already described, and the commissures of the procerebral lobes and antennal ganglia, the floor of the central cavity of the cerebron consists largely of transverse commissural fibres, connecting the opposite lobes of the cerebron and the opposite optic ganglia.

The floor of the central cavity, which separates it from the asophagus, is thin in front, but very thick behind. It is not possible to trace the course of the individual bundles of fibres which form this floor, many of them certainly connect the two optic peduncles, and others probably pass from the right optic peduncle to the left mesocerebral lobes, others are apparently loops, or arciform fibres connecting the lateral halves of the mesocerebron with each other.

The Trabecular System.-The peduncles of the external and internal calices (Pls. XXIX. and XXXII., Fig. 2), plunge into the lobes of the mesocerebron, and unite with each other at an acute angle above and behind the thalamic lobe to form the trabeculax (Balken, Flögel [177]). The trabecula in the Blow-1ly is comparatively short; it is connected with the thalamic lobe (Pl. XXXI., Fig. I) and enlarges above the procerebron into the caput trabecule, which gives off two processes (Pl. XXX., $l a, l i)$, called respectively the anterior and internal tubercles. I regard the anterior tubercle as identical with the anterior horn (Vorderhorn) of likgel [177]; it is the anterior tubercle of Viallanes, and the cauliculus of Newton [180].

In the Criclet the anterior tubercle is far larger than in the Blow-fly, but from Viallanes figures it appears to have the same relations to the surrounding parts.

The connertions of the trabecular system of fibres with the rest of the nervous system are very complex. Although the trabeculac apparently end in rounded extremities, this appearance is due to the radiation and decussation of their fibres with each other. The internal tubercles probably end in the same 
manner as the trabeculx, and in the section from which Fig. I, Pl. XXX., is taken some of these fibres are seen to form a distinct commissure between the two tubercles of opposite sides. The anterior tubercle is apparently connected with the gray matter overlying the frontal lobe, its fibres forming a rudimentary calix similar to, but much less developed than, those of the corpora fungiformia.

The idea that the trabeculæe and their tubercles are disconnected with the rest of the brain is quite inconsistent with what we know of the definite nervous tracts of brains generally.

The trabecula and peduncles of the corpora fungiformia receive distinct fasciculi of fibres from the crura and the antennal ganglia (Pl. XXIX., Fig. 2). The latter decussate in the middle line. Beside these connections, numerous strands of fibres pass out of the trabecular system into the mesocerebron and corpus centrale. Hence it will be seen the corpora fungiformia have extensive and definite bundles of fibres connecting them with almost every part of the central nervous system.

The principal inter-ganglionic tracts are described in relation to the parts which they connect with each other; the most important are the peduncles of the antennal ganglia, the optic peduncles, and the peduncles of the procerebral lobes, the oculoolfactory tracts and Bellonci's bundles.

The Infra-œsophageal Nerve Centres.-The medullary white substance of the infra-œsophageal ganglia consists almost entirely of interlacing fibres; longitudinal fibres, derived from the crura and cephalo-thoracic cord, which they unite with each other; transverse fibres, which arise in the gray cortex of the centre and, after decussating in the middle line, ascend in the opposite crus; and fibres connected with the roots of the maxillary nerve.

The anterior portion of the medulla of the infra-œsophageal centre is distinctly separated from the rest, and forms two distinct fasciculi, separated from each other by a median furrow. These two bundles of fibres are pierced by the deep root of the maxillary nerve, and exhibit a distinct median decussation. Some, at least, of the decussating fibres are readily traced to 
this nerve-root (P'l. XXIX., Fig. 21. There is a distinct analog! between these decussating tracts and the anterior pyramids of the medulla oblongata of Vertebrates.

The Maxillary Nerves. - This pair of nerves arise from the lowest part of the infra-cesophageal ganglia. They are the great nerves of the proboscis, and supply all its structures except the pharynx. The fact that only a single pair of nerves supplics the proboscis is in favour of the view that it consists of only a single pair of metameral appendiges. The ynestion may arise: why should these nerves be terned maxillary rather than labial?

In answer it may be remarked that there is a tendency towards the reduction of the size of the labial, and an increase in that of the maxillary nerves, as we advance from the less to the more highly-specialised Insecta. I know no insects which exhibit the reverse condition. This would not, perhaps, be a cogent argument taken by itself, but it is worthy of note in relation to my contention that the proboscis is dereloped from the maxillæ of the embryo.

The Ganglia of the Crura (Pl. XXX., Fig $3, g(c r)$. - These consist of two distinct lobes in front of the crura, which are covered by a thick layer of nerve cells, occupying the sulcus between the antennal and infra-cesophageal ganglia. They grive origin to the pharyngeal nerves, and probably represent the gancrlia of the antenna of the Crayfish, from which the pharyngeal and antemal nerves arise in close proximity to each other. Gaskell has compared the ganglion of the crus with the locus nierer of the Vertebrate, but it appears to me that evidence is wanting to justify such a comparison.

The Pharyngeal Nerves arise from the crura between the infra(esophageal and the antennal ganglia by two roots, and from the large superficial cells of the ganglion of the crus, which lie in the sulcus between the antennal and infra-cesophageal centres. These nerves are far smaller than the maxillary, and are distributed to the pharyngeal muscles.

The Pyramidal Ganglion.-This is a large pyramidal group of nerve cells, many of which are distinctily stellate. It is 
situated behind the corpus centrale; its base rests on the floor of the central cavity; the metacerebron is immediately behind it, chiefly represented by a transverse commissure. The apex of this ganglion is situated in the posterior part of the longitudinal fissure, between the internal corpora fungiformia; its axis is traversed by numerous fibres, which form the roots of the nerve to the ocelli.

The Nerve of the 0celli. - This nerve is single in the Blow-fly; it emerges from the apex of the pyramidal ganglion as a single cord, which divides into three branches immediately beneath the three ocelli, and ends in the retinæ of these organs.

In the Cricket there are three distinct ocellary nerves-two lateral and a single median nerve.

According to Viallanes [185, Mem. 5], the median ocellary nerve in the Cricket arises by two roots, one on either side. These roots join the deep origins of the lateral nerves, and may be traced in part at least to a small internal tubercle, which projects from the inner surface of the posterior part of the hemisphere. The nerve to the ocelli in the Blow-fly has, I believe, a similar connection with the hemisphere, although many of its fibres come from the nerve-cells of the pyramidal ganglion.

\section{d. The Sensory Ganglia.}

The Olfactory or Antennal Ganglia are a pair of spheroidal ganglia, which project from the front of the brain. They are united with each other by a strong commissure. Each ganglion is connected with the corresponding hemisphere by a peduncle, consisting of four principal bundles of fibres.

I. Bellonci's Bundle traverses the hemisphere from before backwards, and terminates in the gray matter between and below the corpora fungiformia. These fibres were first seen by Bellonci [183] in the Diptera.

2. The Trabecular Bundle (Pl. XXIX., Fig. 2) decussates with its fellow in the middle line, and joins the trabecula of the opposite side. 
3. The 0culo-0lfactory Bundle (PI. XXIX., Fig. 2) passes outwards and backwards to the thalamon. It was first described by Viallanes.

4. The Glosso-0lfactory Bundle descends to the infra-œesophageal ganglion.

The Medullary Substance of the antennal ganglion has a very remarkable structure, exactly similar to that of the olfactory lobe of a Vertebrate. This structure was described by Dietl [175], and more recently by Bellonci [183], who terms it the olfactory ganglion.

In optical sections it appears to be composed of a number of small lobes. These were formerly mistaken by Leydig for

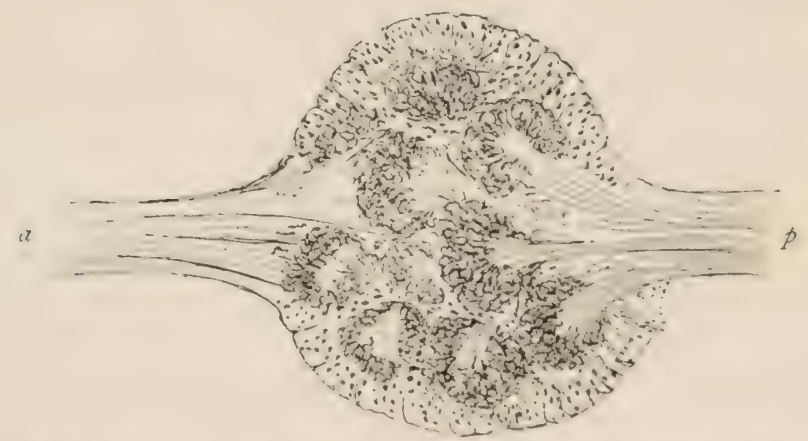

Fu. 60. A section of the Olfactory (antennal) (ianglion, seen with a 1 oil immer. sion objective, showing the reticular glomeruli in which the fibres of the antennal nerve $(a)$ terminate and from the centres of which those of the olfactory peduncle $(p)$ take their origin.

griant cells. Each lobe appears in properly preserved sections as a glomerulus of fine fibres; the centre of each is connected with a fasciculus of fibres from the peduncle of the ganglion; and the periphery is continuous with a reticular network of fibres, which connects the glomerulus with the cells of the cortical substance, and with the fibres of the antennal nerve: these are, many of them, given off from the glomeruli, a small fasciculus arising from each (Fig. 60).

Both the glomeruli and the fibres of the antennal nerve are deeply stained by osmic acirl, whenever this reagent is 
used, to a far greater extent than any of the other nerveelements.

The Antennal Nerve arises partly from the glomeruli and partly from the adjacent cortical substance in which its fibres can be traced into large stellate nerve cells. In the Cricket and many other insects two pairs of antennal nerves have. been described - the large sensory rierve and a smaller motornerve, which supplies the muscles of the antenna. They are, perhaps, united into a single trunk in the Blow-fly. Possibly the nerve-fibres, which arise directly from the large stellate cells, are motor in function.

The 0ptic Ganglion.-This term has been applied with different limitations. Viallanes includes under it all the nervous structures between the inner extremities of the great rods of the compound eye and the hemispheres of the brain, but Berger [178], Ciccacio, ${ }^{*}$ Bellonci, and Cuccati, as I think, correctly limit the use of the term to those parts included under it in the following description, naming the remaining structures the retina; whilst Hicksont proposes to call the whole the retina.

The optic ganglia of the Blow-fly differ but slightly from the same structures in the Insecta generally; these are very similar to the corresponding parts in the Decapod Crustacea.

I shall distinguish and describe the following: (I) The optic peduncle; (2) the inner medulla; (3) the outer medulla; and (4) the cortex. The relations of these parts will be most easily understood by a reference to Fig. 6I. The remaining structures, included by Viallanes as a portion of the optic ganglion, are my optic nerve and retina.

I. The Optic Peduncle is frequently termed the optic nerve. If the term optic nerve is to be used in the Arthropoda, it certainly is inappropriate for the designation of this structure, which unites the optic ganglion and the cerebron. In order to be consistent, if the optic peduncle is to be termed the optic nerve, the optic ganglion should be termed the retina, as Hickson $^{\tau_{i}}$ has done. To do so appears to me to be an un-

* Mem. d. Accad. d. Sc. Bologna, tom. vi., 1884.

† Quart. Journ. Microsc. Sc., vol. xxv., I885. p 215 
warrantable violence to terms in general use, and such a change of nomenclature is quite inconsistent with the homology of the parts from a developmental point of view. The optic peduncle exhibits three very distinct bundles of fibres, which I shall term (I) the commissural fibres $(m, p)$; (2) the thalamic fibres (v), which include the oculo-olfactory bundle; and (3) the mesocephalic fibres ( $m$ ), which form the greater part of the optic peduncle.

2. The Inner Medulla may be described as consisting of an anterior medullary mass $(a c)$, which I shall term the corpus ovale, partially embraced behind by a concavo-convex lentiscus

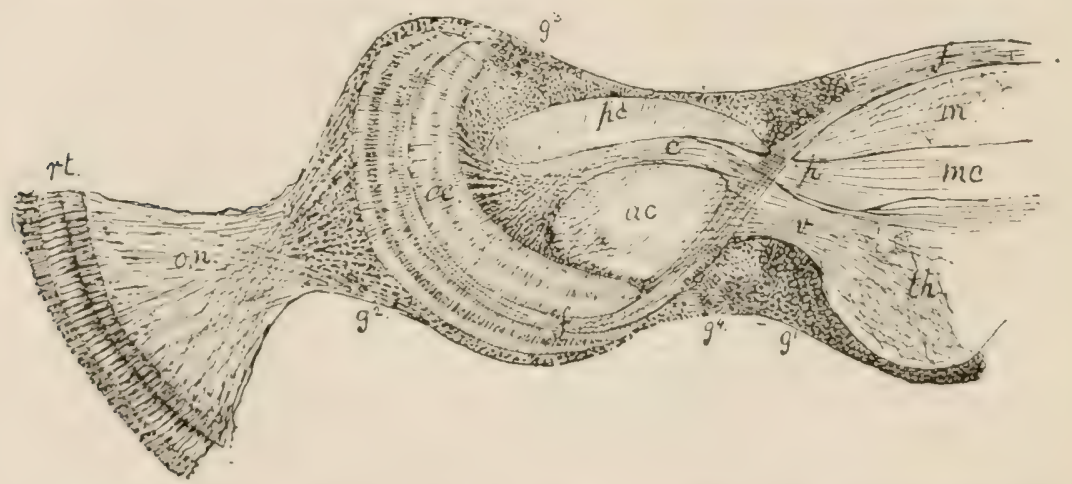

Fyg. 61.-A lateral section of one of the Optic Ganglia: $a c$, anterior capsule ; $r$, middle capsule ; $f f$, the trenia ending in Cuccati's bundle and the posterior commissure; $g^{\mathrm{l}}$, annular region of the cortex ; $g^{2}$, the corona ; $s^{3}$, posterior, and $y^{4}$, anterior, cell groups; $m$, fibres of the peduncle entering the nesocerebron; me, midule commissure of optic garglia traversing the floor of the cavity of the cerebron; oc, external medulia ; on, chiasma of optic nerve; $p$, posterior fibres of the peduncle; $p c$, posterior capsule; $t$, retina ; $t h$, thalamic lobe; $\theta$, thalamic fibres of the optic peduncle entering the thalamic lobe.

(pi): this is the posterior capsule of Viallanes. Between the corpus ovale and the posterior capsule there is an intermediate layer, which differs entirely from the posterior capsule and corpus ovale. This I term the middle capsule (c). Many of the fibres of the midule capsule enter the thalamic bundle of the uptic peduncle, and others are lost in the corpus ovale (ac) and the lentiscus $(p c)$. They diverge radially at their outer 
end, and, after traversing a thin layer of nerve cells, the subcoronal ganglionic layer, they can be traced into the external medulla $(o c)$, and through it into the external gray matter, the coronal ganglionic layer $\left(g^{2}\right)$, where they converge and cross each other, forming the chiasma of the optic nerve (on).

3. The External Medulla, or optic cap $(o c)$, is a large cupshaped, laminated organ. It exhibits three lamellæ, the internal, intermediate, and external.

The internal and external lamellæ closely resemble the corpus ovale and the posterior capsule, and are very dense and opaque. The intermediate lamella is more transparent, and consists chiefly of a sheet of fibres coursing in planes parallel with the faces of the medulla. A number of these leave the anterior edge of the cap and form Cuccati's bundle; the remainder terminate in the cortex $\left(g^{3}, g^{4}\right.$, Fig. 6I). I distinguish this lamella as the trenia, from its band-like appearance in sections.

4. The Cortex.-Viallanes distinguishes several regions in the cortex of the optic ganglion. That portion which surrounds the internal medulla is, in his nomenclature, the wedge-shaped ganglion $\left(g^{1}, g^{4}\right)$ (ganglion $c n$ coin); the part which penetrates between the inner and outer medullary masses is the internal ganglionic medulla; and that on the convex surface of the outer medulla the coronary ganglion $\left(g^{2}\right)$.

As the term ganglion applied to a region of the cortex is misleading, I shall speak of these as regions of the cortex. The ganglion en coin will be termed the annular region, the coronary ganglion the corona, and the internal ganglionic lamella the sub-corona.

Viallanes also distinguishes a group of large nerve cells, which are very distinct from the small round cells which make up the rest of the cortex. These appear to be very constant in different insects. He terms this group of cells the anterior ganglionic mass $\left(g^{4}\right.$, Fig. 6I). It has also been observed by Ciccacio in the Blow-fly. I term it simply the anterior cell group. A second similar group $\left(g^{3}\right)$ has also been described in this insect by Ciccacio; this may be termed the posterior cell 
group. The cells of the anterior group are connected, according to Ciccicio. with the tenia: those of the posterior group appear to be the origin of some of the radiating fibres of the posterior capsule.

The Internal Chiasma.--This term is applied by Viallanes to the radiating fibres of the middle capsule. In some insects these fibres form a distinct chiasma, crossing each other completely: in others, as in the Blow-Hy, there is no distinct chiasmatic crossing. It appears to me that when these fibres cross, those of the optic nerve do not, and icce icrsi ; at any rate, this is sometimes the case. I have therefore discarded the term internal chiasma.

The Fibres of Cuccati pass from the trenia to the posterior part of the pyramidal ganglionic mass, and form a thin commissure between the two optic ganglia. It appears to me probable that the slender bundles described by Cuccati as the fork, which lie behind the pyramid, are derived in part from these fibres, and connect the optic ganglia with the origin of the nerves to the simple eyes. I cannot say positively, however, that such is the case, as I have been unable to trace the bundle of Cuccati, as he has done, to the region in which the fork lies.

The Histological Structure of the External Medulla, or 0ptic Cap. -I know no organ which is more difficult to resolve into its histolosical element than the internal and external medullary substance of the optic ganglion. The structure of the corpus ovale and the posterior capsule is very similar to, if not identical with, that of the outer and inner lamellae of the optic cap, but, owing to the regular arrangement of the elements of the latter, it is more conveniently investigated.

In good radial sections the outer and inner layers of the optic cap appear to consist of very closely-packed prismatic fibres, supported by a distinct neurogla similar to Miiller's fibres in the vertebrate retina. In some sections the prismatic fibres have the appearance of oblong or oroid cells, and I formerly described them as such. My more recent preparations indicate. I think, that my former interpretation of the appear- 
ances is erroneous, as I am quite unable to stain the granules I took for nuclei, except those which manifestly belong to the basket-like fibres; neither can I find any such cells in the same organ in the pupa. I believe the rod-like fibres are either packets of primitive fibrillæ, or medullated nerve fibres. In many specimens they exhibit the appearance of rods of granules. Viallanes says: 'The external medullary mass in the Wasp, as in the Dragon-fly, consists entirely of punctate substance;' but in his later work on the brain of the Cricket, he adds: 'When sections strongly impregnated with osmic acid are examined, the substance of this body is seen distinctly divided into three zones. The internal and external zones are strongly stained. Under low powers, two systems of strix may be observed, one normal to and the other parallel with the surfaces of the organ.' This is a little disappointing from one who has apparently worked so long at the structure in question.

The structure of the optic ganglion is as well described by Berger as by anyone since. In the intermediate layer the radial fibres are thinner, and make way for those parallel with the surfaces of the ganglion, and in young pupæ the layer is almost entirely cellular.

In the pupa the reticular substance is of small amount, and as development progresses it encroaches on the very thick cortex, which is correspondingly reduced in thickness, so that I conclude the reticular medulla originates from the cells of the cortex and from those of the intermediate layer, either by the great development of certain cell processes, which become nerve-fibres, or by the differentiation and fibrillation of the cells themselves.

\section{GENERAL PHYSIOLOGY OF THE NERVOUS SYSTEM IN ARTHROPODS.}

Very little is known of the special functions of the several parts of the nervous system in Arthropods. There is, however, a general similarity between the functions of the ventral chain 
and of the spinal cord and medulla oblongata, and between these of the brain in Arthropods and in Tertebrates.

In the Blow-fly imagro, if the insect is decapitated, the trunk exhilits reflexes, which are co-ordinate, for hours; but there are no movements which can be regarded as voluntary, and with the exception of the rhythmic closure of the inner valves of the thoracic spiracles and quasi-respiratory, irregularly rhythmic movements of the abdomen, none which can be regarded as automatic.

It can scarcely be doubted that the so-called instinctive acts of insects exhibit psychic characters, and belong to that class which we ascribe to volition in Vertebrates, and that these acts are controlled by the cephalic centres, which are also immediately concerned in the senses of sight and smell.

The sense of hearing, on the other hand, is directly dependent on the thoracic centre, and this centre, in the Blow-fly at leatst, is concerned in highly complex co-ordinate reflexes. This is shown by the fact that a decapitated fly will clean dust or water off its winers, abdomen, and tarsi by the same acts as the entire insect - a clear indication that the mere contact of foreign matter with the integument excites reflexes, which at once disposes of the view that insects possess little or no general or tactile sensibility.

The sudden and complete destruction of the thoracic ganglion produces not only the entire cessation of movement and sensibility in the trunk, but also of the parts of the proboscis. 1) cstruction of the thoracic granglion of the higher insects is followed by instantaneous death, just as that of the medulla oblongatia is in Vertebrates; so that even those parts supplied ly the maxillary nerves no longer exhibit reflexes.

In addition to the above, the following statements have been more or less established from experimental evidence by the various authors quoted, and, as has already been shown, some inferences may fairly be drawn from the structure of the erreat nerve centres. It is probable that most, if not all the following statcinents apply to the Blow-fly imagro: but the higher insects are not grood subjects for experiments, and at present, at least, 
we must rest contented with such information as has been obtained from Arthropods generally.

I. The ganglia of the ventral chain are reflex centres of the segment to which the nerves given off by them are distributed. The extent and character of the reflexes which can be obtained after isolation of the ganglia, by division of the ventral nerve cord, varies greatly in different groups. In the Crustacea, according to Yung, reflexes are more marked in the posterior abdominal than in the thoracic region. Movements of the anus, the posterior part of the intestine and of the generative armature can be readily produced after division of the ventral cord; all other reflexes obtained under the same conditions are inco-ordinate, and are often either absent or are not readily excited. Longet* stated that section of the ventral cord in insects produces paralysis behind the point of section, and concluded from this fact that the ganglia have no independent action; but Longet's statement appears too sweeping. Stimulation of the isolated ganglia always produces reflexes, although exhaustion of all nervous power appears to follow section very rapidly; probably the result of rapid degeneration of the conducting tracts.

2. The infra-osophageal ganglia are, so far as function is concerned, similar to the ganglia of the ventral chain, and are the reflex centres of the segments and segmental appendages of the head, at least in the more generalised forms. Faivre found in Dytiscus that they are also concerned in co-ordinating the movements of the thoracic appendages; but this is certainly not so in the Diptera, in which the co-ordinating centres are situated in the thoracic ganglion, nor are reflexes excited by stimulation of the proboscis of the decapitated fly.

3. The supra-œesophageal centres are the sole seat of the determination of voluntary acts (co-ordinate spontaneous movements). When these ganglia are separated from the ventral chain, co-ordinate reflex actions may be excited, but no co-ordinate spontaneous acts occur.

* Longet, F. A. 'Anatomie et Physiologie du Système nerveux de l'Homme et des Animaux vertébrés.' Paris, 8vo., 1842, tom. ii., p. 662. 
4. The right half of the brain is in relation with the left half of the ventral chain, and vici icrsi. There is a complete decussation of fibres between the supra-cesophageal centres and the ganglia of the ventral chain, with which the infraasophageal ganglia must probably be included.

This statement is supported by the experiments of Faivre on 1)ytiscus; and by those of Yung and others on the Crustacea.

Yung says, however, 'Each half of the brain (supra-xesophacreal centre) acts upon the corresponding side of the body, although he also states that lesion of one of the lobes of the brain produces circus movements (mouvements de manége) from the injured to the sound side of the body.

As all observers have stated that such movements occur, it appears to me that this cntirely negatives Yung's contention. Faivre accounts for the circus morements on the supposition that paralysis of the appendages of the uninjured side occurs, and this seems to be the case.

Yung, on the other hand, evidently supposes that the lesion acts as a stimulus. This is most improbable, as Fairre has shown that even the slightest lesions give rise to rapid abrogation of function in all arpuatic insects, from the destructive action of the water which acts upon the injured centre; moreover, the same movements occur when the entire hemisphere is removed and in the same direction. This fact alone shows that Yung has arrived at a false conclusion.

Anatomical investigations lead to the conclusion that the most extensive system of transverse commissural fibres exists in the supra-cesophageal centres, and that by far the greater portion of the conducting tracts decussate around the (esophasus; indeed, there is no evidence of the direct relation of the two halves of the supra-cesophaseal portion of the brain with the corresponding halves of the metameral ganglia.

5. The classical view that the dorsal tracts of the ventral cori are afferent and the ventral tracts are efferent is probably correct. The experiments of lative and Longet are in favour of this conclusion; but Vulpian, Lemoine [174] and Yung [179] conlil find no difference between the stimulation of the dorsal 
and ventral surfaces of the ventral chain in Crustaceans; and Iung says, "The classical opinion that the inferior surface is sensitive and the superior motor is invalidated by my experiments. The nerve-roots are at the same time both motor and sensory.' As no attempt, however, was made by the authors quoted to eliminate reflexes, it is difficult to understand how they could conclude, from the fact that movements occur by stimulation of a given tract, that the function of the tract is motor.

On the other hand, Faivre [171] asserts that by destruction of small portions of the dorsal or ventral surfaces of the ganglia in Dytiscus he was able to produce either motor paralysis or anæsthesia, and proved that the dorsal surface is motor and the ventral sensory in function; but he insists that these results can only be obtained when the lesions are superficial, destruction of the white core gives rise to ambiguous or contradictory results.

Faivre arrived at the following conclusions :

a. Sensibility and excitability are distinctly located. The inferior surface of the ganglia is the special seat for afferent and the superior for efferent (motor) impulses.

b. Paralysis (motor) results, from superficial lesions of the superior surfaces of the pro- and mesothoracic ganglia, in the foot and leg of the same side.

c. By operating on the infero-lateral aspect of these ganglia sensory impulses, propagated from the corresponding leg, produce no result, but the power of movement remains intact.

d. A double paralysis of sensation and motion may be produced by appropriate superficial lesions without impairment of the conductive power of the ventral cord to, or from, the ganglia behind the lesion.

c. Paralysis (motor) is more easily produced singly, i.e., without corresponding anæsthesia, than anæsthesia without motor paralysis.

6 . The ganglionic chain in the Myriopoda (Newport*) con-

* Newport, G., 'On the Structure, Relations, and Development of the Nervous and Circulatory Systems in Myriopoda and Macrourous Arachnida.' Phil. Trans., 1843. Part ii. 
sists of two superimposed cords, an inferior cord with ganerlionic enlargements, and a superior cord which is uninterrupted; and Newport found the same disposition in Insects and Arachnicls. These statements have been amply confirmed, and such strong evidence has been adduced in favour of the view that the dorsal band of fibres in the rentral chain are conductors between the cerebron and the ganglia of the ventral chain, that this can scarcely be doubted: Lemoine states that these longitudinal fibres increase in number towards the brain, and are four times more numerous between the first and second thoracic, than they are between the last and penultimate. abdominal ganglia in the Crayfish (1stacus). They certainly increase rapidly in number in the dorsal band of the thoracic centre in the Blow-fly, from behind forwards.

7. As the dorsal vessel continues to pulsate after the ablation of the whole central nervous system, and after its removal from the body (in Crustacea), it is probable that it has an intrinsic ganglionic mechanism; it also receives accelerator fibres from the stomogastric nerve (Lemoine)-these may be called the nerves of I_emoine-and inhibitory fibres from the thoracic ganglion (the nerves of Dogriel). Y ung confirms these statements. Hence there is a complete analogy between the nerve supply of the heart in Vertehrates and of the clorsal vessel in . Irthropods, lending additional evidence in favour of the view that the thoracic ganglion corresponds to the medulla oblongata, and the stomogastric with the sympathetic system of the Vertebrate.

Injury or ablation of the supra-cesophageal centres has no effect upon the pulsations of the dorsal ressel; but stimulation of the crura, from which the roots of the stomogastric nerres arise, produces acceleration of the pulsations of the dorsal vessel (Yung). 


\section{THE DEVELOPMENT OF THE NERVOUS SYSTEM.}

The origin of the nervous system from the primitive band and procephalic lobes of the embryo has been sufficiently established by numerous observers; but the exact manner in which the ganglia originate is still, I think, doubtful; and the embryo of the Blow-fly is not well adapted for the determination of their origin, as the earlier changes take place with extreme rapidity.

The first appearance of the ganglia of the ventral cord, as definite and recognisable structures, is identical with their first appearance in Hydrophilus, as figured by Kowalevski [97]. They are seen at first as definite groups of cells, occupying only a very small portion of the primitive band.

The generally received view is perhaps accurately expressed by Balfour [43]; he states that the ventral cord originates from two longitudinal thickenings of the epiblast, one on each side of the median line, which subsequently separate from the integumentary epiblast, and give rise to the two lateral strands of the ventral cord; and that these subsequently undergo segmentation and differentiation into the ganglia and their connecting cords.

So far as my observations go, the above statement is not quite accurate. The primitive band is correctly described as

\section{Bibliography :}

187. HAtsc'HeK, B., 'Beiträge zur Entwickelungsgeschichte der Lepidopteren.' Jenaisch. Zeitsch. f. Naturw., Bd. xi., I877.

188. REICHENBACH, H., 'Die Embryoanlage und erste Entwickelung des Flusskrebses.' Zeitsch. f. w. Zool., Bd. xxix., 1877.

189. HEIDER, K., 'Ueber die Anlage der Keimblätter von Hydrophilus piceus L.' Abhand. der Königlichen Akad. der Wissenschaft zu Berlin. Anhang zu den Abhand. (1885), I886.

Heider has since published (189I) a more extended work on the development of Hydrophilus, which I only know from quotations.

190. Viallanes, H., 'Sur quelques points de l'histoire du Développement embryonnaire de la Mante religeuse (Mantis religiosa).' Ann. Science Nat. Zool., série vii., tom. xi., I891.

191. WheELER, W. M., 'A Contribution to Insect Embryology?' Journ. of Morphology, vol. viii., I893. 
consisting of two longitudinal thickenings of the epiblast, it undoubtedly undergoes segmentation, and is subsequently found to consist of an integumental layer of columnar cells, and of deeper layers of irregularly polyhedral cells; but these deeper cells do not become directly converted into the ganglia; the liatter first appear as small groups of cells imbedded in the deeper layer, and only form a very small part of the primitive band. Compare Kowalevski's figures [97, Pl. X., Figs. 3 I to 39]. l'ossibly each sanglion originates from a single cell by rapid cell division, or from a small group of cells; but I am unable to state anything definitely as to the origin of the primitive ganglia. All the cells in each ganglion in my preparations are precisely similar, and are very definitely separated from the larger surrounding cells. It is only subsequently, when the ganglia have attained considerable dimensions, that they assume the form of a segmented cord on either side of a very narrow median fissure.

Quite recently Viallanes has described the manner in which the ganglia are developed in the embryo of Mantis (M. religiosu) [190]. He says: 'At first the primitive band is a simple thickening of the ectoderm-that is to say, a region in which the cells have become columnar and augmented in volume; very soon these cells multiply and divide into two layers, a superficial dermato-genetic, and a decp ganglio-genetic layer. It a period which varies according to the regrion examined, the dermato-genetic layer separates from the ganglio-genetic, and becomes the hypoderm.' Viallanes further states that the granglio-grenetic cells give rise to ganglion cells by division, and that the fibrillar or punctate substance is developed between the latter. Theeler [191], who follows Viallanes very closely, describing the origin of the ganglia in Xiphidium ensiferum, one of the American Locustidat, speals of the sanglio-genetic cells as 'large clear neuroblasts, scattered leneath the superficial cells of the blastoderm.' Such may he the origin of the nervous elements; but the appearances with which I am familiar are very unlike those figured by Whecler. The appearances represented in Viallanes' figures closely 
resemble those exhibited in my sections, but I am unable to regard the large cells as a layer of neuroblastic cells, although the nervous system is undoubtedly differentiated from this layer, and I think it probable that each ganglion is formed from a small number of these cells. Many of the large cells, perhaps the greater number, are probably the origin of the muscles, and originate from the colomic sacs (PI. XIV., Fig. 2); and certainly, in the earlier stages of the development of the Blow-fiy embryo, it is not possible to distinguish the cells in which the ganglia of the ventral chain are first seen imbedded, from those which subsequently form chains from which the muscle fibres of the larva are developed.

Hatschek, Will, Heiden, and others, have described a median inflection of the cutaneous epiblast, between the two lateral chains of ganglia in various Arthropods. Kowalevski did not find any such inflection in Hydrophilus, nor have I seen anything of the kind in the Fly-embryo. It appears to me, from the very advanced condition of the embryos figured by Hatschek, that the involution is secolidary, and is perhaps a rudimentary entosternum. To those who accept Dohrn's views, the existence of such an involution is of primary importance, if it is developed previously to the ganglia and really enters into their formation : but the evidence derived from the study of the Blow-fly embryo appears to me to be quite incompatible with such a supposition.

Balfour, commenting on Hatschek's statements, says: 'It is probable that Hatschek was entirely mistaken as to the entrance of a median element into the constitution of the ventral cord;' but in this I think Balfour is wrong. There is considerable evidence that a median element is present in certain stages of development; even at an early stage, a median inflection of the coelom is seen in certain of my sections, with a distinct mesoblastic wall. It is probably from this that the tracheæ and connective elements, which exist in the median septum of the neuroblast of the larva, originaté.

At a later pericd I have obtained excellent sections, showing the ventral cord (as represented in Pl. XIV., Fig. 2) entirely separated from the surface epiblast. In some of these sections, 
howerer, a kind of neural crest is distinctly seen (Fir. 62), which passes into the epiblast on either side, from which the segmental nerves are developed.

In the earlier stages, the ganglia extend the whole length of the embryo, one pair in each segment, as they do in Chironomus and the Tipulide. As development advances, the nervous chain in the Blow-fly embryo becomes considerably shortened, and the ganglia are drawn together and fused into the short, thick conical neuroblast, which in the recently hatched larva is not more than one-third the length of the body. They are thus shifted from the segments in which they were originally formed. At the time of the escape of the larva from the egrg,

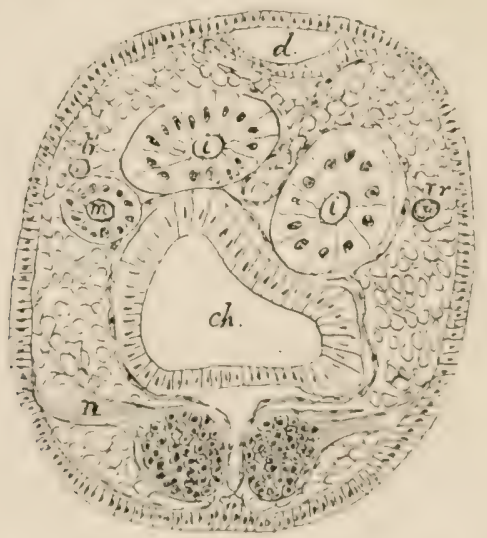

Flli, 62,-A section of an embryo of the Blow-1ly about eighteen hours old, showing the neural crests and the diverticulum of the colom between the vental ganglia. $c h$, the chyle stomach; $d$, dorsal vessel ; $i, i$, the intestine; $m$, a Mal. pighian vessel ; $n$, the neural crest; $t r, t)$, tracheal vessels.

the segmentation of the neuroblast is very obscure, and the existence of a series of ganglia corresponding to those of the ventral chain, in more generalised Arthropods, is only indicated hy slight furrows on the surface, and by the existence of ten pairs of nerves. Indeed, the number of ganglia appeirs to be reduced to six pairs, as it is in the Pupipara, by the atrophy or sreat reduction mo the size of the ganglia, corresponding to the posterior abdominal segments (compare Pl. II, Figs. 7 : 8. 
and 9). The shortening of the ganglionic chain, so characteristic of the Muscidae and their allies, occurs during the second stage of development in the egg,-during the transformation of the nymphoid into the vermiform embryo.

Development of the Preoral Centres.-It has been sufficiently established that the preoral centres originate from the procephalic lobes, and that the latter are the anterior extremities of the two lateral halves of the primitive band; but previously to the appearance of Viallanes' memoir on the development of Mantis [190] no detailed description of the manner in which the hemispheres of the brain are developed had been published. A perusal of Viallanes' paper has convinced me that the development of the brain in the Blow-fly is very similar to that of Mantis, except that the process, which occurs in Mantis in the egg, is prolonged in the Blow-fly throughout the larva and earlier pupal stages; indeed, Viallanes' sixth stase of the development of Mantis in the egg closely corresponds with the completion of the formation of the nymph in the pupa of the Blow-fly during the third or fourth day; while his tenth and last stage of the Mantis embryo presents a nervous system closely resembling that of the Blow-fly on the seventh or eighth day of the pupa stage.

Our knowledge of the first stages of the development of the brain are still exceedingly incomplete; but the structure of the hemispheres in the larva of the Blow-fly affords valuable indications of the prabable changes which occur in earlier stages; I shall therefore commence by a description of the parts in the adult larva, before the changes which occur in the resting stage of the larva take place.

The Hemisphere of the Adult Larva exhibits a complex centra] stroma divided into several well-defined lobes, surrounded by a thick layer of cellular cortex, which presents various characters in different parts of the hemisphere. The cellular cortex is invested by a well-marked layer of columnar cells partially covering the hemisphere and dipping into its substance, separating the optic ganglion and the posterior lobes, which become the corpora fungiformia, from the remaining structures 
of the brain. It will be convenient to term this layer of loner columnar cells the mantle of the hemisphere; it disappears entirely during the later stages of development, and no traces of it remain in the adult fly. The parts of the mantle which remain longest are the disc covering the optic sanglion on the outer and inferior surface of the hemisphere and the deep infolding which separates its posterior from its anterior part (Pl. XXXIV.). The former of these I have already alluded to as the retinal disc; the latter certainly corresponds to the bourrelet intraganglionnaire of Viallanes.

Nature and Origin of the Mantle of the Hemisphere-Viallanes gives a figure of a surface-view of the embryo of Mantis [190, Fig. 4] in which this layer is represented in its earliest stage of development. It is seen to terminate in the antennal rudiment in front, and to cover the whole external part of the hemisphere. The same author gives the following description of the origin of the outer portion of the hemisphere, which he terms the first proto-cerebral lobe, in accordance with his nomenclature, to which attention has been directed on p. 442 of this work; he says:

"We have already stated that the first proto-cerebral lobe consists at first of a single layer of young cells detached from the ectoderm by delamination. These elements, remarkable on account of their large size and the abundance of their protoplasm, give rise indivetly to the formation of the nerve or ganglion cells; they will be denominated ganglio-genetic.

\section{Description OF PIATE XXXIV.}

lik. 1. A sagittal section of the anterior part of the neuroblast of an alult larva through the root of the antennal nerve. $c$, mantle layer dipping into the substance of the ganglion, the bourrelet intraganglionnaire of Viall a

superficial cells of oplic ganglion; $n$, antennal nerve; $n, n$, esophagus ; $x$, rows of cells probably derived from the mantle layer; $y$, large ganglion cells; $z$, dorsal cells of the ventral chain from which the nerves of the larva arise; $y$ and $z$ are probably the functionally active parts of the neuroblast, and undergo histolytic changes in the pupa.

Fin. 2.- I lateral section of the hemisphere of the neuroblast of the alult larva: $a$, antennal ganglion; $c$, supra-osophageal commissure; $c$, mantle layer; $\ell$, portion of the retinal disc; $f$, cells of the pyramidal ganglion; $s$, stomo. sastric ganglia ; e, central stroma of the optic ganglion; s, optic stalk of the eje disc. 


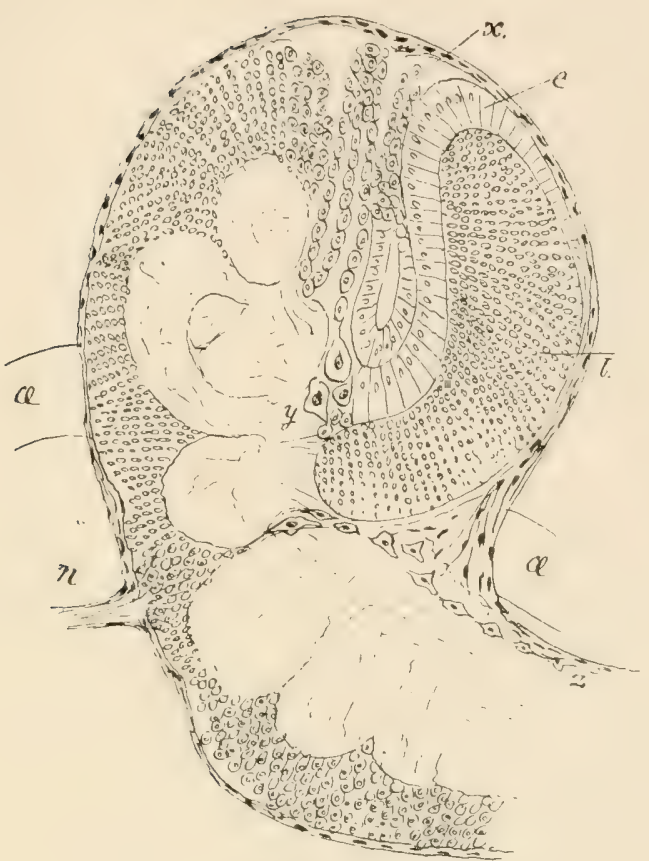

FIl: I.

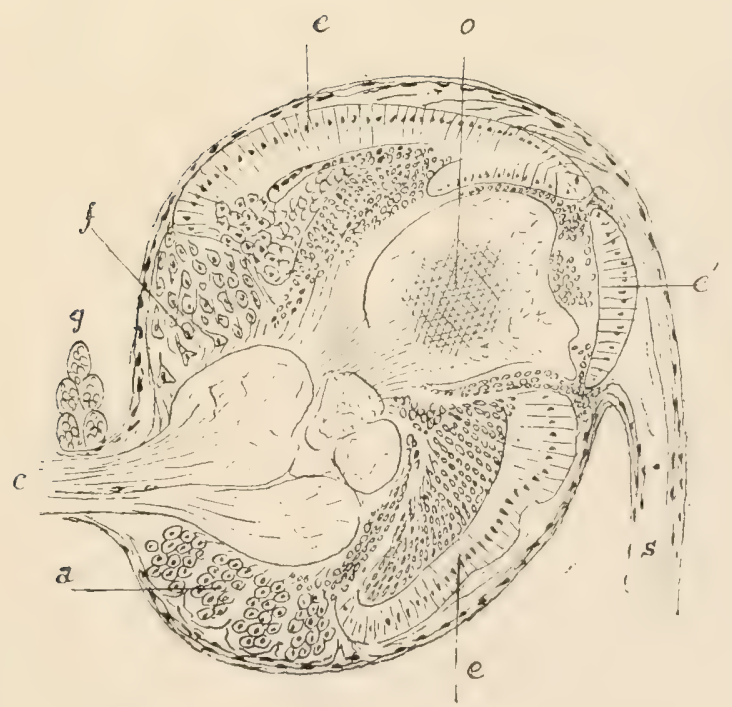

FIG. 2. 

'The ganglio-genetic cells, which at first are few in number, increase and multiply, without, however, changing their character, and always remaining disposed in a single layer.

'In the seventh stage these cells cease to produce elements similar to themselves, and give rise on their deep surface to much smaller elements very poor in protoplasm, with nuclei easily stained by carmine which may be designated as ganglion cells; as soon as these are formed they themselves multiply very actively. Owing to this multiplication, the first protocerebral lobe becomes a mass of cells convex externally and concave within.

'It consists, then, of two layers of cells which are very distinct, a superficial layer on its convex surface of ganglio-

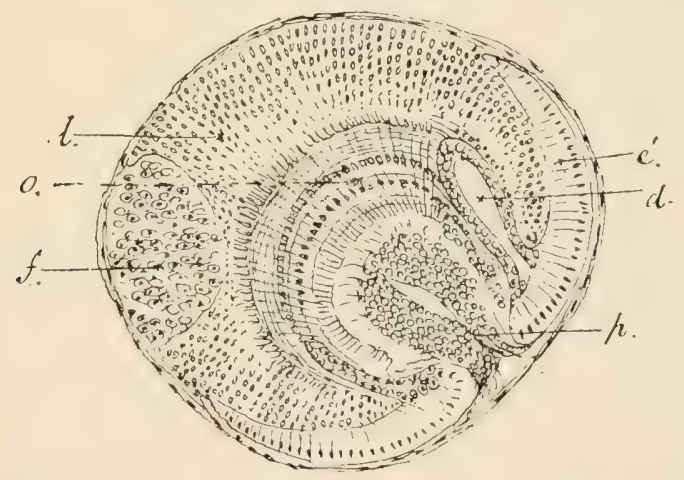

FIG. 63.-A sagittal section through the outer part of the hemisphere of the adult larva showing the invagination of the mantle layer from which the retina of the imago is developed. $d$, invaginated layer surrounding the retinal rudiment; $e^{\prime}$, epithelial mantle layer ; $f$, part of the pyramidal ganglion; $l$, superficial cells of the optic ganglion; 0 , central stroma of optic ganglion; $p$, group of small cells invaginated in the cavity of the rudimentary retina.

genetic cells and a deeper portion consisting of numerous layers of ganglion cells.'

So far Viallanes' description appears to be extremely clear, and to correspond closely with the phenomena observed in the Blow-fly by myself. It is possible that the deeper layers of cells are formed from the mantle layer.

In two regions I have seen appearances which seem to 
indicate that this laver is ganglio-genetic. In the neighbourhood of the pyramidal granglion (Pl. XXIV, Fig. I, x) and of the antennal ganglion the mantle is continuous with groups of large nerve cells, but whether the small round cells are developed from the mantle is still, I think, doubtful ; nevertheless, I regard it as probable that they are in part at least.

Viallanes continues his description of the development of the optic ganglia as follows:

"At the same time that the layers of ganglion cells are produced a layer of fibrillar substance appears, at first on the inner surface of the ganglion layers; it is, so to speak, secreted (excuse the comparison) by the free surface of the ganglion layers. The fibrillar substance once produced is rapidly increased, and at the same time advances into the midst of the ganglion cells by a kind of invagination. The penetration of the fibrillar substance into the layer of ganglion cells appears to me to lie the result of their multiplication, by which the increasing mass of cells tends to enclose the fibrillar substance.'

That the central white substance originates from cells is indubitable, but it appears in the Ilow-fly long before any nerve cells have been produced from the mantle layer. In the newly-hatched larva the fibrillar substance of the brain and ventral cord is already developed (Fig. 64), and both are surrounded by a multiple layer of sanglio-genetic cells. In l'l. II., Iig. 7 , I have already represented this stage, and there is no trace of a mantle layer. Since publishing this figure I have obtained sections showing the mantle layer enclosing a large cavity in front of the brain, and not yet applied to the hemisphere, but in immediate relation with the dermal head-discs.

Viallanes' own figures seem to me to indicate that there are numerous cellular elements in the region from which the brain is developed long before the mantle layer has been laid down over their surface, and in one the white substance is apparently represented amongst these cells [190, Fig. \&, near $p 0]$.

It appears to me that there is evidence, although not conclusive evidence, in farour of a totally new view of the manner in which the preoral ganglia are dereloped-a view 
which is consistent with the developmental history and final condition of the Arthropod brain, and renders a great number of facts intelligible. I advance it with some diffidence, as I am aware of the difficulties which beset any investigation of the development of the nerve-centres, and the ease with which the significance of a layer of cells may be misinterpreted, but I present it as a working hypothesis which may serve as a guide to future investigators. The evidence in its favour depends on but few preparations, and is the result of the study of a single insect; the difficulties of obtaining satisfactory evidence is very great owing to the extreme rarity of good preparations in the earlier stages of the development of the larva in the proper planes for the investigation of the question, as suitable sections are by no means easy to prepare.

In examining the nymphoid state of the embryo, I discovered

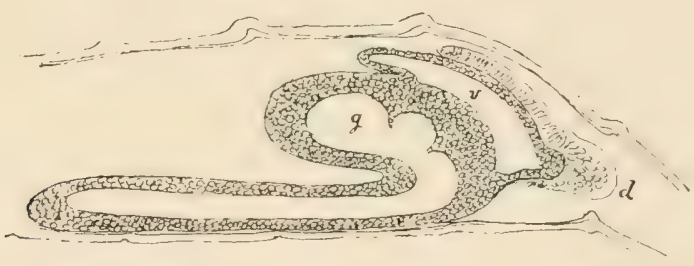

FIG. 64.-A sagittal section of the neuroblast of a newly-hatched larva. $d$, head discs ; $v$, ventricular cavity of the hemisphere; $g$, central stroma of the neuroblast.

a condition, which is figured in Pl. XV., Fig. I, in which the preoral ganglia are apparently vesicular, and subsequently I found the observation borne out by the condition of the nervecentres in the newly-hatched larva (Fig. 64). From these observations, I am strongly urged to the view that the remarkable mantle layer in the adult larva is the roof of a cavity, the remains of which form the ventricular cavities of the brain of the imago.

It is true that the early vesicular stage, which appears to be the probable interpretation of my sections, has not been hitherto suspected in the Arthropod brain, and although Kowalevski [97] discovered a central cavity in the brain of Sagitta, he observed 
an earlier stage in which he says no central cavity exists; and this apparently led him to regard the central cavity as possibly due to shrinkage during the hardening process.

The existence of one or more ventricles in the Arthropod brain has already been mentioned, so that it is possible that a more general cavity exists at an early stage of development. In some of Viallanes' figures of the earlier stages of the development of the preoral nerve-centres of Mantis there are undoubted cavities $[190$, Figs. I I, I 3 bis, If $]$, but he regards these as the result of a partial separation of the neural and dermal rudiments. A comparison of the later stages renders it extremely improbable, however, that the thick layer which he regards as dermal in the young embryo is reduced entirely to the thin layer which

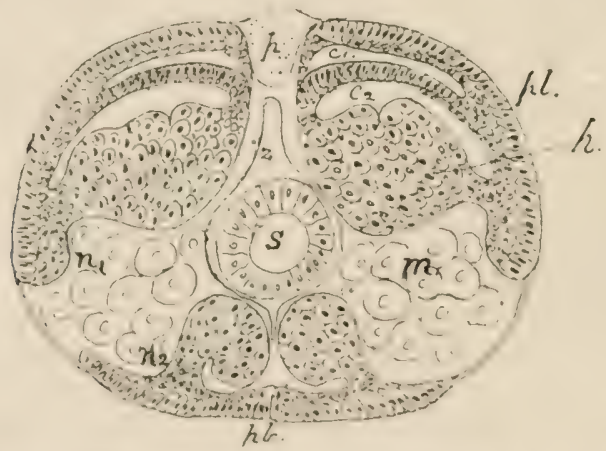

Fu: 65. - . 1 diacram representing the probable relations of the prestomal ganglia and procephalic lobes at an early stage. $c_{1} c_{2}$, cavities formed by the delamination of the epiblast; $h$, hemisphere; $m$, mesoblast; $n_{1}$, neural crest of the hemisphere; $n_{2}$, neural crest of the ventral ganglion; $p$, pericardial space; $p h$, primitive band; $p l$, procephalic lohe; $s$, stomodxum.

he represents in the later stages, so that $I$ regard it as by no means improbable that a large ventricular cavity exists at an earlier stage of development, and that the roof or dermal layer of this cavity becomes differentiated into the mantle which covers so laree a part of the hemisphere in its carlier stages, whilst the central ganglia and the white substance originate in that portion of the primitive brain which forms the innermost part of the wall of the vesicle, and which is from the first continuous with the segmental ganglia of the ventral cord. 
I have already given a diagrammatic figure which will serve to represent the above views, and the diagrams (Figs. 65 and 66) will serve still further to elucidate them. It must be remembered, however, that these are merely hypothetical diagrams, and are not figures of actual sections.

It is worthy of note that the mantle, or roof of the vesicle, is in intimate relation with the pyramidal ganglion, the nerves to the ocelli, the optic ganglion, and the antennal ganglion, so that it probably produces all those parts of the brain which cannot be regarded as central ganglia.

Two portions of the mantle layer have attracted the attention of previous observers-the deep-seated involution in the posterior internal tract of the hemisphere, from which the numerous cells of the pyramidal ganglion and the small cells on the posterior surface of the optic ganglion apparently originate, the bourrelet intraganglionnaire of Viallanes; and the part which I have termed the retinal disc, which is the bourrelet perilaminaire of Viallanes, the invagination of which is figured by both Viallanes and Wheeler. When I stated (p. 326) that it had not been previously observed, I had not seen their recent memoirs.

Viallanes says of the former: "We have described under this term (bourrelet ectodermique intraganglionnaire) a transitory structure, which has the most intimate relations with the nervous system, whilst it takes no part in the constitution of the latter.

'In the course of development, at a point in the procephalic lobe near the optic disc, the ectoderm is invaginated like the finger of a glove; this invagination, which is the bourrelit intraganglionnaive, insinuates itself between the internal medullary mass and the external medullary mass. Then this invagination becomes strangulated at its point of origin, and separates from the ectoderm; later it enters into degeneration and disappears.

' This formation perhaps represents a trachea, or a transitory cephalic gland.'

I take exception to all these conclusions; the identity and 
continuity of the structure in question with the mantle layer renders them in the highest degree improbable. In my preparations the continuity of this layer with the ganglion cells of the prramidal ganglion on the one hand, and with those of the antennal ganglia on the other, is indubitable, and its continuity with my retinal disc is no less certain.

Of the latter Viallanes says, "The bourrelet perilaminaire should be considered as the remains of the layer of gangliosrenetic cells.' The evidence on which he regards one of these structures as different from the other is not very apparent, but I suppose he takes such opposite views of their nature because he thinks that the bourrelet intraganglionnaire is derived from

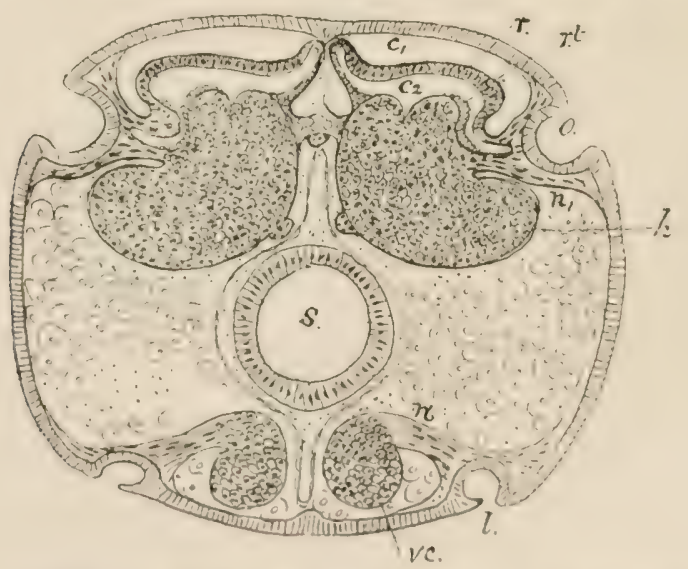

Fu. 66.-A di.gram similar (o) I is. 65, at a later period. is, sploce letween the brain and head capsule ; $c_{2}$, cavity of the hemisphere; $h$, hemisphere ; l, leg disc; $n_{1}$, neural crest of hemisphere; $n$, neural crest of ventral ganglion; 0 , optic disc ; $r$, roof of the cerebral vesicle; $r t$, probable origin of the retinal epithelium or retinal disc; $s$, stomodxum; $v c$, ganglion of the ventral chain.

an invagination of the dermato-genetic layer. In this I think he has fallen into an error, which is due to his regarding the whole of the external layer of cells as dermato-genetic, and he has probably mistaken the involution of a purely nervous layer for an open integumental invagination.

Sections of the Neuroblast of the larva show that its structure 
is exceedingly complex. Not only is the central stroma divided into distinct lobes even in the recently-hatched larva, but the two great commissures, one below and the other above the œsophagus, are already developed. In the adult larva the optic ganglion is not only recognisable, but its central stroma already exhibits the radial and concentric structures so characteristic of the same part in the imago, and the cells of the pyramidal ganglion and of the olfactory ganglia are readily distinguished. In Plate III. two sections of the brain of the larva are represented at a somewhat more advanced stage of development than those which are now published. In Fig. I. the section is entirely behind the optic ganglion, and exhibits the trabeculæ and corpora fungiformia ; and in Fig. II. it is in front of the optic ganglion, and shows the two œesophageal commissures. In several of the sections in the series from which these two figures are taken, the optic ganglia are distinctly recognisable; but owing to these sections having been broken, they were not figured, and the appearances which they presented puzzled me much at the time, as I was then unacquainted with the manner in which the optic ganglia are embedded in the substance of the hemispheres.

Changes of the Neuroblast in the Pronymph. - The first change which attracts our attention in the neuroblast in the early stages of pupation is the rapid increase in the size of the hemispheres. This is accompanied by a similar increase in the rudiments of the infra-œesophageal ganglia, which become segmented from the anterior part of the ventral cone; and by a rapid increase in the size of the osophageal connectives.

The hemispheres at the same time become ovoid, with their long axes transverse to the body. This elongation is due to the rapid increase in the size of the optir. ganglia, which project more and more from the surface of the hemispheres.

Weismann [2], describing the changes which occur on the third day of the pupa, states that: 'Each hemisphere, which during the first two days underwent an extraordinary enlargement, exhibiis a moderately-deep circular groove on its surface, separating a median from a lateral ganglion. These both 
remain spheroidal, but the lateral sanglion, which becomes the optic ranglion, is by far the larere', and he adds: 'On the fifth day of the pupa the optic gangrion is an almost splerical organ, nearly twice the size of the inner or supraœsophageal ganglion.'

This description is perfectly accurate as far as surface-views are concerned, but Weismann was unaware of the previous existence of the optic ganglion imbedded within the hemisphere. The previous condition of this organ was first described and figured by Viallanes [27, Pl. XVI. Fig. 8], so that It is evident that the optic gangrion is not formed as Weismann supposed, by the segmentation of a cellular mass into two ganglia, but that it is developed from a pre-existing structure, which is evaginated from the interior of the hemisphere. The first stage in the evolution of the optic ganglia is characterised by the rapid growth of the retinal disc in the interior of the hemisphere, beneath the optic stalk of the eye-disc; and this structure soon becomes a cup-like projection. As development progresses, and the optic ganglion enlarges, the cup becomes convex instead of concave on its outer surface, and spreads over the outer surface of the now rapidly-increasing spheroidal ganglion.

D) uring the evolution of the optic ganglia the crura and the central fibrillated stroma rapidly increase in size, and the trabeculie are secn penetrating the group of cells which become the corpora funcriformia; whilst the large group of cells, from which the olfactory loles are developed, have become very conspicuous on the inner and antero-inferior surface of the hemisphere. As has been already stated, all these structures are present in the larva, so that the view that the whole neurobast, as it exists in the larva, represents the functionally active nervous system at that stage, and that it undergoes a complete change, falls to the ground; and, as has been already stated, I think the neuroblast must be regarded as an imaginal rudiment, just as the imaginal discs are, from which the several parts of the brain of the imago are developed.

The Peripheral Nervas. - This view is still further supported 
by the condition of the peripheral nerves. All the imaginal discs possess nervous pedicles which, during the life of the larva, must be regarded as without functional activity as nerves-it is from these that the peripheral nervous system of the imago is undoubtedly developed, a conclusion already advocated by Van Rees [147]. With these entirely rudimentary nerve-cords, functionally active nerve-fibres, which supply the muscles and integuments of the larva, are intimately connected; and these, like the structures they supply, undergo complete histolysis during pupation. In this there is a complete harmony with the view I advocate, that the functionallyactive elements of the larval nerve-centres are intermixed with embryonic elements in the nerve-centres, and that the former only undergo histolytic changes. It is true that Van Rees believed that the great thoracic muscles of the imago are developed directly from certain larval muscles in the second and third thoracic segments, and he held that the second and third thoracic muscular nerves are deriver directly from active larval nerves; but, as already stated, I cannot agree with this exceptional origin of the parts in question. Otherwise, my conclusions are in complete consonance with those of Van Rees as to the manner in which the peripheral nerves of the imago are developed.

The Post-oral Nervous Chain.-In the resting stage of the larva, and in the pronymph stage, the ventral cone of the neuroblast becomes distinctly segmented, and the infra-œsophageal ganglia are closely related with the thoraco-abdominal centres. It is only during the evolution of the head that the separation of the cephalic and thoracic centres takes place, by the development of the cephalo-thoracic nerve cord, and this consists at first entirely of fusiform and elongated cells. Thus in the early pupa state the hemispheres are separated from the infraœsophageal centres by the elongated crura, just as they are in the less specialised Insecta. The permanent ganglia of the imago are developed from groups of embryonic cells, totally distinct from the stellate and branching cells which form the active elements of the nervous system of the larva. In this 
stage of development there is a close resemblince between the nervous system of the Muscidae and that of the Arachnida, in which the hemispheres are more distinctly separated from the infra-cesophageal centres than the latter are from the thoracoabdominal nervous mass.

The Stomo-gastric Nerves and Ganglia. - I have been quite unable to follow the changes in the stomo-gastric nervous system, but have found five small ganglia closely related to the hemispheres in the resting larva (Pl. XXXIV., Fig. 2, gr). These are probably the median and lateral ganglia of the stomo-gastric system, and are possibly, I think, developed from the hemispheres at a very early stage of their evolution. Viallanes, however, considers that they are developed, in Mantis, independently of the central nervous system, from cells which lie in close relation to the stomodrum, and I have no observations which throw any light upon the subject.

Morphological Conclusions. - The morphological conclusions at which I have arrived by a study of the brain of the Blow-fly in its various stages are :

I. That there is a distinctly vesicular stage in the development of the preoral centres.

2. That the floor of the vesicle forms the central ganglia, which I have distinguished as the pro-, meso- and meta-cerebron; but I have been unable to distinguish the exact manner in which each of these brain segments is derived from the three masses of white substance seen in early stages of development.

3. That the ganglia of the special senses of smell and sight are developed from the roof of the vesicles, which also apparently give rise to the small cells of the corpora fungiformia.

4. That the retina is developed from an involution of the roof of the vesicle of the cerebron, in relation with the great optic disc and the optic stalk of Weismann.

5. That the nerves to the ocelli, the pyramidal gancrlion, and al their nervous elements, originate from the roof of the vesicle.

6. That the procerebral lobes probably arise from the anterior part of the roof of the vesicle. 
7. That the central ganglia and crura are developed in continuity with the ventral chain of ganglia.

8. That the small cells of the whole cortex of the cerebron are derived from ganglio-genetic cells forming the roof of the vesicle.

9. That the large cells which surround the white matter in the newly-hatched larva are similar to those from which the post-oral centres are developed, and that they are probably some of them converted into ganglion cells, whilst others are concerned in the development of the central stroma; and that the nerve-cells so developed are possibly more intimately connected with the central ganglia, and are concerned in other functions than those of conscious sensation. In other words, it appears to me that the parts derived from the roof of the vesicle are concerned in consciousness and volition, whilst those derived from the primitive ganglia are reflex and automatic, or, to use the language of Meinert, form distinct projection systems.

I0. That there is a distinct analogy between the Vertebrate and Arthropod brain, as Gaskell and others have suggested, but that our knowledge of the Arthropod brain is far too incomplete to allow of any exact comparison of the parts of the brain in these two great divisions of the animal kingdom. 


\section{CHAPTER XIII.}

THE SENSES AND SENSORY ORGANS.

\section{SENSATION IN INSECTS.}

THat insects possess the senses of sight, hearing, smell, taste, and touch is indubitable, and one or more of these senses are usually highly developed in each species, whilst the others play a subordinate part.

There is an argument which is frequently advanced arainst this assertion. It is said that as insects appear to be indifferent to pain, they can hardly possess acute sensibility of any lind. That a wasp will frequently continue to feed on its favourite sweets after the abdomen has been cut away, or that a moth pinned to a cork appears to suffer little inconvenience, and a hundred other facts indicating the absence of pain, may be adduced; and I think there is sufficient evidence that the Arthropoda do not suffer pain, which is quite as conclusive as

\section{Bibliography :}

192. MïILEK, JOHANNEs, "The Physiology of the Senses, Voice, and Muscular Motion, with the Mental Faculties.' 'Translated from the German by W. Baly. Lond., 8vo., 1848 .

193. 'Aasch, A., "Von den Sinnesorganen der Insecten im Allgemeinen. von Gehör und Geruchsorganen im Besondern.' Archiv. f. Naturgeschichte, Jahrgang xxxix., 1873.

('This paper was originally written in $1 S_{4} 6$, but remained in the author's desk until 1873.$)$

194. Fok1:, A., "liestrag zur Kemntniss der Sinnesemptindungen der Insecten.' Mitt. d. Münchener Entom. Vereins, Bd. ii., IS7\$.

195. L.tiBock, Sir J., 'Ants, Bees, and Wasps: a Record of Observations on the Habits of Social Hymenoptera.' 'The Internat. Science Series, Svo., Lond., Paris, and Berlin, 1882. 
that which leads to the conclusion that they possess keen powers of vision, smell, and touch.

Pain.-Evidence of a satisfactory kind indicates that pain is by no means a phenomenon commonly exhibited by the lower forms of life in any high degree; indeed, even in the human race susceptibility to pain is far more developed in the higher than in the lower races of mankind; and the comparative indifference to pain exhibited by some races of savages is notorious.

Dominant Sensations.-Just as in man the sense of sight, in dogs that of smell, and in the timid herbivora the sense of hearing are the most important, so there are insects in which each of these senses is dominant over the others. I have already drawn attention to the remarks of Forel on this subject (p. II). In the Dragontlies, Libcllula, and the Diurnal Lepidoptera, the sense of sight is undoubtedly paramount; the rapid hawking flight of the former is well known, and indicates the keenest vision, and Belt (naturalist in Nicaragua, p. Io8) gives an instance of the manner in which some butterflies avord the webs of spiders indicative of highly developed visual powers. He says :

'A large spider (Nephila) builds strong yellow silken webs, joined one to the other, so as to make a complete curtain of web, in which were entangled many large butterflies, generally forest species, caught flying across the clearing. I was at first surprised to find that the kinds that frequent open places were not caught, although they abounded on low white-flowering shrubs close to the webs; but on getting behind them, and trying to frighten them within the silken curtain, their instinct taught them to avoid it, for, although startled, they threaded their way through open spaces between the webs with the greatest ease.'

Hearing a Warning Sense.-In mammals, hearing is frequently a warning sense, more especially amongst those species which are helpless against their enemies. According to Graber, the Cockroach (Blatta Germanica) is exceedingly sensitive to sounds, especially in the dark, or when its eyes have been blinded. It is familiar to all that children and timid persons are easily 
alarmed by unwonted sounds, especially in the dark, and the bchaviour of Graber's blinded cockroaches was indicative of fear whenever he produced sounds in their vicinity. Graber has also shown that water insects, both Coleoptera and Hemiptera, are readily alarmed by sounds.

Lubbock has stated that Bees, Wasps, and Ants do not apparently take any notice of sounds, but he admits that there is evidence of their possessing the faculty of hearing. I am certain that the large Myrmecias of Australia are excited to take up a threatening attitude when a footfall is heard in the forest, and it appears probable that, in a country like England, where noises are continually occurring, that all but the most timid insects have probably long since learned to disregard them. In the virgin forest the stillness is often oppressive, even to man, and the slightest rustle amongst the foliage is very often more startling than the unexpected firing of a pistol is in a civilized country.

It is only natural to conclude that insects which produce sounds also hear them, and that the grasshoppers and crichets take pleasure in their chirruping song; but it is possible also that the same sounds are pleasant to other insects. My friend R. T. Lewis writes to me that a large lace-winged fly in Natal, Notochry'sa gigantea, is said to assemble in numbers round the head of a singing Cicada; it might be called the 'audience insect,' and he tells me that one which he sent me for examination was caught with nine others flying round the head of one of these insect songsters.

The Olfactory Sense.-The fact that scents are keenly perceived by insects of certain species has been long known; the manner in which carrion-feeding insects discover a dead animal, and the discovery of a female moth enclosed in a chip) box by numerous males of the same species, are rell-known examples of a keen power of scent. Brielly, as Perris says [266], - that this sense is highly developed in the greater number of Arthropods is a fact long agro established; for which there is no longer need of argument or proof.'

With regird to the Incalisation of the olfactory sense, how- 
ever, the case is very different. Kraepelin [273] says: "The seat of smell has for a long time excited the interest of authors. An extensive literature has accumulated, and there is no subject, perhaps, in zoological knowledge which has been treated with more acumen, and in which so extensive a literature has produced so small a result. Even to-day, in spite of the many investigations of the last decade, we are far from a complete solution of the subject.'

I think, however, Kraepelin's masterly work, and the further researches which have followed it, more especially in relation to the structure of the antennal ganglia, justify the view that the antennæ are the main agents of the olfactory sense.

Tactile Sense.-The antennæ are usually regarded as tactile organs, but this sense is also undoubtedly common to the larger setæ, and perhaps to the integument generally. OstenSacken says of the Diptera: I assume, therefore, that the macrochatæ (large bristles) are organs of orientatiun, connected with the nervous system, being in their useful action not unlike the whiskers of a cat.'

I have already observed (p. 774 ) that the phenomena of reflex action, in a decapitated fly, show conclusively that the general integuments, horny as they are, possess a keen sensibility, and the persistent manner in which insects clean themselves, or in which Ants and other social insects lick each other, indicate that the integuments are sensitive.

Sensations Peculiar to Insects.--It has been suggested by many that insects possess senses of which we are totally ignorant; but it is by no means easy to understand what is meant by the suggestion. Johannes Müller wrote: 'The essential attribute of a new sense is, not the perception of external objects or influences which do not act on the senses of man, but that external causes should excite a new and peculiar kind of sensation different from all the sensations of our five senses. The possibility of the possession of such a faculty, by some animals, cannot be denied. No facts, however, are known which establish the existence of such a new mode of sensation' [192]. 
Lubbock [195] has shown, perhaps, that the range of luminous vihrations visible to insects differs somewhat from that of those discerned ly man, and suggests the same with regard to sound viluations. It is very possible that such is the case, but this is no evidence that they possess any kind of sensation entirely different from our own. As the proof of any such sensation is impossible, it is useless to discuss it.

Sporadic Sensory 0rgans. - It is now well known that sensory orrans of great complexity occur in the most unexpected positions in many Invertebrates; not only eyes, but auditory organs, even in closely-allied forms, are found in very various parts of the body. For example, amongst the saltatorial Orthoptera, the Acridida have complex organs of hearing on the first abdominal segment, whilst the Grillida have similar organs on the anterior tibia. In the decapod Crustacea ears have been found on the antennules, whilst Mysis has auditory organs in the tail. Graber has found chordotonal organs in various parts of the thorax and abiomen and in their appendages in both larval and perfect insects. In the Diptera, the halteres present characters which have led many to ascribe an auditory function to them, and they are probably correct in this view; lastly, in many Diptera there is a complex organ in the meso-thorax closely connected in its nerve-supply with that of the halteres, which I recrard as probably auditory.

\section{Bibliography :}

196. SERRE;, MARCEr, 1)E, 'Mémoire sur les leux composée et sur les Yeux lisses des Insectes.' Svo., Montpellier, IS13. Also published in Berlin in German, in 1826.

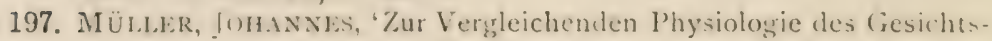
sinnes des Menschen und der Thiere, nebst einem Versuch, ïber die Bewegungen der Augen und ïber den menschlichen Blick.' Svo., Leipzig, 1826.

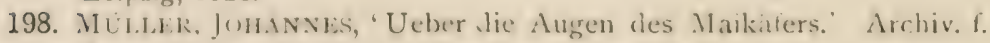
Anat. u. l'hysiol. (Meckel's), 1829.

199. I) toil:s, A., "Observations sur la Structure de l'(likil composé des Insectes.' Ann. des Sic. Nat., tom. $\mathrm{xx} ., 1830$.

200. WAsikR, R., 'Einige Bemerkungen ibber den Bau der Zusammengesetzen Augen der Insecten.' Archiv. f. Naturgecchichte (Wienmann's), Jahrg. I, Bit. i., 1835 . 


\section{ORGANS OF VISION.}

'The term ' eye' is applied to every sensory organ adapted for the perception of light; it is strictly a physiological term, and not a morphological one. In many cases there can be no morphological identity between the different forms of eye. Sometimes

201. Gotтsche, C. M., 'Beitrag zur Anatomie und Physiologie des Auges der Krebse und Fliegen.' Archiv. f. Anat. Physiol. u. wiss. Med., 1852.

202. Claus, C., 'Ueber das Auge der Sapphirinen und Pontellen.' Archiv. f. Anat. Physiol. und wiss. Med., 1859.

203. Claparkide, E., 'Zur Morphologie der zusammengesetzen Augen bei den Arthropoden.' Zeitsch. f. w. Zool., Bd. x.; 1860.

204. Ruete, C. G. T., 'Ueber die Einheit des Princeps im Bau der Augen bei den verschiedenen Thierclassen und besonders über das Sehen der Insecten mit polyedrischen Augen.' 4to., Leipzig, I86I.

205. Dor, H., 'De la Vision chez les Arthropodes.' Bibliothèque Universelle, Paris, I86I.

206. Claus, C., 'Die freilebenden Copepoden mit besonderer Berücksichtigung der Fauna Deutschlands, der Nordsee und des Mittelmeeres.' 4to., Leipzig, I863.

207. Levdig, F., 'Das Auge der Gliederthiere.' 8vo., Tübingen, I864.

208. Leydig, F., 'Tafeln zur vergleichenden Anatomie.' Fol., Tübingen, I 864 .

209. Hensen, V., 'Ueber das Auge einiger Cephalopoden.' Zeitsch. f. w. Zool., Bd. xv., I 865 .

210. Schultze, M., 'Ueber die Endorgane der Sehnerven im Auge der Gliederthiere.' Archiv. f. Mikr. Anat., Bd. iii., I867

211. Helmholtz, H., 'Handbuch der Physiologischen Optik.' 8vo., Leipzig, 1867.

212. SCHUltze, M., 'Untersuchungen über die zusammengesetzen Augen der Krebse und Insecten.' Fol. mit Tafin. IO, Bonn, I868.

213. NEwTon, E. T., 'The Structure of the Eye of the Lobster.' Quart. Journ. Micr. Sc., vol. xiii., I 873 .

214. Exner, S., 'Ueber das Sehen von Bewegungen und die Theorie des zusammengesetzen Auges.' Sitzungsbericht., Acad. Wien, Bd. xxi., 1876.

215. KÜHNE, W., 'Eine Beobachtung über das Leuchten der Insectenaugen.' Untersuch. des Physiol. Inst. der Univ. Heidelberg, Bd. i., I 877.

216. GRENACHER, H., 'Untersuchungen über das Arthropodenauge.' Klin. Monatsblatt f. Augenheilkunde, Beilageheft, Jahrgang x., I 877.

217. Lowne, B. T., An Abstract of Grenacher's Paper, No. 216. The Entomologist. 1877. 
eyes, and well-developed eyes, are found scattered over the integument, just as glands are; for example, in the remark-

218. Chatix, J., 'Recherches pour servir à l'histoire du Bâtonnet optique chez les Crustacés et les Vers.' Ann. Sc. Nat., Zool., sér. vi., tom. v. et vii., 1877-1 878 .

Chicfly interesting for the very complete biblingraphy it contains of the earlier notices on the eyes of Arthropods. Chatin's methods were so primitive that his work is otherwise of little value.

219. I.WNE, B. T., 'On the Modifications of the Simple and Compound Eyes of Insects.' Phil. Trans. vol. 169, Part 2. Lond., I 878. Abstract in Proc. Roy. Soc., March, 1878.

220. Schum', O., 'Die Form der Krystallkegel im Arthropodenauge. Zeitsch. f. w. Zool., Bd. xxx., Suppt., April, I 878.

221. Claus, C., 'Der Organismus der Phronimiden.' Arbeit. a. d. Zool., Inst. der Univ. Wien, Bd. ii., I879.

222. GRENACHER, H., 'Untersuchungen iiber das Sehorgan der Arthropoden.' 4to., pp. 185, pl. xi., Gottingen, 1879.

223. GR.MER, V., 'Ueber das unicorneale Tracheaten - und speciell das Arachnoideen- und Myriapoden-Auge.' Archiv. f. Mikr. Anat., Bd. xvii., I 879 .

224. (ik.1HER, V., 'Morphologische Untersuchungen iiber die Augen der freilebenden marinen Borstenwürmer.' Archiv. f. Mikr. Anat., Bd. xvii., 1879 .

225. (GRENACmER, H., "Ueber die Augen einiger Myriapoden. Zugleich eine Entgegnung an Herrn Prof. Dr. V. Graber in Czernowitz.' Archiv. f. Mikr. Anat., Bd. xviii, ISSo.

226. Noттиағт, J., "Ueber die Gesichtswahrnehmungen vermittelst des Facettenauges.' Abh. Senckenberg. Naturforsch. Gessel., Bd. xii., I880.

227. Mereschkowsky, C., 'Tetra-Erythine.' Comptes Rendus, xciii., p. $1029,188 \mathrm{I}$.

228. LXNER, S., 'Die Fratre von der Functionsweise der Facettenaugen.' Biol. Centralblatt, Bd. i., I88I.

229. I.ANKESTER ANI BOUKNE, "( )n the IIinute Structure of the Lateral and the Central Eyes of Scorpio and of Limulus.' Ouart. Journ. of Micros. Sc., vol. xxiii., r 883 .

230. Lowne, B. T., 'On the Structure and Functions of the Eyes of the Arthropoda.' Proc. Roy. Soc., vol. xxxv, 1883.

231. Cinccio, (;. V., 'Figure I)ichiarative della minuta fabbrica degrlia Occhi de' Ditteri.' Mem. d. Accad. d. Sc. di Bologna, ser. iv., tom. vi.. 1884 .

Figures of the eyes of Ilippoboscidit, (Istridat, Syrphiche, Muscidit, Empidie, Leptidae, Asilidie, Bombylida, 'Tabanidae, Chironomidat, Tipuladic, and Puliodat. (No kind of nerve terminal is represented except in the Ocelli. All his sections were evidently thick, and the structure of the true retina is not clearly figured.) 
able sea-slugs, Onchidium, discovered by Semper, their number and position being most variable, even in individuals of the

232. CARRIÈRE, J., 'On the Eyes of some Invertebrata.' Quart. Journ. of Micros. Sc., vol, xxiv., I 884 .

233. Lowne, B. T., 'On the Compound Vision and the Morphology of the Eye in Insects.' Trans. Linn. Soc, 2nd ser. Zool, vol. ii., 1884 .

234. Schimkewitsch, M. W., 'Étude sur l'Anatomie de l'Epeire.' Ann. Sc. Nat., Zool., sér. vi., tom. xvii., I 884.

235. Exner, S., 'Ein Mikro-Refractometer.' Archiv. f. Micr. Anat., Bd, xxv., I 885 .

236. CARRIÉRE, J., 'Die Sehorgane der Thiere vergleichend-anatomisch dargestellt.' Munchen u. Leipzig, I885.

237. Hickson, S. J., 'The Eye and Optic Tract of Insects.' Quart. Journ. Micros. Sc., vol. xxv., I885.

238. ExNer, S., 'Ueber Cylinder welche optische Bilder entwerfen.' Archiv. Phy. Pflüger, Bd. xxxviii., I 886.

239 Patten, W., 'Eyes of Molluscs and Arthropods.' Mittheilung. a.d. Znol. Stat. zu Neapel, Bd. vi., I886; also in Journ. of Morphology, vol. i., Boston, I887.

(Gives an extensive bibliography from I795 to I885, with eighty-six references to the literature of the eyes of Molluscs, Arthropods, etc.)

240. Locy, W. A., 'Observations on the Development of Agelena nævia.' Bull. Mus. of Comp. Zool., Harvard Coll., vol. xii., I 886.

241. MARK, E. L., 'Simple Eyes of Arthropods.' Bull. Mus. Comp. Zool., Harvard Coll., vol, xiii., I $88 \%$.

242. Kölliker, A., 'Ueber das Zirbel-oder Scheitelauge.' Sitzungbericht d. Physı. Med. Gesellschatt z. Würzburg, p. 5 I, I887.

243. Plateau, F., 'Recherches expérimentales sur la Vision chez les Arthropodes.' i., ii. and iii. Bull. d. l'Acad. Roy. de Belgique, 3rd sér., tomes xiv. and xv., I887-88; and iv. Mém. couronnés et autres, Acad. Roy. de Belgique, tom. xliii., I 888.

244. Exner, S., 'Durch Licht bedingte Verschiebungen des Pigmentes in Insectenauge und deren physiologische Bedeutung.' Sitzungb. d. K. Acad. d. Wissenschaft in Wien, Math. Naturw. Classe, Bd. xcviii., Abth. iii., 1889 .

245. Exner, S., 'Das Netzhautbild des Insectenauges.' Sitzungb. d. K. Acad. d. W. in Wien, Math. Naturw. Classe, Bd. xcviii., Abth. iii., I889. Repertorium der Physik. Bd. xxv., pp. 540-56I, 62 I-64I, I880.

246. Lowne, B. T., 'On the Structure of the Retina of the Blow-fly.' Journ. Linn. Soc. Zool., vol. xx., I889.

247. SzcZawinska, W., 'Contribution à l'Étude des yeux de quelques Crustacés et Recherches expérimentales sur les mouvements du pigment granuleux et des cellules pigmentaires sous l'influence de la lumière et de l'obscurité dans les yeux des Crustacés et des Arachnides.' Archiv. de Biologie, Gand, tom. x., 1890. 
same species. Again, in the Lamellibranchs eyes both simple and compound, and exhibiting very variable types of structure, are scattered along the edges of the mantle, and some of these present the most complex structure, even approximating the vertebrate eye in complexity, as in Pecten. I propose to term such eyes sporadic.

In the Arthropoda and Vertebrata the eyes are cephalic, but several types exist. The paired cephalic eves of Vertebrates and Mollusca, and the paired compound eyes of Arthropods, which differ greatly in structure, resemble each other in their relation to the central nervous system; but they are similar only in position; whether they are derived from a similarly placed pair of eyes in some common ancestral form may be a matter of speculation; but no speculation can derive them from sporadic eyes, the position of which is not only variable, but is rarely cephalic.

Yet a third type of eye is known, the remarkable median unpaired cephalic eyes of Vertebrates, the so-called pineal eyes, which in some respects resemble the ocelli of many Insecta. Whether the paired cephalic eyes are derived from unpaired median cephalic eyes is again a matter of speculation. The eyes of Arachnids tend to the belief that they probably have so arisen, and there are facts connected with the relation between the ocelli and compound eyes of Insects which point to the same conclusion. It will be useful, however, to designate such eyes median cephalic eyes, since it is only by speculation that the paired cephalic eyes can be compared with the median cephalic eyes, which in many points are very different.

248. PANkk.1TH, ()., 'I)as Auge der Raupen und l'hrgganidenlarven.' Zeitsch. f. w. Zool. Bd. xlix., I8go.

249. Witsis. S., 'On the Morphology' of the Compound Fye of Arthropods.' Studies from Biol. Lab. Johns Hopkins Univer., vol. iv., p. 287, 1890.

250. 1'AKKER, G. H., "The Histology and Development of the lige in the Lobster? Bull. Mus. Comp. Zool. Harvard Coll., vol. xx., I 890.

251. I'AkKIK, G. HI., "The Compound Eyes in Crustaceans.' Bull. Mus. Comp. \%ool. Harvard Coll., vol. xxi., 1891. (This paper contains a valuable and very extensive bibliography).

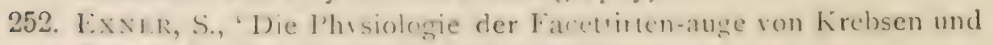
Insecten.' 8vo., Leipzig und Wien, 1891. 
It cannot be asserted ever that all paired cephalic eyes are homologous, although it is possible that they originate from a common but very simple ancestral type, since such a type is unknown. The simplest eye spots, amongst the Annelida, exhibit a very different structure, and are often more probably the ancestral form of median cephalic eyes, than of the more highly developed paired cephalic eyes; the simple eye-like structures of the Ascidian, and of Amphioxus, and some Crustacea are more like the median than the paired cephalic eyes, which in the two former cases at least they undoubtedly represent.

In Insects all three forms of eye are, I believe, represented, for if the remarkable eye-like organs of the Blow-fly larva, which are situated on the maxillæ, are eyes at all, they are undoubtedly sporadic, and it is said that in the larva of Miastor there is a sporadic eye on the fourth segment of the body. The median ocelli, or simple eyes, of many imagines are median cephalic eyes, and the great compound eyes are paired cephalic eyes.

The Researches of Patten on the eyes of Arca, amongst the Lamellibranchiata, do much to break down the distinction between simple and compound eyes; and even in Arthropods it does not appear unlikely that both have been derived from a common ancestral form.

Kölliker [242] has classified the visual organs of animals under three groups:

(I) True brain eyes (echte Hirnaugen), which he defines as ' eyes developed entirely from the medullary plate'-the eyes of the Ascidian larva and the pineal eyes of Vertebrates.

(2) Epiblastic eyes, which consist entirely of ectodermal elements, derived from the superficial epiblast-the eyes of Invertebrates generally.

(3) Eyes developed in part from the medullary plate, and in part from the superficial ectoderm-the paired eyes of Vertebrates.

The Pineal Eye.-With regard to Kölliker's first class, ' echte Hirnaugen.' It is indubitable that the nervous elements of the 
pincal ere are derived from the primitive brain vesicle, and appearances are certainly in favour of the view that the lens when present is developed from the same vesicle; yet I think it hy no means certain that such is the case. The difficulty of finding a primitive involution of the surface ectodern in the cmbryo wonld necessarily be great, even if at one time or other it exists, and I regard the mere apparent continuity of the retinal and lens cells as of little value as evidence of a similar origin for both. The existence of a modified scale and of a parietal foramen points to a surface modification, and I doubt if the last word has been said on this point. It is, moreover, one of no import in relation to my contention, that in Arthropods the retina is developed from the brain, for in these it is certain that the refractive media are dermal structures.

Epiblastic Eyes.-Kölliker's view, that the eyes of Invertebrates senerally arise entirely from the ectolerm, is very generally received, although both Claparede and Weismann distinctly state that in the compound eye of Arthropods the nervous elements grow from the supra-cesophagreal ganglia, a statement which is fully confirmed by my researches. Moreover, Lïlliker himself is evidently in some doubt on the subject, as he has classed the compound eyes of Astacus as eyes developed partly from the medullary plate, and partly from the central nervous system, like the paired eyes of Vertebrates. In this he has apparently followed Bobretzky [Parker, 250], who, however, incorrectly derives the whole eje from the cerebral outgrowth. The evidence on which the received view rests, that the compound eyes of Arthropods are developed entirely from the superficial epiblast, breaks down, as will be seen in the sequel, as soon as the true developmental history of the parts is more completely known.

Origin of the Retinal End Organs.-It is usually held that the special retinal end organs are modified epiblastic cells, and this mat be their origin; but whenever the development of retinal end organs has ben actually traced, except perhaps in the imperfect visual organs of some Iydrozoa, they have been traced to the central or nervous epiblast, and not to the surface 
epiblast. It is true that certain structures usually held to be nervous in the compound cye are derived from the surface epiblast, but my contention is that the so-called retinal elements of the compound eye in Arthropods are not retinal, but refractive organs.

In the eye-like organs of Hydrozoa, in which no special tract becomes primarily differentiated as a neural epiblast, it is possible that certain scattered epiblast cells remain as end organs; but it is otherwise in all those animals in which a distinct nervous epiblast is differentiated, at an early period of development, as a neural epiblast, from which the entire nervous system arises.

In the simple eyes of Arthropods, Grenacher, it is true, derives the retinal organs from the epiblast, but he has not said a word on their development, and his view rests entirely on theoretical grounds; and I shall hereafter show that his conclusion is erroneous. Lankester and Bourne, as well as Mark, have followed Grenacher, and have arrived at similar conclusions, but again without the slightest developmental evidence.

The Eyes of Pecten.-These, as has been already stated, are sporadic eyes; they form a double row on the edge of the mantle, and are supplied by the circumpallial nerve. Patten has investigated their development, and holding as he does the view that the retina is derived from the superficial epiblast, endeavours to show that it is developed in situ from the superficial layer of epithelium; but he gives drawings of these eyes in an early state which appear to be of great accuracy, and which indicate that the retina is developed from neuroblastic cells which underlie the superficial epiblast around the extremity of a branch of the circumpallial nerve [239, Pl. XXVIII., Figs. 3, 4, II, and I2]. Indeed, as the nerve-filaments enter the retinal end organs from their cutaneous surface, it is difficult to understand how they can possibly be derived from the cutaneous epiblast.

The Eyes of Nautilus.-The structure of the paired cephalic eyes of Nautilus is usually relied on as evidence of the origin 
of retinal end orams from the superficial epiblast. Lankester, in his monograph on the Mollusca [Encyclop. Britt., I $\&_{91}$ ], says. "The eye of Niutilus is amongst the most interesting structures of that remarkable animal,' and adds: 'It is simply a slightly projecting hemispherical box like a kettledrum, half an inch in diancter, its surface looking like that of the surrounding integument, whilst in the middle of the drum-membrane is a minute hole. Owen naturally thought that some membrane had cuvered this hole in life, and had been ruptured in the specimens studied by him. It, however, appears from the studies of Hensen that the hole is a normal aperture leading into the globe of the eye, which is accordingly filled with sea-water during life. There is no dioptric apparatus in Nautilus, and in place of refracting lens and cornea we have actually here an arrangement for forming an image on the principle of a "pinhole camera." The cavity is solely' lined by a nakid retina, which is bathed by sea-ieder on one surface, and reccices the fibres of the optic neree on the other' (the italics are mine). To my mind the above is an utterly improbable deduction. There is no evidence that the rutina is naked and bathed with sea-water, later than Hensen's paper [209]. It may be that a very thin epidermal layer covers it, formed like the primary optic depression in the vertelorate embryo by an involution of the epidermal epiblast, and there is ro evidence that the retina is not developed in these animals from an outgrowth from the central nervous system, as it is in Vertebrates.

Analogy with Olfactory and Auditory End Organs. - It has been concluded that the nerve-terminals of the olfactory and auditory nerves are derived from the surface epiblast, and it has been argued that this is the usual manner in which nerve-crel organs originate. The researches of His on the orien of the olfactory cells appear to indicate that they originate independently of the neuroblast from which the olfactory nerve is developed. If this is so it would certainly be an a priori argument in favour of a similar origin for other sensory nerve-terminals. It is difficult, however, to understand the want of continuity in the nervous tract which the 
observations of His presuppose, and it appears to me more probable that the neuroblastic cells penetrate the epithelial layer of the olfactory area than that the cells of this layer become converted into olfactory cells. The investigation of the origin of the olfactory cells presents great difficulties, and cannot be said to have been settled, and the origin of the auditory cells is still more obscure. In the latter case at least it cannot be said that they do not originate from the neuroblast of the auditory nerve, although on theoretical grounds it may be held that they originate from the surface epithelium.

The great difficulty introduced by such a theory, however, is the original discontinuity of the nervous tract, and the difficulty in understanding how the nerve-fibres originating from the epithelial elements find their way to the central nerve-terminals. a difficulty which vanishes when the direct continuity of the neuroblastic tissue is assumed to exist from its first origin.

The origin of the retina from the brain-vesicle in Vertebrates is one of the best-established facts in their embryology, and can be demonstrated without difficulty; it is therefore, I conceive, unwise to rely on the investigations of $\mathrm{His}$ and on incomplete analogies between other sensory terminals as evidence that the retina in Arthropods originates from the cutaneous epiblast, and it appears to me that these have been repeatedly used as an argument in favour of Grenacher's views, and are the strongest argument which is capable of being adduced in their favour. It is certain that the great rods of the compound eye are derived from the cutaneous epiblast, and this certainly, to my mind, is a strong argument against their function as end organs. The view that they are end organs can only be justified by showing that end organs have such an origin in other cases, and this does not appear to have been proved. Whilst it is equally certain that the retina in Vertebrates at least is derived from the neural and not from the cutaneous epiblast; and as structures exist beneath the great rods derived, like the vertebrate retina, from the neural epiblast, this is good a priori evidence, I think, that they are probably the true retina. 


\section{THE MEDIAN OCELLI, STEMMATA, OR SIMPLE EYES.}

\section{a. The Stemmata of the Blow-fly.}

(Pl. XXXV., Fig. 2.)

Median ocelli. or simple eyes, occur in the imago state in most Iiptera, Hymenoptera, and Homoptera, and in many of the Orthoptera. They are usually three in number, rarely reduced to two, as in some Homoptera, or to one, as in some Ants. In the latter insects they are usually obsolete.

In the Blow-fly the ocelli are three in number, and placed in a triangle on the vertex; two are posterior, and one in front. They all have the same structure, a corneal lens, a vitreous, and a retina enclosed in a pigmented prolongation of the nerve-sheath, which consists of flattened cells.

The diameter of the cornea varies from $70 \mu$ to $\mathrm{I} 20 \mu$, and is less in the males than in the females; whilst the great compound eyes are larger in the males than in the females.

The Corneal Lens is very convex both on its external and internal surface, and exhibits a thin external layer which is undoubtedly a continuation of the external layer of the epidermis. Beneath, and intimately united with this external layer, is a biconvex lens, with a distinctly laminated structure which assumes a pink tinge under the action of Millon's reagent. This lens is developed at the expense of a layer of hypodermal cells continuous with the general hypoderm. The inner extremities of the lens-cells form a vitreous, and in the mature insect only exist as a very thin layer, which may in some cases be entirely overlooked in sections. The gradual thinning of the vitreous layer is of importance, as the ocelli have been described as of two kinds in many Insects and Arachnids by some observers, and much difference of opinion exists as to whether the vitreous is absent or present in one of these forms.

The Retina is a cup-shaped expansion of the optic nerve, formed of a single layer of typical rod cells (Fig. 67). Each rod consists of two segments-an anterior extremely trans- 
parent cylindrical rod, and a posterior nucleated protoplasmic cell directly connected with a terminal fibre of the nerve. The external segment varies from io $\mu$ to I $_{5} \mu$, and the internal from $I 5 \mu$ to $20 \mu$ in length.

The rod cells of the retina of the simple eye are strikingly similar to the layer of rods or bacilli to be hereafter described in the compound eye, and also to the rods of Jacob's membrane in the vertebrate eye. The external segments correspond in their transparent appearance and in the manner in which they are acted upon by various reagents with the external ends of the rods of the vertebrate eye, but are not inverted

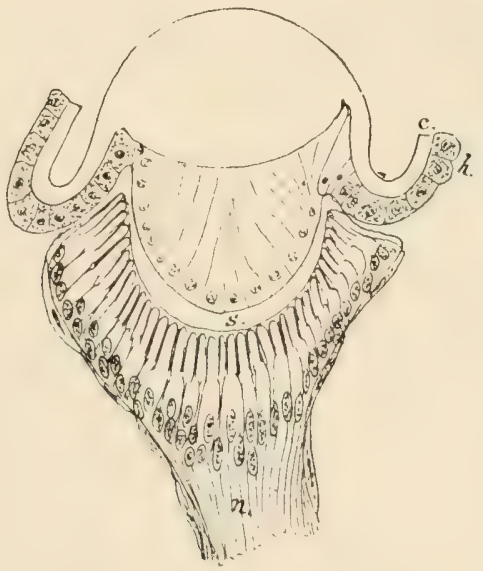

FIG. 67. - A vertical median section through the Ocellus of a Blow-fly Imago. Seen with $\frac{1}{4}$ objective. $h$, hypoderm; $n$, nerve; $s$, preretinal space.

as they are in the vertebrate retina. The inner extremities differ, however, in being nucleated both from the inner extremities of the bacilli in Vertebrates and from the inner extremities of the rodlets in the compound eye which I regard as retinal end organs. These organs are admitted by all previous writers to be the true nerve end organs of the simple eye.

The retina is surrounded by a layer of large but very thin pigment cells, which are apparently continuous with the nerve-sheath. These cells are pigmented with deep rose- 
coloured pigment, which rapidly assumes a yellow colour after death.

The Preretinal Membrane.-The retina is separated from the vitreous by an extremely thin membrane, which is seen in some of my sections to be continuous with the external pigmented sheath; but it is not pigmented, and is so thin that it is only occasionally capable of demonstration; except at its edges it appears to be a mere cuticular layer. Graber [223] and Lankester and Bourne [229, p. IS9] describe this preretinal layer as continuous with the retinal capsule.

\section{b. On the Morphology and Comparative Anatomy of Simple Eyes in Arthropods.}

The ocelli of imaginal insects are exceedingly similar to the simple eyes of Arachnids and Myriapoda, and to the lateral simple eyes of many larva, and their structure has been discussed from a morphological point of view at great length. Grenacher, Lankester and Bourne [229], and Carriere [232], have held that the retina is derived from the hypodermis; and Locy [240] and Mark [241] believe that they have seen evidence of an actual invagination from which the retina originates; on the other hand, Graber [223] and Schimkewitsch [234] state that the retina is developed as an outgrowth from the cephalic ganglia, an opinion which I have long maintained.

Although it must be admitted that it does not follow that all simple eyes in Arthropods arise in the same manner, it is most probable that they do, and I believe that many unnecessary complications have been introduced into the discussion of their origin by the attempt to prove that the retina originates from the cutaneous epiblast.

Lankester and Bourne [229] have introduced the terms 'monostichous' and 'diplostichous' to designate stemmata, in which they believe that a single or a double layer of cells exists bencath the cornea. They maintain that the lateral eyes of Scorpions have a single layer, the retina, behind the corneal lens; whilst the median eyes have a double layer, 
the outer consisting of the vitreous, and the inner of the retina.

Knowing as I do that the whole substance of the hypodermic cells is frequently converted into cuticular structures, and having observed the manner in which the so-called vitreous layer becomes thinner in the Blow-fly as development advances, I cannot admit the importance which has been ascribed to the absence of a vitreous in certain forms of stemmata; and in the face of the direct statements of Graber that he has seen a vitreous in the lateral eyes of Scorpions, it appears to me it is simply a question of age whether the vitreous exists or is absent in the so-called monostichous stemmata. Neither can I admit the theory of Locy and Mark, that the retina is sometimes inverted in the simple eyes of Arthropods.

The view that the retina of the simple eye is developed from the hypodermis is maintained by Grenacher $[216,222]$; but the only evidence he adduces in its favour is the arrangement of the cells of the vitreous in an Acilius and a Dytiscus larva. The arrangement represented in his figures is by no means convincing that his theory is correct, and can be as rcadily explained by a rapid increase of the hypodermic cells. In the Dytiscus eye the section is tangental, and probably has the same value as that of the Acilius larva, which is certainly not the arrangement one would expect to find if his hypothesis were correct, but is one which would readily result from hypertrophy of the cells beneath the cornea.

Moreover, the admission by Lankester and Bourne [229], that Graber's preretinal membrane is continuous with the eye capsule, and the existence of intrusive connective tissue in the retina, described by the same authors, are apparently inexplicable on the theory of its hypodermic origin. Nor is the continuity of the eye-capsule with the subhypodermic tissue indicative of a continuity of retinal and hypodermic cells, if this layer is mesoblastic, as it appears there is every probability it is. The so-called eye-capsule is, in fact, an endothelium, continuous on the one hand with the subhypodermic tissue of Viallanes, and on the other with the sheath of the optic nerve. 
The Development of the Simple Eyes.-Unfortunately, the niserver is met by great difficulties in the attempt to settle the question at issue by the study of the development of the simple eve. The earliest stage in which I have been able to identify. these organs is the third or fourth day of the pupa, when the nerve is easily traced from the nerve centre to the integument. In this stage the nerve ends in three clavate groups of pyramidal cells, with their narrow ends towards the nerve, and their broad cnus applied to the undifferentiated hypoderm beneath the thin cuticle of the vertex. There are no traces of either vitreous or lens at this period, and I can only regard the clavite groups of cells as rulimentary retina developed in relation with the nerve. There is apparently no trace of vesicular structure, and there is certainly no involution of the undifferentiated hypoderm, the cells of which subsequently form the vitreous and lins. The appearances presented at subsequent stages indicate that both these structures are developed from the cells of the hypoderm by the growth and differentiation of their substance. There is never the slightest indication of involution or invagination.

Although, with the exception of those of Mark [241] and I. $\mathrm{cy}$ [240], no direct observations as to the manner in which the median stemmata of Insects are developed have heen pubIshed, Leydig [207, Pl. VI., Fig. 5] gives a figure of the simple wes of Timarchia tenebricosa, in which they are represented in the imago as vesicular organs uneonnected with the integument, but directly attached to the optic ganglia. This figure is, in my opinion, only susceptible of one interpretation: that the retina is produced as an outgrowth from the central nervous system.

The 0celli compared with the Pineal Eye-This comparison is snerested by Gaskell [45], and there are certainly several very striking points of similarity. The pineal eye is undoubtedly a rulimentary on, which tends to disappear even in the lower Vertebrates; whilst the ocelli are chameteristic of the lower Arthroports, and tend to be replared by the compound ages, functionaly at least, in all the hirher forms. In both cases the 
eye is connected with the median region of the brain. From what has already been stated, this relationship with the brain is indubitably very similar in Vertebrates and Insects.

\section{GENERAL REMARKS ON THE COMPOUND EYE.}

\section{(Pls. XXXV. and XXXVI.)}

The great or compound eyes of Insects and Crustaceans are developed from two separate sources-an external portion, which is formed from the hypodermis, or from the eye-disc of Weismann; and an internal portion, which originates from the primitive brain-vesicle. These parts are separated by a cuticular membrane, the basilar membrane, which is similar to the preretinal membrane of the simple eye.

I propose to term that portion of the eye which is exturnal to the basilar membrane the dioptron, and that portion of it which is internal to it the retina.

The Dioptron (Pl. XXXV., Fig. I, d) consists of a chitinous case, formed externally by the compound cornea (Pl. XXXVI., Fig. I, c), and internally by the basilar membrane $(m b)$. These are united to each other by a cuticular ring, which surrounds the whole eye, the scleral ring. The compound cornea and the basilar membrane are nearly parallel surfaces, so that the whole dioptron may be described as a very short truncated oval cone, of which the apex and base are subspheroidal, or more properly cyclioidal surfaces.

The Compound Cornea is divided into a variable number of facets, which are usually convex on their outer surface; but in some insects, especially larve, the outer curvature of the cornea is smooth. When this is the case, the inner surface of the facets is convex, or there is a distinct lens beneath each segment of the cornea. I have elsewhere [233] described the modifications of the compound cornea in detail.

Each corneal facet, with the radially-arranged parts between it and the basilar membrane, may be conveniently termed an ommateum, a term first suggested by Carrière. 
The Number of Corneal Facets is therefore equal to that of the ommatea, or radial segments of the eye. It varies greatly in different insects.

In the Dragron-flies there are from 25,000 to 30.000 facets, while in Eciton there is only I, in Ponera from I to 5, and in Scolenopsis fugax from 6 to 9. Myrmecina Latreilli has I5; Pheidole pallidula, 30 ; Atta barbara from so to 90 in the small workers, and 230 in the large; Camponotus ligniperdus, 500 ; and Formica from 600 to I,200. Most of these numbers are quoted from Forel [194]. In Typhlopone eyes are absent.

In many insects with few facets and in the Myriopoda the separate ommatea are distinct from each other. It was formerly believed that the compound eye took its origin by the multiplication and union of separate simple eyes: but the view held by Grenacher appears to be more correct. He says : ' The stemma, to use a simile, is not the mother of the compound eye, but the sister' ; and he further says: 'The multiplication of the individual elements of the primitive eye has led to the formation of the stemma; the multiplication in the number of simple eyes, their nearer aggregation, and the development of fewer elements in each, has led to the formation of the compound eye' - a view which appears probable.

The 0mmateum.-Each ommateum consists of a corneal facet, a cone or pseudo-cone, and a great rod.

The Cone when present is a highly-refractive body, usually termed the sclero-cone, or crystalline cone, with its base towards the corneal facet, and its apex towards the great rod. In the Diptera this structure is wanting, and its place is taken by a conical cavity, filled with a semi-solid body, resembling a vitreous, which has been termed a pseudo-cone.

The Great Rods.-Each great rod consists of an axial struc-

DESCRITTION OF J'LATE XXXV.

IVI: I. - A frontal section of the compound cye of the lilow-fly seen with a ! inch objective. $d d$, the dioptron; $g$, the optic ganglion; on, the optic nerve; $r t$, the retina; $t r t r$, tracheal vessels in section.

Fif. 2. - Two of the ocelli drawn to the same scale. 


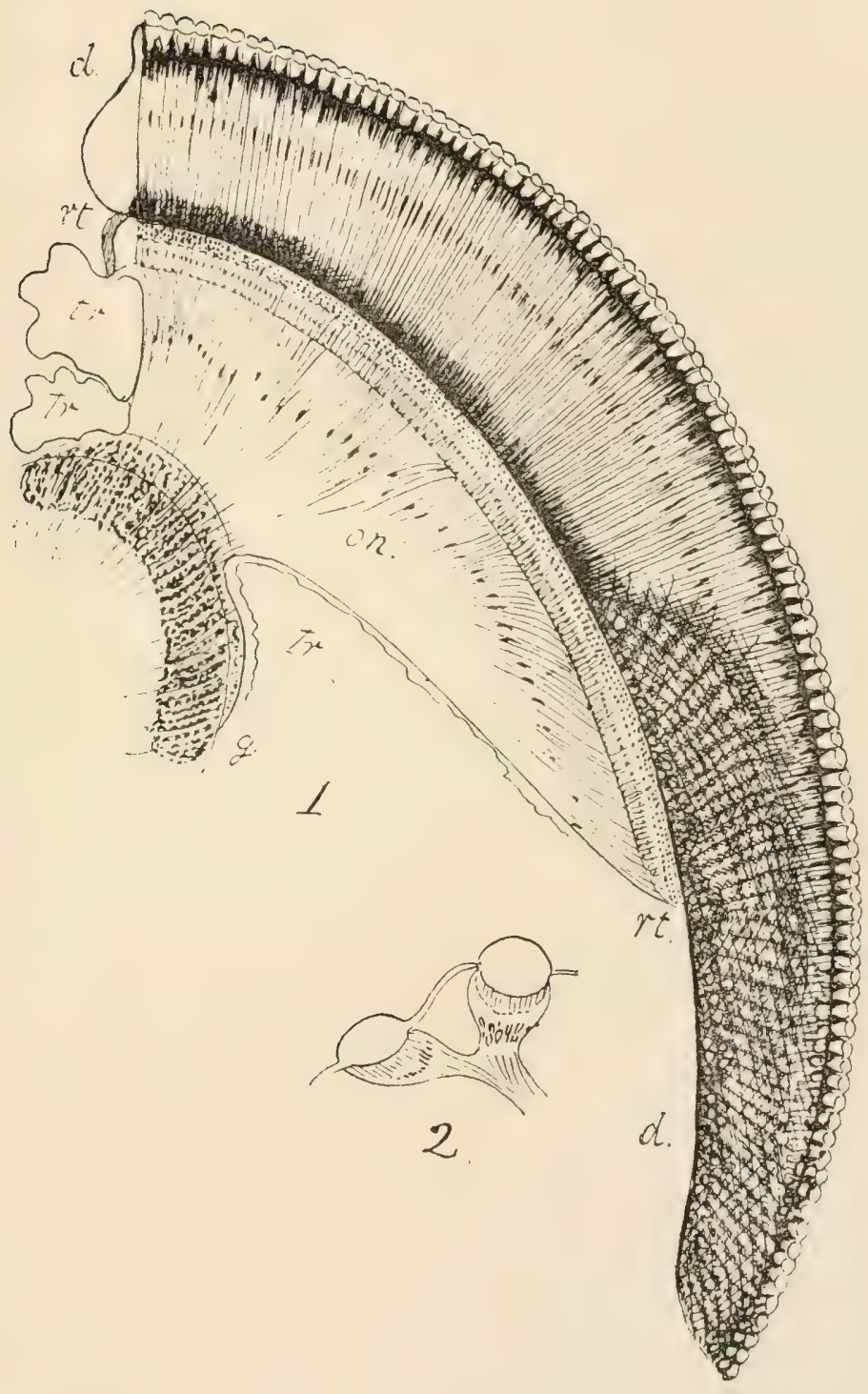



ture, the rhabdome (Pl. XXXVI., Fig. I, rh), usually surrounded by six sheathing cells, enclosed in a pigmented cellular sheath. The sheathing cells I regard as the generating cells of the rhabdome. The cone $(c c)$ is also surrounded by the continuation of the pigmented sheath, which forms a kind of iris (i) around its apex. Each ommateum may therefore be regarded as a transparent tube, surrounded by pigment cells.

The rhabiomes are sometimes solid rods, but are more frequently cuticular sacs, filled with fluid.

Tracheæ.-Between the ommatea in Insects there are usually, perhaps always, numerous tracheæ, which have their long axes parallel with the long axes of the ommatea. These tracheæ are regularly arranged, so that each ommateum may be said to be surrounded by a circle of tracheal vessels. Beside the tracheæ, the ommatea are separated from each other by narrow blood-sinuses.

The Retina (Pl. XXXVI., Fig. I, $r$ ). - The term ' retina' has been applied by me to a layer of nervous elements and pigment cells which lies internally to the basilar membrane, and which is connected with the optic ganglion by the decussating fibres, already described as the optic nerve.

As this layer consists of rod-like elements, identical with those of the simple eye, in which the nerve-fibres obviously end, and upon which a dioptric picture can be shown to fall, this term is not only appropriate but necessary, unless it is to be entirely discarded in relation to the invertebrate eye.

It is now ten years since I first published my views on the compound eye, and I was then sanguine enough to believe that the evidence on which they rest was strong enough to ensure their immediate acceptance. This has not, however, been the case, although my opinions are surely and steadily gaining ground in this country, and are readily accepted by all those who are competent to judge, and who have taken the trouble to examine some of the numerous sections which I possess, and which show the structure of my retina as distinctly as the drawings which are given in this work.

Received Views. - The view usually held as to the structure 
of the compound eye is that the great rods are recipient structures, and that they are the terminals of the optic nerve. That this view rests on hypothesis and imperfect knowledge will appear hereafter, and I shall show that it has never been proved, and that it is not tenable on developmental, anatomical, or physiologrical grounds. I shall commence by reviewing the evidence on which it is asserted that the dioptron is a recipient organ concerned in the transformation of light vibrations into a nerve stimulus.

Leydigr [208] termed the great rods nervous rods, and Max Schultze [210] visual rods, 'Sehstäbchen'; and it has been held by all previous writers on the subject that the basilar membrane is perforated by the terminal fibres of the optic nerve, which are usually supposed to end in one or other of the structures of the dioptron.

So far as the general arrangrement of the parts of the great eyes of Arthropods are concerned, and the arrangement of the different layers, my description given above agrees well enough with that of previous authors; but the interpretation of their nature and their minute structure is altogether different. The first point which struck me years ago was that in some insects at least the basilar membrane is absolutely imperforate, and the second was that the so-called outer layers of the optic ganglion have a structure which is identical with the retina of the simple eye, and only differs in detail from the rod and cone layer of the vertebrate retina. If these points are estallisherl,

\section{DESCRIPTION OF PLATE XXXVI.}

Fici. 1.-A section of a portion of the compound eye of the Blow-fly seen with a 1 inch objective. $c$, the compound curnea ; $c c$, the crystalline cone (pseudocone) ; $i$, iris cells; $l$, the corneal lens; $m b$, membrana basilaris; $n^{1}$, nuclei of the iri cells ; $n^{2}$, nuclei of the unpigmented cells of the shesth of the thatuine; $n^{3}$, nuclei of the inner pigment cells; $n^{4}$, nuclei of the inner limiting uembrane; 1) $n$, optic nerve fibres; $r t$, outer segments, and $r t^{1}$, inner segments of the retinal rods or bacilli ; $r t n$, retinal nuclei ; $v$, chaplet cells of Viallanes.

Fu. 2.-. Transverse sections of the ommatea seen with a ${ }_{2}^{1}$ oil immerion ubjective. a, section through the peudu-cone; bection through the uris cells ; i, section through the rhabdomes of four ommatea. 


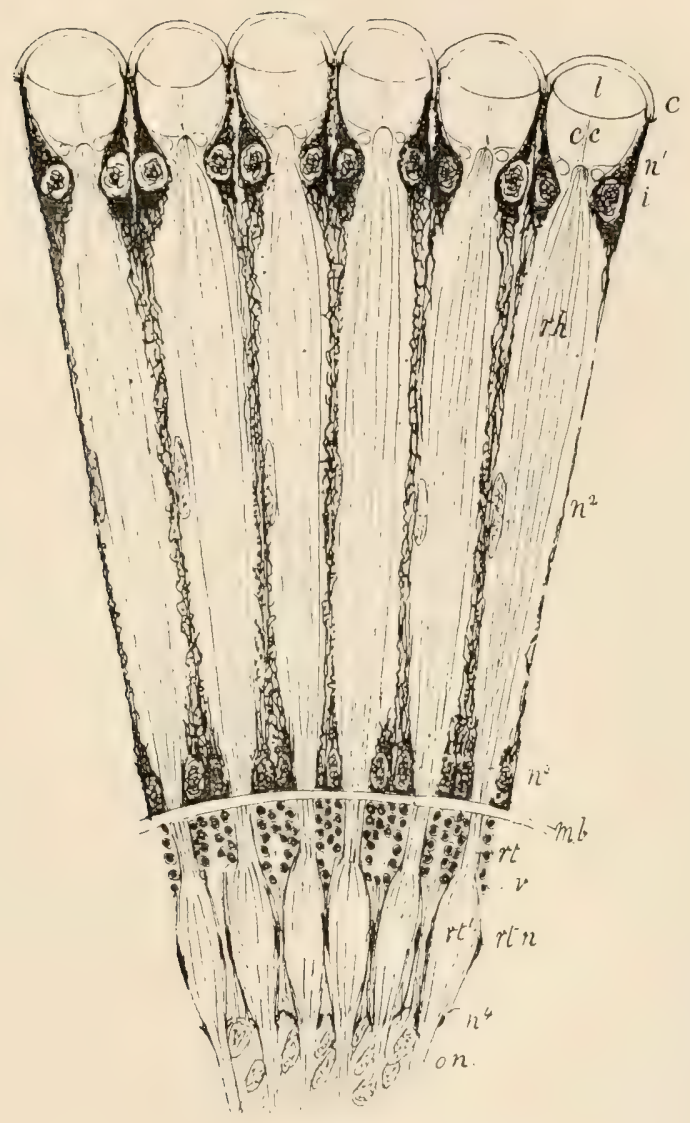

FIG. I.
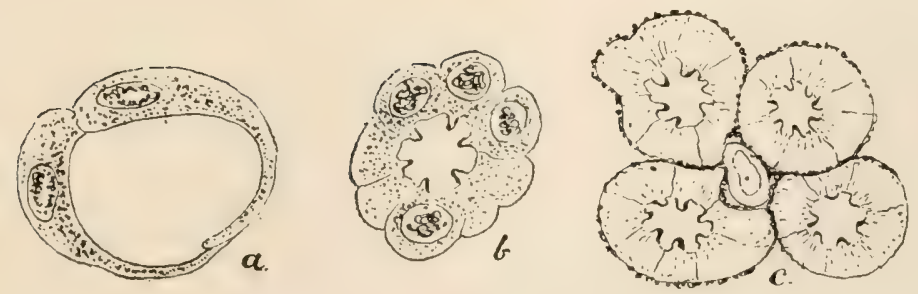

FIG. 2. 

then all the discussions which form a great part of the literature of the subject will become a mere matter of history, and the structure of the organ of vision becomes intelligible on the principles of mechanical optics, just as vision is intelligible on these principles in the Vertebrata.

Now, I shall first endeavour to prove that the view generally received, which is mainly due to Grenacher, is by no means established either by facts or hypothesis.

Grenacher [216 and 222] commences by showing that the crystalline cone ('Krystallkercl'), although commonly found in the compound eye, is entirely absent during the whole of life in many forms of compound eye, and that when it is present in the ultimate stage of development, it is not present during the earlier stages. He says :

" $\mathrm{V}$ e always find in early stages of development a certain number of cells behind each corneal facet, the function of which, in the first place, is the secretion of the facet itself. They have commonly, taken together, the form of a cone, with its apex directed inwards. In by far the greater number of cases there are four of these cells, seldom two or five.

'This is the starting-point, the embryonic stage. The eyes of the definitive form are, however, sharply distinguished by the metamorphosis which these cells undergo.

'In numerous insects these cells persist in an unaltered form ; as in Coleoptera, at least all except the Pentamera, Hemiptera, Heteroptera, Tipularidx, and Orthoptera, at least in the Forficulina.' This form of eye Grenacher terms aconic.

'In other insects, and in the Crustacea, these cells exist as such only for a short time. At an early period a secretion, which is more or less solid, begins in them.' With the increase of this, he states that the cells disappear in great part. 'Generally only the nucleus and cell-wall remain. The cellsecretions run together and form the so-called crystalline cone, the segments of which are equal in number to the original cells.' Such eyes Grenacher terms euconic.

The eyes of the Diptera brachycera are pseudo-conic, according to Grenacher, and he says these differ from the aconic and 
euconic eye in this, that the four cells secrete a fluid, which is held in a funnel-shaped cavity surrounded by pigment cells, and form no true cone.

Grenacher concludes that the cone is a refractive medium, and has nothing whatever to do with the conversion of light into a nerve stimulus; but he adds: 'It is the nervous rod (Nirich-odor Sihstab) which is the true percipient structure.'

Leydig, however, at one time at least, thought otherwise, and regarded the cone as the true percipient element, and lately Patten [239] has gone back to Leydig's view, and has described certain imaginary nerve fibrillæ in the cone, the existence of which Parker [250], using all Patten's methods, was unsuccessful in demonstrating.

Grenacher, in support of his contention that the great rods are percipient organs, says (p. 76) :

'When the visual rod (Schstab) has been hitherto spoken of, it is the inner, sensitive, highly refractive, rod-like axial structure which is usually intended; this is surrounded by a sheath, which is usually intensely pigmented, in which nuclei have been discovered. But in general too little attention has been paid to it.

'The whole so-called visual rod consists of a number of long cells lying parallel to each other; to each of these cells belongs a transparent secretion (Ausscheidungr), which we shall call rods from their analogy with those of the simple eyes, although this appellation is not always appropriate from the form of the structure. Sometimes, but not often, these rods are sunk in the anterior ends of the cells, and then the rods are slightly isolated from each other. More generally they form the inner eilges of the cells, or spread more or less over them, and unice and form the axial rod, or so-called visual rod. The cells to which the segments of this visual rod belong form the sheath. The fibres of the optic nerve enter these cells, and therefore it is clear that they are agrents of vision, and not mere sheathing organs, like the sarcolemma of muscle or the sheath of a nerve.'

Grenacher terms the whole of his percipient cells a retinula, 
and the axial rod, when it consists of the united rodlets, a rhabdome, owing to the fluted structure it exhibits, $\rho a \beta \delta \omega \mu a$ signifying the fluting of a column.

I take exception to the whole of Grenacher's conclusions. In the first place, I maintain that there is not the smallest evidence that nerve-fibres enter either the pigment cells of the sheath or the sheathing cells. In the second place, I maintain that there is not the slightest homology or analogy between Grenacher's Stäbchen and Rhabdomes and the retinal cells of the simple eye. And, in the third place, I consider that the structure of the great rods has been incorrectly interpreted by Grenacher.

I shall discuss these three points in the above order.

On the Supposed Innervation of the Great Rods, or Retinulæ of Grenacher.-If Grenacher has traced the optic nerve-fibres into the cells of the great rods, I would ask why he has not represented this relation in his figures. So important a point would certainly, I think, have been figured if he had ever traced the fibres into the retinulæ, as he terms them, yet I fail to find a single figure showing this relation satisfactorily; and the great majority of his figures indicate a distinct line of demarcation letween the great rods and the nervous structures beneath the basilar membrane, which in the majority of cases Grenacher has not figured at all. On p. 8I of his memoir Grenacher says, speaking of the eye of Tipula sp.: 'On the inner side of the tender cuticular membrane on which the retinulæ rest, the fibres of the optic nerve run' $[222$, Fig. $44, c t]$. There is no attempt to prove that these fibres enter the retinulæ or perforate the cuticular membrane, nor do I think Grenacher has anywhere stated that he has himself traced the nerves into the retinulæ. He contents himself with a general statement. and nowhere attempts to bring distinct proofs in support of it.

It appears to me evident that Grenacher regarded the classical opinion, that the optic nerve terminates in some part of the great rod, as a correct one, and troubled himself no further about it. He perceived that its terminations could not possibly be in the cuticular rhabdome, and regarded the pig- 
mented sheath as the only possible structure in which the nerve can terminate.

The view that the great rods are the nerve terminals apparcntly originated from Müller's statements. Müller [198] evidently thought the great rods mere bundles of nerve-fibres; of end organs in the Arthropod cye he knew nothing, and in his text-book on Physiology [192] he apparently accepted Wagner's [200] theory, that the cones are invested by the fibres of the optic nerve. Leydig [207] even went so far as to believe the crystalline cones to be nerve-terminals. Evidence in favour of such views is untirely wanting. Max Schultze [210] could not agree that either the great rods or cones are nerve terminals, lut he ascribed this function to certain spindle-shaped structures within the great rods in the Lobster. The most recent researches [247] on the structure of the eye of the L.obster appear to me to indicate that these spindles are not part of the great rod, and, although the investigation is beset with technical difficulties, it appears to me probable that it will turn out that the structures described by Max schultze are really retinal, and correspond with the nerve-end organs which I regard as the retina in Insects.

If we except the doubtful evidence afforded by Max Schultze, who, as I think, erroneously regarded his spindles as part of the great rods, there is not the slightest evidence, in any single work published before Grenacher's monograph appeared, that the optic nerve terminates in the dioptron, and this renders it the more difficult to understand the ready acceptance of the theory by Grenacher.

since the appearance of Grenacher's monograph several investigators have attempted to prove that the nerve fibres end in the dioptron. Patten remarks $[239, \mathrm{p} .669]$ : 'It camnot be said that Grenacher or any of his predecessors, perhaps with the exception of Max Schultze, who has represented the fibrous natrkings of the style and calyx (the retinula), have succeeded in demonstrating anything like nerve endings in the Arthropod eyc.' With regard to l'atten's own statements, I do not for a moment deny the existence of such a network of fibres as 
Patten has described and figured in Mantis; I only say I have never seen the same thing in any insect. What I maintain is that, even if it is admitted to be a real structure, Patten does not adduce the slightest evidence of its nervous nature, and the entire absence of end organs precludes the conclusion that it is a retina.

Hickson [237], in a paper which was intended as a refutation of my views published in $188_{4}$, describes what he terms a neurospongial network, and traces this into Grenacher's retinulæ. Anything more unlike nerve terminations cannot be conceived. His figures are good, and represent the connective reticulum and tracheal vessels only; all traces of any representation of nerve endings are absent in most of his figures, and his view, like Patten's, is too improbable to require serious investigation.

The above is the whole of the evidence on which the received view rests. No author has satisfactorily represented the nerve terminating in the dioptron, and no two authors who have imagined such terminals agree in the details they describe.

On the Supposed Homology of the Great Rods and the Retina of the Simple Eye.-Anyone who will take the trouble to compare the figures given by Grenacher of the retina of the simple eye with those of the rhabdomes of the compound eye will be at once struck with the slight similarity which they exhibit.

Lankester and Bourne have, however, represented the retinal nerve terminals of the Scorpion, and in some of their figures there are structures which certainly bear a striking resemblance to the rhabdomes of a compound eye. I have not had the opportunity of examining their specimens, but in some noctuid Moths almost identical structures exist in my retinal layer, which are certainly not anything like rhabdomes, although in specimens bleached with nitrous acid they approximate very closely in appearance to those represented by Lankester and Bourne. Therefore, unless my retina and the great rods are homologous', this apparent similarity of structure between the rhabdomes of, say, Tipula as represented by Grenacher and of the retinæ of Scorpions represented diagrammatically by 
Lankester and Bourne must be deceptive. In many of the figures given by the last-named authors the 'yellow bodies' in the retina do not appear to be normal structures, and from what I have myself seen in many preparations bleached with nitrous acid are, I believe, artificial products resulting from the action of the acid upon the proteid of the circulating fluid. Nothing can be well less like a normal structure than the irregular masses of structureless material shown in their figures.

I have little doubt as to the similarity of the pre-retinal lamelle of simple eyes and the basilar membranes of compound eyes, and I am quite convinced that in both the simple and compound eyes all the parts on the inner side of these membranes are developed as outgrowths from the central nervous system.

On the Structure of the Great Rods.-Grenacher's figures indicate that the great rods vary extremely in structure in a most puzzling manner in different Arthropods, and anyone who has worked at transverse sections of these organs knows how variable the appearances are which they exhibit, even in the same species, in different sections. Compare, for example, the figures given by Grenacher [222, Figs. 125, 126] with those by Lankester and Bourne [229, Figs. 20-26] of the so-called retinule of Limulus. These are typical representations of gigantic rhabdomes. I have no reason to distrust the figures given by either, because I have frequently observed equal discrepancies in transverse sections of rhabdomes prepared by slightly different methods from insects of the same species.

In I882, on examining the eye of a Plume Moth, Ptirophorus, after dissociating the elements of the dioptron with needles in normal saline solution, I was surprised to find that the great rods presented appearances which had not been previously observed. Each great rod consisted of an ovoid transparent body (1'l. XXXVIII., Fig. $3 \mathrm{~h} h$ ); this rapidly underwent changes of form evidently due to the escape of fluid from its interior, and ultimately split up into a number of empty tubules. These were neither more nor less than the 
stäbchen of Grenacher. In the living insects these form the segments of an ovoid lens divided by longitudinal septa.

In the Blow-fly the uninjured great rods before they undergo any post-mortem change appear as very long, highly-refractive, cylindrical bodies, the anterior extremities of which project into the pseudo-cones, and are nearly hemispherical. These rods when dissociated become twisted or curled, and exhibit phenomena similar to those which I observed in the Plume Moth (Ptcrophorus) except that they do not split into longitudinal segments.

The so-called axial threads, or longitudinal striæ, are not axial at all, but are mere ridges in an elastic sheath (Pl. XXXVI., Fig. 2, $b$ and $c$ ) and are so placed that they could

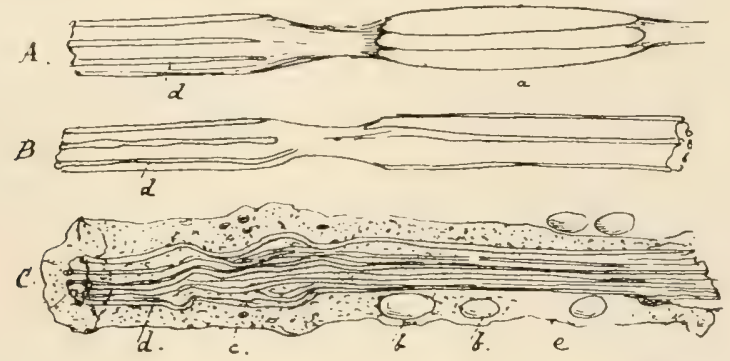

FIG. 68.-Isolated portions of the rhabdomes of a Blow-fly in various stages of disintegration. $A$ and $B$, isolated portions of the internal membrane ; $a$, filled with fluid; $d d$, so called axial threads; $C$, the rhabdome still surrounded by its protoplasmic sheath; $b \quad b$, vacuoles; $c$, granules; $d$, so-called axial threads; $e$, sheathing substance.

not be affected by an axial pencil of light. I shall, however, return to this subject when I discuss the optics of the compound eye.

I would especially draw attention to Grenacher's figures [222, Figs. 62, 63, 80-82, 85, 88, and 126] and his optical longitudinal sections [222, Figs. 44, 47, 49, and 65], as these are quite consistent with the views here adopted and the phenomena observed by me, and they ill accord with the views he has put forward as to the nature of the great rods in his text. 


\section{THE COMPOUND EYE OF THE BLOW-FLY.}

\section{a. The Structure of the Dioptron.}

The dioptron consists of the cornea, the basilar membrane, and the scleral ring, which form its case, and of the ommatea or radially arranged eyelets. Each ommateum corresponds to a corneal facet, and there are between 4,000 and 5,000 facets in each eye.

The Cornea.-I have already shown elsewhere [233] that there are several very distinct forms of cornea in the Arthropoda. These I named the continuous cornea, the faceted cornea, the kistoid cornea, and the lenticular cornea.

The cornea of the Blow-fly is a kistoid cornea. That is, it consists of a thin cuticular lamina with concaro-convex facets, each facet strengthened and supported by a hexagonal frame which separates the adjacent lenses from each other.

Thus the cuticular lamina of the cornea exhibits very shallow hexagonal alveoli with concave ends when viewed from its inner surface. These alveoli are filled up by bi-convex lenses.

The substance of the lenses stains readily in mature pupe, is hishly refractive during life and shortly after death, but soon loses its refringent power. In dried specimens, each lens is seen split into four segments, and the same result is brought about by treating a fresh cornea with ether. These segments drop ont in sections and leave only the cuticular alveoli. In well-preserved specimens the lenses remain in situ and exhibit no apparent structure. In specimens preserved with osmium peroxide the lens is well seen. it is stained a pale hrown, and is strongly bi-convex, withont, so far as I can see, a trace of apparent structure. In pupe about eight days old the lens is represented by four nucleated cells.

In the Cockroach (Flalla) and the Earwig (Forficula) the cormea is kistoid, and I have frequently separated the lenses; this I have been unable to accomplish in the Flow-fly. The lenses so separated may be ruptured by pressure, and then 
appear to consist of a thin capsule, from which a fluid of high refractive power may be seen escaping.

From the above facts I arrive at the following conclusions: (I) The cornea consists of a cuticular membrane with lenses beneath it. (2) That the lenses are each developed from four cells. (3) That the lenses consist of a stroma infiltrated with an oil-like fluid. Hickson [237], without troubling himself about my facts, takes exception to this view, and says he sees nothing to justify it.

The Nuclei of Semper.-The 'Nuclei of Semper' play a very important part in many of the descriptions of the compound eye hitherto published, although it is difficult in all cases to know what nuclei are referred to.

Claparede, in I860, wrote: [203] 'In the spring of last year I travelled from Altona to Paris with Carl Semper, who was about to depart for the Philippine islands'; and we learn that Semper gave him a box of slides of insects' eyes, and pointed out to him 'four nuclei between the cornea and crystalline cones,' which Claparède determined to name 'Semper's nuclei,'

Now, fortunately, Claparède figured these so-called nuclei [203, Fig. I], and it is evident from his figure that he had not nuclei before him, but a lens split into four parts.

Claparède also figured the partially-developed eye of Sphinx Euphorbiæ, and represented the nuclei of the cells from which the corneal lens is developed, he also called these 'Semper's nuclei' and these nuclei have been confounded with the four segments of a split lens ever since.

Nor is this all. As Claparède has shown, and as is perfectly clear in my preparations, numerous nuclei are seen in relation to the cone, cornea and surrounding cells at one period or other of development, and it is exceedingly difficult to identify 'Semper's nuclei,' so that various nuclei have been described as 'Semper's'; this has led to considerable confusion. I shall therefore cease to speak of 'Semper's nuclei,' and designate the nuclei as corneal or nuclei of the cone, or of the pigment cells. 
Weismann [2], whilst he admits that four nuclei appear in the cell from which the corneal lens is developed, says there is only one cell, and not four-one cell with four nuclei. Hickson says that 'Semper's nuclei' have nothing whatever to do with the formation of the corneal facets; but these 'are formed from a continuous layer of protoplasmic substance which underlies the whole surface of the cornea, and remains as a living protoplasmic lamina until the eye is fully developed, and then shrivels up' [237, p. 23]. Such a statement is surely an anachronism in a paper published in $I S S_{5}$, it would have looked better in one written in $I 850$. In every case when such continuous nucleated layers have been described, subsequent observations have dispelled the illusion.

Grenacher describes the cornea as nearly flat on its inner surface. I have frequently seen sections in which this is the case, but they are ill preserved. Specimens which have been kept for some time in spirit are usually in this condition. The convexity of the inner surface of the cornea is only preserved in specimens fixed in osmium peroxide. He also represents the remains of the membrana propria of the cone as the pseudo-cone [222, Fig. 63]. In other respects our descriptions and figures are very similar, indeed, almost identical. Grenacher's specimens, he says, had been preserved in alcohol; evidently without any special precautions, as he observes: 'I came across specimens of M. vomitoria, preserved amongst numerous others in alcohol (Himecist), which had lost their pigment and had become white' [222, p. 90]. It was from these he drew his figures and description.

The Cone.- The cone of the ommateum in the Blow-1ly is pseudo-conic. On the seventh or eighth day of the pupa state, however, it consists of four transparent cells, Grenacher's aconic stage.

The psendo-cone in the imago (Pl. XXXVI., Fig. I, c, c) cxhibits no trace of structure; it is surrounded by a thin memhrana propria, and by several larese, flat epithelial cells, loaded with bright crimson granular pigment. This pigment assumes a brown colour in chromic acid and alcohol. 
The pseudo-cone lies immediately beneath the corneal lens, and the outer end of the axis of the rhabdome is imbedded in its apex.

The Great Rods (Pl. XXXVI., Fig. I, $r h$ ) occupy the greater part of the dioptron; each rod extends from the apex of a pseudo-cone $(c, c)$ to the basilar membrane $(m b)$, and consists of an axial rhabdome $(r h)$ and its sheath. Five pigment cells, the iris cells (i), surround its outer extremity; a similar number $\left(n^{3}\right)$ are seen at its inner extremity on the basilar membrane. Both sets of cells give off pigmented fringes, which lie upon the surface of the great rods, those of the iris cells meeting and interlocking with those of the inner pigment cells.

The great rods in transverse section (Pl. XXXVI., Fig. 2) exhibit a distinct lumen, surrounded by a transparent wall. The wall stains readily with carmine stains, and has the appearance of granular protoplasm ; it is not stained by nuclear stains.

On the inner surface of the transparent wall there is a delicate, apparently cuticular membrane, resembling the intima of a tracheal tube; but, instead of transverse thickenings, it exhibits six or seven longitudinal threads. In the recent state, and in well-preserved sections, the lumen of the great rod is very distinct, but there is a strong tendency for the sheath to contract; in many transverse sections this contraction is so marked that the axis of the great rod appears to be completely occupied by the highly refractive dots, which are the transverse sections of the fine longitudinal threads. Under these circumstances the great rods are seen to be separated from each other by considerable spaces, but in good preparations they are only separated by very narrow ones, owing to their larger diameter and the considerable lumen they enclose.

Grenacher's figures almost invariably represent the lumen more or less contracted by the infolding of the inner cuticular layer.

Very generally in the fully formed imago each great rod exhibits a single nucleus, midway between its ends, but in an earlier stage there are usually several nuclei at its extremities. 
The conclusion at which I have arrived, from the appearance of the great rods before they contract and expel their contents, is that they consist of an elastic sac filled with a highly refractive fluid. This sac is apparently divided by radial septa into six chambers. It frequently happens that parts of the tubes are more completely emptied than the rest, so that they exhibit the appearances represented in Fig. 68. I regard the rhabdome as a lens of great thickness and very short focus, which forms a magnified image of a part of the sub-corneal image, upon a retina situated beneath the basement-membrane of the dioptron.

The Pigment Cells.-These cells are situated at the inner and outer ends of the great rods.

The outer set form a kind of iris (Pl. XXXYI., Fig. I, i) around the apex of the cone. The inner set $\left(n^{3}\right)$ rest on the basilar membrane. Each set gives off a close series of parallel pigmented fringes, which interlock with those of the other set. The pigment is granular, and in the recent state has a brilliant crimson colour. In sections it usually assumes an orangebrown colour, but, in specimens fixed in absolute alcohol and stained with Erhlich's logwood, the natural colour is very nearly restored. This is possibly due to the staining of the cells, and not to a restoration of the normal condition of the pigment. It indicates, perhaps, that the normal pigment is complex, and that it loses its blue element in spirit, chromic salts, etc., and that the blue of the logwood takes its place. Except in stained sections and recent eyes I have never seen the pigment crimson, it is always yellow or orange-brown. Light has no action upon this pigment, so far as its colour is concerned, but its position is undoultedly changed by the intensity of the light to which the eye is exposed in the living insect (see p. 532).

The Tracheæ of the Dioptron.-There are a number of fusiform thick-walled trachea between the great rods. These are arranged with sreat regularity (Pl. XXXVIII., lige. 7, C. $(r)$. In sone preparations they appear as dilated thin-walled sacs, in others as thick-walled trachea with a narrow lumen. The distension of the trachea accompanies the shrivelling of the 
rhabdomes; hence, I conclude that it is abnormal. I have been unable to discover tracheal capillaries on the pigment cells of the great rods or cones in the Blow-fly, but I have no doubt they exist; indeed, I suspect that the beautiful network represented by Patten around the cones of Mantis [239, Fig. I 8 ], really consists of fine, empty capillary tracheæ-as I have dctected distinct tracheal capillaries on the great rods of some Dragon-flies, Agrion puella [219, p. 587].

The Pigment Cells of the Cone are large flat cells, which extend from the cornea to the apex of the cone. I am not able to state positively the number of cells which surround each cone, as transverse sections usually only exhibit one or two nuclei, but there are, apparently, only two cells as a rule; I have occasionally seen three, and the whole structure of the ommatea indicates the probable existence of four. These cells are very thin and deeply pigmented, their edges overlap each other; probably their number varies in different ommatea. In Moths, Dragon-flies, and many other insects these pigment cells are represented by fringes from the iris cells, and in the Hymenoptera by deeply pigmented palisade-like cells, which appear to be connected with the iris cells. I have spoken of these elsewhere as ciliary rods [233], and regarded them as sensitive to light, and Parker [250] has fallen into a similar error and regards them as retinal end organs, his ' distal retina.'

The Iris.-This term has been used to designate the circle of deeply pigmented cells which surround the inner extremity of the cone or pseudo-cone. They are the 'pigment cells' of the second order of Grenacher and the 'iris tapetum' of S. Exner [252]. Exner has not, however, distinguished between the iris cells and the cells surrounding the cone, which Grenacher terms 'pigment cells of the first order'; as these are absent in many insects, and are replaced by pigmented fringes from the iris cells, it is probable that Exner had such insects in his mind when he used the same term for both sets, although he repre. sents them as distinct in a figure of the eye of Eristalis [252, Fig. 6o].

The iris cells of the Blow-fly are five in number, and send 
processes between the great rods, which are probably drawn from between the rods in dim light and extended again in sunlight. The changes in the position of the iris-pigment is most marked in nocturnal insects, such as noctuid moths. S. Exner [244] has investigated the disposition of the pigment in insects which have been kept in the dark and in those exposed to light, and finds that in the latter the pigment fringes extend more deeply between the great rods than in the former.

The Membrana basilaris (the Membrana fenestrata of Exner). - This membrane is merely spoken of by Grenacher as a cuticular layer. It is so distinct and sharply defined that it cannot be overlooked, yet it has not received the investigation which it deserves, although it is very carefully figured by Grenacher as a continuous membrane in several of his figures [222, Figs. $4 f^{-} f$, II $\left.f-I I 7\right]$. In immature flies and in mature nymphs it is seen to lie between two layers of cells, the inner pigment cells of the rhabdomes and a layer of epithelioid branching cells, which in most insects become the pigment cells of the true retina. That it is perforated by the tracheal vesscls of the dioptron in insects, and by the blood ressels in the Crustacea, is indubitable, but I have sought in vain for any connection between the retina and the great rods by nerves perforating this membrane, and, as I have already stated, no such nerves traversing it are fisured by Grenacher. Certainly there is no appearance of such a perforation in the Diptera, although in some insects, the Diurnal Lepidoptera especially; this membrane forms a kind of honeycomb, each cell enclosing a fasciculus of retinal end-organs, a retinula, so that it is difficult to see the same marked division between the dioptron and the neuron which is so plainly seen in Flies and many. Moths, more especially as the septa between the retinulae are deeply pigmented.

Mechanism of Accommodation.-In the Blow-fly the edge of the basilar membrane is thickened, and forms a ringr closely resembling that which surrounds the thoracic trachea at the inner valve; this ring receives the insertion of a muscle, which undoubtedly alters the tension of the basilar membrane. In- 
creased tension of this membrane must increase the length of the great rods, hence I regard it as a muscle of accommodation (Pl. XXXVIII., Fig. 2). I shall hereafter explain that its probable action differs from that of the ciliary muscle in Vertebrates, although I have spoken of it as 'accommodation' for want of a distinctive term.

\section{b. The Retina and Optic Nerve.}

The Retina is termed the periopticon by Hickson. It consists of true bacilli or retinal rods, which extend from its inner to its outer surface. The inner extremities of these rods rest upon a fine membrane, the membrana limitans interna, and are continuous with the fibrils of the optic nerve. Their outer ends are contiguous with the membrana basilaris of the dioptron. These rods are arranged in fasciculi, retinulæ, and each retinula corresponds with an ommateum, and consists of a central rod surrounded by six or seven peripheral rods. Each retinula is surrounded by a delicate membranous sheath, which extends from the basilar membrane to the membrana limitans interna.

The bacilli or rods are formed of two segments, like the bacilli of the retina of the simple eye, an outer cylindrical transparent segment and an inner granular protoplasmic segment. The inner segments differ from the inner segments of the rods of the simple eye in not having any nucleus; in this respect they resemble the inner segments of the cones of the vertebrate eye.

The principal difference between these elements and the rods and cones of the vertebrate retina is, that the transparent, rod-like outer segments correspond with the outer segments of the cones and rods of the Vertebrate; the rods are not reversed, but are turned towards the light, not from it, as they are in vertebrate retina. In all other respects-size, form and structure - the two are exceedingly similar.

The outer ends of the retinulæ are closely surrounded by numerous small round cells, the chaplet cells of Viallanes; the existence of these cells renders the observation of the outer 
ends of the rods difficult, as in all but very thin sections these cells cover either the upper or lower surfice of the rods.

The Chaplet Cells of Viallanes.-The outer segment of each retinula is only about half the diameter of its inner segment, and the interspaces between the retinula are filled with these cells; so that the retina appears in many sections to consist of two layers, an inner palisade layer (the layer of Carriere) and an outer layer of cells, the round nuclei of which bear so close a resemblance to those of the nerve cells of the optic ganglion that one is tempted to believe that they are nerve elements. Similar cells are seen in the retine of many insects, but they are by no means universally present. In thin sections the fact

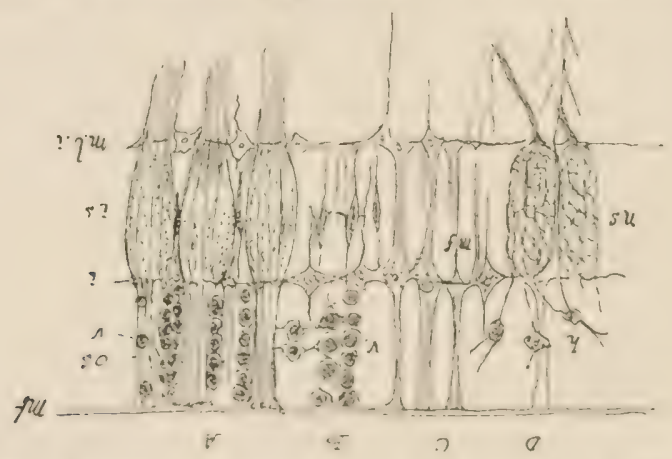

FIc. 6y.- I semi-liagrammatic representation of the retina of the lihow-1ly showing the various appearances seen in different preparations. A, the normal appearance of the hacilli; $J$, spaces from which lacilli have disapprarcd, showing the connective reticulum and the chaplet cells of Viallanes; $C$, the connective reticulum only, showing the flat surfaces of the connecting bands between the internal and external limiting membranes; $D$, Tracheal network and cells, "the neuro-spongial network' of Hickson; $m$ l, membrana limitans externa ; $m l i$, membrana limitans interna; $i$, intermediate fibro cellular reticulum ; $o s$, outer segments of the bacilli; $i$ s, inner segments of the bacilli ; $v$, chaplet cells of Viallanes; $m f$, Millerian fibres; $n s$, tracheal capillaries surrouncling the inner segments of the bacilli; h, cells connected with the finest tracheal capillaries.

that these cells merely surround the bacillary elements is easily demonstrated.

There are two views with regard to the nature of these cells. They may be the representatives of the pigment cells (tapetum) which surround the outer ends of the rods in many insects; as pirment is absent or very feebly developed in this region in the 
Blow-fly and in those insects in which the chaplet cells are most conspicuous; or they may be true nervous elements.

My own opinion inclines entirely to the first of these views. I regard them as mesoblastic elements which form the outer surface of the neuroblast from which the retina is developed, and which grow in between the bacillary elements, and form a kind of sustentacular framework. They are possibly analogous to the pigment epithelium of Vertebrates, although, like the choroid of the latter, they have a mesoblastic origin.

In support of this view, I may mention that they first appear as an invagination (Fig. 63, p), and that their behaviour with stains is somewhat different to that of the nerve cells of the ganglia. They colour more feebly. In specimens prepared with gold chloride they exhibit the form of a continuous network (Pl. XXXVIII., Fig. 5, $f$ ), and in their deeper layers this is easily seen in tangental sections; they are entirely replaced by fringed pigment cells in noctuid Moths and in many other insects.

It must be admitted, however, that, tempting as this explanation of their nature is, the observations of Viallanes and of Hickson lead to a different conclusion. Viallanes states that they form chaplets and are not connected with each other transversely, and Hickson gives some remarkable figures from specimens fixed with gold chloride and subsequently teased out. I confess I have been unable to obtain specimens such as he figures. His figures are, however, very remarkable [237, Figs. I6 and I7). What he terms a neurospongium is evidently, I think, a tracheal capillary network, but he represents fine fibres, which he regards as nerve fibres, connecting these cells on the one hand with the optic nerve, and on the other with the socalled palisade cells of Carriere, my proximal segments of the bacilli.

The Pigmented Tapetum.-One of the principal objections advanced against the views here advocated is that in most insects a thick layer of opaque pigment intervenes between the palisade layer of Carriere and the membrana basilaris. This is especially the case in noctuid Moths. This pigmented layer takes the place of the chaplet cells, and, according to my 
observations, surrounds, but does not cover, the outer ends of the retinal rods, which perforate the pigmented tissue and terminate in juxtaposition with the membrana basilaris. If these pioment cells are the representatives of the cells, the nuclei of which are termed chaplet cells by Viallanes, as I believe they are, the latter are clearly not nervous elements in the sense in which the term is used by previous writers, although the cells in question undoubtedly originate from the retinal neuroblast.

The Palisade Cells of Carrière-These are undoubtedly the structures which I describe as the proximal elements of the retinulae. Carriere describes them as nucleated cells. Hickson discovered that the nuclei lie in their sheaths, and this statement is undoubtedly correct. They contain no nuclei, and each consists of a bundle usually of seren fusiform enlargements of the fibres of the optic nerve. These elements, which I formerly termed fascelli, are surrounded by a sustentacular sheath, and each sheath exhibits a single nucleus. The sustentacular sheath is pigmented in Noctuids and consists of threadlike fibres similar to the fringes of the retinal pigment cells of Vertebrates.

The Distal Segments of the Bacilli are usually very slender, but expand at their outer ends; they are highly refractive, and frequently exhibit longitudinal strice in preparations fixed in osmium peroxide. They are frequently curved and vacuolated. The demonstration of these elements is difficult, but in successful preparations their similarity to the outer segments of the rods and cones of vertebrates is most striking, and everyone who has worked at the histology of the vertebrate retina knows that in many Vertebrates it is by no means easy to preserve these structures in a satisfactory manner.

Lilie the distal outer segments of the vertebrate retina, these structures resist most stains, but they can be coloured with diffuse aniline stains; the coloration is, however, usually evanescent. Such preparations should be cleared with xylol and carbolic acid, as oil of cloves usually removes all traces of the stain in a few minutes. 
In P1. XXXVIII., Fig. 5, some of the various forms assumed by these elements are represented, the most remarkable of which are perhaps the twin cones. I am unable to localise the precise localities characterised by these, as I have only seen them in specimens in which the retinal elements were dissociated by teasing with needles.

The Optic Nerve, the external chiasma of Viallanes, consists of large, very definite fibres crossing each other in the horizontal plane. In preparations fixed with osmium peroxide these fibres are much blackened and their outline is very distinct. In preparations made after prolonged treatment with alcohol and chloroform, as in all paraffin imbedded sections, the optic chiasma has lost its opaque character. In many insects, as in Noctuids, the optic nerve fibres form huge bundles which suddenly cease in the end organs of my retina. The fine fibres supposed by Hickson, Patten, and others to enter the great rods, are minute structures. Their aggregate bulk is not, perhaps, one thousandth part of that of the fibres of the optic nerve. If the great bundles of nerve fibres of the chiasma passed into the great rods the connection would be apparent enough. But no one has seen such a connection. It is true Hickson gives a figure [23\%, Fig. 2I] of what he takes to be the passage of nerve fibres into the dioptron in Agrion bifurcatum, but his nerve fibres end abruptly, and the supposed connection consists of cells which, I have not the slightest doubt, are in reality connective-tissue elements. I cannot understand how he reconciles this figure with such figures as he gives of what he terms his neurospongial network [237, Figs. I6, I7, 3I-32].

The supposed terminals in the great rods and cone described by Patten, and in the great rods by Hickson, are as fine as the intra-epithelial corneal nervous network of a vertebrate, and bear about the same proportion to the optic nerve of the Arthropod as this bears to the optic nerve in the Vertebrata. The authors who maintain that such fine fibres exist in the dioptron and are really nerve terminals of the optic nerve, seem to have lost sight of the fact that the optic nerve of an 
insect is far the largest nerve in its body, that it is connected with enomous xanglia, and that the whole of the nerve fibres they imagine they have seen would not make up one-thousandth part of its bulk.

No doubt the optic nerve appears much less bulky in specinens made by imbedding the object in paraffin; when, however, the optic nerve has been treated with alcohol, chloroform, often with ether, and soaked for hours in hot paraffin, it is no longer opaque, but transparent, and all but its proteid constituents have been dissolved. The optic nerve seen in the recent condition is large and opaque, is quite white, and its fibres are by no means fine. Whilst the recent dioptron is transparent the whole of the nervous structures are opaque with the exception of the outer ends of the retinal rods.

The Tracheæ of the Retina.-Two sets of tracheal vessels may be said to belong to the retina. One set, which are very fine and which penetrate between the fibres of the optic nerve, form a delicate network all over each fasciculus of retinal end organs, as far as the outer extremity of their inner segments. The other, which consists of moderate-sized vessels, form a reticulum in the basilar membrane between the retinule and give off the tracheal vessels of the dioptron, which perforate the cuticular layer of the basilar membrane and course outwards between the great rods.

In Eristalis the vessels of this reticulum are very much larerer than in the I3low-fly, and the corresponding vessels of the dioptron are also very large. Exner speaks of such trachex as a tapetum.

\section{THE DEVELOPMENT OF THE COMPOUND EYE.}

\section{a. In Arthropoda generally.}

It has long been known that the number of ommatea in the compound eye increases with each ectysis in many Crustacea, new ommatea appearing around the circumference of the eye. The same kind of increase takes place in the ametabolic 
Insecta, a fact which must be very well known, although I have been unable to find an explicit statement that such is the case.

In some young Cockroaches (Periplaneta orientalis), less than I centimetre long, I found the compound eye has about 200 ommatea, in which the pigment is developed, surrounded by two or three rings of non-pigmented ommatea. In the half-grown insect I estimated that the number has increased to about 4,000 , with a narrow ring of non-pigmented ommatea ; whilst the full-grown Cockroach has about 8,000 ommatea, all pigmented, in each eye.

In the Metabola, in which the compound eyes are not developed until the final ecdysis, there is no such peripheral growth of the eye; but I observed long ago that the peripheral ommatea are much less perfectly developed than the central ommatea in all the earlier stages of development, and in the Flies they frequently remain rudimentary throughout the whole life of the insect.

In the Cockroach, as I observed formerly [233], there is a great difference between the changes which occur in the different ecdyses. Usually new nerves bud out from the hemispheres with each addition to the number of ommatea, so that in the young Cockroach the compound eye is innervated by bundles of thick nerves, each supplying a small group of

\section{Bibliography :}

253. Bobretzki, N., Ke Émbriologhī Chlenīstonoghìkh ("On the Embryology of Arthropods'). Zapīskī Kiev. Obshchest. Estestvois., iii. (part 2), 1873, pp. 129-263: 6 pls.

254. BObRetzki, N. V., Ke voprosu o proīskhozhdeniī blastodermuí u nasyekomuikh ('On the Origin of the Blastoderm of Insects'). Zapīski Kiev. Obshchest. Estestvois., v., I877, pp. 239-256.

255. Reichenbach, H., 'Studien zur Entwicklungsgeschichte des Flusskrebses. Abh. Senckenberg. Naturf. Gess., Bd. xiv., I 886.

256. Kingsley, I. S., 'The Development' of the Compound Eye of Crangon.' Journ. of Morphology, vol. i., I887.

257. Bernard, H. M., 'The Apodidx; a Morphological Study.' Nature series, 8vo, London and New York. 1892.

258. Johınsen, H., 'Die Entwicklung des Imagoauges von Vanessa urticæ.' Zoologische Jahrbücher (Spengel), Band vi., Abth. Anat., 1893. 
ommatea; but when the final ecdysis occurs, a new optic nerve and retina is developed, which replaces all the partial nerves and retine of the larval form (Fig. 70). This is formed within the hemisphere, and grows outwards until it reaches the inner surface of the dioptron; the partial retine undergo histolytic degeneration during its development. I think it

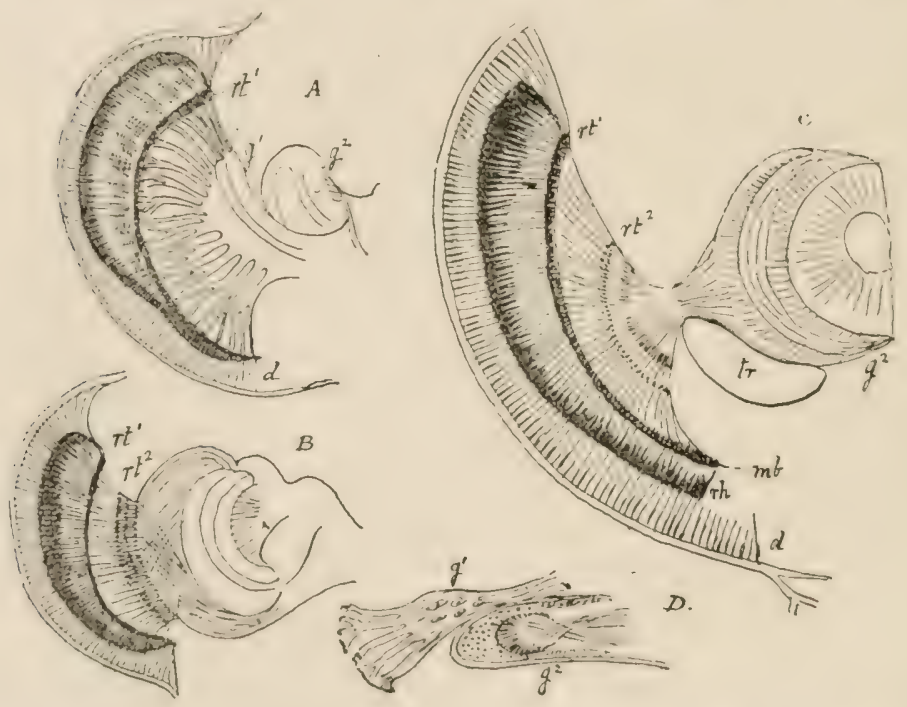

FIG. 70.-The development of the retina in the compound eye of a Dragon-fly (Agrion) and of the Cockroach (Periplaneta). A, a section of the eye and optic nerves of the larva of agrion from a specimen $12 \mathrm{~mm}$. long; $B$. a similar section from a more advanced larva; $C$, a similar section from the nymph of the same; 1), a section through the optic ganglion and nerve of a young Cockroach larva; $d$, the dioptron; $s^{\mathbb{I}}$, the ganglion from which the larval optic nerves arise; $\xi^{\prime \prime}$, the optic ganglion of the imago in a more or less rudimentary condition; $m b$, the membrana basilaris; $r t^{1}$, the retina of the larva consisting of separate retinule; $r t^{2}$, the retina of the imago in a more or less rudimentary condition; tr, tracheal vessel. Reproduced from my paper [233] in the Trans. of the Limn. Soc.

exceclingly probable that the remarkable 'kidney-shaped' bolies described by Newton [213], in the optic ganglia of the lobster, are retine and optic nerves, which replace the old retinx in successive ecdyses.

Even in the Metabola there are traces of the development 
characteristic of the Ametabola. In many insects, as the noctuid and crepuscularian Moths (Lepidoptera hetcrocera), the retina is segregate-that is, groups of ommatea have distinct nerves, just as in the larval Neuroptera (Libellula). In the Muscidæ and the imago of the Libellulidæ the retina is always continuous, and a single thick decussating nerve supplies the whole eye. In the Gnats and Tipulidæ (Diptera ncmatocera) the retinæ are always, so far as I know, segregate, and the compound eyes come into functional activity in the active nymphs in the aquatic species. The several stages in the development of the continuous retina of the Dragon-flies (Libellula) are represented in Fig. 70.

Historical and Critical-Recent writers on the development of the compound eye in Arthropods have almost entirely devoted their attention to an attempt to form a plan or scheme which shall serve as a morphological type to bring into accord the various kinds of compound eye, which they believe exist in Arthropods.

The statements made are chiefly supported by little evidence and much argument; some, as Carrière [232] and Parker [250], maintain that the whole structure originates in a simple thickening of the epidermal layers, and there is no doubt, as far as the dioptron is concerned, this statement is partly correct. Others, as Bobretzki [253], Reichenbach [255], Kingsley [256], and Patten [239], state that it is formed as an invagination of the epidermic layer. That the eye is situated in many Arthropods, both Crustacea and Insecta, either permanently or temporarily in an invagination of the integument is indubitable-compare for example the eye in Apus (Bernard [257]), and the invaginated eye-disc of the dipterous larva-so that, in some Arthropods at least, the truth is apparently on the side of the invagination theory. All these observers, however, think that the eye is developed from the whole invagination, which becomes, according to them, flattened out, so that three layers are subsequently formed, and they are all at variance as to what becomes of these layers. According to Reichenbach, the cavity of the vesicle disappears at an early 
period, and a mass of cells results from the fusion of its inner and outer layers. Two new layers now make their appearance, not necessarily corresponding to the inner and outer layers of the vesicle. The superficial epidermis and the outer layer are then supposed to fuse with each other, and to give rise to the retina (my dioptron). The inner layer becomes the nerve ganglion of the eye: the crystalline cones are developed from the superficial epidermis, and the rhabdia from the deeper layer. I have little doubt that Reichenbach's view has arisen from a misinterpretation of the manner in which the primary involution, when it exists, disappears. Certainly there is nothing in the development of the Blow-fly to support his view.

Bobretzki has not apparently seen the involution, and in other matters he entirely agrees with or follows Reichenbach.

Patten thinks that the superficial epidermis forms the cornea, that the outer layer of the flattened vesicle disappears, and that the inner layer forms the rest of the dioptron, which he calls the retina; whilst Kingsley says the outer wall of the vesicle (in Crangon) forms the retina (my dioptron), whilst the inner wall is converted into part of the optic ganglion.

Parker [250] has examined the eye in its most rudimentary form in the same Crustaceans as the authors above quoted, and denies that any invagination occurs. He says the dioptron, which he calls the retina, is developed from a thickening of the epiblast.

According to Parker, the eye in the Crustacea is formed close to the neural plate, so that the supra-cesophageal ganglia lie at its inner margin, and are continuous with the cells from which the dioptron is developed. This may be so, but judging from Parker's drawings, an outerowth of the neural plate extends bencath the dioptron, separated from it by a distinct fissure; and the appearances he represents are susceptible of an interpretation, which is quite consistent with the view I have adopted.

Buth Claparide and Weismann, however, gave a totally 
different description of the manner in which the compound eye is developed, and their observations agree very closely with my own. Claparède, describing the development of the eye in Vanessa and in some Hymenoptera, stated that it is formed from two layers-one derived from the supra-œsophageal ganglion, from which the nervous elements are formed, and the other from the cutaneous hypoderm, which becomes the nonnervous part of the eye. He says: "The eye is formed from two parts, which remain for a long time distinct, of which one, derived from the hemisphere of the larva, becomes the purely nervous part, the optic ganglion; whilst the other forms the faceted cornea, the chamber, the crystalline cone, and the prismatic so-called nervenstab and its envelopes. All these parts originate from the same cell mass, out of which the antennæ, the proboscis, and the whole head are developed.'

Weismann, describing the development of the eye in Musca, says: 'On the fifth day of the pupa the optic ganglion consists of a nearly spherical cell mass, which is about double the size of the rest of the supra-œsophageal ganglion, from which it is developed by the formation of a constriction. I term this purely nervous part of the eye the bulbus. The bulbus is attached by a broad base to the supra-œsophageal ganglion, and is covered on its outer surface by the lappet-like (lappenformigen) eye disc.

'Between the bulbus and the disc a thin layer of fat and granule cells penetrates, from which very probably the cells are developed, which unite the two surfaces.

' Let us first follow the development of the eye disc, which is a thin cellular layer of considerable extent, enveloping the anterior part of the central nervous system like a watch-glass. Its outer surface at the time of going into the pupa exhibits already an arrangement of cells, representing the corneal facets. They are like the cells of the other imaginal discs but larger, spheroidal, very transparent, and covered by a thin membrane.

' The thickness of the eye disc, even on the twelfth day, in Sarcophaga is so little that it is easy to believe that it only forms the cornea. It is then only ${ }^{\circ} \mathrm{O} 5 \mathrm{~mm}$., but it contains all 
the elements which belong to the dioptric apparatus, including the great rods (Nervenstäbe).'

With regard to the manner in which the bulbus comes into relation with the eye disc Weismann's description is not very clear, but he insists "that in Sarcophaga the union between the eye disc and the bulbus is not complete on the twelfth day, and that it is easy to separate them with a hair pencil,' and he says 'much intervening fat is still found'; and concludes by saying, "The morphological value of the different parts of the eye is as follows: the cornea is the chitinous skeleton; the other parts of the eye-chamber (the crystalline cones, nerverods, and their investments) are modified hypodermis; all the central structures (the ganglion layers and bulbus) are formed as outgrowths from the nervous system.'

Thus so far as Weismann's observations carried him he entirely agrees with my own views, but it must ke admitted that he thought that the nervous elements penetrate the visual rod (schstab), and he supposed that the nerve fibres are developed in the layer of fat between the outer part of the bulbus and the disc from the remains of the stalk of the optic disc, a view which is entirely disproved by the examination of sections made at various periods of development.

As has been already stated, I hold that the compound eye is developed from two distinct sources, that the dioptron originates from the dermal epiblast, and that the retina is an outgrowth from the central nervous system or from the neural plate. The intervening parablastic cells from which the trachex (or bloodvessels in the Crustacea) are derived, also play an important part in the development of the dioptron similar to that which the mesoblast takes in the development of the vertebrate eye.

I shall now proceed to grive an account of my own observations and conclusions in detail.

\section{DESCRIPTION OF PLATE XXXVII.}

A lateral section through the cephalic nerve-centres and part of the dioptron of a Blow-lly nymph on the fourth day of the pupa state. $c c$, the sub-dioptric space; $d$, dioptron; $0 g$, optic ganglion; $0 n$, the zone of the optic nerve; $o s, o s$, optic stalk; $p$, pyramidal ganglion; $r$, retina; $t h$, the thalamon. 


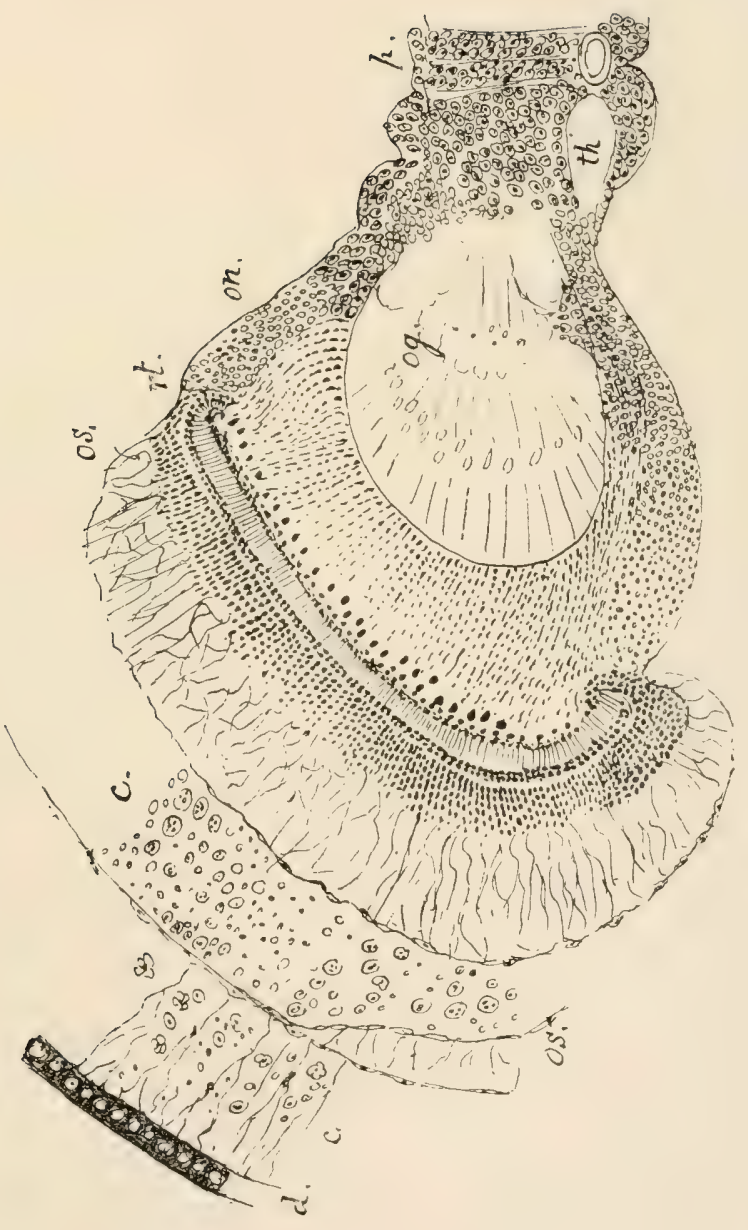

$\dot{\Delta}$
$\vdots$
0
0
0
$z$
0
0
0
$z$
0
0
0
0
0 



\section{b. The Development of the Compound Eye in the Blow-fly.}

It will be convenient to divide the development of the eye into four stages.

First Stage of Development.-In the larva of the Blow-fly the optic disc is connected with the central nervous system by the optic stalk, WVeismann's Nervensticl, so that it has the form of a mushroom, the optic stalk forming its stem. The relation of the optic stalk with the central nervous system indicates undoubtedly that it is a rudimentary optic nerve; it consists chiefly of neuroblastic cells and their processes, and exhibits a distinct central cavity (Pls. III. and IV., os). It expands beneath the optic disc, and may represent a rudimentary retina; and it is covered by a thin layer of parablastic cells, its peritoneal covering.

In this stage the eye disc differs in no respect from the other imaginal discs, so that there is no reason to suppose that its nervous stalk possesses any functional activity as a nerve of sight. The disc is neither pigmented nor has it any special end organs. I regard the stalk of the optic disc as the morphological representative of the optic nerve and retina of the larval eye in the Ametabola.

Second Stage of Development.-This stage is seen in nymphs on the third day of the pupa. The neural disc of the optic stalk separates from the dermal disc except at its periphery (Fig. 7I); and the intermediate space, the sub-dioptric space, is seen to be occupied by a delicate reticulum of branching cells, the inter-spaces of which are filled with blood and granule cells.

The neural disc exhibits distinct fibres, resembling those of the stalk, and these either end in cells, which are imbedded in the substance of the disc, or in flattened epithelial elements which form a distinct layer on the external surface of the disc. These cells are apparently continuous with the peritoneal investment of the optic stalk (Pl. XXXVIII., Fig. 6, $n d)$.

The branching cells of the sub-dioptric space are connected 
on the one hand with the epithelioid membrane covering the neural disc, and on the other penetrate the integumental layer or optic disc. These connecting fibres are at first exceedingly fine and are frequently torn through by the contraction of the tissues which accompanies their hardening, but a day or two later they are very distinct (Pl. XXXIX.).

The cells of the integumental disc are scen to be arranged in columns, each column corresponding to a future ommateum.

It is exceedingly difficult to determine the number of cells

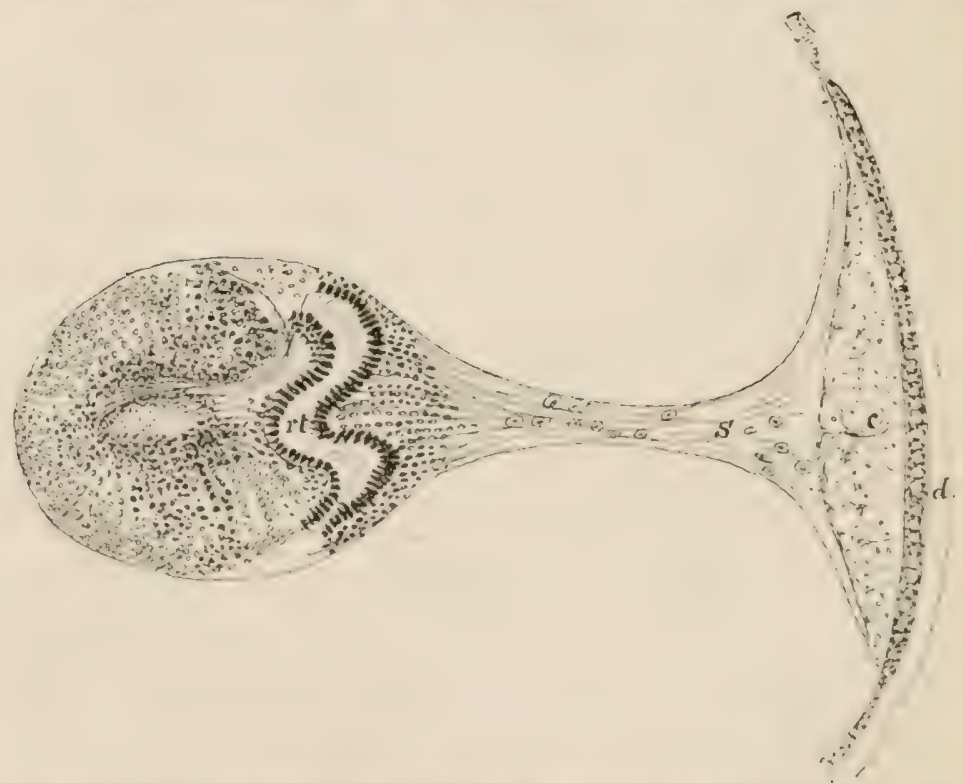

Fici. 7I. - A section through the optic disc and ganglion of a Blow-fly nymph about the middle of the third day of the pupa stage. c, the sub-lioptric space; $d$, the optic dise; $s$, the optic stalk, spreading out into the neural disc; $r t$, the rudimentary retina of the imago.

in cach column, but it is quite evident that they are very numerous and form four more or less distinct layers, a corneal layer, a series of bundles of long fusiform cells beneath the corncal layer, a double layer of round cells, and an inner columnar layer.

When seen from the surface the integumental disc already 
appears to be faceted, each column of cells forming one facet. This led Viallanes [27] to describe the disc in this stage as consisting of a layer of large cells, which he termed optogenic cells.

During these changes the optic stalk becomes hollow and exhibits a distinct central cavity which extends to the surface of the retinal disc (Fig. 46).

Third Stage of Development.-On the fourth day of the pupa state, or immediately after the evolution of the head, the optic stalk has become greatly elongated, and the neural layer of the disc is already very thin; the sub-dioptric cavity has greatly increased in size and contains many granule cells. It is seen to be lined by a cellular membrane, and the processes of the cells, which form a reticulum connecting the neural and epidermal discs, can be traced into the integumental disc (Pl. XXXVIII., Fig. 6). At this period the eye disc measures $7 \mathrm{~mm}$. in its short and about $\mathrm{I}^{\circ} 4 \mathrm{~mm}$. in its long diameter, but it is only OI $5 \mathrm{~mm}$. thick, whilst its neural layer is separated from it by a space ${ }^{\circ} 05 \mathrm{~mm}$. deep in the centre of the eye, and is itself not more than ${ }^{\circ} 005 \mathrm{~mm}$. thick.

Each ommateum is now seen to contain an ovoid body which does not stain with logwood, and which has a gelatinous appearance similar to the bulb-like so-called nerve terminals of the King-crabs (Limulus). This body is undoubtedly connected with a fibre from one of the cells of the sub-dioptric space, and is, therefore, of mesoblastic origin. In some of my sections the cells of the rhabdome, which subsequently become pigmented, are seen forming a distinct layer on the surface of these ovoid bodies (Pl. XXXVIII., Fig. 6).

The Eye of Limulus.-The eye of Limulus has been described by Grenacher [222], and by Lankester and Bourne [229]. The former speaks of the rhabdome as resembling an orange, the great cells representing the quarters. Lankester and Bourne figure this body as a hollow spheroid, and state that it is surrounded by intrusive connective tissue. Both authors agree in describing this body as a retina. My contention is that it is the homologue of the rhabdome of an insect's eye, 
and in this I agree with the authors cited, but I deny its possible retinal character. How Lankester could have thought the organ represented in his figures, and especially in Fig. 20, [229], could be a retina, is incomprehensible to me. A comparison of this organ in Limulus with the same structures represented by me in the simple eyes of Caterpillars [233] and reproduced in Pl. XXXVIII., Iig. S, renders it probable that the true retinal end organs have been hitherto overlooked in Limulus, and a comparison of these figures with Grenacher's representation of an ommateum from Hyperia Galba 222, Fig. IO.t], which is almost identical with my figure of the eyes of Caterpillars, appears to me conclusive that the true retina of Limulus has been overlooked. What Grenacher

Description of Plate XXXVili.

The details of the compound eye :

Fic. I. - A portion of the dioptron of a Blow-fly Nymph on the ninth or tenth day of the pupa state, showing the relation of the tracheal vessels $(t r)$ to the cells of the sub-dioptric space $(m)$.

FIG. 2.-The dioptron of a Blow-fly seen from its inner surface, showing the sclerite in the margin of the basilar membrane ; $m c$, ciliary muscle; $t r$, trachere surrounding the retina. The retina and all the nervous structures have been removed.

Fig. 3. - Two of the ommatea of a I'lume Moth (Pterophorus) showing the lens-like rhabdomes. $c$, corres $s$, crystalline cone; $l$, corneal lens; $m b$, membrana basilaris.

FiG. 4-A section of the eye of Copilia (after Claus copied from Exner [252]). C, cornea; $l$, lens; $v$, vitreous space; $r / h$, rhabdome; $r l$, retina; $n$, optic nerve. The nomenclature of the structures is in accordance with my own views.

FIG. 5.-Modificatiuns of the nerve end organs of the retina. $a$, dissociated twin cones from the retina of a Blow-fly; $b$, a group of similar cones from the retina of a Cockroach (Periplaneta orientalis); $c$, vacuolated rods from the retina of a Blow-fly, osmic acirl preparation; $d$, isslated rods from the retina of a Noctuid Moth (probably lyluflutia s.) ; $c$, two of the retinulie of a Sphinx Moth (Acherontia sp.), from a large foreign pupa received in spirit; $f$, a tangental section through the outer part of the retina of a Blow-fly pupa in an advanced stage of development showing the reticulum formed by the chaplet cells of Viallanes.

Fra. 7.-Fortions of tangental sections through the dioptron of a Blow-fly just before the end of the pupa stage. $A$, the pseudo-cone ; $B$, iris cells; $C$, section through a group of rhablomes; $A$, pigment fringes; th, rhabdome; $t /$, tracheal vessels.

FIG. S. A ralial section of the eye of a Noctuid Caterpillar copied from my paper in the Linn. Soc. Trans. [233]; $c$, cornea; l, lens; $r$, rhabdome; rt, retina; $p c$, pigment cells, and $n$, optic nerve.

FIs. 9. - A diagram showing the manner in which the images are formed, according to the dioptric theory, by an ommateum. $s i$, sub-corneal image, and $r i$, retinal image. 
FIG. I.
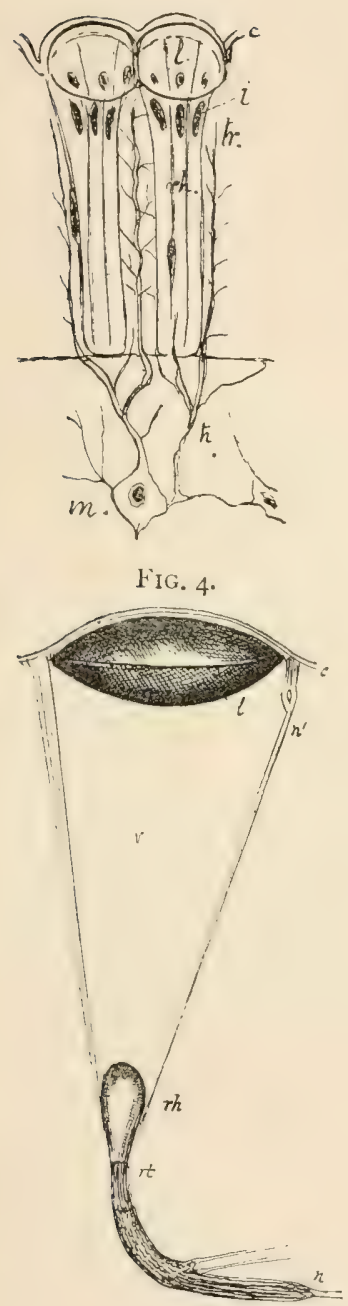

FIG. 5.

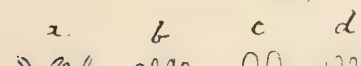

(1)

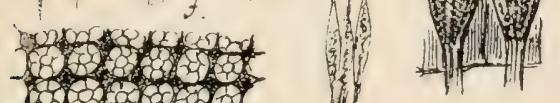

Fig. 2.

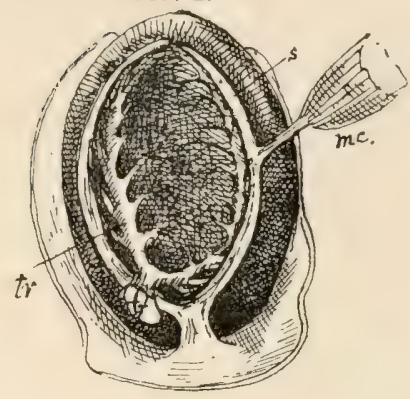

FIG. 6.

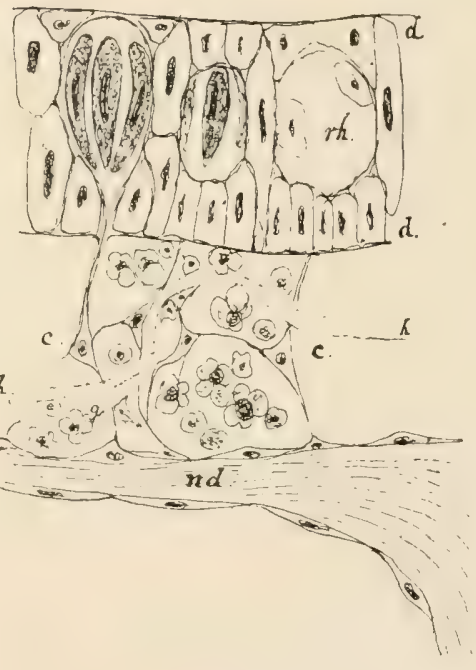

FIG. 7.
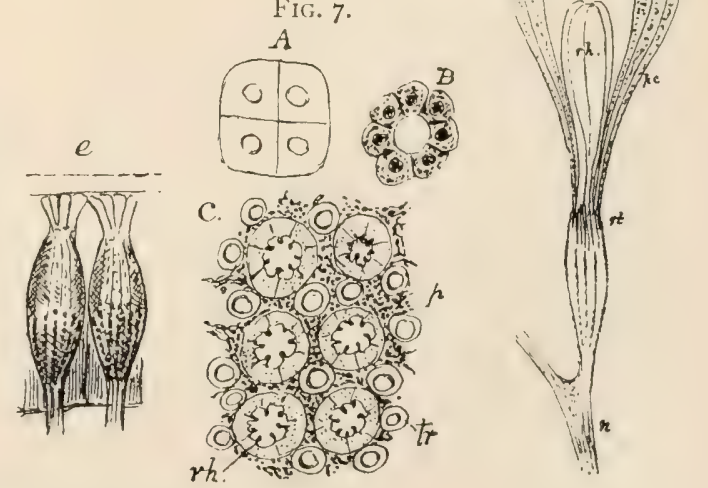

FIG. 3 .

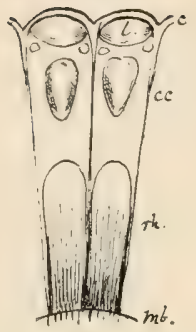

FIG. 9.

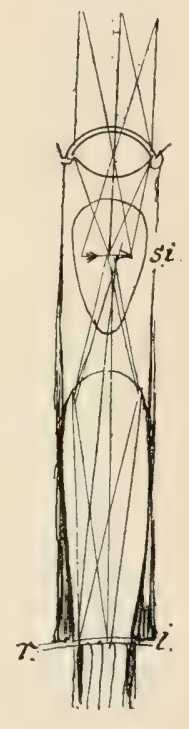

FIG. 8.

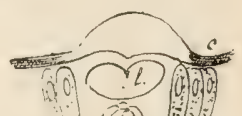

DETAILS OF THE COMPOUND EXE. 

terms a crystalline cone ( $\mathrm{Kk}$ in his figure), is so evidently a rhabdome, whilst he actually figures a retina (Scnsu mitii) beneath it, which he terms a rhabdome $(R m)$.

The Origin of the Rhabdome from the mesoblast was certainly unexpected by me until very recently, but this origin accounts for the very remarkable similarity which exists between the rhabdomes of insects and the tracheal vessels, and it further accounts for its intrusion into the epithelial layers as well as its intimate relation with the retinal end organs of Hyperia, of the-simple eyes of Caterpillars, and in the compound eyes of the larval form of the Ametabola as well as of the Crustacea generally, for although in the higher Insects it is always easy to separate the retina from the rhabdomes, in many Arthropods the connection is undoubtedly very intimate, and it is possible that in some no retina exists, the eyes being in that case functionless, as they are undoubtedly in the Blow-fly nymph, and in the larvæ and pupæ of most Metabola.

In this stage of the Blow-fly nymph I have been quite unable to discover any retinal end organs, but if the connective cell uniting the neural disc with the rudimentary rhabdome were replaced by a nerve fibre ending in a single retinal end organ, or by a small bundle of nerve fibres terminating in a group of end organs, the condition of the eye would be similar to that seen in the simple eyes of Caterpillars, in the ommatea of the larval Gnat, and in such Crustacea as Hyperia. The absence of nerves and end organs in the rudimentary ommatea of the Blow-fly nymph is quite explicable as the result of their total want of functional activity.

Fourth Stage of Development (tenth or eleventh day of the pupa).-In this stage the rhabdomes are greatly increased in length, so that the epidermal disc has attained a thickness of I2 $5 \mathrm{~mm}$. The number of cells is apparently the same as at the earlier stage, but as these have not become greatly enlarged they are more widely separated. The principal change which has occurred is that the ovoid body has become cylindrical, and numerous tracheæ are seen between the rhabdomes with branching nucleated cells on their walls (Pl. XXXVIII., Fig. I). 
The fact that each rhabdome has only a single nucleus on its surface which projects from it, is very manifest at this and in all subsequent stares in the nymph; such rhabdomes are figured by Weismann $[2(\mathrm{Fig} \cdot 55, \mathrm{~F}$.) $]$ with only a single nucleus.

The epithelial elements at this stage are four sub-corneal nuclei, the five iris cells and five cells at the inner extremity of each rhabdome.

In Immature Diptera, Eristalis and Musca even some hours after their escape from the pupa, the rhabdomes are seen to be connected in some specimens at their inner extremities with large stellate cells (Pl. XXXIX.) which lie in great numbers between the outer surface of the retina and the inner surface of the dioptron in the pupa. I formerly figured this connection [219, Figs. 9, I2, and I3], and mistook them for ganglion cells ; these cells gradually disappear as the retina comes up to the basilar membrane. I have recently examined a number of specimens prepared by my friend Brigade-Surgeon Scriven, in which the connection of these cells with the rhabdomes is very distinctly seen in an immature imagro, although the retina is close to the inner end of the rhabdomes, and the cells in question are flattened. These cells surround the trachea of the sub-dioptric space, but are distinctly separated from the retinal end organs by the flattened pre-retinal cells (Pl. XXXIX.pr).

The Morphology of the Rhabdome-It appears to me that the rhabdome must be regarded as a mesoblastic, or parablastic structure, developed from the same kind of cells as the tracheal vesscls. It is worthy of remark that the formation of a cuticular sac within a single cell only occurs in the trachea and the rhabdomes; and when the tracheal intima is first developed within the cells from which the smaller trachea origrinate, this sac is filled with fluid, which is only subsequently replaced by air.

That the parablastic elements of the trachea penetrate the dioptron is undoubted, and in many of my preparations the gelatinous ovoid body from which the rhabdome is developed is undrubtedly connected with the branching cells from which the trachea origrinate. In its mesoblastic origin the rhabdome 
therefore, if I am right, corresponds with the vitreous in the Vertebratæ.

Multi-nucleate Rhabdomes.-Although the rhabdomes of the Blow-fly only exhibit one nucleus in the shaft (PI. XXXVIII., Fig. I) there is no doubt whatever that in many Arthropods the rhabdomes are multi-nucleate cells. Grenacher's figures are sufficient evidence of this, and I would draw attention to the strong tendency of the parablastic elements of the mesoblast to become multi-nucleate. Although I have not been able to satisfy myself that this condition is characteristic of any stage of development in the Blow-fly, it is very possible that it is. Amongst the crowded nuclei at the outer end of each rhabdome indicating the pigment cells of the irides and the chamber, it. is impossible to say that some of these do not lie within the great rod; indeed, some appear as if they do. When several nuclei exist in one great rod, portions of the original cell may become independent cells, as they certainly do in Tipula.

The Origin of the Pseudo-cone.-The pseudo-cone is formed from four cells which appear beneath the cornea. Some observers believe these cells are the four sub-corneal cells; this is the opinion of Grenacher, but Patten strongly advocates the view that they form a second layer of cells beneath the sub-corneal cells. I am very much inclined to think they do. It appears to me that the sub-corneal cells are converted into the corneal lens, and that their shrivelled nuclei persist as four minute nuclei, which are always present at the edges of the corneal lenses; I am not, however, in a position to state this with certainty.

The pseudo-cone is undoubtedly formed by the vacuolation of four cells, which are not apparent until a late stage of development, and it appears to me possible that these four cells are developed from the anterior end of the great rod by the separation from it of four nucleated portions of protoplasm. If so, then the pseudo-cone, which encloses the anterior end of the rhabdome, is also mesoblastic in origin. Certainly the cells of the pseudo-cone have nuclei, which are very unlike the four sub-corneal nuclei of an earlier stage. 
Whatever the origin of the cells of the pseudo-cone, I think they are distinct from the sub-corneal cells, but they appear to correspond morpholosically with the cells from which a true cone is developed in the euconic eye, and I am doubtful if this is a mesoblastic structure. It is possible that the cells of the pseudo-cone originate from epiblist, and it is difficult to say at what period they first appear, as they lie amongst the cells which subsequently become pigmented, and form the outer sheath of the chamber and the outer iris cells.

Development of the Basilar Membrane.-Nthough in the adult imago in the Blow-fly and most other insects the basilar membrane is represented by a thin and apparently chitinous transparent membrane with a layer of cells on either surface, the manner in which this membrane is developed indicates that it is by no means so simple as it appears in the adult imago. All the elements of the pre-retinal space disappear during its formation, and the condition of things in the newly-emerged imagro indicates that it is derived from the compressed connective-tissue elements of the pre-retinal space, and that the pre-retinal tracheal network is really imbedded in the substance of this membrane, instead of lying, as it appears to lie, on its inner surface. It is, however, possible that the membrane is formed from the inner surface of the imner pirment cells, which are undoubtedly of epithelial origin, but from its relation to the great rods it appears to me more probable that it is derived from the cells of the pre-retinal lamella or from the intermediate layer of cells in the pre-retinal space, or all three layers of cells may be concerned in its formation.

Development of the Retina.-The origin of the retina from the roof of the vesicle of the cerebron which forms the retinal disc has already been referred to. The evolution of the invaginated retinal rudiment apparently takes place in the following manner :

\section{DESCRIPTION OF PIATE XXXIX.}

A section through a portion of the dioperon and retina of a lilow-ny pupa, three or four days before the end of the pupa stage. b, basilar membrane; s, s, granule cell in the sub-dieptric space; $\hat{f}$, large unesubla-tic cells : $\hat{\imath} r$, pre-retinal lamella ; $r$, retina. 


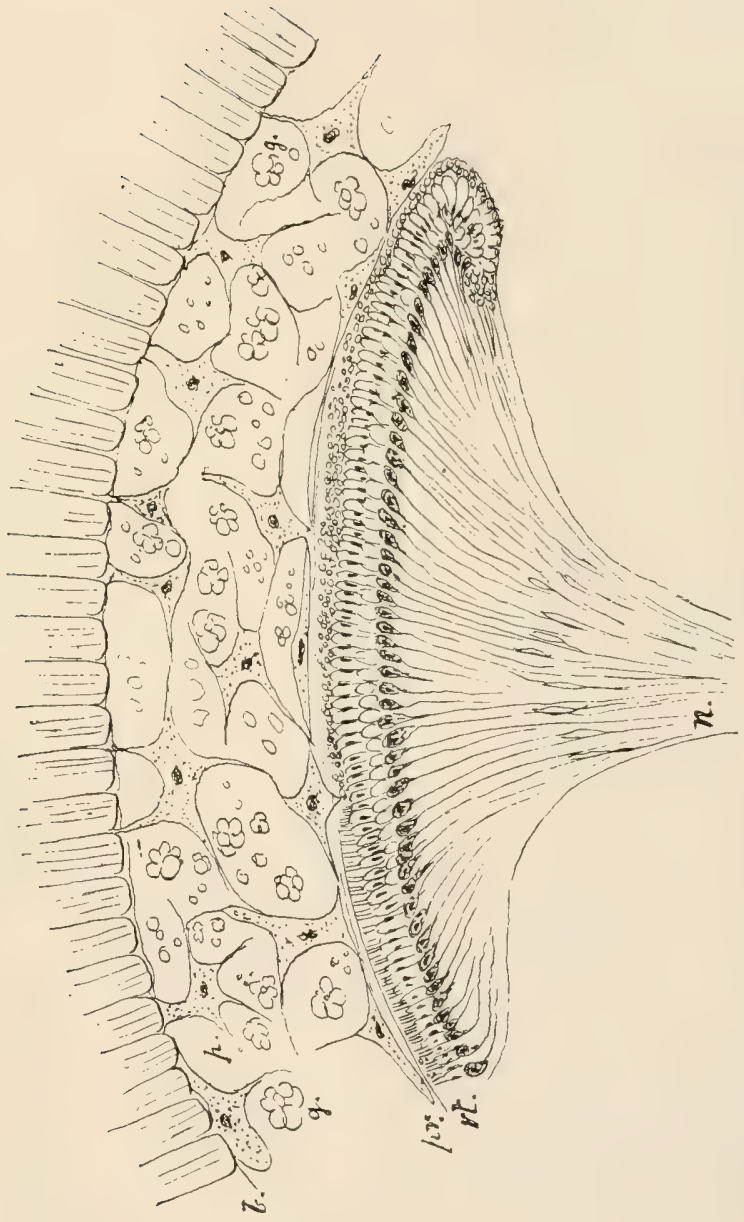

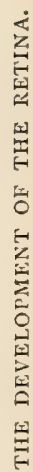



During the third stage of the development of the dioptron, the optic stalk and neural portion of the disc expand and their tissue becomes spongy. The fibrous structure of these parts becomes indistinct, and its elements widely separated from each other. They eventually disappear entirely and the space which they occupied is seen to be filled with delicate retiform tissue.

In the meantime the sub-dioptric space becomes larger, and the mesoblastic cells which occupy it become more numerous and increase rapidly in size. These give off processes which grow into the dioptron, and are gradually converted into tracheal vessels.

In the fourth stage of development the retina has extended into the cavity of the neural portion of the disc, taking the place of the retiform tissue and eventually filling the whole space bounded by the peritoneal coat of the expanded optic stalk and its neural disc.

During the last three or four days of the pupa stage the subdioptric space gradually disappears, and the pre-retinal membrane comes into immediate relation with the basilar membrane.

The Development of the Rotinal End Organs.-These appear to be developed from the epithelial elements of the retinal disc, but I have been unable to follow the whole process. It appears to me that the cells from which they originate undergo considerable elongation, and that their nuclei are displaced inwards so that they lie beneath the end organs, between them and the optic nerve fibres.

The non-inversion of the terminal elements in the sense in which they are said to be inverted in the Vertebrate eye, has already been used as an objection to the views which I have expressed; but there is no involution of the neural epiblast from the commencement, and if the roof of the vesicle of the cerebron originates by delamination from the hypodermis, as I have suggested, no inversion of the retinal elements would occur. Nor do I think that the importance of the position of the rodlets is of so much importance as has been ascribed to 
it morphologically, as it has never been shown that the two ends of a columnar cell are necessarily physiologically dissimilar.

The development of the nerve end organs in the Vertebrate has never been actually traced to the epithelium of the primary optic vesicle; nor have those of the Arthropod been traced directly from the epithelial layer. In both cases their origin from the cells of an earlier stage has been assumed rather than proved.

\section{THE THEORY OF ARTHROPOD VISION.}

Müller's Hypothesis. - Johannes Müller [197], in the year I826, enunciated his well-known theory of 'mosaic vision.' He concluded from the radial arrangement of the Arthropod eye that the retinal image is direct and not inverted, that it consists of a number of points of light corresponding to the number of ommatca, hence the term mosaic, as he compared the picture so formed with a piece of mosaic-work.

Müller conceived that each great rod is a very narrow straight tube isolated from its fellows by a coat of opaque pigment, capable of transmitting a very narrow pencil of light from a point or from a very small surface in the direction of the axis of the tube, to the sentient retina.

It appears to me that Muiller considered the great rods as essentially dioptric structures, although he at one time described them as nerves [198], but since his exposition of the theory these have been regarded, as has been already stated, as nerve terminals. Indeed, Huxley in Isso said : "The only modification needed in the origrinal form of the theory of mosaic vision, is the supposition that part, or the whole, of the visual rod is not merely a passive transmitter of light to a nerve fibre, but is itself in some way concerned in transmuting the mode of motion, lisht, into that other mode of motion which we term nervous energy. The visual rod is, in fact, to be re-

* Iluxley, T. 11., 'The Crayfish : an Introduction to the Sudy of Zoology,' Internat. Sc. Ser., vol. xxviii., London, Paris, and Berlin, 1830. 
garded as the physiological end of the nerve.' In this form the original theory of Müller has been very generally accepted.

I have already discussed the morphological and developmental grounds which lead me to reject this view, and it remains for me to discuss the optical principles on which, I hold, it must be laid aside.

Gottsche [201] first attacked Müller's hypothesis on the ground that a real inverted image is formed behind each corneal lens. The existence of such an image is easily demonstrated and was even known to Leeuwenhock. But various views have been held in relation to its significance. If we admit that the position of this image does not correspond with any receptive or retinal surface, which has been abundantly demonstrated, it can only be regarded as a source of radiant light. It has been argued by some writers that the image is adventitious, that every oil drop produces a similar image; but how this argument can avail those who believe in its nonexistence, or assist in getting rid of a collection of real focal points from which light radiates in diverging pencils, is beyond my comprehension. The sub-corneal image cannot be thus lightly disregarded, as every convex facet must produce pencils of converging rays, just as every spheroid of oil has a focal image of objects behind it. Nor could such a focal plane be neglected if an oil drop were interposed in any optical apparatus. The presence of a sub-corneal image is in itself absolutely destructive of Müller's hypothesis, since all the light proceeding from it must consist of widely divergent pencils. So that the result of the presence of a lens in front of each of Müller's radial tubes would be that less light would penetrate it than if no such lens existed.

Grenacher's Hypothesis.-Grenacher, who is at present generally admitted to be the authority on the compound eye, adopts Müller's view, with the modification already quoted from Huxley, that the great rods are light-transmuting organs. It is difficult to trace the origin of this modification: I think Grenacher first enunciated it in so many words, but there is evidence that it was in the minds of many writers before 1877 , 
when Grenacher first published an abstract of his views [216]. It would appear at first sight that the evidence brought forward by Grenacher must be conclusive, or his views would not have been so generaliy accepted, yet I cannot find a single fact in Grenacher's great monograph [222] which supports his theory. Its only basis is the opinion that the great rods are composed of elements similar to the retinal rods of the simple eyes in Arthropods. Even a cursory glance at Grenacher's figures is sufficient to render such a statement extremely doubtful. The whole theory rests upon this supposed identity, and upon nothing else. The great dissimilarity of the great rods in different Arthropods, the variable size and disposition of the so-called stäbchen, the almost protean appearances they present under different modes of preparation, more especially the diverse characters they present in his own transverse sections, are all ignored, and he takes his stand upon a morphological presumption.

Grenacher discusses the manner in which he supposes the compound eye has been evolved in support of his theory, but attempts no mathematical analysis of the conditions of vision. The outcome of the whole theory from a physical point of view is as follows. Grenacher says:

'If we turn our attention to such an ommateum (Einzelaugc) we learn which rays are physiologically effective on the rhabdome. It is manifest that a thin beam reaches it, parallel with the optic axis. The section of such a beam may be estimated by two factors, the curvature of the refractive media and the thinness of the connecting thread. When the crystalline cones are very pointed, as in Phryganca, the size of this pencil must evidently be very minute, as only straight, that is unrefracted, pencils can pass through, for which the surfaces of immergence and emergence are parallel, which for the apex of the crystalline cone must be minimal.'

Eren admitting that such a narrow pencil has a physiological worth, I would ask, Is it possible that a complex refractive apparatus has been elaborated by nature, not to aid visionnot even as a uscless addition to the eye, but absolutely to 
render the action of the light less effective upon the nerve end organs? A minute transparent rod with a plane surface and low refractive index would be a much more effective mechanical contrivance.

Although Grenacher has attempted no further optical analysis of the function of the compound eye, this has been done by Notthaft, who is a great supporter of Grenacher's views.

Notthaft's Hypothesis.-Notthaft [226] shows at considerable length that objects having a surface equal to a square centimetre are the smallest which produce a distinct visual impression at from half a metre to a metre from an insect eye, and he concludes that for all practical purposes, half a metre to a metre is the greatest distance that vision is possible, and even at this distance it is very defective.

After showing to his own satisfaction that insects are practically blind, he says that it is evident that they are able to guide themselves in their flight, and he explains the manner in which this is accomplished by a very remarkable hypothesis: he supposes that it is only a very thin pencil of parallel rays which excites the retinal end organs; he arrives at the conclusion that the intensity of the illumination of objects, as seen by the insect, decreases with the square of their distance, hence he concludes that it is only near objects which are seen in a dark field of vision, and that insects, when flying, always seek darkness, as in darkness there are no solid objects with which they can come into collision. He seems to forget that black objects would not be seen.

He admits that insects fly to the light of lamps, and thinks that they do so with the idea of settling on a near solid body when they are tired of seeking darkness.

These extraordinary views of Notthaft's appear to be a kind of reductio ad absurdum. If Notthaft's theory were accepted, it would follow that darkness and distance are associated sensations, and all dark places or objects would be infinitely distant. Can one imagine a bee seeking the dark entrance of its hive as an infinitely distant object?-certainly the idea suggests a 
seeking of the infinite scarcely compatible with the practical needs of life.

let it appears that Notthaft's conclusions are consistent with Grenacher's theory of a minimal pencil of parallel rays only acting upon a retina.

If Notthaft's paper had been written to prove the untenable character of Müller's hypothesis from an optical point of view, it would be intelligible; but if I understand it, Notthaft is serious and believes that he has aided in proving its validity.

That he had doubts in his own mind is clear, for he quotes Bates, who asserts that it was long before he could distinguish Humming-birds from the Humming-bird Hawk-moth, Macroslossa titun; and asks 'If it is possible that one of these little creatures can see well and the other hardly at all ?' He carefully proves that insects see as well as birds, or appear to do so; and yet he apparently tries to convince himself of the truth of his 'darkness hypothesis,' as he is satisfied that the compound cye is constructed as Grenacher describes it, and that no other hypothesis can explain its function on principles which are optically possible.

Effect of the Subcorneal Image.-The existence of a subcorneal image, in itself, renders Müller's theory completely untenable. Since the conditions of vision under the theory are most perfect for objects seen by pencils of parallel rays, and every lenticular system which tends to render the rays of light either convergent or divergent would render vision less distinct, and as the small axial pencil only could be effective, since the power of this pencil would be rendered less with every increase of convexity in the lens, it is evident that the existence of a lens would be a disarlvantage and not a benefit to the possessor of a compound eje.

It has been suggested that the lens acts as a condenser, and causes a larger pencil to act upon the nerve end organs; but it is evident that this could only be effected by an increase of the angular aperture of the lens and a corresponding deficiency in the acuity of vision, as it is only by collecting the light from a large surface and condensing it upon a small focal point that a condensing lens is effective. 
It is evident if we regard the great rod as a receptive end organ that the light must either act at some part or throughout the whole length of the rod.

In the latter case the same objections hold good as in Müller's original theory, such a condition would only give anything like vision with pencils of parallel rays; the same thing is true if the inner portions of the great rod are the seat of stimulation.

If the outer extremity of the great rod is the receptive structure, it would receive its illumination from the subcorneal image, and the light rays from every part of this image would fall upon every part of the extremity of the great rod, hence the smallest distinct visual point would be the representative of the subcorneal image. And as this image is similar in all the adjacent facets, there could be no distinct mosaic representing its several parts, and hence all acuity of vision would vanish. Müller's theory, even in its modified form, is therefore optically untenable.

Exner's Views.-S. Exner has done great service in his optical investigation of the compound eye. He does not ignore, as Notthaft and Grenacher do, the refractive structures, and he has shown that an image may be formed by refraction in the absence of convex surfaces.

Refractive Cylinders.-S. Exner investigated the subcorneal image which exists in the cone of Dytiscus. The corneal facets of this insect are very slightly convex, and he states [252] that the subcorneal image is but little affected by the medium in which the cornea is immersed, a condition which he explains by his theory of refractive cylinders.

Exner found that the entire crystalline cone of Dytiscus produces an image at a focal distance which led him to determine its refractive index as $I$ : [245]. I found formerly the refractive index for the corneal facet of a Hornet (Vespa.crabro) to be equal to $2^{\circ} \mathrm{O}$ in a similar manner. Such high refractive indices are unknown amongst organic substances, and indicate an error. Exner [235], therefore, investigated thin slices of the cone, and found that they have a refractive index equal 
to $I^{5} 55$. In a similar manner I determined the refractive index in the cornea of the Hornet, and fourd it to be ${ }^{\circ} 53$ [219].

It is well known that a lens composed of layers increasing in density towards the centre has a higher refractive inclex than the highest refractive index of any of its layers, and Exner accounts for the high refractive index of the entire crystalline cone in Dytiscus on the same principle. He believed it to be a cone consisting of a series of envelopes increasing in refractive power towards its axis. There is little doubt, I think, that this affords a true solution of the discrepancies previously observed.

Exmer terms such a cylinder a refractive cylinder, and shows that such cylinders act exactly as convex lenses do, and that the focus of a refractive cylinder is a recurring function of ? where $c$ is a constant, and $l$ the length of the axis of the cylinder within certain limits (see p. 572). Cylinders have been made of glass annealed in a special manner which exhibit all the properties of Exner's refractive cylinder.

Exner believes that the subcorneal image lies in the middle of such a cylinder, the crystalline cone, and that rays which were parallel before entering the refractive media of the insect's eye leave the inner extremity of the crystalline cone as parallel rays. If this were the case, it is difficult to understand the optical purpose of the refractive media, as no other result would be attained than a diminution of the amount of light falling upon the retinal end orran, unless such parallel rays were subsequently brought to a focal point, since the density of a pencil of light can only be increased by the convergence of the rays of which it is composed (see page 575).

The Dioptric Theory, which I enunciated in ISSt [233], is that the pencils leaving the crystalline cone are brought to a second focus by the rhabdome, which acts as a lens; these pencils may be either diverent, or parallel pencils as Exner supposes, and in this way a magnified image of a part of the subcomeal image is formed at the inner extremity of the rhabdome, and as there is a double reversal, it is directed in the same mamner as the external object and is an erect image 
It further corresponds with the layer which I believe to be the sentient retina (see Pl. XL., Fig. I).

The Erect Image in the Eye of Lampyris.-Although Exner rejects my view of the position of the retina, he gives a figure of a section of the eye of Lampyris splendidula [252 Taf. I. Fig. I] in which he represents the dioptron and retina exactly as I do, only he terms the dioptron a vitreous.

Exner further found an upright image of external objects immediately beneath my membrana basilaris, and he not only saw, but photographed this image. It is reproduced in his book [252, frontispicce], but in its printed form it is reversed; the reversal, however, is due, as he explains, to the method of photo-printing employed.

Exner's Theory of Super-position of Images.-Exner supposes that all the rays which fall from a point upon all the lenses of the compound eye form, after refraction, the envelope of a caustic curve, the cusp of which forms a point in the image and lies upon the retina. He regards his so-called vitreous as a perfectly transparent medium in which the caustic surfaces formed by the intersection of the refracted rays lie. This theory might be conceivable if such a vitreous existed in the compound eye, but, unfortunately for the theory, no such vitreous exists in any insect I have examined; if it exist in Lampyris spendidula the compound eye of this insect would be utterly unlike that of any other Arthropod; and there are indications in Exner's figure that his so-called vitreous differs in no marked manner from the great rods, as they appear in the recent eye, with the pigment but little developed.

With regard to his mathematical demonstration, he assumes that the surface of the cornea is a segment of a sphere. Now, so far as my observations go, it never is a segment of a sphere. He further assumes that the light-rays leave the cone as a parallel-rayed pencil, and his circles of confusion have approximately a diameter equal to the radius of the corneal facet, $\frac{7}{00}$ of an inch or more. Such pencils would produce no definite picture even if the super-position were perfect, which is far from being the case when the cornea deviates from a 
splerical comea, and Exner has not even shown that the plane of the retina corresponds with the theoretical plane in which such super-position could occur.

Moreover, Exner's 'super-position theory' is admitted by him only to be applicable in certain rare instances where he assumes the dioptron to be an optically homosencous vitreous, an assumption which $I$ do not think is ever justified. Exner, therefore, falls back on what he terms the theory of images by 'apposition,' in which he assumes that each ommateum acts independently.

If Exner's view is accepted with regard to the condition of the light-rays after leaving the lens or refractive cone, I can see no difference in this view and Müller's theory of 'mosatic vision.' If, however, instead of parallel pencils the foci of converging pencils fall upon the receptive surface, Exner's apposition theory and mine are identical, and the retina receives a second image which is not inverted.

Exner compares each ommateum to an astronomical telescope, but he does not apparently see that if the focal lengths of the refractive agents are slightly altered it is possible that a second real image may fall on the receptive surface of each ommateum when his theory and mine are identical.

Exner chiefly worked with eyes in which the crystalline cone is well developed, whilst my observations have been principally directed to eyes in which there is no crystalline cone properly so called.

If we adnit Exner's theory of the formation of an imacre by a refractive cylinder, and suppose that the rays would leave the cylinder as parallel pencils, when the cylinder is a real cylinder and the first image lies midway between its ends, and then add a spherical surface to the inner end of this cylinder, it is possible to so arrange the curvature of this surface that a real image is formed, the convex extremity of the cylinder acting as a plano-convex lens (see P'l. XL., Iisr. 2, C, D).

On the other hand, in the IBlow-fly imaso and in the Dragronflies no such cone exists, and the subcorneal image is produced ly a corneal lens. If a second inage is produced at all, it must 
be by a second lens, and such a second lens exists in the Blowfly in the rhabdome. The diagrams (Pl. XL., Figs. I and 2) will show how images which are not inverted are capable of being formed in both cases.

In the majority of insects, in which a crystalline cone exists, both the rhabdome and the convex surface of the cone probably act as a single refractive system, the function of which is to bring each divergent pencil of rays from the subcorneal image to a second focus on the retinal plane, and by a second inversion to produce an erect image.

As soon as such a second refraction and the formation of an erect image of external objects on a retinal plane is admitted, all the optical difficulties inherent in the theory of mosaic vision vanish-we have no longer the extremely minute axial pencil of parallel rays.

The difficulty arising from the variable number of facets in different insects has always been admitted as one of great moment. When only a dozen, or even thirty or forty, ommatea exist it is impossible that any visual picture of any value could arise under the 'mosaic' theory, but under the dioptric theory, as each element of the picture is itself a picture, we have only to assume that the receptive elements beneath each ommateum are more numerous in eyes with fewer than in those with more numerous ommatea.

Unfortunately I have not examined the eyes of Insects with very few facets with a view to elucidating this question, as my attention has only recently been directed to its import, so that I can only speak generally on the subject. In Tipula, where the ommatea are comparatively few, the retinal end organs are more numerous in each retinula than in the Blow-fly where the ommatea are numerous, and it is well known that in the simple eyes of Arthropods the retinal elements are very numerous. Therefore it is probable that there is an inverse ratio between the number of ommatea and the number of receptive elements in each ommateum.

The Theory of Total Reflection.-In the compound eye of some Crustacea, especially in the Phronimidæ (Claus and Oscar 
Schmidt, the crystalline cones are drawn out into long fine threads, often curved more or less in their long axes. Schmidt [220], and myself independently [219], made experiments on rlass rods, models on a large scale of the cones of the Phronimidie. Schmidt found that when the convex conical end of the rod is illuminated the light is emitted in a divergent pencil from the other end of the gliss thread. In my experiments I used rods su of an inch in diameter and an inch in length: these were enclosed in a capillary glass tube filled with water, and whether curved or straight they transmitted light, although so little passed through the lumen of the tube that it appeared black when seen with a half-inch objective. The capillary tube was placed in the axis of the microscope so that the end nearest the object-glass was level with the stage; the lower end was illuminated directly by the lamp. When the focus of the microscope was altered, so that the ends of the rods were beyond it, the discs of light enlarged, showing that the emitted light was divergent.

The light which enters a cylinder with divergent rays after any number of total reflections, emerges from it with divergent rays and the angle of divergence remains the same. When the cylinder is also a refractive cylinder it will have a focus like a lens, and this focus will be a recurring function of its length (see p. 572); so that whether the thread conducting the light-rays is a simple cylinder, with a lens situated near or at its extremity, or whether it is a refractive cylinder, in Exner's sense, a small image is capable of being formed beyond its emergent surface.

The conditions necessary for the formation of such an image are that the conducting-rod shall be a cylinder, and not a cone, as total reflection from the inner surface of a cone produces diverent pencils at its apex, and the internal surface of the rod must be capable of reflecting the incident light.

I have found that small glass threads do not possess this power when the outer surface is blackened with soot, or even with black varnish. The blackened surface absorbs and does not reflect incident pencils; even a narrow ring of pignent prevents 
the transmission of oblique pencils, and such rods transmit only axial pencils. It is theoretically possible to obtain an image by the light transmitted when only parts of the rods are blackened, even when the rod is curved. As part of the surface of each great rod at least is pigmented in all Arthropods, it is possible that only such light passes through them as is suitable for the production of an image, and such light, even in the remarkable eyes of Phronimids, may be concentrated by a second refraction upon one or more retinal elements.

The most remarkable indication of the truth of the view advocated by Exner and myself is afforded by the structure of the eye in Copilia. In this remarkable Crustacean the cornea has a true lens beneath it separated from a lenticular cone by a space filled with a vitreous-like body. Gegenbauer described a muscular apparatus for effecting the requisite accommodation in these eyes, and although the presence of muscles was subsequently denied by Claus, it seems hardly possible that a means of accommodation is absent (Pl. XXXVIII., Fig. 4).

Grenacher saw that the eye of Copilia represents one of the ommatea of a compound eye [222, p. 73]. But he compares the second refractive body (Pl. XXXVIII., F:g. 4, $h$ ) with the crystalline cone, and the pigmented portion of the eye with the great rod. If we compare the vitreous space of Copilia, however, with the pseudo-cone and the second refractive lens with the rhabdome, then the whole structure becomes intelligible, and I cannot see on what grounds Grenacher arrives at the conclusiou that the second refractive body of Copilia represents the crystalline cone. It is not difficult to see that the second refractive body in Copilia cannot be regarded as a cone, and that it should rather be compared with a solid lenticular rhabdome.

Grenacher concludes that the complex and beautiful eye of Copilia is useless, and cannot perceive an image. I agree with Exner that this conclusion is scarcely probable, and I am more inclined to accept Exner's conclusion, which is, that the second refractive body and retina are capable of moving over the picture produced by the lens, which Copilia explores as it were 
by this method, and so learns something of the nature of surrounding objects [252, p. I37].

Accommodation.-That accommodation really occurs in the simple eyes of spiders is indicated by the scintillations of the luminous reflex when viewed with the micro-ophthalmoscope. The great elasticity of the great rods and rhabdones and the remarkable muscle which regulates the tension of the basilar membrane (Pl. XXXVIII., Fig. $2, m c$ ), render it extremely probable that the ommatea of the compound eye are capable of being adjusted for distinct vision. Exner's theory of super-position reverses the conditions of accommodation, and would require a shortening of the great rods for near vision, and, as Exner remarks, no mechanism is present by which this can be arcomplished. The distinct mechanism for the lengthening of the rods is only another argument against an untenable theory.

It is true that the plane in which the subcorneal image lies varies so little, even for very near objects, that accommodation appears unnecessary, under the dioptric theory; but it is probable that variations in the tension of the rods themselves occur during life which need a readjustment of the dioptric apparatus. Chaneres in the hlood pressure or the tracheal pressure probably affect the length and tension of the great rods, and it is conceivable that insects accommodate not for nearness, but to counteract other disturbing influences. The dioptron is supplied with blood and air from the general head cavity ; the circulating fluid enters it and leares it by sinuses round the edge of the membrana basilaris, which have a valvular arrangement in Drason-flies: and it may be that the contraction of the tensor muscle of this nembrane affects its tension long after the contraction has passed away, as such contractions must necessarily alter the conditions under which air and blood pass into and out of the dioptron. The stretching of the great rods would undoubtedly alter their foci, and when once adjusted it may be a long time before readjustment is necessary.

Extent of the Visual Field.-If the extreme angular divergence 
of the normals to the corneal surface are taken as the measure of the visual field, this must be very large; it varies in different insects from over $180^{\circ}$ in each eye in one or more meridians, and is seldom less than $120^{\circ}$ in any direction; but the sharpness of vision clearly varies greatly in different parts of the visual field, just as it does in the vertebrate eye.

Sharpness of Vision. - The sharpness of vision in insects is a subject which has led to numerous discussions. Some (Marcel de Serres, Claparède, Dor, and Patten) hold, as I do, that insects see with great distinctness both near and distant objects. Evidence of this is abundant, and numerous facts will occur to the practical entomologist which are inexplicable under the view that insects see indistinctly, the hawking of Flies and Dragon-flies, the close mimicry of the Volucellas, the manner in which the Hymenoptera find their nests or their favourite flowers, and the fact that Bees will visit artificial flowers, are all indications of sharp vision.

Other authors, including Lamarck, Treviranus, J. Müller, Grenacher, Notthaft, Hickson, Carriere and Forel, have arrived at the conclusion that the compound eye is a very defective organ of vision, and that insects see little more than moving shadows.

Plateau [243] cites numerous observations and experiments, from which he concludes that vision in insects is very defective. These experiments and observations may be divided into three groups :

I. Experiments made on gratings and free openings of exit from a chamber, or gratings, the bars of cages, etc., in the open air. He found that insects usually fly to a grating rather than to a free aperture when the former is larger and admits more light, even when the grating is an absolute obstacle to escape. He subsequently found, however, that birds do exactly the same thing; therefore either his experiments do not show defective vision, or birds have an equally defective sense of sight.

2. Experiments made with cardboard labyrinths, in the centre of which cursorial insects were liberated. In these experiments he found that the insects ran up to the obstacles, 
and then took a new departure, only to run against a second obstacle. From this he concludes that they do not see the obstacles. It might have occurred to Plateau that such insects live either on the ground or amongst shrubs, branches, grass, etc. It is their habit to climb over obstacles and not to gro round them; it is, perhaps, an error of judgment when a Beetle or Grasshopper runs at a vertical wall of cardboard, but such vertical walls are a new experience to the insect. Again, it is at the edges of stones that many predatory insects find their prey; they run round them, and not over them, examining the edge; why should not an insect mistake a card for a stone, and, finding it an unwonted object, start to examine the next obstacle? Such experiments prove nothing.

Bees appear to aroid obstacles of this kind better than most insects, but their nests are labyrinths.

3. Observations made in the open air, in which he thinks that insects evince a want of clear vision. He cites a Dragonfly which, after having been disturbed, made a long fiight and frequently realighted upon exactly the same spot, as Dragonflies will. He thinks this insect could not see his net, because he succeeded in capturing it by keeping the net still, and argues that the insect sees ill; but how does he explain its periodic return to the exact spot it had left? if it could not see the net, how could it see the twig on which it was accustomed to rest? How can the mazy dances of insects be explained? How is it the Lepidoptera do not tear themselves on projecting brambles in their flight if they camnot see them? Why does Volucella resemble a hymenopterous insect? Why are the Syrphida like Wasps? Every entomologist whose judgment is not warped by a desire to verify Müller's theory of vision will recall a thousand instances in which he has been impressed with the belief that insects see most acutely.

Plateau forgets in many cases the strong influence of curiosity amongst animals; who has not observed the manner in which animals and even insects investigate unknown objects? When lie tells us that a syrphus hovered in front of his finger, with which he had pushed away the flower before which the insect 
was poised, how does he know the insect could not detect the change? How does he know that the insect was not curious to know what the finger was which had suddenly obtruded itself on its consciousness?

When I accepted Muiller's theory, and believed that each ommateum produces only a single visual stimulus, I calculated the possible sharpness of vision for the central part of the visual field of a Blow-fly as $\frac{1}{60}$ of that of man; this means that objects seen as distinct by man at sixty feet distance would be so to the insect one foot from the eye. On the view I now hold, as each retinula consists of seven rods, three in a line, the acuity of vision would be $\frac{1}{q} \overline{0}$. So that objects twenty feet from the eye of man, which are recognised as distinct, would be so distinguished at one foot by the insect. Objects at half an inch would correspond to those seen by man ten inches from the eye, whilst objects ${ }_{10}^{1}$ of an inch from the eye of the insect would appear as they do to man under the microscope with an inch objective. By the same calculations, the sharpness of vision in the Dragon-flies, the Bee, and the Wasp is from eight to ten times greater, or about $\frac{0}{4} \mathrm{~S}$, , or half that in man. Such sharpness in vision might well account for the manner in which these insects find their nests or their prey.

Exner by a different method, by the direct investigation of the images, arrived at the conclusion that, in the Glow-worm, Lampyris splendidula, the acuity of vision is about $\frac{1}{66}$; but as his methods undoubtedly diminish the clearness of the image, the sharpness of vision is probably greater.

In the above attempt to compare the sharpness of vision of an insect with that of man, the assumption has been made that each retinal rod forms a single visual area, and that the distinctness of perception is determined by the number of retinal rods which the image covers. This is the only possible hypothesis which we can assume with our present knowledge; but there is evidence that one retinal rod may give rise to a complex sensation. In small birds the retinal rods (cones) are as large, or even larger, than they are in man, so that as the images formed upon them must be smaller in direct proportion to the 
antero-posterior diameter of the eycball, the distinctness of vision if this hypothesis were correct would diminish with the size of the ere. Now, the evidence goes to prove that birds see guite as distinctly as we do; a Hawk with an eyeball having an antero-posterior diameter of 5 or $6 \mathrm{~mm}$. should not see oljects as distinct which subtend an angle less than $3^{\prime}$ or $4^{\prime}$, whilst in man the estimated angle is less than I' ( $59^{\prime \prime}$ is usually siven). It is therefore probable that each retinal element in such birds produces a complex sensation, and the same may be and probably is, true in insects. So that although on the above hypothesis an insect such as the Blow-fly appears to have only $\because 1$ of the acuity of vision which man possesses, if it were compared with a bird, it is possible that $\frac{1}{4}$, or eren ?, would be a nearer estimate; and it must be remembered that Dragon-flies and Hymenoptera have vision which is many times sharper than that of the Blow-fly when calculated on the same method. My own estimate of the vision of the Iragon-flies (Aschua) and Masps (Vespa) is that they have seven or eight times the acuity of vision possessed by the Fly, and this would equal that of the Hawk or Swallow-a conclusion which is, I think, borne out by the experience of those who have watched these insects in a state of nature.

The Illumination of the Retinal Image-Every microscopist is aware that the higher the magnifying power and the smaller the front lens of the objective the sreater is the need to increase the illumination. It will be manifest that the smallness of the corneal lenses necessitates a brilliant light, if, as I have maintained, a real inage is formed at the inner extremity of the great rods. As a matter of fiet most insects require a brilliant light, and are only artive when the sun is shining. Many insects, as the Noctuids and Sphingida, are, however, remarkable exceptions. In these the large size of the great rods is conspicuous, and I have observed the same thing in all nocturnal insects, and especially in the Tipulidx and Gnats.

Many nocturnal insects are remarkable for the large size of the corncal facets, and the great reduction in the number of the ommatea in the compound eye. There is a marked con- 
trast, on the other hand, in insects which are only abroad in the sunlight, as these have long, slender great rods, which must transmit far more slender pencils of light. Many of the experiments of Plateau and others are vitiated by the fact that they have tried experiments on such insects in diffused daylight instead of in brilliant sunlight, which in many insects appears to be indispensable for acute vision.

I have given some calculations of the intensity of the illumination of the retinal image in insects (p. 575), but the subject is one which has hitherto been neglected, and further experiments are needed. All small birds which are diurnal in their habits are apparently quite incapable of vision in a feeble light, and are readily tamed in the dusk; the absolute helplessness of diurnal insects in the dusk has already been remarked upon by Forel and others, and indicates that a powerful light is generally necessary for distinct vision in such creatures.

Movements of Objects in the Visual Field.-Both Plateau and Exner believe that the movement of objects in the visual field renders their perception more easy, although I confess I do not appreciate the manner in which movement can render an imperfect picture more perfect. It seems to me that, by adding a new condition, this hypothesis merely makes the comprehension of the manner in which vision is effected more obscure. On the principle by which many accept a mathematical formula they do not understand as a proof, some will undoubtedly accept a complex theory beyond their comprehension as good, rather than one which they are capable of testing and in which they are able to detect errors. The movements of objects in the visual field undoubtedly affect visual judgments as to distance, and I have no doubt that in some way insects do know the distance of the objects amongst which they are moving. As, however, we do not know how we determine the distance of objects unless they are seen by binocular vision, it would be useless to discuss the manner in which insects determine distance.

Binocular Vision.-In some parts of the visual field of insects 
there is unloubtedly binocular vision, and possibly for very near objects this may be stereoscopic. I do not know, nor does it appear to me likely that we shall ever know, whether such binocular vision has any physiological importance amongst the Arthropoda.

\section{FURTHER REMARKS ON THE OPTICAL PROPERTIES OF THE COMPOUND EYE.}

It has been thought unadvisable to complicate the foregoing section with certain problems of a somewhat more difficult character, which will occur to some who are more fully acquainted with the science of optics, than is needed for a perusal of the thesis which I have endeavoured to establish.

These problems will be now examined, and although they necessarily require some mathematical knowledge, every endeavour has been made to render the explanations of the views adrocated as simple as possible. The student of crolution will probably be chiefly interested in the conclusions arrived at by the author, as the result of Exner's theory of refractive cylinders, which will be found upon page 574 .

a. On the Optical Properties of Refractive Cylinders, and the Probable Relation of the Several Types of Compound Eye in the Arthropoda.

The following account of the optical properties of a refractive cylinder is taken from Exner [252]; it is extracted by him from his brother's paper in Ann. f. I'hy'sik und Chemic, xxvii., IS6S:

Let ss, is (Pl. XL., Iigr. 2, 13) be a cylinder, the refractive index of which is a maximum in its axis; let the refractive index diminish on the line $y y^{\prime}$. A ray of light proceeding from $x$, when it crosses the line $y^{\prime} y^{\prime}$, instead of proceeding to $p$ will be refracted from the perpendicular to $q$ : when it again crosses the surface $y$ ' $y$, it will be bent towards the perpendicular, and instearl of proceeding to z will pass to $x^{\prime}$. If a series of such planes occur, the course of the ray will be a curve $x$ y $x^{\prime}$. 
At first sight it may appear that the ray, after it becomes parallel to the axis, will remain parallel, but this is an error. One has only to consider the elementary wavelets of a disturbance to perceive that those nearest to the axis will be retarded most: we have before us the limit of geometrical optics.

Karl Exner finds that when every layer increases in density in a definite function of its distance from the axis, and this function is parabolic, every ray proceeding from the focus $f^{\prime}$ will fall upon the focus $f$. *

The same result is arrived at by physical optics, since if $f^{\prime}$ be a luminous point, and $w$ w the wave front falling upon the cylinder, the convexity of the wave front will diminish until it arrives in the position $b b$, after which it will increase in a negative direction until it emerges as $w^{\prime} w^{\prime}$, the focus of which is $f$.

If the refractive cylinder is elongated (Pl. XL., Fig. 2, A, $a, b, c, d)$, a series of foci will be formed at $f f f$. Calculation shows that the distance $F$ from $c d$ is a recurring function of $\frac{c}{l}$ where $c$ is a constant, and $l$ the length of the cylinder within certain limits, the limit being the distance between $f$ and $f$. Neither Exner nor his brother appear to have considered the effect of a convex surface at $c d$ on the emergent pencil. Suppose the length $f c$ to be such as to give a negative value to the focus, the rays $f g f g$ would be rendered parallel or convergent by the lens surface $c h d$.

Pl. XL., Fig. 2, C is copied from Exner's work [252]. It represents the inverted image, $b a$, in the crystalline cone, and the course of parallel rays from the points $a b$ of a distant object; these are brought to foci in the plane $b a$, and leave

* It may be objected by some that it is extremely improbable that the density of the cone should increase towards the centre exactly as a parabolic function of the distance of each part from its surface, but if we suppose the cone to be deposited in successive layers, and to increase uniformly in diameter, it will not appear improbable that its density would vary inversely as the mass of material deposited in the unit of time ; and this is exactly the relation supposed by Exner in his calculations.-B. T. L. 
the cone as parallel pencils $p^{\prime} p^{\prime}$ and $m^{\prime} m^{\prime}$. If, however, the lenticular surface of the cone is considered, these pencils will unite in focal points at $p^{\prime} m^{\prime}$, Fig. $2, \mathrm{D}$, and the only effect produced hy a second refracting surface $r r$, bounding a denser medium beyond it, will be to increase the convergence and shorten the focus, i.e., reduce the magnifying power of the system.

Exner gives an elegant proof of the second inversion of the image by the cone [252], to which I must refer the reader who is curious in such matters.

The Evolution of the Compound Eye.-For the above reasons it is clear that the lenticular function of the rhabdome is not ntecssary except when the crystalline cone is absent, or its focal length is greater than the distance of the retina behind it. In Lampyris the rhabdomes are not apparently lenticular ; in the noctuid Moths there is apparently a large lenticular rhabdome, and in all insects in which the cone is absent the lenticular rhabdome serves as a second refractive medium. We thus see the stages by which a euconic eye, the more primitive form of the compound eye, may have gradually become an aconic eye; the Moths form an intermediate link, in which both forms of refractive media are present.

It is possible that, in the most primitive form of compound eye, that of the Phronimida, total reflection is larerely concerned in the visual function; from the thread-like refractive structures of these animals it is not difficult to conceive the origin of refractive cones, such as those of the King-crabs and Crustacea generally. In some insects this kind of eye is but little altered; in the Moths two lenses, a conical lens and a rhabdial lens, appear, with a segregate retina, whilst in the I)iptera and Neuroptera the cone has disappeared, the retina has becone continuous, and the only refractive media are lenticular: and this may be regarded as the most perfect form of compound eye.

Such an origin of the various forms of compound eye from a simple type other than that which persists in the ocelli appears probable. The agrregation of simple eyes to form a 
compound eye has been rendered most improbable by a more complete knowledge of the structure of the compound eye, and the above optical considerations are strongly in favour of the more recent view, that the simple and compound eyes have been perfected by divergent evolutionary stages.

\section{b. On the Illumination of the Retinal End Organs under the Dioptric and Mosaic Theories of Vision.}

Allusion has already been made (p. 556) to the unsatisfactory character of the 'mosaic theory' of vision in relation to the illumination of the retinal image, and it has been stated that the corneal lenses cannot increase the quantity of light which acts on the retina, unless a real image is formed upon it by a second refraction. It is perhaps necessary to elucidate this statement more fully.

It will be seen that a single lens cannot intensify the illumination of the retinal end organs of an ommateum, by the following (P1. XL., Fig. 3):

Suppose a plane luminous wave of the intensity $I$ to fall upon the surface $l l=a$, and to be transmitted to $l^{\prime} l^{\prime}$ without appreciable loss of intensity, the illumination of the surface $l^{\prime} l^{\prime}$ will be $a I$.

Next let the surface $l l$ be a convex refractive surface which condenses the wave, and brings it to a focus $f$ at a distance $d$ from $l l$; at the distance $2 d$ from $l l$ the wave will have the same intensity as at $l l$, or again $a I$. Let the receptive surface $l^{\prime} l^{\prime}$ be at a distance $n d$ from $f$, then the illumination of $l^{\prime} l^{\prime}$ will be only $\frac{a I}{n^{2}}$; since it is evident that all the light which falls upon the segments of the lens $l p l p$ will afterwards diverge to the segment $n q u q$, and the efficient wave front which acts on $n n$ will be the same as that which falls on $l l$, although the image at $r r$ is more intensely illuminated than if the segments $l p l p$ were protected by an opaque diaphragm.

If, however, a second refraction occurs, beyond $r \gamma$, which brings the rays of light in the segments $n q n q$ to a focus with those which fall on $n n$, the illumination of $l^{\prime} l^{\prime}$ will be in- 
creased in the same ratio with that of the subcorneal image by increasing the effective angular aperture of the corneal lens.

The actual illumination of the retinal image will then vary inversely as the magnifying power or the square of the linear magnification $\left(m^{2}\right)$ of the second image as compared with the first, and directly as the intensity of the illumination of the first image, which increases with the surface of the corneal lens, and the angular aperture of the second lens.

The surface of the corneal lens is generally very large as compared with the surface $(a)$ cut by the axial pencil $\left(l l l^{\prime} l^{\prime}\right)$; let it be equal to $A$. Then the illumination of every point of the subcorneal image will be equal A I, and of the retinal image to $\frac{\mathrm{A} I}{m^{2}}$, which will evidently be very large in comparison to $\frac{a \mathrm{I}}{n^{2}}$ distributed over the whole surface $(a)$, since $A$ is usually greater than $m^{2}$, or, in other words, the waves of light are concentrated by the lens systems.

In the above the reflection or absorption of light at the refractive surfaces and in the media has been neglected, but this is immaterial to the argument.

It appears, therefore, that the presence of a corneal lens can only aid vision when an image actually falls upon a recipient structure, and as it can be shown that no such structure exists in the position of Gottsche's image, the inference is that a second refraction must occur beyond the image, and that a second real image is formed, the existence of which has been demonstrated by Exner's photograph.

To suppose that a retinal image can be produced by the divergent pencils beyond the focal plane of Gottsche's image without a second image being formed is as inconceivable as that a pin-hole camera would form a picture if a small convex lens were added at the pin-hole and the receptive surface were at a distance behind it equal to many times the length of the principal focus of this lens. 


\section{c. Accessory 0ptic Phenomena in the Compound Eye.}

Exner says: ' It is manifest that, in so complex a structure as the compound eye, phenomena must occur from refraction, reflection, absorption, etc., which are not directly connected with vision. Owing to the great variations in the structure of this organ, these phenomena vary in different species, but certain phenomena are typical, especially the internal light and pseudo-pupils,' which he proceeds to discuss.

The Internal Light is a brilliant metallic reflection from the interior of the compound eye, which occupies a greater or less surface of the cornea opposite to the eye of the observer. It is characteristic in the Sphingidæ and Noctuæ, and is apparently confined to nocturnal and semi-nocturnal insects.

If a large moth (a Sphinx or Noctuid) is kept in the dark for a ferv hours, the eyes are seen to shine like those of a cat. In a bright light the luminous reflection gradually contracts in diameter, becomes more and more feeble, and disappears in a shorter or longer time-from a minute to five minutes in daylight-and more rapidly the brighter the light. The phenomenon only recurs after the insect has been kept in the dark for from half an hour to three or four hours.

Leydig described this reflection as similar to a glowing coal, and ascribed it to a reflection from a tapetum. He says that the tapetum is tracheal, and considers that the reflection either depends on a fuller condition of the tracheal vessels, or on a dilated condition of the pupils or perforations in the subcorneal pigment.

Max Schultze regards the reflection as being produced by the laminated structure of the visual rods, which he describes, and not by the tracheal vessels.

Exner [252] says that, by the help of an ophthalmoscope, most faceted eyes, although not all, exhibit a reflex-that is, the light which enters the eye returns in exact analogy with what happens in Vertebrates. This reflex is limited to a circular spot, which is nearly or absolutely identical with the optical appearance known as a pseudo-pupil. 
Exner ascribes the appearance to a reflection from a tapetum behind and between the great rods; he further considers that the disappearance of the reflection is due to an alteration in the disposition of the iris pigment.

There are, I think, many objections to the view that the reflection originates from the great rods or from the tracheal tapetum, if this term is to be applied to the tracheal network between and behind the great rods, especially as this tapetum is least developed in those very insects in which the reflection from the eye is most brilliant, and is most developed in those insects, as the majority of Diptera, in which there is no vestige of luminous reflection. The insects in which the luminous reflection is most brilliant are, however, all distinguished by the large size of their crystalline cones. Now, it is manifest that the reflection of the light which enters the eye will be most marked where the refraction of the rays is most powerful, and where the highly-refractive medium is concave towards the source of light. The convex surface of the cornea disperses the light which is reflected from it; but the apex of the crystalline cones is virtually a concave mirror, and the light reflected from it through the corneal lens will leave the eye as a pencil of parallel, convergent, or slightly divergent rays.

Such a reflection will only occur from the internal surface of the crystalline cones where these are not covered externally by dark or black pigment. In the nocturnal Lepidoptera which have been kept in the dark the iris pigment is withdrawn from the apex of the cone, so that a considerable portion of its surface acts as a concave reflector. I find that the reflection from this surface corresponds with a luminous image of the cone apex, subtending an angle of $20^{\circ}$ to $25^{\circ}$ from the optic centre of the corneal lens. As the adjacent lenses have an angular divergence of about one degree, the images produced will overlap and intensify each other.

Hence the light which emerges from the insect's eye gives an imare of a bright disc, apparently situated behind the cornea. The diameter of this disc is equal to that of from twenty to 
twenty-five facets, which accords with the calculated diameter on the view which I have taken of its origin.

Under all the theories which have been suggested, only very small pencils of light can enter or traverse the great rods, and such pencils could only produce a very feeble reflection, or a very minute one. The minute image so produced can indeed be seen with an ophthalmoscope in the centre of a dark disc, which in most insects replaces the luminous reflection above described. The dark disc is known as a pseudo-pupil, the nature of which will now be discussed.

The Central or Principal Pseudo-pupil.-Exner says [252]: 'I now come to the consideration of a remarkable optical phenomenon, the attempted explanation of which has cost me many a headache. Once more Leydig first observed the phenomenon, but it was scarcely discussed until Thompson Lowne again observed it. Lowne remarked in a butterfly (Pieris brassica) six black spots arranged around a central spot, and explains it as a diffraction image.'

These spots are seen with the naked eye or with a simple lens, and whatever the position of the insect the central spot is exactly opposite the observer's eye. The central spot is the primary or principal pseudo-pupil, and I think it is undoubtedly due to the fact that the light which falls directly upon the cornea is feebly reflected, whilst that which falls on it obliquely is reflected more powerfully. In other words, the cornea in the region of the central pseudo-pupil is seen as a transparent object, and the dark pigment beneath it absorbs the light, whilst the surrounding cornea is seen as an opaque object, and by reflected light.

If the central pseudo-pupil is observed with an ophthalmoscope adapted to a microscope, from which the eye-piece has been removed, with a powerful light - direct sunlight is best-a small central bright spot is seen within the dark pseudo-pupil. This phenomenon is described by Exner. The light by which this bright spot is seen undoubtedly traverses the great rod, and is, I think, reflected by the retinal rods; by careful focussing, the image of the retinula (in sensu milii) is 
seen in optical section. This image is rose-coloured or green. I have seen such an image in all the insects' eyes I have examined in this way; it is brilliant in the Diptera, which do not exhibit the phenomenon of pseudo-pupils.

The central pseudo-pupil is small, intensely black, and circular. In this it differs entirely from the pseudo-pupils of the second and third order, which are larger, dim, and irregular in form. All the pseudo-pupils appear to be beneath the cornea.

Pseudo-pupils of the Second Order.-These are six in number; they are twice as large as the central pseudo-pupil, and gray in colour. I have little doubt these are diffraction images; they correspond with the angles of a hexagon circumscribed around the central pseudo-pupil as its centre.

Pseudo-pupils of the Third Order.-These are approximately twice the diameter of those of the second order, more irregular, and grayer. They are twelve in number, but generally only two or three are visible at once, as they fall outside the compound cornea. The whole circle can never be seen at the same time, but they may be brought into vicw in succession by causing the central pseudo-pupil to fall on the edge of the cornea, and to travel round it by moving the insect.

The pseudo-pupils of the second and third order correspond with the diffraction images produced by a hexagonal grating.

Exner gives a totally different explanation of the pseudo. pupils of the second and third order, and ascribes them to the manner in which the pigment of the chamber is arranged. For his explanation I must refer the reader to his monograph [252].

It will be seen that whatever the true explanation of the pseudo-pupils may be, the phenomenon throws no light on the manner in which images are formed on the retina, although the bright image of the retinula seen with the ophthalmoscope and microscope combined tends towards the verification of the hypothesis I have adopted in these pages, since it shows that a real imase of the retinula can be produced in front of the eye, just as a real image of the vertebrate retina can be seen with the ophthalmoscope. 



\section{DESCRIPTION OF P'J.ATE XL.}

FIf. I.-A diagram illustrating the course of the light rays in the compound eye according to the Dioptric theory of vision : $a$, b, the object: $a^{3}, a^{2}$, points from which light radiates; $l^{1}, l^{2}$, corneal facets ; $i i$, subcorneal images; $a^{1}, b^{1}$, retinal iınage.

Fig. 2.-Diagrams illustrating the optical properties of refracting cylinders :

A, A refracting cylinder, with several focal points : $f p$, parallel rays of light ; $a, b, c, d$, the cylinder ; $f f f$, successive foci ; $n n, n^{1} n^{1}$, successive forms of the wave front $a, b ; c, h, d$, curved face of emergence; $g s$, direction of rays leaving the cylinder by its face $c, d ; F$, focus of the same rays after refraction at the surface $c, h, d$.

$B, A$ diagram illustrating the optic properties of a refractive cylinder on the principles of mechanical optics (see p. 572) : $a a, b b$, successive forms of the wave front; $x, 1, x^{1}$, path of a ray of light refracted at the surface $y y$.

C, A refractive cone after Exner: $a, b$, object; $b, a$, subcorneal image; $p^{1} p^{1}, m^{1} m^{1}$, circles of confusion due to the pencils $p p, m m$.

$\mathrm{D}$, A refractive cylinder on the Dioptric theory: $p^{1}$, $m$, retinal image; $r r, a$, second refracting surface, causing a more rapid comvergence of pencils of light.

Ft: 3. - I dingram illustrating the relative illumination of the retinal image uniler the Mosaic and Dioptric theories (see p. 575). 
PLATE XI.

FIG. I.

FIG. 2.
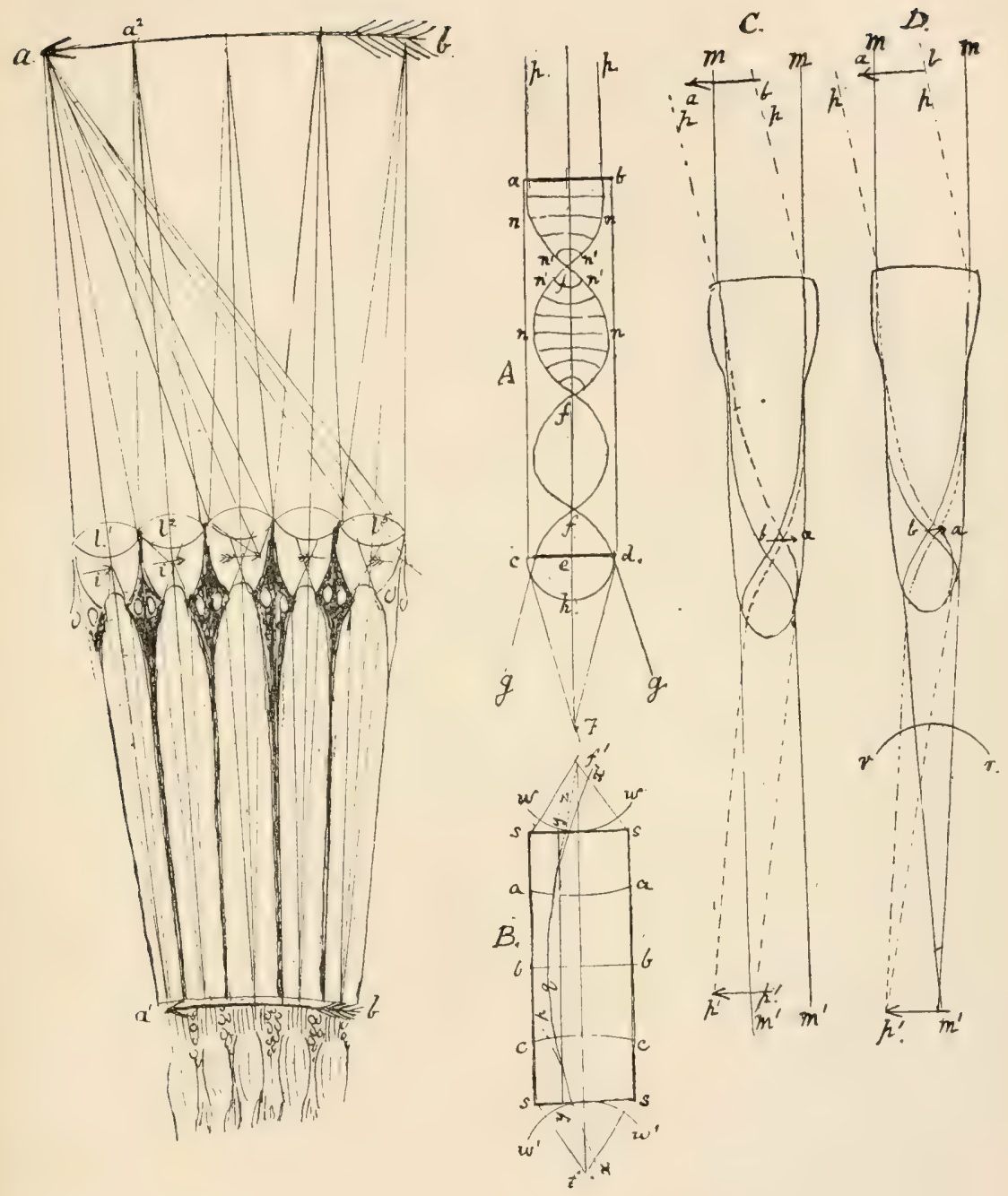

FIG. 3.

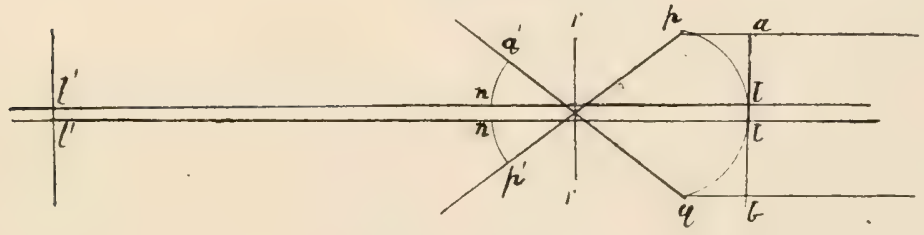

OI'TICAL DIAGRAMIS. 



\section{d. Optical Constants of the Compound Eye of the Blow-fly.}

Constants obtained by calculation have an * prefixed.

Number of ommatea in each eye

- 4,000 to 5,000 .

Radius of curvature of compound cornea :

Central region

- $\quad 2.00 \mathrm{~mm}$.

Peripheral region

Angular divergence of adjacent ommatea, from $1^{\circ}$ to $6^{\circ}$. Corneal lens:

Diameter

Radius of curvature of anterior surface $(r)$ - $\quad$ - $\quad-\quad$ - $\quad 024 \mathrm{~mm}$.

Radius of curvature of posterior surface $(s)$

* Refractive index of entire lens - $\quad \mathrm{I} 65$.

Posterior focus $(f)$ - : -

Magnitude of subcorneal image cor-

responding to $I^{\circ}$ diameter $d=f \sin . I^{\circ}=\cdot 000357 \mathrm{~mm}$. Anterior focus of rhabdome - $\quad$ - $\quad .008 \mathrm{~mm}$.

Length of cone

Length of great rod

*Estimated magnifying power of rhabdome

* Posterior focus of great rod

*Estimated radius of curvature of anterior surface of rhabdome, between

* Refractive index of the rhabdome, be-

\section{tween}

Diameter of the rhabdome - 0 I8 $\mathrm{mm}$. .02I mm.

- 025 to $.03 \mathrm{~mm}$.

Angular measure of Gottsche's image - $20^{\circ}$ to $25^{\circ}$. *Angular measure of the smallest distance of distinct points in the visual perception - $20^{\prime}$.

(See p. 567.)

Acuity of vision in man

$-S=\frac{60}{60}$. 
Probable acuity of vision in the Blow-fly from $\frac{18}{60}$ to $\frac{3}{60}$

(See p. 569.)

Size of retinal elements :

\begin{tabular}{|c|c|c|}
\hline Length of bacilli & - & $075 \mathrm{~mm}$. \\
\hline Length of outer segments & - & o3 mm. \\
\hline Diameter of outer segments & - & $.002 \mathrm{~mm}$. \\
\hline Diameter of retinulæ - & - & oo8 to or $\mathrm{mm}$ \\
\hline
\end{tabular}

\section{ON THE STRUCTURE AND FUNCTIONS OF THE ANTENN死.}

a. General Considerations (Plate XLI., Figs. I and 2).

The antenne in the Insecta are always a single pair of jointed organs, rarely reduced to a single joint, situated in front of or above the great compound eyes. The function of the antennat will be discussed hereafter, but I will premise here that I regard them as olfactory organs-an opinion which is now, I think, very generally held. C. Claus ("Grundzüge der Zoologie,' I $\$$; 6 ) regarded this as established, and Kräpelin, in a critical monograph [273], came to the same conclusion.

\section{Bibliography :}

259. LEHMANx, M. C. ('., 'De sensibus externis animalium exsanguium.' 4to., Goettingx, I798.

260. Linmax, M. C. G., 'I)e antennis insectorum disscrtatio prior, fabricam antennarum describens.' 12 mo., Hamburgi, 1799.

261. LeHM..NN, M. C. G., 'De antennis insectorum dissertatio posterior, usurn antennarum recensens.' I2mo., Hamburgi, I Soo.

These three works are the most important in the older literature, especially from an experimental point of view.

262. LFFEBTRL, A., 'Note sur le sentiment olfactif des Antennes.' Ann. Soc. Entom. France, tom. vii., 1838.

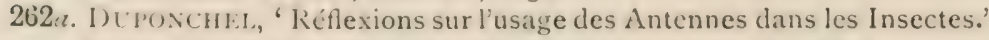
Revue \%oologique per la Société Cuvierienne, tom. jii., 1840.

263. ERichsns, WV. F., 'De fabrica et usu Antennarum in Insectis.' fto. Berolinii, 1847 . 
Kräpelin says the great variety of special sensory structures which have been described on the antennæ, or sunk beneath their surface, resolve themselves into 'organs of a single type, a more or less developed, free, or deeply-seated seta, connected by a wide pore canal with a multi-nucleated (?) ganglion cell, which sends an axis cylinder into the seta.'

264. Burmeister, H., 'Beobachtungen über den feineren Bau des Fiihlerfächers der Lamellicornier (Scarabeoiden) als eines mutmasslichen Geruchwerkzeuges.' Zeitung für Zoologie, Bd. i., I 848 .

265. PERris, E., 'Mémoire sur le siége de l'odorat dans les Articulés. Ann. Sc. Nat., sér. iii., Zool., tom. xiii., I 850.

266. Lespés, C., 'Mémoire sur l'appareil auditif des Insectes.' Ann. Sc. Nat., sér. iv., tom. ix., I 858 .

267. Claparède, E., 'Sur les prétendus Organes auditif des Antennes chez les Coléoptères.' Ann. Sc. Nat., sér. iv., tom. x., I 858.

This work is an answer to the views of Lespés.

268. Hicks, B., 'On a New Structure in the Antennæ of Insects.' Linn, Soc. Journ., Zool., vol. xxii., I 857.

269. LeydiG, F., 'Ueber Geruchs- und Gehörorgane der Krebse und Insecten.' Müller's Archiv Jahrg., I860.

An important anatomical investigation of the olfactory pits and cones in the antennæe and palpi.

270. GRABER, V., "Ueber neue otocystenartige Sinnesorgane der Insecten. Archiv f. Micros. Anat., Bd. xvi., I 879.

271. MAyer, P., 'Sopra certi Organi di Senso nelle Antenne dei ditteri.' Atti Reale Acad. Lincei., tom. ii., 1877-78.

272. Hauser, G., 'Physiologische und histologische Untersuchungen über das Geruchsorgan der Insecten.' Zeitsch. f. w. Zool., Bd. xxxiv., I 880 .

273. KRÄPELIN, K., 'Ueber die Geruchsorgane der Gliederthiere, eine historisch-kritische Studie.' Oster-Programm der Realschule des Johanneums. Hamburg, 4to., I883.

This paper gives a bibliography of fifty-nine papers, and the author has reviewed the whole critically. As most of the papers recited are rather of historical than scientific interest, all but the most important have been omitted in the present list.

274. SAZEPIN, B., "Ueber den histologischen Bau und die Vertheilung der nervösen Endorgane auf den Fühlern der Myriopoden.' Mém. de l'Acad. Imper. de St. Pétersbourg, tom. xxxii., I884.

275. DAHL, F., 'Das Gehör- und Geruchsorgane der Spinnen.' Archiv f. Micros. Anat., Bd. xxxiv., I885.

276. LuBbock, SiR J., 'On the Senses, Instincts, and Intelligence of Animals, with Special Reference to Insects.' Internat. Sc. Ser., 8 vo., London, Paris and Berlin, 1888.

277. Ruland, F., 'Beiträge zur Kenntniss der antennalen Sinnesorgane dex Insecten.' Zeitsch. f. w. Zool., Bd. xlvi., I888. 
The following special sensory organs have been described:

I. Special sensory setx intermixed with ordinary tactile and protective bristles ; Kräpelin.

2. Olfactory cones (Richlikolben); Leydig, Forel, and Lubbock (Pl. XLI., Fig. 2, C).

3. Simple pits containing a filiform hair; Lubbock.

4. Simple pits containing a papilla; Erichson.

5. Champagne-cork organs; Forel.

6. Complex cones; Hauser.

7. Stethoscope-like organs; Forel and Lubbock.

8. Tympanules; Hicks. Simple pits; Kräpelin.

9. Setiferous sacs or canals; Kräpclin (Pl. XLI., Fig. 2, B).

The first five of these are figured by Kräpelin, and, although he regards them all as modified setx, I think he has disregarded a very important fact-the deciduous character of the special sensory setie of the antenne. I have observed all the appearances in the antenna of the Blow-fly, but they result from the true sete having been detached, leaving more or less of their hases and contents attached to the antennie. Very commonly a flame-shaped process, or protoplasmic cone, or only the naked axis cylinder remains. Where the base of the seta is sunk bencath the surface, a projecting ring of chitin is left in the pore canal, giving rise to the champagne-cork-like organ of Forel.

With regard to the complex cones of Hauser, liripelin was unable to find anything like them, although he sought for them in the insects in which Hauser described them. They are apparently the same thing as the stethoscope-like organs of lorel. In the mature insect it is often very difficult, where the antenna are very hard, as in the Hymenoptera, to obtain sections; inence inmature insects, or even nymplis, have been used.

In the Blow-1ly nymph the sensory seta of the antenna are developed in follicles, and their hases closely resemble the bull, of the stethoscope-like organs of Forel. I am inclined to regard these as partly developed sensory seta: as, how- 
ever, I have not seen the organs themselves in the Ant, in which Forel described them, I am unable to speak with any certainty on the subject.

The tympanules of Hicks and the simple pits of Kräpelin appear to me to be nothing more nor less than the open pore canals left after the complete removal of the sensory setæ; possibly closed by a thin plate of chitin, the result of the healing of the pore, after the sensory seta is shed.

Setiferous sacs and canals are largely developed in the Muscidæ, and are typical in the Blow-fly. They were mistaken by Graber for sacs containing otolith-like organs [270].

\section{b. In the Blow-fly Imago.}

As has been already observed, I regard the antennæe of the Blow-fly as six-jointed, with a greatly-enlarged third joint-a view which was adopted by Robineau-Desvoidy, but one which has met with little acceptance from entomologists. This is due to the fact that the two basal joints of the threejointed bristle are so short that they are only seen with the microscope. This organ is usually regarded as a mere seta.

If the so-called bristle of the antenna is regarded as the representative of the terminal joints of the organ, Leptis and the Tachina exhibit a transitional condition, between the filiform antennæ of the Nematocera and the sub-cylindrical antennæ of the majority of the Muscidæ. In Leptis (Fig. 72, A) there is a manifest enlargement of the first three joints without any lateral projection of the third joint; whilst in Tachina (Fig. 72, B) the third joint is enlarged, but to a less degree than in most Muscidæ.

Description of the Antenna in the Blow-Fly.-The first joint of the antenna is a narrow ring (Fig. $72, \mathrm{C}, \mathrm{D}, \mathrm{I}$ ), with several stiff setæe on the front of its distal margin. It articulates by syndesmosis, by its proximal border with the torulus (see p. I22), and by its distal border with the second joint of the antenna.

The second joint (Fig. 72, C, D, 2) has the form of two irregular pyramids placed base to base. The distal pyramid projects into a cavity at the proximal extremity of the third joint, so that it is not seen externally. The proximal pyramid is the largest ; it overhangs the proximal extremity of the 
third joint. Its outer surface bears several stiff seta, one of which is longer than the rest. It also has sensory setic on its anterior and external surface in relation with a special ganglion, which has usually been regarded as a chordotonal organ. It is certainly very similar to Müller's organ (see p. 592), and is possibly an exceedingly rudimentary auditory structure.

The cavity of the second joint communicates freely with the first joint, but only by a comparatively narrow foramen (Fig. $72, \mathrm{D}$ ) with that of the third joint. It contains a ganglionic enlargement of the antennal nerve.

The third joint is ovoid and obscurely triquetrous; the integument is thinner than that of the other joints; about cighty large sacculi open on its surface by large irregular pores, chicfly on its posterior, or facial, and inner aspects. In Syrphus the sacculi are replaced by one or more long convoluted canals, and this also appears to be the case in many of the Muscidr.

The fourth and fifth joints are mere rings at the base of the seta, which is inserted on the outer side of the third joint. The seta is plumose; the lateral appendages of the feather are scales with a greatly elongated apex, and do not appear to be hollow seta. I have been unable to trace a special nerve to this structure, and its cavity is occupied by a blood sinus and a tracheal vessel. As it is lined by a distinct hypodermal layer, it is probably supplied by fine cutaneous nerves: but it is not apparently the seat of any special nerve-terminals. It is probably a mere persistent rudiment of the terminal joints of the antenna.

\section{DESCRIPTION OF P'IATE XLI.}

The Antenna and Palpus of the Blow-fly.

FIG. 1. - A longitudinal antero-posterior section of the antenna of a Blow-fly.

$a^{1}, a^{2}$, and $a^{3}$, the first, second, and third joints ; $g$, ganglionic enlargement of the antennal nerve in the second joint; $n$, antennal nerve; $s, s$, sacculi on the posterior aspect of the third joint.

Fili. 2. - Sections of the integument and subjacent ganglion cells of the same, seen with a $i^{2}$ oil immersion lens. A, a portion of the surface of the antenna. $g$, ganglion cells; $h$, hypoderm cells; $p s$, protective setx; $s$, sensory setx. $B$, one of the sacculi ; s, orifice of the sac. C, Flame-like process $(f)$, or cone, left after the isctachment of a seta; s, ganglisn cell, partly situated in the sul,jacent pore canal.

Fyg. 3.-A portion of one of the maxillary palpi. $1 t$, nerve; $t r$, trachea.

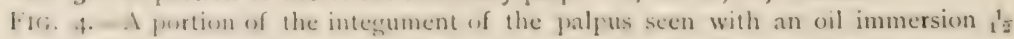
objective. s, ganglion cells; $h$, hypoderm ; $h$, nerve ; $s$, sensory setx. 
PLATE XLI.

FIG. I.

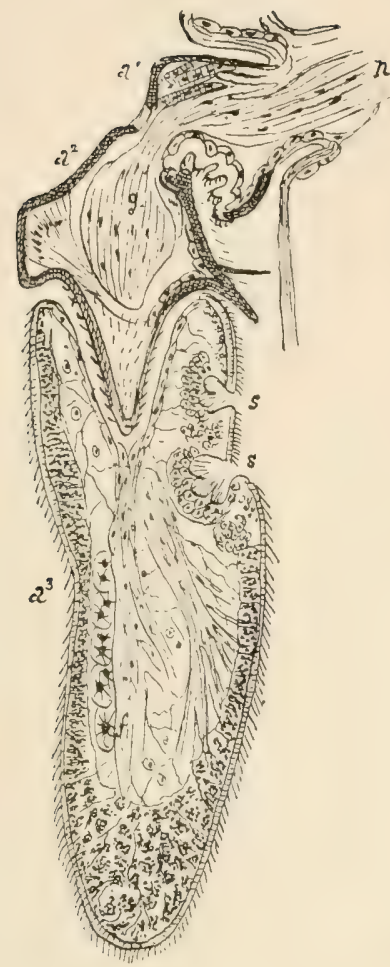

FIG. 4 .

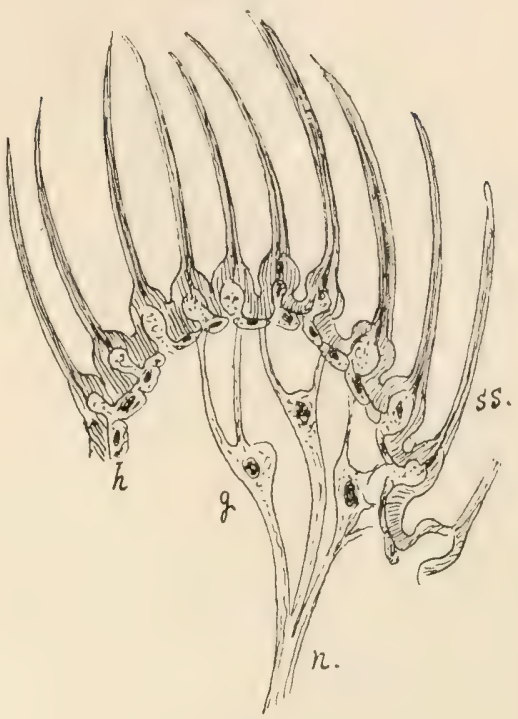

FIG. 3 .

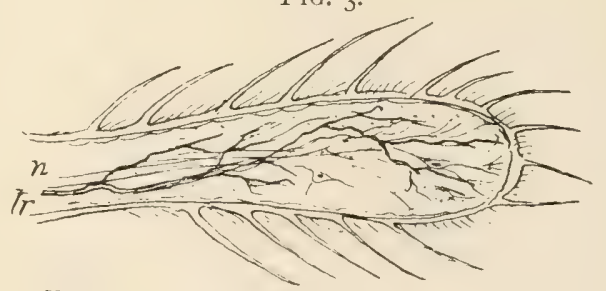

FIG, 2.

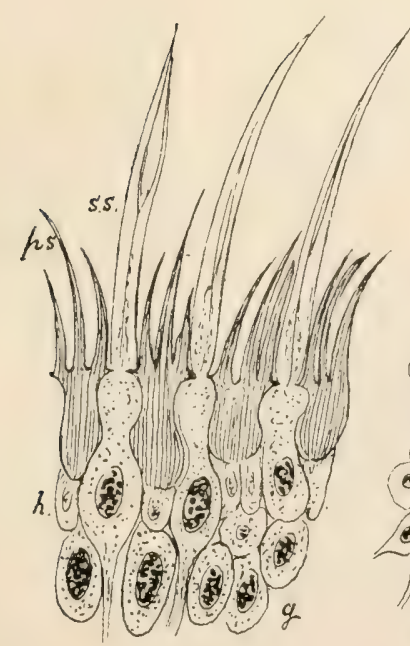

A.

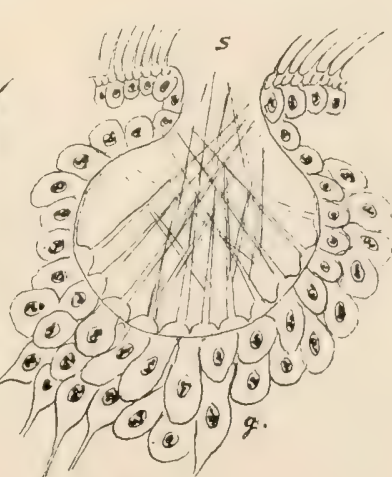

B.

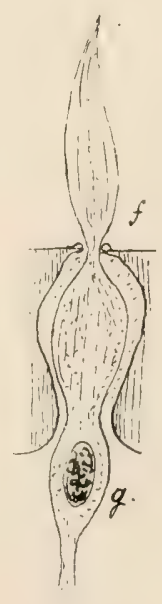

c. 

The minute structure of the antenna can only be satisfactorily studied in thin sections; those from antennæ fixed with osmium peroxide or Flemming's mixture are far the best. The osmium peroxide stains the whole organ and the fibres of the olfactory nerve intensely.

The cuticular layer of the integument of the third joint is not more than I2 $\mu$ in thickness, except near the base on its outer aspect, where it is thicker than elsewhere. Surface-
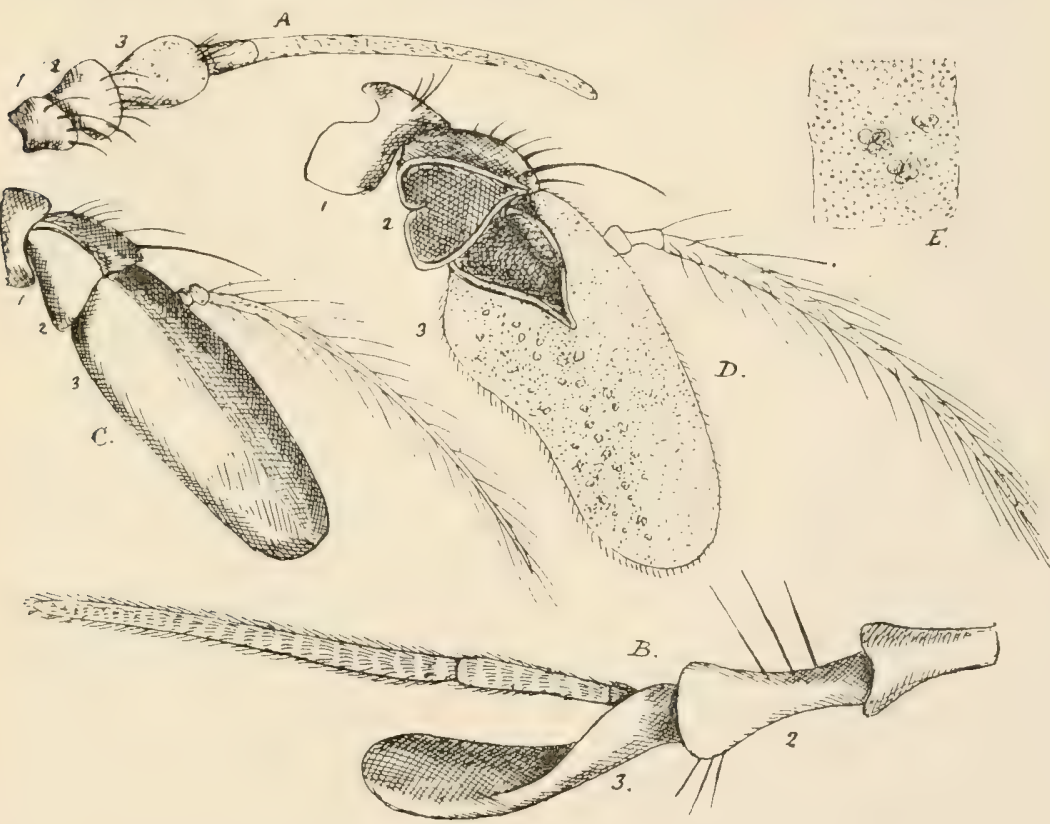

FIG. 72.-The antennæ of Leptis, Tachina, and Calliphora.

$A$, the right antenna of Leptis triangularis, $\delta$, Linn. From a cabinet specimen seen as an opaque object.

$B$, the right antenna of Tachina vulpina $\delta$, Fall. From a cabinet specimen seen as an opaque object.

$C$, the left antenna of a male Blow-fly seen as an opaque object.

$D$, the left antenna of a female Blow-fly, from a compressed specimen, which has been cleaned in caustic soda and mounted in Canada balsam.

$E$, a portion of the integument of the same seen with a $\frac{1}{4}$ inch objective.

views show that it is densely covered with fine curved setæ, from $20 \mu$ to $25 \mu$ in length, with minute transparent dots 
between them - the so-called pore plates - of which each antenna has from $I_{7}, 000$ to $\mathrm{I} 8,000$. These are about $5 \mu$ in diameter (Fig. 72, E).

Sections show that the pore-plates are the orifices of flaskshaped canals (Pl. XLI., Fig. 2, A). The canals are surmounted by transparent sensory setre, $50 \mu$ in length. These sensory setre are nearly straight; they are conical, and in many preparations exhibit the appearance of having a slit running down one side and ending toward the apex of the seta in an oblique opening. Each contains a process from a ganglion cell, which is partially embedded in the pore canal. These sete are very easily detached, and leave their contents projecting from the pore canal as a flame-shaped process-the olfactory cone of authors. Sometimes the term 'olfactory cone' has been applied, however, to the seta. In a few preparations I have observed a fine axis cylinder only projecting from the pore canal; but I believe, like the flame-shaped cones, this is only the result of the detachment of the seta from its base, the greater part of its contents having been torn away with the seta itself. All these conditions have been figured by Kräpelin, who took them for modifications of a typical seta.

The short, thick, opaque seta which spring directly from the epidermal cuticle are only about half as long as the sensory seta. Their function is probably to protect the bases of the sensory setæ.

The arrangement of the hypodermal and ganglionic cells beneath the cuticle will be readily understood by a reference to the figures (Pl. XLI., Figs. I and 2).

The subcutancous ganglion cells are the superficial layer of the terminal ganglion of the antennal nerve; beneath these there are numcrous layers of far smaller round cells, which form its deep layer. This ganglion consists of a continuous layer, $50 \mu$ or $60 \mu$ thick, over the whole inner surface of the integument of the third joint of the antenna. Its cells are supported and bound together by a fine reticular stroma. Some of the terminal branches of the nerve can be traced directly to 
the larger superficial cells, but many apparently end in the small round cells beneath them.

The large Sacculi have an average diameter of $50 \mu$ (Pl. XLI., Fig. 2, B). Each sacculus consists of a very thin cuticular layer, usually inflected so as to form a group of sacs opening into a single central cavity, more rarely as a simple flask-like sac. This membranous cuticle supports a vast number of very fine, straight, broad-based setæ, which converge towards, and sometimes project from, the orifice of the sacculus. The orifice of the sacculus is generally irregular in form, bounded by several short curves; but it is occasionally circular, when the sacculus has no secondary sacculi in its walls. The nervous structures beneath the sacculi are identical with those under the rest of the integument, but the large superficial ganglion cells are more numerous in relation with the sacculi. I have occasionally seen flame-shaped cones in the sacculi, and suspect their origin is similar to that of the cones on the surface of the antennæ. Those in the sacculi are smaller, proportionately to the finer setæ which they contain.

\section{c. On the Functions of the Antennæ in Insects generally.}

Oken regarded the antennæ as organs of hearing, and Lefebvre [262], in 1838 , was apparently the first who attempted to controvert this opinion and to attribute an olfactory function to them. It is true that Reaumur suggested the possibility that they subserve the olfactory sense, but he brought forward no evidence in favour of this view; and the majority of authors who touched upon the subject before 1847 followed Oken.

Erichson [263], in the latter year, investigated the minute structure of the antennæ, and concluded from his anatomical investigations that they are olfactory organs. Erichson's knowledge of their minute structure was necessarily very imperfect, and, although his conclusion was apparently correct, he had no facts to justify it.

Leydig [122], in I855, reinvestigated the subject, and traced the antennal nerve to the end organs discovered by Erichson, although he gave a figure of the olfactory setæ of Calliphora, 
without indicating that they are the terminal organs of the antennal nerve; and he, on other occasions [269], described what he regarded as auditory end organs in the antennic of insects.

Anatomy can only guide us in seeking the function of a part when the structures are similar to those of the human body. As the so-called olfactory setie of Invertebrates are entirely unlike the olfactory rods of Man and Vertebrates generally, the structure of these end organs cannot guide us to their function. I only know one anatomical fact which in itself is a sruide to the function of the antenna: the structure of the antemnal ganglion, which is similar to that of the olfactory bulb of the Vertebrate; but this was unknown until it was discovered by Dietl [175] in $I 876$. The credit of having first established the olfactory function of the antenna must be accorded to Perris [265], as he was the first who made a systematic investigation of their function in living insects by carefully devised experiments.

Lespés [266] ignored the researches of Perris, and returned to the view of Oken. Claparede [267], in I\$5\&, published a paper in controversion of Lespes' views; and Graber [270], in I8,9, believed that he had discovered otolith-like organs in the antennac of flies, and returned to Oken's view. P. Meyer in the same year published a short paper in the 'Zoülogische Anzeiger,' in which he correctly stated that Graber's supposed otolith-like bodies have no real existence.

The views of Perris have been completely confirmed by the repetition of various experiments, and may be said to have been accepted, although, owing to the apparent multiplicity of the forms which the nerve terminals exhibit, there are still many who think that the antenna may have an auditory as well as an olfactory function in some insects.

Fraipelin [273] has given so complete a history and criticism of the works of previous writers, that I shall content myself with the above short account of the history and bibliography of a controversy, of which the last-named author says:

' In extensive literature has grown in the course of years, 
and names of the first rank come before us in the investigation of the history of this controversy; no subject, perhaps, in zoology has been treated with greater acumen, and yet to-day (I883), in spite of the many essays of the last ten years, we are far from a final solution of the questions involved.'

Kräpelin gives references to more than one hundred papers on the subject, ranging from I730 to I883.

Lubbock [276], in I888, said: "The evidence is, I think, conclusive that the antennæ are olfactory as well as tactile organs, and I believe that they also serve as organs of hearing.'

Observations in Favour of an Auditory Function.-Kirby ('Introduction to Entomology') observed movements of the antennæ in a Moth and in a Weevil when he made a distinct sound in their vicinity, and other observers have asserted that the antennæ are set into vibration by sounds. Mayer went a step further, experimenting with the feathered antennæ of a male mosquito (Culex), he found that some of the hairs are thrown into vigorous vibration, when a note with 5 I2 vibrations per second is sounded. Lubbock [276], who quotes the observation, adds: "It is interesting to observe that the hum of the female Gnat corresponds nearly to this note, and would, consequently, set the hairs into vibration.' To my ear, however, the note of the female Gnat is certainly not middle C, which has 5 I2 vibrations, but $A$, as is usually stated with 420 double vibrations.

It may be remarked that the vibration of the setæ in response to certain notes is a physical necessity, but it is not evidence that they are endowed with auditory sensibility; neither is the voluntary movement of the antennæ when an insect is excited by sound better evidence. A terrier will certainly sniff when he hears a rat, but this is not evidence that he hears with his nose; the dog is simply using his most acute sense to determine the cause of a sound. And so insects may use their antennæ when excited by sounds, even if they do not hear with them. Lehmann [261] believed that insects hear with their antennæ, and he found that those of a Cricket (Acheta domestica) vibrate 
to certain notes, yet he admits that this insect undoubtedly hears when the antennæ are removed.

Neither is the anatomical and histological evidence more satisfactory. Leydig, Graber, and Hurst have described structures which they believed to be auditory. Leydig's chordotonal organs in the antenne of Dytiscus are very doubtful. Graber describes similar organs in the antennæ, palpi, under lip and legs of Dytiscus and Telephorus without figuring them. Hurst [156] describes and figures a structure in the basal joint of the antenna of Culex, and Hammond has shown me some very beautiful sections of this organ. Both observers regard it as an ear; but, I think, on very insufficient evidence. The scape of the antenna is supported by a thin membrane, beneath which there are, undoubtedly, very remarkable nerve terminals.

This organ is certainly an exceptional one, and it may be admitted that the presence of an ear at the base of the antennule in some Crustacea is an argument in favour of the view of Hurst and Hammond. It appears to me more probable, however, that the pressure communicated to the tense membrane by the action of the air on the great plumose antenna during flight would affect this membrane more powerfully than sound vibrations, and I think it more probably a balancing organ than an auditory organ in the strict sense of the word. I do not wish, however, to deny the existence of auditory organs in con. nection with the antenna, although I feel that the evidence in favour of such organs is far from convincing. The structure in the second joint of the antenna of the Blow-fly certainly resembles a rudimentary group of chordotonal organs, and perhaps indicates the existence of auditory organs in the antenna. I have not been able, however, actually to make out chordotonal threads, and it appears to me improbable that the antennee are organs of audition in insects.

Experimental Evidence in Favour of an 0lfactory Function.-Perris [265] gives numerous experiments which led him to the conclusion that the antenne are olfactory organs, and Hauser [272] arrived at the same result. The latter says that neither Silpha 
nor its larva could find its food after the removal of the antennæ, and that Flies of the genera Sarcophaga, Calliphora, and Cynomyia were unable to discover a large piece of rotting flesh when the antennæ were removed, although they were flying in a room in which it was freely exposed. He also states that males of Melolontha vulgaris, Saturnia pavonia, and Ocneria dispar, seldom found the females of the same species, even when confined in the same case with them, after their antennæ had been removed, and contrasts their behaviour with that of entire insects.

Forel [194] removed the wings of some Bluebottle-flies (Calliphora) and placed them near a decaying mole; they immediately walked to it and began to lick it and lay their eggs upon it. He then took them away and removed their antennæe, after which, even when placed close to the mole, they did not appear to perceive it. Plateau* made experiments on four Cockroaches (Periplaneta), from two of which he removed the antennæ, and from the other two the palpi. The insects were under observation from June 29 to July 31, in a glass vessel in which a card box was placed containing bread moistened with beer. Those without the antennæ, with a single accidental exception, never found the food, whilst the others were observed feeding almost every day. Lubbock [276] states that Ants withdraw their antennæ when stimulated by the odour of musk, and Graber himself found that a Beetle (Silpha thoracica) showed no perception of asafœtida after the antennæ were removed, although it responded to stimulation by oil of rosemary.

Oil of rosemary gives off an irritant vapour, whilst asafœetida is a true odour. All the essential oils give rise to taste as well as olfactory sensations, and are also direct irritants acting on the respiratory tract. Probably the statements made by authors as to the persistence of the sense of smell after the removal of the antennæ are due to their having used essential oils and other irritants, like ammonia, sulphurous acid, or vinegar to test the olfactory sense, instead of non-irritant odours.

Hygroscopic Function of the Antennæ.-Lehmann [261] and * Ann. Soc. Entom. Belgique, tom. xxx., I886, p. cxx. 
Duponchel [262a] regarded the antenne as hygroscopic organs; but lath 133 says there is no proof of any such function. Watery vapour has many of the physical properties of odorous bodies, more especially in its relations with radiant energy (Tyndall). It is, however, clear that it could not excite the olfactory membrane of Vertebrates, since this is always surrounded by air, saturated with aqueous vapour, and is itself moist. The end organs of an insect's antenna are, however, placed under very different conditions. That they can act as hygroscopic bodies in the physical sense is extremely improbable, since the hypodermis would certainly prevent their ever becoming dry enough to absorb moisture like a dried vegetable or animal fibre; but there is no reason why the nerve end organs should not be stimulated by a moist atmosphere.

It has long been argued that Bees and other Hymenoptera discover the approach of rain by the hygroscopic condition of the atmosphere; and I have made a series of careful observations on the House Cricket (Acheta domestica). It is well known that these insects drink with avidity, and cannot live long without a supply of water. I have repeatedly kept Crickets under a glass shade for months, supplying them with food and water. When the supply of water is withdrawn for two or three days, even in winter, and for a less time in summer, these insects become very thirsty. I introduce a supply of water in a watchglass, concealed in a cardboard tray, so that it cannot be seen by the insect. The antenne are at once raised, the insect runs about and soon finds the water, always seeking it by swaying its antennie. As soon as these organs are brought near the water, the insect groes straight to it. Crickets which have incen freshly captured, and kept a day or two without water, find it almost directly; and I have observed in cold weather that they first seek it close to the glass bell, where the vipour condenses most rapidly, but in a few minutes or less go straight to the water. The manner in which the antemna are moved and the rapidity with which the insects find the water imme. diately after the tips of the antenna come vertically orer the 
watch-glass is very convincing that they use these organs in seeking it.

The search for water is probably one of the most important functions of the antennæ in many insects, especially in those which feed on dry food.

The Antennæ as Tactile Organs.-Although the antennæ are popularly known as 'feelers,' it is very doubtful if they are ever used as tactile organs in the great majority of insects. Except in the Ants and Bees, I have never seen them so used, and most insects carefully avoid contact between the antennæ and all solid bodies. Certainly the more complex forms of antennæ are ill adapted for such a purpose.

\section{AUDITORY AND SOUND.PRODUCING MECHANISMS.}

\section{a. Chordotonal Organs.}

Johannes Müller in I826 [197] and Siebold in I844 [278] first described a tympanic ear in some Orthoptera, and in I 860 Leydig [269] concluded that certain organs described by Braxton Hicks [292-293] in the wing nervures of some insects, and in the bases of the halteres of the Diptera, are auditory in function. Graber [284] made a comparative study of the nervous end organs of these structures, and of others frequently present in larval insects, and designated the essential nerveterminals chordotonal organs. He held that the nerveterminals of the tympanic ear, of the halteres, and of what he termed the primitive chordotonal organs of larval insects, are essentially similar in structure; and he classified these as primitive, poriferous, and tympanic chordotonal organs; and, reasoning from the manner in which chordotonal organs are scattered over the body, concluded that the general integument and setæ are more or less affected by sound-waves. He regarded the chordotonal organs as segmental in the sense that they may be present in any or in several segments, or in their appendages, and held that the tympanic organs are highly modified forms of the primitive and poriferous organs. 
Primitive Chordotonal Organs are typically represented in many. larvie, as in Tabanus, most species of Chironomus, and Syrphus. They appear as cords, connected at two points with the integument, like a stretched string, the chordotonal ligament. The chordotonal ligament is connected with the terminal ganglion of a nerve, about midway between its ends (Fig. $74, B$ ).

The chordotonal ligament is a fibrous band connecting the nerve gangrlion with the integument, and is probably a modification of the nerve-sheath. It encloses a peripheral nerve-cell, or a group of cells, and one or more remarkable spindle-like quasichitinous elements, the auditory rods (Haurstiftc). Graber restricts the term ligament to the non-nervous proximal part of the chordotonal organ, and terms the distal part the terminal nerve string; but it appears to me that the connective nervesheath extends in both directions as a ligament, and, for convenience of description, I have used the term for the whole of the stretched cord which encloses the nerve terminals. Each

\section{Bibliography :}

278. Sifrold, C. J. von, 'Ueber das Stimm- und Gehïrorgan der Orthopteren.' Wiegmann's Archiv f. Naturgesch., Jahrg. IO, I844.

279. Leydig, F., 'Anatomisches und Histologisches iber die Larve von Corethra plumicornis.' Zeitsch. f. w. Zool., Bd. iii., 185 I.

280. Hrassex, V., 'Ueber das Gehïrorgan von Locusta.' Zeitsch. f. w. Zool., Bd. xvi., 1866.

281. LandoIs, H., 'Die Ton- und Stimmapparate der Insecten in anatomisch-physiologischer und akustischer Beziehung.' Zeitsch. f. w. Zool., Bd. xvii., 1867 .

282. Schmi)T, O., 'Die Gehïrorgane der Heuschrecken.' Archiv. f. Mikros. Anat., Bd. ii., 1875.

283. GR.Aik, V., 'Die tympanalen Sinnesapparate der Orthopteren.' Denkschrift. d. Kais. Akad., IVien, Bd. xxxvi. (1875), 1876.

284. GrabEr, V., 'Ueber die stiftefuhrenden oder chordotonalen Sinnesorgane bei den Insecten.' Zool. Anzeiger, I88I, No.9I.

285. (iRABER, I'., 'Die chordotonalen Sinnezorgane und das Gehör der Insecten.' I. Morphologische Theil. Archis: fo Mikros. Anat., Bd. $x x_{.}, 1882$.

286. (GRABER, V., 'Die chordotonalen Sinnesorgane und das (iehör der Insecten.' II. Physiologische Theil. Archiv. f. Mikros. Anat., Bd. xxi., 1882 .

287. Swintox, A. H., 'Insect Variety, and its I'ropagation and Distribution.' Svo., London, Paris and New York. Published about ISS2, but without any date. 
chordotonal organ may contain one or many, Io to 20 or more, auditory rods, forming a fasciculus: when more than one rod is present there is a ganglion in place of a single nerve-cell.

The Auditory rods are minute, more or less fusiform organs, consisting of a body terminating in a long, fine, straight thread, unipolar rods (Mononcmatiscle Stifte), or each end of the body may have a rod or thread-like prolongation, when the organ is bipolar (Amphinematische Stifte). The second prolongation is always distal, and may be represented in the unipolar rods by the short conical point.

I have never found primitive chordotonal organs either in the imago or larva of the Blow-fly.

Poriferous Chordotonal Organs.-Graber applies this term to certain organs at the bases of the halteres of the Diptera, and

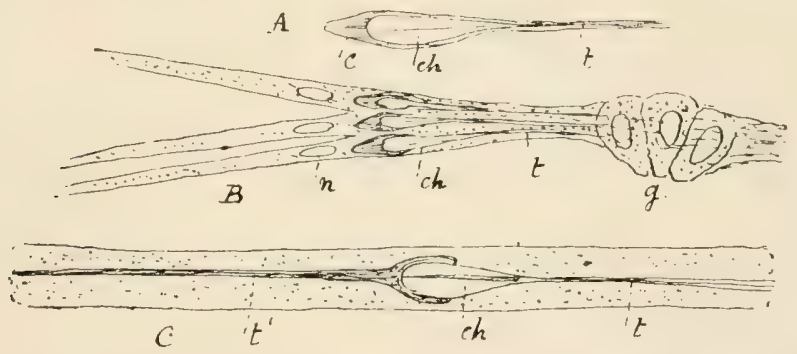

FIG. 73.-Three chordotonal end organs, after Graber: A, the quasi-chitinous rod and bulb of the unipolar variety; B, a group of unipolar end organs, from a larva of Tabanus autumnalis; C, a bipolar chordotonal end organ, from a Syrphus larva; $c h$, head of the auditory rod; $c$, pyramidal prolongation in the unipolar variety ; $\delta$, ganglion cells ; $t$, proximal, and $t^{\prime}$, distal end of the chordotonal thread.

on the wing nervures of insects. These are essentially chordotonal organs, somewhat modified in their minute structure, in which the capitate extremity of the rod is in relation with a thin plate, or pore, in the epidermis, or with the base of a specially modified seta. These will be more minutely described with the halteres (p. 6og).

The tympanic chordotonal nerve-terminals are treated of on p. 600 .

Graber's Views on the Stimulation of Primitive Chordotonal 
Organs.-Graber compares the primitive chordotonal organs of Insects with the outer hair cells of the organ of Corti in the Vertebrata (Fig. 74), and remarks that in both cases the vibrations act vertically upon the membranes, between which the end organs are stretched. In the case of the hremal end organ the analogy is still more complete, as in this case it is the movement of the surrounding fluid of the body cavity, which acts upon the membranes supporting the end organ. The diagrams show a very complete accordance between these structures in the Arthropod and the Vertebrate, and make the view he has adopted very plausible. It must, however, be admitted that the representation is extremely diagrammatic in the case of the Vertebrate end organ, and that in details

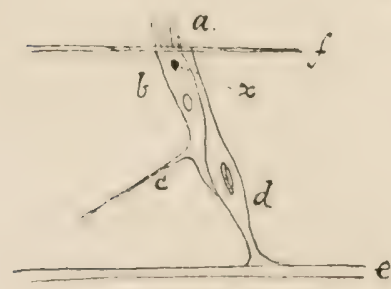

A

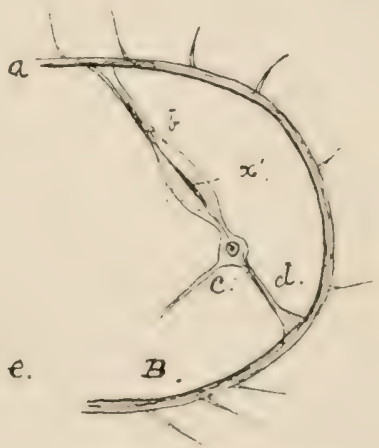

Fig. 74. - A dingrammatic comparison of the outer hair-cells of Vertelrates with the chordotonal organs of Arthropods, copied from Graber [286].

A. A diagrammatic representation of one of the outer hair-cells of the organ of Corti after Waldeyer : $a$, hair-like processes; $b$, the hair-cell; $c$, nerve fibril ; $x$, minute granule of roubtful nature; $d$, supporting cell ; e, basilar membrane ; $f$, reticular membrane.

13. A diagrammatic representation of a primitive chorclotonal organ, after Graber: $a$, outer integument of the larva; $b$, chordotonal organ; $c$, nerve fibre and ganglion cell; $d$, chordotonal ligament; $x$, chordotonal thread, which (iraber compares with $x$ in Fig. A.

the structures are very different. I think, however, that the similarity is sufficient to give a very high degree of probability to Graber's view that these end organs are auditory in function. 


\section{b. Tympanic 0rgans.}

The terms tympana and mirrors have been applied to certain more or less transparent tense membranes, protected by over-lapping plates, or situated at the inner extremity of a short tubular depression of the integument, or upon the exposed surface of one of the elytra. Such are (x) the tympanic ear-like organs of certain Orthoptera (Acridide), which were fully described by Siebold [278]; (2) the sound-intensifying mirrors of the Locustidæ; and (3) the so-called tymbals and mirrors of the Cicadæ.

The Tympana of the Orthoptera are thin, round or oval membranes. One half of the tympanum is usually thicker and darker than the other, and a small sclerite projects
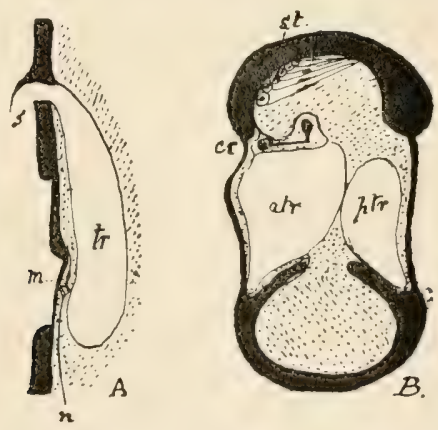

FIG. 75.-Diagrammatic representations of the ear-like organs of the Orthoptera, copied from Graber's paper [286].

A. The ear-like organ from the first abdominal segment of an Acridium : $m$, Miillerian organ, on the inner surface of the tympanic membrane; $n$, nerve fibre; $s$, spiracular opening; tr, subtympanic tracheal sac.

B. A section of the anterior tibia of a Locusta; $a$ tr, anterior, and $p t r$, pos. terior, subtympanic tracheal sac; $\mathrm{Cr}^{2}$, crista of the organ of Siebold; st, supratympanic oigan, or organ of Graber.

inwards from its border, and has a resemblance at least to the auditory ossicles of a Vertebrate. This sclerite is sometimes connected with a tensor muscle. Beneath the tympanic membrane there is always a large tracheal sac connected with the exterior by a spiracle of peculiar construction.

There is always a special nerve end organ, and sometimes 
several different end organs, in relation with the tympanic apparatus. Three forms of end organs have been described, of which two, or even all three, are frequently present in the same insect. These special structures are the organ of Müller, the organ of Siebold, and the supratympanic organ, discovered by Graber, which may be termed the organ of Graber. These structures are situated at the extremity of a large nerve which springs from the thoracic ganglion.

Muller's Organ.-Müller first described the tympanic apparatus in the Acrididx, and discovered a ganglionic structure situated upon the inflected angle of the tympanic sclerite. This organ has been carefully described by Siebold, Leydig, and more recently by Graber; it is undoubtedly a terminal
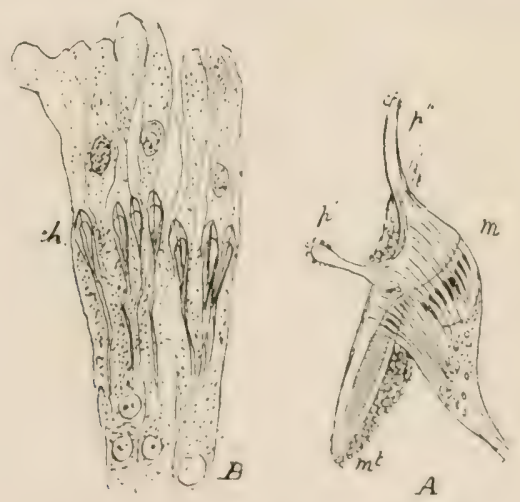

FIG. 76. - Details of the Miillerian organ, after Graber [283].

A. The Millerian ganglion $(m)$, and a small portion of the tympanic membrane ( $m t$ ) of I'achytylus striclulus, showing the two processes of the tympanic sclerite which project from its inner surface. Their position in the figure is due to displacement in the process of mounting the specinen.

B. A portion of the Miillerian ganglion of Acridium tartaricum. From a specimen teased out in Miiller's fluid.

nerve ganglion surmounted by a group of chordotonal organs, and enclosed in a minute sac filled with fluid. It has been aptly compared with the membranous labyrinth.

Siebold's Organ is much more complex than Müller's, which is freruently quite rudimentary. It consists of two parts, which I shall term the bulb and the crista. The bulb closely resembles 
Müller's organ both in form and structure; it is situated on the tracheal sac beneath the tympanic membrane. The crista consists of a ridge which extends from the bulb, in a longitudinal direction, over the sac. This ridge is formed of cuboid cells which become smaller as they recede from the bulb. These cells enclose the enlarged capitella of the chordotonal threads. The chordotonal ligaments extend from the cuboid cells to the adjacent integument. The ligaments are longest at the proximal end of the crista, that nearest to the bulb, and become gradually shortened as they approach the distal end of the crista. The chordotonal rods are frequently bent at right angles, where they join the capitella, and are sometimes jointed in the middle.

The Supratympanic Organ (Graber's organ) (Fig. 78) resembles a large Müllerian organ, which is fan-shaped in section. It is attached to the integument, near the tympanic membrane, and lies upon a ganglion, in which a branch of the auditory nerve terminates. It is only indirectly connected with the tympanic membrane and its air-sac through the medium of the circulating fluid; it lies in a distinct blood sinus, one of the walls of which is formed by the tracheal air-sac.

The Mirrors of the Locustidæ are thin, tense areolæ of a circular form, situated on the base of the elytra of the sound-producing males. They are usually regarded as organs for the intensification of the sound produced

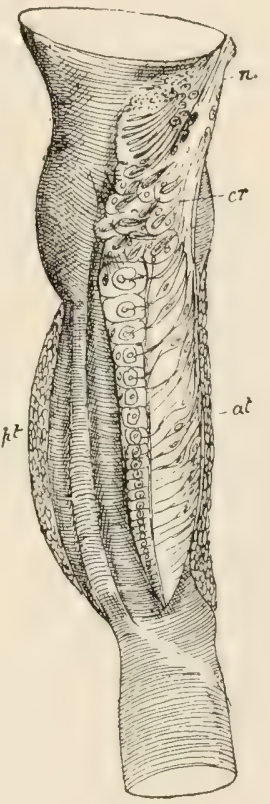

FIG. 77.-The crista and tympanic (Siebold's) organ of Ephippigera vitium, Serv,, after Graber [283] : $\mathrm{cr}$, the bulb of the crista acoustica ; at, pt, anterior and posterior tympanic membranes ; , auditory nerve.

- resonating organs. This view of their nature is rendered more probable since these insects possess ear-like organs on the anterior tibiæ in both sexes.

The Mirrors and Tymbals of the Cicadæ are situated in special cavities on the sides and below the base of the 
abdomen. The mirrors in many respects resemble the tympanic organs of the Acrididx, but they have been insufficiently investigated. The tymbal is a large plicated membrane moved by a strong muscle, which has been observed to cxhibit pulsating movements during the emission of sound. As the note of the Cicadre is very high, no visible vibrations or

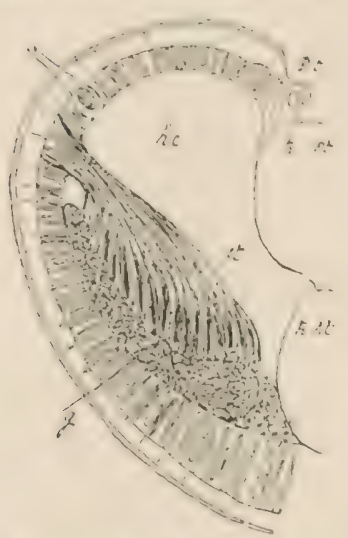

FIc. 78.-The supratym. panic (Graber's) organ of Gryllus campestris, after Graber [283]: s, ganglion; he, hremal cavity; pt, pos. terior tympanum; ; $:$, supratympanal organ; trat, tr pt, anterior and posterior tym. panic sacs. changes of form can even be the cause of its deepest ground tone. As there is undoubtedly a narrow spiracle opening into the special cavity in which the mirrors are situated, it appears to me probable that the so-called tymbals are functionally bellows which produce the sound by expelling air through this spiracle. It further appears probable that the air so expelled impinges upon the mirrors and sets up a vibratory movement of the air in the drum-like cavity in front of them. Landois [281] refers the sound to an expiratory current from the posterior thoracic spiracles, which he erroneously asserts open into the cavities in which the tymbals lie; the spiracles are separated from these cavities by the opercula, and are quite distinct from the spiracles which open into the mirror chamber. A structure somewhat intermediate between the sound-producing organs of the Cicade and the tympanic apparatus of the Orthoptera occupies the tympanic fissure in the 13 low-fly. It receives small nerves which are branches of the great nerves to the halteres (see p. 623). 


\section{THE HALTERES OF THE BLOW-FLY.}

\section{a. General Structure and Morphology (Plates XLII. and XLIII.).}

The halteres, which are commonly known in the Diptera as 'balancers,' are rarely absent in the order. Weismann [2] showed that they are developed from the upper metathoracic imaginal discs, and they are now generally admitted to be homologous with the posterior wings of other insects.

When it is said, however, that they are rudimentary wings,

\section{Bibliography :}

288. SCHELver, F. J., 'Entomologische Beobachtungen, Versuche und Muthmassungen über den Flug und das Gesumme einiger Zweiflügler Insecten, und insbesondere ïber die Schwingkülbchen und Schïppchen unter den Flügel derselben.' Wiedermann's Archiv f. Zool., Bd. ii., I8OI.

289. Audouin, V., Art. 'Balancier.' Dictionnaire classique d'Hist. Nat., tom. vi. et viii., I820-1822, Paris.

290. Robineau-Desvoidy, 'Einiges u. die Thätigkeit der Schwinger.' Bull. Sc. du Départ. du Nord, 2nd sér., Ann. I., pp. 217-2I9, 1828 .

291. Goureau, CH., 'Mémoire sur les Balanciers des Diptères.' Ann. Ent. Soc. de France, sér. ii., tom. i., 1843.

292. Hicks, J. Braxton, 'On a New Organ in Insects.' Journ. Linn. Soc. Zool., vol. i. (I 856$)$, I 857 .

293. Loew, H., 'Ueber die Schwinger der Dipteren.' Berlin Ent. Zeitsch., Bd. ii., I 858 .

294. HiCks, J. BRAXTON, 'Further Remarks on the Organs found on the Bases of the Halteres and Wings of Insects.' Trans. Linn. Soc., vol. xxii. (1857), I859, Lond.

295. Hicks, J. BRAXton, 'On certain Sensory Organs in Insects hitherto Undescribed.' Trans. Linn. Soc., vol. xxiii. (1860), I862, Lond.

296. GIRARD, 'Note sur diverses expériences relatives a la fonction des ailes chez les insectes.' Ann. Soc. Ent. de France, sér. iv., tom. ii., I 862 .

297. AIRY, G. B., 'On Sound and Atmospheric Vibrations with the Mathematical Elements of Music.' 2nd edition, London, I87I.

298 JousSET DE BELLESME, ' Recherches expérimentales sur les Fonctions du Balanciers chez les Insectes Diptères. Paris, I878.

299. LEE, A. Bolles, 'Les Balanciers des Diptères, leurs Organes sensifères et leur Histologie.' Recueil Zool. Suisse, tom. ii., I 885.

300. WEINLAND, E., "Ueber die Schwinger (Halteren) der Dipteren. Zeitsch. f. w. Zool., Bd. li., I8gI. 
their great complexity is overlooked. That they are highly modified wings is true, but that they are rudimentary organs is in no sense true.

The halteres obtain their greatest complexity in the Muscidæ, and are apparently more highly developed in Calliphora than in the great majority of the Diptera ; indeed, I know no insect in which the special structures at their base are so highly developed.

General Description.-The superficial resemblance of the halteres to drumsticks is well known, but the proximal extremity (Pl. XLII.) forms a dilated subpyramidal organ, which may be termed the scabellum. This, with the stalk, or scape, and the head or capitellum must be included under the term halter.

The halter of the Blow-fly varies from $\mathrm{I}^{\cdot} \mathrm{I} \mathrm{mm}$. to $\mathrm{I}^{*}+\mathrm{mm}$. in length, the scabellum is $0^{\circ} 3 \mathrm{I} \mathrm{mm}$., the scape is $0^{\circ} 5 \mathrm{I} \mathrm{mm}$. in length, and the head is from $0.28 \mathrm{~mm}$. to $0.34 \mathrm{~mm}$. in diameter. The scabellum articulates by a freely movable joint with the crutch-like crura of the metapleuron (Pl. VIII., Figs. Io and II), and is moved by four muscles, which are attached to minute processes arising from the proximal border of the scabellum.

Movements.-The halter moves with the wings, but apparently

\section{DESCRIPTION OF Plate XLII.}

The halteres of the Blow-fly and of Eristalis:

Fig. I.-The right halter of a Blow-fly seen from above. $c$, the cupola; $c h$, chordotonal membrane; $s c$, scala superior; $s t$, squamoid scale; $t$, ovoid elevation at the base of the halter.

FIG 2.-The left halter seen from below. l, Lee's chordotonal organ; sc', scala inferior: $s q^{\prime}$, the squamuloid scale.

Fi:. 3. - A semi-cliagrammatic representation of the right halter of Eristalis tenax seen from below and behind. s, the septum of the capitcllum; sc, scale. The arrows represent the direction of the movement of the fluid in the canals towards the scalix.

Fi: 4. - A surface view of a part of two of the ridges of the cupola of a Blow-fly seen with a ${ }_{1}^{1}$ oil immersion objective.

III: 5. - A surface view of a part of one of the transwerse arcades of the scala of a llow. fly, seen with a th oil immersion objective.

Fu, 6. A surface view of the chordotonal membrane (ch, Fig. 1), secn with a $\frac{1}{4}$ inch objective.

Fu. 7 . I surface view of two of the oval bodies of the same seen with a $2 \frac{1}{2}$ oil $\mathrm{im}$. mersion. These are apparently groups of chordotonal threacis. 
PLATE XLII.

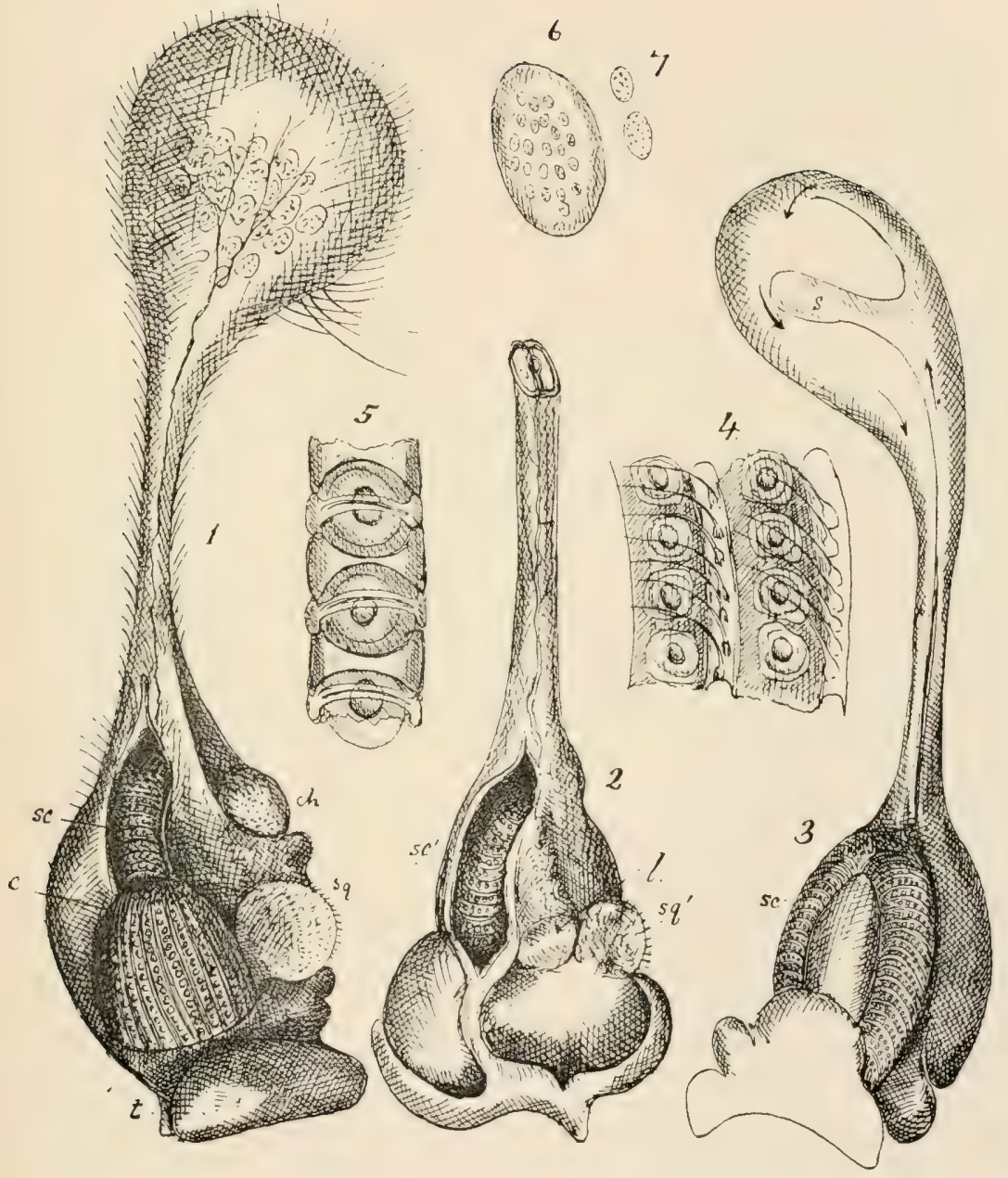



by the action of its own muscles, so that the head and scape vibrate in a conic surface which has its apex within the thorax, in the axis of the organ produced. Sections of the plane of its movement would probably vary from a circle to a straight line passing through the various phases of Lissajous' curves, as the plane of movement depends upon the composition of two vibrations-one in the vertical and one in the horizontal plane.

The Scabellum exhibits externally two semicircular ridges, one above and one below, which extend on to the scape. They are frequently termed scapal organs $\left(s_{. s .} ; s_{.} c^{\prime}\right.$.). They will be distinguished here as the superior and inferior scalæ. At the base of the superior scala is a hemispherical swelling, termed the basal plate by Graber, which I shall distinguish as the cupola $(c)$.

The cupola and the two scalæ exhibit numerous regularly arranged organs on their surface, which are known as pores or papillæ, according to the view taken by different observers of their nature. These will be designated as scapal or basal organs, according to their position.**

The Nerve Supply.- The halter receives the largest nerve in the insect, next to those which supply the compound eyes and the antennæ. This fact was pointed out by Braxton Hicks [292]; but Loew [293] contended that Hicks had not established the fact that this nerve is a sensory nerve, and not a motor one supplying the muscles of the halter. Such a contention has now, however, no value, as it has been abundantly proved that the nerve to the halter ends in a series of distal ganglia which are related to special sensory organs (Pl. XLIII., Figs. I and 2). The nerve divides into two branches-a small one which enters an organ which I shall term Lee's chordotonal organ, and a large one, which subsequently divides into three branches and ends in three special sets of organs, the scapal and basal organs, which are situated in the scalæ and cupola respectively. Besides these, there are also undoubtedly two

* The terms scapal and basal organs have been frequently applied by various writers to the scalæe and cupola. These have also been called poriferous plates, but it is always easy to see what is meant by the context. 
small branches which are distributed to two groups of chordotonal organs which have not hitherto been described, or which have been confounded with Lee's group of chordotonal organs.

The Form and Structure of the Halteres vary within narrow limits in different families of the Diptera. They are sometimes straight, as in Tipula; sometimes curved, as in Eristalis and Leptis. Sometimes the scape passes almost imperceptibly into the conical capitellum, as in Leptis and Tipula, or it may be sharply defined where it joins the subspherical head, as in Musca.

In all those insects which I have cxamined, the halter appears, however, to have a very similar structure. The scape usually consists of two distinct tubes. These appear to me to correspond with the marginal nervure, and the remigium of the wing respectively. The cavities of these tubes intercommunicate in the capitellum, but they are distinct in the scape of the halter.

Canals. - The marginal nervure is in front and below, and the submarginal or remigial nervure is above and behind. I shall term the cavity of the former the anterior canal, and that of the latter the posterior canal, of the scape. The anterior and posterior canals of the scape communicate with distinct blood sinuses in the base of the halter. It is not easy to trace these; but the posterior canal is seen to be in close relation with a membrane (Pl. XLIII., Fig. I, mb) which supports the special nerve end organs. In Eristalis (Pl. XLII., Fig. 3) it divides into two branches, one under each scala; and although I have been unable to demonstrate the same division in the lilow-fly, it appears probable that these canals present a sinilar arrangement in that insect. The anterior canal is more simple; it extends from a blood sinus in the scabellum to the anterior surface of the capitellum (Pl. XLII., Fig. 3).

The Cavity of the Scabellum. - There is a third cavity which contains the nerve and its ganglia, and which communicates with the cavities of the scalat and cupola. It is continued into the scape in the septum, between the anterior and posterior canals, and contains a small tracheal vessel. This septum 
extends into the capitellum, where it encloses a number of fatcells, and multi-nucleated cell-chains, over which the tracheal vessel of the scape ramifies in a capillary network.

The form of the cavity of the scabellum is exceedingly complex, and it must be regarded as part of the body cavity.

Rudiments of the Lamina of the Posterior Wing and Small Groups of Chordotonal Organs.-The scabellum exhibits several scales on its external surface, which are undoubtedly the remains of the lamina of a wing. One of these springs from the posterior margin of the cupola (Pl. XLII., Fig. I, sq); this is connected by its proximal margin with a second scale (Pl. XLII., Fig. 2, $\left.s q^{\prime}\right)$. These bear a striking resemblance to the squama and squamula of the wing respectively. Beneath the posterior-inferior or squamuloid scale there is a small depression-the external surface of a group of minute chordotonal organs. It is represented in section in Pl. XLIII., Fig. 2, ch.

A folded remnant of the wing itself projects from the posterior border of the scala inferior, and a somewhat hemispherical swelling is seen at its base (Pl. XLII., Fig. 2, l); this also contains a group of chordotonal organs; it is apparently the structure described by Bolles Lee [299], and may be distinguished as Lee's organ.

Lastly, a third and much larger group of similar end organs is covered by a projecting hemisphere of thin integument on the posterior aspect of the halter (PI. XLII., Fig. I, ch).

There are thus three small groups of very minute chordotonal crgans, covered by thin integument at the base of each halter; and three highly-sculptured elevations of the integument, containing much larger and more complex organs-the two scalæ and the cupola.

The Capitellum, or head of the halter, is a subspherical membranous bulb, divided into two parts by a helicoid septum formed of elongated cells. This septum is continuous with the septum between the two canals of the scape.

The capitellum is described by numerous authors as subspheroidal in form, and it is undoubtedly subspheroidal in the living insect; but after death, and especially when 
mounted entire as a microscopical object, its form is more compicated. Lee was, I believe, the first who accurately described the form it assumes, but he regarded it as its natural condition.

The integument of the capitellum is soft, except in three lines, two of which are prolnngations of the anterior, and one of the posterior, portion of the scape. When the capitellum is shrivelled or compressed, these portions of the integument become salient, and the proximal portion of the capitellum becomes subpyramidal with three triangular faces. The distal portion is then seen to be deeply grooved, so that it is divided into a proximal and distal portion. This groove is not visible in the fresh halter, but is very apparent in most preparations. It forms a spiral and is the line of attachment for the septum. The groove commences on the inferior surface, close to three or four large bristles, and terminates at a point nearly in the same line, but at a more distal part of the capitellum. It is deepest at its commencement.

A curved sheet of elongated cells extends from this groove to the septum of the scape, and forms the septum of the capitellum. One of the canals of the scape terminates on either side of this septum; and the two cavities into which it divides the capitellum communicate at the free edge of the septum, so that a current of fluid passing from one canal to the other takes a spiral course in the capitellum.

It is not easy to describe the exact course of the septum in the capitellum, but it may be compared to a single turn of the spiral septum of a cochlea. Its edges are seen in a compressed halter as a figure of $\delta$. Its proximal portion is attached on either side to one of the ridges on the capitellum proceeding from the anterior canal of the scape. It is subtriangular, and its plane is axial to the scape and capitellum; its distal part curves into a plane approximately transverse to the axis of the scape, and is inserted into the spiral line already described; it presents a free edge where it terminates in the vicinity of the three or four long sete, where the spiral groove formed by its insertion is deepest. The relations of the 
two cavities of the capitellum are more simple in Eristalis, and are shown in Pl. XLII., Fig. 3.

The Structure of the Septum.-The septum consists of a basal layer of elongated cells which Bolles Lee describes as modified hypodermal cells. These cells closely resemble those which form the attachment of some of the muscles of the thorax, which I have described as fibrillated hypodermal cells (p. 283), but I have been unable to find any traces of muscle fibres in the septum. On the distal surface of this fibrocellular layer there are numerous fat-cells and multi-nucleated cell-strings. Both surfaces of the septum and the whole inner surface of the capitellum are covered by a single layer of thin pigmented cells, and similar cells line the canals of the scape and are continued over the basilar membrane of the scalæ and cupola in the scabellum.

The pigment they contain is orange-coloured and in minute granules. The pigment in the capitellum is not evenly distributed, but forms numerous circular spots visible through the pellucid chitinous integument.

\section{b. Special Sensory Structures.}

Historical.-In the years $1856-57$ Braxton Hicks [292, 294] first described the sensory organs at the base of the halteres. This author only examined the chitinous structures, although he drew attention to the great nerve of the halter. He described the three special plates, the cupola, and the scalæ as containing rows of vesicles. In I860 Leydig [269] undertook the reinvestigation of these vesicles; he regarded the vesicles as closed externally and open internally, and described auditory hairs unconnected with the vesicles as the true nerve end organs.

In 1882 Graber, in his paper on chordotonal organs [285], held that the papillæ of the scapal and basal plates each contain an auditory rod (Hörstift), and that the basal and scapal papillæ differ, inasmuch as the former are closed externally and each of the latter opens by a narrow slit on the surface. 
Lee, in I\$ $\$ 5$ [299], investigated these organs in the Blow-fly, and came to the conclusion that the chordotonal organs of the halter are not in relation with the pores of the basal and scapal plates, but form a special organ.

According to Lee, the basal papillie open externally by a narrow funnel which is sometimes round, sometimes slit-like; at the bottom of the funnel is a cushion, which is perforated by a fine fibril given off by a subjacent bipolar ganglion cell. In fivourable objects Lee claimed to have seen a very fine, often bent, hair projecting from the cushion through the funnel. The scapal papille were regarded by Lee as similar to the basal papilla, but more difficult to investigate, owing to the more complex sculpturing of the cuticular layer.

Weinland [300] describes the scapal papillas as opening externally by a slit which communicates with a cavity containing a cone-like nerve terminal. The basal papilla differ, however, according to him, in having a kind of chitinous operculum closing the orifice of the cavity which contains the nerve terminal. I have made the most careful and repeated examination of the organs in question, and although I have seen all the appearances figured by WVeinland at different times, I do not think his conclusions correct. Other appearances which are frequently seen are quite inconsistent with the view he takes, and he has, I believe, fallen into error in mistaking oblique sections of fragments of the halter for sections vertical

\section{Description of Plate xliII.}

The halter and tympanic organ of the Blow-fly.

FIf. 1.-A longitudinal section of the scabellum anci part of the sape of a halter. b, hasilar membrane separating the canal of the scape from the chortotonal organs; $c_{1}$, superior, and $c_{2}$, inferior canal of the scape; $c h$, Lee's chordotonal organ; cu, cupola; $n$, nerve; $t$, tubercle at the base of the halter, seen with a it: oil immersion objective.

1. 1r. 2, - A transverse section through the scalellum. $a$, anterior; s, superior, and $p$, posterior surface; $c$, a portion of the inferior canal; $c_{1} c_{1}$, a portion of the superior canal; ch, small chordotonal organ; $n_{1}$ to $n_{4}$, branches of the nerve; $x$, an inflection of the external integument, seen with a ${ }_{1}^{1}$ oil immersion objective.

Fic. 3. - The right tympanic fissure of a 13low-fly; $d$, sclerite in the floor of the fissure; $p$, propterygium of the wing; $s_{1}$, squama or great wing scalc; sqa, spuamula; $t:, t y m p a n i c$ sclerite in the upper part of the membrana tympani; $: 0$, part of the wing; $\Delta$, deltoid, and $\tau$, tau of the wing. 


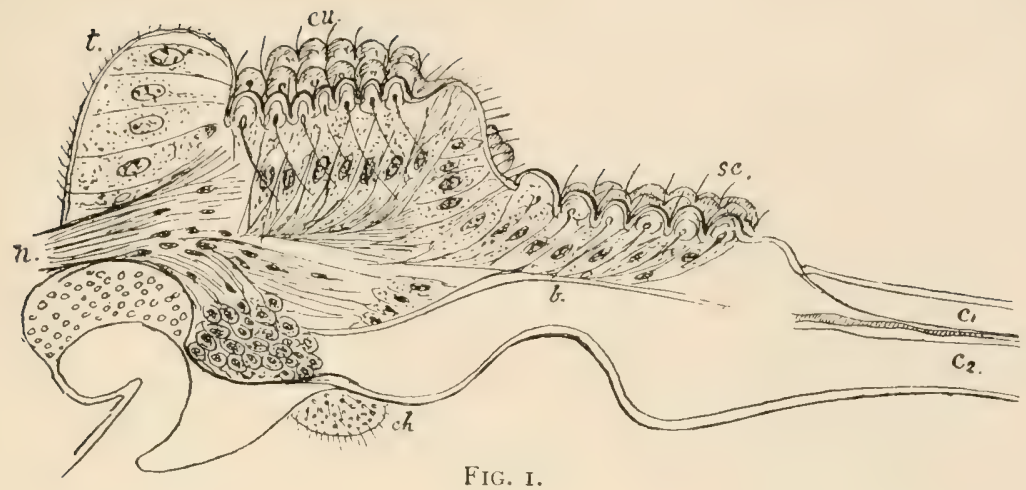

s.

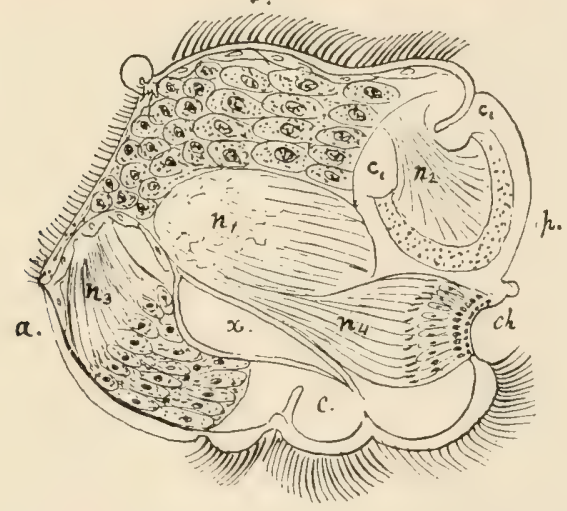

FIG. 2.

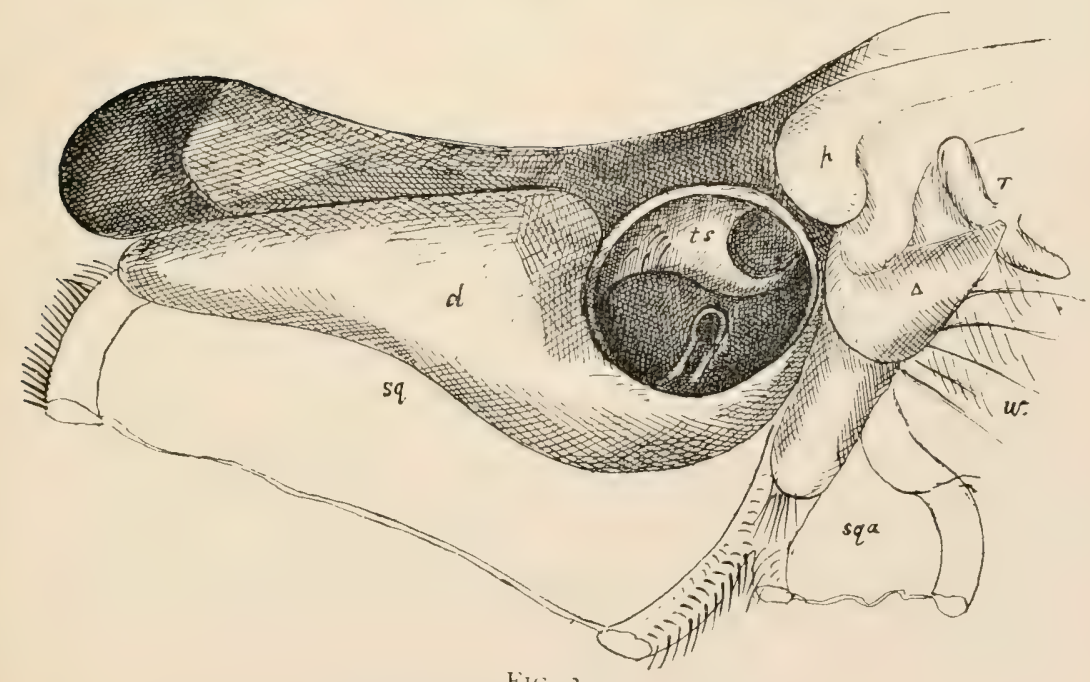

Fil. 3 .

THE HALTER AND TYMPANIC ORGAN. 

to the plates and papillæ. My own conclusions are entirely at variance with his, and I do not believe that either the basal or scapal sensory organs have any external opening.

The Basal and Scapal 0rgans.-Surface views of the organs in question can be obtained with a $\frac{1}{1}$ th oil immersion by mounting the entire halter from an insect the tissues of which have been fixed either in chromic acid or absolute alcohol. These exhibit thin transparent areas about 5 to $6 \mu$ in diameter in the basal plate or cupola. Each has beneath it a vesicle containing a highly refractive central spot (Pl. XLII., Fig. 4). The transparent areas have an average diameter of $25 \mu$, and are situated in rows on convex longitudinal ridges, between which setæ arise which cover the whole surface of the cupola. The scapal organs are more complex. In Tipula they are scattered over the surface of the scapal canals, but in Musca, Calliphora and Eristalis they lie in arcades which are transverse to the axis of the scapal canal. These arcades are moniliform convex transverse ridges the integument of which is very thin and transparent. Each arcade is supported by a series of semi-rings which are not unlike the pseudo-tracheal semi-ring of the proboscis without a bifurcated extremity (Pl. XLII., Fig. 5). Beneath the integument, and held by the extremities of each semi-ring, is a distinct vesicle containing a central highly-refractive corpuscle. The semi-ring corresponds with the lips of the fissure which Graber, Lee, and Weinland describe as opening externally. I feel convinced that the opening does not exist.

The fact that the bright spots disappear when the contents of the halter are removed by crushing it, or by the action of caustic alkalies, was mentioned by me in 1870 [62], and Weinland's figures confirm this statement [300, Figs. 28 to 34]. Neither does he represent any slit such as he describes in these figures, in which, if it existed, it could not fail to be distinctly seen. The appearances of the organs seen in surface views are represented in Pl. XLII., Figs. 4 and 5.

The best preparations I have made showing the scapal and basal organs are from halteres fixed in osmium peroxide. 
These show that the vesicles seen in surface sections surround true chordotonal organs: the bright highly-refractive central dot is the capitellum of a chordotonal thread. Fig. 79 is a semi-diagrammatic representation of the relations of the vesicle and chordotonal rod. I have been unable to make out the exact manner in which the nerve-cells $g$, gr are connected with the chordotonal threads, but as the latter are distinctly fixed at either end, and the nerve-cells certainly communicate with the vesicles, I think it indubitable that the connection is similar to that of other chordotonal organs, and is correctly represented in the central organ in the figure.

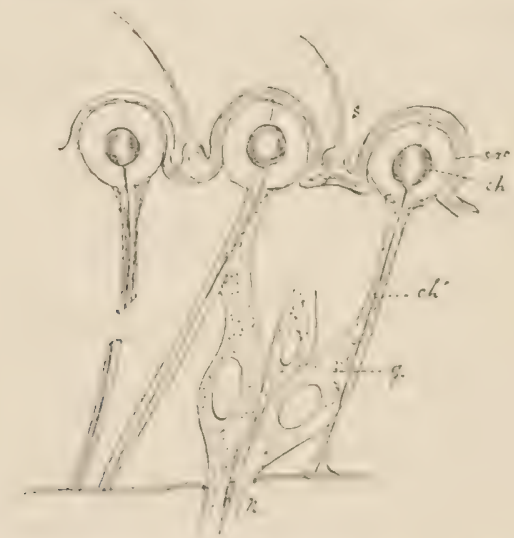

Fi: 79.-A semi-diagrammatic representation of three of the nerve end organs of the cupola of the halter of a Blow.1ly. $i$, capitellum of the choriotonal thread; $c h^{1}$, the chordotonal thread; $g$, ganglion cell; $n$, nerve-fibres; $s$, seta on the surface between the so-called papillie; sac, sac containing the suspended capitellum of the chordotonal thread.

These organs are similar to those of the wing nervures of many insects (p. 620) and of the pygidia of Notochrysa (p. 629).

I think there can be no doubt the chordotonal thread is developed in relation with the nucleus, perhaps from the nucleus itself of the cell which contains it, as in some of my preparations stained with picro-carmine the head of the chordotonal thread is intensely stained. The vesicle which contains it is in this case a large vacuole, and the tissue 
supporting the chordotonal thread is probably developed from the cell protoplasm.

Lee's Chordotonal Organ.-Lee correctly describes a remarkable organ situated on the under and posterior part of the scabellum (Pl. XLII., Fig. 2, l). This organ consists of a thin dome of integument containing a sensory ganglion surmounted by a number of minute sensory rods, $3 \mu$ to $4 \mu$ in diameter, or even less, containing exceedingly minute chordotonal threads. Lee [299, p. 368] says: "The nerve to the halter divides as soon as it enters the base into four principal branches; one enters a ganglion (bouquct) of great fusiform cells, and supplies the organs of the basal plate; two others pass in the halter beyond this ganglion, and, diverging from each other, enter ganglia similar to that of the basal organ and terminate in the scapal organs; whilst a fourth and smaller branch quits the principal trunk on a level with that to the basal ganglion, passes to the opposite side of the halter, and enters a ganglion formed at its proximal end of great fusiform cells with large nuclei; beyond these there is a mass of minute nuclei, and then a layer of minute highly refractive bodies in the form of stylets, and a second layer of minute nuclei immediately below the hypodermis. Transverse sections show the structure of this organ better, which in these appears as a perfectly normal chordotonal organ, one may say a typical one. The fusiform cells are the ganglion cells, the proximal mass of small nuclei represent the basal nuclei, the typical chordotonal elements, stylets or forks are the scolopifera (Nervenstifte, scolopale Köperchon), and the small distal nuclei the distal nuclei of Graber. In all these points the organ differs in no respect from chordotonal organs in general. The stylets only demand special consideration.'

'It is well known that Leydig [269] described two kinds of stylets in the nerve terminations of the halteres-a slender form with acuminate capitella, and a thick form with rounded heads; these two forms are not found intermixed, but arranged in two bundles so that the slender stylets, about a dozen, form a group well separated from the far more numerous 
thick-set stylets which are found in another part of the ganglion.'

Lee's description of this organ, so far as my observations go, is correct; but he was quite wrong when he denied the chordotonal character of the end organs in the scalie and cupola. I can only explain this on the supposition that he worked with imperfectly fixed specimens, as it is only occasionally that sections exhibit the chordotonal organs of the cupola and scala, and it is probable that the chordotonal threads are casily torn away by the razor in cutting the sections.

The various appearances presented by the chordotonal organs of the halteres are very difficult to understand. That
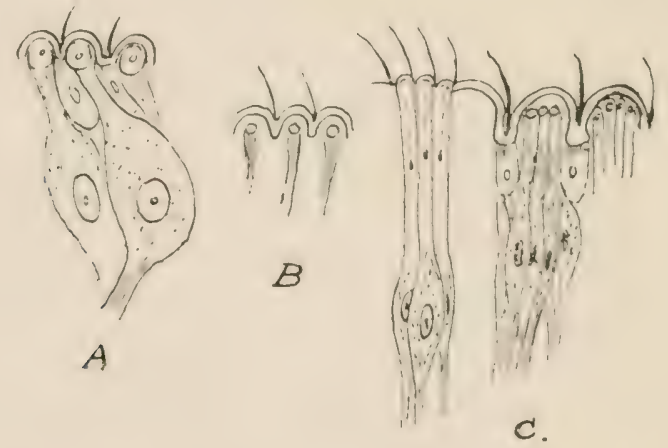

Fic. So.--Three groups of chordotonal organs from the halter of a Ijlow fly, seen with a $\frac{1}{4}$ inch objective. $A$, from the cupola; $B$, from Lees organ; and $C$, from the scala inferior and adjacent integument.

there are two kinds is indubitable, and in general the slender rods are found in the smaller groups, whilst those of the cupola and scape are the larger form. In some sections, evidently through the scala inferior, I have observed small chordotonal organs in groups (Fir. So). These are, I believe, only found close to Lee's organ.

\section{c. 0n the Functions of the Halteres.}

The halteres have been regarded by various authors as(1) sound-producing organs; (2) olfactory organs; (3) organs 
having a purely mechanical function, producing currents of air, or limiting the excursions of the wing; (4) organs of hearing; and (5) organs of equilibration, balancers.

Historical and Critical-Gleichen [3], in I 764 , thought them to be analogous to drumsticks, which produce the hum of the insect by striking the great wing scales; and Landois [281] held that their vibrations set in motion a portion of the spiracular valve, which he termed the 'Brum-ring.' Neither of these views are tenable, and have received little, if any, support.

Braxton Hicks, in $1856-57$, thought their function olfactory ; and Loew [293], discarding Hicks's view, suggested that they assist in respiration, by producing currents of air in the vicinity of the metathoracic spiracle. These views are not only unsupported by evidence, but are quite inconsistent with the results of direct experiments; and it may be remarked, in relation to Loew's theory, that the result of their vibration would be immaterial as compared with the currents of air produced by the movements of the wings; further, if I am right in my contention that carbon dioxide is not excreted from the spiracles, such currents are unnecessary for the respiration of the insect.

Jousset de Bellesme, in entire ignorance of the complexity and minute structure of the halteres, supposes that they act as stops to the wings; he regards them as stiff pegs which check the backward and downward movement of the wing by acting on what he terms the axillary areolus. His brochure is a record of some apparently carefully carried out experiments, one of which, if it can be credited, is of the highest interest, as he states that insects deprived of the balancers have the power of flight restored if a tail of horse-hair several centimetres long is glued on to the extremity of the abdomen. Whether this observation is correct or not, the conclusions of Jousset do not appear to me to be justified by his facts, and a theory which entirely ignores the great complexity of the halteres and their gigantic sensory nerves, great ganglia and sensory nerve endings, cannot be accepted as satisfactory. 
The only views which appear at all probable are that the halteres are concerned in the functions of equilibration, and that they are possibly connected with the sense of hearing.

Comparison with the Semicircular Canals of Vertebrates. - I think it may be concluded, from what is known of the internal ear in Vertebrates, that the functions of the halteres and of the semicircular canals are in some way related to each other. The results of experiments on the semicircular canals of the vertebrate ear, and on the halteres of the Diptera, are in many respects identical. It is well known that in Birds, at least, destruction of the semicircular canals leads to loss of power to maintain equilibrium during flight, and similar results appear in Mammals during rapid movements.

The existence of chordotonal organs in the halteres, as well as in the recognised tympanic ears of insects, shows that halteres are closely related to the organs of audition.

Dercham [86], in I7II, I7I2, was the first to ascribe the function of balancers to the halteres.

Robineau-Desvoidy [290], in IS2S, was apparently the first who made any experiments on the functions of the halteres. He says that, having heard from some children in a village in Dauphine that flies from which the balancers had been removed cannot fly, he was led to make experiments on the subject. He found that when one balancer is destroyed the insects fly badly, and that when both are removed they cannot fly at all. He adds that removal of the wing-scales, and even perforation of the abdomen, does not affect flight, but that after the removal of the balancers the insects crept away and hid themselves.

Goureau [291], in Is +3 , entirely confirmed Robineau-Desvoidy's statements.

Jousset de Bellesme [298], in I $8 ; 8$, also came to the conclusion that the powers of llight are injured by the removal of the balancers, that all power of steering is lost, and that insects so injured fall in a parabolic curve to the earth.

l:. Weinland [300], in ISy , stated that the total loss of the balancers causes the insects to descend very rapidly, and that 
Eristalis and Calliphora usually fall perpendicularly when thrown into the air, and do not attempt to fly; that a Calliphora in which both capitella had been removed could not fly more than two to three metres; and he states that he has kept Blow-flies alive from thirty-five to forty-four days after the operation.

Further, he says that the loss of one balancer renders flight difficult. 'The animal flies badly, with uncertainty, unsteadily, and is easily caught.' And he thinks that Eristalis, Musca, and Calliphora are less able to fly when the head of the halter is destroyed than when the whole organ is removed.

It is most difficult to remove the entire halteres without doing violence to other parts at the same time; and, bearing in mind the large size of their nerves, it is almost impossible to say how far the thoracic ganglion suffers from their entire ablation, however skilfully performed.

My own experiments lead me to the following results: It is only possible to remove the whole halter by tearing it away with forceps. When this is done, such serious injuries usually result that the insect becomes perfectly helpless and soon dies. I have already referred to the results of this operation (p. 377).

Grave injuries to the thoracic ganglion also apparently complicate the phenomena observed, and paralysis of the legs, commencing in the hinder pair, usually follows the injury if the animal lives three or four hours.

Cutting off the head of the halter and part of the stalk can be effected without inflicting other serious injuries, by a skilful operator. When this is done, removal of part of one halter renders flight difficult and clumsy. The insects are easily caught again. Removing the distal part of the second halter gives rise to almost entire loss of the power of flight. Insects so mutilated cannot fly more than a few inches, and when thrown into the air they fall perpendicularly.

In bright sunlight, however, they will fly clumsily several metres, but they never do so in diffused daylight. This is probably the result of the need of a strong light for 
distinct vision (see p. 570). They run well, but will not climb vertical surfaces; and if placed upon their backs, they recover themselves like a beetle, with their legs.

Conclusions.-I conclude from the above facts that these organs are organs of co-ordination, acting through the nervous system, and that the organs at the base are probably concerned in receiving sensory impulses, which enable the insect to maintain equilibrium; in other words, that they are analogous to the semicircular canals of Vertebrates in their functions.

It was formerly commonly belicved that the halteres act mechanically, like the pole of a rope-dancer; hence the term 'halteres,' which signifies a rope-dancer's pole. Their small size is obviously against such an hypothesis.

Weinland apparently thinks they act by shifting the centre of gravity or the centre of equilibrium by their rapid movements, and speaks of the weight of the capitella. This view is certainly untenable from a mechanical point of view. The movements of the wings, legs, and abdomen must be a thousand times more important than those of the halteres, which cannot have more than a minimal effect on the moment of inertia, or on the centre of gravity of the body of the insect.

The Halteres considered as Organs of Hearing.-Leydig [269] first ascribed the function of hearing to the halteres. I formerly suggested [82], in 1870 , that their structure is similar to that of an auditory organ. Graber [285], whilst he describes chordotonal organs in the halteres, does not do more than suggest that they are concerned in audition.

The probability of their possessing some power of perceiving sound vibrations appears to me to be a problem which rests on precisely similar grounds with the auditory function of the semicircular canals of Vertebrates.

Effect of the Vibrations of the Halteres. - It has been objected that the vibrations of the halteres render them unfitted to receive sound-vibrations, but this objection appears to me to be invalid on physico-mathematical grounds; indeed, I am inclined to regard their vibration as a circumstance greatly cnhancing their value as sound-perceiving organs. 
Since the density of the atmosphere varies with the phase of a sound-wave, and as such variations of density are an efficient cause of retardation, and acceleration in a body vibrating in air, it may be assumed that the rate of the vibration of the halteres is affected by them. It can be shown that the more rapidly a body moves, the greater the resistance of the atmosphere becomes; and this resistance increases with the square of the velocity of the moving body (see p. 387). Sound vibrations must therefore affect the moving halter and produce disturbances of its movement. The more rapid the movement of the halter itself the greater these disturbances become; and as they are produced by the varying density of the air through which it moves, or by the waves of sound, we may regard these disturbances as vibrations superimposed upon the proper vibrations of the halter due to the action of its own muscles. Since every form of ear possesses the power of analysing sound-waves or separating superimposed vibrations, the vibrating halter endowed with such a power would become a most efficient organ of hearing.

Airy [297, p. I 42$]$ states that: "The only experiment which is sufficiently delicate to give a measure of the pressure of a sound-wave is the observation of its influence on the movement of a pendulum whose bob is a sphere'; and he shows that the effect is directly proportional to the square of the number of vibrations per second or to what comes to the same thing, the square of the mean velocity of the moving pendulum bob. As we know that the movements of the tympanic membrane of the ear are entirely due to changes of the density of the air in its vicinity, it is clear that these changes would have a marked effect on a minute vibrating halter. So the velocity of the movement of the insect in flight would give rise to variations of a similar character, differing, however, from those of sound in not being rhythmic, but more or less constant pressures modifying the envelope of the curves in which the halter vibrates.

We may further assume that the fluid in the capitellum, stalk and scalæ of the halter moves as a rigid body, like the fluid in 
the semicircular canals and cochlea of a Vertebrate; and vibrations of this fluid would be an efficient cause acting upon the chordotonal elements of the halter. The vibrations of this fluid would necessarily be greatly intensified by the varying pressure on the elastic capitellum of the halter.

I think it probable that some such action occurs as that which I have indicated. The halteres appear to me to be microphones of a most efficient kind, which probably enable these insects to perceive sounds the intensity of which is far less than those which affect the human ear.

\section{THE WING ORGANS.}

The wings of most Insects contain organs which are similar to the chordotonal organs of the halteres of the Diptera. These were discovered by Braxton Hicks [292], and have been more fully described by Graber [285].

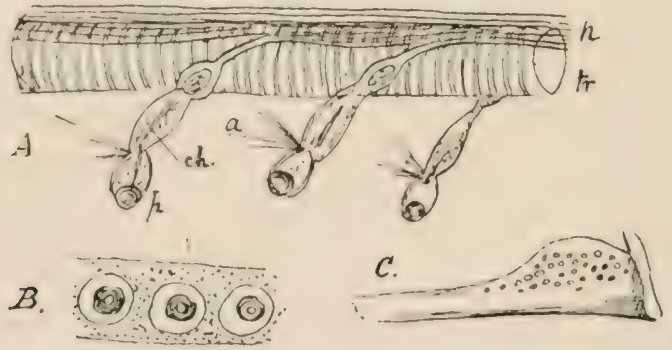

Fic. Sr.-.The wing organs of Clytus and Chrysopa, after Giraber [2S5]. A, the trachea and nerve of the submarginal nerwure of the wing of Clytus, seen as a transparent object; $B$, surface view of three of the organs from the same; $C$, group of pores on the base of the submarginal nervure of the wing of Chry. sopa; a, bands uniting the organs with the integument; ch, chordotonal thread; $n$, nerve; $f$, pore or vesicle; $t r$, trachea.

After investigating these organs in various insects, Graber obtained a very satisfactory preparation from the subcostal nervure of the wing of Clytus, which he describes in the following terms: 'I observed a group of closely-packed and relatively small pores on that part of the subcostal nervure which 
is united with the marginal nervure by a small transverse branch; each pore exhibits a dark brown margin, enclosing a small circular opening, around the margin of which there is a clear space surrounded by an outline which exhibits a double contour.

' This collection of pores is prolonged in either direction in a single line of similar pores. After clearing the wing with potash and compressing it, a very distinct view of its interior was obtained. A thick tracheal stem is observed.' After describing the position of the vessel, he continues: 'Closely related to this tracheal tube there is a nerve of moderate size which gives off a series of branches to the pores, resembling the nerves to the crista of the Locustidx in their arrangement. These branches terminate in end organs, which are related to vesicles beneath the integument. The vesicles are somewhat elongated, and lie almost at right angles to the end organs.

'The vesicles are the clear spaces surrounded by a double contour already mentioned. Each vesicle lies under a cuticular pore-the transparent spot surrounded by a dark margin in surface views.

'The nerve terminals consist of a nucleated enlargement, which is to be regarded as a ganglion-cell followed by a second fusiform enlargement, in one of which there is a thread-like structure ; this is not, however, very distinct.'

Graber concludes that if his observations are correct, this is a chordotonal thread, and adds: 'Opposite to the place where the vesicle is related to the cuticular pore, several diverging bands spring from a single point, and are inserted into the integument (Fig. $8 \mathrm{I}, A, a$ ), giving them the character of chordotonal organs.'

From Graber's drawing and my own observations on the Blow-fly, I think it indubitable that the bright spot which he regards as a pore is really due to the presence of a corpuscle beneath the integument similar to that which I have figured from the great chordotonal organs of the halteres. In the Blow-fly the wing organs are situated on the remigium, or base 
of the subcostal nervure, and the surface view is represented in Fig. 82, A.

Graber states that he has not obtained any satisfactory sections of the wing nervures showing these organs, nor have I been more successful except in the advanced pupa of the lilow-fly. I have represented a section of the integument and underlying structures from the remigium of a pupa, and this shows the partially developed wing organs, and leads me to the vicw that each nerve terminal is connected with a vesicle enclosing a suspended spherical particle, which Graber mistook for a pore in the integument. If this is the case, we have in the wing organs the less specialised condition which attains its fuller development in the halter.
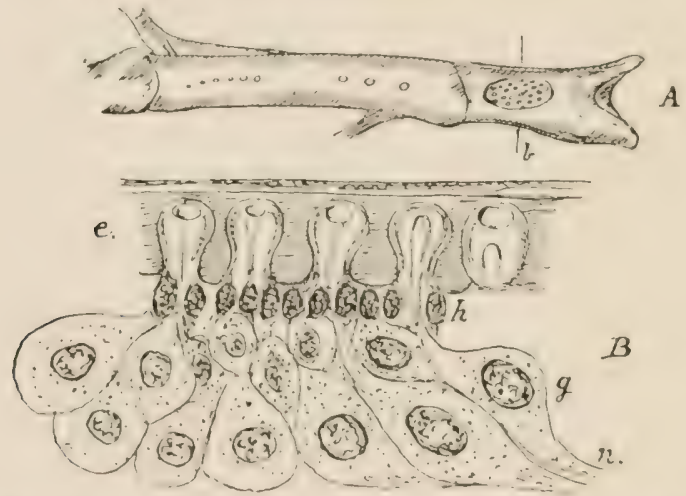

Fis: S2.-The wing crgans on the remigium of the I3low-fly. $A$, surface vicw ; $B$, section through the line $b$ in $A ; \varepsilon$, epidermis ; $s$, ganglion cells; $h$, hypodermal cells ; $n$, nerve.

Such organs are commonly found on both the anterior and posterior wings of insects, but are usually more highly developed on the posterior pair. Thus it will be seen that in the I)iptera the halteres not only replace the posterior wings of other insects, but exhibit organs which are usually found on the posterior wings, and which have probably a function similar to that of the organs at the bases of the halteres. 


\section{THE TYMPANIC ORGANS OF THE BLOW-FLY.}

\section{a. Structure of the Tympanic Organs.}

(Plate XLIII., Fig. 3, and Plate XLIV.)

The tympanic organs of the Blow-fly have apparently hitherto been entirely overlooked. Their external parts are revealed by an examination of the tympanic fissure, when the wings are drawn as far forward as possible. A small pit is then seen about $7 \mathrm{~mm}$. in diameter immediately behind the wing-root. The inner wall of the pit is formed by a circular tympanic membrane supported by a marginal ring-like sclerite.

This membrane is very similar to the tympanic membrane of the Acrididæ, which was described by Siebold [278] in the following manner:

"The thorax of all the Acrididæ examined exhibits three pairs of spiracles, of which the first pair is situated between the pro- and meso-thorax, and the second between the mesoand meta-thorax. The anterior pair lie entirely behind the prothorax in the soft syndesmosis. The posterior spiracles are close to the articulation of the intermediate coxæ with the thorax, in the seam between the meso- and meta-thorax. These four stigmata have horny lips. The third pair of thoracic spiracles are behind the thorax, in relation with the tympana.

"The dorsal half of the first abdominal segment has an oval emargination on each side in front, in which the tympanum is situated. The edge is a thickened horny rim, which more or less completely surrounds an extremely thin membrane, by which the emargination is closed. The horny margin of this membrane is triangular in front and below, and surrounds the third thoracic spiracle. This spiracle differs from all the other spiracles in having no lips, so that it remains permanently open. The oval tympanic membrane is darkly punctate; the punctation is augmented in places, so that the membrane assumes a brown colour.

' The tympanic membrane examined from its inner surface, 
after the removal of the soft parts, exhibits a small triangular and a large somewhat complex chitinous piece attached to the membrane; these sclerites can be seen from without through the thin membrane. The larger sclerite has two uncqual arms united at an obtuse angle; the shorter is directed upwards, and the longer backivards, and from the angle of junction a third short process projects inwards into the body cavity, this process is connected with Miiller's ganglion. The horny ring beneath the stigma exhibits a process projecting into the body cavity, which has already been observed by Burmeister.'

The Tympanic Membrane of the Blow-fly is about $5 \mathrm{~mm}$. in diameter; it is nearly circular, and is surrounded by a circular sclerite - the tympanic ring. It has a triradiate sclerite attached to its central portion, with two processes in the plane, and a third at right angles to the plane of the membrane. The upper and posterior part of the membrane is thicker than the lower and anterior part, and bears a group of sete. The triradiate sclerite is connected with the attached margin of the great wing-scale by two folds (Pl. XLIII., Fig. 3).

A Minute Spiracle, ${ }^{\circ} 5 \mathrm{~mm}$. in diameter, surrounded by a hard margin, remains permanently open at the deepest part of the tympanic pit below, and in front of the tympanic membrane. This spiracle, although its orifice is permanently open, is closed by a valvular arrangement, a short distance within the external spiracular opening. The valve is similar to the valves of the abdominal spiracles.

There is no structure in the Blow-fly which has given me

DEscription OF Plate XLIV.

The tympanic apparatus of the Blow-fly.

Fri. I.- I semi-diagrammatic section of the tymanic apparatus, at right anesles to the tympanic membrane in a vertical plane. st, supra-tympanic organ; $s$, ganglion cells; $h$, hypodermic cells; $m b$, membrana basilaris; $m g$, Müllerian ganglion; $n$, nerve to Miillerian ganglion; $t$, tympanic membrane ; $t r t r$, tracheal sacs; $f$, foldis of membrane uniting the tympanic membrane with the outer wall of the tympanic fossa. The dotted parts of the diagram are blood sinuses.

FiG. 2. $-A$ and $B$, actual sections through the supratympanic organ. $b$, bulb of the crista ; ch, chitinous integument; cho, chordotonal organs; $e$, epithelium forming the roof of the organ; the odver letters as in Fig. I. 
PLATE XLIV.

FIGi, I.

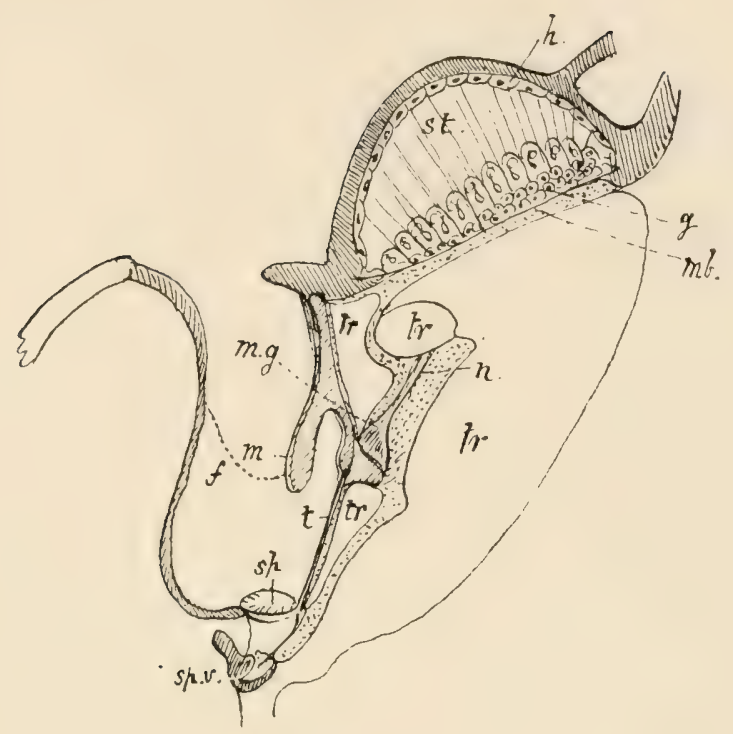

FIG. 2.

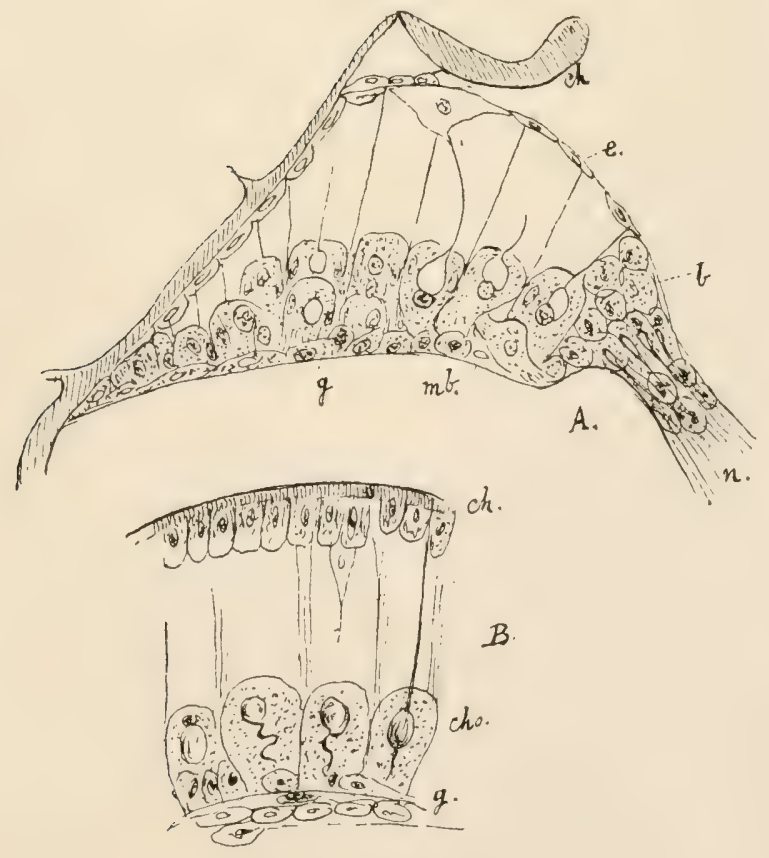

THE AUDITORY MECHANISM. 

more trouble to make out than the precise arrangement of the parts above described. Owing to the extreme hardness of the sclerites in this region, I have been very unsuccessful in scctions, and it is only by examining recent dissections that I have been able to make a satisfactory examination of the tympanic membrane and spiracle; Pl. XLIV., Fig. I, represents a diagrammatic section of these parts.

The Mirror (P1. VII., 23 ; p. I85) is a tense transparent membrane, semicircular in form, with a free upper straight edge, which bounds the cavity of the tympanic bulla internally. Its edge is connected by a small, round ligament with the upper margin of the tympanic membrane.

The tympanic bulla is occupied by a large air-sac. This extends from the tympanic membrane and mirror to the membrane, which closes the notch in the tympanic bulla, already described (p. I84) under the term 'membrana tympani major.' It appears to be a large resonance chamber.

Müller's ganglion lies between this air-sac and the membrana tympani. The relations of these parts will be more readily conceived by a reference to the diagram (P1. XLIV., Fig. I).

The air-sac of the tympanic bulla is connected with the great air-sacs of the scutellum, and is perhaps continuous with: them, and is therefore in close relation with a supratympanic organ, which lies close to the scutellar air-sac on each side, in the anterior angle of the scutellum, close to the scutellar bridge.

The Supratympanic Organ scarcely differs in structure from the supratympanic organ of Locusta. It consists of several rows of large chordotonal cells, which rest upon the air-sac, and which are connected by chords, chordotonal ligaments, with the adjacent integument; both cells and ligaments vary in size, and are apparently arranged in a series, and gradually decrease in size and length. Owing to the extreme difficulty of cutting sections in this region, which is due to the great hardness of the adjacent chitinous structures, I am only able to indicate the existence and general structure of this organ, and its similarity to the supratympanic organ of Graber, and I feel 
that much more work is needed before it can be said that these remarkable structures have been satisfactorily worked out.

\section{b. On the Probable Function of the Tympanic Organs, and their Relation to the Halteres.}

Edison's phonograph shows that the same membrane may alternately act as a sound-producing and sound-receiving organ ; and there is no a priori reason for denying such a double function to the tympanic membranes and mirrors in insects; but I shall endeavour to show that there is much evidence in favour of the view that these membranes are concerned in the perception rather than in the production of sounds.

The existence of sound-receiving tympanic membranes has hitherto been only admitted in the case of certain Orthoptera, the Acridida and Locustida. The latter at least possess a complex auditory mechanism. Siebold's and Graber's organs are found highly developed in relation with the tracheal sacs connected with the subgenual or tibial tympana, which cannot be regarded as sound-producing organs, since the sounds are clearly produced by the elytra.

On the other hand, in the Acrididee (Field Crickets), the tympanic organ is much larger, and only exhibits, so far as is known, Müller's organ, a group of chordotonal organs situated in a terminal ganglion, which is directly applied to the tympanic membrane. It is further probable that such ganglia exist in relation with the mirrors of the Cicade, as Swinton affirms [287]. Hence it appears to me far from improbable that the mirrors of the Acridida, and those of the Cicade, are analogous structures.

liurther, the tympanic membranes in the Locustide, in the Gryllide, and the mirrors in the Cicade, exhibit a chitinised plate which occupies a moiety of the membrane, and I have shown that a similar sclerite exists in my newly discovered trmpanic membrane in the Blow-fly. Whether these memlianes are subgenual, thoracic or abdominal, they exhibit precisely similar peculiarities. There is therefore an a priori argument in favour of a similarity of function. Although the mirrors of the Cicade are usually regarded as sound-producing 
organs, it is not supposed that they are the primary organs concerned, and their function is regarded as that of resonators ; that is, it is supposed that their vibrations are sympathetic, and serve only to intensify the sounds otherwise produced. A membrane set into such vibrations is essentially similar to the tympanum of a vertebrate ear, and evidence is wanting that such vibrations produce any sensible effect on the volume of sound produced; even the larger tympanum of a phonograph produces sounds of small intensity when set into vibration, and except when it is directly connected with the ear by a tube, or its vibrations are intensified by a trumpet, sounding-board or other resonator, they are scarcely audible; on the other hand, it is undoubtedly a most efficient receptive surface, and the tympanic mirror of a Cicada supplied with a receptive nerve mechanism would be a most perfect auditory apparatus. The fact that the mirrors are equally developed in the mute females and in the strident males is a fact which points to a soundreceiving rather than a sound-producing function. And M. Solier* affirmed that the perforation or tearing of these parts produces but little effect on the volume of sound emitted by the insects.

The humming produced by the Diptera and Hymenoptera is usually attributed to the rapid vibrations of the wings. If this movement produces the sound emitted, it is difficult to understand why even the most rapid flight is usually unattended by humming. In the Blow-fly at least, the emission of sound is entirely under the control of the insect.

Landois [281], although he attributes some part of the sound to the movements of the wings, regards the humming of the Diptera as due to an expiratory effort, and, further, attributes it to the rapid vibration of the valves of the thoracic spiracles. I am convinced that it is not due to the expulsion of air through those spiracles; when an insect is humming the spiracles are closed. Moreover, I have already shown that the ordinary spiracles are not expiratory.

It appears probable that the sound emitted is due to an * Ann. Entom. Soc. de France, tom. vi., 1837. 
intermittent expulsion of air from the tympanic spiracle, and the vibration of the air in the tympanic bulle and scutellum, as the whole thorax vibrates distinctly when the insect is held between the finger and thumb. The vibration of the wings in Eristalis during the production of sound is not a vibration due to a movement of the wing on its articulations, but a wave which proceeds from the root to the apex of the wing, as if it were produced by a current of air impinging upon the wing from below. IVhen I observed this phenomenon, the wings were at rest over the back, and the current apparently came from the tympanic spiracles.

The mere coincidence of the number of wing vibrations with the ground tone of the sound emitted is not conclusive, as is sometimes apparently held, that the note is due to these vibrations; both the vibrations of the wing and the rhythmic impulses which produce the sound are probably directly dependent on the number of muscular contractions per second which are normal to the species, and it is probable, therefore, that in both cases the number of vibrations per second would be the same; the mere fact that silent flight is possibly as rapid, or even more rapid than the buzzing flight supposed to be constant in these insects, is in itself conclusive against the usually received view. And as Landois asserts, the note emitted is frequently an octave higher than the ground tone, or of an even higher pitch.

The close relation of the tympanic apparatus of the Blow-fly with a supratympanic organ, and the presence of a Müllerian organ, apparently indicate that this structure is concerned in the perception of sounds. If the halteres are organs of audition, it may appear at first sight highly improbable that two such complex organs are both concerned in the reception of sounds. When, however, the complex character of the internal ear in Vertebrates is borne in mind, the improbability becomes less manifest. That insects must hear the sounds they produce is evident, and that they distinguish between these sounds and others is scarcely doubtful. That the function of the halteres differs from that of the tympanic apparatus is indubitable, but 
the similarity of the special nerve-terminals in both is indicative of an auditory function. The innervation of the end organs of the tympanic apparatus by the same nerve as the halter is also worthy of note. If the sound is produced as I have suggested, the tympanic apparatus may act as an auditory mechanism especially sensitive to sounds having the same pitch as those which the insect is capable of producing. On the other hand, the range of vibrations capable of affecting the halteres is probably larger. With our present knowledge, this can only be regarded as a possible hypothesis, but it may serve to indicate some line of observations in the future adapted to throw more light on this intricate subject.

\section{CONCLUDING REMARIS ON THE PHENOMENA OF HEARING IN INSECTS.}

The great variety in the form and size of the various chordotonal organs, and the remarkable diversity of the structures with which they are connected, suggests a few concluding remarks.

As has been already stated, the wings of many insects, the halteres of the Diptera, tympanic organs situated in various parts of the body, primitive chordotonal organs, and possibly structures of a special character in the antennæ, are probably organs of hearing, and these by no means include all the modifications of a mechanism which is more or less probably auditory. Many insects possess structures on one or more of the abdominal segments, which are possibly auditory organs, and are usually termed pygidia. The pygidium of the Fleas is well know to microscopists, and some Neuroptera possess similar organs.

My attention was directed by Mr. R. T. Lewis to the large pygidia of Notochrysa gigantea, and $I$ found that the end organs in these structures resemble those of the cupola of the dipterous halter very closely. Though the want of fresh material rendered the investigation extremely difficult, I saw enough to suggest to me the probability that I had true chordotonal organs before me. 
The great majority of insects probably hear sounds. Yet it is the exception to find highly complex organs on the surface of the body which can have the function of hearing ascribed to them. The membranous wings of insects are certainly well adapted to receive the vibrations of the atmosphere, and when we remember that in Fishes the vibrations of sound are not conducted to the internal ear by any special mechanism, it appears less improbable that the expanded surface of the wing should act as a recipient of sound vibrations. Will [305] concludes that each species of insect is limited in its responses to a very narrow range of sound perceptions, yet there is a very fine appreciation of minute differences within that range. For example, he is convinced that different species of Lamellicorns recognise their mates by the stridulations they produce, and also that they hear them at a distance at which they are quite incapable of being heard by the human ear ; and he states that whilst they are apparently deaf to all sounds except those which concern them, they at once respond to these if they are sufficiently well imitated by artificial means.

When we remember the wide range of sounds which different insects produce, although the range of those which affect any one insect may be small, yet dissimilar insects must exhibit very different auditory powers; and that this is really so is suggested by the very variable character of the auditory apparatus. Crickets appear to be but little excited by any sounds except those natural to the species. The notes of some insects are far more variable than those of others, and suggest a much wider range of auditory perception, and it is in such insects that we might expect the greatest complexity in the auditory mechanism.

\section{THE SENSE OF TASTE AND THE GUSTATORY ORGANS.}

That insects generally possess the sense of taste camnot be douluted, and Will [305] has shown that this sense is sometimes very highly developed. He says: "Of all the insects I experimented upon, a pair of Andrenas had perhaps the most acute sense of taste. They were very fastidious, and, as the 
last and finest experiment, I placed before them a concentrated solution of sugar-candy. They smelt and tasted it, and yet, although they had been kept several hours without food, they would not feed upon it. I cut off their antennæ, when they took it in small quantity, but soon left it, although they took pure honey with avidity.'

Will's experiments with Wasps are exceedingly interesting. He placed coarsely-powdered white sugar on a paper in the open air, and after allowing them to feed on it for some hours, he replaced it by powdered alum. "This the Wasps attempted to take, but scarcely had they tasted it than they started back in the drollest manner and cleaned their tongues repeatedly with their fore-feet to rid themselves of the disgusting substance.

'Their first sad experience did not, however, prevent their making a second trial, with similar results, after which most of them flew away. One pair of obtuse individuals, however, persisted in trials of the alum; but when they had taken a certain amount they rolled themselves upon the table, evidently in the greatest discomfort,' although they also flew away sooner than he expected.

Other Wasps came, but by three o'clock in the afternoonlong before these insects are accustomed to give up workno more came to taste the alum.

\section{Bibliography :}

301. Wolf, C. J. B., 'Das Riechorgan der Biene.' Nova Acta. d. K. L C. Akad., Bd. xxxviii., I875.

302. JosepH, G., 'Zur Morphologie des Geschmacks-organes bei Insekten.' Amt. Bericht. der 50 Versammlung deutscher Naturforsch. u. Arzte in München, I877.

303. KüNKEL ET GAZAGNAIRE, 'Du siége de la gustation chezles insectes diptères.' Comptes Rendus, Bd. xcv., I 88 I.

304. Forel, A., 'Etudes myrmecologique.' Bull. Soc. Vaud. Sc. Nat., tom. xx., 1884.

305. WrLL, F., 'Das Geschmacks-organ der Insekten.' Zeitsch. f. w. Zool, Bd. xlii., I 885 .

This paper is one of the most interesting contributious to the better understanding of the senses in insects with which I am acquainted, and should be studied by every young naturalist. It is a model of research and experiment. 
The next day Will made the same experiment with sugar, followed by gypsum (dolomite). The Wasps licked the dolomite until the evening, before the idea dawned upon them that the insoluble material was not adapted for food.

Will purposely selected these three substances on account of the similarity of their appearance, and the absence of any odour to guide the insects.

The avidity for sweets exhibited by Flies is well known, and it is quite evident that they are guided in the selection of food by the sense of taste. I have not, however, made any special experiments on the subject.

If the determination of the seat of the sense of smell is difficult, it is still more difficult to locate the sense of taste in any special organs. I have already given reasons for supposing

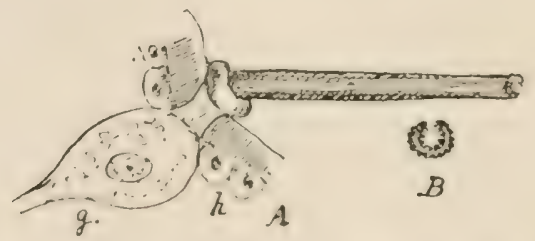

Fic. $S_{3} .-A$, one of the large gustatory sete from the oral lobe of the proboscis of the Blow-fly; $B$, a transverse section of a similar seta; $g$, ganglion cell; $h$, hypodermal cells.

that the oral lobes and maxillary palpi are both concerned as organs of taste (p. 403).

Will considers that the end organs of taste must necessarily come into contact with the dissolved food, and that the setre which subserve this function must be either perforated at their top or grooved at the side. As I have already remarked, the setie of the palpi are perforated, and those of the oral lobes are rrooved on one side. A comparison of the end organs of the palpi of the Fly with those of the antenne (P'. XLI., Firs. 2 and 4 ) shows a marked difference, and, as might perhaps be expected from their position, the palpi of the Muscida are much less developed than those of most Insects.

The end organs connected with the grooved seta on the oral 
sucker are, however, very highly developed, and are unusually large (Fig. 83). I have been quite unable to find any organs which can be regarded as special nerve-terminals, either on the ligula or in the interior of the mouth. I believe, as compared with the Hymenoptera, the power of taste in the Muscidæ is much less highly developed.

\section{THE PROSTERNAL ORGAN.}

Allusion has already been made to the prosternal organ (p. I79). This is one of the most incomprehensible structures, having the characters of a sensory organ. I ventured to suggest that it is concerned in registering, as it were, the movements of the head and fore-limbs, but with the further knowledge of this structure which I now possess, I entertain the gravest doubts of the possibility of such an explanation of its function.

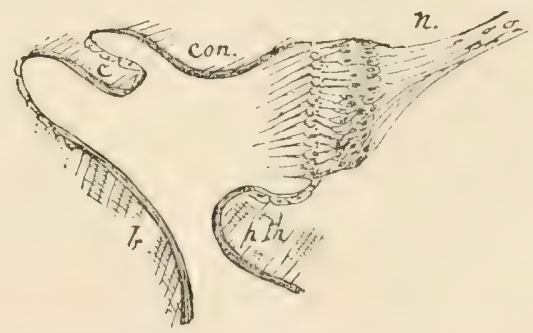

FIG. 84.-One of the lobes of the prosternal organ seen in section; $b$, basilar plate of the head; $c$, cervical sclerite ; con, condyle; $n$, nerve ; $p$ th, part of the prothorax.

Although I drew attention to it in my former work [62] in I870, it does not seem to have attracted any attention since, neither have I found any description of a similar organ in any other insect.

This structure lies in a deep cavity between the basilar plate of the head and the manubrium (Fig. 84), on either side, and consists of a plate covered with long fine setæ (Pl. VIII. Fig. 3, b), beneath which there is a layer of large ganglion cells, connected with a branch of the prothoracic dorsal nerve. 
The setæe are on an average $0^{\circ} \mathrm{I} \mathrm{mm}$. in length, and each apparently receives a process from one of the subjacent ganglion cells. A layer of small cells lies immediately beneath the cuticle, and these apparently send processes into the bases of the seter. The deeply-seated position of this organ in a small pouch on either side of the front of the prosternum renders it

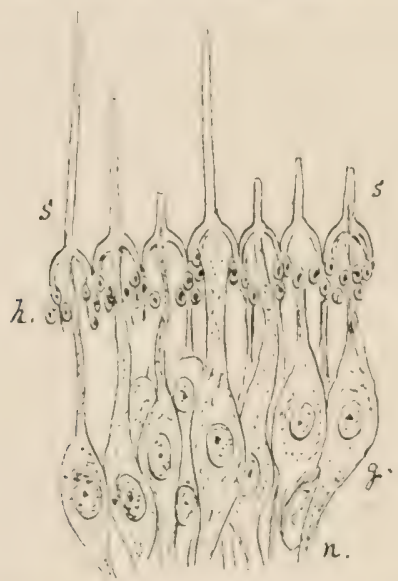

FIs. S5.-A highly magnified section of a part of the prosternal organ; s, ganglion cells; $h$, hypodermal cells ; $n$, nerve ; $s$, transparent setæ.

most improbable that it is a tactile organ, and its setæe present a similarity to the large olfactory setre in the sacculi on the antenna, which is very striking, although they are twice as long. Further observations are needed to throw light upon the nature of this most puzzling organ. 


\section{CHAPTER XIV.}

THE CIRCULATION OF THE BLOOD AND THE DORSAL VESSEL.

\section{THE CIRCULATION IN INSECTS GENERALIY.}

THE circulation of the blood is maintained by the pulsations of the abdominal or ventricular portion of the dorsal vessel. Its anterior or thoracic portion conveys the circulating fluid to the head ; the blood is there poured into numerous sinuses between the various organs, and returns by the great ventral sinuses to the abdomen, and, after bathing and nourishing the organs of the body, passes again into the ventricular part of the dorsal vessel. The relations of the blood sinuses and the tracheal vessels have been already alluded to (p. 367).

Historical.-Although Swammerdam [4] and Malpighi [148]

\section{Bibliography :}

306. BAKER, H., 'On the Microscope.' 8ro., London, 1755.

307. CARUS, C. G., 'Entdeckung eines einfachen Herzen aus beschleunigten Blutkreislaufes in den Larven netzflüglicher Insecten.' Leipzig, I 827.

308. Carus, C. G., 'Lehrbuch der Zootomie.' Svo, 2te Aufl. Leipzig, I 834. 309. BOWERBANK, J., 'Observations on the Circulation of the Blood in Insects.' Entomol. Mag., vol. i., I833.

310. BOWERBANK, J., 'Observations on the Circulation of the Blood, and the Distribution of the Tracher in the Wing of Chrysopa Perla.' Entomol. Mag., vol. iv., 1837.

311. VerLOREN, 'Mémoire sur la Circulation dans les Insectes.' Mém. Couronnes et Mém. Sav. Etrang. Acad. Roy. Belgique. I845-46.

312. MAYer, H., 'Ueber die Entwicklung des Fettköpers der Tracheen und der keimbereitenden Geschlechtstheile bei den Lepidopteren.' Zeitsch. f. w. Zool. Bd. i., 1849.

313. GRABER, V., 'Ueber den propulsatorischen Apparat der Insecten.' Archiv. f. Mikros. Anat., Bd. ix., 1873. 
understood the function of the dorsal vessel, Cuvier denied the existence of a circulation in Insects. C. G. Carus [307] made many observations on this phenomenon, and clearly established the fact that not only the blood circulates, but in many Insects, perhaps in all, the course of the hrmal fluid is circumscribed by very definite channels.

Indeed, long before, Baker [306] in I755 described not only the pulsations of the dorsal vessel, but observed the blood flowing in very definite channels in the wing of a species of Locust; and in $I_{37}$ Bowerbank [310] gave a detailed account of the circulation in the wings of Chrysopa perla. He describes the blood current as flowing steadily through all the nervures towards the apex of the wing, and as returning by a single channel, running in the posterior margin of the wing, in a more rapid stream, to the thorax.

Definite Course of the Blood in the Appendages.-Verloren tried to account for the circulation in the wings and legs by the supposed existence of small accessory hearts, similar to lymph hearts, in each appendage, but he had no evidence to offer in favour of the view, and to this day no such hearts have been discovered. In aquatic larve the circulation in the leaf-like gills and in the anal sete is most rapid, and it is altogether similar to that in the legs, wings and elytra of perfect insects. In the former, lymph hearts could not fail to be seen if they existed.

The great cavitios of the body of the imaginal insect are divided from each other by narrowings, the small openings in the diaphragmata, and the narrow ablominal pedicle of the Wasp, for example; and not only transverse, but longitudinal more or less complete septa traverse the body. Similar septa also exist in the appendages. Thus the blood llows into the head above the tentorium, and leaves it below the tentorium; and the circulation through the proboscis is provided for by blood sinuses on its dorsal surface which conmunicate with the resion above the tentorium, and on its ventral surface with the regrion below it these intercommunicate by narrow channels offering considerable 
resistance to the flow of blood. Again, the circulation through the wings is dependent on the efferent channels of the nervures communicating with sinuses in front of the mesophragma: whilst the afferent channels which return the blood to the thorax communicate with cavities behind it. The circulation is thus maintained by the arrangement of the peritracheal passages in which it flows, and not by the existence of subsidiary hearts. These definite sinuses resemble the lymphatic capillaries of Vertebrates, and under certain circumstances the course of the circulating fluid may be arrested or reversed in direction, but in general its direction and course are constant and uniform in all the large tissue spaces or peritracheal sinuses of the insect.

The Dorsal Vessel consists of two parts, the ventricles, situated in the pericardial cavity in the abdomen, and the aorta, which is not contained within a pericardium and which traverses the thorax to the head. The whole may be described as a cylindrical muscular tube, which is dilated into a series of ventricles, one behind the other, in the abdomen, and narrowed into a uniform cylinder, which extends from the anterior part of the anterior abdominal ventricle to the head. In some insects the number of ventricles reaches eight, but there are usually fewer. Generally the anterior ventricle is the largest.

The Pericardial, or Auricular Sinus.-This cavity is separated from the general cavity of the abdomen by a horizontal fibromuscular septum, perforated by numerous pores, by which the blood flows into it from the abdominal cavity. The septum is termed the pericardial septum.

The Alar Muscles.-The pericardial septum is largely formed by a series of fan-shaped muscles, which arise by narrow origins of a tendinous character from the integument of the dorsal region on either side of the middle line, usually one pair from each abdominal ring. The muscles spread out fan-wise and unite with each other in the middle line of the pericardial septum.

By their contraction they cause the septum to descend, thus 
enlarging the pericardial cavity at the expense of the abdominal cavity and causing the blood to flow into it.

The Ventricles of the Dorsal Vessel are fusiform enlargements of the abdominal portion of a muscular tube, which extends from near the posterior extremity of the abdomen into the head. Each ventricle communicates with the pericardial sinus by a pair of ostia, or openings guarded by valves opening inwards, so that the blood can pass freely from the pericardial sinus into the dorsal vessel, but cannot return from the vessel into the sinus.

Each valve consists of a pair of valve flaps, the arrangement of which is similar to that of the auriculo-ventricular valves of the vertebrate heart. The free edges of the valve-flaps are held in their places by fine cords, chordæ tendiner, which are inserted into the wall of the ventricle in front of the ostia in the middle line, both on the dorsal and ventral wall of the vessel.

There are also inter-ventricular valves, which are very variable in structure. In some insects they consist of sphincters of muscle-fibres, and in others there are membranous valves which permit only of a forward movement of the circulating fluid in the narrow inter-ventricular parts of the vessel and at the root of the aorta.

The Aorta.-The cylindrical anterior portion of the dorsal vessel, which is not surrounded by a pericardial sinus, conveys the blood to the head. Like the ventricular portion, it is a muscular tube. It is deeply placed in the thorax, and lies immediately over the chyle stomach and cesophagus.

Anterior Termination of the Aorta.-Authorities are not agreed as to the exact manner in which the dorsal vessel terminates in the head. Newport [9] described its bifurcation and numerous lranches given off from the two trunks into which it divides in Sphinx ligustri; Verloren [311] does not deny such an anterior termination, but says he was unable to observe it. In IS 70 [62] I described independently a similar branching of the vessel in the Blow-1ly, but the observation of its anterior termination is far from easy. 


\section{THE DORSAL VESSEL OF THE IMAGO OF THE BLOW-FLY.}

The dorsal vessel commences near the posterior border of the fifth abdominal segment, arches forward immediately beneath the integument, and terminates in the aorta at the inferior margin of the mesophragma.

It can be most readily seen in situ by making a vertical longitudinal section, a little on one side of the median line,

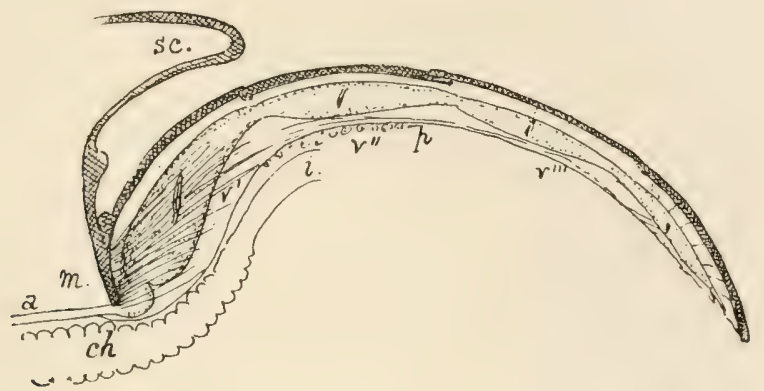

FIG. 86. - A section through the dorsal part of the abdomen of a Blow-fly, showing the lorsal vessel. $a$, aorta ; $c h$, chyle stomach ; $i$, intestine; $m$, mesophragma ; $p$, pericardial septum ; sc, scutellum ; $v^{\prime}, v^{\prime \prime}, v^{\prime \prime \prime}, 2$ nd, 3 rd, and 4 th ventricular enlargements of the dorsal vessel. The longitudinal fan-like alar muscle is seen covering the two anterior enlargements.

through the body of a Blow-fly which has been previously hardened in a I per cent. solution of potassium bichromate, and afterwards in strong alcohol (Fig. 86).

The anterior part of the dorsal vessel is then seen between the intestine and the abdominal wall; the posterior part is more difficult to trace, and can only be studied in serial sections and when the whole pericardium and dorsal vessel have been removed from the body of an insect.

This can be done by taking away all the structures which lie beneath it, so as to leave the pericardium on the inner surface of the dorsal wall of the abdomen. The posterior 
chambers of the dorsal vessel will be seen as a fine white line between the two lateral groups of subcutaneous fat cells. The pericardium may then be removed with the dorsal vessel attached to it, spread out carefully on a slide, and examined under the microscope. To make this dissection, the abdomen of a large Blow-fly should be opened on its ventral surface, and the insect placed in a $0^{\circ} 5$ per cent. solution of potassium bichromate, or in dilute Filemming's mixture for an hour or two; the dissection can then be proceeded with in the same fluid.

It is by no means easy even with practice to remove the whole of the dorsal vessel uninjured; but parts are easily obtained in this way, and their relations to the pericardial septum are readily made out, or the pericardium may be removed from the vessel itself with needles.

The abdominal or ventricular portion of the dorsal vessel consists of five chambers; the most anterior of these is nearly spherical, and not half the diameter of the second chamber, which is the largest of all. I term the anterior chamber the aortic bulb, and the second chamber the anterior ventricle.

The Aortic Bulb (Pl. XLV., Fig. S6) lies close to the margin of the mesophragma; it gives off the aorta (a), which dips under the margin of the mesophragma, and enters the thorax.

In Eristalis, in which these parts are far larger and more readily studied than in the Blow-fly, the aortic bulb appears to give off three vessels, the thoracic aorta and a pair of smaller lateral vessels, which diverge from each other and enter the thorax, one on each side of the mesophragma. They lie in the walls of the two great sinuscs, which enter the pericardial sinus in front (see p. 648).

\section{DEscriplion OF PLATE XLV.}

The anterior part of the dorsal vessel and pericardium of the IBlow-fly.

The pericarlium has been removed on the right side to show the three anterior chambers of the dorsal vessel. $a$, aorta; $a \mathrm{~m}$, alar muscle; $f f$, fat bodies; $s \xi$, ganglion cells; $p p$, pericardial inembrane; $t r$, tracheal vessels. 
PLATE XLV,

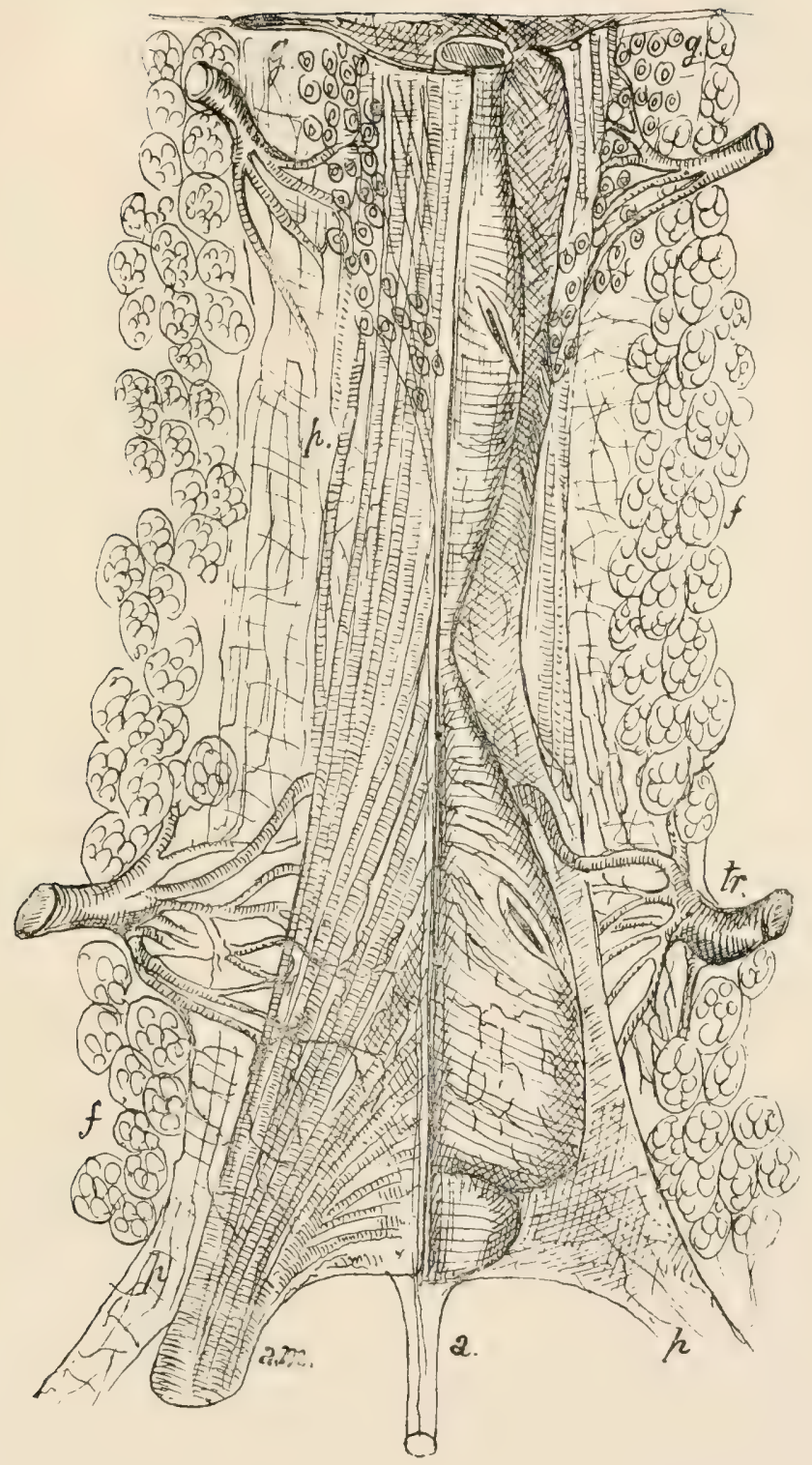



The Anterior Ventricle (Pl. XLV., Fig. 86, $v^{\prime}$ ) is pyriform, about I'O $\mathrm{mm}$. in length, with a pair of large obliquely-placed ostia; its broadest part is in front, where its diameter is about $.25 \mathrm{~mm}$. Its posterior extremity is narrowed, and communicates with the third chamber of the heart.

The third chamber of the heart is fusiform and not more than half the diameter of the anterior ventricle. It has a pair of obliquely-placed ostia midway between its extremities.

The two remaining chambers are very long and narrow, not more than $06 \mathrm{~mm}$. in breadth, and are more intimately connected with the pericardium than the anterior chambers.

The Valves of the 0stia.-Each lateral opening is protected by a pair of semilunar valve flaps, which project forwards into the cavity of the ventricle. These valve flaps are partly membranous and partly muscular, and their free edges are attached by fine fibres to both the dorsal and ventral median line in front of the ostia.

Owing to the small size of the parts in the Blow-fly, it is exceedingly difficult to make out the precise disposition of the valves, as sections are not favourable to their investigation. So far as I can make out they seem to be very similar to those described by Graber in the Cockchafer, and by Verloren in the larva of Rhyncophora (see p. 638).

Inter-ventricular Valves.-No inter-ventricular valves exist in the dorsal vessel of the imago of the Blow-fly, but there are, apparently, a pair of valves opening forwards in the aortic bulb, which serve to prevent the regurgitation of the blood from the aorta. Neither Verloren nor Graber describe any true inter-ventricular valves in the imago stage of the insects which they examined. If such valves ever exist they must be exceptional. Inter-ventricular valves have, apparently, only been observed by recent investigators in the larval stage.

The Position of the 0stia has been the subject of much difference of opinion. Verloren places them at the junction of the several ventricular cavities, and Graber midway between these points. My own observations on the Blow-fly agree 
with those of Graber. The narrow parts of the dorsal vessel also appear to be inter-segmental.

The Pericardial Septum is $75 \mathrm{~mm}$. wide in front, and gradually narrows as far back as the posterior margin of the second abdominal segment, where it is about $4 \mathrm{~mm}$. in breadth.

It consists of a delicate fenestrated elastic membrane, and of two great bundles of striated muscle, the alie, which arise, one on each side, from the posterior surface of the mesophragma (Pl. XLV., $a m$ ).

Straus Durckheim [40] described the alar muscles of the heart in Melolontha as 'paired broad fan-shaped muscles, which arise from the anterior margins of the eight superior arches of the abdomen. These muscles spread out into a web of minute bands, of which an inferior set unite with a membrane adhering to the inferior surface of the heart, and with those of the opposite side; whilst a superior set pass directly into the sides of the heart itself, and those directed towards the auriculo-ventricular openings (ostia) form littie arcades around them.'

In most insects the alar muscles arise as Straus Durckheim describes them in the Cockchafer, but in the Blow-fly I have been quite unable to discover any such lateral muscular alæ; only the single pair of muscles above described enter into the formation of the septum. The posterior part of the pericardial septum maintains the same width throughuut its entire length; it is seen as a transparent streak about $f$ mm. wide between the subcutaneous fat bodies.

The pericardial septum may be described as a thin sheet of fibro-muscular tissue which separates the pericardial sinus from the general cavity of the abdomen. It is attached to the fat bodies and hypodermis on each side. Numerous lateral sinuses, especially on the surface of the great abdominal airsacs, communicate with the edges of the pericardial sinus, and at these spots it is evident that the septum is not attached to the abdominal wall, but is continuous with the endothelial wall of the sinus. The anterior extremity of the sinus communicates with two large sinuses, which diverge from each 
other and extend to the edges of the mesophragma, where they communicate with the lateral venous sinuses of the thorax. These sinuses have a wall which is indubitably formed by a prolongation of the pericardial septum, so that they resemble veins, and can be dissected out and removed from the abdominal wall with the pericardium. But the smaller sinuses, which extend over the air-sacs, cannot be recognised after the pericardium has been removed from the body of the insect.

In preparations of the fresh pericardium treated with silver nitrate, I have observed indications of an endothelium, consisting of thin cells of irregular form on the dorsal surface of the pericardial septum. These form the endothelial lining of the pericardial sinus.

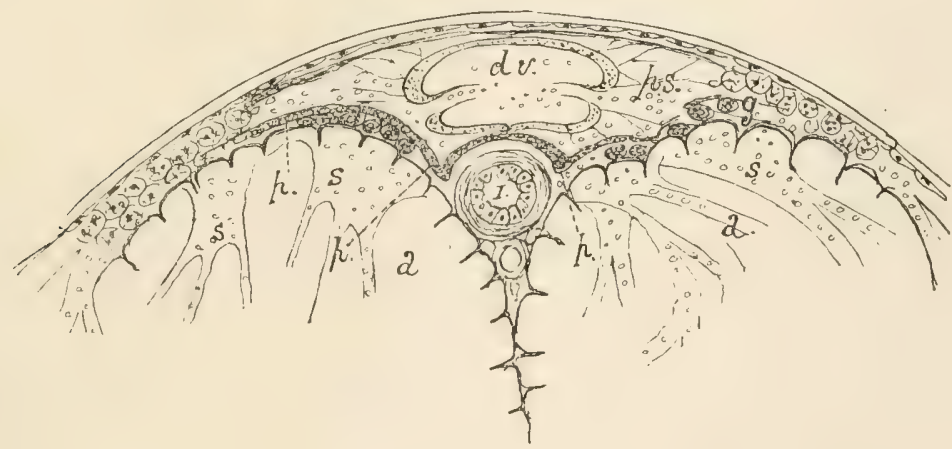

FIG. 87.-A transverse section through the pericardial sinus and the parts in immediate relation with it. $\alpha, a$, great air-sacs; $d v$, dorsal vessel; $g$, ganglion cells ; $I$, intestine; $p$, pericardial septum; $p s$, pericardial sinus; $s, s$, blood sinuses on the surface of the air-sacs opening into the pericardial sinus.

\section{The Relation of the Dorsal Vessel and Pericardial Septum} (Fig. 87).-The dorsal vessel lies loosely in the pericardial cavity, but in transverse sections, slender muscle fibres and fine adenoid tissue are seen crossing the pericardial space, which unite the wall of the dorsal vessel with the walls of the pericardial sinus. The union is more intimate in the posterior part of the pericardial space than in front; the anterior portion has only the most delicate reticulum of stellate cells, 
but in the posterior part, and especially in the region of the last chamber, numerous exceedingly fine muscular fibrillat extend from the dorsal vessel to the lateral and dorsal walls of the cavity, whilst the ventral wall of the dorsal ressel and the pericardial septum are intimately united.

Histology of the Dorsal Vessel.- The older writers on insect anatomy all held that the dorsal vessel is a compound organ, consisting of muscle fibres, cells and connective tissue. This opinion is supported by Leydig, Graber, and many others. IVeismann, however, regarded it as a single hollow muscle fibre, consisting of a sheath, contractile elements, and nuclei. Although this view has received comparatively little support, I am inclined to regard it as correct.

Graber describes three coats in the dorsal vessel, and compares it with an artery; Villanes, as has been already remarked, compared it with a capillary bloodvessel. Graber described an external tunica adventitia, an intermediate tunica musculosa, and an internal tunica intima, or endocardium.

The Tunica Adventitia.-The existence of a true adventitia was denied by Weismann [2], although Graber [313] say's it is easily demonstrated in the majority of the insects which he investigated, and especially in such large insects as Locusta viridissima, and Carabus cancellatus. The figures given by him apparently settle the question, and indicate that his adventitia is merely a portion of the pericardial septum. Owing to the great elasticity of this structure, it easily wraps itself round the dorsal vessel when the latter is removed, and may readily be mistaken for a true adventitia; and it is extremely difficult to remove the vessel without a portion, at least, of the pericardial septum. Sections show that there is no connective tissue in immediate relation with the external structureless muscle sheath, although it is probable that the whole pericardial sinus is lined with an endothelial layer, which is reflected over the dorsal vessel itself. Branches from these endothelial cells form the reticulum, uniting the dorsal vessel with the pericardial septum.

The Tunica Media, or Muscular Layer-This is described by 
Graber in various Coleoptera, Orthoptera etc., as consisting of circular fibres about $8 \mu$ to ro $\mu$ in diameter, distinctly striated transversely, and easily separated from each other by the action of dilute acids; and he states that the dorsal vessel of Musca has similar characters. Longitudinal sections of the dorsal vessel do not, however, support the view that it consists of circular muscle fibres. The whole section exhibits no trace of such fibres, but is uniformly covered by areas of Cohnheim. The regular position of the nuclei, and the division of the entire tube into segments is adverse to the muscle fibre theory of its structure; but is quite consistent with Weismann's view.

Longitudinal muscle fibres have been described forming an external layer. Graber says: 'Longitudinal muscle fibres can seldom be demonstrated in the middle or muscular coat. I have only been able to make out such with certainty in Musca, and the longitudinal fibres in the hearts of Gryllotalpa, Caloptenus and other Orthoptera belong to the connective tissue adventitia.'

In Musca I have certainly convinced myself that the longitudinal layer of muscles is entirely pericardial. I have repeatedly seen it as it is represented by Graber in his figures, but on examining preparations of the entire vessel with a binocular, it is easy to see that these fibres all lie on the ventral surface of the vessel, and there is no trace of any longitudinal fibres in sections, with the exception of those which lie in the pericardial septum.

The Tunica Intima.-Graber has described a fine membranous intima, and I have seen indications of an extremely fine cuticular layer on the inner surface of the muscle layer. Graber is doubtful whether it is a mere cuticular layer or a connective tissue, as Leydig holds it to be. He admits that it is extremely difficult to observe any trace of structure. The complete absence of connective elements in the muscular coat is quite destructive of Leydig's view. Graber has failed to demonstrate an endothelial lining by the application of silver nitrate, and my own researches in this direction have only given negative results. 
The Structure of the Pericardial Septum (Pls. XLV., XLVI.).Graber has investigated the structure of the pericardial septum in various insects, and describes it as consisting of muscle fibres, some of which are derived from the alar muscles, and of connective tissues, elastic and tendinous fibres. These tissues are intermixed with various forms of cells, and he regards all these-except the muscles of the alie-as modifications of the tissue which forms the fat bodies generally. It is, in point of fact, a septum developed like the fat bodies from the mesoblast.

The elastic tissue of the pericardial septum is well developed in the Blow-fly, and consists of a membrane with well-marked fenestre. Whether these are to be regarded as openings between the interlacing fibres which bound them is, I think, very doubtful. I am rather inclined to think that it is similar to the fenestrated membrane from the artery of a Vertebrate and that the so-called fibres are thickenings of a continuous membrane. Graber, however, who has examined the pericardial membranes of large insects, regards them as actual perforations. In surface views it is very difficult to decide whether they are perforations or not, owing to the transparency of the membrane; in sections I have failed to discover anything but a continuous membrane.

The edges of the septum are fringed by fat-cells; numerous tracheal ressels and muscle fibres are attached to the inferior surface of the membrane, and in many places fat-cells are interspersed between them. The upper, or pericardial surface appears to me to be covered by a layer of endothelial cells.

The elastic fenestrated septum does not apparently extend backwards so far as the muscle fibres, and these are attached to the wall of the posterior chamber of the dorsal vessel itself, especially on its ventral surface.

\section{DESCRITION OF PIATE XLVI.}

A pretion of the pericarlial septum of an adult Blow-fly, seen with an oil immersion $x^{1} g, f, f$, fat cells; $m, m$, muscle libres of alar muscle; $n, n$, nerve fibres; $n c$, nerve cells ; $f$, fenestrated pericardial membrane. 


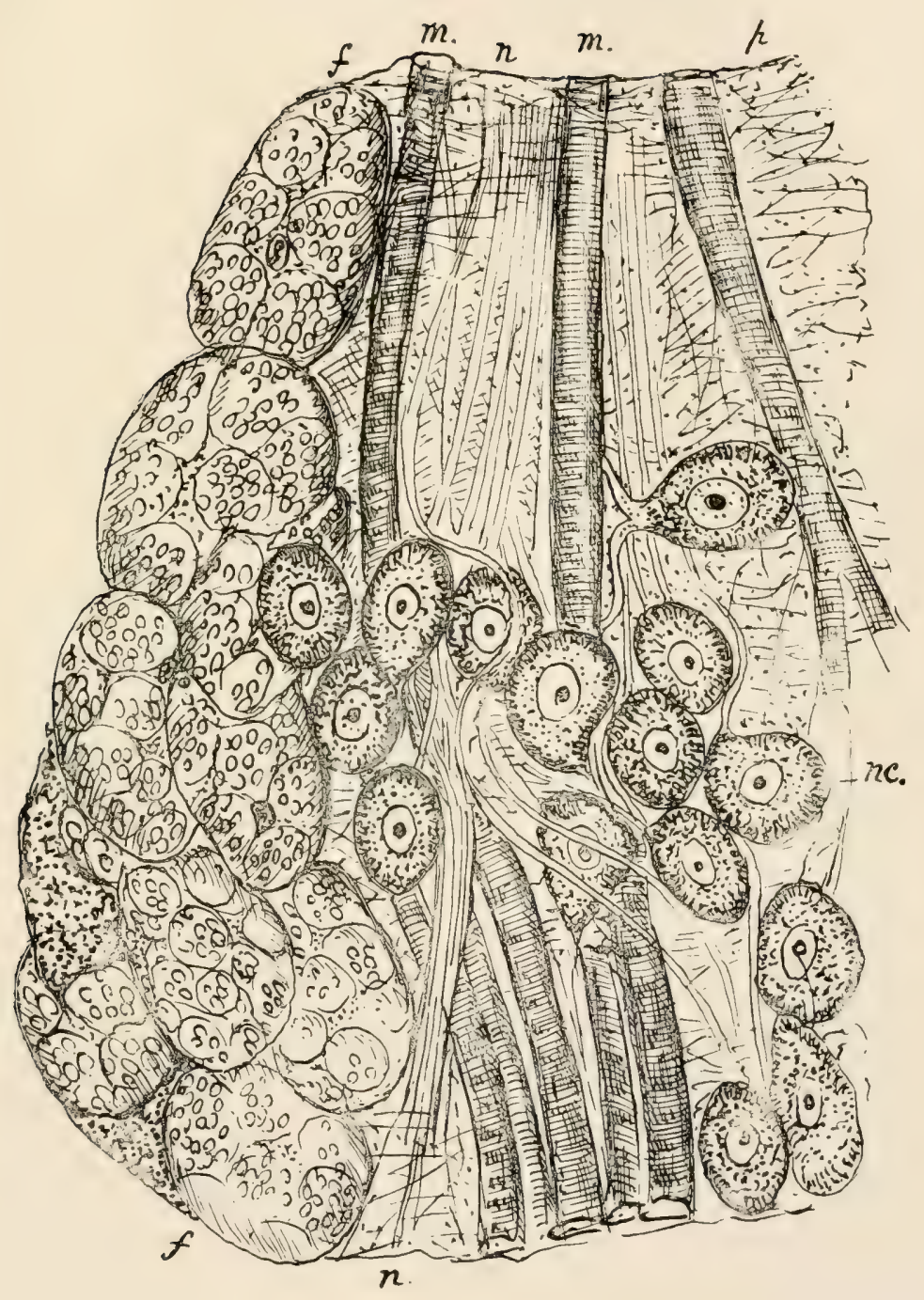



According to Graber, the alar muscles in most large insects -Orthoptera, Coleoptera, Hymenoptera and Lepidopteraare united with the heart itself, so that it is evident that they cannot be separated from it by a continuous fenestrated layer, as they are in the Blow-fly. In these insects the muscle-fibres appear to lie in the substance of the fenestrated layer, and probably perforate it obliquely.

Graber, who has examined the structure and chemical relations of this menbrane with great care, says it is not exactly like any of the tissues of Vertebrates, but resembles most closely the ligamentum pectinatum iridis. I regard it as a cuticular membrane derived from the connective-tissue cells of the septum, so that it is either continuous with the myolemma of the muscle-fibres, or covers both their surfaces in the median region of the septum. Graber also states that it is sometimes continuous with the tunica adventitia of the heart. So that it may be reflected over the dorsal vessel as a thin subendothelial layer in some cases.

The cells which are adherent to the pericardial septum are termed by Graber 'pericardial ' cells.

Pericardial Cells.-I think it is evident from both the figures and descriptions given by Graber, that he includes very different forms of cells under the term 'pericardial.' He says : 'In conjunction with R. Wagner, Leydig speaks of a special cellular layer of the heart, which consists of large cells with green or brown pigmented contents, and of a continuous transparent ground or connective substance, in which the tendons of the alar muscles are spread out and lost; and Weismann further states that the cellular layer is connected with the heart by a loose muscular sheath in which the alar muscles are imbedded.' Graber adds: 'My own observations lead me to a view not consonant with the above, for the pericardial cells form a single peculiar layer enclosing the space in which the heart lies, and not infrequently have no connection either with the heart itself or the alar muscles, but are continuous with the connective layer of the hypodermis.'

As there is no connective layer of the hypodermis, I suppose 
Graber means the subcutancous adipose tissue of the insect: and there is no doubt most of the cells are fat-cells in various stages of development.

There are, however, other forms of cells in the pericardium, large stellate cells of the mesoblast connected with the tracheal vessels and with the muscular tissue. The processes of the latter are frequently seen to be striated muscle-fibres, and these cells, which are figured by Graber [313, Fig. I3], are precisely similar to the muscle-cells of the peritoneal coat of the ovary; they are probably the form of tissue which Weismann described as an intervisceral muscular network. These and the endothelioid plates on the surfaces of the pericardium, the cells of the trachea, and the various forms of fat-cells are probably all modifications of the cellular mesoblast-parablast cells. Lastly, there are large pigmented branching ganglion cells and nerve-fibres, which will be further described hereafter.

I am quite unable to discover any special pericardial celis containing 'respiratory pigment' such as Graber supposes; the pirmented cells are either large ganglion cells, or fat bodies which contain bright green or red pigment. Cells of this kind are seen in many Lepidoptera, but when they occur the fat bodies elsewhere are similarly pigmented.

The Aorta, or anterior part of the dorsal vessel, extends from the mesophragma to the posterior surface of the brain; it is cylindrical, not divided into chambers, and without any pericardial investment; it bifurcates into two lateral branches in the head, and each of these apparentlyends in several branches which are distributed over the brain. Its average diameter is o7 mm. There are possibly two other vessels given off from the bulb, one on either side, which accompany the anterior venous sinuses of the pericardial septum and enter the thorax. It is, however, very difficult to trace such vessels, and until some means of injecting the dorsal vessel has been devised it would be rash either to assert or deny the existence of these lateral thoracic vessels, or of thoracic vessels given off from the aortic trunk in its course through the thoras. 
The dorsal vessel of Eristalis is far larger and more easily examined than that of the Blow-fly, but has a very close resemblance to it, and in this insect I believe I have seen lateral thoracic vessels, which accompany the sinuses opening into the anterior end of the pericardium.

Swinton has given a description of the dorsal vessel in Sphinx ligustri, and he represents a ventral sinus in the abdomen, which he believed to be connected with the heart. This sinus, if it exist, is probably a venous sinus opening into the pericardium; and the short trunks, which he calls efferents, are all probably connected with the pericardial cavity, and are not efferent or arterial, as he apparently supposes, but afferent vessels. He cites Graber in support of his views, but Graber's sinuses are afferent or venous. Such have been repeatedly described in different insects.

I have been unable to detect any valves in the aorta, but such valves may probably be assumed to exist and would represent the intra-ventricular valves of the intermediate part of the dorsal vessel of the larva (see page 9I).

Cardiac Nerves.-The dorsal vessel undoubtedly receives a double nerve supply. The cardiac nerve is a continuation of the main trunk of the stomogastric, which lies between the chyle stomach and the pericardium. It can be seen as a fine white line on the ventrical surface of the pericardium, after the removal of the intestine, with an inch objective. About a millimetre behind the edge of the mesophragma it divides into two lateral branches, which diverge to the edges of the pericardium, where they form a plexus and communicate with a great number of large ganglion cells (Pl. XLVI.). I have been unable to trace the cardiac inhibitory nerves from the thoracic ganglion, but they probably run in the stomogastric cardiac nerve, which they probably join as it passes beneath the mesophragma or in the thorax, as stimulation of the cardiac nerve near the mesophragma produces a cessation of the pulsations of the dorsal vessel.

The Nerve-Cells of the Pericardial Plexus are found in groups on the margins of the pericardial septum. They are stellate 
or hipolar; each has a large vesicular nucleus and a distinct nucleolus: they are loaded with brown granular pigment, and exhibit distinct capsules surrounding the cell protoplasm. I am inclined to regard some of Graber's figures of pericardial cells [313, Figs. I3 and 23] as representing ganglion cells. He, however, figures the branches of the cells in Fig. I3 as transversely striated, and the cells in Fig. 23 as binucleate; otherwise I should have said that they are typical ganglion cells. In the I3low-19y the cells of the pericardial plexus average jo $\mu$ in their long diameter, and are exactly like the nerve-cells of the sympathetic ganglia of fishes.

The Tracheæ of the pericardium and dorsal vessel are very numerous. The principal vessels form fan-shaped groups (Pl. XLV.), which diverge from a single large trachea, and resemble in their general arrangement the alar muscles of those insects in which fan-shaped alar muscles occur. Then seen with the naked eye or a pocket lens of insufficient power, it would be easy to mistake the tracheal vessels for lateral muscular alæ.

\section{PHYSIOLOGY OF THE DORSAL VESSEL.}

Movements of the Dorsal Vessel.-Pulsations of the dorsal vessel, or rather, of the pericardial sinus which surrounds it, were first observed by Malpighi in the larva of the silk-moth, lombyx Mori [148]. These movements, which are visible through the transparent skin in many larve, have been frequently seen and described since. The general view of the manner in which the dorsal vessel acts was for a loner time derived from the writings of Straus Durckheim [40], who, after describing the dorsal vessel of the Cockchafer, says :

- When the posterior chamber of the dorsal vessel dilates, the blood in the abdominal carity rushes into it through two auriculo-ventricular openings. When the posterior chamler contracts, the semilunar valves of these openings close and prevent the exit of the blood, which by its pressure opens the inter-ventricular valves between the posterior 
and second chamber. But besides the blood which enters the second chamber in this way, the latter has received blood, during its diastole, through its auriculo-ventricular openings. The second chamber then contracts, and the blood is prevented from passing backward by the inter-ventricular valves between it and the posterior chamber; it therefore enters the third chamber, which dilates to receive it. The blood thus passes successively from chamber to chamber until it is poured out into the head, from which it returns to the abdomen.'

The above description of Straus Durckheim is not perhaps precisely accurate, but it appears to me by no means as absurd as Verloren pretends.

Verloren has evidently entirely misunderstood the description given by the earlier writers, and although he has given a more detailed description, it differs from theirs rather in detail than in principle. He incorrectly represents the views of Straus Durckheim, and attributes absurd statements to him which he afterwards shows are untenable. He admits that the dorsal vessel is constricted at intervals, but denies that the segments contract separately, and he describes the contraction as a wave which commences at the posterior extremity of the vessel and passes rapidly to its anterior extremity. The time occupied, according to Verloren, in the passage of the contraction wave from the posterior to the anterior extremity is short as compared with the whole period of systole and diastole. So far, I think, Verloren is right, but the wave is certainly delayed at the junctions of the successive chambers, so that, although it travels forward rapidly, each chamber contracts in succession, and the more posterior chambers are fully contracted before those next in front commence contracting. Verioren figures the ostia and their valves and describes them with greater accuracy than Straus Durckheim, if Graber's statements are correct, which is, I think, indisputable.

Verloren also stated that the volume of blood in the dorsal vessel and its velocity increase as it moves forward, since each chamber receives a supply from the pericardium through its 
own ostia, and the contraction of each accelerates the velocity of the moving fluid.

The figures of the valves given by Verloren sugrgest that the flow of fluid into the dorsal vessel is due to ihe velocity of the axial stream, which undoubtedly acts as an injector and draws blood in through the ostia; but he does not apparently regard this as a factor in the circulation, or, if it occurred to him, he does not mention it.

Graber [313] attempted an explanation of the diastole, which I am not sure I fully understand; but he says, after describing the passage of the blood through the narrow space between

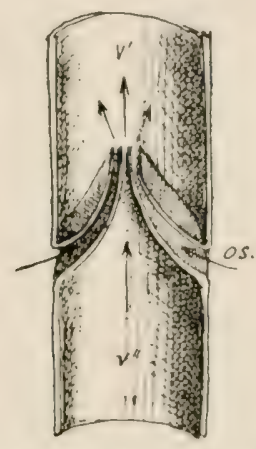

Fili. SS. - A dingrammatic figure of the ostia. The narrow orifice between the ventricles, $c^{\prime \prime}, a^{\prime}$, is supposed to act as an injector, drawing blood through the ostia, os, in the direction of the arrows.

the ostia: " $\Lambda$ the same time blood is sucked through the ostia.'

The dilatation of the dorsal ressel is by no means easy to comprehend, lying as it does in the pericardial space. After the blood has been expelled and the muscular walls relax, there is no very apparent reason why the blood in the pericardial space should pass into its interior. The filling of the dorsal vessel cannot be due to pressure outside it, and it is not easy to discover any effective mechanism by which it can actively dilate. The fine fibres which connect the dorsal vessel with the pericardium no doubt may assist by causing a small quantity of blood to enter through the ostia, especially in the 
posterior chambers, which are narrow and of small capacity. As soon, however, as the blood begins to move forwards in an axial stream, it is not difficult to see that this stream will draw in blood through the ostia. The more posterior chamber, by its contraction, sets up an axial stream in the chambers in front; each chamber in turn becomes distended by the contraction of the chamber behind it and the accompanying inflow by the ostia, and each chamber contracts as soon as it is fully distended.

The only difficulty to my mind is to account for the inflow of blood into the posterior chamber, and this is probably brought about by its more intimate connection with the pericardial wall, so that the expansion of the pericardial cavity also fills the posterior heart chamber. The structure of the dorsal vessel in the Blow-fly imago is entirely consistent with the above theory.

I conclude, therefore, that (I) the pericardial chamber and the posterior part of the dorsal vessel itself are filled by the descent of the pericardial septum, which is due to the contraction of the alar muscles.

(2) When the pericardial sinus is fully distended, a contraction of the posterior chamber of the dorsal vessel occurs which sets up an axial stream through the whole length of the vessel, but chiefly affects the second chamber.

(3) This axial stream causes an inflow at the ostia, which increases with the velocity of the axial stream. In this action the dorsal vessel acts like an injector.

My observations on the dorsal vessel in living insects also show that--

(4) As soon as the second chamber is distended it contracts, and so increases the volume and velocity of the axial stream.

(5) Each chamber contracts in succession, but only a very short time after the one behind it.

(6) The period of rest in each chamber is long in comparison with the period of active contraction, so that all the chambers are emptied before the pericardial muscles again contract.

(7) The contraction of the pericardial muscles immediately 
precedes the contraction of the posterior chamber of the dorsal vessel. After the contraction of its anterior chamber, a period of rest sets in, the duration of which exceeds the whole period of contraction of the pericardium and dorsal vessel.

Verloren [311] states that if the number of pulsations is taken as 60 in a minute, there is a period of active contraction, occupying ' $\mathrm{I}^{5}$ ', and a period of maintained contraction of $\cdot 25$ ". These periods occupy, therefore, ' 4 ", and constitute the systole.

According to the same author, the period of diastole occupies $\cdot 6$ ", which he divides into a period of active dilatation occupying ' 2 ", and a period of distension occupying ' $f$ ". The latter division is, in my opinion, incorrect, and Verloren's error arose from his not having sufficiently separated the movements of the dorsal vessel from the flow of blood into the pericardium. The distension of the pericardial sinus is apparently lue to two factors: (I) the flow of the blood into it, resulting from the contraction of the ventricular cavities, which drives the blood into it through all the venous sinuses. This distension of the pericardial space commences with the contraction of the dorsal vessel itself, and (2) the contraction of the alar muscles of the pericardial septum, which completes the distension of the pericardium, and initiates the contraction of the dorsal vessel.

Verloren makes the pause follow the diastole, and precede. the systole. It can easily be seen in the blow-fly and in Eristalis that the dilatation of the pericardium due to the contraction of the alar muscles immediately precedes the contraction of the ventricles of the dorsal vessel, and that the pause succeeds both contractions, and does not intervene between them.

The pulsations of the pericardium and dorsal ressel of the Blow-fly are visible for a short time through the transparent integument of the imago, immediately after its escape from the pupa, but, except that they are extremely rapid-about 200 per mmte-it is not possible to observe any details. More information can be obtained from the observation of the dorsal 
vessel in a decapitated fly. The easiest method of exposing the dorsal vessel and pericardium is to cut off the posterior half of the abdomen, and then carefully remove the intestine and great air-sacs. This brings the pericardium into view, and its rhythmic contractions can be observed; very generally they are inhibited by the dissection of the parts, but soon recommence; they are very rapid, from 200 to 250 per minute, and occasionally the pulsations of the dorsal vessel itself can be observed through the pericardium. After a time, sometimes nearly half an hour, the pulsations of the pericardium become slowed down to about 60 in the minute, and then the dorsal vessel itself can sometimes be seen contracting, its systole immediately following the contraction of the pericardial muscles.

In such a dissection the dorsal vessel is not intact-its posterior chambers have been cut away with the posterior part of the abdomen. It is much less easy to expose the whole length of the vessel, owing to the lateral curling of the dorsal portion of the abdominal wall after the removal of the ventral parts of the somites. I have been unable to obtain a satisfactory view of the dorsal vessel by this means in the living insect.

Stimulation of the pericardium with a needle will inhibit its pulsations and those of the dorsal vessel for some minutes, after which the pulsations recommence. At first these follow each other very slowly, not more than one a second; they gradually increase in frequency as the effect of the inhibitory influence passes off, and in a few minutes have regained the normal rhythm of about 200 per minute.

I have frequently observed that when the action of the dorsal vessel begins to flag, destruction of the thoracic ganglion again accelerates its rhythm, showing that it exerts a constant inhibitory influence on the heart.

Injury to the pericardium causes its pulsations to cease, and the dorsal vessel itself then ceases to pulsate; but if the dorsal vessel is removed with the pericardium, and the latter is entirely separated from it, rhythmic pulsations of the dorsal 
vessel frequently recommence. I attribute this to the removal of the inhibitory influence of the ganglion cells attached to the pericardial septum.

The blood which enters the pericardial septum passes over the erreat air-sacs of the thorax and abdomen, and from this fact, and the large number of fine trachea on the septum, there can be little doubt it is charged with oxygen. The dorsal ressel is, therefore, a true arterial heart, like that of the Crustacea, which sends arterial, i.e., oxidized blood to the head.

\section{THE DEVELOPMENT OF THE DORSAL VESSEL.}

The manner in which the dorsal vessel is developed in the embryo Insect is insufficiently known. Weismann says [2, p. 85], describing the development of the embryo of the Blow-fly: 'From the position of the dorsal ressel in the larva, it is possible to conclude that it is developed from the deepest of the superficial cell layers of the embryo. During embryonic life I have not been able to observe it, although it is beautifully: seen in the posterior part of the body of the young larva, in which it contracts 56 times in a minute.'

Buitschli [126] states that in the Bee embryo it is developed from two cell strings, which form the edges of the somatopleure from the neck to the posterior extremity of the larva; but he gives no details, and does not indicate whether there are several rows of cells, or only one row on each side. Jaworowski [315] admits that he was unsuccessful in tracing the development of the dorsal vessel in the embryo of Chironomus, and I have been equally unsuccessful in the Blow-fly embryo.

\section{Bibliography:}

314. D) IR1_il1, ( ¿., 'Note sur 'e Développement du Vilisean dorsal chez les Insectes.' Archiv. d. Zool, experimental, tom. ii., I 873 .

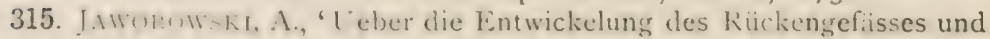
speciell der Musculature bei Chironomus und einigen anderen Insecten?' Sitzb. der k. Acad. der Wissensch. Wien., 8vo, Bd. Ixxx., 1579. 
Jaworowski, however, says that the dorsal vessel in the newly-hatched larva of Chironomus 'consists of two lateral halves, in which every nucleus indicates a muscle-cell. Each muscle-ring, which is gradually differentiated from a pair of cells, therefore consists of two lateral halves. For a long time both the cells and the enclosed muscle-fibres are seen.' He further states that 'the valves are developed from the same musclecells.'

From the manner in which the nuclei are arranged in the dorsal vessel, I think there can be no doubt it is at first a tube formed by two lateral rows of cells. Sections show that in the

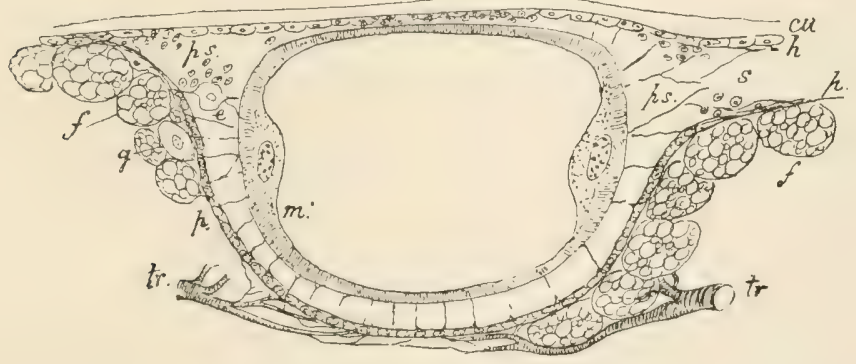

FIG. 89.-A transverse section through the pericardium and dorsal vessel of a Blowfly nymph just before its escape from the pupa case. cu, cuticular layer of the abdominal integument; $f$, fat bodies; $\varrho$, ganglion cells; $h$, hypodermis ; $m$, muscular coat of the dorsal vessel; $p$, pericardial septum; $p s$, pericardial sinus; $s$, blood sinus opening into pericardial sinus ; $t r, t r$, tracheal vessels.

pupa of the Blow-fly, the fibrillæe which surround the dorsal vessel are gradually differentiated from the cell substance of large cells, which surround the lumen of the tube. The nuclei of these cells are very large, and project into the interior of the tube. As to the origin of the muscle-cells, either in the embryo or pupa, nothing is certainly known; but so far as is known, the manner in which the dorsal vessel originates is in favour of Weismann's view that it is a hollow muscular tube, and not a complex organ consisting of connective and muscular tissue. For further details on the development of the dorsal vessel of the pupa see p. $34^{\text {I. }}$ 


\section{CHAPTER XV.}

THE GENERATIVE ORGANS.

Ix all insects the sexes are distinct; hermaphrodism only occurs as an abnormal phenomenon. Normal hermaphrodism is unknown in the class, unless Brandt's observations on the larvie of some Ephemeridæ are correct. He states that both rudimentary ovaries and testes are present in the males of Perla maxima and Cephalotis, but the ovaries subsequently atrophy.

\section{Bibliography :}

316. DOYERE, M., 'Obrervations anatomique sur les Organes de la Génération chez la Cigale Iemelle.' Inn. Sc. Nat., tom. vii., I $\$_{37 .}$

317. KölikER, A., 'Observationes de prima Insectorum genesi.' Turici, 4 to, 1842 .

318. LOEW, H., 'Hora Anatomicae; Beitrïge zur genaueren Anatomischen Kenntniss der Evertebraten.' Abth. i., Posen, I8+1.

319. STrix, F., "Vergleichende Anatomic und Physiologie der Insecten in Monographien bearbeitet, erste Monographie: Die weiblichen Geschlechtsorgane der Käfer.' Berlin, 4 to, s 847.

320. Lubiock, J., 'On the Ora and Pseudova of Insects.' I'hil. Trans. Roy. Soc., London, 1859.

321. HuXles, T. H., 'On the Agamic Reproduction and Morphology of Aphis.' Trans. Linn. Soc., London, vol. xxii., 1859.

322. L.1.1m, F., 'I)er Eicrstock und die Samentasche der Insecten.' Zugleich ein Beitrag zur Lehre von der Befruchtung. Nova Acta L.C.A., tom. xxxiii.. 1866.

323. I.Axum1s, I.., 'Anutomie des Hundeflohes (Pulex canis 1)ugìs) mit berucksichtigum verwander Arten und Geschlechter.' Nova Acta L.C.A., tom. xxxiii., I\$66.

324. Iik-1 1. , F... 'Studien uber die Entwickelung der Sexualdriisen bei den Lepidopteren.' Zeitsch. f. w. Zool., Bd. xvii., 1867.

325. BatbinNi, E. G., 'Mémoirc sur la Génération des Aphides.' (a) Introduction et Appareil male; (b) Suite, Appareil femelle ovipare; 
Insects frequently exhibit secondary sexual characters, as differences of size, form and colour. In the Blow-fly the shape of the forehead and position of the eyes varies in the two sexes (see p. I20), and the males are somewhat smaller than the females.

The generative organs of both sexes may be classified in three groups: (I) The generative glands or gonads, and their segmental ducts; (2) The secondary ducts; and (3) The external organs, which usually consist of one or more pairs of abdominal appendages termed gonapophyses.

(c) Suite, Développement de l'Eeuf pondre. Ann. Sc. Nat. Zool., Ser. v., I869-1870. (a) Tom. xi. ; (b) tom. xiv.; (c) tom. xv.

326. GRIMM, O., 'Die Ungeschlechtliche Fortpflanzung einer Chironomusart, und deren Entwickelung aus dem unbefruchteten Ei.' Mém. Acad. Pétersbourg, tom. xv., I870.

327. Brandt, A., 'Ueber die Eiröhren der Blatta (Periplaneta) Orientalis.' Mém. Acad. St. Pétersb., Bd. xxi., I 874.

328. Rajewski, 'Ueber die Geschlechtsorgane von Blatta Orientalis.' Nachr. d. kais. Gesellsch. d. Moskauer Universität, Bd. xvi., I875. Abstract in 'Hofmann and Schwalbe Jahresbericht,' I 875, p. 425.

329. Gerstacker, A., 'Die Klassen und Ordnungen der Arthropoden.' Bronn's 'Theirreich,' Bd. v., I866-79.

330. Brandt, A., 'Ueber das Ei und seine Bildungsstätte. Ein vergleichend-morphologischer Versuch mit Zugrundelegung des Insecteneies.' 8 vo, Leipzig, 1878.

Brandt gives a bibliography with references to 248 papers, anủ many have been published since. Those which treat of the ova of Arthropods more or less directly are, however, only 90 in number, some very lengthy; and in wading through this immense mass of literature one cannot but be struck by its barrenness-continual repetitions of a few known facts, with lengthy discussions as to the nature and origin of the germinal vesicle. All the observations before 1878 , including Brandt's, were made by methods which are now obsolete, and deal with the deceptive appearances produced by 'optical sections.'

331. Schneider, A., 'Ueber die Geschlechtsorgane der Insecten.' Zoologische Beiträge, Bd. i., I883.

332. Palmen, J. A., 'Ueber paarige Ausführungsgänge der Geschlechtsorgane bei Insecten.' 8vo, Helsingfors, I884.

333. LOWNE, B. T., 'On the Structure and Development of the Ovaries and their Appendages in the Blow-fly.' Journ. Linn. Soc. Lond. Zool., vol. xx., I889.

334. Tetens, H., 'Resultate der anatomischen Untersuchung eines lateralen Zwitters von Smerinthus Populi, nebst einigen daran geknüpften allgemeinen Betrachtungen.' Berlin Entom. Zeitsch,, Bd. xxxvi., I89I. 


\section{DESCRIPTIVE ANATOMY OF THE INTERNAL GENERATIVE ORGANS OF THE MALE BLOW-FLY.}

The internal generative organs of the male Blow-fly are (I) a single pair of testes and their vasa efferentia ; (2) the paragonia, usually termed vesicula seminales; (3) the vas deferens; (4) the ejaculatory sac; and (5) the ejaculatory duct.

These parts are found very generally in male insects, but those in which the penis is absent have usually no ejaculatory sac or duct, and the vas deferens opens on the surface between a pair of more or less complex genital appendages. In some larva, Ephemerida (Palmen), the external openings are paired, so that the vasa efferentia (segmental ducts) open directly on the surface.

The Testes are a pair of simple follicles, situated one on either side of the median line in the dorsal part of the fourth segment of the abdomen. They are pyriform, and often exhibit an hour-glass constriction between the fundus and duct of the gland. They are of a pale orange colour externally, due to the pigmented epithelium which forms the wall of the follicle. In the adult insect the testes consist of an epithelial capsule filled with semen. It measures $75 \mathrm{~mm}$. to $98 \mathrm{~mm}$. in its long diameter, and $5 \mathrm{~mm}$. in its transverse diameter. The cells of the capsule are so thin that they are readily mistaken in sections for a cuticular layer; but in surface views their outlines are very distinct. In fresh preparations the capsule is readily torn into fragments by moving the cover-glass, when if any cuticular layer existed it could not fail to be apparent.

These cells are hexacronal, they have an average diameter of $.02 \mathrm{~mm}$., and are pigmented with orange-brown granular pigment-they have large oval nuclei.

Externally to the epithelium just described, the testis is covered by a thick layer of small, usually multi-nucleated fatcells, precisely similar to those which separate the ovary from the abdominal wall in the female insect. Each nucleus in these cells is surrounded by a stellate protoplasmic mass, the 
processes of which reach the cell wall or similar processes from other nuclei; the interspaces are clear vacuoles filled with fluid or, more rarely, with oil globules (see pp. 275, 276). They are exhausted, or semi-exhausted fat-cells, and form the peritoneal coat of the organ.

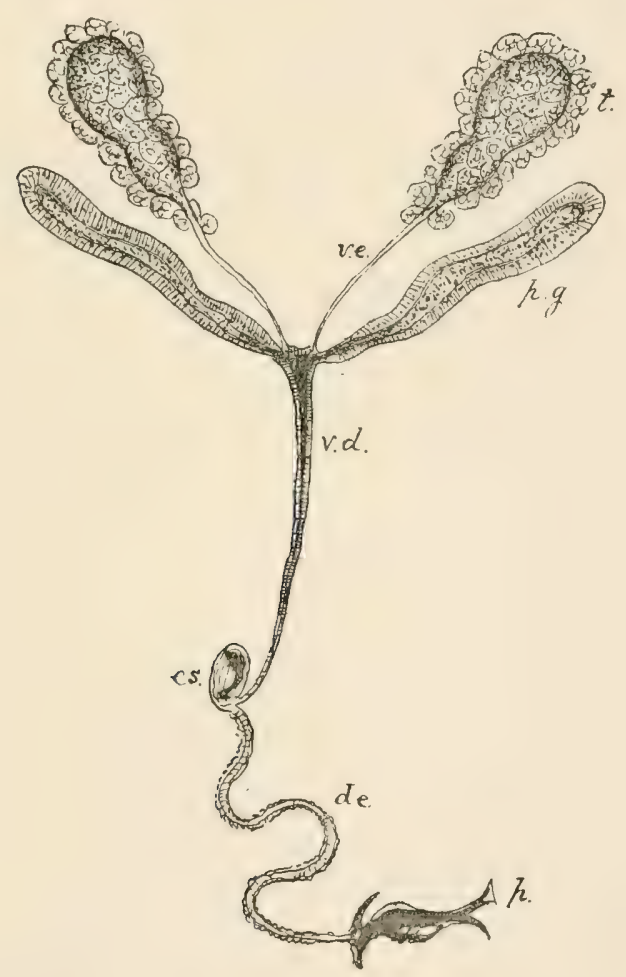

FIG. 90.-The generative' organs of the male Blow-fly. de, ejaculatory duct; es, ejaculatory sac; $p$, penis; $p g$, paragonium; $t$, testis ; $v d$, vas deferens ; $v e$, vas efferens.

In the advanced pupa and the mature insect before the act of copulation, the interior of the testis is divided into loculi by processes or septa from the epithelial coat. These septa are exceedingly delicate and bound irregular spaces; those towards the fundus of the organ are packed with spermatogenic cells, and those nearer the duct contain fully developed spermatozoa. 
The testes of many insects consist of several or numerous follicles, which either open separately into the vas efferens or unite to form a common cavity ; sometimes, as in the Lepiloptera, the two testes are fused into a single median organ, but there are always two ducts, which often have transverse inter-communications.

The Duct of the Testis, Vas Efferens. - It is convenient to distinguish the paired and azygos ducts of the testes by distinct names; authors usually term both 'vasa deferentia,' I have preferred to use the term 'vas efferens' for the duct of the testis, and 'vas deferens' for the azygos duct-formed by the union of the ducts of the testes and of the so-called vesiculic seminales, or paragonia.

In the Blow-fly the vas efferens is a thick walled tube about $0.7 \mathrm{~mm}$. in length. It has an external diameter of $05 \mathrm{~mm}$., but its lumen is less than half this diameter; its walls consist of small columnar cells; the outer surface is covered by a thin peritoneal layer continuous with the adipose tissue which covers the capsule of the testis.

The Paragonia (Fig. go, p $r$ ), the so-called vesicula seminales of authors, are a pair of large sacs $\mathrm{I}^{\circ} 5 \mathrm{~mm}$. in length and $3 \mathrm{~mm}$. in diameter, which open with the vasa efferentia into the vas deferens. The wall of the sac consists of a single layer of long colummar cells covered externally by a thin layer of peritoneal tissue. The sac is filled with a granular, highly coagulable milky fluid.

The paragonia of many insects are much convoluted, and in others exhibit numerous follicles. The term vesiculie seminales is certainly misleading, as they never, so far as I know, contain any seminal filaments. The Cockroach, Periplaneta, is an apparent exception, but I think that the real paragonia in this insect never contain seminal filaments.

The relation of the Paragonia and Testes.-It is well known that in Periplancta the vas deferens is short and wide and terminates in front in a large number of cecal gland tubules, which constitute the so-called mushroom-like gland of Huxley. These sacculi are of two kinds, and have been distinguished as 
utriculi majores and utriculi breviores. The former are milk white and surround the latter, which are more or less translucent. Sections through this organ show that the utriculi majores are precisely similar to the paragonia of other insects, whilst the utriculi breviores differ in no way from the glands which are recognised as the testicle in the majority of insects : they contain sperm-cells and sperm in all stages of development. The vas deferens divides into two main branches at its anterior end, and each of these terminates in a number of both kinds of utriculi-so that, except in the nature of their contents, the utriculi majores and breviores are apparently identical and are morphologically similar.

Rajewsky [328], in 1875, published a paper in Russian, in which he describes what he regards as the true testes, and heconsiders the whole of the utricules of the mushroom-shaped body as vesiculæ seminales. The testes described by Rajewsky undoubtedly exist in the immature male, and are present in the adult male in an exceedingly atrophied condition, so that it has been concluded that the testes undergo atrophy in the adult male. It has been supposed that the mother cells of the spermatozoa are formed in the glands which Rajewsky regards as testes, and descend into the utriculi, where they undergo further development. If this were really the case it is remarkable that no sperm-cells are ever found in the utriculi majores, and it seems to me that the supposition is exceedingly improbable. On the other hand, it may be that the glands of Rajewsky are really the more anterior follicles of a testis, and this more especially as they are persistent in Blatta Germanica, and are functionally active in the adult insect.

Functions of the Paragonia.-The secretion of these glands coagulates with great rapidity in the ejaculatory duct, or in the vagina of the female insect, and is apparently concerned in the formation of spermatophores. In the Orthoptera, in which paragonia are very largely developed, the spermatophores are usually of large size, and only one or two are discharged, and either attached to the exterior of the sexual orifice of the 
female within the cloacal pouch or ovipositor, or are introduced into the orifice of the utero-vaginal tube.

In the Cockroach there is no vestige of a penis, and the right and left gonapophyses are unsymmetrical. The left gronapophysis is provided with a long movable hook, but the right one contains a cavity protected by a spring lid, which closely resembles the organ on the palpus of male spiders. I have little doubt it serves to contain a large spermatophore, which is transferred by the hook to the cloacal pouch of the female. Cornelius, * who gives a description of the sexual act in this insect, describes it as being accomplished with great rapidity, and it is highly improbable that the sperm could be transferred directly from the short wide vas deferens of the male to the oviduct or receptaculum of the female. The probability that a large spermatophore is simply transferred to the cloacal pouch of the female is rendered greater by the fact that such is very generally the nature of the act of copulation in the Orthoptera.

The Vas Deferens varies greatly in length in different insects; it is sometimes wide and short, as in the Cockroach, sometimes long, narrow and much convoluted. In the Blow-fly it is $1.5 \mathrm{~mm}$. in length, and is thickest at its commencement, where it has a diameter of $\cdot 2 \mathrm{~mm}$., tapering gradually towards its termination, where its diameter is about ${ }^{\prime} \mathrm{mm}$. It has the same structure as the paragonia and vasa efferentia. It terminates in the ejaculatory sac.

Segmental Ducts. - The vasa efferentia, paragonia and vas deferens are apparently morphologically related to segmental tubes. I shall, however, return to this subject. They are constantly present, and so offer a marked contrast to the remainder of the senital tube, the ejaculatory sac and duct, which I regard as the 'secondary duct.' This is developed from the hypodermis, and is frequently entirely wantines, as is apparently always the case when there is no intromittent penis, or when this organ is replaced by a pair of more or less complex gonapophyses.

\footnotetext{
* 'L -ilruge zar nalern Kienntniss der Periplaneta orientalis.' Ellerfeld. IS53.
} 
The Ejaculatory Sac and Duct (Fig. 9I) differ from the parts already described in having a thick cuticular intima; this often exhibits a remarkable sclerite in the wall of the ejaculatory sac, which forms the inner extremity of the ejaculatory duct.

In the Blow-fly the ejaculatory sac is ovoid in form; it measures $\cdot 25 \mathrm{~mm}$. in its long diameter. A remarkable fanshaped sclerite is developed in its intima. The sac consists of a thick muscular coat; the loops of muscle which surround the organ and form this coat arise from, and are inserted into, the sclerite.

The vas deferens and ejaculatory duct are both connected with the same pole of the ejaculatory sac, which appears to be

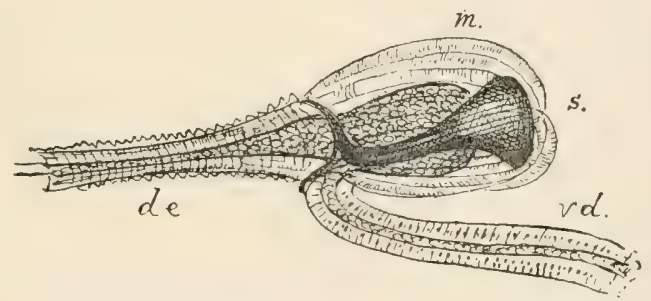

FIG. 9I.-The ejaculatory sac of the Blow-fly. de, ductus ejaculatorius; $m$, musculur coat covering the sac; s, sclerite; $v d$, vas deferens.

a vesicular dilatation of the cuticular intima of the ejaculatory duct.

In many Diptera, as in Tipula, the sclerite in the wall of the sac exhibits a long lever-like process, which projects into the body cavity. Its strong muscular wall suggests that it acts as a pump and drives the seminal fluid through the narrow ejaculatory duct by its contractions.

The Ejaculatory Duct (Fig. $9 \mathrm{I}$ ) is nearly $2^{\circ} \mathrm{O} \mathrm{mm}$. in length, and extends from the ejaculatory sac to the free extremity of the penis. Its wall exhibits a muscular coat from its commencement to the root of the penis; its lumen measures about $.2 \mathrm{~mm}$. in diameter. It has a thick, apparently homogeneous, cuticular intima. It is very elastic and extensile. 


\section{DESCRIPTIVE ANATOMY OF THE INTERNAL GENERATIVE ORGANS OF THE FEMALE BLOW-FLY.}

The internal generative organs in the female Blow-fly are a pair of ovaries and a pair of parovaria; the oviducts, the utero-vaginal tube and its appendages the spermatophorous sacs, which are three in number.

The Ovaries.-In the egg-laying female of the Blow-fly the ovaries are a pair of discoid organs, which occupy the greater part of the abdominal cavity and distend it so that its ventral syndesmoses are extended to their full extent.

Each ovary is oval in form, concave on its dorsal and internal, and convex on its ventral and external surfaces; $35 \mathrm{~mm}$. in its long diameter, $3 . \mathrm{mm}$. in its transverse diameter, and $I .5 \mathrm{~mm}$. thick.

These organs are so situated that they are only separated from the ventral and lateral walls of the apex of the abdomen by a layer of adipose tissue $75 \mathrm{~mm}$. thick. They meet in the middle line beneath the oviducts and intestine, and extend to the margins of the pericardial septum dorsally. They extend forwards to the crop and the great air-sacs at the base of the abdomen.

Structure of the 0vary.-Each ovary is enclosed in a thin capsule of peritoneal tissue, which covers the whole gland and is continuous with the peritoneal coat of the oviduct.

This capsule encloses the egre-tubes, of which there are from (iohty to one hundred, and sends incomplete septa between them, thus dividing the cavity into as many loculi as there are egg-tubes.

The oviduct terminates in a pair of tube, the tuba of the oviduct, which are short and funnel-shaped.

One of these tubie is connected with each ovary ; it is united

\section{DESCRIPTION OF PTATE XLVII.}

The intermal senerative urgans of the female Blow-lly. f; fat bodies; o, ovary ; od, oviduct ; $p$, parovarium; $\ell$, tuba ; $s$, sacculus; $u$, uterus ; and $v$, vagina. The three woil benlies between the parovaria and the uterus are the spermathece. 


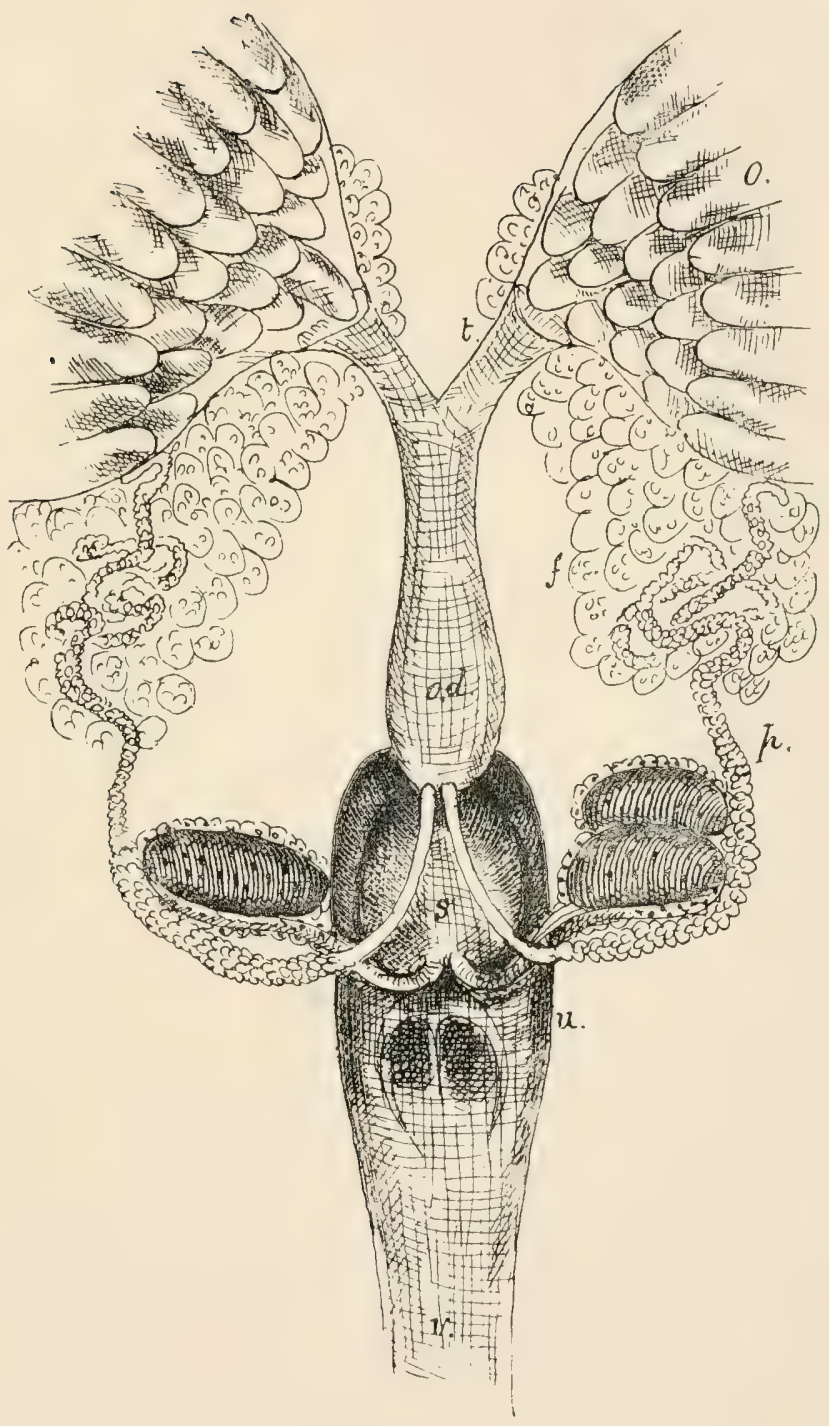



by its peritoneal coat with the capsule of the ovary, but the edge of its epithelial and muscular coats can be seen beneath the peritoneal coat, forming the rim of an open funnel. The connection between the tuba and the ovary is secondary, and its orifice opens into the sub-peritoneal spaces, in which the egg-tubes lie.

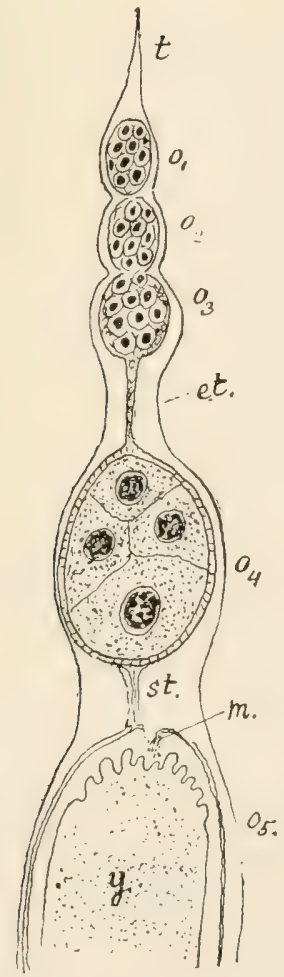

FIG. 92.-A portion of one of the egg tubes from the ovary of a Blow-fly. Seen with a $\frac{1}{4}$-inch objective. et, egg-tube ; $o_{1}$ to $o_{5}$, ova ; st, egg-stalk ; $t$, terminal thread ; $m$, micropyle; $y$, matured yelk of $o_{5}$.

The Egg-Tubes.-Each egg-tube consists of a thin, apparently homogeneous membrana propria. It is divided by constrictions into several chambers, each of which contains an ovum; these are termed egg-chambers. The ova in these chambers are seen in several stages of development; one only is matured, 
the ovum which is situated at the posterior end of the egg-tube, or that nearest the convex surface of the ovary and the oviduct; the others, three or four in number, remain rudimentary, but are probably matured in succession after the mature ova are deposited (see p. 5). The most anterior chamber has been named the terminal chamber; it is the smallest and most rudi. mentary. The membrana propria of the exry-tube is prolonged beyond the terminal chamber, and forms the terminal thread ly which the egg-tube is connected with the peritoneal tissue of the concave surface of the ovary.

The Relation of the Egg-tubes to the 0viduct.-The egrg-tubes have no direct connection with the oriduct. If the fullydeveloped ovaries are removed from the insect, the egrg-tubes can be easily separated from each other after the rupture of the capsule of the ovary. They then diverge from each other and assume a radial arrangement, only remaining attached to the capsule by the terminal threads.

The relation of the egg-tubes to the oviduct is such that the ova can only be discharged into it by the dehiscence of the tunica propria of the egg-tube, and I have frequently found the cmpty remains of the membrana propria of the large eggchamber attached to the rudimentary ova in the anterior part of the egg-tube after the discharge of the orum from its interior.

A large number of tracheal vessels are seen covering the external surface of the ovary; those on its convex surface are very large, and have a stellate arrangement; they arise from two or three large trunks, and give off numerous branches which ramify in the septil tissue of the ovary, and also minute branches which pass at once on to the exrg-tubes. These small ressels fix the convex blind end of the exgretube to the convex surface of the ovarian capsule. They are easily ruptured, and it is owing to this that the exg-tubes diverge from eatch other when the peritoneal capsule is ruptured.

The Structure of the Ovaries in various Insects. - The ovaries of many Colcoptera, perhaps of all, and certainly those of Melie, which I have carefully examined, of many Hymeno- 
ptera and some Orthoptera, are precisely similar to those of the Blow-fly. In those insects, however, in which there are but few ovarian tubules, such as Periplaneta, and the Lepidoptera, the structure is somewhat different. In these each eggtube, instead of containing one ripe ovum at a time, contains from 20 to 50 or more in a linear series. In these insects the egg-tubes are apparently continuous with the oviducts, which appear to divide into as many branches as there are egg-tubes. Instead of the whole ovary being surrounded by a peritoneal capsule, each egg-tube has been described as possessing a peritoneal coat; so that, as these investing sheaths of peritoneal tissue are continuous with the peritoneal coat of the oviduct, the latter appears to divide into as many branches as there are egg-tubes. If, however, the development of these ovaries is similar to that of the Blow-fly's ovary, it appears probable that the continuity of the oviducts and egg-tubes is an acquired but not a primitive condition. I shall have to refer to this hereafter, when I describe the manner in which the egg-tubes are developed.

Histology of the Peritoneal Coat of the 0vary.-In studying the writings of various authors on the structure of the ovary it becomes evident that the term peritoneal coat is used in a very variable sense. Perhaps, strictly speaking, the term is not justified at all, but it is convenient and is applied to the external connective tissue investment of various organs by most writers on the anatomy of insects. The existence of a true serous coat is nowhere capable of demonstration. Those authors who have denied the existence of a peritoneal coat in the case of the ovary have endeavoured to distinguish a true serous coat, or have attempted to separate a special coat from the capsule of the ovary. The term is usually applied to the covering of the individual egg-tubes, when these are few in number and easily separated; and Brandt used it in this sense in describing the egg-tubes of Periplaneta. In describing the ovary of the field Cricket, Gryllus campestris, the same author says, "In this insect the Ioo to I5o egg-tubes have no separate investment, instead of which they are surrounded loosely by a 
net-like anastomosis of connective tissue, not connected with the tunica propria of the egg-tubes. This tissue is thickened on the surface of the ovary, and forms a capsule which is continued over the end fibres and the oviduct.'

Brandt does not consider this as a peritoneal tissue, and says that 'it differs widely from the peritoneal tissue of Peri-

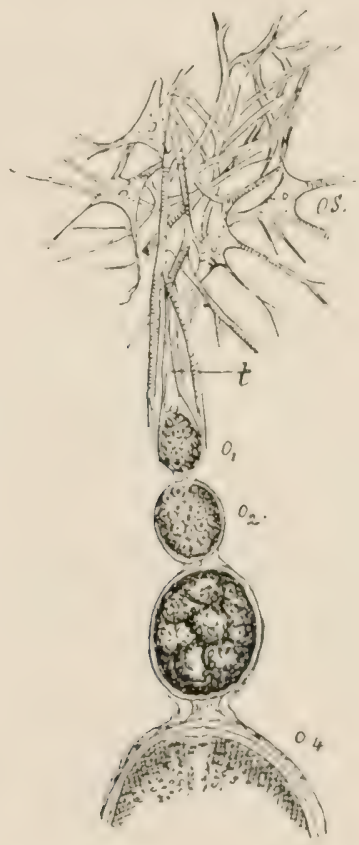

Fir. 93- A portion of the ovarian stroma of one of the egry-tubes from the urary of a 13hiw-fly, drawn from a specimen dissociated in Flemming's mixture, and :een w ith an oil immersion, $\frac{1}{12}$ oljective. $o_{1}$ to $O_{4}$, ova in successive stages of development; os, ovarian stroma; $t$, terminal thread of the oviduct.

planeta in not being formed from the tissue of the fat bodies, but from a connective tissue.' To attempt such a distinction leads too far, since in the majority of cases tissues termed peritoncal are merely cellular connective elements mixed with fibres and tracheal vessels, and the fat hodies themselves are mere modifications of the same tissue. 
In most insects in which the egg-tubes are numerous, the ovarian stroma and capsule present similar characters.

In the Blow-fly the peritoneal tissue (Fig. 93) which forms the stroma and capsule of the ovary consists of adenoid tissue similar to that which invests the other organs, but denser and permeated by muscle-fibres which diverge in a stellate manner from large cells, the processes of which are clearly differentiated into muscle-fibres. A similar condition is described by Graber in the pericardial septum of the larva of Phryganea striata [313, Pl. IX., Fig. I3]. In the septa which separate the eggtubes numerous muscle-fibres extend from the concave to the convex surface of the ovary. In the young ovary these septa are seen to be the walls of distinct blood sinuses filled with pseudo-yelk; so that, if they are not to be regarded as peritoneal tissue, it would be better not to use the term for any of the tissues of an Arthropod.

The 0viducts commence by wide-open trumpets which are attached to the capsule of the ovary and open freely into its cavity. They are directed forwards, and unite beneath the ovaries in the middle line to form the azygos oviduct. This curves upon itself and opens into the utero-vaginal tube on the dorsal aspect of the latter. The oviducts are very muscular, exceedingly distensile tubes; in the empty condition their walls are strongly plicated. There are two dilatations at the terminal extremity of the azygos oviduct, immediately before it joins the utero-vaginal tube. The anterior of these is similar in structure to the oviduct itself. I term it the sinus of the oviduct. The more posterior, unlike the oviduct proper, is lined by a plicated cuticular layer. I term it the sacculus.

The oviduct consists externally of a peritoneal layer continuous with the capsule of the ovary; beneath this there is a thick muscular coat, consisting of two layers of striated musclefibres, an external longitudinal and an internal circular layer. The tube is lined by large cubical epithelial cells, which in the distended oviduct are flattened out into a pavement layer.

In the contracted state the trumpet-shaped tubæ measure about $75 \mathrm{~mm}$. in length, and have a diameter of $5 \mathrm{~mm}$. in 
their widest part. The azygos oviduct in the same condition is about $2 \mathrm{~mm}$. in length, and is nearly $\mathrm{I} \mathrm{mm}$. in breadth when seen flattened out after dissection. During the transit of the ova the oviducts become greatly elongated; the tubre usually each contain an ovum, whilst the azygos oviduct often contains

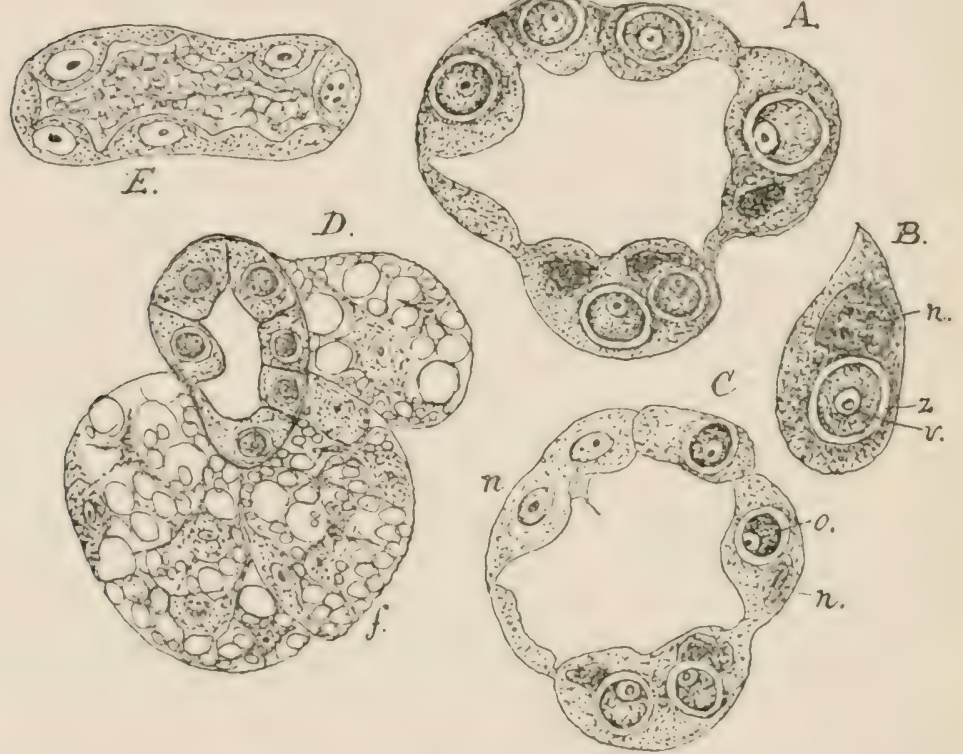

Fig. 94. - Transverse sections of the parovaria of the Blow-fly. A, section through a mature parovarium; $B$, a single cell from the same, showing the included corpuscle, the germ ovum, and the nucleus; $C$, a section of the parovarium in a less developed condition; $D$, a section showing the adjacent fat body; $E$, section through an immature parovarium. All the figures except $D$ represent the structures as they appear with a $x^{1}$ oil-immersion objective. $f$, fat-cells; $n$, nuclei ; 0 , germ ovum; $v$, vitelline vesicle ; $z$, zona radiata.

two or three, so that the whole length of the tube must exceel of mm. And sections show that its course is exceedingly tortuons. The ducts of the parovaria open into the anterior part of the sacculus.

The Parovaria. - The slames which I term parovaria in the Blow-lly are simple tortuons, mather than convoluted, tubes, 
which have usually been regarded as colleterial or glue glands.* There are a single pair which open into the sacculus of the oviduct by a pair of ducts. These glands lie one on either side of the oviduct, embedded in adipose tissue, and each extends along the outside of the corresponding tuba, and terminates in a cæcal extremity which is attached to the ovary. They are white, with a pearly lustre, and exhibit a beaded appearance due to the projection of the outer surfaces of the cells which line them.

In sections they exhibit a peritoneal coat, and consist of a structureless basement membrane, lined by a single layer of large epithelial cells. The lumen of the gland is occupied by a granular fluid or semi-fluid substance of a highly coagulable character. The granules suspended in this fluid are intensely blackened by osmium peroxide.

The general structure of these glands is similar to that of the vas deferens and paragonia of the male; but the epithelial elements are much larger, and are irregular in form; the cells measure on an average $80 \mu$ in diameter, and are from $30 \mu$ to $40 \mu$ thick.

Many of these cells contain very remarkable spherical corpuscles, usually one in each cell. The corpuscles bear a striking resemblance to the ova of many Mammalia; they exhibit a zona pellucida with distinct radial striæ, enclosing a granular protoplasm, which exhibits a vesicular nucleus with a minute highly refractive particle in its interior comparable with the well-known germinal spot (Fig. 94).

Beside these corpuscles, many of the cells also exhibit an oblong nucleus, surrounded by a clear area.

The largest of the contained corpuscles measure $25 \mu$ to

* Colleterial or glue glands are glands which open into the posterior part of the genital canal, close to the external orifice, and secrete a viscid fluid by which the eggs are varnished or attached to each other, or to leaves, branches, etc. Such glands are found largely developed in the Lepidoptera, and resemble the sericterial or sill: glands in structure and in the nature of their secretion. There are no colleterial glands in the Blow-fly, and the cement with which the eggs are united with each other when deposited is probably secreted by the walls of the utero-vaginal tube; the genital fossæ are frequently found filled with a similar material, which is apparently a coagulable albuminous fluir. 
$30 \mu$ in diameter. When fully formed the clear outer ring, zona radiata, is $+\mu$ in breadth, and exhibits a distinct radial striation. The clear vesicular nucleus measures $5 \mu$ to $S \mu$, and the contained refringent spherule $2.5 \mu$ in diameter.

That the parovaria should have been so constantly confounded with true glue glands-which, when they exist, are totally unlike them both in structure and position-is not a little remarkable, especially as Malpighi [148] described and figured both these and the true glue glands in Bombyx mori; and Herold [140] figured both in Pieris brassica. He termed the single parovarium of this insect 'Das einhornige Absonderungs-Organ,' and says: 'Nalpighi has described and figured this secreting organ in the silk-moth. He thought that it pours a fluid into the common oviduct. This cannot be denied, but future observations must decide its import in the sexual process.'

Such observations were not, however, attempted, and the gland in question received no further attention until I made a series of observations upon it, which have already been published [333].

The parovaria have been observed in all, or in almost all, groups of insects. Stein figured the large parovaria of Hydrobius fuscipes, and in this insect they are obviously part of the ovaries; and Gerstacker [329] says 'the colleterial glands'alluding to the parovaria-'are so like the ovaries in many Insects, that it is only possible to distinguish them by the nature of their contents.'

Jackson [351] apparently regards the parovaria of Vanessa as spermatheca, but as he only describes and gives figures of them in the pupa, I am by no means sure that the structures he so names are the parovaria. True glue glands-colleterial glands-do not exist in the Blow-1ly, but they attain a large size in many Lepidoptera, and open into the oviduct close to the vulva. In these insects the parovaria and glue glands co-exist, and cannot be mistaken for each other.

I had hoped to have made a series of observations on the parovaria of various insects, but up to the present I have been 
unable to find the time to make more than a few cursory observations. I have examined numerous sections of these glands in Smerinthus populi, and their general structure is similar to those of the Blow-fly, but the cells are much smaller, and more columnar; the spherical corpuscles are also far smaller, and exhibit no zona radiata. I am, however, of opinion that they are similar in character, and their appearance, although less convincing than in the Blow-fly, is highly suggestive that they are concerned in the formation of germ ova. I shall return to this subject in a future section of this work.

The Utero-vaginal Tube is the homologue of the ejaculatory duct and sac of the male. It is a thick-walled muscular tube, extending forwards from the vulva to the anterior edge of the fourth abdominal segment, when the long tubular ovipositor is retracted; but when the latter is exserted it is drawn out of the abdomen proper, and lies entirely in the interior of the ovipositor.

Its anterior part, which is pyriform and has very thick walls, may be termed the uterus; the posterior part, which is cylindrical and has thinner walls, may be termed the vagina.

The utero-vaginal tube is lined by a thick cuticular intima, which is separated from the muscular coat by a layer of pavement epithelium, resembling that of the cutaneous hypodermis.

The Uterus, or bursa, clearly corresponds with the bursa copulatrix of the Lepidoptera and Homopterous Hemiptera. It measures rather more than $\mathrm{I} \mathrm{mm}$. in length; its muscular wall is well developed, 'I mm. thick. Its cavity is ovoid, and lined by a strong cuticular intima. It exhibits a pair of deep pouches, the genital fossæ, on its dorsal wall, which are separated by a well-marked ridge, the genital spine. The cuticular intima is very thick in this region, and exhibits a distinctly laminated structure. The ducts of the receptacula seminis open into the uterus immediately in front of the anterior extremity of the genital spine, close to the median line. The oviduct also opens into it on its dorsal wall, ' $\mathrm{I} \mathrm{mm}$. in front of the anterior extremity of the genital spine. 
In the egg-laying female, the uterus often contains an egg in which the embryo is in an advanced stage of development. In Sarcophaga and Tachina it is developed into a large cavity, which is rolled spirally on itself, and contains a large number

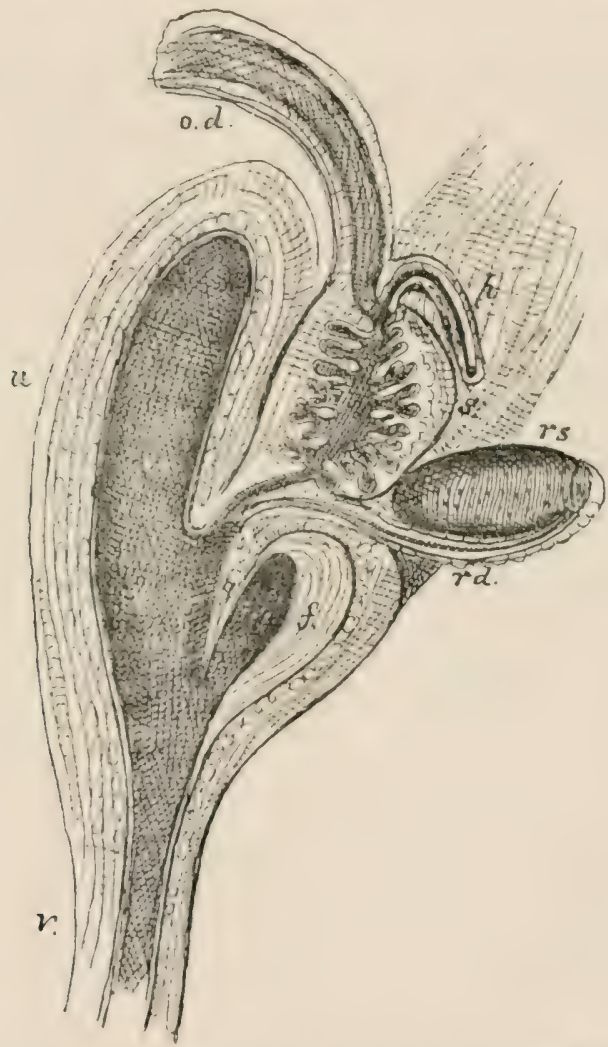

Fu: 25.-A median vertical section of the uterus of a mature Hlow-fly. $f$, cuticular pad of the genital fossa; $s$, genital spine; od, oviduct; $p$, duct of the parovarium; $r d$, duct of the receptaculum seminis; $r s$, receptaculum seminis; $s$, sacculus ; $"$, uterus ; $v$, vaginal tube.

of exgrs which are hatched within its cavity, so that these insects deposit living larval. In the pupiparate the uterus is also larely developed, and contains but one embryo at a time, which grows and devein's until it is ready to become a pupa. 
The Genital Fossæ.-These remarkable depressions in the dorsal wall of the uterus are probably concerned in the act of copulation. They are fully developed in the female when it emerges from the pupa, and are protected by a thick laminated cuticle. They probably lodge the curved spines of the penis during copulation. Although the distance of this fossa from the vulva is very considerable in the adult female when the ovipositor is exserted, in the young female it lies close to the vulva. The ovipositor is closed up by its joints being withdrawn one within the other, like the tubes of a portable telescope, and the vagina is also invaginated in four folds, one withın the other, so that the bursa, as the young uterus is termed, opens directly through a very short segment of the vagina by the vulva.

The Receptacula Seminis. - These organs serve as a receptacle for the sperm of the male; for although Insects have the sexes distinct, the sperm is transferred from the male by a single sexual act to the bursa, or to the receptacula seminis of the female, where it remains for days, months, or even for years before the ova are fertilised. Fertilisation is effected as the ovum passes through the oviduct, so that the actual act of fertilisation is not effected by the union of the sexes.

In the Lepidoptera, the bursa does not communicate directly with the oviduct, and opens externally by an orifice on the ventral surface of the abdomen, in front of the orifice of the oviduct. The sperm is afterwards conveyed into the oviduct by the spermatic canal, which unites the two cavities.

In most insects the sperm is preserved in the spermatic capsules, or receptacula seminis. In the Diptera these are always three in number, two on one side, and one on the other.

In the Blow-fly the receptacula seminis, or spermathecæ, are small capsules, which have a long diameter of $\cdot 2 \mathrm{~mm}$., and a short diameter of about $125 \mathrm{~mm}$. There are two on the right side, and one on the left, connected with the uterus by long muscular ducts, one to each capsule. The orifices of these ducts are close together, immediately in front of the 
genital spine. The receptacula and their ducts are lined by a cuticular intima. This membrane is of a dark-brown colour in the capsules, and exhibits transverse rings like those of a tracheal vessel. The intima of the duct is colourless, and exhibits only faint rings.

The duct is a thick-walled tube with walls of from $20 \mu$ to $25 \mu$ in thickness. In the young imago, externally to the intima, both the capsule and duct have an epithelial and peritoneal layer, and are closely surrounded by fat-cells. In the adult insect the epithelial layer is no longer demonstrable, but both capsule and duct are covered by a layer of highly-dereloped striated muscle-fibres. In the impregnated female, the capsules are filled with closely-coiled spermatic filaments.

\section{ON THE STRUCTURE OF THE EGG IN THE BLOW-FLY.}

The Egg.-The mature egg of the Blow-fly measures I' +2 to $\mathrm{I} .49 \mathrm{~mm}$. in length, and has the form of an elongated ellipsoid, which is smaller at its anterior and broader at its posterior end. Its long axis is slightly curved, so that its ventral surface is convex and its dorsal surface is flat, or even slightly concave. It exhibits a micropyle at its anterior end, from which a canal, or rather groove, extends to very near the posterior pole of the egg, along its dorsal aspect.

In the ovaries and oviducts the anterior extremities of the eggs are directed forward, and in the uterus the dorsal aspect of the egr is towards the dorsum of the insect. The embryo is

\section{Bibliography :}

335. MISSNER, G., 'Beobachtungen über das Eindringen cier Samenelemente in den Dotter.' Zeitsch. f. w. Zool., Bd. vi., 1855.

336 LEUCK.IRT, R., 'Ueber die Micropyle und den feincren Bau der Schalenhaut bei den Insecteneiern.' Archiv. f. Anat. und Physiol., 1855 .

337. Kokscheli, E., 'Zur Bildung der Eihïllen, der Micropylen und Chorionanhänge bei den Insecten。' Nova Acta C. L. C. Acad., Bd. li., 1887 .

338. Cholonosky, N., Ueber einige Formen des Blastopors bei meroblastischen Eiern.' Zool. Anzeig. Jahrg. xiv., p. 159, I891. 
also developed with its dorsum towards the dorsal aspect of the egg, and its cephalic extremity at the anterior end.

The Chorion, or egg-shell, is opaque, with a pearly-white lustre. Its whole surface is divided into beautiful regular hexagonal fields, having a long diameter of $04 \mathrm{~mm}$. and a short diameter of $02 \mathrm{~mm}$. The surface of each field exhibits a fine punctation. After the deposition of the eggs, the chorion, which is at first tough and leathery, becomes so brittle that it

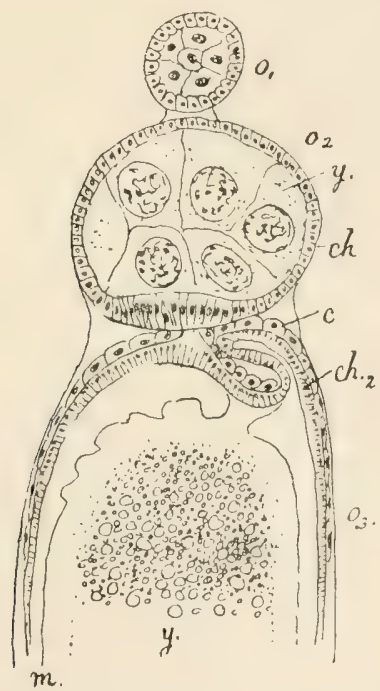

FIG. 96. - Three ova from a mature egg-tube. c, outer cellular layer of the chorion ; $c h$, epithelial chorion of a young egg ; $c h_{2}$, inner layer of the chorion of mature egg; $o_{1}, o_{2}$, and $o_{3}$, eggs in different stages of development; $o_{3}$, a portion of a mature egg showing the infolding of the chorion at the micropyle; $y y$, yelk cells and yelk.

can be readily removed with a pair of needles and a little practice from the subjacent vitelline membrane. This enables the student to observe the developing embryo in optical section through the transparent vitelline membrane. I have found it useful to make a sketch in this way of hardened embryos before embedding them for sections. The whole process is of course performed in the fluid in which the eggs are preserved. I prefer Flemming's mixture. 
Structure of the Chorion.-In the ripe ovarian ova the yelk is seen to be enclosed in a double layer of cells and a structureless membrane. The latter is next the yelk, and is known as the vitelline membrane, the two layers of cells form the chorion. In some of the ovarian eggs both layers of cells are very distinct ; in others the cellular character of the inner layer is lost, and it appears to be converted into a cuticular membrane, with distinct but fine striæ vertical to its surfaces.

The cells of this layer are exceedingly small columnar cells, $3 \mu$ in diameter. The cells of the outer layer are larger, and correspond with the hexagonal fields seen in surface views. They are thickest and most easily demonstrated at the anterior egg-pole.

The question whether the chorion is a cuticular or cellular membrane has been the subject of much controversy. The earlier writers all regarded the chorion as cellular, but the tendency in modern times has been to follow Leydig [322], who regarded it as a cuticular membrane.

The young ova in the ovary are indubitably surrounded by a single layer of columnar epithelial cells, and I have traced these cells in numerous sections to their final condition, in which they form a continuous striated layer, when the nuclei of the original cells are still readily seen in sections stained with carmine. Other eggs in the same ovaries no longer exhibit these nuclei.

The second layer of cells, that corresponding with the hexagronal fields, appears later, and is only seen in ova approaching maturity. I have been unable to trace the origin of these cells with certainty, but they appear between the deeper epithelial layer and the tunica propria of the eser-tube. Kiorschelt [337] has figured numerous young ova in which the epithelial layer exhibits a double layer of nuclei, so that it is probable that the outer layer of epithelial cells is developed from the inner layer.

These cells form the outer layer of the chorion, and not, as Korschelt supposes, its whole thickness. Whether they are directly transformed into the cuticular tissue of this layer, or 
whether this cuticle is an exudation from their inner surface, is a question similar to that involved in the origin of the cuticular structures of the integument, which has already been discussed. Leydig, who believes that all cuticular structures are formed as exudations from the surfaces of cells, naturally regards the chorion as having a similar origin, and the hexagonal fields as imprints of the cells. As I have no doubt that cuticular membranes are formed by the direct metamorphosis of the surface layers of the cell protoplasm, I regard the chorion as the result of such a metamorphosis.

In the Blow-fly I believe the whole thickness of the cellular
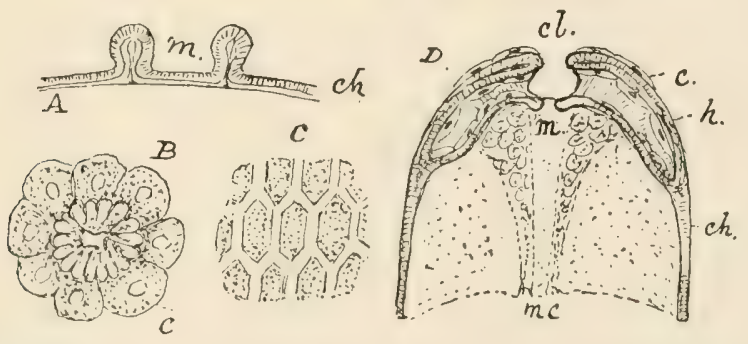

FIG. 97.-Details of the structure of the chorion. $A$, a transverse section through the micropyle canal, near the equator of the egg; $m$, micropyle canal, $\frac{1}{12}$ oil, immersion ; $B$, a surface view of the micropyle ; $c$, rosette of cells, $\frac{1}{12}$ oil immersion; $C$, a surface view of the chorion showing the punctate hexagonal fields, $\frac{1}{4}$ objective; $D$, a diagrammatic section of the anterior pole of the chorion; $c$, outer cellular layer of the chorion; $c h$, cuticular layer of the chorion; $h$, hood of the micropyle; $\mathrm{cl}$, cleft in the hood continuous with the micropyle canal; $m$, micropyle; mc, micropyle canal seen through the semitransparent chorion.

layer is transformed into cuticular tissue. In those insects in which the epithelial layer of the chorion is shed as a 'corpus luteum' in the oviduct or left in the egg-tube, it appears probable that only a part of the outer epithelial layer is cuticularised, or the chorion may consist of the inner layer of cells only in its final stage of development.

The Micropyle is a minute opening at the anterior pole of the egg, variable in form, sometimes quadrilateral and sometimes circular, of from $2.5 \mu$ to $5 \mu$ in diameter, surrounded by a rosette of epithelial cells (Fig. 97). I believe the variations in size and form which I have observed are due to the contraction of 
these cells, which are apparently capable of opening and closing the micropyle.

The micropyle is situated in a cup-like depression of the chorion, nearly I mm. in depth, the edges of which arch over its carity and form a kind of hood. The cavity is prolonged as a groove to near the posterior egg-pole along the dorsal surface of the egg. This is the micropyle canal.

The Micropyle Canal is about ' I mm. wide at the anterior extremity of the egg, gradually narrowing slightly towards the posterior egg-pole. It is formed by two parallel ridges of the chorion, which extend backwards from the edges of the hood over the micropyle, and is open dorsally throughout its whole length (Fig. 97).

When the chorion is removed from the egg and flattened out, a surface view of the micropyle canal can be obtained. It is then seen to exhibit a granular appearance, which renders it darker and less transparent than the rest of the chorion. The granules appear to lie in the substance of the chorion between the outer and inner layers.

The significance of the micropyle canal is unknown. Henking [350] states that he found spermatozoa in the canal in eggs which had just been deposited; and it appears indubitable that it is in some way concerned in the fertilisation of the egg. Herold thought that it is concerned in supplying the larva with air during its development, as both the micropyle canal and the cavity at its anterior extremity in which the micropyle is situated are filled with air in the eggs a short time after they are laid. There is no reason, I think, to ascribe a respiratory function to it, as the anterior extremity of the egg is exposed to the air, and the micropyle canal falls short of the posterior egrry-pole and ends by becoming more and more shallow, so that it could hardly be efficient in conducting air from the anterior to the posterior egg-pole.

I think there is some reason to believe that the original position of the micropyle in the earliest forms of insects may have been at the posterior egg-pole, and that the micropyle canal represents a long micropyle apparatus produced by the 
transfer of the micropyle from the posterior to the anterior egg-pole.

The Vitelline Membrane is a structureless membrane in immediate contact with the yelk. Although many writers have even questioned the existence of this membrane, there cannot be the slightest doubt of its existence in the mature ovarian eggs of the Blow-fly. In the earlier stages of development its presence cannot be demonstrated. Korschelt says, 'A vitelline membrane is present in Musca vomitoria, and in species of Vanessa, but in the former insect its first appearance is somewhat late, later than the first rudiments of the chorion.'

My sections afford indications that the vitelline membrane is connected with the chorion at the margin of the micropyle, and Leydig [322] describes the union of the vitelline membrane and chorion in this region.

The Yelk.-When the freshly laid egg of the Blow-fly is crushed on a glass slide, and the yelk is examined, it is found to consist of a great number of oil globules less than $\mathrm{or} \mathrm{mm}$. in diameter and of minute granules about I $\mu$ in diameter suspended in a clear fluid.

Sections made from ovaries imbedded in paraffin show that the yelk is shrivelled and irregular in outline; this is probably the result of the solution of the fat, as no fat granules are found in the yelk, although some preparations exhibit vacuoles in their place. The granules stain readily with logwood and carmine, and are probably proteid granules. In such sections the granular yelk is seen surrounded by a clear zone in which both granules and fat droplets are absent. This layer is present in the eggs which lie in the ovarian follicles. It was observed by WVeismann in impregnated eggs, and he termed it 'blastoderm plasma,' and believed that the blastoderm is developed from it. Although I have prepared vast numbers of serial sections of ovaries filled with ripe eggs, and examined them most carefully section by section again and again, I have never found any structures which resemble a germinal vesicle or spot. I believe, however, that leucocyte corpuscles similar to those of the blood of the mother are recognisable in some 
of my sections. Such cells are, however, very difficult to identify in the general mass of granular material.

Weismann [2] described the yelk of the newly-laid eggs of the Blow-fly as consisting of oil droplets and granules of immeasurable fineness suspended in a clear fluid, and was unable to find any' germinal vesicle, which he says 'had already disappeared' in recently impregnated eggs. (See Section 4, h. of this chapter.)

\section{ON THE DEVELOPMENT OF THE INTERNAL GENERA- TIVE ORGANS.}

\section{a. The Earliest Appearance of the Gonads in the Embryo and Larva.}

The rudiments of the gonads, ovaries and testes are well known to appear, in many insects, imbedded in the fat bodies in

\section{Bibliography :}

339. SUCKow, F. W. L., 'Geschlechts-organe der Insecten.' Heusinger's Zeitsch. f. Organ. Physik, Bd. ii., 1828.

340. CiAUs, C., 'Beobachtungen iiber die Bildung des Insecteneies.' Zeitsch. fo w. Zool., Bd. xiv., 1864.

341. Mrtschnikow, E., 'Ueber die Entwickelung der Cecidomyienlarven aus dem Pseudovum.' Archiv. f. Naturgeschichte, 1865.

342. Lleckart, A., 'Die ungeschlechtliche Fortpflanzung der Cecidomyienlarven.' Archiv. f. Naturgeschichte, I 865.

343. Ginis, M., 'Beitrïge zur Erkenntniss der Entwicklungsgeschichte bei den Insecten' ('On the Development of P'atygaster, Ophidneurus and Teleas'). Zeitsch. f. w. Zool., Bd. xix., I869.

344. Bexthex, E. VAN, 'Recherches sur la Composition et la Signification de l'CEuf.' Mem. couronnes et Mem. d. Sav. Etrang, Acad. de Belgique, tom. xxxiv., I870.

345. LeIwIG, II., 'Ueber die Eibiliung im Thierreiche. Fine von der philosophischen Facuhtat der Universitiat gekrönte Preisschrift.' IVürzburg, 1874. See also Verhand. d. Würburger Phys. Med. Gesellschaft, Bd, vii., I874.

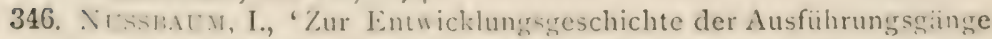
der Sexualdrüsen bei den Insecten.' Zool. Anzeiger, Bd. v., p. 637, 1882 .

347. B.11:11.XI, L.. (.., 'Contribution a l'Eude de la Formation des Organs sexuels chez les Insectes.' Rec. Zool. Suisse, tom. ii., 1885.

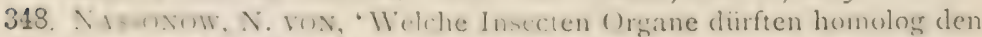
Sumental or:anen die Wurner zu halten sein.' Biolog. Centralblat., Bd. vi., p. 458,1886 . 
the dorsal region on either side of the median line at a very early period of development, in the form of a pair of minute pyriform or reniform corpuscles composed of embryonic cells, each of which is connected with the hypodermis, on the ventral surface in front of the eighth abdominal segment, by a long fine cellular cord, the genital cord. Herold [140] and Suckow [339] discovered the differentiated rudiments of the sexual glands in the caterpillars of the Lepidoptera; and Herold found distinctly differentiated ovaries or testes in caterpillars which had only escaped from the egg a few hours, and concluded from this that the organs must be present in the embryo. Suckow [339] states that he actually saw the gonads in the embryo stage of Bombyx pini by the aid of a lens (?). He says 'The first appearance of the sexual organs is, in the earliest stage of embryonic life, as a bud from the alimentary canal, which at a later stage is divided into two lateral halves by a fissure extending from the alimentary canal and forms two hollow threads. Towards the latter end of embryonic life the rudiment of the sexual organ is separated from the alimentary canal as a bulb at the anterior end of the two threads.' These observations of Suckow's are exceedingly imperfect, and do not agree with more recent investigations; he evidently mistook the rudiments of the oviducts and bursa for the sexual organs, and his description of these is inaccurate.

Brandt [330] rejected Suckow's views as erroneous, and says

349. KORSCHELT, E., 'Ueber einige interessante Vorgänge bei der Bildung der Insecteneiern.' Zeitsch. f. w. Zool., Bd. xlv., I887.

350. Henking, H., 'Die ersten Entwicklungsvorgänge in Fliegenei und freie Kernbildung.' Zeitsch. f. w. Zool., Bd.xlvi., I 888.

351. JACKSON, W. HATChetT, 'Studies in the Morphology of the Lepidoptera.' Trans. Linn. Soc., Lond., vol. v., I890.

352. Ritter, R. von, 'Die Entwickelung der Geschlechtsorgane und des Darmes bei Chironomus.' Zeitsch. f. w. Zool., Bd. l., I 890.

353. Poulton, E. B., "The External Morphology of the Lepidopterous Pupa, its relation to that of other stages, and to the origin and history of Metamorphosis.' Trans. Linn. Soc., Lond., vol. v., I890-I89I.

354. Heynows, R., 'Die Entwicklung der weiblichen Geschlechtsorgane von Phyllodromia (Blatta) Germanica.' Zeitsch. f. w. Zool., Bd. Jiii., I89I. 
he found the gonads in the embryo of Pieris Brassice as red dots in the dorsal region of the eighth segment of the body right and left of the dorsal vessel. Brandt's description of these bodies in the embryo tallies with Herold's description of them in the caterpillar. Brandt adds, 'In this stage they' are elliptical bodies consisting of embryonic cells, with amoboid nuclei, and are either attached to their ducts by the side or the posterior end; in the former case they are testes, and in the latter, ovaries.'

Brandt gives figures representing the several stages of the development of the ovaries and testes from these bodies, which are quite convincing as to their origin.

Ganin [343] says the sexual organs, in Platygaster, first appear as two rounded cellular masses on each side of the primitive band close to the termination of the digestive tube; these two masses are united with each other, one elongates and becomes the duct, and the other becomes the gonad.

Weismann concluded that the rudiments of the gonads make their appearance in the embryo in Musca and Sarcophaga, but he was unsuccessful in discovering them before the larvæ had attained the length of a centimetre; he, however, saw and described them in the newly-hatched larva of Corethra, which, owing to its transparency, is a favourable object for the investigation.

I have sought for these bodies in both the embryo and larva of the Blow-fly, but have failed to find them either in the embryo or newly-hatched larva. The investigation is one of great difficulty, however, owing to their minute size and the fact that there is no means of recognising them and distinguishing them from other groups of embryonic cells.

In the larva of about one centimetre in length I have found in sections one or occasionally two pairs of encapsulated groups of small cmbryonic cells, situated in the fifth abdominal segment imbedded in the fat bodies on either side of, and dorsally to, the alimentary canal, which correspond in general characters and position to rudimentary gonads. The difficulty in my 
mind is to account for the occurrence of more than a single pair of these rudimentary organs. Ganin's observations on Platygaster, however, appear to be in favour of the existence of two pairs of such rudiments. These groups of cells resemble the imaginal discs, and are solid ovoid masses of small epithelioid cells measuring $2 \mathrm{~mm}$. in their long diameter. I have no absolute evidence as to their true nature.

The earliest stage in which I have been able to identify the gonads with certainty is the first day of the pupa state, when they are occasionally seen in sections as ovoid groups of small epithelial cells enclosed in a cellular mesoblastic capsule, which stains more readily than the cells enclosed within it. The long diameter of the capsule is $2 \mathrm{~mm}$.

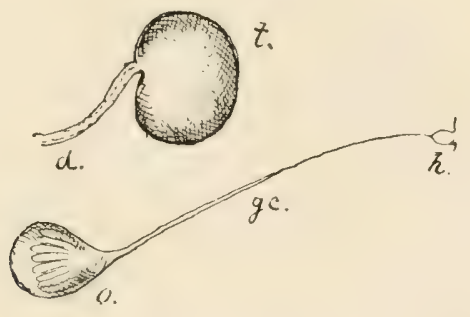

FIG. 98.-The ovary and testis on the third day of the pupa stage; from dissections. $t$, testis ; $d$, duct of the testis ; 0 , ovary ; $\delta c$, genital cord ; $h$, hypodermis. Seen with an inch objective.

On the third day of the pupa I have succeeded in dissecting out both the ovaries and testes, which are now very distinct, and in sections exhibit a marked differentiation of structure.

The Testis on the third day of the pupa is a glistening white reniform body $4 \mathrm{~mm}$. in diameter. The genital cord is attached to it laterally at the hilus; this is a slender cellular cord invested by a distinct peritoneal membrane which extends backwards towards the apex of the abdomen; it subsequently becomes the vas efferens. Its length is about I mm.; it unites with its fellow at an acute angle, and forms the rudiment of the vas deferens, which is attached to the hypodermis a little in front of the position of the future anus. 
The body of the testis is seen at this period, in sections, in the anterior part of the fifth abdominal segment. It consists of small closely-packed cells which have a radial arrangement, surrounded by a distinctly differentiated capsule of mesoblastic cells.

The Ovary is smaller than the testis on the third day; it is pyriform, and measures $2 \mathrm{~mm}$. in its long diameter. The genital cord is continuous with its posterior extremity or apex. The genital cord of the ovary is much more slender than that

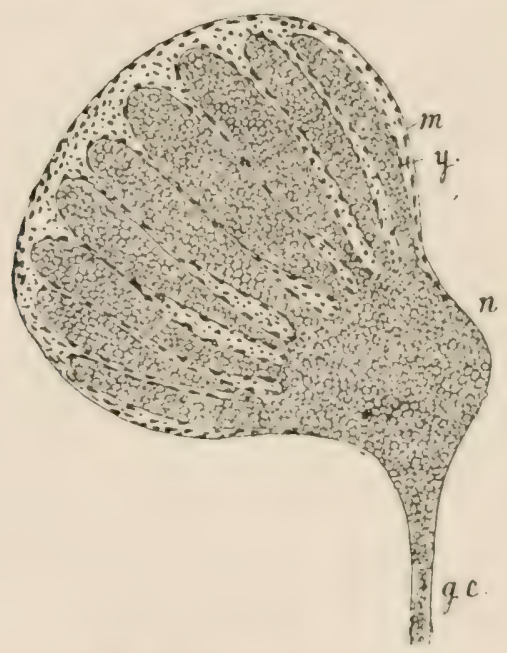

Fin. 99. - A section through the ovary and genital cord, from a pupa aluut three days old. $s c$, genital cord; $m$, mesoblastic stroma of the ovary ; $n$, neck of the ovary ; yryelk-stocks.

of the testis, it does not join its fellow, and has a length of about $2 . \mathrm{mm}$; it terminates by joining a minute vesicular invagination of the hypodermis on the ventral surface of the abdomen immediately in front of the position of the future anus. At this period the genital cord is a solid string of small cells similar to those which form the apex of the ovary, surrounded by a very thin, apparently structureless, sheath continuous with the peritoneal coat of the ovary.

In sections, the oviry is seen to consist of a solid ccllular 
neck, which is continuous with the genital cord, and with a number of diverging finger-like processes, the rudimentary egg-stocks, which radiate towards the convex surface of the ovary. These consist of cells precisely similar to those of the neck of the ovary. The egg-stocks are enclosed in a thick capsule of mesoblastic cells, which sends processes between them, separating them from each other. Like the capsule of the testis, this tissue stains much more deeply with hæmatoxylon than the epithelial elements (egg-stocks) which it surrounds.

The rudimentary gonads and the genital cords in both sexes are surrounded by, and attached to, the remains of the larval fat-bodies, and the mesublastic tissue of the ovary forms a

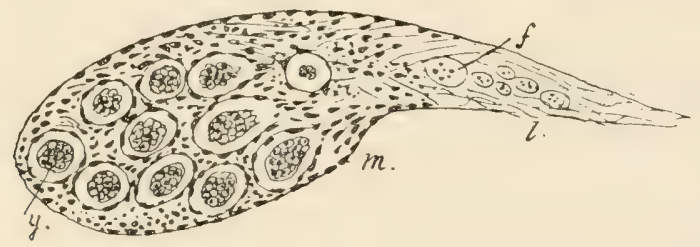

FIG. IOO.-A section through the ovary of a pupa about four days old. $f$, fat-cells ;

$l$, mesoblastic ligament continuous with the fat bodies; $m$, mesoblastic stroma; $y$, yelk-stocks.

kind of broad ligament connecting it with the hypodermis in the region from which the oviducts are formed (Fig. IOO). The above description of the gonads in the Blow-fly pupa agrees in all essential particulars with Brandt's description of the rudimentary gonads in the larva of Pieris Brassicæ.

\section{b. On the supposed Origin of the Rudimentary Gonads in the Embryo from the Polar Cells of Weismann.}

The investigations of Metschnikow [341] and Leuckart [342] on the development of the ovaries in the viviparous larvæ of Cecidomyia have led many authorities to regard the polar cells of Weismann as the origin of the gonads. According to the above-named observers, the four polar cells are formed by the proliferation of a single cell, which is separated from the 
blastoderm as the original polar cell. These four cells, which are at first outside the blastoderm at the posterior pole of the exro, pass in some unexplained manner into the yelk; here they are seen lying, two on either side, embedded in a mass of cells above the primitive band.

Metschnikow and Leuckart further believed that they traced the development of the ovaries to these cells. Their views were favourably received and strongly supported by Balbiani.

In I 882 the latter indicated, in a brief communication to the Academy of Sciences in Paris, that he had traced the development of the gonads in the sexual forms of Chironomus to the polar cells, and subsequently published his observations in cxtenso [347].

Balbiani believed that he had actually traced the passage of the polar cells through the blastoderm, but his observations appear to me to be very doubtful on this point. He says: 'At a certain moment the group of polar cells appear to be elevated above the posterior pole of the blastoderm and to penetrate the vitellus. First the posterior pole of the blastoderm appears slightly flattened, then it surrounds the polar globules as if to enclose them in a depression, afterwards this depression is elevated into the vitellus, and its summit is seen to be surmounted by the polar globules and to be surrounded by the yelk. The mass has therefore passed from the exterior into the interior of the blastoderm.' So far Balbiani seems to have observed a real phenomenon; it is only his subsequent remarks to which I take exception. He asks how this passage is effected, and admits that the actual observation of the manner in which it occurs is rendered very difficult by the superposition of the polar globules and cells of the blastoderm in many layers and by the opacity of the yelk; like all observations made on organs and structures $c n$ masse, it is impossible to be sure of the exact disposition of the cells. Balbiani sugresests two solutions -one is that the blastoderm (epiblast) is deficient in the recrion of the polar globules, and the other, which he apparently arlopts, is the actual passage of the polar cells between the epiblastic elements. Balbianis observations are in favour, I 
think, of the view I have already suggested-that the so-called polar globules are really the segmentation spheres of the vegetative pole of the egg. Their passage through the epiblast takes place, I conceive, by the blastopore; and I think it highly probable that some of these cells, or their descendants, are those from which the ovaries are developed.

The number of polar cells described by Balbiani is eight. Other observers have seen sixteen, and some say twelve. The first gonad cells are only two in number, or, at most, four. Balbiani believes that the eight or more polar cells unite by fusion, and give rise to the primitive pair of sexual cells; this appears to me highly improbable, and it is supported by no direct evidence. It appears, however, that to a certain extent Balbiani's statements are in consonance with my own observations: he saw the entrance of the polar cells into the yelk by the blastopore, and traced the development of the gonads to a single pair of cells from the group of cells which I regard as the primitive hypoblast ( $\mathrm{p} .247$ ).

Brandt does not endorse the view that the primitive gonads originate from the polar cells, and rightly remarks that the resemblance of the first sexual cells to the polar cells in some insects cannot be regarded as evidence of their identity, and, further, "that all embryonic cells are similar to the polar cells, as they have a similar origin.' And I agree that all the hypoblastic elements, which originate from the polar cells if my views are correct, are precisely similar in appearance. I think that the observations of Balbiani undoubtedly show that the gonads are developed from the tissue which originates from the polar cells; but I do not regard them, as he apparently does, as the polar cells. I think, however, they, as well as all the hypoblastic tissues, originate from the polar cells.

\section{c. The Development of the Testes and their Ducts, and of the Paragonia in the Pupa of the Blow-fly.}

After the third day of the pupa the rudimentary testis is no longer reniform, but becomes pear-shaped and the genital 
cord is seen as a prolongation of the narrow end; Brandt observed a similar change of form in the testis of the larva of Pieris Brassice. The principal changes it now undergoes are, the whole organ grows rapidly in size, and the genital cord becomes hollow and forms the vas efferens; which is seen at a very early period to consist of an external coat, similar to and continuous with the mesoblastic capsule of the testis; this becomes the peritoneal coat, and exhibits numerous closely adherent multi-nucleated cells-young fat-cells.

The capsule of the testis extends inwards in the form of fine septa of adenoid tissue, and divides the testis into numerous loculi. These septa in the Blow-fly are exceedingly thin and delicate; in Pieris, according to Brandt, the testis divides into three or four lobules by the ingrowth of the external capsule. The septa in Musca are the only indications of lobulation which occur in this insect. These loculi are all filled with small round cells which are at first similar to each other throughout the whole testis, but these do not long remain so; those nearest to the duct are rapidly converted into young spermatozoa, whilst those at the fundus remain unchanged, even after the insect escapes from the pupa.

The paragonia are apparently developed as diverticula from the point where the vasa efferentia unite. In the earliest stage of development there is apparently no trace of these organs, and they only subsequently make their appearance as short cecal diverticula of the vas deferens. In the pupa of the cirhth day the paragonia and vasa efferentia are each nearly' I mm. in length, and the vas deferens is only slightly longer.

\section{d. Spermatogenesis.}

The formation of the spermatozoa in the testis takes place in the pupa, and the male insect is sexually adult a few hours after leaving the pupa case. Owing to the fact that the cells in the testis do not undergo simultaneous changres all the stagres of spermatogenesis can usually he observed in male insects a few hours after their escape from the pupa, and the process 
can be investigated in a single section. Even as early as the eighth day of the pupa the posterior half of the testis-that nearest to the duct-is found full of half-formed bundles of spermatozoa; whilst the cells in its fundus remain unaltered. These unaltered cells, or mother-cells, I shall term spermatospores, using the nomenclature adopted by Gilson [357].

The Spermatospores apparently undergo many divisions, and originate from a few primordial cells. In young males, a few hours after their escape from the pupa, many of these spermatospores still remain near the fundus of the organ. They are precisely similar to the cells found in the young testis on the third day of the pupa stage.

The spermatospores average from $7 \mu$ to $\delta \mu$ in diameter, and have a granular appearance; they are polyhedral in form, and are arranged in groups. Each group is sometimes surrounded by a thin capsule, so that it appears as if the final stages of multiplication take place by endogenous cell division; i.e., a portion of the protoplasm of the mother-cell remains as a capsule, enclosing a number of daughter-cells.

Origin of the Primordial Sexual Cells.-All attempts to trace the origin of the first cells, from which the mother-cells are derived in the Muscidæ, have hitherto failed; but the earlier stages of spermatogenesis in the Blow-fly pupa and the immature imago are so precisely similar to those described by Hertwig [356] and Lee [358] in the Chætognatha, that it may probably be assumed they originate in a similar manner. According to Lee, Sagitta bipunctata offers exceptional facilities for the investigation of the origin of the primordial sexual

\section{Bibliography :}

355. Bütschl, O., 'Nïhere Mittheilungen über die Entwicklung und den Bau der Samenfäden der Insecten.' Zeitsch. f. w. Zool., Bd. xxi,, I87I.

356. Hertwig, O., 'Die Chætognathen.' Jena, i88o.

357. Gilson, G., 'Etude comparée de la Spermatogénèse chez les Arthropodes' (3me partie, conclusions). La Cellule, tom. iv. (I887), I889.

358. L.Ee, A. Bolles, 'La Spermatogénèse chez les Chétognathes.' La Celiule, tom. iv. (1887), I889. 
cells, owing to the great transparency of its embryos. Lee's observations conform with those of Hertwig, who says :

"When the cavity of the Gastrula (in Sagitta) begins to enlarge, two cells appear in the endoderm, which touch each other, and which are situated at the aboral pole of the blastoderm. These cells are conspicuous owing to their size, as they are much larger than the ordinary embryonic cells at this epoch; but what renders them still more remarkable is their large vesicular nuclei and numerous nucleoli. These are the primordial sexual cells.'

I have already referred to the observations of Balbiani, who considers that the sexual cells in the Muscida originate from the polar cells of Weismann; and if, as has been maintained here, these cells represent the primitive endoblast, derived from the complete segmentation of a germ yelk, the origin of the primitive sexual cells in the Muscide would correspond with that of the same cells in the Chretognatha. It must be remembered that there are no direct observations that can be considered quite convincing on the subject. I think, however, there is much evidence in favour of the view that the primitive sexual cells in Insects originate from the primitive endoderm of a segmenting morula, since, as has been already stated I regard the polar cells as part, at least, of the vegetative pole of this morula.

Polyblasts are large multinucleated cells, which are seen in groups lying next the spermatospores and their encapsulated daughter-cells. They are apparently formed by the rapid growth of the daughter-cells, accompanied by very active divisions of the nucleus. The polyblasts are from $15 \mu$ to $25 \mu$

\section{DESCRIITION OF P'LATE XI,VIII.}

Section of the te-tis of the mature male Blow-fly. A, a section of the testis and surrounding fat body, seen with a $f$ inch objective. $b$, a portion of a similar preparation, seen with a $y^{\frac{1}{2}}$ oil immersion objective. The fat-cells are not figured. C, immature spermatozon, seen with a it: immersion lens: a, cellular capsule of the le-tis; l, nucleated cell, prolsally trabecular tissue dividing the testis into loculi; c, capsule enclosing spermatic filaments; $m$, capsule of the testis; $t$, polyblast cells; $s, s$, spermatospores ; $s f$, spermatozoa. 

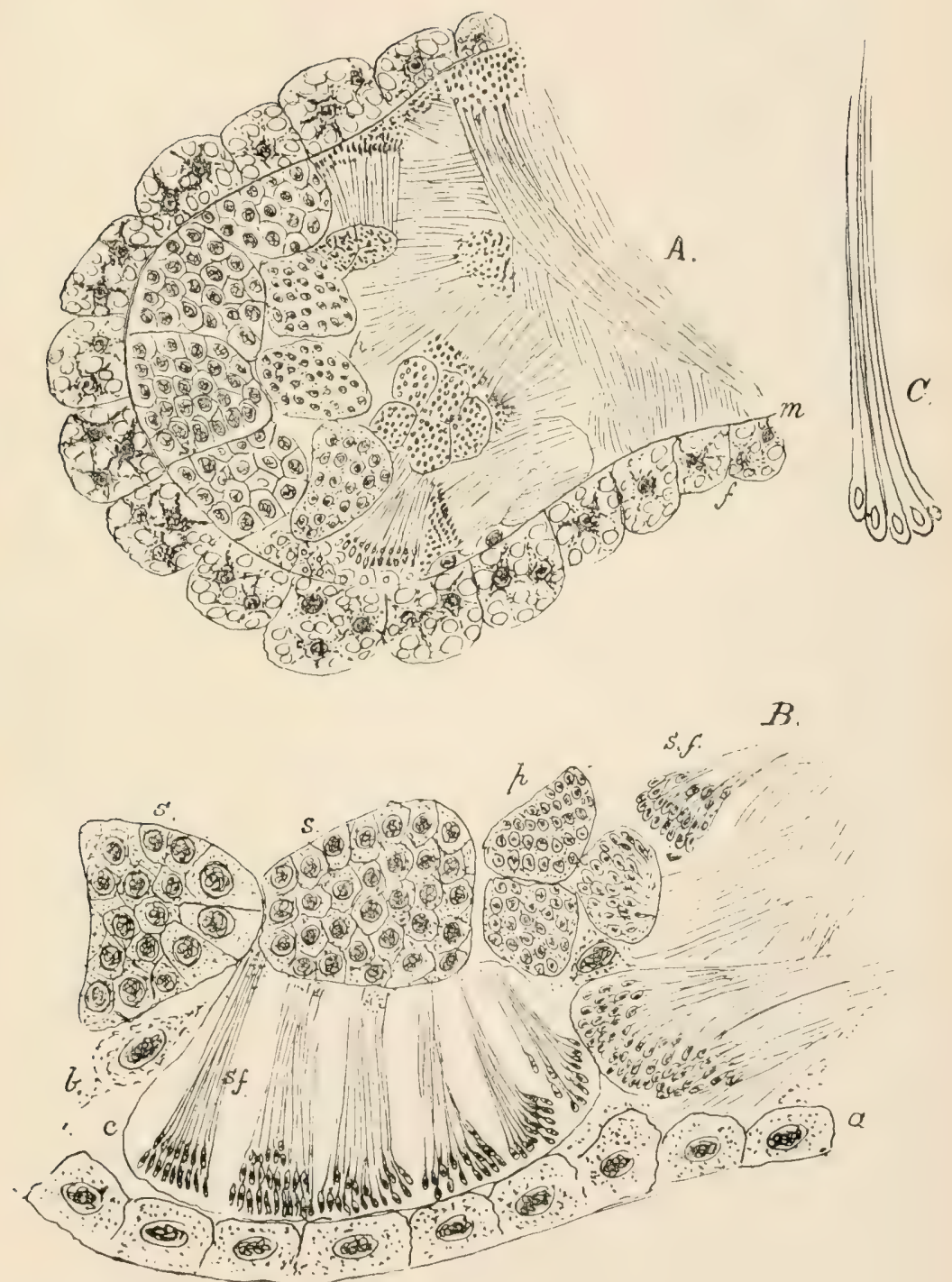

in diameter. Their nuclei vary in size from I $\mu$ to $2 \mu$ in diameter. They are arranged in rows very regularly, and the rows are frequently seen to radiate from the centres of the polyblasts. There is no indication of the division of the cell substance between these nuclei.

Lee has certainly observed the formation of the polyblasts by the repeated division of the nuclei of the spermatospores in Sagitta, and his figures leave no doubt upon the question in my mind, although he says in his text, 'I have been unable to follow the genesis of these polyblasts.'

From this stage onwards there is no conformity in my observations and those of Lee; this is undoubtedly due to the fact that the formation of the spermatozoa takes place somewhat differently in the Chætognatha and the Muscidæ.

The Spermatozoa are formed in packets, each packet corresponding to a polyblast. The polyblasts become pyriform, with the thick end towards the surface of the testicle, and all the nuclei are arranged near this thick convex end. The polyblasts then split up into a number of fusiform segments. These are the young spermatozoa; each at this stage exhibits a distinct vesicular nucleus.

All my best preparations are stained with picrocarmine and the nuclecli of the young spermatozoa are most definitely stained, whilst the cell substance is sufficiently coloured to render it very distinct. In such preparations there is no trace of a secondary nucleus (Nebenkern).

The succeeding stages are very simple: the nuclei cease to exhibit a distinct vesicular character, and their size is less than that of the nuclei in the young spermatozoa. The nuclear vesicle has evidently disappeared, leaving only a small ball of chromatin surrounded by a thin layer of protoplasm, which is continuous with the tail. The tails increase rapidly in length, so that they not only extend across the whole diameter of the testis, but are frequently curved; at the same time they acquire the property of staining deeply, and exhibit a distinct yellow tinge, owing to the action of the picric acid.

The size of the bundles of spermatozoa varies considerably, 
and some are seen to be surrounded by a distinct sheath, which occasionally exhibits a large nucleus. These sheaths are probably the remains of the daughter-cells, which have been only' partially converted into spermatozoa by endogenous cell formation.

These observations agree with those of Gilson [357], who holds that when the spermatozoa are seen enclosed in a capsule, this consists of the remains of a cell of a previous generation; he further regards each spermatozoon as a distinct differentiated cell, and says that in all other points variations exist in the manner in which spermatogenesis occurs in different animals. I would go even a step further, and think that not only do such variations occur in different animals and sroups of animals, but that the process of cell multiplication which precedes spermatogenesis varies under different conditions in the same animal. Thus, the size of the polyblasts in the Blow-fly varies within wide limits. In some cases they are comparatively small and contain few nuclei when the formation of spermatozoa commences; whilst others are very large, and contain numerous nuclei. Again, some of the spermatospores remain enclosed in a distinct nucleated envelope, and others are separated by the exogenous division of the mother-cells. It appears to me that exogenous and endogenous cell multiplication occur in all stages of the process. Sometimes a spermatospore continues to multiply by exosrenous division for a long time; whilst in a sister-cell endorenous multiplication takes place without previous exoyenous division. In the former case small, and in the latter large polyblasts arise; small bundles of spermatozoa originate in the small polyblasts, whilst large ones are formed in the large polyhlasts. Some of these remain enclosed within the mothercells, whilst others are apparently free and unenclosed.

There is no doubt active karyokinetic changes occur throughout the whole process, but I have not attempted the sturly of the nuclear figures, as I feel that the complexity of the phenomena hitherto described, and the yreat discrepancies which exist in the statements of various observers, are such 
that it would require many years devoted to the special investigation of the subject and much preliminary work before any observations of value could be expected.

The accessory nucleus (Nebenkern) in the developing spermatozoa, which has been observed so frequently by various observers, is not visible in any of my preparations, but it apparently needs special methods for its demonstration; and whether it has any real existence, or is merely the result of the methods employed, remains doubtful. Oscar Hertwig, in his recent researches, has not confirmed its existence in the sense of Lee's statements, although inert nuclei are observed and have been regarded by him as similar to the polar globules discharged from the ova.

The whole of this intricate subject must be considered at present as unsettled, and will probably require many years before any final settlement is arrived at.

The Mature Spermatozoa consist of extremely fine filaments, measuring nearly $25 \mathrm{~mm}$. in length, with a thick elongated neck about $20 \mu$ in length, which contains a bright, highlyrefracting nuclear particle, the head $2 \mu$ in diameter. Such spermatozoa are found enclosed within the spermatic capsules of the impregnated female.

The spermatozoa removed from the testis of the male do not exhibit active movements, and the long filament is often detached from the head and neck. The detached head and neck assumes the form of a spherical corpuscle. I formerly [IS69] dissected a female fly, which had been some hours in spirit, in which I found the oviduct full of active vibrating spermatozoa. I supposed the insect had been captured immediately after union with a male, and that the spirit had not permeated it [62], but I have never seen anything similar since, nor am I sure that the insect in which I observed this phenomenon was Calliphora erythrocephala, as at that early period of my work I frequently used Tachinæ for my observations. I have no doubt, however, that the spermatozoids of the Blow-fly are active when they are discharged from the spermathecæ at the moment of the fertilisation of the ova. 
Whether they are active when first discharged from the male I do not know. I formerly supposed this to be the case, and that they find their way into the spermatic capsules by their vibratile movements. I now think this extremely improbable.

The spermatozoa removed from the testis often exhibit a transparent disc-like organ at one extremity of the filament. I formerly mistook this for the head and neck of the spermatozoon; it is usually regarded as the coiled extremity of the filament. I am doubtful as to its true nature, and am rather inclined to consider it as the result of a post-mortem change produced by the imbibition of fluid, causing the neck to become swollen into a thin-walled, flattened vesicle; it certainly resembles the stroma of a human red blood corpuscle after the discharge of its colouring matter, by the addition of water to the blood.

The examination of the spermatozoa of this insect is attended with technical difficulties, as it is exceedingly difficult to obtain any of the sperm in an uncoagulated condition; I had intended to pay some attention to this subject last summer, but as my time was fully occupied in other investigations I did not do so, and I am therefore unable to give a more precise description of the spermatozoa.

\section{e. The Development of the Ovaries and 0va in the Pupa and Young Imago.}

The development of the ovaries progresses very slowly in the pupa stage. The pyriform ovary gradually becomes a disc

\section{DESCRIPTION OF P'LATE NI.I.}

The development of the ovaries and ova of the Blow-tly.

Fui. 1.-A section of the ovary of a Blow-fly pupa on the eighth day of the pupa stage, seen with a $f$ inch objective. $c$, epithelial cells developed from the neck of the ovary; $m$, mesoblastic stroma ; $p y$, pseudo yelk; $s$, cavity of the ovary; t, tubules; $y$ ', yelk-stocks.

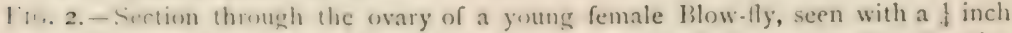
olijective. ,h, chorion of young ens : $c$, young uva (yelks); m, mesoblastic cells : $o f$, ovarian follicles; $o t$, ovarian tubules; $f$, peritoneal coat of the ovary; $s t$, egg-stalk; $t$, terminal chaml:er ; $t r$, tracheal vessels. 


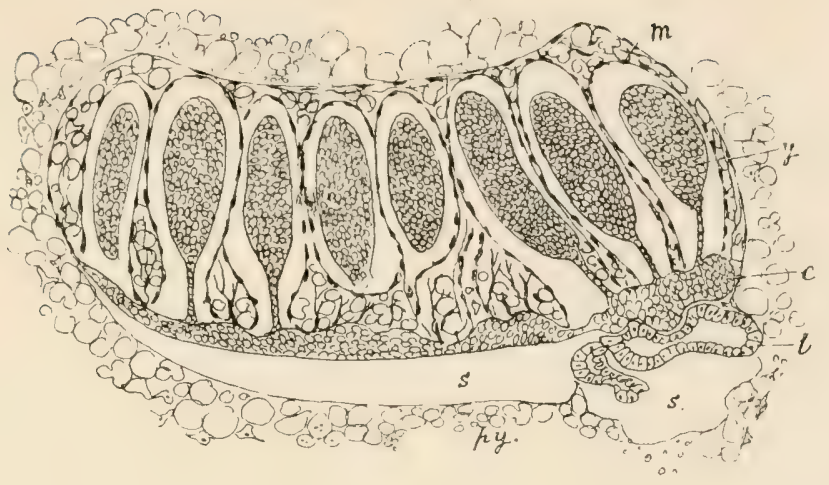

FIG. I.

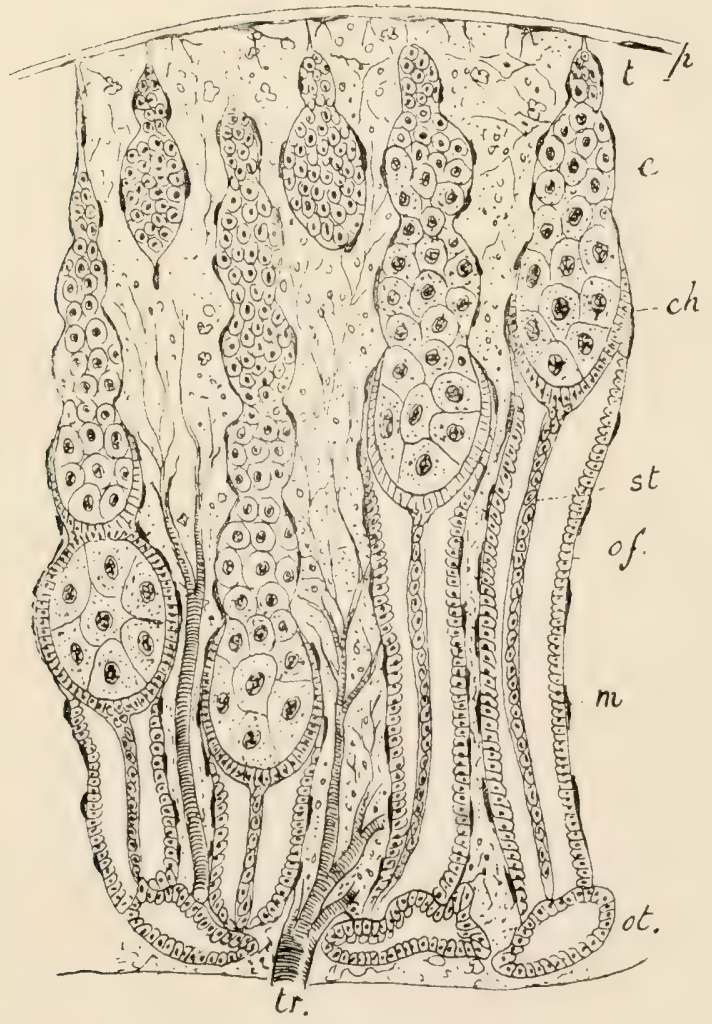

FIT. 2. 

- $2 \mathrm{~mm}$. in thickness, and towards the end of the pupa state this disc becomes convex on its posterior, and concave on its anterior, surface. Even then it scarcely measures $9 \mathrm{~mm}$. in diameter.

The convex surface of the disc corresponds with the apex of the pyriform ovary, and the epithelial elements of the neck become spread out into a thin layer several cells thick, over the whole surface of the ovary. Towards the middle of the pupa stage the capsule of the ovary apparently becomes separated from this surface layer, so that a cavity is formed between the epithelium and the capsule; this I term the ovarian cavity.

The egg-stocks, which in the early stages are finger-like processes extending from the epithelial layer into the body of the ovary (Fig. 99), become converted into flask-shaped bodies, each connected with the epithelial layer by a long stalk, the egg-stalks. By the middle of the pupa stage these stalks are about ${ }^{\circ} 03$ mm. long (Pl. XLIX., Fig. I), and consist of a single row of small cells. The cells of the egg-stocks are precisely similar and are about $5 \mu$ in diameter. There is no differentiation of epithelial and yelk-cells, all the cells are precisely alike. A little later each egg-stock and its stalk is invested in a fine structureless cuticular membrane, the membrana propria of the future egg-tube. This membrane is very generally wrinkled transversely over the egg-stalk, which gives it a striated appearance. This probably led Schneider [331] to regard the eggstalks as striated muscle fibres. Towards the end of the pupa stage and in the mature nymph many of the egg-stocks exhibit nipple-like processes at their anterior ends; these are the rudiments of the terminal chambers.

The Ovarian Follicles.-During the changes above described the septal mesoblastic tissue of the ovary becomes converted into a series of follicles, one enclosing each egg-stock. These follicles invest the egg-stocks loosely, and are separated from each other by spaces, blood sinuses, which contain an abundance of pseudo-yelk, and the retiform tissue from which the tracheæ of the ovary are developed. 
In the latest stages of the pupa numerous larese tracheal vessels are seen covering the convex surface of the ovary and extending through the ovarian cavity into the spaces between the ovarian follicles.

Some of my sections from pupe about the eighth day (Pl. XLIX., Fig. I) exhibit the section of one or more convoluted epithelial tubes lying in the ovarian cavity at the inner limit of this cavity. I believe that these are sections of the cæcal end of the parovarium.

In the investigation of the further changes which occur in the ovary it is necessary to have recourse to flies which have been on the wing for some time, and therefore the age of these insects is unknown. Development of the ovary progresses very slowly in these insects when bred and liept in captivity.

As such insects never unite with the males, there is no certainty that development progresses in the same manner as in impregnated females, and, so far as my experience goes, the ovaries of captive insects are always arrested, and no mature egg-tubes are ever formed.

In the stage represented in PI. XLIX., Fig. 2, the egg-stocks are divided by superficial constrictions into several segments, usually five or six. The stalk is greatiy increased in length; in some cases it measures as much as ${ }^{2} 5 \mathrm{~mm}$. in length. The anterior extremities of the egg-stocks are closely surrounded by ovarian stroma, whilst the posterior end and the exg-stalk lie in a well developed ovarian follicle. The ovarian follicles are now lined by a well-marked epithelial layer, apparently derived from the epithelial tissue which covers the convex surface of the ovary.

At this period the oviducts spread over the inner margin of the convex surface of the ovary, and are seen in section as a cavity behind the ovary. There is no evidence that the follicles open into this cavity, but at a somewhat later period the contimuity between these and the cavity of the oviduct becomes established by the shedding of the epithelial layer of the follicles. In the adult ovaries I have found no traces of the follicular eprithelium. The lind end of the tuba of the oviduct appears 
to occupy the space which, in the earlier period of development, is formed between the ovarian capsule and the epithelial layer, from which the egg-stocks spring.

Development of the 0va.-The lowest rudimentary ovum in the egg-stocks is seen to be in different stages of development in the different egg-stocks. The chorion of the young eggs is a cellular layer derived apparently from the upward growth of the egg-stalk. In some of the ova it is seen as a cup partially enclosing a number of small yelk-cells. These cells are about $7 \mu$ in diameter. This chorionic cup ultimately encloses from ten to twelve yelk-cells, and then begins to form a second cup around a second group of similar cells.

The young yelk-cells enclosed in the chorion measure about Io $\mu$ in diameter, and become polyhedral by mutual pressure. These cells then grow rapidly; one of them, that nearest to the egg-stalk, however, soon becomes far larger than the others. There is at first no difference in the nuclei of these cells, and in the later stages of development the only difference which can be observed in the yelk-cells is a difference of size.

Panöistic and Meröistic 0va.-The ova of insects generally exhibit two distinct types, which have been described as Panöistic and Meröistic ova. In some Insects, as in the Orthoptera, the vitellus consists from the first of only a single yelk-cell, enclosed in an epithelial chorion; in the second form several cells are enclosed within the chorion as in the Blow-fly. This condition is common to all the Diptera, and is very general in the Insecta.

The Egg-cell.-Brandt termed the larger basal cell of the Meroistic ovum the egg-cell, and the remainder of the cells nutrient cells. In the Blow-fly at least the cells are all at first precisely similar, except that one appears to possess a greater power of growth than the others; but, as will be seen hereafter, all these cells undergo a precisely similar series of changes, and are ultimately broken down and form the granular yelk already described (p. 683).

The part played by the so-called nutrient cells is a subject on which there is a great divergence of opinion. Brandt's view, 
which has been very generally adopted in text-books and widely accepted, is that the egg-cell only is enclosed in the chorion, and that the nutrient cells remain outside the primitive chorion in contact with the micropyle, and ultimately disappear or are absorbed in the nutrition of the egg-cell.

This view is very tempting on theoretical grounds; and if it were true many difficulties in the interpretation of the nature of the Merüistic ova of Insects would disappear. The Merüistic and Panöistic ova would then only differ in the manner in which the egr-cell is nourished, and the yelks would represent single cells, the nuclei of which might be regarded as germinal vesicles.

A careful examination of the ova in all stages of development has, however, convinced me that there are no grounds in the IBlow-fly at least for Brandt's view. Weismann [2] states distinctly that the nutrient cells are enclosed within the chorion with the egg-cell, and that they all take part in the formation of the yelk by fusing into a single mass.

It is a fact of great significance in this relation that the nutrient cells do not shrivel and disappear, but they increase in size like the egrg-cell, only more slowly, and they continue to increase in size after the egg-cell is entirely converted into yelk and in turn become converted into yelk themselves.

Numerous drawings have been published, notably by liorschelt [349, Fig. 49], and Henking [350], in which the chorion is represented between a group of cells and the mature, or nearly mature, ovum. These puzzled me for a long time, until I discovered a similar appearance in one of $\mathrm{my}$ own sections. Since then I have several times seen the same thing, and it is clearly due to the displacement of an immature ovum, which, leing soft, has formed a kind of cap over the anterior end of a mature ovum behind it.

The so-called alternating yelk bodies and germ ova, which are seen so frequently in the ovarian tubules of many insects in which numerous ova are developed in each tubule, are more difficult to explain; but it appears to me probable that in such cases several series of ova are developing at the same time; and that the group of cells described as intervening between 
the more fully-formed ova may probably be destined in turn to be enclosed in a chorion, and to form an intervening ovum.

It has also occurred to me that in many of the drawings this appearance is due to the section having been tangental to the egg-tube, so that a portion of the yelk mass appears outside the chorion. Many of Brandt's drawings indicate that this may be the case. I am inclined to think that it is more probable that some such explanation may account for the appearances, than that there is such a wide difference in the manner in which the Meröistic ova are developed in different Insects, since there is certainly no question as to the multicellular origin of the ova in the Blow-fly.

\section{f. The Development of the Utero-Vaginal Tube and its Appendages, and of the 0viducts and Parovaria.}

It is now well established that the utero-vaginal tube and its appendages, the receptacula seminis, are developed in Insects from the hypodermis independently of the genital cord; but the oviducts and their tubæ are believed to be developed from the genital cords, and to correspond, therefore, with the vasa efferentia and vas deferens of the male.

Witlaczil [102] stated in general terms that the secondary ducts, my utero-vaginal tube, ejaculatory duct and sac originate in Aphides as involutions of the hypodermis; and Mayer [312], Bessels [324], and Ludwig [345], believed that the oviducts are developed independently of the ovaries. In I877 Huxley wrote :

'Nothing is certainly known respecting the origin of the vagina and oviducts, though it may be suspected that the posterior prolongations of the ovaries give rise to the latter. "*

The first precise observations on the development of the secondary sexual ducts are due to Nussbaum. His paper is, unfortunately, in Polish; but his conclusions, as given by himself [346], are to the following effect :

(I) The current impression that the primitive ducts (sexual * 'Anat. of Invertehrated Animals,' Lond., I877, p. 444. 
cords) unite and give origin to the whole system of sexual ducts is incorrect: they only form the vasa deferentia (my vasa efferentia) or the oviducts.

(2) All the other parts of the efferent canal are developed from the hypodermis.

(3) The connective tissue and muscaluture are derived from the mesoblast.

(4) The efferent ducts originate as paired rudiments; all the azygos parts of the efferent apparatus are at first paired. The azygos efferent apparatus of Insects must, therefore, be regarded as morphologically a secondary and more complicated form.

(5) The male and female efferent ducts are strictly homologous.

(6) The cavitics of the oviducts arise independently, and come into relation secondarily with the primitive ducts of the gonads, which are developed from the solid genital cord.

Hatchett Jackson [351], in an important memoir on the development of the oviducts and accessory sexual apparatus in Vanessa Io, has shown conclusively, I think, that the bursa, vagina and azygos oviduct of this insect are developed from the hypodermis, which are at first paired pouches, imaginal discs. These pouches unite and form an open groove on the ventral surface of the pupa from which the bursa and azygos oviduct are subsequently developed. The author has not apparently investigated the manner in which the paired oviducts arise, but assumes that they are formed from the genital cords.

The Genital Cord in the Blow-fly undoubtedly becomes converted into a hollow epithelial tube surrounded by a peritoneal investment of extreme tenuity at a very early period in the development of the pupa. On the sixth or seventh day of the pupal stage, I have succeeded in dissecting out the whole of the genital ducts and ovaries. A drawing of the preparations is given in lig. IoI. It will be seen that the genital cords have indubitably become the tubular parovaria. The anterior ends of these organs are closed, and are imbedded in the 
substance of the ovaria excentrically on their convex surfaces near their inner margins. This is more readily observed at a later stage, as in the earlier stages the ovaries are so friable that only portions of the egg-tubes were seen adherent to the extremity of the parovarium.

The Parovaria are in a very advanced stage of development on the seventh day in the pupa. They exhibit two distinct parts : a duct lined with small columnar cells, about $5 \mathrm{~mm}$. in length, and a glandular portion $\mathrm{I}^{\circ} 5 \mathrm{~mm}$. in length, widest towards its cæcal end, where it is about ' $I \mathrm{~mm}$. in diameter.

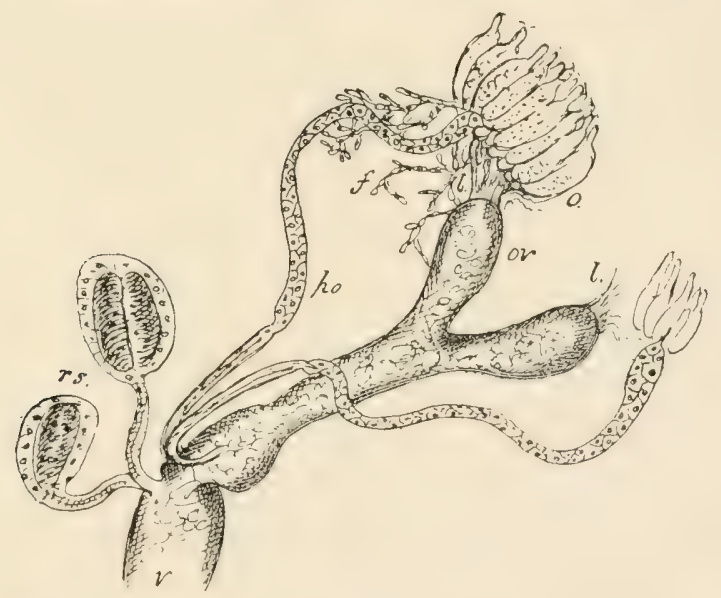

FIG. Ior.-The oviducts and parovaria on the sixth or seventh day of the pupa. $f$, fat bodies; $l, l$, ovarian ligaments; $o$, ovary; ov, oviduct; po, parovaria; $r s$, receptacula seminis ; $v$, vagina.

This portion of the tube is beautifully transparent, and is lined with large glandular epithelial cells, with distinct nuclei, similar to those of the fully-developed parovarium.

The Utero-Vaginal Tube and Oviduct is a pouch of the hypodermis, and the oviduct exhibits two blind tubæ which are connected with the ovary by delicate bands of peritoneal tissue. In some earlier stages which I have seen (Fig. IO2), the tubæ are undeveloped and the oviduct is a mere pouch at the anterior end of the bursa into which the ducts of the parovaria open. 
At a still later period, when the nymph is covered with black hairs and is nearly mature, the paired oviducts, tubr, still end in cercal ends, and are seen to be connected with the ovarian capsule by broad ligamentous bands. The termination of the parovarium in the substance of the ovary is also well seen in this stage of development.

These observations lead me to the following conclusions:

I. The paired oviducts are not developed from the genital cords, but, like the azygos oviduct, originate from the hypodermis.

2. The paired oviducts are not homologous with the duct of the testis in the male, but, like the Müllerian ducts of the Vertebrate, originate from distinct embryonic structures.

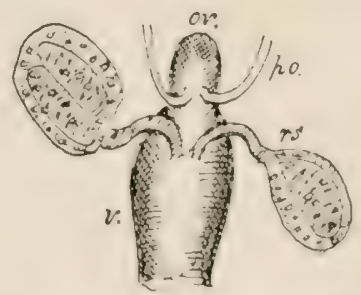

Fis. 102.-The utero-vaginal tube ancl oviduct on the fifth day of the pupa stage. $o v$, rudimentary oviduct; $p o$, ducts of the parovaria ; $r s$, receptacula seminis; v, vagina.

3. The parovaria correspond with the vasa efferentia and vas deferens, and are part of the primitive gonad.

The investigation of the condition of the gonads and their ducts in Hermaphrodite Insects is of great importance in relation to these views. Unfortunately the information on this subject which we possess is too small to allow any definite conclusions to be drawn from the phenomena of hermaphrodism. The rarity of such forms is well known, and those who possess them seldom allow a specimen to be dissected. With the exception of Tetens [334], I know no author who has described the internal organs of hermaphrodites in detail, and, unfortunately, the dissections made by him throw no light on the relations of the vasa efferentia and the oviducts. 
Nassonow [348], from an examination of the rudimentary testes in Lepisma saccharina, concluded that the ducts closely resemble segmental tubes. The great similarity of the rudiments of the sexual glands of insects with the rudimentary nephridia of Vertebrates, the manner in which the tissue forming the neck of the ovary becomes converted into irregular tubules and the origin of the egg-stocks, lend, I think, additional probability to this view.

\section{g. On the Nature of Ova and the Relations of the Germ to the Vitellus.}

General Observations on the Nature of the 0vum.-The ovum of almost every animal, from the highest to the lowest, is known to consist, in its earliest stage of development, of a single cell; this cell, the primordial ovum, exhibits a distinct nucleus, which subsequently becomes vesicular.

The large vesicular nucleus of the ovum was termed by its discoverer, Purkinje, the germinal vesicle. In young ova it is always present, and has a very characteristic appearance. It consists of a transparent nucleus, usually from $6 \mu$ to Io $\mu$ in diameter, and contains a single highly refractive nucleolus, the germinal spot (macula geminativa, Wagner). In older ova it enlarges rapidly, and is seen to consist of a nuclear membrane enclosing a clear material or matrix, embedded within which are strands of nucleoplasm, enclosing one or more well-marked nucleoli. Frequently there is but one nucleolus, the germinal spot.

In its simplest form the ovum retains its original condition, and consists of a cell, with or without a special envelope. The cell substance is a slightly granular protoplasm, enclosing the germinal vesicle, and is termed the germ yelk; after the impregnation of the ovum it undergoes cleavage throughout, the nucleus dividing previously to the cell, so that the entire ovum divides successively into $2,4,8,16,32$, and 64 , or more cells, from which the embryo is developed. Such ova are termed holoblastic. 
Very generally, however, a certain amount of food material, deuteroplasm or food yelk, is seen embedded in the cell substance, usually leaving the original protoplasm clear in the vicinity of the germinal vesicle. When this food substance is abundant, as in Birds, Reptiles, and some Fishes, the ova attain enormous dimensions. The food yelk then serves as a store of food material for the development of the young. This accumulated food material apparently interferes with the process of segmentation, which in extreme cases is confined to the clear protoplasm in the vicinity of the nucleus. Such ova are said to be meroblastic.

The secondary or food yelk is admitted to result from the activity of the cells which surround the orum; but opinions differ as to whether it is transferred from the nutrient cells to the egg-cells, or whether the former are broken up into the yelk which surrounds the latter. The first of these alternatives is more usually accepted in the case of oviparous Vertebrates.

In certain Worms, however, it is indubitable that the yelk has a separate origin, and at a later period the germ yelk is imbedded within the food yelk.

Amongst the Platyhelminthes, Cestodes, Trematodes, and most Turbellaria, the secondary yelk and the germ ova are developed in distinct organs, termed yelk-glands and germglands. In these animals the two elements are united in the uterus or oviduct, and there receive a common investment.

The 0va of the Insecta. - The great yelks developed in the ovary are admitted to be composed, for the most part at least, of foed or secondary yelk; and a vast number of investigators have sought to demonstrate a germ yelk or grerminal vesicle in these eggs.

In the case of the Panioistic ova it is easy to suppose that the large nucleus of the yelk-cell is a germinal vesicle, and, although it differs entirely in appearance from the germinal vesicle of any other group of animals, many have been satisfied that it is the germinal vesicle which afterwards becomes surrounded by an abundant secondary yelk. 
In the case, however, of the Meröistic egg, where a number of cells unite to form the yelk, such an explanation of the nucleus is inadmissible. Most observers have solved the difficulty, however, by regarding one of the cells as a germcell and the remaining cells as yelk-cells.

If such were the case, it is evident that some difference would be expected to exist between these cells, even from their earliest origin.

Claus [340] thought he recognised a difference in the nuclei of cells of the young Meröistic ova; he says: "The questions, the answers to which are of the highest importance, are--whence is the germinal vesicle derived? and what are its relations to the great yelk-cells?' He answers these questions as follows: 'I believe my own observations enable me to prove that the epithelial cells, the yelk-forming cells, and the germcells are modifications of identical elements.' Which merely means that he found all the cells contained in the youngest parts of the ovarian tubes precisely alike-a conclusion already arrived at by numerous observers. Yet Claus believes that in partially formed ova he could distinguish the egg-cell from the rest 'by the smaller size and clearer contents of the nucleus.'

Mayer [312] thought that each egg contains several germinal vesicles, each making an attempt as it were to form an egg, the lowest only succeeding, and all the others perishing.

I have examined hundreds of young insect ova to see if there is any difference in the nuclei, and I have entirely failed to find any. Sometimes one, sometimes several, are a little clearer than the rest, but there is no constant difference whatever.

The terminal chamber of the egg-tubes is usually regarded as a germogen, in which germ ova are developed. Stein [319] appears to have been the first who distinguished the germinal chamber from the rest of the egg-tube and termed it the germ chamber (Keimfach). He regarded the cells in it as free from yelk; but no one has explained the origin of the yelkcells, nor the manner in which the germ-cells of the terminal 
chamber could enter into the formation of the eggs, so that, although authors still speak of the terminal chamber as the germ chamber, it is evident that, as Lubbock maintained, these cells become yelk-cells if the ova in the terminal portion of the oviduct ever become mature.

Balfour [43], the most learned embryologist of his day, in ISSI wrote: "The following points need elucidation with regard to the ova of Insects:

'(I) The relation of the germogen to the vitellogen, and (2) the relation of the yelk to the germ.' It is evident, therefore, that he was dissatisfied with the explanation given in the voluminous literature of the subject, and regarded the questions at issue as unsettled, and I am not aware of any investigations which have been made since then, with the exception of my own, which tend to throw any further light on the subject.

The remarkable corpuscles first found imbedded in the epithelium of the parovaria by myself, in IS8S, are so strikingly like the germ ova of other animals that I have no hesitation in regarding it as the germ-gland, just as I have no hesitation in regarding the great ovaries as yelk-glands.

The question as to how these germ ova reach the yelk and enter the egg is a subsidiary one, but one which it is not difficult to answer, although it is by no means easy to find direct proof of the truth of the answer.

As the eggs pass down the oviduct, each remains for a brief space in the sacculus, with its micropyle closely related to the orifices of the ducts of the parovaria. It is therefore quite possible for a germ ovum to enter it by the micropyle. The egrg next passes into the uterus, and rests with its micropyle in immediate relation with the ducts of the spermathece, from which no one doubts the sperm-cells enter the egrg.

It may be objected by some that developing ova are frequently. found in the oviducts; but it must be remembered that such cegrs must have been impregnated, and therefore have evidently been in the uterus, hence they must have passed the orifices of the ducts of the parovaria in their descent; and the fact that 
they are found in the oviduct shows that they have been passed back into the oviduct, instead of having been deposited. It may also be objected that the development of my germ ova within the epithelial cells of the parovarium is not consistent with the view that they are really germ ova. Brandt [330, Fig. I28], however, gives a remarkable figure of the young ovary of the Amphibian Pelobates fuscus, which presents the same appearance as a section of the parovarium of the Blow-fly. He says it is a tolerably thin section of the ovary, and that ' it consists of an oval ring, smooth externally, bounded by a flattened epithelium, which is tuberculated internally by the projecting ova.' In the figure there is no question as to the position of the ova; they are clearly represented in the interior of the epithelial cells.

In concluding this section I would again draw attention to the fact that the original structure of the genital cord and the ovary are identical, so that the parovarium is merely a differentiated portion of the ovary, one portion of which becomes a vitellogenous gland and the other a germ-gland.

\section{h. On the Changes which occur in the Germinal Vesicle and Free Nuclear Formation.}

It was formerly believed that the germinal vesicle disappears either before or immediately after fertilisation. Milne Edwards [361], expressing the opinion of the majority of his contemporaries, said: "The disappearance of the germinal vesical is a consequence of its natural death,' and Leuckart** expressed the same idea in different words; he regarded the germinal vesicle as 'Concerned in the elaboration of the ovum, but not in the development of the embryo.'

Johannes Müller [359], in I852, declared that the germinal vesicle does not disappear in the egg of Entoconcha mirabilis, but that it divides and produces the first pair of segmentation

* R. Wagner's 'Handwörterbuch der Physiologie,' art. 'Zeugung,' by Leuckart. 
nuclei, and Leydig [344], from observations made on numerous Rotifers, arrived at a similar conclusion.

Leuckart, in his memoir on the Pupiparæ [20], said, "We have learned, by a series of observations, that the segmentation nuclei are no new formation, but the descendants of the primitive germinal vesicle. Such observations lead to the belief that there is a specific connection between the first bright spots in the surface layers of the yelk in Melophagus, and the germinal vesicle, yet I am unable to substantiate this opinion by my own observations.'

Weismann, in I 863 [2] said: 'A germinal vesicle is no longer present as a rule in the freshly-laid egg of the Blow-fly. I have often directed my observations to this and have come to the above conclusion, although in two cases I found a great spherical vesicle in the yelk $88 \mu$ in diameter, surrounded by

\section{Bibliography :}

359. MIÜ1.LER, Johannes, 'Ueber Synapta digitata und über die Erzeugung von Schnecken in Holothurien.' Berlin, I852.

360. Robin, C., 'Sur la P'roduction du Blastoderm chez les Articulés.' Journ. de l. Physiologie, tom. v., I862.

361. Minda-Enwards, H., 'Leçons sur la Physiologie et l'Anatomie comparée de l'Homme et des Animaux.' Svo, Paris, tom. viii., I863-65.

362. STR ICK LR, S., 'The General Characters of Cells': 'Manual of Human and Comparative Histology.' 'Translated by H. Power. New Sydenham Soc, Lond., Svo, vol. i., 1870.

363. Stuhlmand, F., 'I Die Reifung des Arthropodeneies, nach Beobachtung an Insecten, Spinnen, Myriopoden und Peripatus.' Berichte der Naturf. Gesellsch. zu Freiburg, Bd. i., 1886.

364. Bu.ochmann, F., 'Ueber die Eireifungr der Insecten.' Biol. Centralblatt, Bd. vi., I 886.

365. Brocmans, F., "Ueber die Reifung der Eier bei Ameisen und Wespen.' Festschrift. d. n. Med. Ver. zum 500 Jährigen Jubiliium der Ruperto Carola. Heidelburg, 1886, pp. 143-172.

366. Fumminc, W., 'Neue Beitrige zur Kenntniss der Zelle.' Archis. f. mikroskop. Anat., Bd, xxix., 1887.

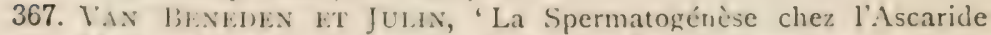
Megalocéphale.' Bull. d. l'Acad. royale de lielgique, jme ser., lxiv., 1887.

368. II .KTW1;, O., 'Vermleich der Ii und Samenbildung bei Nematoden.' Archiv. f. m. Anat., 13d. xxxvi., 1890.

The author gives a full bibliography of recent works on this intricate subject. 
a distinct membrane.' This phenomenon was regarded by Veismann as exceptional, and probably due to the accidental non-fertilization of the eggs.

Metschnikow [341] says that he failed to discover a germinal vesicle in Insects' eggs, and Ganin [343] states that in all the Ichneumonidæ which he examined the germinal vesicle disappears at a very early period of egg-formation, before the mother organism escapes from the pupa.

Stuhlmann [363], like Brandt, believes that the ovarian egg in the Blow-fly is developed from a single cell, and that the so-called nutrient cells undergo atrophy and remain outside the chorion. He regards the nucleus of this cell as the germinal vesicle, and says, 'I have been enabled, by a large number of observations on Insects' eggs, to establish the extrusion of nuclear particles from the germinal vesicle, which are afterwards lost in the egg-plasma. Later the germinal vesicle disappears, until at last we find it again at the upper egg-pole as a segmentation nucleus.' The 'outstreaming of nuclear particles,' described by Stuhlmann, is quite unlike the extrusion of the polar globules in other ova. It undoubtedly occurs from all the nuclei of the yelk-cells and also from those of the various larval organs during their degeneration in the pupa. It is a phenomenon characteristic of the histolysis of the tissues and the breaking up of the nuclei of effete cells.

Lastly, the identity of the first segmentation nucleus with the nucleus of the egg-cell is assumed by Stuhlmann, and not proved, as the disappearance of one structure and the subsequent appearance of another cannot establish a genetic connection between them.

Henking [350], like his predecessors, has attempted the identification of a germinal vesicle in the egg of the Blow-fly. He says, "The unripe egg contains a germinal vesicle and germinal spot. The former is clear and does not stain deeply with borax carmine.' In some of my sections I have found one or even two yelk nuclei, which resemble Henking's germinal vesicle, but the same nuclei in the next section in the series exhibit characters which are indistinguishable from those of 
the other yelk-cells. Henking further claims to have discovered the rudiment of a germinal vesicle in ripe eggs and to have traced the first segmentation spindles. As the latter could only occur after impregnation, the important question in relation to the views I have expressed is, whether a germinal vesicle really exists in the unripe ovarian eggs, and on this point Henking's results appear to me to be no more satisfactory than those of his predecessors. I cannot admit that there is any evidence that his germinal vesicle differs from the nuclei of the other yelk-cells.

The changes which occur in the germinal vesicle previously to fertilisation are now very well known in many Invertebrates, Echinoderms, Ascaris, etc., and have also been observed in some Vertebrates, as in the Rabbit, so that there is no doubt these phenomena are of very general and probably universal occurrence.

Either before, or immediately after, the ovum is discharged from the ovary it undergoes changes preparatory to, but entirely independent of, fertilisation. The germinal vesicle approaches the surface of the vitellus, loses its distinctness of outline and after exhibiting karyokinetic changes which are characteristic of a nucleus about to divide, first one and then a second portion separates and is extruded from the yelk. The two minute bodies which are extruded from the yelk are known as polar bodies or directive corpuscles. The remainder of the nucleus, which remains within the yelk, is termed the female pronucleus.

The Polar Bodies or Directive Corpuscles are not to be confounded with the polar globules of Weismann. They are developed before, and not after, impregnation. Weismann's polar slobules are nucleated cells, and their appearance is contemporaneous with the formation of the blastoderm. They are precisely similar to segmentation spheres. It is unfortunate that two structures so entirely different should have received similar names, but the term polar globule was used by Weismann before directive corpuscles were known.

The Formation of Directive Corpuscles in Insects.-Robin [360] 
believed that he observed this phenomenon in the eggs of Chironomus, but the appearances which he described are entirely dissimilar to those which have been repeatedly observed in Echinoderms and Worms; it is probable that the changes he saw were due to the contraction of the yelk, as he described the outgrowth of amœboid processes which subsequently became separated from the yelk. Whatever the explanation it is indubitable that Robin saw nothing like the separation of true polar bodies or directive corpuscles. He evidently regarded Weismann's polar globules as true directive corpuscles. His observations were made on the entire eggs.

Amoboid contractions of the peripheral layer of the yelk were observed by Brandt in Donacia, and it is possible that Robin saw similar contractions in the eggs of Chironomus.

The attention of many observers has recently been directed to the nuclear changes which occur in the so-called germinal vesicles of Insects' eggs. Heider, Henking, Korschelt, Rath, Wheeler and others have written in considerable detail on these changes. Henking's work appears to me the most exhaustive, and his observations may be divided into two sets. (I) The changes which occur before impregnation, and (2) those which occur in the eggs immediately after their deposition; whether the eggs have been impregnated or not.

The first set, dealing with eggs which have not been passed through the oviduct, consist of minute observations on the number and position of the fragments of chromatin contained in the so-called germinal vesicle, or the nucleus of the lowest egg-cell. These observations, judging by the figures given, appear to me to be highly unsatisfactory; and it is incomprehensible to me that, admitting the correctness of the observations, any conclusions whatever can be arrived at from such variable appearances; a few irregular granules, sometimes in chains, at other times isolated and scattered apparently without order in the interior of the nucleus, have been marshalled into the most definite order, and the author sees in them indications of the most definite changes.

The second set of observations deal with eggs which have 
been deposited, and which therefore, on any theory, contain germ-yelks-whether the spermatic capsules of the female contain sperm-cells or not. In such eggs, Henking sees a definite nucleus surrounded by a protoplasmic area, in which he figures nuclear spindles, and from which he says directive corpuscles are produced. It appears to be very generally admitted by those who have examined the phenomena, that the directive corpuscles are formed very soon after the eggs are deposited, and after the entrance of the sperm-cells into the yelk. Without in any way wishing to offer an opinion as to the validity of the discoveries claimed in this direction by recent observers, I would remark that they are equally consistent with my own views and those of the writers themselves. It is possible and probable, I think, that the germ-yelk undergoes changes similar to those described as soon as it enters the yelk, and that the simultaneous formation of a male and female pronucleus results; these subsequently unite to form the first segmentation nucleus.

Some of the figures representing the phenomena observed, are certainly suggestive of a scries of changes corresponding with those repeatedly observed in ova which exhibit more favourable conditions for observation. Others are, however, far from satisfactory, and scarcely appear to support the great superstructure of hypotheses which has been raised upon so slender a basis.

Free Nuclear Formation.--Schwann held that cells originate by the differentiation of a structureless substance, 'blastema, which, according to its chemical qualities and grade of vitality, possesses a greater or less capacity of effecting the development of cells.' But the experience of embryologists was soon found to be in opposition to his views. Prevost and Dumas observed the process of yelk sermentation in the frog in $I \&_{4} 6$, which led to the statement that the segments into which the yelk splits are cells. It was not, however, until I 855 that Virchow marle his well-grounded statement, Omnis collula c cillula, that every cell is developed from a pre-existent cell, which is the basis of the present almost universally accepted view. 
Although no axiom in physiology is now better supported than Virchow's aphorism, even Stricker, in I87o, said, 'The formation of fresh nuclei within cells must be admitted to proceed not only from the fission of old nuclei but from the growth of entirely new ones.' Such a belief is, however, now entirely superseded, as the observations of Volkmann and Steudener, Metschnikoff, and others have repeatedly shown that such appearances are entirely deceptive, and due to the invasion of leucocytes, whilst the researches of Flemming, Strasburger, and others have placed the question of nuclear division upon an entirely new footing. Nevertheless, writers on the embryology of Insects are very prone to return to views which are substantially the same as those originally held by Schwann, and to adopt the hypothesis that nuclei may originate in a blastema, whilst others maintain that nuclei may be developed from preexisting nuclei, and exist as such in a blastema, or formative material foreign to that of the cell in which they are formed, and that new cells are developed by the aggregation of this material around such originally naked nuclei. Thus Brandt, in I 878 [330], said a general investigation of the manner in which the blastoderm is formed, in Insects, is not unnecessary at the present time, as several conflicting views are held which culminate in two extremes; according to one of these the cells of the blastoderm arise spontaneously in a peculiar peripheral layer of the yelk - the yelk blastema; according to the other, the cell-substance only is derived from this layer, and the nuclei arise from the division of the germinal vesicle.

The result of Brandt's investigations were the following conclusions : the germinal vesicle does not disappear in the yelk, but is itself a cell-in other words, a germ-cell, the nucleus of which is the true germinal vesicle-that the division of this germ-ovum gives rise to the cells from which the blastoderm is developed.

So far Brandt, therefore, arrived at the same conclusion as myself; but there is this difference, Brandt apparently believed that the products of the segmentation of the germ-ovum are 
amceboid cells, which wander through the yelk to its periphery and there again unite and form the blastoderm.

The improbability of such a theory is so great that it would require far stronger evidence than has yet been adduced to make it acceptable. No other instance occurs in nature of an embryo originating from numerous wander-cells, or parablastic elements. Moreover there is nothing to show that the germyelk does not form a continuous blastoderm by its segmentation, just as it does in other animals.

If no such cell as the germ-cell can be found in the yelks whilst still in the ovary-since it is highly improbable that such a cell is formed around a nucleus, which in the first instance is the nucleus of a yelk-cell-such a germ-ovum must have a separate origin and must enter the egg from without, during its passage through the oviduct.

It is true that in the egg of a bird the yelk consists chiefly of food material, in which the germ-cell is included, but the whole developmental history of the bird's egg is different, and no one doubts the existence of the germ-yelk at an early period of development as a well-marked structure. I admit that if the ova of insects could be shown to consist at first of a single cell, that the above argument would be less valid, but even then the changes which the nucleus undergoes would not permit it to be compared with a germinal vesicle-the degeneration is marked, and all the details of the process resemble those which occur in degenerating nuclei.

\section{i. On the Development of the Germ-0va in the Epithelial Cells of the Parovarium.}

In the earlier stages of development the parovarium is lined with a distinct layer of large epithelial cells, and this condition persists for a long time in the anterior or blind end of the yland. In many of my sections the epithelial lining of the gland appears as a continuous layer of protoplasm, in which numerous nuclei are embedded. So that in this respect 
the structure of the parovarium is identical with that of the germogen in the solid-bodied worms.

In a more mature condition some of the epithelial cells contain two nuclei (Fig. 94, C). Others contain one, or even two included germ-ova; the epithelial cells which contain germ-ova also contain nuclei which exhibit a dividing nucleolus-some of these have one and others as many as four nucleoli.

The deductions I draw from the appearances presented are: (I) that the cells of the germogen are undergoing active multiplication, and that the nuclei divide and subdivide with or without the subsequent division of the mother-cell.

(2) That some of the nuclei assume the form of germinal vesicles, whilst others undergo still further divisions, and ultimately degenerate.

(3) That the protoplasm of the germ ovum becomes definitely separated around the germinal vesicle from the protoplasm of the mother-cell by the formation of a distinct membrane, the zona radiata.

Similarity of the Processes of Germ and Sperm Formation.It appears, therefore, that there is a strong resemblance between the manner in which the sperm-cells and germ-cells are developed. In both the reproductive elements are developed by endogenous cell-formation, and in both a part of the original cell and its nucleus remain surrounding the reproductive elements. The germ-ova are, however, much larger than the spermatozoa, so that fewer are formed from each cell, and the division of the mother-cells in the parovarium is far less active than the division of the spermatospores in the testicle; so that in the second generation, whilst the polyblasts of the testicle have numerous minute nuclei, the daughter-cells of the parovarium have, at most, two or three, one of which, or at most two, by subsequent division form a germinal vesicle and an apparently inert or degenerating nucleus.

Hertwig [368] has recently described similar relations between the development of germ-ova and spermatozoa in Ascaris. He says: 'The formation of the ova and the spermatozoa are similar processes, and the knowledge of the one 
is necessary for the comprehension of the other. Van Beneden and Julin [367], with a correct appreciation of this fact, followed out their investigations on the development of the spermatozoa in Ascaris megalocephala; and more recently the literature of the subject has been enriched by many partial investigations, and some very suggestive studies amongrt nematoid worms.'

The subject is one which is so complex, and which bristles with so many contradictory statements, that I cannot enter further upon it ; that in the main the view of Hertwig is correct, appears to me indubitable, but those who wish for further information are referred to the memoirs, a list of which is given on page 7 I2, and to the extensive bibliographies which they contain.

The Development of Germ-0va in various Animals. - The manner in which germ-ova originate in Worms and Crustaceans has been frequently studied, and does not appear to differ materially from the process as it occurs in the Mammalia.

Van Beneden wrote [344]: 'One may say that in all the Worms, Crustacea, and even in the Vertebrates, the first rudiments of the egg are formed in the same manner. It is probable that it is the same in all the members of the animal kingdom.

'The first rudiments of the egrg, the germs, are formed at the expense of a common layer of protoplasm, holding in suspension distinct nuclei. When these nuclei have attained a certain volume the protoplasm aggregates itself around them in a distinct layer, and from this moment the germs consist of the essential parts of a cell.

' It is incontestable that in certain cases this phenomenon is accomplished by the formation of furrows, which extend inwards from the surface.

'In other cases the protoplasm appears to become more dense around the nuclei, and separates from the common natss. This phenomenon occurs in the greater number of Trematcdes, Cestodes, and in certain Turbellarians, such as the Planarians and Nemertids, in some Nematodes, and in the greater number of Crustacea.' 
Judging from the above description, it appears that the intracellular development of germs is a widely-spread phenomenon, and that germ-ova originate by true endogenous cellformation; and this view is still further borne out by the endogenous development of spermatozoa.

Later authors have rather confined their observations to the manner in which the nuclei multiply; but I think it is clear that the continuous layer of protoplasm in which the germova develop is, as Van Beneden suggests, either a single cell with many nuclei, or consists of a group of cells, the individual limits of which have not been distinctly observed-probably the result of the processes employed for their preservation.

\section{k. Some General Remarks on the Similarity of the Generative Function in Insects and Trematodes.}

Although the Trematoda are always hermaphrodite, and the Insecta are invariably unisexual, there is a remarkable similarity in the general disposition of the female generative organs of the two groups, especially when the generative organs of the highest Trematodes, the Rhabdocœlian Turbellaria, and Insecta are compared.

The diagrammatic representation of these organs in a Rhabdoccelian (see next page) would serve as a representation of the same organs in a female Insect. In both cases there is a bursa and a receptaculum seminis, or spermatheca; in both the vitelline glands apparently correspond with the testes of the male; and in both, if I am right in my conclusions, there is a distinct germ-gland. Moreover, the germ-gland in the Turbellarian is very similar to the parovarium of the Insect.

There are, of course, points of dissimilarity, the most important of which is the structure of the vitellogenous gland. This in the Turbellarian is an ordinary racemose gland, the ducts and follicles of which are continuous; but this condition is by no means uncommon in the Arthropoda, and is the form usually ascribed to the ovaries of Insects. 
As has already been pointed out, there are apparently closer affinities between the Insecta and the solid-bodied Worms, than between the Insecta and the Annelida, which are more frequently compared with them.

The Turbellaria have the same spongy reticulum between their internal organs; as has been already stated, both the

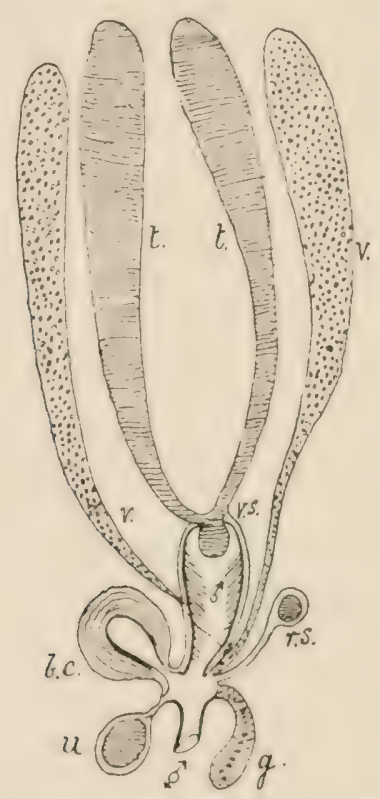

Fic. 103.-Dingram of the generative organs of a Rhabdococlian (after Graff).* $b c$, bursa copulatrix; $s$, germogen ; $r s$, receptaculum seminis $q ; t, t$, testicles; $u$, uterus; $v, v$, vitellogen; $v s$, vesiculus seminalis $\delta ; \sigma_{x}^{*}$, common genital duct.

remarkable metamorphoses of Insects and some peculiarities of their cmbryo are foreshadowed in the Nemertid Worms; and, lastly, the water vascular system of the solid-bodied Worms is probably the homologue of the tracheal system of the Insect (p. 358).

Two phenomena are observed in the reproductive process in many Trematodes and in some Insects; these are ascxual or

* I'lanarians, Zool. article 'Encyclopæedia Britannica,' Lond., I Syr. 
parthenogenic generation and protandry; and, although these are by no means confined to the Insecta and Trematoda, there is no other group of highly-developed organisms comparable with the Insecta which exhibit parthenogenesis, and I am not aware that any other highly-developed group of organisms exhibit protandry, without at the same time exhibiting normal hermaphrodism.

Parthenogenesis.-The development of ova without previous impregnation is of frequent occurrence in Insects, either as a more or less rare phenomenon occurring in otherwise perfect females, or as an alternation of generation occurring in imperfect females, which alternate with perfect normal females.

The latter, which is undoubtedly the normal form of parthenogenesis, is supposed by Lubbock to be the result of an acquired power of developing young in the larval form, and the phenomenon as it occurs in the larvæ of Cecidomyia is certainly highly suggestive of such an explanation; and I would draw attention in this connection to the remarkable similarity of this phenomenon and the reproductive process in the larval forms of parasitic Trematoda, Cercaria.

Protandry.--Although in many Insects, as, for example, in most Lepidoptera, the ovaries are mature when the insect escapes from the pupa, it is more generally weeks or even months before the ova are fully matured. In such cases the act of sexual union occurs long before the ova are mature. Thus the nuptial flight of the Queen Bee occurs in the summer, but the ova are not deposited until the ensuing spring.

The same is general in the social Hymenoptera. In the Muscidæ the act of copulation takes place whilst the ova are still very rudimentary; and occasionally, at least in many Orthoptera and Hemiptera, it occurs in the larval or nymph stage. I observed [369] this myself in 1864 in a large species of Petasia in Palestine, and published an account of the pheno-

\section{Bibliography :}

369. Lowne, B. T., 'Observations on Immature Sexuality and Alternate Generation in Insects.' Trans. Ent. Soc., Lond., vol. I871, pp. 193202. 
menon in $S_{j} I$, with some observations communicated to me by the late distinguished Coleopterist, Dr. J. A. Power.

The early maturation of the sperm may be termed Protandry, and compared to the analogous condition in hermaphrodite plants. Protandry is widely spread amongst hermaphrodite invertebrates, and the early transference of the sperm to the female organism in Insects is perhaps an indication of an hermaphrodite ancestral condition. The protandrous condition of Insects does not appear to have attracted the attention which this remarkable phenomenon deserves.

If one may venture to generalise, it appears to me probable that the existence of spermathecæ in the developed female is connected with this protandrous condition. In the Lepidoptera, in which it does not exist, I have sought in vain for spermathecæ; their place is probably taken by the large bursa, which is connected with the oviduct by the spermatic canal, and, so far as I can judge, those who have described spermathecæ in these Insects have mistaken other structures for them. They certainly exhibit nothing like the spermathecæe of the Diptera and Hymenoptera.

The single so-called spermatheca of the Cockroach-Periplaneta orientalis - is evidently a bursa similar to the bursa of the Lepidoptera.

In the Diptera, as has been already stated, there is no bursa properly so called, and it appears probable that this organ is represented by the uterus, in which the ova in some genera are normally retained until the embryo is fully developed, or even until the larva is ready to pass into the pupa stage.

\section{THE EXTERNAI GENERATIVE ORGANS.}

\section{a. General Considerations and Nomenclature of the Abdominal Segments.}

Although in some Insects the external generative organs are exceedingly simple, in others their complexity is very great; yet no definite nomenclature has been established by which the 
several parts can be distinguished. Kraatz, in I88I [376], remarked that no critical nomenclature then existed, and I am unaware that any has been since suggested. There is no subject in Insect anatomy which has received less attention, and I have been unable to find any works on the subject except Lacaze-Duthiers' well-known memoirs on the female genital armature, and three or four on the ovipositors of Insects, especially on the stings of the aculeate Hymenoptera.

More or less detailed descriptions of the male genital armature are found in memoirs on various Insects, but each author has adopted a separate and very imperfect nomenclature, so that the homologies of those parts, which occur in almost all the more differentiated forms of Insects, are very little understood, and are still a subject of speculation and controversy.

Views of Lacaze-Duthiers. - Lacaze-Duthiers [370] was the first author who attempted any clear exposition of the nature of the parts, and his work was confined to a study of the comparative

\section{Bibliography :}

370. LAC.AZE-DuthiERs, 'Recherches sur l'armure des Insectes femelle.' (a) Hymenoptères ; $(b)$ Neuroptères, Coleoptères, Diptères, etc. ; (c) General. Ann. Sc. Nat. Zool., ser. iii. (a) tom. xiii., xiv. and xvi.. I849-I 852 ; (b) tom. xix. ; (c) tom. xix., I853.

371. PACK $\triangle$ RD, A. S., 'Observations on the Development and Position of the Hymenoptera, with Notes on the Morphology of Insects.' Proc. Boston Soc. Nat. Hist., vol. x., p. 279, I866.

372. Packard, A. S., 'Guide to the Study of Insects.' Salem, Mass., 8 vo, I869.

373. Ouljanin, 'Entwickelung des Stachels der Arbeitsbiene.' Zeitsch. f. w. Zool., Bd. xxii., p. 289, 1872 .

374. KRÄPELIN, K., 'Untersuchungen über den Bau, Mechanismus und Entwicklungsgeschichte des Stachels der Bienenartigen Thiere.' Zeitsch. f. w. Zool., Bd. xxiii., I873.

375. Dewitz, H., 'Ueber Bau und Entwickelung des Stachels und der Legescheide einiger Hymenopteren und der grïnen Heuschrecke.' Zeitsch. f. w. Zool., Bd. xxv., I875.

376. Krantz, G., 'Ueber die Wichtigkeit der Untersuchung des männlichen Begattungsglied der Käfer für Systematik und Art-Unterscheidung.' Deutsche entomolog. Zeitsch., Bd. xxv., pp. I13-126, I 88 I. 
anatomy of the female generative armature. At the time he wrote the importance of embryological investigations in elucidating homologies was less understood than it is at present, and he did not even attempt any study of the manner in which these parts are developed. Lacaze-Duthiers' most important generalisations were:

(I) The external orifice of the sexual duct is very generally situated between the eighth and ninth abdominal segments.

(2) The stings and ovipositors of all Insects conform in their general plan of structure, and exhibit homologous parts.

(3) These parts are mainly formed by a modification of the sclerites forming the ninth abdominal somite, and are not homologous with ventral appendages, abdominal feet.

With regard to Lacaze-Duthiers' first generalisation, it is apparently correct, but owing to the confused nomenclature of the abdominal segments and the extensive modifications which the posterior segments undergo, the statements of other investigators appear to show that there is no constancy in the position of the external generative orifice.

His second generalisation is indubitably correct, although in matters of detail there are considerable discrepancies in the views which have been propounded by different writers on the subject.

The third generalisation is, I think, undoubtedly erroneous. Ifuxley, in 1877 , wrote: "Thus it would appear that, while there can be no doubt as to the general unity of plan of ovipositors and stings, the view of Lacaze-Duthiers must be modified. It must be admitted that these apparatuses appertain to the eighth and ninth somites, and not to the ninth alone; and that there is reason to suspect that their chief constituent parts are modified limbs.' Such modified limbs are usually termed gonapophyses.

Comparison of the Male and Female Genital Armature- - I ith regard to the male organs of copulation, Kripplin [374], who examined the development of these parts in the I)rone, and the modifications found in hermaphrodite liees, is led to the con* 'The Anatomy of Invertebrated Animals,' London, 1877, p. 43.3. 
clusion that they are developed from the eighth and ninth somites of the abdomen, and first suggested that they are homologues of the parts of the sting in the female.

In the Muscidæ the male organ is, however, apparently situated behind the fifth or sixth abdominal somite, whilst in the female the generative aperture is obviously between the eighth and ninth. The question therefore arises, Are these appearances deceptive, or is the position of the genital orifice differently situated in the two sexes? Similar discrepancies in the position of the generative apertures in the two sexes are of common occurrence. Thus, Huxley, after describing the sternal plates of the abdomen in the two sexes of Periplaneta orientalis, wrote: "While in the female the opening of the recto-genital chamber lies between the tenth tergum and seventh sternum, in the male it lies between the tenth tergum and ninth sternum;' and he concludes, speaking of the gonapophyses of the male, by stating that 'though they are of the same nature as the gonapophyses of the female, they are not their exact homologues."*

It follows, therefore, that either the number of abdominal somites is incorrectly estimated, or that there is no constancy in the position of the genital apertures and their armature in the two sexes.

Nomenclature of the Abdominal Somites.--I shall now endeavour to show that such discrepancies are the result of the manner in which the identification of the abdominal somites is usually attempted. In my opinion the method adopted, that of counting these from before backward, is wrong in principle, and has given rise to much confusion. In order that such a system should give results of any value, it must be assumed that the variation in the number of somites which occurs in the abdomen in different Insects is entirely due to the non-development of the apical segments. If the number of basal segments varies, as I shall show it undoubtedly does, then the fifth abdominal somite of one Insect may be the morphological representative of the eighth, ninth, or tenth of another.

$$
\text { * 'The Anatomy of Invertebrated Animals,' p. } 406 .
$$


The evidence that the number of segments in the basal portion of the abdomen does vary is very convincing. In the common Cockroach-Periplaneta orientalis - there are only seven visible abdominal sterna in front of the sexual orifice of the fomale, but in Periplaneta americana I find two very rudimentary sterna in front of these, so that there are nine sterna in front of the genital orifice, and the same number is common to the males in both species. It is obvious, therefore, that in these Insects the number of basal segments varies in the abdomen, and the two sterna nearest to the thorax are always feebly developed in Cockroaches whenever they are present, so that one or both may be easily overlooked.

With the exception of Periplaneta, in which the genital aperture is normally situated behind the ninth somite, in all the other large Orthoptera which I have examined it is behind the eighth.

I propose to term the sternum, which is situated immediately in front of the genital aperture, the progenital sternum. It is usually the eighth counted from the base of the abdomen, rarely the ninth as in Periplaneta americana. Occasionally it appears to be the sixth, as in the males of Calliphora; in this case, however, eight terga exist in front of the sixth sternum, and there is evidence to show that the sterna which are absent are the two immediately in front of the progenital sternum.

The number of segments behind the progenital sternum in mature insects varies from one to three. When only one is present it surrounds the anus; I therefore term it the Anal Somite. The two possible somites which intervene between the progenital and anal I term the Meso- and Meta-genital Somites; one or both are usually represented by a pair of appendages; and the progenital and anal somites frequently also exhibit more or less developed appendages. These appendages are termed Gonapophyses, or Cerci, according to the form which they assume.

In the male Hymenoptera there are manifestly two pairs of sonapophyses, which surround the penis; they are developed from the pro-and meso-grenital somites. In the female these 
organs form either the ovipositor or the sting (aculeus). The ovipositor in the Orthoptera has a precisely similar construction and consists of four gonapophyses, those of the pro- and mesogenital somites; in the female Locusts the meso- and metagenital somites exist as distinct annuli, and there is usually a pair of jointed cerci articulated between the tergal and ventral plates of the meta-genital annulus; sometimes a second pair spring from the anal segment.

From the examination of the skeletal structures of a great number of Insects, I have arrived at the conclusion that theoretically there are three genital somites, one in front of, and two behind, the external genital orifice, either or all of which may exist as distinct annuli in the perfect form; that each of these somites may have a pair of ventral appendages, the gonapophyses and cerci; that in many cases when the annuli are undeveloped their gonapophyses remain, and that there is always a more or less developed anal somite behind the three genital somites, which frequently bears a pair of distinct appendages.

Development of the Abdominal Somites.-It is a very wellestablished fact that the number of abdominal somites present in an embryo Insect is from eight to eleven, a number which is too small to account for the formation of the four genital somites which the theory I have advanced requires; but it is very generally admitted that the posterior abdominal somite of the embryo is a complex of two or more somites.

Poulton [353] says, speaking of the number of abdominal somites in the larva of the Lepidoptera, which is generally held to be ten: "There is no difficulty about the seven anterior abdominal segments, each of which bears a spiracle. Behind the seventh, however, there is a somewhat confused mass of segments, bearing a single spiracle on its anterior part; this spiracle is usually larger than those on the other abdominal segments. This confused mass is sometimes described as a single segment, and sometimes as two; a careful comparison with the pupa proves that it is certainly made up of three segments.' 
In other words, there are certainly three somites in the pupa, representing what is apparently one somite in the larva.

The manner in which the eight anterior segments of the abdomen of the pronymph of the Blow-fly originate has been already described, and it is evident that they correspond with the eight obvious abdominal somites of the larva. In the female imago, the external orifice of the genitalia is situated behind the eighth of these somites, which are all represented by complete chitinous rings; but there is another segment between the genital orifice and the anus which has no representative in the larva. This somite bears a pair of appendages, and is apparently developed from the hypodermis of the last larval somite at a later period.

In the male insect, instead of one post-genital segment there are probably three all developed, with the eighth or progenital somite, from the last obvious somite of the larva.

Fïnckel d'Herculais [25] figures and describes three pairs of appendicular discs in the last larval segment of Volucella. It is evident, therefore, I think, that the number of somites in the cmbryo and larva cannot be regarded as equal to the number in the fully-developed imago, and it has long been known that in the Myriapoda the number of somites is increased by each ecdysis. The same phenomenon is seen to an even more marked extent in the Crustacea; so that little surprise need be felt if it also occurs in the Insecta.

\section{b. Development of the External Generative Organs in Insects Generally.}

As the study of the development of the external sexual organs in the Blow-fly is exceedingly difficult, I have had little success in the investigration of the earlier stagres in this insect, partly from the fact that these stages occur at a very early perind in the pupa, when it is exceedingly difficult to obtain satisfactory sections near the extremity of the abdomen, owing to the density of the cuticular exuvia of the larva ; and partly 
because sections are not well adapted to throw light upon the subject. I have, therefore, thought it well to give an account of what is known from the observations of other observers on various Insects which exhibit more favourable conditions.

Development of the External Organs of Generation.-Ouljanin [373], in $I 872$, traced the development of the sting in the hive Bee to imaginal discs, and concluded that it consists of modified abdominal limbs. Kräpelin [374] traced the development of the external genital organs in the male Bee to a similar source; and Packard [372] states that, in Insects generally, 'the male genital organ is originally composed of three pairs of tubercles (two pairs apparently in Æschna) arising from the ninth abdominal ring.' The latter is undoubtedly, as already stated, a complex of several somites.

The most detailed description of the development of these organs in both sexes is found in a paper by Dewitz [375]. He has arrived at the following conclusions:

In the female, the sting, or ovipositor, consists of six principai parts, of which two are frequently united into a median organ: these are developed from six ventral papillæ. Two arise from the ante-penultimate somite, and four from the penultimate somite of the larva or nymph. These papillæ are developed from imaginal discs, similar to those from which the thoracic limbs of Corethra are developed.

In the Hymenoptera these discs are primarily involutions of the hypodermis, but in the Locusts they first appear as projecting papillæ.

Dewitz says that these papillæ are not developed in the same order in all Insects. In the male larvæ of the species observed only two papillæ were developed on the penultimate somite, and none apparently exist on the ante-penultimate somite. This statement does not agree with the observations of Packard, and the discrepancy probably arises from different species having been investigated.

Dewitz regards it doubtful whether the four papillæ on the penultimate somite are to be regarded as two pairs of limbs, or as a single pair of biramous appendages. There appears to be 
a very clear agreement on the part of all who have investigated the subject that the male organ and the sting, or ovipositor, are homologous structures. Poulton, who has recently investigated the development of the external organs in the Lepidoptera, in which the armature of the penis is but little developed, finds the male genital armature is represented in the young pupa by a single pair of papilla behind the eighth somite, probably my progenital somite, with a furrow between them, which ultimately becomes a deep pit, the origin of the ejaculatory duct.

The question formerly discussed as to whether the papilla (rhabdites) from which the external armature is developed are true limbs or not, appears to me to have been completely settled by the observations of Dewitz, and I think the view held by Lacaze-Duthiers that this armature consists, in part at least, of the modified sterna of the genital somites must be held to be no longer tenable.

\section{c. Comparative Morphology of the External Generative Organs.}

The parts developed by the modifications of these abdominal appendages have received different names in different insects. The anterior and posterior zygapophyses (or claspers) in both sexes, the valves of the ovipositor and the parts of the sting in female insects, and the armature of the penis of the males are highly modified structures formed from one or more pairs of these appendages. Cerci are probably also lateral ventral appendages of the metagenital and anal segments, but their development has not been traced. Lastly, the so-called podical plates are possibly merely divided sternal plates.

The Anterior Gonapophyses are developed as a pair of papilla from the posterior part of the eighth abdominal somite, my progenital somite. They correspond with the inferior blades of the ovipositor in the female of Locusta, and the great claspers of male Insects. They are often exceedingly complex, and in Tipula amongst the Diptera exhibit three distinct rami 
in the form of hooks and scales. In many male Insects they have been described as the external sheath of the penis.

The Posterior Gonapophyses.-These appear in the embryo in the Orthoptera and Hymenoptera as the external pair of papillæ on the posterior border of the mesogenital somite, usually the ninth abdominal somite. They are the superior blades of the ovipositor in the female of the Orthoptera, and the internal sheath of the penis in the males of many Insects. In the Hymenoptera they are seen as jointed rods, one on either side of the penis.

The Internal Papillæ of the Mesogenital Somite.-The existence of two pairs of papillæ on the ventral surface of the mesogenital somite in the nymph of the Hymenoptera and Orthoptera has been sufficiently proved, and Dewitz has shown that the internal papillæ are developed from the same source as the external; but some doubt exists as to the fate of this second pair of papillæ.

Dewitz [375] states that in Locusta they subsequently unite with each other and with the external papillæ to form the upper valves of the ovipositor; and in Apis mellifica he says they form together the large dorsal sheath of the sting, whilst the lateral papillæ become its well-known lateral sheaths. He regards the two anterior pairs of papillæ as the darts of the sting. It does not appear, however, that Dewitz has actually traced the changes of these papillæ, and he has apparently arrived at these conclusions on theoretical grounds only.

The 0vipositor of Sirex gigas. - There cannot be the slightest doubt that the sting in the aculeate Hymenoptera and the ovipositor of Sirex and other boring Hymenoptera are identical structures. In Sirex the dorsal sheath and lancets form a hollow ovipositor, through which the eggs are passed, and these structures correspond with the dorsal valve of the ovipositor of Locusta; if this is the case, they must be developed from the four papillæ on the mesogenital somite. The lateral sheaths of the ovipositor are clearly the homologues of the inferior blade of the ovipositor of Locusta; they also articulate 
without doult with the progenital somite, and represent the anterior gonapophyses of the male.

The manner in which the ventral portion of the genital somites is drawn forwards luring development, so that the six papillat all appear to arise from the same place, renders it exceedingly difficult to trace the development of the individual elements of the ovipositor, or sting, and gives rise to the deceptive appearance as to the relation of the bases of the parts, as those belonging to the posterior somites are frequently drawn further forwards than those arising from the anterior somite. The only certain criterion as to their nature is the position of the orifice of the sexual duct.

The difficulty of accounting for the passage of the ova through the sting in the aculcate Hymenoptera, and through the narrow channel in the Terebrantia, has led to the view that the sexual duct opens either behind or in front of the sting. It certainly opens through the terebra, and I have sought in vain for any other opening of the grenerative duct in the aculeate Hymenoptera. In these Insects I suspect that the parts of the sting, or terebra, are separated during oviposition, although it is exceedingly difficult to understand how this occurs, as the parts are closely locked together when used as a borer or sting. The anatomy of the parts renders it certain that such a separation is effected in the Bees just as it is in the parasitic Hymenoptera, in which there can be no doubt the passage of the ova is through the terebra. The ora in the aculeate Hymenoptera do not, perhaps, pass through the whole length of the sting, but only through its base; but the oviduct certainly neither opens in front of nor behind the base of the sting, but through its cavity. Irrapelin held that the external orifice of the oviduct is in front of the base of the sting, and even if this is the case, homology indicates that the latter is developed from the mesogenital, and not from the procenital, somite. If such an orifice exist, I cannot understand how I can have failed to discover it.

The Penis. - It is well known that the efferent ducts of the gonnds in the Crustacea are paired, and situated in the basi- 
podite of one or other of the lateral appendages, and in the males accessory organs are frequently formed by the modification of a pair of abdominal feet, which serve to direct the everted genital ducts. In the Chilognatha, amongst the Myriapoda, the genital apertures in both sexes are situated on the basal joints of one or other of the anterior pairs of feet, usually on the third pair.

In Insects the existence of this primitive form of external generative organs is exceptional; but Palmen [332] has shown that in Labidura and in the Ephemeridx, in the larva and pupa, the orifices of the genital ducts are paired, and are usually situated on or in relation with papillæ. The union of these papillæ in the median line, and the formation of an azygos ejaculatory duct, appears to be the advanced form, and it is probable, I think, that the median external structures which result from this advance are the result of the partial fusion of the corresponding abdominal appendages.

In some Insects the penis consists mainly, if not entirely, of an eversible ejaculatory duct, which is placed between the anterior and posterior gonapophyses. The latter, which are dorsal to it, are frequently very complex, and form an armature connected with a permanently everted duct or a papilla corresponding to the orifice of the ejaculatory duct. When the posterior gonapophyses assume this form they support the penis, and consist of two rami, so that they correspond with the canula and lancets of the sting of the aculeate Hymenoptera, and with the upper blade of the ovipositor of the Orthoptera and Hymenoptera.

In many Insects the penis possesses a very rudimentary armature, but is withdrawn within a membranous sheath, the so-called prepuce of the earlier writers. In those forms in which these parts are very large, there are frequently no traces of the somites behind the progenital; but when, however, the prepuce is large, and the penis comparatively small, the genital armature is usually highly developed, and the prepuce forms the genital pouch or sinus, within which the gonapophyses are retracted. 
The Cerci.--One or two pairs of simple or jointed appendages frequently exist, which arise from the ventral edges of the metagenital and anal terga. These were regarded by Licaze-Duthiers as dorsal appendages, and he termed them tergo-rhabdites. As neither pleure nor ventral plates are usually developed in these segments, and even when sternal plates are developed, no pleure have been discovered, there is apparently no sufficient reason to regard them as dorsal rather than ventral appendages. In Locusta and Blatta, I think it is obvious that the cerci are the ventral appendages of two terminal somites.

The Podical plates of Blatta and some other Insects are perhaps parts of the anal annulus, possibly sternal plates; but their homology is very doubtful.

\section{d. The External Generative Organs of the Male Blow-fly.}

In the male Blow-fly the abdomen exhibits only five rings externally, and the fifth sternum is deeply cmarginate behind. The notch in the fifth sternal plate is the external opening of a large cavity, the genital sinus. Iiour obvious segments are invaginated within this sinus, represented by distinct tergal plates, but only two sternal plates can be distinguished; the anterior of these is in front of, and the posterior behind, the genital armature.

There are therefore nine visible somites represented by more or less complete annuli in both the male and female of this insect; and if, as appears probable, the male and female grenital apertures correspond, they are both situated behind the eighth sternal plate, which is the progenital sternum. In the female this is perfectly obvious, but in the male it is more

\section{DESCRIPTION OF PIATE L.}

The invasinated segments of the ablomen of a male Blow-liy with the right side partially removed to show the male genital armature. vi., vii. and viii., the

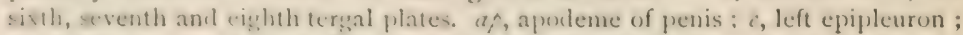

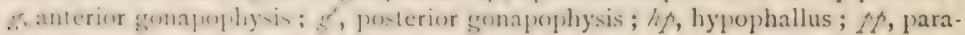
ihallus; st, genital sternum; $v$, valvula externa. 
PLATE L.

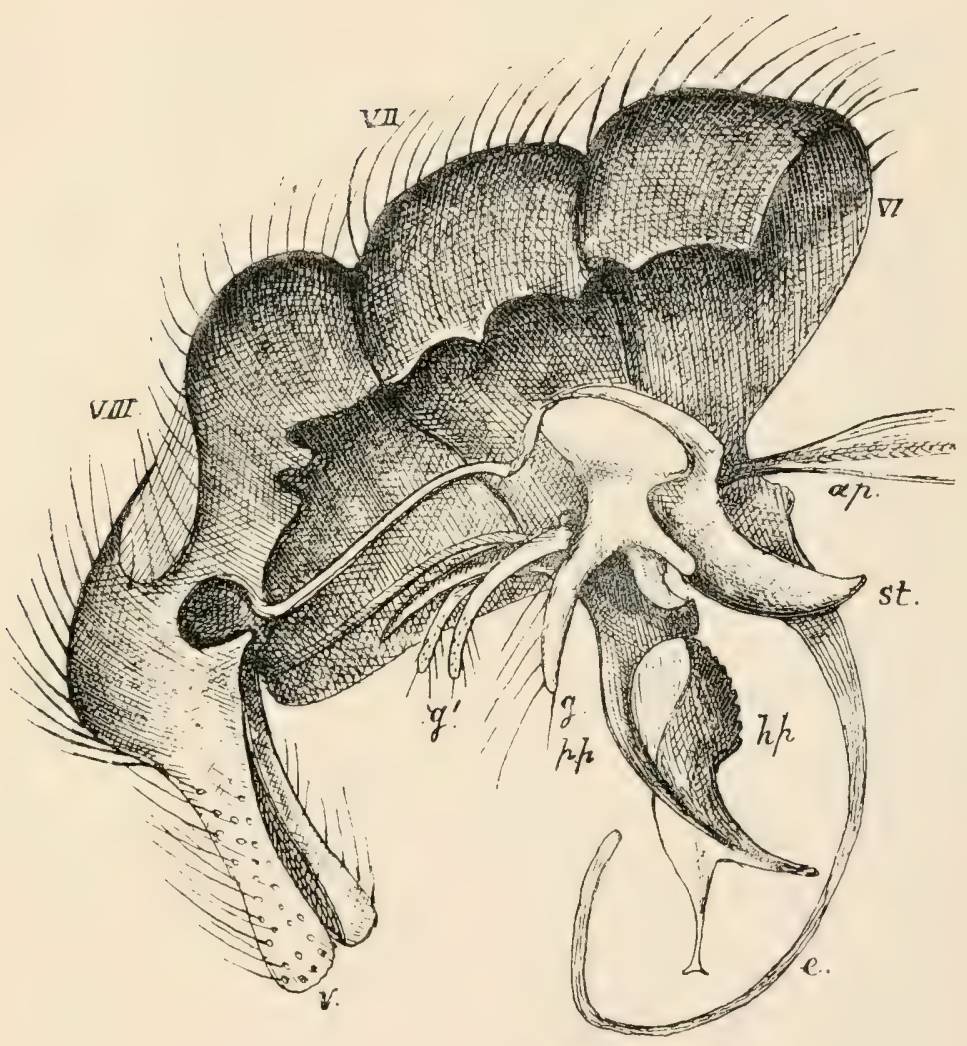

INVAGINATED SEGMENTS OF MALE. 

difficult to arrive at this conclusion, as the progenital sternum is immediately behind the fifth sternum. It is therefore apparently the sixth, and two pairs of gonapophyses intervene between it and the anal somite. If, therefore, the malc and female genital orifices correspond in being behind the eighth somite, there are traces of one, or possibly of two, additional somites in the male between the eighth or progenital, and the ninth or anal, somite, which are entirely absent in the female insect. The abdomen of the male has, if this is the case, eleven somites in its composition, whilst that of the female presents only nine.

In the Tabanidæ, Tipula, and the majority of the Diptera, the genital armature of the male is obviously behind the eighth abdominal somite, as it is in the female, and, as has been already stated, this is the usual position of the anterior gonapophyses and the genital orifice. A detailed study of the invaginated segments of the male Blow-fly leads to the conclusion that two sterna are undeveloped between the fifth and progenital sternum, and that two somites are represented by appendages only between the progenital and anal somites.

The largest element in the invaginated portion of the abdomen is the tergal plate of the eighth obvious segment. I shall term it the progenital tergum (Pl. L., viii.).

The Progenital Tergum is similar to the terga of the abdominal somites of the Crayfish in having its inferior edges prolonged as epipleura (see p. ${ }_{5} 56$ ). The inner edge of each epipleuron has a thickened margin or ridge, the epipleural ridge. These ridges on either side are connected by a thin membranous integument which forms a roof over the penis. The anterior extremities of the epipleural ridges are prolonged forwards, are overarched by two tergal plates, the sixth and seventh, and articulate with a cordate sternal plate, the progenital sternum.

The posterior angles of the progenital tergum are prolonged as a pair of broad, hollow processes, valvæ externæ, covered by stiff setæ; they are separated from each other by a deep emargination in the tergum, roofed over by thin membranous 
integument. A notch is seen in front at the base of each, which is suggestive of an articulation with an appendage, but no such appendage exists (Fig. Iof).

between the valve externat are a second pair of rod-like organs, which belong to the anal segment; these I term valvit interna. The four valye are directed forward when at rest, and close the genital sinus, filling up the emargination in the fifth sternum.

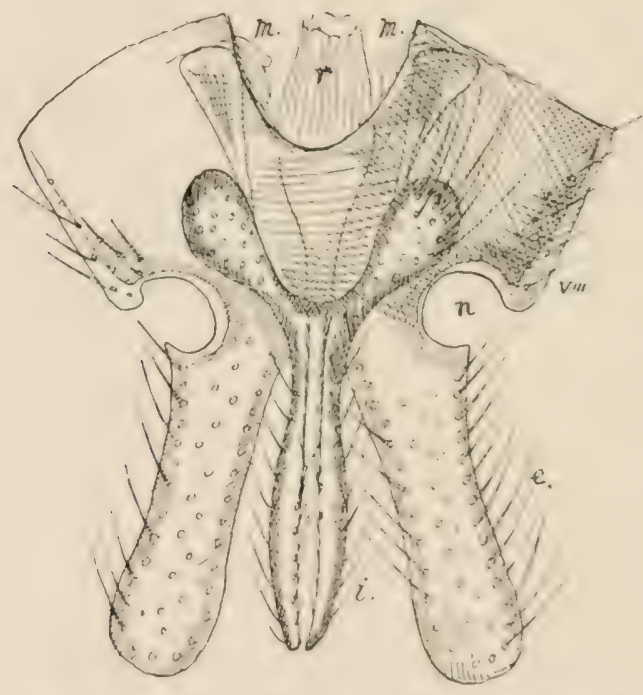

Jis. 104. - A dorsal view of the progenital tergum of the male libow-fly, showing the external and internal valves. e, external valve; $i$, internal valves ; $m m$, muscles; $n$, notch; $r$, rectum.

The Dorsal Arches of the Sixth and Seventh Abdominal Annuli are very similar to each other; the former has two spiracles on cach side near its posterior angle, and the latter only one.

\section{DESCRITION OF T'TATE I.I.}

Sidle view of the penis of the IBlow-ny. a, apociemes of the penis; $b$, bulb; $c$, epipleural riclge ; 5 , posterior gonapophyysis ; $g s$. genital sternum; lif, hypophallus ; $m m$, muscles; 0 , orifice of the ejaculatory duct ; $f \rho$, paraphallus; $s$, spine. 


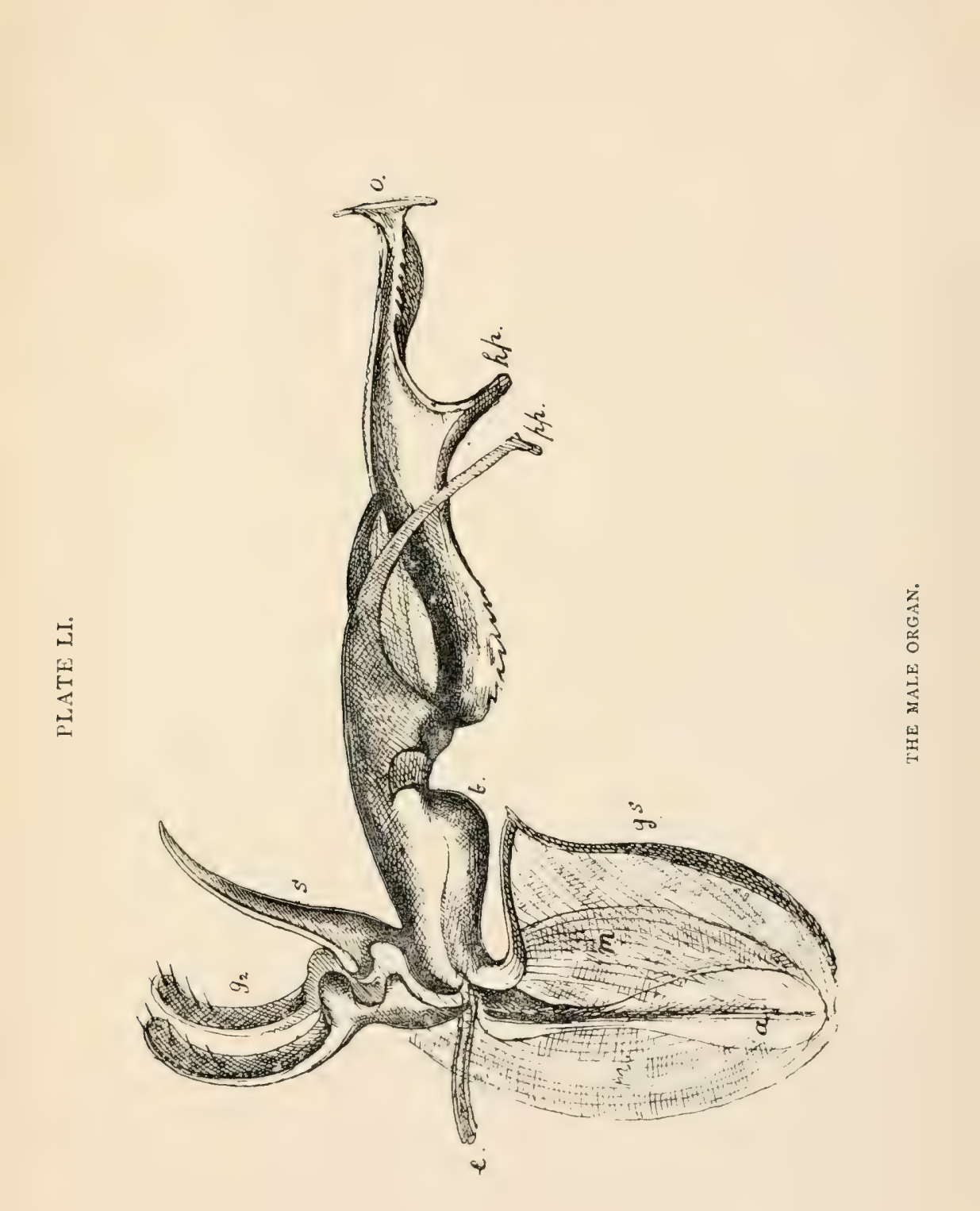



These two plates are unsymmetrical, and are fused into a single plate on the left side. This want of symmetry is most marked in Dolichopus, where it is so great that the tergum of the progenital annulus is completely inverted.

Where these annuli are united they are highly chitinised and prolonged into a long tapering process, which curves round the floor of the genital sinus. This is probably an epipleuron, and the muscles inserted into it serve to move the whole of the invaginated somites. A rudimentary epipleuron is found on the right side, but it is a detached sclerite, not united with either tergum.

In removing the invaginated somites the long curved left epipleuron brings away the whole thin anterior wall of the genital sinus, in the form of a kind of hood, connecting this sclerite with the progenital sternum.

The Progenital Sternum.-In front of the penis there is a single cordate sternal plate-the progenital sternum. It articulates behind by its concave border with the penis and with a pair of claw-like appendages - the anterior gonapophyses. Its convex anterior border is continuous with the thin membranous integument of the floor of the genital sinus, and it articulates by its two external posterior angles with the prolonged epipleural ridges of the progenital tergum.

The absence of the sterna of the sixth and seventh segments in the Blow-fly is not by any means an isolated phenomenon; as in Myopa, all the sterna of the abdomen, except the first two or three and the progenital sternum, are absent; although the tergal arches are well-developed. And the sterna are often very narrow or even wanting in the Tachinidæ, especially those with a narrow abdomen, the tergal plates meeting on the ventral surface where the two halves are only separated by a narrow strip of thin flexible integument. Nor can I find any traces of sternal plates corresponding to the sixth and seventh terga in the Dolichopidæ.

The Anterior Gonapophyses.-These are a pair of large clawlike appendages; each has a fringe of long setre on its convex edge, and articulates by a broad basal portion with the genital 
sternum in front and with the sicles of the penis internally. They are undoubtedly the homologues of the great claspers of the male Hymenoptera, and of the so-called external sheath of the penis. Their position immediately behind the progenital sternum shows that they are the lateral appendages of the progenital or mesogenital somite, and their developmental history, as well as the position of the claspers in the Hymenoptera, renders it almost certain that they are appendages of the progenital somite.

In this case they clearly correspond with the inferior blades of the ovipositor in Locusta viridissima.

The Penis in the Muscida is a very complex organ. It consists of a membranous, papilla-like projection from the thin

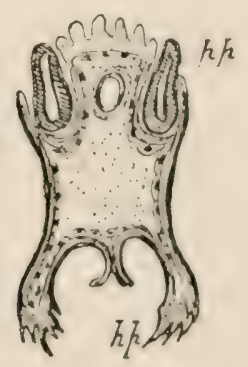

Fici, 105.-A transverse section of the penis of a Blow-fly. ht, hypophallus; $t p$, paraphallus.

integument of the roof of the grenital sinus, at the extremity of which the ejaculatory duct opens externally.

This membranous papilla contains a large blood sinus and is capable of erection; it is supported and protected by a complex chitinous framework, which consists of a pair of paraphalli enclosing its base, and of a large, curved, ventral plate, which I shall term the hypophallus. 
PLATE LII.

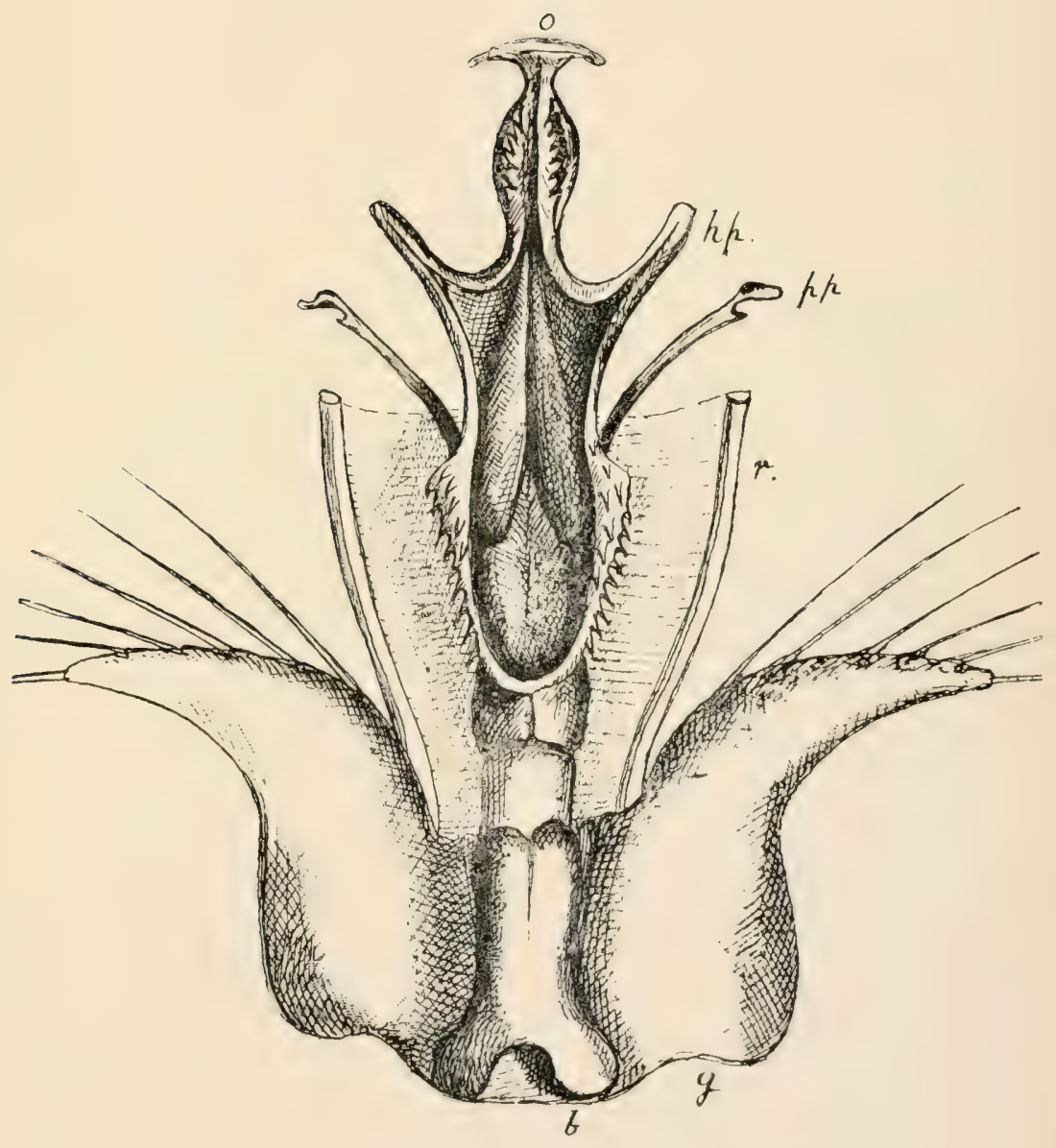



A saddle-shaped plate, which unites the paraphalli at their proximal end, supports a curved spine, the epiphallus, and gives articulation to a pair of small palp-like organs, which I term the posterior gonapophyses.

The penis when at rest in the genital pouch lies in the median plane and has its long axis at right angles to the axis of the abdomen; its dorsal surface looks backwards and its ventral surface forwards. When it is exserted from the genital pouch its extremity is directed forwards, its ventral surface upwards and its dorsal surface downwards.

In describing its several parts I shall regard it as exserted. The hypophallus in this position is above the ejaculatory duct and penis proper, the paraphalli curve upwards; the inner and outer valves of the genital pouch are below and behind the penis, and are directed forwards; and the dorsum of the metagenital somite looks downwards.

In fact, the whole extremity of the abdomen is curved when exserted, so that its extremity is directed forwards. To apply the description of the several parts to the penis when withdrawn it is only necessary to read backwards for downwards, and forwards for upwards.

The Hypophallus is a broad plate, convex below and concave above; its edges are serrated, with the serrations directed backwards. It is the ventral wall of the penis proper. Two spine-like processes, the cornua, project upwards. It articulates behind with the ventral processes of the paraphalli, and in front by its cornua with their extremities. In front of the cornua the hypophallus is prolonged as a median spine, which supports the extremity of the penis.

The Paraphalli form a saddle-shaped sclerite under the proximal fourth of the dorsum of the penis. This saddle bears a strong curved azygos spine. The anterior edges of the saddle are prolonged as two long hollow hooks, which are broad at their base. A wide curved process embraces the penis and unites with its fellow on its ventral aspect. These processes of the paraphalli support the posterior edge of the hypophallus, with which they articulate by syndesmosis. 
The paraphalli are continued forwards, one on each side of the organ, as long curved hooks, which articulate with the cornua of the hypophallus.

These hooks probably rest in the pouches on either side of the senital spine of the female during copulation, and the hollow on the ventral surface of the hypophallus rests on the spine itself. If this is the case, the orifice of the penis would be in immediate relation with the ducts of the receptacula seminis.

Mr. Hammond has shown me a number of beautiful drawings of the utero-vaginal tube and external generative organs of Tipula. In this insect the utero-vaginal tube is very long, so that the ducts of the receptacula are at a considerable distance from the vulva; and the penis is also greatly prolonged by the exsertion of a loner curved chitinous flasellum, which is apparently a prolongation of the ejaculatory duct. The length of this flagellum corresponds with the length of the utero-vaginal tube. The penis itself is very short, and has no salient armature. Copulation is effected by the highly complex gonapophyses, and the flagellum of the penis is brought into immediate relation with the receptacula.

In the Blow-1ly the act of copulation has been rarely observed, and for many ycars I never saw this insect in critu. I itely. I have seen it several times. It takes place in the sunlight in the early morning. The male is above the female. These insects never copulate on the wing. They are very shy when united, and immediately separate when captured, so that I have been unable to ascertain the position of the parts during copulation.

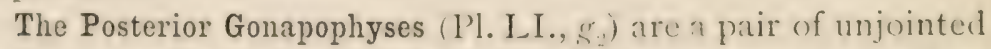
hollow palp-like organs at the root of the penis, one on either side of the azygos spine. They articulate with the posterior part of the saddle of the paraphalli hy distinct joints. Each cxhibits a curved process at its base, which articulates with a similar process arising from the proximal edge of the corresponding anterior gonapophysis. The extremity of the posterior gonapophysis exhibits a group of minute sensory setat. 
The Great Apodemes.-The whole penis is supported by two great apodemes, which are united in the middle line. They articulate with the saddle of the paraphalli and receive the insertion of a large mass of muscles, which arise partly from the genital sternum and partly from the terga of the genital somites. The action of these muscles is to rotate the penis from its position of rest, and to render tense the loose syndesmosis by which the saddle of the paraphalli is articulated with the

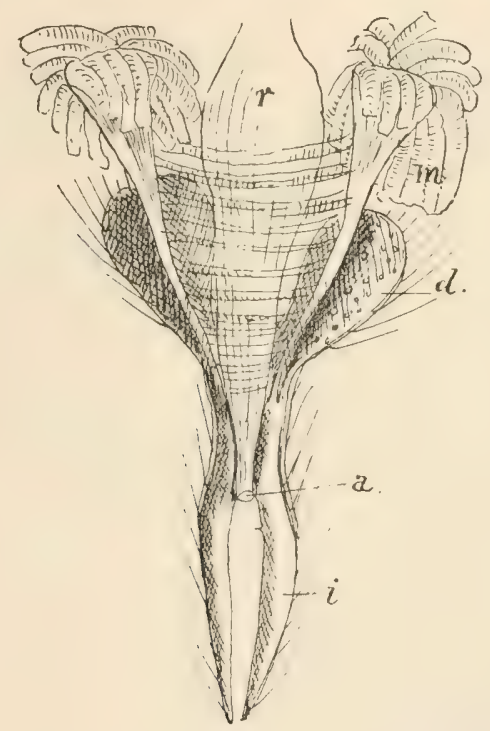

FIG. 106.-A ventral view of the internal or anal valves of the male Blow-fly. $a$, anus; $d$, dorsal scale of valve; $i$, internal valve; $m$, retractor muscle; $r$, rectum.

genital sternum. The organ is considerably elongated by this movement; probably its length is increased by about one half.

The Bulb (Pls. LI. and LII., b).- Two chitinous plates on the upper aspect of the root of the penis, behind the ventral processes of the paraphalli, form a bulbous enlargement at the base of the organ. This bulb is notched in front, so that it exhibits two rounded lobes.

The Meso- and Meta-genital Somites.-These somites are un- 
represented in the male Diptera, unless the penis and posterior conapophyses are to be regarded as the ventral appendages of one or hoth these somites. I am inclined to regard the whole of the armature of the penis proper as the modified ventral appendages of the mesogenital somite, and as corresponding with the internal or posterior gonapophyses of Blatta. In the Hymenoptera the great hook-like internal gonapophyses are exceedingly similar to the paraphalli of the Blow-fly. It is possible, however, that the complex penis corresponds with its armature to two pairs of ventral appendages, those of the mesoand meta-genital somites.

The Anal Somite (Fig. ro6) is reduced to very small dimensions; it is tubular, and terminates behind in a pair of spathulate processes, one on either side of the anus. These are the valve interne already alluded to. They are covered with reflexed setæ, and lie between the valvæ externæ.

The Internal Valves (Fig. Io6, i) lie one on each side of the anus, and dorsally to it. Each is moved by a strong apodeme ; they form a kind of canula as their ventral edges are united by a minute sclerite, which probably represents a sternal plate.

I do not think that either the external or internal valves are true appendages, but believe both to be prolongations of the posterior edge of the terga of their respective segments.

The Epipygium.-This term has been applied to the external and internal valves collectively. It is convenient, and I have already used it in this sense (p. 210).*

* In the description of the abdominal skeleton (pp. 200, 210) I regarded the sternum, which I now term progenital. as the sternum of the seventh obvious tergum, a view which I have since rejected. This led to my regrarding the antcrior gonapophyses as appendages of the seventh segment. In the clescription referred to the term seventh segment should, according to my present views, be read fromenilal (ighth) sigmint, and the term ninth segrment should be replaced by anal sisminl, which is theoretically the clevcuth, and not the ninth. 


\section{e. The External Generative Organs of the Female Blow-fly.}

The tubular ovipositor of the Muscidæ differs entirely in structure from the ovipositor proper of the Orthoptera, Hymenoptera, and many other Insects. Burmeister [8, p. I94] distinguished it by the term 'vagina tubiformis,' and correctly remarks, 'it is a mere continuation of the abdomen, and consists like it of rings, which gradually decrease in compass, so

A
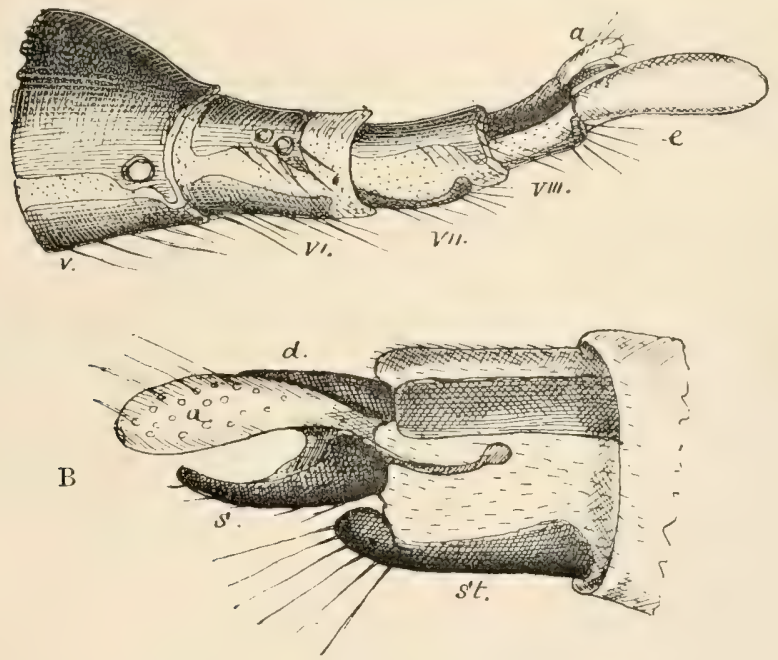

FIG. 107.-A, The ovipositor of the Blow-fly exserted. vi. to viii., sixth to eighth abdominal somites; $\alpha$, anal scales; $e$, egg. B, Terminal somites of the ovipositor of a Blow-fly. $d$, dorsal scale of the anal somite; st, sternum of the eighth abdominal somite; $s$, sternal plate of the anal somite.

that the largest and most anterior, exactly as in the case of a telescope, receives within it all the rest when this organ is withdrawn within the abdomen, wherein it lies concealed.'

The 0vipositor consists of four somites. The first of these is the sixth abdominal ring. It exhibits two sclerites, a dorsal and a ventral plate (Fig. I07 A, vi.), and the former, like the corresponding tergum of the male, has two spiracles instead of one at each of its posterior angles. It is united with the annuli both in front and behind by very broad, flexible 
syndesmoses, so as to allow of the complete invagination of the ovipositor when at rest.

The second annulus corresponds with the seventh abdominal somite. Its dorsal plate is narrow, suddenly broadening near its posterior extremity; it has no spiracle. Its ventral plate is also very narrow, and is shorter than the dorsal plate.

The third segment of the ovipositor is the progenital. It exhibits two narrow dorsal plates, one on cither side of the median line. These articulate behind with the anal segment.
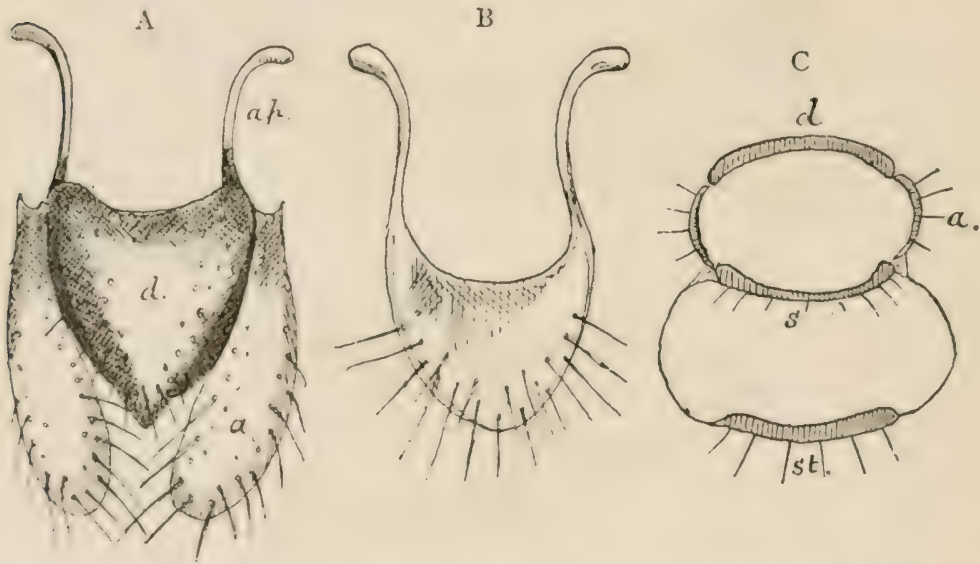

Fir. IOS.-1, Dorsal view of the plates of the anal somite of a female Iblow fly. $a$, anal scale; $d$, dorsal plate; $a p$, apodeme of the sternal plate. 1 , The ventral plate of the anal segment. $C, A$ transverse section through the extremity of the ovipositor. $d$, dorsal plate of the anal somite; $a$, scales; s, sternal plate; st, sternal plate of the eighth abdominal somite.

Its ventral plate is very narrow, but terminates behind in two cornua, which form the ventral edge of the sexual opening.

The terminal, or anal somite, consists of four sclerites, which surround the anus. These are a triangular dorsal plate, which in form resembles the telson of a Crustacean (Firs. IO7, ros, d!, a scoop-shaped ventral plate with two long apodemes (Fig. Ios, B), and a pair of scales, which articulate with the dorsal plates of the progenital somites, and the dorsal and rentral plate of the anal somite (Figrs. IOT, IOS, a). It 
must be, therefore, an open question to which somite these scales belong. I regard them as modified ventral appendages. They either represent the gonapophyses of the progenital somite, of the undeveloped mesogenital somite or they may possibly be the representatives of the anal cerci. The vaginal orifice when at rest is apparently closed, so that it is not easy to see that any opening exists between the ventral plates of the anal and progenital somites. It is only when an egg is actually passing that it is possible to determine the position of the vaginal orifice in the living insect. I determined its position by observing the deposition of the eggs by the aid of the microscope. This is easily accomplished by decapitating an egg-laying female and fixing it so that the passage of the eggs can be observed. This continues uninterruptedly in the decapitated insect.

It is not easy to prepare sections which show the orifice of the sexual canal distinctly, owing to the invagination of the ovipositor; but when once its position has been determined by observation in the living insect, the relation of the parts, even in slightly oblique sections, is not difficult to interpret. 


\section{ERRATA AND ADDENDA.}

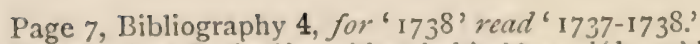

Page $\mathrm{i} 7$, line 8 , for 'hypoblast behind ' rud' hy poblast behind the blastopore.

Page 18 , line 2 from bottom and footnote, for 'Faivre' romt 'Fabre.'

Page 30, line 12 from bottom, for 'Hypoboscidic' rad 'Hippoboscidic.'

Page 33, last line, for 'xvi.' read ' $x i v$.'

Page 35, paragraph 3. Newport's Segment.-The further discussion of Newpor's segment has been omitted ; the questions involved have. however, been discussed in relation to the genital segments. I regard Newport's segment as of post-embryonic origin, and, like the cephalic post-oral somites, as unrepresented in the embryo. On the post-embryonic somites, consult p. 729.

Y'aye 38 , line 6 , '(see Sensory organs)'--the portion of the work referred to will be found on p. 71 .

Page 65, in footnote, for ' $\mathrm{K}$. L. C.' read' C. L. C.'

Page 77, in foctnote, for 'Chironomus' read 'Corethra.'

Page 210 , line I, 'seventh segment of the male,' see note to p. 744 .

Page 26,2, Dibliography, ' 127 ' is printed a second time in error before 'Viallanes,' and should be omitted.

l'age 292, Bibliography', 'See also \%ool. Anzeig., Bd. viii.,' etc., should lie included in 145, and 146 should be: "146. Kown.riski, A., "\%um Verhalten des Rückengefiisses, und des gruirlandenfïrmugen \%ellenstringes der Musciden wihrend der Metamorphose." Hiol. Centralblatt, 13d. vi., p. TH, 1886.'

Page 332, line 14 from bottom, for 'Pl. VIII.' read ' Pl. XVIII.'

Page fro. The pyramidal ganglia are perhaps the representatives of the ganglia of the habenulie; the connections with the ocelli and the posterior commissure and crura are very suggestive of this view.

P'age 478 , for ' $\mathrm{Y}$ ung ' read ' $\mathrm{Y}$ ung.' 


\section{N D E X.}

\section{ABDOMEN, I 2}

imaginal discs of, 329

respiratory movements of, 376

tracheæ of, 226

Abdominal cavity, contents of, 2 I 7

Abdominal fold in pronymph, 303, $3 \mathrm{I} 8$

Abdominal integument, development of, in nymph, 328

Abdominal segments, development of, 729

nomenclature of, 724,727

number of, in embryo, 1 5, 729

number of, in larva, 33, 730

Abdominal spiracles, 363,364

Abdominal terga in male, 738

Absorbent cells, 279

Acalypterata, 30

Accessory nucleus. See Paranucleus

Accommodation of compound eye, 532,566

Acephalous larvæ, 27

Acheta, antennæe of, 594

anterior tubercle of, 464

cerebron of, 454

corpora fungiformia of, 462

corpus centrale of, 459

nerve to ocelli of, 467

Achromatin, 266

Acilius, spiracles of, 157

Aconic eyes, 519

Acrididæ, Müller's organ in, 600

Active nucleus. See Nucleus

Aculeus of Hymenoptera, 729

Adenoid cells in larva, 85

Adenoid reticulum, 274

Aerial insects, I I air-sacs in, 224

Aerostats, 217
Eschna, development of male organ in, 731

movements of wing in, 164

Air-channels of proboscis in pupa, 398

Air expired during flight, 383

Air-sacs, 224

appearance of, 365

azygos, 398

modifications of, 365

of proboscis, 396

sternal, 226

structure of, 365

thoracic, 2 I 7

Airy on sound-waves, 619

Alar apophysis, great, 175

of scutellum, 176

Alar muscles, 637, 647

Alar syndesmosis, 167

Alary nerves, 64

Alimentary canal, 227, 389, 407

bibliography of, 389

changes of, in nymph, 3 I I, 33 I

comparative morphology of, $5 x$

development of, in embryo, 42 I

development of, in nymph, $33 \mathrm{I}$, 426

histolysis of, $3 \mathrm{II}, 3 \mathrm{I} 2$

of imago, 227, 389, 407

of imago and larva compared, 227

of larva, 55

of resting larva, 3

relations of, in imago, 227

Ametabola, metamorphosis of, Ig number of eggs in, I 9

Amnion, 24I

developed from epiblast, I6

relations to primitive band, 24 I

Amœboid cells, 265 
Amocboid protoplasm, fixation of, 272 Amphinematische Stifte, 597

Amphipneustic larva, 28

Ampulla, great, 182

lesser, Is 2

Ampullar muscle, 182,220

Anal area, I9S

somite, 728, 744, 746

Analogy of exoskeleton with vertebrate skeleton, 99

Andrena, sense of taste in, 630

Anisotropous substance, 285

Annuli, 8

Antenna, 582

auditory function of, 591

bibliography of, 582

development of, 322

functions of, $122,585,592$

hygroscopic function of, 593

minute structure of 587

morphology of, 108

olfactory function of, $582,585,592$

position of, 122

special sensory organs of, 584

tactile function of, 595

Antennal bristle, 122

Antennal ganglion, 445

of larva, $7 \mathrm{I}$

of nymph, 327

structure of, 467,468

Antennal insects. II

Antennal ridge, 12 I

Anterior abdominal fold, 303, $3 \mathrm{I} 8$

Anterior gonapophysis, 733, 739

Anterior legs, function of, 191

Anterior parascutum, 176

Anterior spiracle. See Spiracle

Anterior tubercle, 461, 464

Anterior ventricle of brain, 449

Anterior ventricle of dorsal vessel, 640

Anthony on suckers of proboscis,

394,401

Aorta, 637,638

Aortic bulb, 640

Aphaniptera, 20)

Aphis, amnion of, 243

primitive band in 245

sexual organs, development of, in, 703

sexual rudiments in, 248,251

yelk segmentation in, 237

Apis mellifica, alimentary canal, development of, in, 422
Apis mellifica, procerebral lobes in 457

trachex of, 353

Apodeme, II, I05

of laiorum, 140

of penis, 743

Appendages. Sec Lateral appendages

Appendicular discs of head, $8 \mathbf{2}$

Appendicular skeleton, IOI

Archenteron, 13

development of, 247

Aregmagene Insecten, 256

Arnold on intracellular origin of leucocytes, 309

Arthropods, limbs of, II 3

vision in, 554

Arthrosis, 10I, $\mathrm{IO2}$

Articulation, kinds of, Ior coxo-trochanteric, 193 posterior coxo-sternal, 192 tarsal, 194

Ascaris, spernatogenesis in, 720

Astacus, archenteron, development of, in, 249

brain of, 443

compound eye of, 506

optic ganglion of, 540

retinula of, 522

Atrium of tracher, 352

Atta, eyes of, 516

Auditory and olfactory end-organs, development of, 508

Auditory mechanisms, 595, 629

Auditory perceptions, 630

Auditory rods, 596, 597. Sec Chordotonal organs

Audouin on metapleuron, 174

on thorax, 155

on trochantin, 179

views of, 99

Auricular sinus, 637. See Pericardium

Axial threads of great rods, 525

Axis of head, changes in, 124

Axis cylinder of nerve, 67

nuclei of, 289

BACILLI of retina in compound cye, 533

in simple eye, 5 II

Balancer. Sec Halter

Balbiani on origin of gonads, 690

on polar cells, 690 
Balbiani on salivary cells, 267 on sexual rudiments, 248,690

Balfour on antennæ, 108 on biramous appendages, I 13 on development of nervous system, 479

on ova of insects, 7 10

on relation of germ to vitellus, I 2

Balken, 464

Barrois on embryology of Nemertids, 24,75

Basal ganglia. See Central ganglia.

Basement membrane, 37, 282

Basilar membrane of compound eye, 5 I 5,532

development of, 552

Bee. Sce Apis.

Bellesme. See Jousset de B.

Bellonci on corpora fungiformia, 446

Bellonci's bundle, 465, 467

Beneden, Van, on development of germ ova, 720

on spermatogenesis, 720

Biramous appendages, I 13,158

Blanchard on peritracheal circulation, 367

Blaps, maxilla of, I 33

Blastoderm, I3

origin of, in Insects, 233

relation of, to yelk, I7

Blastoderm plasma, 683

Blastopore, 24I, 248

Blastula stage of embryo, 23I, 233

Blatta, antennæ functions of, 593

brain of, I I 2,448

bursa of, 724

cœlom, development of, 255

compound eye, development in, 539

cornea of, 526

corpora fungiformia of, 462

dorsal organ of, 254

egg-tubes of, 669

generative organs of, 662, 664

hearing in, 497

intestine of, 410

number of abdominal segments in, 728

ovary of, 669

podical plates of, 736

primitive trace in, 253

salivary glands of, 404

spermatheca of, 724
Blatta, sutures of head in, I I 7 supracsophageal nerve centres of, 448

visceral nerves of, 65

Blood, 270 wings of, 160

Blood corpuscles, 27 I

division of, 270

of larva, 86,87

Blood crystals, 272 ,

Blood sinuses, 87 thoracic, 225

Blut-heerde, 274

Bobretzky on development of retina, 506,542

on origin of the blastoderm, 233

Bombus, mesosternum of, 168

tracher of abdomen in, 227

Bombylius, mouth-organs of, I 50

Bombyx mori, development of wing in, $2 \mathrm{I}$

Bombyx pini, sexual glands of, 685

Bourrelet intra-ganglionnaire, 489

Bourrelet perilaminaire, 490

Brachia of corpus centrale, 459

Brachyceræ, 29, 30

Brain, $45^{\circ}$

an automatic centre, 228

calices of, 46I

comparison with vertebrate brain, 450, 495

cortex of, 460

crossed relations of, 476

development of, in embryo, 44I, 483

external form of, 451

fibrous tracts of, 463

general morphology of, Iog

general structure of, I I 2,440

of Insects and Crustacea compared, 44I

nomenclature of Viallares, 442

size of, 440,450

structure of, II 2,450

tracheæ of, 365

Brandt, A., egg-cell of, 70I

on development of egg-tubes in Periplaneta, 669

on free nuclei, 717

on germinal vesicle, 7 I 7

on gonads, development of, 685 , 691

on normal hermaphrodism in Perla, 658 
Brandt, $\mathbf{A}$., on origin of blastoderm, 717

on ovary, 670

on ovary of Gryllus, 669

on ovary of Pelobates, 7II

on peritoneal coat of ovary, 670

Brandt, E., on infra-cesophageal nerves in Lepidoptera, $6_{3}$

Brauer on diaphragmata, ISo

on Dipterous larvix, 28, 29

on hypermetamorphosis, $\mathrm{I} \delta$

on metamorphosis, 20

Braulidx, 30

Brullé on the maxilla, I32

Bulb of optic nerve, 543

Bulb of penis, 743

Bulbus. See Bulb

Bulla. See Tympanic bulla

Burmeister on ecdysis of Diptera, 2

Bursa copulatrix, 675

development of, 704

of Hemiptera and Lepidoptera, 675

Buitschli on development of the dorsal vessel, 656

development of the embryo, 13

Malpighian tubes, 422

Buitschli and Schewiakoff on structure of muscle, 285

C ECXE of chyle stomach, 227, 410

Calices of cerebron, 461

Calliphora, 30, 31

cognata, 31

erythrocephala, 3 I

vomitoria, 31

Calypterata, 30

Campodea, is

larva of, 19

Canals of halter, 606

Capitellum of coxa, 174

of halter, 606, 607

of mesothorax, 191

Capsule of corpus centrale, 458

of neuroblast, 69

Carbolic acid a clearing agent, 348

Carbon dioxide, expiration of, 381

Cardiac nerves, 649

Carina, 187

Carnoy on nuclei, 268

Carriere palisade, layer of, 535

Cartilaginous tissue, So

Caterpillars, segmentation of, 729
Caterpillars, simple eyes of, 548

Cauliculus, I I2, 464

Cecidomyia, development of gonads in, 689

viviparous larve of, 723

Cell chaplet, 6I, 9 I

karyomitosis in, 270

of nymph, 343

Sce Pericardial fringes

Cell contents, 265

division, 269

growth in larva, 267

nests in chyle stomach, 58

substance, 264

Sec also Cells

Celloidin for imbedding, $34 \mathrm{~S}$

Cells, adenoid, 85

chitinogenic, 278

epithelial, 277

fibrillation of, 279

gangliogenetic, 480

intercalated, 276

mother, 276

mucigenic, 279

pigmented, 279

salivary, of larva, 60

serous, 279

spermatogenic, 693

trichogenic, 279

Cells for mounting objects, to make, 214

Central ganglia, 443

developinent of, 488,494

functions of, 495

Central nervous system. Sce Nervous system

Centrolecithal segmentation, 232

Cephalic cavity, contents of, 215

Cephalic discs. Sec Head discs

Cephalic involution, 315,316

Cephalo-pharyngeal band, 77

Cephalo-pharyngeal sclerite, 44

Cephalo-pharynx, 44, 40

muscles of, 51

Cephalo-thoracic discs in larva, 77

Cephalo-thoracic nerve-cord, 437

Cerci, 728, 736

Cerebron, 453

crura of, $46_{3}$

in Astacus, 447

in Acheta, 454

morphology of, 455

Cervical sclerites, II9

Chabrier on wings, 206 
Chatophora, I I

Chretotaxy, Io

Chaplet cells, 533, 534

Chiasma, internal optic, 472

Chilognatha, sexual ducts of, 735

Chironomus, development of dorsal muscles in, 337

development of nervous system in, 482

ganglia of, $6 ;$

oinocytes in, 276

polar globules of, $238,248,7$ I 5

Chitin, 8, 9, 265

Chitingabel, I4I

Chitinogenic cells, 278

Cholalic acid in Malpighian tubes, 415

Cholodkowsky on the coelom of Blatta, 253

on development of Blatta, 253

on segmentation cavity of Blatta, $25 \mathrm{I}, 252$

Chordotonal ligament, 596

Chordotonal organs, 2.29, 595

classification of, 595

compared with organ of Corti, 598

poriferous, 597

primitive, 596

Chorion, I2, 679

structure of, 680

Chromatin granules, 266

Chromo-acetic solution, 94

Chrysopa, circulation in wings of, 636

wing organs of, 620

Chun on rectal papillæ, 418,420

Chyle stomach in larva, 57

in imago, 217, 227, 409

cæca of, 227,410

cell nests in, 58

histolysis of, 312

Cicada, cause of sound produced by, 602

epistome of, I2 I

tymbals of, $60 \mathrm{I}$

Cicindela, abnormal ocelli in, I I 5 galea of, I33

Ciliary muscle, 533

Ciliary rods, $53^{\mathrm{r}}$

Cimbex, thorax of, I 88

Circulation in Insects, 635

Claparède on development of retina, $506,5+2$
Claparede on nuclei of Semper, 527

Claus on meröistic ova, 709

Claviculæ, 178

Claws. See Ungues, 194

Cloaca of male, 218

Cloacal pouch, 209

Cloëon, larva of, I8

Clouding during mounting, 98

Clypeus, 43, 107, I26, I 35, I 54

Clytus, wing organs of, 620

Cochleariform process, 144

Cockchafer. See Melolontha

Cockroach. See Blatta

Colom, 7 of larva, 85

of nymph, $340,3+2$

secondary cavities of the, 252

Coelomic plates, 253

Colomic sacs, 249, 25 I, 252

of Blatta, 253

segmentation of, 252

Cohnheim, fields of, 285

Coleoptera, anterior spiracle of, I8 r labium of, 14

movements of trachere in, $3^{83}$ wings of, 165

Collare, 165

Collembola, trachea of, 35 I

Colleterial glands, 673

Collodion, use in imbedding, 348

Collodionising sections, 347

Commissure of procerebral lobes, 456

Commissures of cerebron, 464

Compound eye, 515-526 accessory optic phenomena of, 577

accommodation in, 532, 566

aconic, 5 I 9

cornea of, 5 I 5

development of, 326, 538, 545

dioptron of, 515

euconic, 5 I9

evolution of, 574

general remarks on, 515

great rods of, 516

illumination of retinal image in 575

morphology of, 544

optical constants of, $58 \mathrm{r}$

pigment cells of, 530

pseudo-cone in, $516,528,55 \mathrm{I}$

pseudoconic, $5 \times 9$

pseudo-pupils in, 577 
Compound eye, received views on, 517

retina of, 533

trachece of, $365,530,538$

Compound sclerites, 105

Compressor muscle of frontal sac, 217

Compressor vestibuli muscle, 361

Condyle, I I9, I70, I79

Cone. See Crystalline cone

Connective reticulum, 273

Copilia, eye of, 565

Copulation, act of, 742

Coracoid, 199, 201

Corethra, discs in, 304 prothoracic horns of, 370

sexual rudiments in, 686

Cornea, compound, 515

development of, 527

kistoid, 526

number of facets in, 516

of Blow-fly, 526

structure of, 526

Cornea, simple, 5 Io

Corneal lenses considered as condensers, 558

Cornelius on the sexual act in Periplaneta, 664

Cornicula, $\mathbf{1} 79$

Cornu of fulcrum, 137

Cornu, stigmatic. See Stigmatic cornu

Coronary ganglion, $47 \mathrm{I}$

Corpora fungiformia, I I2, 327

comparative anatomy of, 46 I

compared with cerebellum, 446

development of, 483

discovery of, 461

in Astacus, 445

in 13latta, 449,462

in Diptera, 462

in Hymenoptera, 46I

in larva, 63, 70

Corpcra lutea of alimentary canal, $33 \mathrm{I}, 333,430$

Corps rosea, 273,297

Corpus centrale, 457

capsule of, 458

brachia of, 459

Corpus fungiforme. See Corpora fungiformia

Corpus luteum. Sec Corpora lutea

Corpus ovale, 470

Corical substance of the brain, 67 , 460
Cortical substance of optic ganglion, 471 of neuroblast, 69

Corvina. See Musca corvina

Costa, 169,182

Costal area, 198

Costal nervure, 201

Cotyloid cavity, 118,123

Coxa, 190

Coxo-sternal articulation, 192

Coxo-trochanteric articulation, 193

Cranefly. See Tipula

Crayfish. See Astacus

Cricket. See Acheta

Crista acoustica, 600

Crista, cephalic, 119

Crop, comparative anatomy of, 52 of imago, 2I 8,407

of larva, 56

of nymph, 213

Crura, ganglia of the, 466

Crura of the cerebron, 447

in Blow-fly, 463

development of the, in Blow-fly, 493

Crura of hemispheres of larva, $\sigma_{3}$

Crustacea, brain of, 444 development of metenteron in, 432

efferent genital ducts of, 734

integument of, 9

stalked eye of, 15

Crystalline cone, 516,528

functions of, 559

of Blow-fly, 528

of Mantis, 53 I

pigment cells of, $52 \mathrm{~S}$

refractive index of, 559

varieties of, 519

Crystals in blood, 272

in Malpighian tubes, 414

Ctenophora, trachee of pericardium in larva, 88

Cuccati, fibres of, 472

on corpus centrale, 459

Culex, larva of, 30

notes emitted by, 591

spiracles of, 472

Culicida, mouth organs of, I 50

Cupola of halter, 605

Cutaneous muscles of larva, 50

Cuticle, \&

Cuticular layers of integument, 28I structures, origin of, 280 
Cuvier on absence of circulation in Insects, 636

Cycloraphic Diptera, 29

lunula of, 125

Cynomyia mortuorum, 3 I

Cytogenic cells, 274

tissue, 274

DEGLUTITION in imago, 402

Delamination of nervous layers, 484

Deltoid sclerite, 203

Dens, 199

Dereham on fly's foot, 196 on halteres, 6 I6

Dermato-genetic cells, 480

Desvoidy. See Robineau - Desvoidy

Deuterocerebron, 442

Deuteroplasm, 708

Development, effect of temperature on, 4

of embryo in egg, 230

bibliography of, 230, 292

of nymph, 292

See also under each organ.

Dewitz on closed tracheæ, 358,380

on development of external generative organs, 731, 733

on development of limbs in vermiform larvæ, 2I

on passage of gases through integument, 379

on relation of spiracles to gills, 37 I

Diaphragmata, Io6

Diarthrosis, posterior thoracic, I7 I, 183

Dietl on antennal ganglion, 590 on Marksubstanz, 66

Dilator pharyngis muscle, 390

Dimmock on proboscis, 398

Dioptric theory of vision, 560 illumination of the retina in, 575

Dioptron, 5 I 5 of Blow-fly, 526

pigment cells of, 530

structure of, 526

tracheæ of, 530

See also Compound eye

Diplostichous ocelli, 5 I 2

Diptera chretophora, I I

development of, in egg, 230

eremochata, II
Diptera, ganglia in, 64

general characters of, 25

larva of, 27

metamorphosis of, 20

nematocera, 30

relations of, to other insects, 26

sub-orders of, 29

wings of, I64

Direct nuclear division, 270, $27 \mathrm{I}$

Directive corpuscles, 7 I 4

Disc. See Imaginal disc

Disc holder, 2 I 2

Discal area, 198

Discal sclerites, I 43

Discophore, 148

Dissecting microscope, 212

Dissection, directions for, 2 I I

Distal intestines of larva, 58

Distal retina of Parker, 531

Dogiel, nerves of, 478

Dohrn on development of nervous system, 48I

on development of Malpighian tubules, 423

on metenteron of Hymenoptera, 423

on relations of Insects to Vertebrates, Iog

Dolichopus, anterior legs of, I9I genital armature of, 739

Dolium, I83, I87

Dominant sensations, 497

Donacia, amœboid movements of yelk in, 7 I 5

Dorsal aspect of the thorax, 166

Dorsal muscles, 187,223

action during respiration, 377

development of, 336

functions of, I 87,377

histology of, 283

Dorsal organ, I7, 254, 255

Dorsal plate. See Dorsal organ

Dorsal valve of thorax, I75

Dorsal vessel, bibliography of, 635 , - 656

development of, 656

Dorsal vessel of imago, 639 alar muscles of, 637,647

Dorsal vessel, demonstration of, in action, 655

dissection of, 639

histology of, 644

inhibition of, 655

physiology of, 650 
Dorsal vessel, rate of pulsation in, 654,655

relations of, 639

relations of, to pericardial septum, 643

valves of, 638,641

valves, action of, 652

Dorsal vessel of larva, 87

structure of, 91

ventricle of, 87

Dorsal vessel of nymph, 340

changes during development, 341

morphology of, 92

Dorso-pleural costa, 175

Dorso-pleural diarthrosis, 176

Dorso-pleural suture, 167

Dragon-fly. See Libellula

Dufour, aërostats of, 217

on inter-segmental spiracles, 35 )

Dujardin on corpora fungiformia, $46 \mathrm{I}$

Duponchel on hygroscopic function of antenna, 594

Duration of larval stage, 2 of pupa stage, 3

Dytiscus, experiments on nervous system of, 476

EARWig. Sec Forficula

Eau de Javelle, 349

de Labarraque, 349

Ecdysis, I7

of larva, 2

relation to metamorphosis, 23

of tracheal intima, 307, 339, 356

Echinodermata, development of embryo in, 230, 231

metamorphosis of, 24

Eciton, eyes of, 516

Ëgg, development in, 230

development of, 701

bibliography of, 678

deposition of, 5

fecundation of, 1

form of, 678

of Birds and Insects compared, 12

position of embryo in, 678

size of, 678

ligg-celi, 701

Egg-stocks, 699
Egg-tubes, 607

Ehrlich's Hacmatoxylin solution, 96

Eingesprengte zellen, 274

Ejaculatory duct, 665

Ejaculatory sac, 665

Ellipsoidal body, 458

Embryo, 13, 230

lepidopterous, $24 \mathrm{I}$

number of segments in, 15

nymphoid stage of, 257

position of, in egg, 678

preparation of, 347

retrograde development of, 2

Embryology, 12, 230

bibliography, 230, 235

Embryonic cells in salivary gland, 60

Embryonic epithelium, 278

Embryonic membranes, 241

Embryonic rudiments, nomenclature of, 22

Emery on proventriculus, 409

Empis, anterior legs of, I9I

Enchylema, 264

End-organs, motor, 289 of proboscis, 402

End-plates. See End-organs

Endogenous cell division, 693, 696, 719

Endolecithal, 245

Endopophysis, I06

Endosclerites, 105

Endoskeleton, 9

Endosternum. See Entosternum

Endostracum, 9, 10, 36

Endothelioid cells, 85

Endothelium, 273

Entocephalon, 123

of Syrphus, 124

of Volucella, 124

Entoconcha, germinal vesicle of, 7 II

Entopleuron, great, 172

Entosternum, I06 development of, in Hydrophilus, 481

Entothorax, 172

Eosin, use of, 348

Epaulet, 200

Ephemera, genital ducts of, 735 tracheal gills of, 180

tracheal system of, 355

Epiblast, I 3 delamination of the, 484

Epicondyle, 179

Epicosta, is: 
Epicranial suture, i 7

Epifrontal sclerite, I 15

Epifurca, I43

Epilecithal, 245

Epimeron, 182, I86

Epiostracoid layer, 280

Epiostracum, 10, 35, 280

Epiphallus, 74I

Epipharynx, r37 of larva, 46

Epipleuron, 160

Epipygium, 210,744

Episternum, I 82 of metathorax, I86

Epistome or Epistomum, I I 5, I 2 I

Epithelia, 277

Epithelium of crop in imago, 407

Epitrochlear plate, 169

Epitrochlear sclerite, 174

Eremochæta, II

Erichson on function of antennæe, 589 on labium, I3I

Eristalis, dorsal vessel of, 284,649 humming sound of, 628

trachere of retina in, 538

vibration of wings in, 628

Escape from pupa case, 216

Eucephalic larvæ, 28

Evagination of head and thorax, 317

Evanescent sclerites, 105

Exner on compound eye, 559, 561, $577,579,664$

Exogenous cell division, 696

Exosclerites, 105

Exoskeleton, 99, 2 I I

of abdomen, 209

of legs, 190

Expiratory pressure, 378, 379

Extension of wing, 202

External generative organs, 724 comparative morphology of, 732 development of, 730

of female, 745

of male, 736

Exuviæ, artificial, 212

Eye, a physiological term, 50 I cephalic, 504 epiblastic, 506

median, 504

pineal, 504,505

sporadic, 505

See Compound eye and Ocellus

Eye-like organs of larva, 7 I

nerve to, 82
FABRICIUS, rostellum of, I 39

Fabre on hyper-metamorphosis, I 8

Face, I2I

Faivre on nervous system, 476, 477

Faltenblatt, 244

Fan-shaped body, 459

Fat bodies, 274

development of, $236,253,274$

histolysis of, 307

Fat-cells of imago, 275

of larva, 85, 274

Fat, relation of, to proteids, 309

Femoro-tibial rudiment, I 59

Femur, 192

Fenestra of coxæ, I9I

Ferment theory of histolysis, 3 II

Ferments of Malpighian secretion, 416

Fillet of nodulus, 456

Films, action of gases on, $3^{3} 2$

Fixation of tissues, 94, 349

Flea. See Pulex

Flight, 206, 385, 387

air expired in, 383

mathematical theory of, 387

movement of wings in, 203

rapidity of, 386

work of, 385

Flögel on the brains of Insects, 440

Food-yelk, I3, 708

Foot of fly, I94

bibliography of, I9o

mechanism of, 197

Fore-gut, I3. See Stomodeum

Fore-head, I20

invagination of, in embryo, 26I

Forel on aeria and antennal Insects, I I

on function of antennæe, 592

Forficula, cornea of, 526 epicranial suture of, II 7

larva of, 18

moults of, 18

skeleton of head in, II

Formicidæ, eyes in, $5 \mathrm{I} 6$

proventriculus of, 409

Free formation of nuclei, 7 I I, 7 I 6

Frons, I 21

Frontal sac, 4, J 24, 216

morphology of, II 5

relation to proboscis, 397

Fulcrum, 44, I 37

morphology of, 138

muscles of, 392 
Fulcrum of imago, 137

of larva, 44

See Pharynx

Furca, 143 muscles of, 392

Furlonge on movements of tracheal vessels, 383

GALEA, I33, I34, I 50, I 52

in Cicindela, I 33

Gammarus, ventral appendages of, 129

Ganglia, cells of. See Nerve-cells development of, 494

intestinal, of larva, 59

number in Diptera, 64

optic, 469

pharyngeal, 93

primitive, 64

sensory, 443

thoracic, 435

Ganglio-genetic cells, 480

Ganglion en coin, 471

a côtes de melon, 72

Ganin on development, of Gonads, 686

of imaginal discs, 74,76

of integument of abdomen, 328

of mesoblast, 335

Ganin's ring, 58, 427

Gases, partial pressure of, 382

Gaskell, hypothesis of, 99, I IO, 44I

Gastric glands, 54

Gastrula stage, $2+0$

of Amphioxus, 247

of Echinoderms, $2+7$

Gastrulation, 240

Gegenbauer on tracheal gills, 356

on wings, $\mathrm{I} G \mathrm{r}$

Generative aperture, position of, 727

Generative armature of male and female compared, 726

Generative organs, 658

bibliography of, 658

See also Internal and External generative organs

Genital. Sec also Generative

Genital cord, 687,704

Genital fossa, 675,677

Genital spine, 675

Germ, I 2

relation to vitellus, 236,707
Germ gland. Sce Germogen

Germ ova, 675

development of, 718,720

Germinal spot, 707

Germinal vesicle, 707

Germogen, 709, 721

Gerstfeldt on fulcrum, ${ }_{3} \mathrm{~S}$

Gills. Sce Tracheal gills

Gilson on spermatogenesis, 693,696

Glands of fly's foot, 198

Glands, wax, 279, 352, 360

Gleichen on halter, 615

on proboscis, 398

Glomeruli of olfactory lobe, 468

Glosso-olfactory bundle, 468

Glosso-pharyngeal apophysis, 138 , 140

Glycerine, mounting objects in, 214

Glycogen in Malpighian tubes, 416

Gnat. See Culex

Gonads, 659 origin of, 684

in Aphides, 248, 251

in Cecidomyia larva, 689

Gonapophysis, 659, 728

anterior, 732

posterior, 733

Gosch on Latreille's segment, I 89 on spiracles, 181

Gottsche on mosaic vision, 555

Graber on antennx, 592

on chordotonal organs, 595

on development of fat bodies, 236

head discs, 261, 300

on dorsal vessel, 644

on hearing in Insects, 498

on Malpighian tubes, tit

on nymph, 300

on ovary, 671

on pericardial septum, 646 ,

on ptycoblasts, 243

on segmentation cavity, 252

on special nerve organs, 609

on thorax, 165

on tracheal gills, 160

on wing organs, 620

Graber, oryan of, 601

Gracilis muscle, 221

Graff on Rhabdocolia, 722

Graham on transpiration, $3 \mathrm{~S} 2$

Granule cells, 273, 297

Gray cortex of nerve centres, 67 of thoracic ganglion, 438 
Great apodeme of penis, 743

Great cephalic disc. See Head disc

Great entopleuron, I72

Great hooks of larva, 40, 45

Great rods of compound eye, 516 axial threads of, 525

functions of, 559

morphology of, 523

post-mortem changes in, 525, 529

structure of, 524, 529

supposed innervation of, 52I, 522

theory of, 530

Great thoracic muscles, 223

action of, 224

Grenacher on compound eye, 519

on cornea of compound eye, 528

on eye of Limulus, 547

on innervation of compound eye, $52 \mathrm{I}$

on membrana basilaris, 532

on ocelli, 5 I6

on retinal end-organs, 520

on vision in Arthropods, 555

Griffith on Malpighian tubes, 4 I 5

Gryllotalpa, development of, 233

Gryllus, ovary of, 669

supra-tympanic organ of, 602

HAARSTIFTE, 596

Habits of Blow-fly, 5

Haeckel on the position of the Diptera, 26

Hæmal surface, 8

Hæmatoxylin solution, 96

Halliburton on Pettenkofer's reaction, 4I 5

Halter, 25, 603

basal organs of, 6 I I

canals of, 606

capitellum of, 607

chordotonal organs of, 607 , 613

comparison of, with semicircular canals, 616

cupola of, 605

development of, 612

effect of sound vibrations on, 618

experiments on, 616

functions of, 6I4, 6IS

ganglia of, 435
Halter, general description of, 604

hearing, relation to, 6 I 8

homologies of, I 88

morphology of, 188,603

movements of, 604

nerves to, 217, 229, 605

of Leptis, 606

of 'Tipula, 606

removal of, 377,617

rudiments of wing in, 607

scabellum of, 604

scapal organs of, 6i I

septum of, 608, 609

special end-organs of, 609

Hammond on genital organs of Tipula, 742

on head of Tipula, 28

on thoracic muscles, 223

Hamulus, 202

Harvey on metamorphosis, 19, 24

Hatschek on nerve ganglia, 48 I

Hauser on functions of antennæ, 592

Haustellum, I.35

muscles of, 392

Head, axis of, 124

of larva, 33,37

Head capsule, I 19

bibliography of, I I 9

contents of, 2 I 5

development of, II 3

general morphology of, I06, I I3

muscles of, 2 I 9

nomenclature of, $\mathrm{IO} \mathrm{F}$

of immature imago, I 24

posterior surface of, I 22

segmentation of, I 4

Head, development of, in nymph, 320

Head discs in larva, 77

invagination of, in embryo, 259

Headless larvæe, 27

Hearing, a warning sense, 497

centres of, 474

in Blatta, 497

organs of. See Auditory organs

Heart. See Dorsal vessel

Hearts, accessory, 636

Heathcote on Julus, I 57

Heber, 363

Heiden on median element in ganglia, $48 \mathrm{I}$

Hemiptera, head of, II 5

protandry in, 723

Hemispheres of imago, 45.3 of larva, 68, 483 
Henking on germinal vesicle, 713 on micropyle canal, $6 \$ 2$ on nuclear changes in ovum, 7 I5 on nutrient cells of eagr, 702

Hensen on eye of Nautilus, 508

Hepato-pancreas, 417

Hermaphrodism, 65

Herold on abdominal ganglia, 439

on dorsal vessel in pupa, 340

on micropyle canal, 682

on origin of gonads, 685

on parovarium, 674

Hertwig on mesenchyme, 235

on spermatogenesis, 693, 694, 719

Hicks on function of halter, 6 I 5

on special end-organs, 609

on wing organs, 620

Hickson on compound eye, 523 on development of cornea, 527

Hilaire, G. de St., views of, 99

Hind-gut. Sec Metenteron.

Hinterast, 46 I

Hippoboscida, 30

His on origin of sensory end-organs, 508 on parablast, 235

Histoblast, 22

Histoblasts in chyle stomach of larva, 5 S, $31 \mathrm{I}$

Histology of tissues, 262 bibliography of, 262 Leydig on, 47

Histolysis, 22, 23, 273, 29? of alimentary canal, 311

of fat bodies, 30;

of hypodermis, 299

of larval muscles, 297

of muscle nuclei, 299

of salivary glands, 310

Hofer on visceral nerves, 6 ;

Holoblastic ova, 236, 707

Homoptera, cephalocale in, 115

Honey-bas of Bee, 52

Hooks of larva, 40,45

Humerus, 169

Humming of Diptera, 627

Hurst on functions of antennac, 592 on spiracles of Culex, 370

Huxley on development of archenteron in Astacus, 249

of utero-vaginal tube, 703

on homologies of external generative organs, 726
Huxley on nomenclature of layers of skin, 9

on procephalic lobes, I Io

Hyaloplasm, 264

Hybernation, 6

Hydrophilus, dorsal organ of, 255

entosternum of, 481

nervous system of, 479

trachex development of, 353

Hygroscopic function of antenna, 593

Hylotoma, embryo of, 246

Hymenoptera compared with Diptera, 26

development of eye in, 543

gonapophyses of, 728,733

hind-gut of, 423

labium of, If

male organ of, 728

median segment of, I\&S

metamorphosis of, 20

mouth organs of, 128

operculum of, 179

ovipositor of, 731, 734

sting of, 729, 73I

wings of, 164

Hyoid sclerite, 148

Hyper-metamorphosis, IS

Hyperia, ommateum of, $54 \mathrm{~S}$

Hypoblast, 13

origin or, 247

Hypoderm, 8,37

cells of the, $27 \mathrm{~S}$

histolysis of, 299

of larva, 37

Hypoglossa, I 4 I, I 43

Hypophallus, $7+1$

Hypopharynx, 137, 147, 154

errors regarding the, 1.32

of larva, 44

Hypopleural suture, I6S

Hypopterygium, 202

Hypostomal sclerite, 44

Hypotreme, 173

IDEAL thoracic segment, 150

I maginal discs, 21

abdominal, 329

anterior spiracular, $S_{f}$

appendicular, of hear, 82

bibliography of, 72

causes of immunity to histolysis, 310 
Imaginal discs, cephalothoracic, 77 development of, 74, 305 evolution of, 305

history of discovery of, 73 inferior thoracic, 83

labial, 83

$\operatorname{leg}, 83$

maxillary, $8_{3}$

mesoblast of, 77,334

morphology of, $72,73,304$

number of, 4

origin of, 74

relations of, in nymph, 315

relation to paraderm, 303

structure of, 334

thoracic, in larva, 83

upper thoracic, 319

Imaginal rudiments. See Histoblast Imago, 4

development of, from nymph, 344

escape from pupa, 4

immature, 4,216

Imbedding, methods of, 95

Immature head capsule, 124

Immunity of imaginal tissues in pupa, $3 \mathrm{IO}$

Indirect cell division, 269

Infra-œsophageal ganglia, 465

functions of, 475

of pronymph, 313

Insects, anatomy of, bibliography to, 7

relation of, to Vertebrates, 109

Instincts of female Blow-fly, 5

Integument, abdominal, 328 development of, 280, 3I 8, 344

of head and thorax, 318

of larva, 35

Intercalated cells, 276

Intercellular matrix, 264

Intermediate substance of musclefibres, 285

Internal generative organs, descrip. tive anatomy' of, in female, 666 in male, 660

bibliography of, 684

development of, 684

Internal anal valves, 744

Internal light of retina, 577

Internal ridges of thorax, 185

Internal skeleton of head, I I9

Internal tubercle, $46 \mathrm{I}$

Intersegmental muscles, 2 I9
Intersegmental spiracles, I8I, 319, 359

Intestinal coil, in embryo, 426

in nymph, 430

Intestinal ganglia of larva, 59

Intracellular digestion, 297

Intratracheal pressure, 377

Intratracheal valves, 366

Invagination of head discs in em-

Iris, 531 bryo, 259

Iris cells, 529

Isotropous substance, 285

Jackson, H., on head segments, Io8 on development of oviducts, 704 on parovaria, 674

Jaw orowski on dorsal vessel, 285 , 656

Joints, IOI

Jousset de Bellesme on halter, 6I 5, 610

Jugum, I I9, I22, I23

Julus, Heathcote on, I 57

Jurine on flight, 206

Karop on mounting objects in glycerine, 214

Karyokinesis, 269, 270

in muscle, 287

in spermatogenesis, 696

Karyomitosis. See Karyokinesis

Karyoplasm. See Nucleoplasm

Keimfach, 709

Keimstreif, 245. See Primitive band

Kennel on yelk segmentation, 237

Kistoid cornea, 526

Kolliker on eye of Astacus, 506 on classification of eyes, 505

Körnchenkugeln, 273, 297. See Granule cells

Korotneff on development of Gryllotalpa, 233

Korschelt on chorion, 680 on vitelline membrane, 683 on nutrient cells of egg, $7 \mathrm{O} 2$

Kowalevski, dorsal organ of, 17, 254 on cell chaplets, 343

on development of brain in Sagitta, 487

on development of nervous system in Hydrophilus, 479 
Kowalerski on development of salivary glands, $43 \mathrm{I}$

on dorsal vessel of pupa, $34 \mathrm{I}$

on histolysis, 298

on histolysis of alimentary canal, 3II

of chyle stomach, 312

of fat bodies, 307

Kraatz on nomenclature of generative armature, 725

Krancher on spiracles, 361

Kräpelin on flow of saliva, 378

on frontal sac, 397

on function of antennx, 583,590

on hermaphrodite Bees, 726

on male generative organs, 726 , $73 \mathrm{I}$

on muscles of proboscis, 39I

on proboscis, 14r, 39r, 396

on smell in Insects, 499

Krause, membrane of, 283,287

Künckel d'Herculais on development of abdominal somites in Volucella, 730

on end-organs of proboscis, 403

on histoblasts, 22

on maxillary discs, $8_{3}$

on mesoblast of discs, 77

on wing muscles, 220

LABHAL discs of larva, 82

Labial glands, 393, 405

Labial palpi, 132

Labium, I31

morphology of, 129

of larva, 43

Labral nerves, 63

Labral sclerite, 45

Labruni, 154. See Prelabrum development of, in embryo, 258 of larva, 43

Labrum epipharynx, 154

Lacaze-Duthiers on generative armature, 725

Lachât and Audouin on imaginal discs, 73

Lacina, 133

Lamellibranch and Insect embryo compared, 244

Lampyris, eye of, 561

Lancets, paired, of Diptera, $15 \mathrm{I}$

Landois on blood of Insects, 272 on sound production, 627

on spiracles, 361,363
Landois on trachere, $38_{3}$

Lankester and Bourne on preretinal membrane, 512, 513

on diplostichous ocelli, 512 on eye of Limulus, 547

Lankester on endothoracic skeleton, 80

on eye of Nautilus, 507

Larva, aceplualous, 28

anatomy of, 32

bibliography of, 32

ecdysis of, 2

external form of, 32

formation of, from embryo, 257

length of life of, 2

of Cloc̈on, I 8

of Forficula, 18

of Staphylinus, i 8

Lateral fissure of cerebron, 454

Lateral ganglia, 65

Lateral nerves, 64

Lateral plate, 168, I 72

of fulcrum, 137

Latreille, median segment of, I 55 I 88

on chitin, 9

on posterior thoracic spiracle, I 88

Lee, chordotonal organ of, 607, 613

on end-organs of halter, 610

on spermatogenesis in Chretognatha, 693, 695

Leeuwenhoek on Fly's foot, 196

Lefebre on function of antenna, 589

Leg, anterior, functions of, I9I

muscles of, 221

Leg discs, 83,320

Lehmann on antennx, 591, 593

Lemoine, nerves of, $47 \mathrm{~S}$

Lendenfeld on flight, 207

Lenses, cylindrical, 559

of compound eye, 526

Lenticular bodies of integument, 37

Lentiscus, 470

Lepidoptera, abdominal somites of larva of, 729

amnion of, 241

infra-cesophageal nerve in, 63

mouth organs of, 128

in larva, 39

relation of embryo to yelk in, 24I

spermathecae of, 724

trachee of, 365

vision in, 497 
Lespés on antenna, 590

Leptis, halter of, 605

Leuckart on development of alimentary canal, 423

on germinal vesicle, $7 \mathrm{I} 2$

on gonads in Cecidomyia, 689

on nerves in Pupiparæ, 65

on origin of blastoderm, 234

Leucocytes, in fat-cells, 308 intracellular origin of, 309 multiplication of, in muscle, 299 origin of, 274

See Blood corpuscles

Leucomaines, 310

Lewis on Notochrysa, 498

Leydig on chordotonal organs, 613

on chorion, 680

on cuticular structures, 28 I

on functions of antennæ, 589

on halter, 609

on internal light of compound eye, 577

on rectal papillæ, 420

on relations of Insects to Vertebrates, 109

on Sehstäbchen, 518

on tracheal capillaries, 47

on wing muscles, 283

Libellula, cephaloceles of, I I 5, I I9

compound eye of, 516

flight of, 207

rectal glands of, 420

thoracic muscles of, 223

wings of, 162

Life history of Blow-fly, I bibliography of, I

Light, action of, on eye pigment, 532

Ligula, I 47 in larva, 42, 44

Limulus, compound eye of, 547

Lina, amnion of, 255

Lingual glands, 405 of larva, 59

Lobster. See Astacus

Locusta, genital armature of, 729 gonapophyses of, 732 maxillæ of, I 33

Loew, scutellar bridges of, 167

Logwood stain, c5

Longet on functions of nervous system, 475

Loss of weight in pupa, 309

Lubbock on functions of antennæ, 591
Lubbock on parthenogenesis, 723

on sensations peculiar to Insects, 500

Lucilia, 30, 3I

salivary glands of, 406

Lunula, I21, I24, I26

Lyonet on respiration, 376

Macleay on thorax, 157

Macloskie on mouth of larva, 38,44

Macula germinativa, 707

Malleolus of coxa, I9I

Malpighi on circulation in Insects, 635

Malpighian tubes, changes of, in pupa, 312

development of, 249, 4I 4

general morphology of, 54, 4I4

hepatic nature of, $4 \mathrm{I} 6$

in imago, 412

in larva, 61

in nymph, 332

secretion of digestive power in, 430

Mandible of Tabanus, 128

Mantis, development of nervous system in, 480

nerves to cone of compound eye, 523

prothorax of, 180

Mantispa, metamorphosis of, I8

Mantle layer of brain, 489

Manubrium, I73

Marey on flight, 206, 207

Matrix, intercellular, 264

Matrix sclerites, 105

Maxilla, I 32

development of, in larva, 258

eye-like organs on, 7I

galea of, 133

morphology of, 132

of Cicada, I 3 I

of Locusta, 133

of Phytophaga, I33

of Xylocopa, I 33

synonymy of, I34

upper lobe of, 134

Maxillary discs, 82

Maxillary palpi, I 35, I 5 I

functions of, 403,632

of Pulex, 152

of Tabanus, I 50

Mayer on development of hind-gut, 432 
Mayer on development of (rachea, 354 on meröistic ova, 709)

Mechanism of tlight. See Flight

Mechanism of Fly's foot, 197

Median eyes, position of, I2I

Median fissure of cerebron, 453

Median ganglia of larva, 93

Median segment, 188

Median tooth of larva, ti

Medulla of nerve ganglia, 66

Meigen on abdominal ganglien, 436

Melöe, metamorphosis of, $\mathbf{I} 8$, ovary of, $668^{\circ}$

Melolontha, dorsal organ of, 255

dorsal vessel of, 650

flight of, $3^{85}$

muscles of, 2 I 9

post-scutellum of, 186

respiration in, 374

wing sclerites of 201

Membrana basilaris of dioptron, 532 developmient of, 552

Membrana fenestrata. See Membrana basilaris

Membrana tympani. See Tympana, and 'Tympanic membrane

Membrane of Krause, 287

Membranes of egg, 12 embryonic, of Insects, 24 I

Mentum, 143

Menzbier on development of proboscis, 322

on fulcrum, 1.38

on head discs, 322

on head slieleton of larva, 40

Meroblastic ova, 708

Meröistic oval, 70I, 709

Mesencephalon, 444. Sic Cerebron

Mesenchyme, 235, 333. Sce Parablast

Mesenteron, I3 general morphology of the, 53 of embryo, 249

redevelopment of the, $33 \mathrm{I}, 426$, 427

Sce also Alimentary canal

Mesoblast, 13

of discs of larva, 77

origin of, in embryo, 251

Sice also Mesoderm

Mesocerebrnn. 445,453

lobes of, 453

of Astacu=, 445

Sic Cerebron
Mesoderm, 333, 335

Mesofrontal sclerite, 115

Mesogenital somite, 728,743

Mesolabrum, II 5

Mesophragma, 17 I, I85

Mesopleural syndesmosis, I67, I87

Mesopterygium, 163

Mesosternum, 171 of 13 ombus, 168

Mesothoracic muscles, 223

Mesothorax, i5t

Metabola, metamorphosis in, 23

Metacephalic ring, 122

Metacerebron, 444 of Astacus, 447

Metacranial annuli, I 8

Metafurca, 174

Metagenital somite, $728,7+3$

Metalabrum, II 5

Metamere, 8

Metamorphosis, I8, 23

Metapleuron, I\%0, I74, IS6

Metapneustic larvæe, 28

Metapterygium, 163,203

Metasternum, 174

Metathorax, 155, I 86

Metencephalon, 444

Netenteron, I7, 53, 249, 33 I, 4I I

Methods of study, 93, 347

Metschnikoff, or Metschnikow, on causes of immunity from histolysis, 3 ro

on development of Simulia, 254

on germinal vesicle, $7 \mathrm{I} 3$

on gonads in Cecidomyia larva, 689

on intracellular digestion, 247

on yelk segmentation in Scorpions, 239

Meyer. Sie Mayer

Micropyle, 6SI

Micropyle canal, 682

Mid-cut. Sec Mesenteron

Milne Edwards on germinal vesicle, 711

Mirror, IS5, 626

of Cicada, 6or, 625

of Locusta, 60 I

Mononematische Stifte, 597

Monostichous ocelli, 512

Morula, formation of, 239

Moseley on salivary glands, 54

on trachee, 356

Mother cells, 276 
Motor end-organs, 289

Motor tracts, 476

Moults, larval, 2

Mouth armature of larva, 37

Mouth of imago, I 36, 390

of newly-hatched larva, $4 \mathrm{I}$

organs of Bombylius, 150

of Caterpillars, 39

of Culex, I 50

of Lepidoptera, I 28

of Tipula, I 50

Movement, effect of, on vision, 57 I

Movements of proboscis, I39 of wings, 203

Mucin, 265

Mucinogenic cells, 279

Mucoid degeneration of cells, 265

Müller on auditory mechanisms, 595

on compound eye, 522

on germinal vesicle, 7 I I

on parovaria, 674

on sensation, 499

theory of vision of, 554

Müller's ganglion, 624, 625 organ; 586,600

Musca corvina, 30 domestica, 30

Muscidæ, 30

amnion of, 243

development of, 230

development of nervous system in, 483

Muscles, classification of, 2 I $\&$

cutaneous, of larva, 50

development of, 287,336

dorsales, I87, 223

great thoracic, 187 development of, 336

histology of, 282

histolysis of, 297,298

lateral, 220

nerve terminations in, 289

of head, 219

of larva, 50

of legs, $22 \mathrm{I}$

of proboscis, 39I

of wings, 220

somatic, varieties of, 282

visceral, structure of, 283

wing, structure of, 283

Muscular system, 2 I 8

Musculus accessorius, 220 compressor vestibuli, $36 \mathrm{r}$
Musculus dilator pharyngis, 390

gracilis, 22 I

Myopa, abdominal sterna of, 739

Myrmecia, hearing in, 498

NACHEMBRYOLOGIE, I 2

Nassonow on segmental organs in Insects, 707

Nautilus, eye of, 507

Nebenkern, 269. See Paranucleus

Neck, 178

development of, 320

Nematocera, 29, 30 antennæe of, 585

See Culex and Tipula

Nemertids, embryology of, 24

Nephila, webs of, 497

Nerve-cells, 67, 289

of pericardium, 649

Nerve-centres, 66, 433

relation to those of Vertebrates, I I I

See Brain, Thoracic ganglion, Stomogastric nerve, etc.

Nerve end-organ. See End-organ, Retina, Chordotonal organs, etc.

Nerve-fibres, 289

Nerve, median, of larva, 57 pericardial, 649 roots of thoracic ganglion, 435 terminations in muscle, 289

Nerves, abdominal, 436 accessory dorsal, 436 antennal, 469 cardiac, 649 cells in, 289 cerebral, 453 development of, 324,328 dorsal, 436 infra-cesophageal, 63 labral of larva, 63 lateral of larva, 64 maxillary, 466 of Dogiel, 478 of Lemoine, 478 of mouth organs, II 3 of ocelli, 467 of proboscis, 402 of rectal papillæ, 420 of simple eye in larva, 82 pharyngeal, 466 stomogastric, 228 
Nerves, structure of, 288 thoracic, of imago. 435 visceral, of larva, 63

Nervous system, $62,228,433,479$ bibliography of, $62,433,479$ comparative morphology of, 62 development of, 479

functions of, 228, 473 morphology of, 494 See also Neuroblast

Neural crest, 482

Neural disc of optic stalk, 545

Neural surface, 8

Neuroblast, 22, 67, 68 cells of, 480 changes of, in nymph, 324 changes of, in pronymph, 49I of adult larva, 490 position of, in pronymph, $3 \mathrm{I}_{3}$

Neuromeres, 157

Neurospongium, 535

Newly-hatched larva, 2 nerves of, 65 stomal disc of, 42

Newport on alary nerves, 64 on aorta, 638 on lateral nerves, 64 on nervous system of Myriopoda, 477

on trachex of Bombus, 227 on visual organs of Cistrus larva, $7 \mathrm{I}$

Newport's segment, 34, 35, 748. Sec Metacephalic ring

Newton on Cauliculus, 464 on optic ganglia of Lobster, 540

Nodes of Ranvier, 289

Nodulus, 456,458

Notochrysa, hearing in, 498 pygidium of, 629

Notthaft on vision in Arthropods, 557

Nuclear division. Sec Karyokinesis and Direct nuclear division

Nuclear nucleoli, 268

threads, fibres, or skeins, 266

Nucleolus, 268

Nucleoplasm, 266

Nucleus, 264 accessory. See Paranucleus active, 269

free, 716

histolysis of the, 308, 713 of Graber, 613
Nucleus resting, 266

Nussbaum on development of sexual ducts, 703

Nutrient cells ol egg, 701

Nycteribix, 30

Nymph, development of, 292 bibliography, 292

on fifth day, condition of, 330

relations of imaginal discs in, 315 sections, mode of preparing, $34^{8}$ tracheal ecdysis of, 339

Nymphoid stage of embryo, 257

OCELLUS, abnormal, in Cicindela, II 5

compared with pineal eye, II5 514

development of, 5 I4

in nymph, 345

lens of, $5 \mathrm{IO}$

morphology of, 512

nerve to, 467,494

pigment cells ot, 5 II

preretinal membrane of, 512

retina of, 5 IO , 5 II

structure of, 510

Oculo-olfactory bundle, 468

Esophageal commissures of larva, 491

connectives in Orthoptera, 449

Esophagus of imago, 407

of larva, 56

of nymph, $3 \mathrm{I} 4$

Estrus, pharynx of larva, 46 pronymph of, 293

visual organs of larva of, 7 I

Oinocytes, $27 \%, 276$

bibliography of, 276

Oken on antennx, 589

Olfactory bulbs. See Antennal ganglia

cones, 588

sense, $49^{\circ}$

Omentum of larva, S6. See Fat bodies

Ommateum, 516

compared with astronomical tele. scope, 562

development of, 546

$\mathrm{Sec}$ Compound eye

Ongulaire, 209

Operculum, 4

of Hymenoptera, 179 
Optic cap, 452, 472 development of, 473

Optic constants of compound eye, 581 Optic cup, 326

Optic discs in larva, 8o in nymph, 327

Optic ganglion, 45 I, 469

in Astacus, 446

cell-groups in, $47 \mathbf{I}$

development of, 483

evolution of, in pronymph, 492

structure of, 469

Optic nerve, 469,470

external chiasma of, 537

supposed terminations of, in great rods, 537

Optic peduncle, 452,469

Optic stalk, 8o, 8I, 327, 545 development of, 327

Optogenic cells, 547

Oral lobes, 395

Oral sucker of proboscis, 135

function of, 397

inflation of, 397

internal structure of, 393

skeleton of, 135

Orthoptera, auditory organs of, 595 brain of, 462

chordotonal organs of, 595

labium of, I4

mesosternum of, 168

metameres of, I 5

protandry in, 723

sexual act in, 664

tympana of, 599

vitellus of, 701

Orthoraphic Diptera, 29

Oscornutum, I83

Osmium peroxide, action of, on nerve centres, 66, 468, 473

Osten-Sacken on chætotaxy, Io on metapleuron, I74

on sensory bristles, 499

on sutures of thorax, 166

Ostia of dorsal vessel, 64I

Ouljanin on development of external sexual organs, $73 \mathrm{I}$

Ova, origin of, 720. See Ovum, Germ, Vitellus, and Egg

Ovarian follicles, 699

Ovary, 666

development of, 69r, 698 epithelial tubes in, 700 neck of, 689
Ovary, peritoneal coat of, 669 structure of, 666

Oviduct, 666, $67 \mathrm{I}$ development of, 705

termination of, in Hymenoptera, 736

Ovipositor, 733,745

Ovum, I2

changes in, before impregnation, 714

development of, 7 O I

early changes in formation of blastoderm, 230

general observations on, 707

holoblastic, 236, 707

meroblastic, 708

meröistic, 70I, 709

nature of, 707

panöistic, 701, 708

Owsjannikow on nerve fibres, 437

Oxygen, relation of, to work done, 384

Pachytylus, Müller's organ in, 600

Packard on development of male organ, 73I

Pain doubtful in Insects, 497

Palisade cells of Carrière, 535,536

Palmén on morphology of tracheæ, 356

on paired genital ducts, 660, 735

on tracheal gills, I80

Palpi. See Labial and Maxillary palpi

Palpiger, I 33

Palpigerous scales, I 35

Pancreatic glands of Invertebrates, $4 \mathrm{I} 6$

Panöistic ova, 7or, 708

Parablast, 234

origin of, 333

Parablastic tissues, 270

Paracephala, I I 4

of imago, I2I

of nymph, I 16

Paraderm, 296 contraction of the, 303

formation of the, 299

relation of, to discs, 303

Parafrontals, I2 I

Paragastric tracheæ, 225

Paraglossæ, I32, 147

Paragonia, 662 development of, 69I, 692

functions of, 663

Paranucleus, 269 
Paranucleus in sperm-cells, 695,697

Paraphallus, 74I, 742

Paraphyses, I II, 143

Paraphysal muscles, 393

Parapteron, I83, 203 muscles of the, 220

Parascutum, anterior, I76 posterior, 176

Paratreme, 170,178

Parker on development of the retina, 542

Parovarium, 672 development of, 705 function of, 710,718

Pars basilaris, I 23

Parthenogenesis, 723 theory of, 238

Passalus, coxæ of, I9I

Patagium, 198

Patten on compound eye, 520, 522 on cones of Mantis, $53 \mathrm{I}$

on eyes of Arca, 505

on eyes of Pecten, 507

on nervous system, $44 \mathrm{I}$

on segmentation of thorax, I 57, 180

Pectoral sclerites, 178

Pedicle of procerebral lobes, 456

Peduncle of corpus centrale, 458 of procerebral lobes, 450

Pelobates, ovary of, 7 I I

Penis, 734.740

Pepsis, maxilla of, 133

Pericardial cavity, 637 development in embryo, 252

Pericardial cells, 647 experiments on, 34.3

in nymph, 343

l'ericardial plexus, 642

Pericardial septum, 642 in larva, 89

Pericardial trachex, 650 in Ctenophora, 88

Pericardium. See P'ericardial cavity

Peripatus, segmental organs of, 253 segmentation of yelk in, 237 trachex of, 357

l'eripheral nerves, development of, 328,492

Periplaneta. Sec Blatta

Peripneustic larve, 28

P'eritoneal tissues, 670

l'eritreme of spiracle, 49

P'erla, hermaphrodism in, 658
Perris on function of antenna, $590,59=$ on olfactory sense, 498

Petasia, protandry in, 723

Pettenkofer's reaction, 4I5

Pettigrew on flight, 206

Peyron on analysis of tracheal air, 375,382

Phagocytes, 273

Pharyngeal nerve, 63

setæ, 404

sinus, 46

tube, 137

Pharynx of imago, I 54, 137, 390 function of, 390

of larva, 43 function of, 46

Pheidole, eyes of, 516

Phronomidæ, eyes of, 563

Phryganea, development of, 256

Phytophaga, maxilla in, 133

Picrocarmine and eosin, use of, $34 \mathrm{~S}$

Pieris, development of gonads in, 692

Pigment cells of dioptron, 530, 531

Pilzstiel, 46I

Flanta, 194, 195

Plaques of Dufour, 73

Plastron, I68, 171

Plateau on sense of smell, 593

on vision, 567

Platygaster, origin of gonads in, 686

Pleural region, I8I

Pleuron, 156,182

Plume moth. See Pterophorus

Poculum of proboscis, 144

Podical plates, 736

Polar bodies, 714 cells. See Polar globules

P'olar globules, $238,248,714$

Pollenia, 30

Polyblasts, 694

Ponera, eyes of, 516

Porchinski on Musca corvina, 3 I

Pore-canals, 282

Pore-plates, 588

Poriferous chordotonal organs, 597

Post-dorsum, 186

Posterior gonapophysis, 733,742 spiracle of larvis, 49

thoracic diarthrosis, 17 I

thoracic spiracle, $171,188,373$

wing-root, 199, 221

Post-oral appendages in embryo, 257

Post-oral ganglia, 63 development of, 493 
Post-scutellar region, I 83, I 85

Post-scutellum, I69, I70, I83

Poulton on development of male organ, 732

on number of abdominal segments, 729

Power on foot of $\mathrm{Fly}, 195$

Prefacial region, II 5

Prelabrum, I 1 5, I48, I 50

Preoral ganglia, 63

Preoral somites, I5

Preparation of embryo, 347

Preretinal membrane, 512, 513

Prescutum, I66

Prestomal sclerite of larva, 43

Prestomum, I 44

Presutural ridge, 176

Primitive band, I3, 243, 245

contraction of, 246

relation of, to membranes, $24 \mathrm{I}$ to nervous system, 479 structure of, 246

Primitive fibrillæ of muscle, 285

Primitive groove, 246

Primitive trace, 253

Primordial sexual cells, 693

Proboscis, 127, 390

air channels of, 398

air-sacs of, 396

azygos air-sac of, 398

bibliography of, 127

comparative anatomy of, I 49

development of, I30, 148 in nymph, $32 \mathrm{I}$

exoskeleton of, I 27

exsertion of, 377

immature condition of, 148

mechanism of, 390, 395

morphology of, 130,147

movements of, 139

muscles of, 39I

nerve end-organs of, 402

oral lobes of, 393

soft parts of, 390

suckers of, 4 or

Procephalic lobes, I4, 63, II4 changes of, in embryo, 259

Procerebral lobe, 455 development of, 494

Proctodeum, 248 cuticle of, 282 of imago, $4 \mathbf{I} 2$

Prodorsal arch, 177

Progenital somite, 728
Progenital sternum, 728, 739

Progenital tergum, 737

Pro-imago, 340

Pronymph, 296 contractions of, 303

infra-œsophageal ganglia of, $3 \mathrm{I} 3$

Prophragma, I77

Propterygium, 163

Prosternal area, 178

Prosternum, I73, I 89 sensory organs of, $179,217,633$

Protandry, 723, 724

Prothoracic apodeme, 177

Prothoracic horns. See Stigmatic cornua

Prothoracic region, I79

Prothorax, dorsal arch of, 166

Protocerebron, 442

Protoplasm, 264

Proventricular ganglion of imago, 409 of larva, 57

Proventricular ring, 57, 3I 4

Proventriculus, 52, 408 cell fibrillation in, 280

development of, in embryo, 422

function of, 409

general morphology of, 52

of imago, 408

of larva, 56

Proximal intestine, 410 of larva, 58

origin in nymph, 429

Pseudo-cone, 516,528 origin of, $55 \mathrm{I}$

Pseudo-conic eye, 519

Pseudo-hæmal vessels, 358

Pseudo-labium, I 4 I

Pseudo-pupils, 577,579

Pseudo-tracheæ, 146 structure of, 393

Pseudo-yelk, 298 formation of, 4 use of, 4

Pterophorus, eye of, 524

Ptychoblast, 24I, 243, dorsal, 255

Pulex, mouth organs of, $15 \mathrm{I}$ movements of trachere in, 383 pygidium of, 629

Pulvillus, 195

Pupa, 20 coarctata, 20

loss of weight in, 309

obtecta, 20 
Pupa sheath, 330

stage, 3

Sce Nymph

Pupiparx, 29, 30

development of alimentary canal in, 423

of nervous system in, 482

of trachex in, 354

number of ventral ganglia in, 65

Pygidium, 629

functions of, 629

Pyramidal ganglion, 466, 748

development of, 494

Pyrrhocoris, dorsal organ of, 255

Rabl-Rückhard on corpora fungiformia, 446

Ranvier, nodes of, 289

Raphé, 3

Reaumur on act of suction, 399

on ecdysis, 2 I

on proboscis, 400

on respiration, 376

Receptaculum seminis, 677

Rectal glands, 54

Rectal papille, 417

function of, 420

morphology of, 420

nerves of, 420

pulsations of, 42 I

secretion of, 42 I

trachex of, 419

Rectal valve, 428

Rectum of imago, 412

of larva, 58

Recurrent nerves, 63

Rees, Van, on changes in crop of nymph, 3 I 4

on development of dorsal muscles, 336

on development of salivary glands, 431

on metamorphosis, 300

on morphology of imaginal discs, 304

on origin of imaginal discs, 261

on pro-nympli, 300

Reflex acts in Crustacea, 475

Refractive cylinders, 559

Refractive index of compound cornea, 55)

Regmagene Insecten, 256

Regnault and Reiset on respiration, 373
Rejewsky on generative organs, $66_{3}$

Remigium, 199, 201

Respiration, act of, 224,373

abdomen, movements of, in, 376

absorption of oxygen in, 380

activity of, 373

excretion of $\mathrm{CO}_{2}$ in, $3 \mathrm{~S}_{\mathrm{I}}$

muscles of, 222, 377

organs of, in imago, 224

in larva, 47

physiology of, 373

Respiratory quotient, 374

Rete mirabile, 2 16, 396

Retina, 533

continuous, $54 \mathrm{r}$

development of, in pronymph, 326

in nymph, 552

distal of Parker, 53 I

historical and critical observations on, 54I

of compound eye, $5 \mathrm{I} 7$

of Neuroptera, 54 I

of Noctuids, 541

of simple eye, 510,523

origin of, from cerebron, 494

segregate, 54 I

trachere of, 538

Retinal disc, 326

in larva, 70, 81

Retinal end organs, 506

absent in nymph, 549

development of, 553

non-inversion of, 553

Retinulx, 520, 533

Retractor muscle of frontal sac, 217

Rhabdocœlia, generative organs of, $72 \mathrm{I}$

Rhabdome, 517

in immature Diptera, 550

morphology of, 550

origin from mesoblast, 549

Sce Great rods

Ring in larva, 77

Rings of pseudo-tracher, 393

Roberts' macula, 272

Robin on polar bodies, 714

Robineau-Desvoidy on halter, 616

on Myodaires, 107, II9

on proboscis, 130

Rods and cones. See Bacilli of retina

Rostcllum, 139

Rostrum, 134, 136, 148, I 54

muscles of, 392 
Rotula, 179

Rupture of blastoderm, 256

SACCULUS, 202

of oviduct, $67 \mathrm{I}$

Sagitta, spermatogenesis in, 693

Salivary cells, 267

Salivary duct, I 47

Salivary glands, 404

accessory, 39I

development of, 43I

histolysis of, 3 IO

labial, 39t, 405

morphology of, 54

nerves to, 6 I

of larva, 59

position and number of, 228

Salivary reservoirs, 404, 406

Sand-fly. see Simulia

Sapyx larva, I 8

Sarcoglia, 285

Sarcolemma, 285

Sarcomeres, 286

Sarcophaga, 5, 6, 30

development of eye in, 543

uterus of, 676

Sarcostyles, 286

Savigny on hypopharynx, 44, I32 on mouth organs, 128 views of, I07

Scabellum of halter, 604, 605

Scalæe of halter, 605

Scapal organs of halter, 6I I

Scapula of Burmeister, 169

Scatophaga, 5

Schäfer on amoboid protoplasm, 272

Scheiber on pharynx of Estrus, 46

Schindler on Malpighian tubes, 4I3

Schiner on dipterous larvæ, 27 on number of segments in larva, 34

Schiödte on mesothoracic spiracle, 188

Schizocœele, 253

Schmidt, experiment of, 564

Schneider on development of ovaries, 699

Schultze on retinulæ, 522 on great rods, 518

Schwann on origin of cells, 716

Scleral ring, II9

Sclerites, IO, IOO methods of examination, 213

Sclero-cone, 516. See Crystalline cone Scolopale Körperchen, 6I3
Scolopendra, neuromeres of, 157

Scorpio, eyes of, 512 neuromeres of, I 57

yelk segmentation in, 237, 239

Scutellar bridges, 167

Scutellum, I67

Scutum, I66

Secondary cœlomic cavities, 252

Sections, mode of preparation, 95

Sedgwick on blastopore, $24 \mathrm{r}$

Segment médiaire, 155 , I 88

Segmental ducts, 277,664

Segmental organs, 253, 277

Segmental spiracles, I8t

Segmentation. See Yelk segmentation

Segmentation cavity, 251, 252

Segments, abdominal, 209, 724 cephalic, I I 4

of larva, 33

thoracic, I 54

Sehstäbchen, 5 I 8

Selenka on origin of hypoblast, 247

Sella, 170, I78

Semper, nuclei of, 527 on eyes of Onchidium, 503

Sensation in Insects, 496

Senses and sensory organs, 496 bibliography of, 496

Sensory bristles, 499

Sensory nerve terminals, 290

Sensory ganglia, 443,467 development of 494

Sensory organ on prosternum, 179,633

Sensory organs, 496 of larva, 7 I sporadic, 500

Sensory papillæ of larva, 36

Sericteria. See Salivary glands.

Serosa, 24I, 244

Serous gland cells, 279

Sesamoid sclerite, I 35

Seta, Io sensory, 29I

development of, in Lepidoptera, 2 I

Setiferous sac of antenna, 585

Sexual development, time required for, 5

Sexual ducts, development of, 703

Sexual rudiments. See Gonads

Shäffer on leucocytes, 274

Sharpness of vision, 567,569

Siebold on tympanic organs, 623

organ of, 600 
Simulia, 154

development of, 254,256

mouth of, I54

Sinus, pericardial, of larva, $S_{7}$. Sce

Blood sinus, Pericardial sinus

Sirex, ovipositor of, 733

Sitaris, metamorphosis of, I 8

Skeletal muscles, development of, 287

Skeletal structures of proboscis, 127

Skeleton, appendicular, IOI somatic, IOI

Smaller house-fly. See Musca corvina

Somatic nervous system, 8, 62, 433 of larva, 67

Somatic skeleton, IOI

Somatopleure, I6 development of, 251 segmentation of, 252

Somites, 8 number of, in embryo, 15 primary, I 57

Sound-producing organ, 217, 595

Sound-waves, Airy on, 619

Specific characters of Blow-fly, 3I

Sperm and Germ development compared, 719

Spermatheca, 677

Spermatogenesis, 692, 720

Spermatospores, 693

Spermatozoa, 695, 697 movements of, 698

Sphinx euphorbix, eye of, 527 ligustri, aorta of, 638

Spiracles, 12, 319, 358 abdominal, $359,363,373$

anterior of larva, 50

anterior thoracic, 167,361

in Coleoptera, I8I order of succession of, 372

inter-segmental, 181, 319, 359

mechanism of, $36 \mathrm{I}$

median thoracic, 188

nomenclature of, 180,358

posterior, of larva, 49 development of, 369

posterior thoracic, 17 I, 188, 373 segmental, 359

thoracic, 359

tympanic, $358,363,624$

upper prothoracic disc. Sce Spiracular disc

vestibule of, $50,352,361$

Spiracular disc, $84,316,319$

sac, 352,353
Spiracular trunks, 225

Spiral thread of trachea, 355

Splanchnic nerrous system, 65,92

Splanchnoblast, 22

Spongioplasm, 264

Squama, 165

Squamuia, 165

Staining, methods of, 95

Staphylinidx, larva of, is

Stemma, stemmata. See Ocellus

Stenobothrus, segmental organ of, 277

Sterno-dorsal muscles. Sce Muscles

Sterno-pleural suture, 168

Stigmatic discs. See Spiracular disc.

Stigmatic cornua, 3 I9

in Corethra, 370

Stigmatic plate of larva, 369

Sting of Hymenoptera, 729, 731, 734

Stomal plate, I 43

Stomodeum, 13, 422

cuticle of, 282

development in nymph, 315

of nymph, 346

Stomogastric nerve, 57,65

development of, in pupa, 494

Straus Durckheim on homologies of muscle, 2 I 9

on leg muscles, $22 \mathrm{I}$

on mechanism of dorsal vessel, 650

on wing muscles, 220

Stricker on origin of nuclei, 7 I 7

Stroma of nerve centres, 66

Stuhlmann on egg, 713

Sub-corneal image, 555,558

Sub-corona, 47 I

Sub-dioptric space, 545

Sub-epaulet, 201

Sub-hypodermal cells of larva, 37

Suckers of proboscis, 394

Suckow on origin of gonads, 685

Suction, act of, 399

Supra-csophageal nerve centres, 448 , 475

Supra-tympanic fissure, 176 organ, 6or, 625

Sutures, IOI median, 102 morphology of, 103 sterno-pleural, 168 transverse ventral, I69

Swammerdam on alimentary canal of Bee larva, 422 
Swammerdam, on circulation of the blood, 635 on imaginal discs, 73

Swinton on dorsal vessel, 649 on mirror in Cicadæ, 626

Sylpha, function of antennæ in, 592

Symphysis, I02

Synapta, morula of, 239

Syncytial segmentation, 237

Syndesmosis, I0, I02, I87

Synonymy of head capsule, I26

of mouth organs, $\mathbf{1} 54$

of thoracic skeleton, I 89

of wing sclerites, 209

Syrphidæ, entocephalon of, 124 epistoma of, I2 I

lunula of, 126

salivary glands of, 404

TABANIDE, mandibles of, 128 palpi of, 150

Tabanus, 30 chordotonal organs of larva, 596

Tachina, 5 abdominal sterna of, 739 antennæ of, 585 uterus of, 676

Tactile sense, 499

Tænia, 470-472

Tanystomata, 30

Tapetum, pigmented, 535 tracheal, 538

Tarsal articulations, 194 glands, 198 muscles, 222

Tarsus, 194

Taste, organs of, 403 sense of, 630

Tau, 203

Teeth of proboscis, I 46

Telson of Crustacea, 209

Tendinous cords of oral sucker, 395

Tentorium, 215 rete mirabile of, 216,396

Tergum, 156

Terminal ganglia, 29I

Termites, gills of, 160,356

Testis, 660 development of, 687, 69I early stages of, 687

Thalamencephalon, 444

Thalamon, 444

Theca, I 35
Thoracic appendages, development of, 158

blood sinuses, 225

discs. See Imaginal discs. ganglion, 435, 437, 439 in nymph, 345

muscles, 223

nerve centre, $435,437,439$

sclerites, I7 I nomenclature of, 166

segment, ideal of, 156

skeleton, I 54, 166 bibliography of, 154 morphology of, I 54

spiracles. See Spiracles

Thorax, I I

anterior surface of, 169

contents of, 217

development of, 83,318

dorsal aspect of, 166

evagination of, 317

lateral aspect of, $\mathrm{I} 67$

modifications of, 165

posterior aspect of, 170

theory of, 156

ventral appendages of, 158

ventral surface of, 169

Thyroid sclerite, I4I, I 42

Thysanura, I8

tracheæ of, 357

Tibia, 193

Tichomirow on primitive trace, 253

Tiger beetle. See Cicindela.

Timarchia, ocelli of, 5 I4

Tipula, 30

anterior gonapophyses of, 732

eye of, 521

halter of, 606

mouth of, 150

Tissue elements, 263

Tissues, classification of, 263

Topography of muscles and viscera, 215

Topping, preparation of proboscis by, $I_{4} 2$

Torulus, 1 I 7 , i2 I

Total reflection, vision by, 563

Trabeculæ, I I 2, 445, 46I, 464

Trabecular bundle, 467

Tracheæ, I I, 47, 35 I

abdominal, 226

appearance of, 364

arborescent, 353 
Trachex, ascending thoracic, 226

atrium of, 352

changes during ecdysis, 48

closed, 358

development of, 353,368

ecdysis of intima, 356

embryonic, in pupa, 427

histolysis of, 306

influence of, on after-development, 427

intra-cellular, origin of, 273

longitudinal trunks, 352

morphology of, 355

movements in, 383

new branches of, 368

origin of, 357

relations to blood, 367

relations to pseudo-hremal system, 358

spiral thread in, 355

structure of, in imago, 364 in larva, 48

transverse, 225

vestibule of, in imago, 352 in larva, 50

Tracheal capillaries, 49

arrangement of, 367

development of, 49,273

Tracheal gills, $160,351,355$

Tracheal intima, 48 ecdysis of, 307

Tracheal system, 35 I, 358 development of, in nymph, 338 ideal plan of, 225

of imago, 358

of larva, 47

of nymph, 338

Tracheal vessels. Sec Trachea

Trematodes, generative organs of, 721 origin of ova in, 708 yelk-glands of, 708

Trichogenic cells, 10, 279

Trichosoma, thorax of, ISS

Trito-cerebron, 442

Trochanter, 192

Trochantin, 179

Trophic nerve-cells, 289

Tuba of oviduct, 666

Tubular nerve fibres, 289

Tuffen West on Fly's foot, 196

Tymbals of Cicada, 601

Tympana of Orthoptera, 599

Tympanic air-sacs, 217 bullax, 169,184
Tympanic fissure, 187

membrane, 624

notch, I 85

organs, 623, 626

ridge, 185

spiracles, 363,624

Tympanules, 584

Typhlopone, absence of cyes in, 516 corpora fungiformia of, 446

UNCINATE process of parascutum, 176

Ungues, 194

Unguiculus, 201

Urates in distal intestine, 430

Utero-vaginal tube, 675 development of, 703

Uterus, 675

VAGINA tubiformis, 745

Valve of lingual duct, 406

Valve plate of spiracles, 363

Valves, intra-ventricular, 641

in larva, 91

intra-tracheal, 366

of dorsal vessel, 638

action of, 652

of larva, 90

of ostia of dorsal vessel, 641

of posterior spiracle, 36I

Van Beneden. Siee Beneden

Van Rees. Sce Rees

Vanessa, development of retina in, 543

Io, development of oviducts in, 704

Vas deferens, 664

Vas efferens, 662

Velocity of flight, 386

Ventral appendages, 8, I4 abdominal, 731

thoracic, 158

Ventral chain of ganglia, 62 development of, 479 nerves of, 64

Ventricles of the brain, $447,448,488$

Ventricles of the dorsal vessel, 638 in larva, 87

Verloren on accessory hearts, 636 on action of dorsal vessel, 65 I on valves of dorsal vessel, $64 \mathrm{r}$, 652

Vermiform larva, 19

Verschluss Band, 363 
Verschluss Bügel, 363

Verson on development of wings, 2 I

Vesicular condition of nervous system, 487

Vespa, brain of, $440,459,462$ sense of taste in, 6.31

Vestibule of trachea in larva, 50

Viallanes on brain of Insects, 440

on central nervous system, 70, 442

on cerebron of Cricket, 454

on chaplet cells, 533,534

on corpus centrale of Cricket, 459

on development of brain in Mantis, 480, 488

on dorsal vessel of larva, 91

on ganglia of intestine, 59

on ganglion a côtes de melon, 72

on mantle layer of brain, 484

on morphology of discs, 74

on nerves, structure of, 288

on optogenic cells, 547

on sub-hypodermal cells, 37

on white nerve substance, development of, 486

Vibrations of the wing, 203

Vibrissæe, ro

Virchow on origin of cells, 7 I 6

Visceral arches and Arthropod limbs, II 3

Visceral muscles, 283

Visceral muscular network, 59

Visceral nervous system, 57, 65, 494

Vision, acuteness of, 567, 569

binocular, 57 I

effect of movement in, 571

experiments on, 567

extent of field of, 566

in diurnal Lepidoptera, 497

organs of, 50 I

in CEstrus larva, 71

Vitelline membrane, $12,68_{3}$

Vitellus. See Yelk

Viviparous Flies, 5 habits of Musca corvina, 3 I

Voeltzkow on polar cells, 248 on primitive band, 243

Volucella, entocephalon of, 124

lunula of, 126

proboscis, development of, in, 322

terminal abdominal segments of, 730
Volucella, wing muscles of, 220

Voluntary acts, 475

Vorderhorn, 464

Vorderkopf, I I4

WAsp. See Vespa

Watery vapour an olfactory stimulant, 594

Wax glands, 279, 352, 360

Weinland on functions of halteres, 6 I6

on scapal papilla, 6 ro

on special organs of halter, 6 Io

Weismann on alimentary canal, 3 I I

on blastoderm, formation of, 233

on cell chaplets, 6I, 9I

on central nervous system of larva, 68

on compound eye, 543

on development of cornea, $\mathbf{5 2 8}$

of Diptera, I

of larva, 259

on dorsal vessel, 92, 644

on Faltenblatt, 244

on germinal vesicle, 712

on gonads, origin of, 686

on great rods of eye, 544

on halter, 603

on imaginal discs, 3,21

on Malpighian tubes, 424

on mouth organs of larva, 38

on nervous system, 49I

on neuroblast of larva, 68

on nutrient cells of egg, 702

on nymph, 317

on optic disc, 80

on optic ganglia of nymph, 492

on polar cells, 238

of Chironomus, 248

on pharynx of larva, 43

on proboscis, I 30

on procephalic lobes, 259

on prothoracic spiracle, I 8 I

on ring of larva, 78

on thoracic appendages, I 58

on tracheæ, 48,354

on tracheal capillaries, 49

on visceral muscular network, 59

West, Tuffen, on Fly's foot, 196

Wheeler on development of nervous system, 480

Wielowiejski on Oinocytes, 276

on parablast, 236

Will on amnion in Aphis, 243 
Will on gastrulation, 240

on median elements of ganglia, 481

on sense of taste, 630

on sexual cells in Aphis, $25 \mathrm{I}$

Willis, views of, 99

Wing, development of, 20, I6I discs in larva, 84 in nymph, 320

extension of, 163,202

homology of, 160

morphology of, 160,163

movements of, $\mathrm{I}_{3}$

muscles of, 220,283

nervures of, 163

organs, 620

passive rotation of, 208

posterior muscles of, 221

rudiments of, in larva, 84

structure of, 162

sclerites of, 199

typical form of, I62

vibration, 203

See also Flight

Winter Flies, 6
Wistinghausen on tracheal capillaries, 47

Witlaczil on development of uterovaginal tube, 703

Wright on Anthony's suckers, 394

Xiphidium, development of nervous system in, 480

Xylocopa, maxilla of, 133

YELK glands of 'Trematodes, 708 segmentation, 13, 232, 237 spherules, 13 structure of, $68_{3}$

Yellow bodies of retina, 524

Yung on brain of Arthropods, 442 on reflex acts in Crustacea, 475

Zaddach on number of primitive ganglia, 65

on origin of blastoderm, 234

Zoea stage of Crustacea, 30

Zona radiata of germ ova, 719

Zopfgräten, 29

Zungenbein, 44 


\section{INDEX OF AUTHORS QUOTED.}

ADOLPH, IgI

Airy, 603

Amans, I9I

Anthony, 127, 395

Audouin, 72, 99, 100, 603

BAKER, 635

Balbiana, 262, 658, 684

Balfour, 12, I06

Barfurth, 292

Barrois, 24

Basch, S., 389

Batelli, 33

Becher, I28

Bellonci, 106, 434

Beneden, 684

Beneden et Julin, 712

Berger, 433

Bernard, 539

Bessels, 658

Biackwall, 196

Blanchard, 127, 367

Blockmann, 230, 7 12

Bobretzki, 230, 539

Borellus, 198

Bouché, 32

Bowerbank, 635

Brandt, A., 659

Hrandt, E., 62, 65

Brauer, 18, 20, 25, 29, 30

Bruce, 230

Brulle, 127

Burmeister, 7, $5^{8} 3$

Bütschli, 13, 23I, 262, 263 , 693

CARNOY, 262

Carrière, 503

Carus, 635

Chabrier, 154

Chatin, 502

Cholodkovosky, 23I, 253, 254,678

Chun, 389

Ciaccio, 469, 502

Claparède, 501,583

Claus, 275, 50r, 502, 684

Cornelius, $66_{4}$

Cuccati, 434

Cuvier, I3I
DAHL, $5^{8} 3$

Daresté, 656

De Geer, 7

Dereham, I9o

Dewitz, 21, 72, 352, 725

Dietl, 66, 433

Dimmock, 128

Dogiel, 433

Dohrn, I09

Dor, 501

Doyère, 656

Dufour, 32,72

Dujardin, 433

Duponchel, $5^{82}$

EIMER, 268

Emery, 276, 389

Erichson, I27, 582

Exner, 50I-503

FABRICIUS, 7

Faivre, 433

Faussek, 262

Flemming, 712

Flögel, 433

Forel, II, 496, 63I

Frenzel, 262

Furlonge, $3^{8} 3$

GANIN, 72, 684

Gaskell, I06

Gegenbaur, I6I, 35I

Gerstacker, 659

Gerstfeldt, I27

Gilson, 693

Girard, 603

Gleichen, I

Gosch, I54

Gottsche, 501

Goureau, 603

Graber, 7, 127, 23I, 254, $502,583,596,635$

Graff, 722

Grenacher, 501, 502

Griffiths, 352

Grimm, 659

HALLIBURTON, 4I5

Hammond, 33, 5I, II5

Harvey, 24

Hatschek, 479
Hauser, 583

Heider, 479

Helmholtz, 5 or

Henking, 685

Hensen, 501, 596

Herold, 292

Hertwig, 235, 693, 712

Heymonds, 685

Hicks, 583, 603

Hickson, 503

His, 235

Hofer, 65,389

Hooke, I90

Hunt, 127

Hurst, $35^{\mathrm{I}}$

Huxley, 9, 249, 554, 658

INMAN, 190

JACKSON, 685

Jaworowski, 285, 656

Johansen, 539

Joseph, 63I

Jousset de Bellesme, 603

Jurine, I54

KENNEL, 230

Kingsley, 539

Kölliker, $503,65^{8}$

Korotneff, 230

Korschelt, 678, 685

Köstler, 389

Kowalevski, I7, 57, 230, 292

Kraatz, 725

Krancher, 35I

Kräpelin, 128, 583

Kuhne, 5 or

Künckel d'Herculais, 22, 33 , 631

LACAZE-DUTHIF,RS, 725

Lầchat, 72

Landois, H., 262, 272, 35 I, 596

I andois, L., 207, 658

Lankester, 80, 100, 502

Latreille, 99, I54

Lee, 275, 603, 693

Leeuwenhoek, Igo

Lefebvre, 582

Lehmann, $5^{82}$ 
Lemoine, 433

Lendenfeld, I98

Lespés, $5^{8} 3$

Leuckart, $33,423,678,684$, 7 II

Leydig, 47, 106, 262, 50r, $583,596,65^{8}$

I, ocy, 503

Loew, I55, 603, 658

Longet, 475

Lowne, 4I, 127, 128, 190, 292, 389, 50I-503, 659, 723

Lubbock, 496, 583, 658

Ludwig, $68+$

Lyonet, 418

MACLEAY, I5x, I 55

Macloskie, 44,127

Malpighius, 35 I

Marey, 198

Mark, 503

Marno, 33

Marshall, 287

Mayer, or Meyer, 127,273 . $35 x, 432,583,635$

Meinert, 128

Meissner, 678

Menzbier, 40, 82, 119

Mereschlowsky, 502

Metschnikoff, or Metschnikow, 230, 2.54, 292, 684

Meynert, 446

Miall, 100

Michels, 434

Milne-Edwards, 7 I2

Moseley, 356

Miiller, $65,496,500,712$

NAssonow, 684

Newport, 7, 62, 477

Newton, 434,501

Notthaft, 502

Nussbaum, 684

OKEN, I5I
Osten-Sacken, I I , 25, 155

Ouljarin, 725

Owsjannikow, 433

PAASCH, 496

Packard, 434, 725

l'almén, 35r, 659

Patten, I06, 503

P'erris, 583

Pettigrew, I98

Peyron, 352

Plateau, 503, 593

Poulton, 685

Power, rgo

RABL-RUCKHARD, 446

Rajewski, 659

Rath, 263

Reaumur, I, 7

Rees, 292

Regnault, $35^{2}$

Reichenbach, 479, 539

Ritter, 685

Robin, 712

Robineau - Desvoidy, I19, 603

Roffredi, I 27

Rolleston, 106

Rösel, I 5 I

Ruete, 50 I

Ruland, $5^{83}$

SAYIGNYY, 99

Sazepin, $5^{83}$

Schifer, 263,272

Scheiber, 33

Scheiner, 25

Schelver, $60_{3}$

Schiemenz, 389

Schimkewitsch, 503

Schindler, 389

Schiödte, I 55

Schmidt, 502,596

Schneider, 659

Schröder V. D. Kolk, 32, 14
Schuleze, 5or

Selenka, 230

Semper, 35I

Serres, 500

Shäffer, 262

Shuckard, 7

Siebold, 596

Solier, 627

Stein, 658

Straus Durckheim, Ioo

Stricker, 7 I 2

Stuhlmann, 712

Suckow, 684

Suffolk, 127

Swammerdam, 7

Swinton, 596

Szczawinska, 503

TASCHENBERG, I 52

Tetens, 659

Treviranus, $3^{89}$

VERALL, 30

Verloren, 635

Verson, 21

Via!lanes, $33,434,479$

Voelizkow, 23 I

W $A$ GNER, 33

Weimland, 603

Weismann, I, 72, 77, 230, 262,292

VIest, rgo

Wheeler, 479

Wielowiejski, 235, 276

Will, 23I, 63I

IVistinghausen, 47,378

Witlaczil, 230

Wolf, 63I

Wright, 395

YUNG, 433

ZADDACII, 230

THI: ENI). 





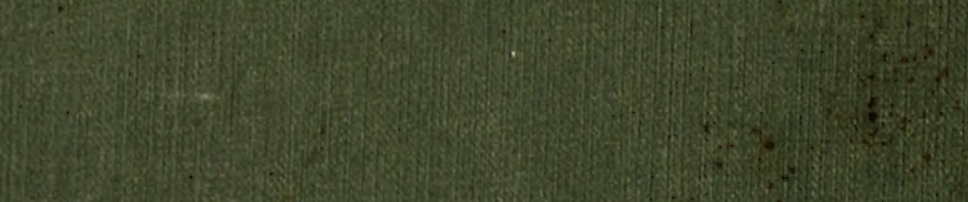

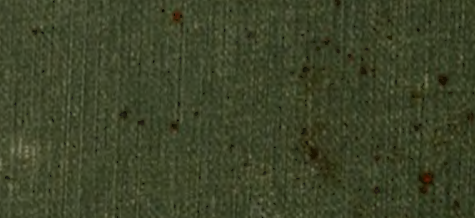

57.2.

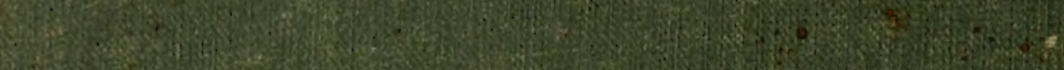

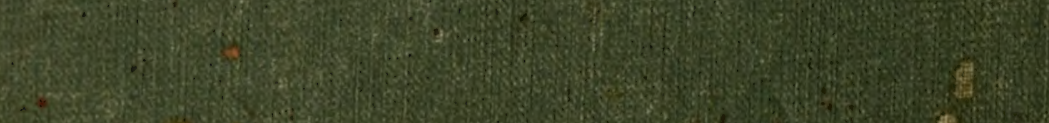

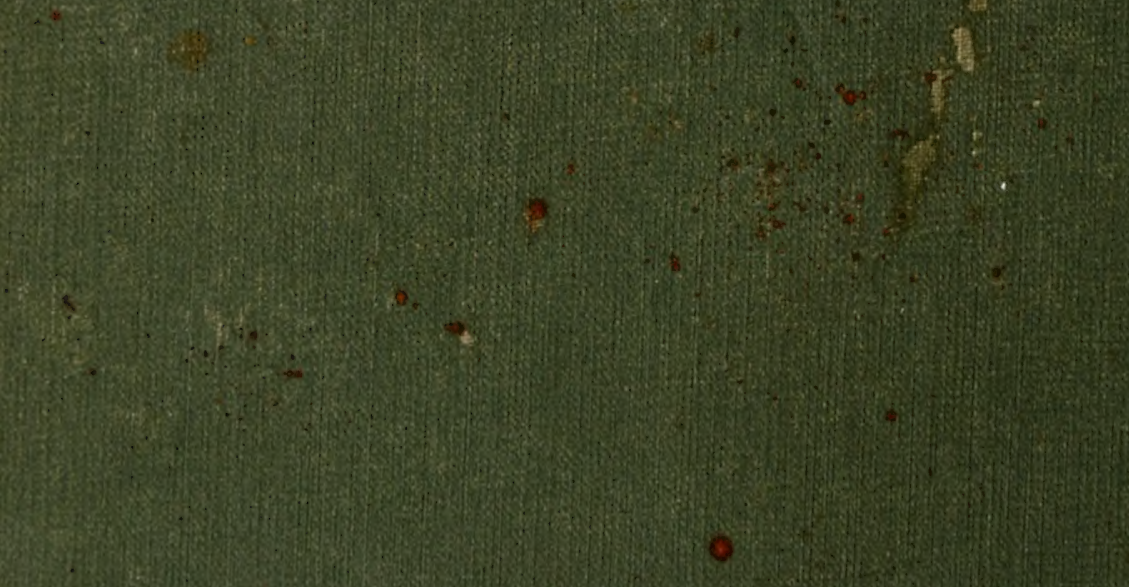

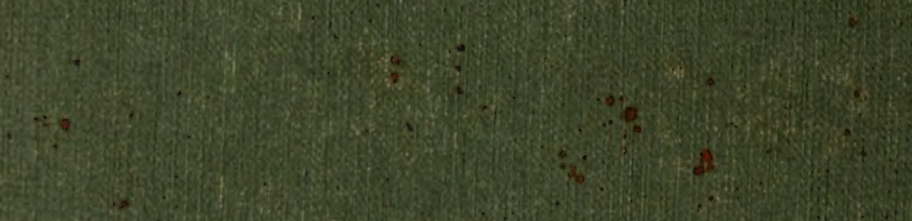

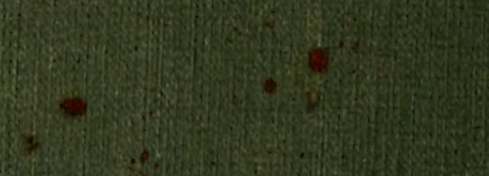

1.

N-20 